\title{
The Synthesis of Malonganenone Analogues for Antiparasitic Structure-Activity Relationship Analyses
}

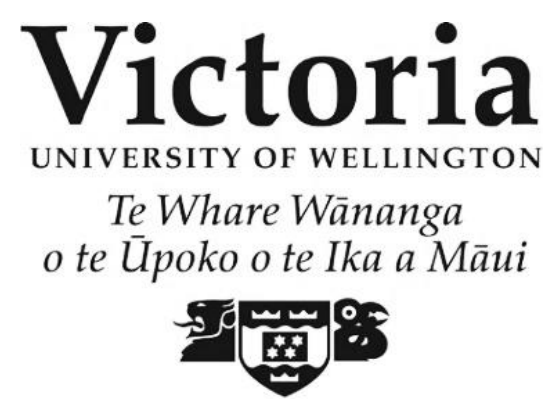

A thesis submitted to Victoria University of Wellington in partial fulfilment of the requirements for the degree of Master of Science in Chemistry

School of Chemical and Physical Sciences

Victoria University of Wellington 


\section{Abstract}

The most lethal causative species of malaria, Plasmodium falciparum, has been reported as developing resistance against current antimalarial drugs in South-East Asia. New antimalarial drugs, especially those with novel modes of action, need to be established before resistance spreads.<smiles>[R]n1cnc2c1c(=O)ncn2C</smiles>

A<smiles>[R]n1cnc(N(C)C(=O)O)c1C(=O)NC</smiles>

B<smiles>[R][R]CCC=C(C)CCC=C(C)CCCC(C)=CC(=O)CC(C)C</smiles>

The marine natural products malonganenones $\mathrm{A}, \mathrm{B}$, and $\mathrm{C}$, isolated from the gorgonian Leptogorgia gilchristi, have recently been shown to inhibit $P$. falciparum parasite growth. Therefore, a library of malonganenone analogues were synthesised for structure activity relationship analysis. A range of purines, purinones, and pyrimidines were alkylated with simple terpenoid chains to generate malonganenone $\mathrm{A}$ and $\mathrm{B}$ analogues, while malonganenone $\mathrm{C}$ analogues were made by acetylation or formylation, then methylation of terpenoid amines.

The compounds were moderately active against $P$. falciparum infected red blood cells, but exhibited significant activity against Trypanosoma brucei, the parasite responsible for African sleeping sickness. Off target activity was assessed by assay against Escherichia coli, Staphylococcus aureus, Steptococcus uberis and HeLa cells. The overall structureactivity relationship analysis resulted in the identification of lead candidate, geranylgeranyl imidazole (146), which had $\mathrm{IC}_{50}$ values of $10.2 \mu \mathrm{M}$ and $3.4 \mu \mathrm{M}$ against P. falciparum and T. brucei, respectively.

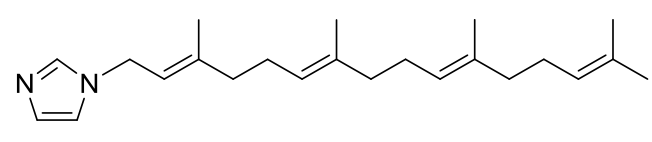

146

In addition, the minimum inhibitory concentration of 146 against $S$. uberis and $S$. aureus was $16-32 \mu \mathrm{M}$ and $128 \mu \mathrm{M}$, respectively. Compound 146 was inactive against E. coli and was also non-toxic to HeLa cells. In addition, a geometric mixture of $E$ and $Z$ isomers at the alkene closest to the imidazole head group was more active than just the $E$ isomer 
as for 146, which suggested the $Z$ isomer was more active than the $E$ isomer. Therefore, the lead compound identified within this project was the $2 Z$ isomer of geranylgeranyl imidazole. 


\section{Acknowledgements}

First and foremost, thanks to my supervisor Dr. Rob Keyzers for his unparalleled enthusiasm and support. An additional thank you for isolating the malonganenones that inspired this project, which has been challenging and rewarding.

Thanks to our collaborator Aileen Boshoff at Rhodes University in South Africa for testing the antiparasitic activity of the compounds and another thanks to our collaborator Greg Cook at the University of Otago for the antibacterial testing.

A further thanks to the financial aid provided by the Curtis-Gordon Research Scholarship in Chemistry. Thank you to all the staff and students who made this experience so enjoyable. 


\section{Table of Contents}

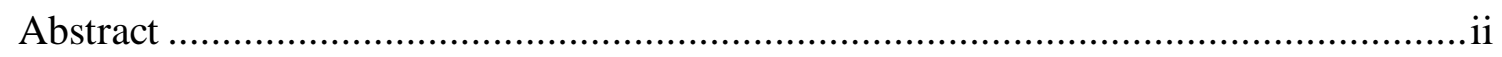

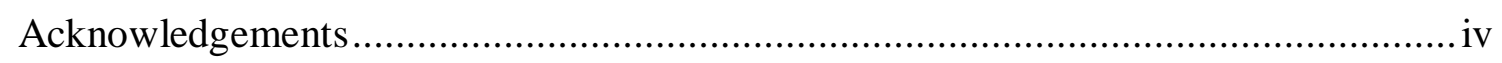

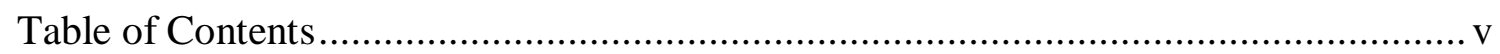

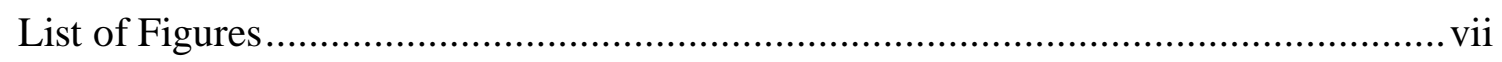

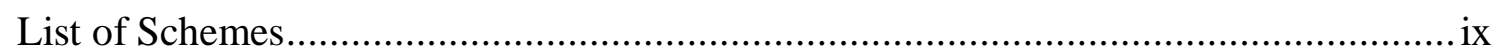

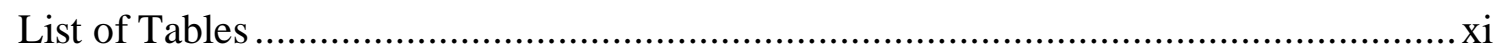

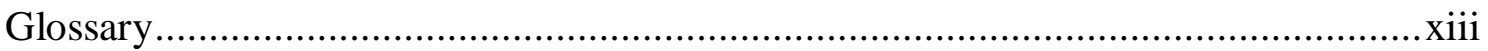

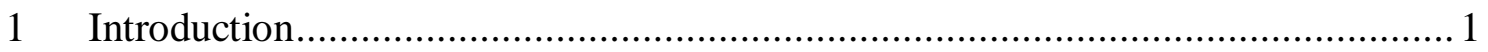



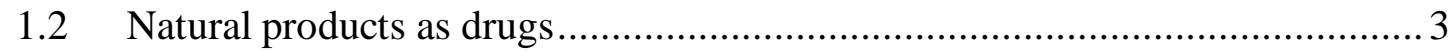

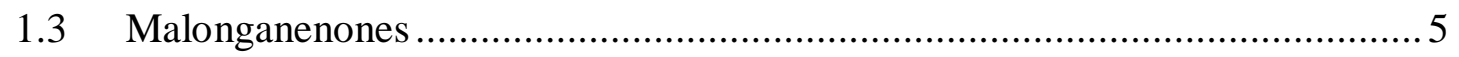

1.4 Malonganenone and nuttingin bioactivities ............................................. 7



1.5 Synthesis of malonganenones............................................................... 8

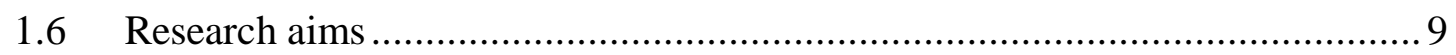

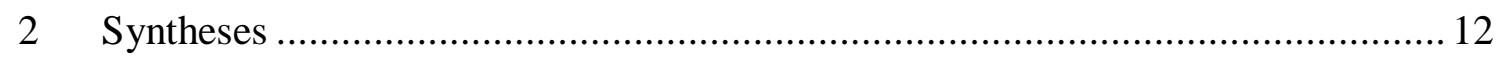

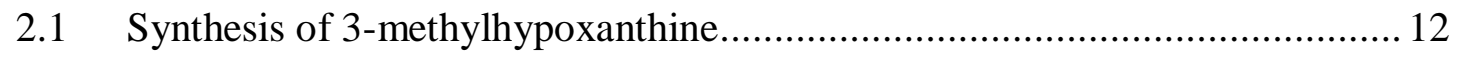

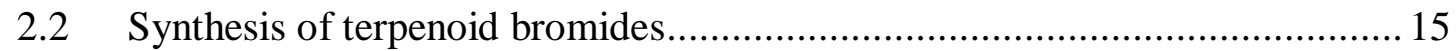

2.3 Structural elucidation of the terpenoid chains ........................................ 17

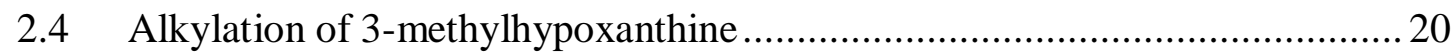

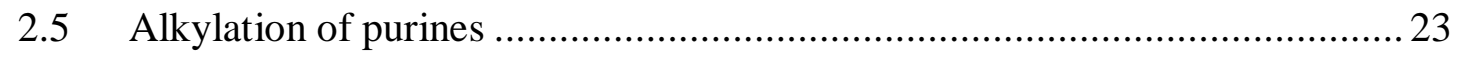

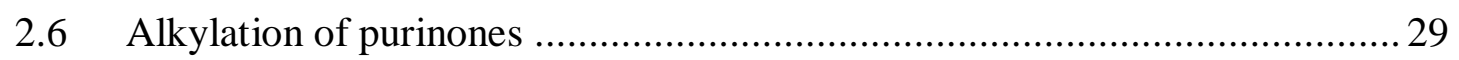

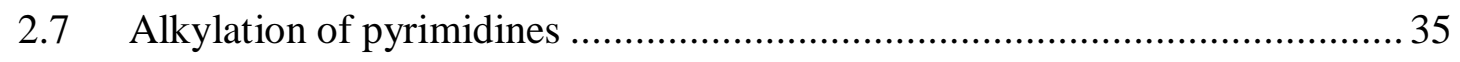

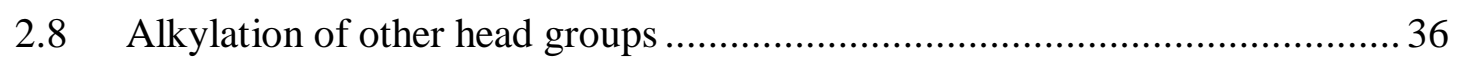




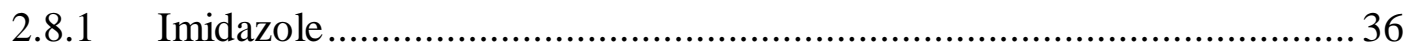

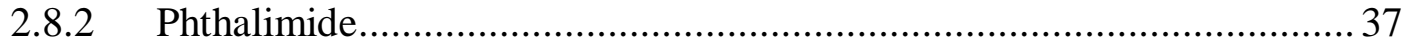

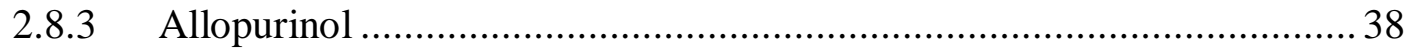

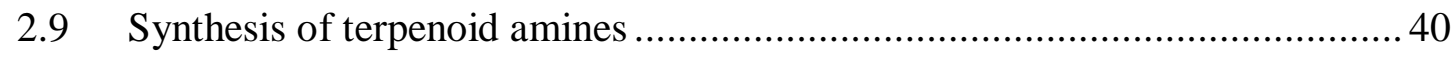

2.10 Formylation and methylation of terpenoid amines .................................. 41

2.11 Acetylation and methylation of terpenoid amines ................................... 42

3 Structure-activity relationship analyses................................................. 45

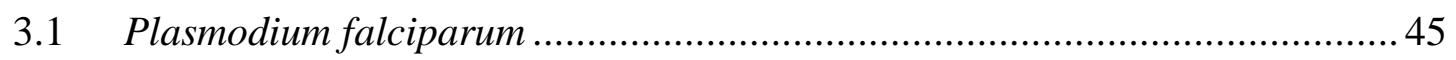

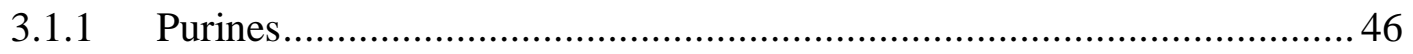

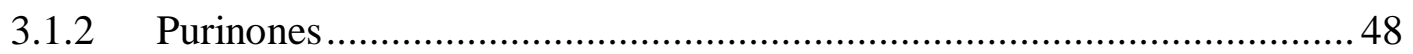

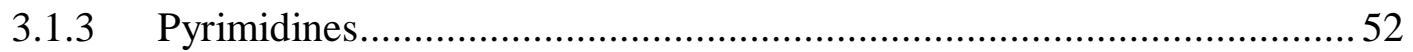

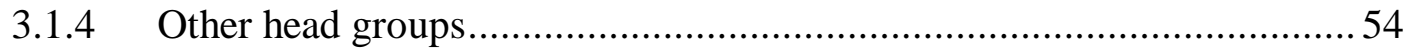



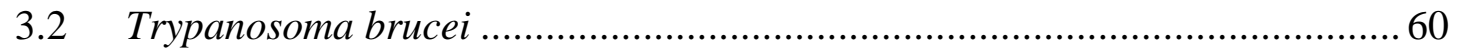

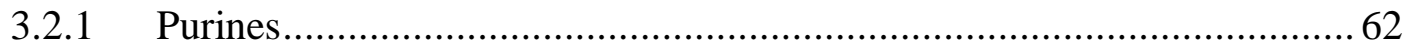



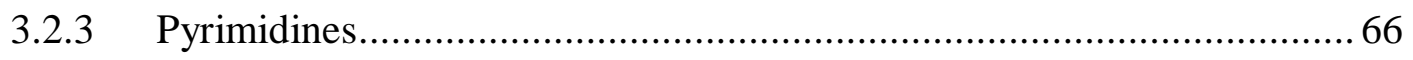

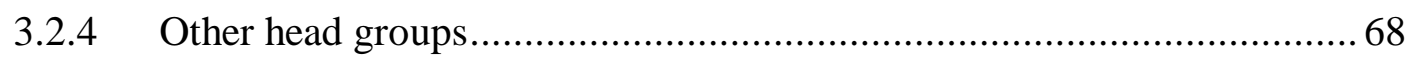



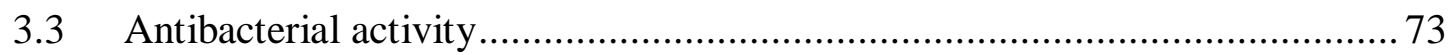

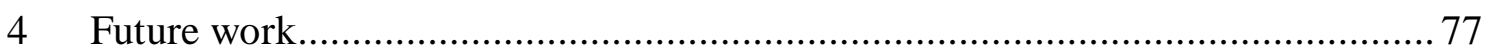

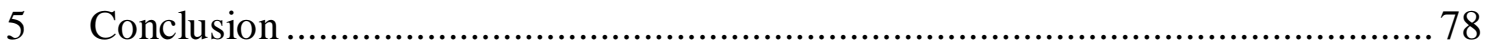

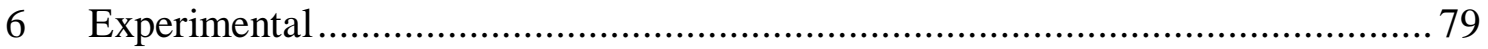

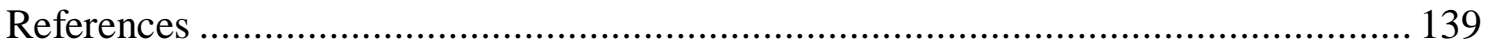

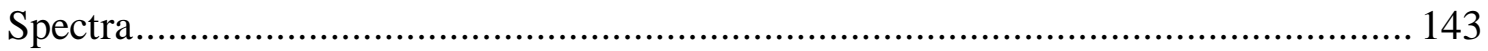




\section{List of Figures}

Figure 1.1 Lifecycle of Plasmodium parasites. ...................................................... 1

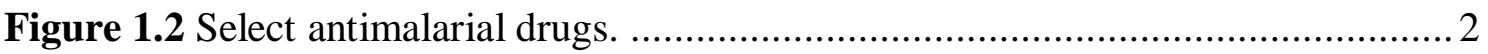

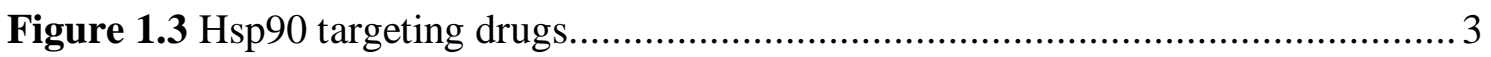

Figure 1.4 Select natural products. ................................................................... 4

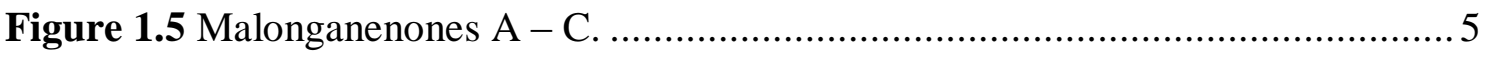

Figure 1.6 Malonganenones D - K and nuttingins A - F....................................... 6

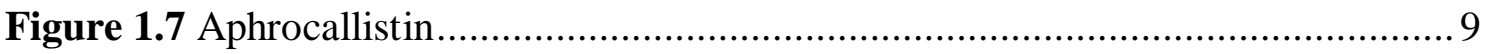

Figure 1.8 The natural product side chain of malonganenones $\mathrm{A}-\mathrm{C}$ and substitutes. . 10

Figure 2.1 ${ }^{1} \mathrm{H}$ NMR spectra of crude and recrystallised 2-mercapto-3-

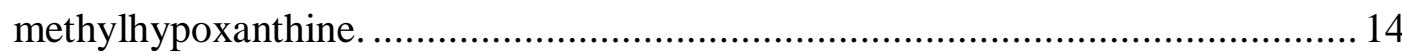

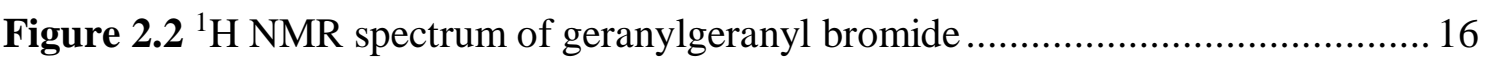

Figure 2.3 Numbering of the geranylgeranyl side chain and 2D NMR correlations used

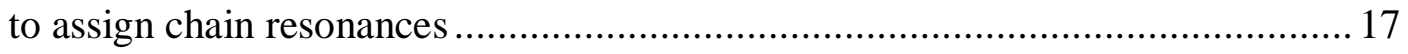

Figure 2.4 ${ }^{1} \mathrm{H}$ NMR spectra of geranylgeranyl theophylline geometric isomer ............ 19

Figure 2.5 Hydrolysed by-products isolated during the literature synthesis of malonganenone $\mathrm{J}$.

Figure 2.6 Tetraalkylammonium salt by-product isolated during the literature synthesis

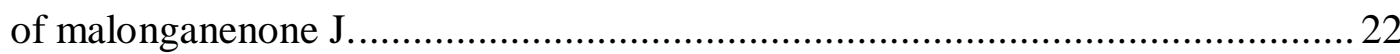

Figure 2.7 HMBC correlations used to assign purine head group resonances.............2 25

Figure 2.8 HMBC correlations for purine regioisomers .....................................2 25

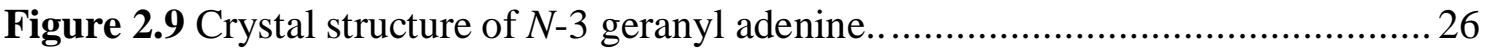

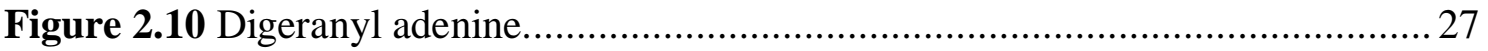

Figure 2.11 ${ }^{1} \mathrm{H}$ NMR spectra of geranyl 6-(dimethylamino)purine regioisomers......... 28

Figure 2.12 HMBC correlations for purinone analogues and regiosiomers................... 30

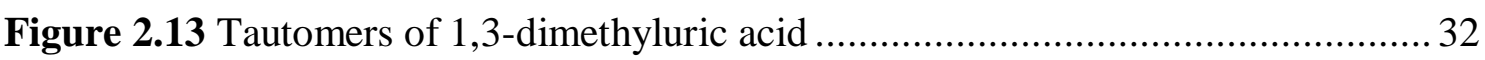

Figure 2.14 HMBC correlations of proposed $C$-5 farnesyl 1,3-dimethyluric acid ........33

Figure 2.15 HMBC correlations for pyrimidine analogues and regioisomers. ............. 35

Figure 2.16 HMBC correlations of imidazole analogues........................................ 37

Figure 2.17 HMBC correlations of allopurinol analogues ......................................... 39

Figure 3.1 Purine-based analogues tested against $P$. falciparum. ............................ 46

Figure 3.2 Bar graph of purine-based analogue activities against $P$. falciparum......... 48 
Figure 3.3 Purinone-based analogues tested against $P$. falciparum.......................... 49

Figure 3.4 Bar graph of purine-based analogue activities against $P$. falciparum......... 51

Figure 3.5 1,3-Dimethyluric acid analogues tested against $P$. falciparum................... 51

Figure 3.6 Pyrimidine-based analogues tested against $P$. falciparum .......................52

Figure 3.7 Bar graph of pyrimidine-based analogue acitivities against $P$. falciparum.. 53

Figure 3.8 Other head group-based analogues tested against $P$. falciparum................54

Figure 3.9 Bar graph of other head group-based analogue activities against $P$.

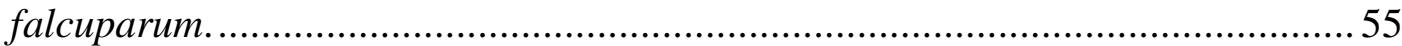

Figure 3.10 Amide-based analogues tested against $P$. falciparum. ............................56

Figure 3.11 Bar graph of amide-based analogue activities against $P$. falcuparum .......57

Figure 3.12 Purine-based analogues tested against $T$. brucei ................................ 62

Figure 3.13 Bar graph of purine-based analogue activities against T. brucei ..............6 64

Figure 3.14 Purinone-based analogues tested against $T$. brucei............................. 64

Figure 3.15 Bar graph of purinone-based analogue activities against $T$. brucei..........66

Figure 3.16 Pyrimidine-based analogues tested against $T$. brucei........................... 67

Figure 3.17 Bar graph of pyrimidine-based analogue activities against T. brucei ........68

Figure 3.18 Other head group-based analogues tested against T. brucei .....................6 68

Figure 3.19 Amide-based analogues tested against $T$. brucei. ............................... 70

Figure 3.20 Bar graph of amide-based analogue activities against $T$. brucei............... 71

Figure 3.21 Bar graph of all analogue activities against T. brucei ............................ 72

Figure 3.22 Compounds active against $S$. uberis and $S$. aureus. .............................. 74

Figure 3.23 MIC values of analogues active against $S$. uberis and S. aureus..............76 


\section{List of Schemes}

Scheme 1.1 Proposed biosynthetic pathway for interconversion of the malonganenones and nuttingins

Scheme 1.2 Literature synthesis of malonganenone $\mathrm{J}$.......................................... 8

Scheme 1.3 Literature synthesis of 3 -methylhypoxathine route 1 .............................. 8

Scheme 1.4 Literature synthesis of 3-methylhypoxathine route 2 ............................ 9

Scheme 1.5 Proposed route to malonganenone A analogues..................................... 11

Scheme 1.6 Proposed route to malonganenone $C$ analogues...................................... 11

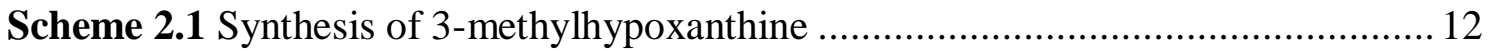

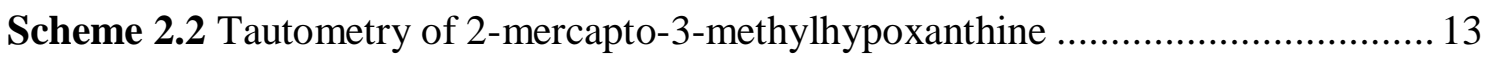

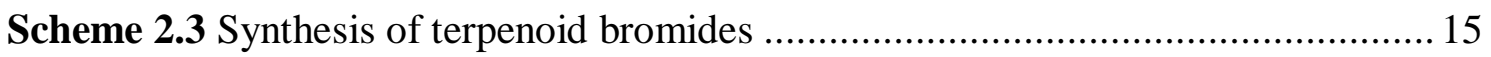

Scheme 2.4 Sodium 3-methylhypoxanthide alkylation............................................ 20

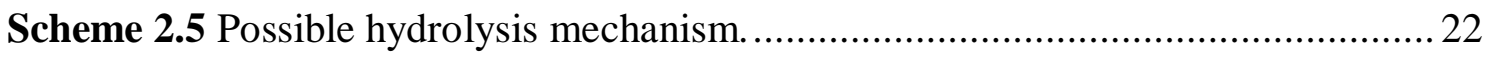

Scheme 2.6 Literautre synthesis of $\mathrm{N}-6$ terpenoid adenines ....................................... 23

Scheme 2.7 Literature synthesis of geranylgeranyl adenine derivatives .....................23

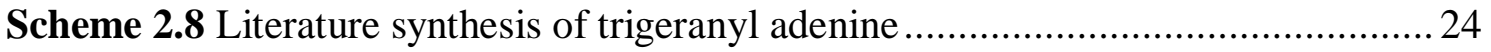

Scheme 2.9 Literautre synthesis of geranylgeranyl 6-chloropurine ............................2 24

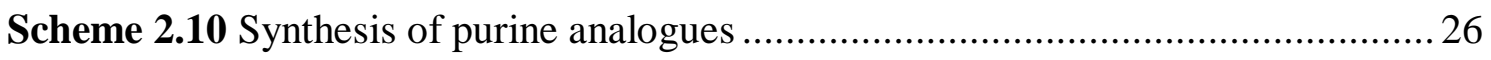

Scheme 2.11 Resonance structures of a literature $N-3$ alkylated purine ...................... 28

Scheme 2.12 Literature synthesis of diallyl xanthine.............................................29

Scheme 2.13 Synthesis of purinone-based analogues. .............................................. 30

Scheme 2.14 Synthesis of 3-methyl-2-thioxanthine-based analogues. ........................ 31

Scheme 2.15 Synthesis of a 1,3-dimethyluric acid-based analogues.......................... 32

Scheme 2.16 Alkylation of 1,3-dimethyluric acid with iodopropane .......................... 34

Scheme 2.17 Possible mechanism for $C$-5 alkylation of 1,3-dimethyluric acid............ 35

Scheme 2.18 Synthesis of pyrimidine-based analogues........................................... 35

Scheme 2.19 Synthesis of imidazole-based analogues.......................................... 37

Scheme 2.20 Synthesis of phthalimide-based analogues ......................................... 38

Scheme 2.21 Synthesis of allopurinol-based analogues ........................................... 39

Scheme 2.22 Literature Gabriel synthesis of primary amines .................................. 40

Scheme 2.23 Synthesis of terpenoid amines........................................................ 41

Scheme 2.24 Formylation and methylation of terpenoid amines.............................. 41 
Scheme 2.25 Acetylation and methylation of terpenoid amines ................................ 43 


\section{List of Tables}

Table 2.1 Summary of the conditions for terpenoid bromide syntheses. 16

Table 2.2 Summary of the conditions for sodium 3-methylhypoxanthide alkylations .. 20

Table 2.3 Summary of the conditions for purine alkylations. 27

Table 2.4 Summary of the conditions for in purinone alkylations............................... 30

Table 2.5 Summary of the conditions for 3-methyl-2-thioxanthine alkylations............ 31

Table 2.6 Summary of the conditions for 1,3-dimethyluric acid alkylations. ................33

Table 2.7 Summary of the conditions for pyrimidine alkylations. .............................. 36

Table 2.8 Summary of the conditions for imidazole alkylations................................ 37

Table 2.9 Summary of the conditions for potassium phthalimide alkylations. .............. 38

Table 2.10 Summary of the conditions for allopurinol alkylations. ............................ 39

Table 2.11 Summary of the conditions for terpenoid amine syntheses....................... 41

Table 2.12 Summary of the conditions for formylation of terpenoid amines. .............. 42

Table 2.13 Summary of the conditions for terpenoid formamide methylations............42

Table 2.14 Summary of the conditions for terpenoid amine acetylations....................43

Table 2.15 Summary of the conditions for terpenoid acetamide methylations. ............43

Table 3.1 The activities of purine-based analogues against $P$. falciparum ................... 46

Table 3.2 The activites of purinone-based analogues against $P$. falciparum ............... 49

Table 3.3 The activities of 1,3-dimethyluric acid analogues against $P$. falciparum ......51

Table 3.4 The activities of pyrimidine-based analogues against against $P$. falciparum.52

Table 3.5 The activities of other head group-based analogues against $P$. falciparum...54

Table 3.6 The activities of amide-based analogues against $P$. falciparum...................56

Table 3.7 $\mathrm{IC}_{50}$ values for select malonganenone A analogues...................................58

Table 3.8 The activities of purine-based analogues against $T$. brucei....................... 62

Table 3.9 The $\mathrm{IC}_{50}$ values of purine-based analogues against $T$. brucei..................... 62

Table 3.10 The activities of purinone-based analogues against $T$. brucei................... 65

Table 3.11 IC $_{50}$ values of purinone-based analogues against $T$. brucei......................65

Table 3.12 The activities of pyrimidine-based analogues against $T$. brucei. ...............67

Table 3.13 The $\mathrm{IC}_{50}$ values of pyrimidine-based analogues against $T$. brucei .............67

Table 3.14 The activities of other head group-based analogues against T. brucei. ...... 69

Table 3.15 The $\mathrm{IC}_{50}$ values of other head group-based analogues against T. brucei.....69

Table 3.16 The activities of amide-based analogues against $T$. brucei....................... 70 
Table 3.17 The $\mathrm{IC}_{50}$ values of amide-based analogues against $T$. brucei.................... 70

Table 3.18 MIC of compounds active against S. uberis and S. aureus.......................75 


\section{Glossary}

$\delta$

br $\mathrm{s}$

Calcd.

COSY

Complex m

Cytosol

d

dd

DCM

DMA

DMF

DMSO

EA

$\mathrm{Et}_{2} \mathrm{O}$

EtOH

FAM

Gametocyte

HMBC

HRESIMS

HRESIMS/MS

Hsp

HSQC

$\mathrm{Hz}$
Chemical shift (ppm)

Broad singlet

Calculated

Correlation spectroscopy

Overlapping multiplets

The fluid portion in a cell that surrounds organelles

Doublet

Doublet of doublets

Dichloromethane

$N, N$-dimethylacetamide

$\mathrm{N}, \mathrm{N}$-dimethylformamide

Dimethyl sulfoxide

Ethyl acetate

Diethyl ether

Ethanol

Formic acid and acetic anhydride mixture

Gamete precursor that only activates in the mosquito gut

Heteronuclear multiple-bond correlation

High-resolution electrospray ionisation mass spectrometry

High-resolution electrospray ionisation tandem mass spectrometry

Heat shock protein

Heteronuclear single-quantum coherence

Hertz 


\begin{tabular}{|c|c|}
\hline $\mathbf{I C}_{50}$ & Half maximal inhibitory concentration \\
\hline IR & Infrared spectroscopy \\
\hline$J$ & Scalar coupling constant $(\mathrm{Hz})$ \\
\hline LiHMDS & Lithium hexamethyldisilazide \\
\hline $\mathbf{m}$ & Multiplet \\
\hline$m / z$ & Mass to charge ratio \\
\hline МeOH & Methanol \\
\hline Merozoite & Parasite form that invades red blood cells \\
\hline NMR & Nuclear magnetic resonance spectroscopy \\
\hline NOESY & Nuclear overhauser effect spectroscopy \\
\hline $\boldsymbol{P}$. & Plasmodium \\
\hline PE & Petroleum ether \\
\hline PfEMP1 & Plasmodium falciparum erythrocytic membrane protein 1 \\
\hline PfHsp & Plasmodium falciparum heat shock protein \\
\hline RT & Room temperature \\
\hline $\mathbf{S}$ & Singlet \\
\hline SAR & Structure-activity relationship \\
\hline Sporozoite & A motile, infectious spore-like parasite \\
\hline $\mathbf{t}$ & Triplet \\
\hline TEA & Triethylamine \\
\hline THF & Tetrahydrofuran \\
\hline TLC & Thin layer chromatography \\
\hline
\end{tabular}




\section{Introduction}

\subsection{Malaria}

Malaria is a disease caused by parasites of the genus Plasmodium and the parasites cycle between humans and female Anopheles mosquitos. Briefly, the general life cycle of the parasites begins when infected mosquitoes inject immature forms of the parasite into the body, these rampantly multiply in the liver, and then in the blood in a vicious cycle and eventually, sexual gametocytes are ingested by a feeding mosquito where they can reproduce to begin the cycle again (Figure 1.1). ${ }^{1}$ These mosquitos thrive in tropical and subtropical areas, which puts almost half the world's population at risk of contracting a causative parasite. Over 200 million cases of malaria resulted in more than 500000 deaths in 2013 alone. $^{2}$

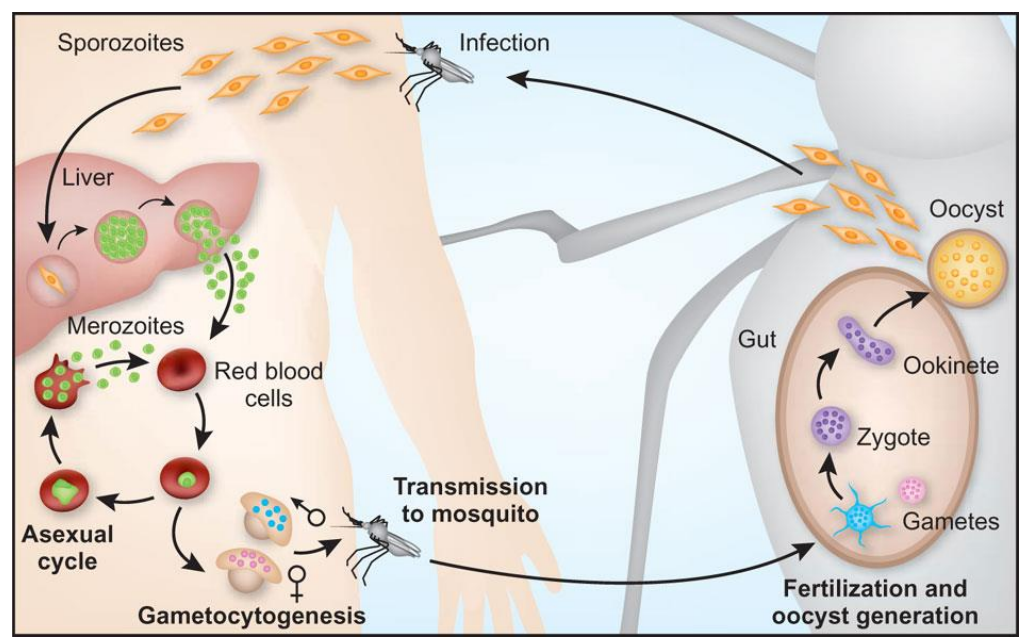

Figure 1.1 General life cycle of Plasmodium parasites. When an infected mosquito takes a blood meal, it also injects sporozoites into the blood stream. These invade and mature in the cells of the liver, before releasing merozoites back into the blood stream. Merozoites invade red blood cells and reproduce asexually in a rampant cycle. Eventually gametocytes form, which will undergo sexual reproduction when ingested by a mosquito to complete the cycle. Reprinted with permission from Macmillan Publishers Ltd: Nature Genetics 42, 284-285, () 2010.

Malaria caused by Plasmodium falciparum, one of the five malaria causative Plasmodium species, is responsible for around $90 \%$ of all malaria related deaths. ${ }^{3}$ In the blood stage, the body would normally clear foreign material inside the red blood cells or eliminate them altogether via the spleen. ${ }^{4}$ However, $P$. falciparum avoids clearance by remodelling the host red blood cell to form surface protrusions called knobs. These knobs present proteins from the P. falciparum erythrocyte membrane protein 1 (PfEMP1) family, which aid in adhering the cell to the blood vessel walls. ${ }^{5}$ In addition, there are a variety of 
PfEMP1s that can be expressed to help the parasite evade the immune system. When the adaptive immune system manages to raise a response to one type of PfEMP1, it will be replaced by another variant. ${ }^{6,7}$ If left untreated cerebral malaria can occur, where infected cells form blockages in the brain capillaries to cause neurological defects and eventually death. $^{8}$

The current major classes of drugs for treating $P$. falciparum malaria are based around artemisinin (1), ${ }^{9-11}$ quinine (2), ${ }^{12-14}$ sulfonamide (3) and pyrimethamine (4) ${ }^{15,16}$ (Figure 1.2), which target various Plasmodium metabolic pathways. ${ }^{17-22}$ Recently, P. falciparum malaria has become resistant to some front line drugs ${ }^{23-30}$ in various regions. Counteractive measures saw the development of drug analogues, but a drug that has the same target is likely to meet the same type of resistance over time. New drugs, especially those with different modes of action must be established before resistance to frontline antimalarial drugs becomes widespread.

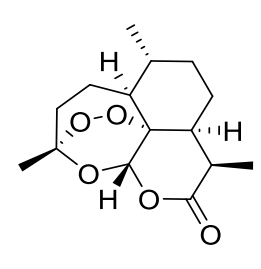

1

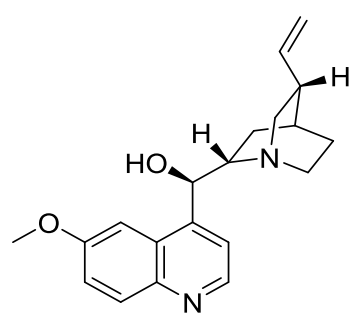

2

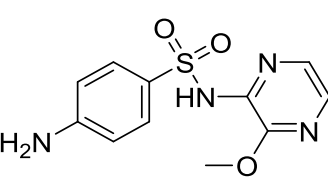

3<smiles>CCc1nc(N)nc(N)c1-c1ccc(Cl)cc1</smiles>

4

Figure 1.2 Structures of some antimalarial drugs used to treat $P$. falciparum malaria.

Stress or heat shock proteins (Hsps) are highly conserved molecular chaperones that maintain proteins. They have been implicated in protein folding, refolding and disassembling aggregates, as well as degradation and trafficking. When cellular stress occurs, during changes in temperature or normal cell growth, proteins are susceptible to denaturing or forming aggregates. Stress can induce or upregulate certain heat shock proteins to restore and maintain protein function. ${ }^{31,32} P$. falciparum parasites experience significant heat shock during the cycle between cold blooded mosquitos and hot blooded mammals, and also during the periodic fevers associated with malaria. To deal with the constant heat shock and establish a successful infection, $P$. falciparum has an array of heat shock proteins, encoded by $2 \%$ of genes within the genome. ${ }^{33,34}$ Furthermore, some of these heat shock proteins actually increase pathogenesis during heat stress. ${ }^{35}$ Plasmodium falciparum heat shock protein 70-1 (PfHsp70-1) is the most well studied Hsp70 in the species and it is present at all stages of the parasite life cycle in the blood 
phase. Plasmodium falciparum heat shock protein 70-x (PfHsp70-x) has not been fully characterised and it was only shown to have in vitro chaperone activity in $2014 .{ }^{36}$ PfHsp70-x is only produced by P. falciparum, which suggests it has a central role in pathogenesis. PfHsp70-x has been implicated in protein transport ${ }^{37}$ and it was also shown to be exported to the red blood cell cytosol, which suggests it is likely responsible for maintaining the function of all other exported proteins. ${ }^{38}$ Bioinformatic studies have further suggested PfHsp70-x co-localises with PfEMP1, the class of proteins responsible for the severe pathogenic nature of $P$. falciparum. ${ }^{39}$

PfHsp70-1 and particularly PfHsp70-x are attractive drug targets since they are vital for normal growth, function, and pathogenesis of the parasites. Furthermore, the ubiquitous nature of heat shock proteins suggests evolutionary divergence is slow. Therefore, drugs that target heat shock proteins are less likely to meet resistance over a short period. Heat shock proteins have already been established as a valid target. For example tanespimycin (5), a less toxic ${ }^{40}$ analogue of geldanamycin (6) (Figure 1.3) from Streptococcus hygroscopius,${ }^{41}$ targets a different class of heat shock protein called Hsp90s and is already progressing through cancer clinical trials. ${ }^{42}$



Figure 1.3 Structures of Hsp90 targeting drugs.

\subsection{Natural products as drugs}

The inherent biological activity of natural products has been exploited by mankind for both beneficial and harmful purposes for centuries. These range from medicines, fragrances, flavours and colours, to poisons and hallucinogens. The highly toxic glycolipid protein ricin from the castor oil plant Ricinus communis has been used as a chemical weapon, ${ }^{43}$ while the poppy plant, Papaver somniferum, has yielded opiate drugs such as morphine (7) and the synthetic derivative codeine (8) for pain relief (Figure 1.4). ${ }^{44}$ 
Including these poppy opiate derivatives, nature has often been the source and inspiration of many drugs currently used today. The latest review by Newman and Cragg revealed natural products, or closely related derivatives, made up $49 \%$ of approved anticancer drugs over a 34 year period from 1981 to $2014 .{ }^{45}$ In addition, the medicinal significance of natural products is apparent in the 2015 joint Nobel Prize in Physiology or Medicine for the discovery of two antiparasitic natural products (Figure 1.4), avermectin (9) from Streptomyces avermitilis ${ }^{46,47}$ and the antimalarial artemisinin (1) from Artemisia annua, ${ }^{48}$ which are significant in relation to this thesis.

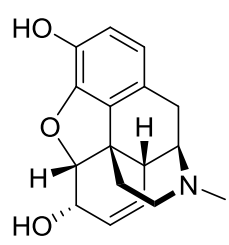

7

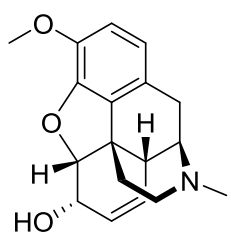

8

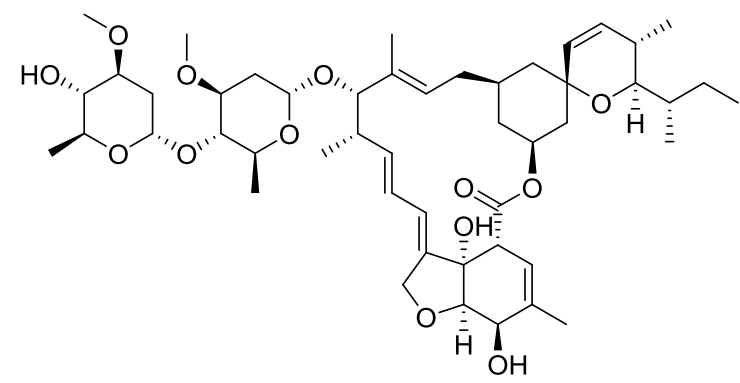

9

Figure 1.4 Structures of select natural products.

Most natural products have been isolated from terrestrial organisms due to ease of accessibility, while the marine environment was largely untapped until the advent of SCUBA in the 1940s. ${ }^{49}$ Currently, the marine environment serves as a rich source of bioactive compounds. Sponges, corals, and algae among many other organisms have provided thousands of marine natural products, which are reviewed yearly. ${ }^{50-52}$ 


\subsection{Malonganenones}

10<smiles>C/C(=C/C(=O)CC(C)C)CCC/C(C)=C/CC/C(C)=C/Cn1cnc2c1c(=O)ncn2C</smiles><smiles>CNC(=O)c1c(N(C)C=O)ncn1C/C=C(\C)CC/C=C(\C)CCC/C(C)=C\C(=O)CC(C)C</smiles>

12<smiles>C/C(=C/C(=O)CC(C)C)CCC/C(C)=C/CC/C(C)=C/CNC=O</smiles>

Figure 1.5 Structures of malonganenone A - C.

Malonganenones A (10), B (11), and C (12) (Figure 1.5) were isolated from Leptogorgia gilchristi, a gorgonian sea fan collected near Ponto Malongane, Mozambique. ${ }^{53}$ Malonganenone A was the first example of a 3,7-disubstituted hypoxanthine isolated from a marine organism while malonganenones $\mathrm{B}$ and $\mathrm{C}$ were the first gorgonian-derived formamides. Furthermore, all three feature an $\alpha, \beta$-unsaturated ketone side chain, which has an unusual $Z$ configuration. Shortly afterwards, malonganenones $\mathrm{D}-\mathrm{H}(\mathbf{1 3}-\mathbf{1 7})$ and the closely related nuttingins A - F $(\mathbf{1 8}-\mathbf{2 3})$ were isolated from another African gorgonian, Euplexaura nuttingi, collected near Pemba Island, Tanzania. ${ }^{54}$ In addition, malonganenones I - K (24-26) were isolated from Euplexaura robusta collected from Weizhou Island of Guangxi Province in the South China Sea (Figure 1.6). ${ }^{55}$ 
(1)

13, $R=b$

14, $R=c$

24, $R=d$

25, $\mathrm{R}=\mathrm{e}$

$a=$<smiles>[Y9]C/C=C(\C)CC/C=C(\C)CCC/C(C)=C\C(=O)CC(C)C</smiles>

$b=$<smiles>CCCC=C(C)CCC=C(C)CCC=C(C)CC(=O)CC(C)C</smiles><smiles>[R]n1cnc2c1c(=O)n(C)c(=O)n2C</smiles><smiles>[R]n1cnc2c1C(=O)N(C)CN2C</smiles><smiles></smiles>

18, $R=b$

$19, R=a$

20, $R=b$

21, $R=c$

22, $R=a$

$c=$

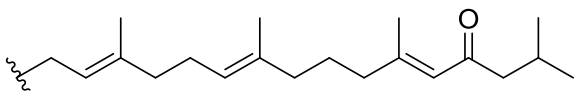

$\mathrm{d}=$

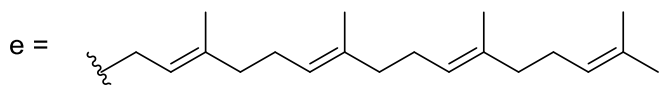

Figure 1.6 Malonganenones $\mathrm{D}-\mathrm{K}$ and nuttingins $\mathrm{A}-\mathrm{F}$.

The nuttingins $(\mathbf{1 8}-\mathbf{2 3})$ are closely related to the malonganenones $(\mathbf{1 3}-\mathbf{1 7}, \mathbf{2 4}-\mathbf{2 6})$ and the proposed biogenic intermediate is nuttingin $\mathrm{F}(\mathbf{2 3})$, an $N$-heterocyclic carbene precursor (Scheme 1.1). ${ }^{56} \mathrm{~N}-1$ Methylation of the malonganenone A head group could yield 23, which is a common intermediate to all nuttingins and malonganenones. Hydrolysis of $\mathbf{2 3}$ at C-2 could produce the head group of malonganenone B. Oxidative degradation of $\mathbf{2 3}$ at $\mathrm{C}-2$ could give rise to nuttingins A and B. Lastly, enzymatic reduction of $\mathbf{2 3}$ could yield nuttingins $\mathrm{C}-\mathrm{E}$.

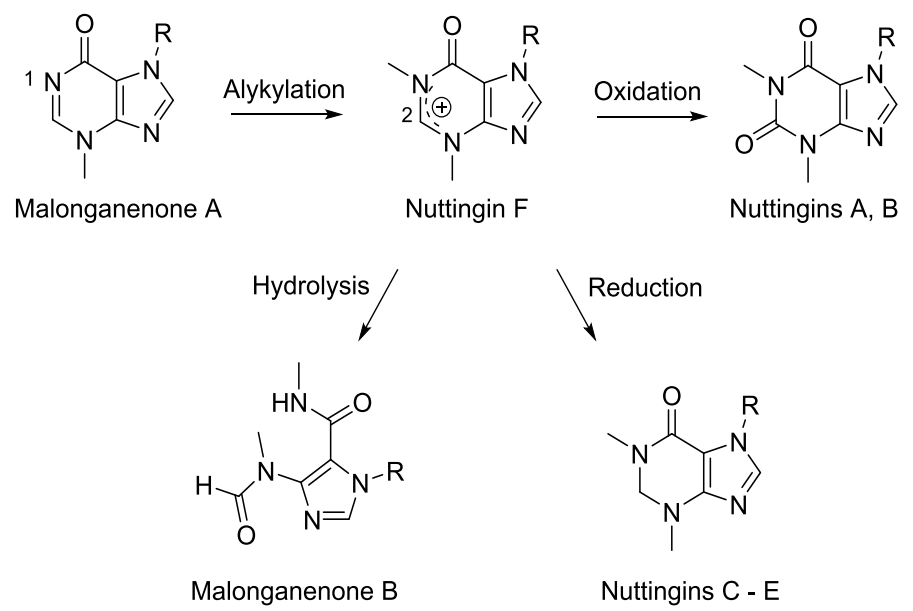

Scheme 1.1 Proposed biosynthetic pathway for interconversion of the malonganenones and nuttingins. ${ }^{57}$ 


\subsection{Malonganenone and nuttingin bioactivities}

Malonganenones A (10), B (11), and C (12) had moderate cytotoxic activity against several oesophageal cancer cell lines (WHCO1, WHCO5, WGCO6, KYSE70, KYSE180, KYSE520, MCF12) with various $\mathrm{IC}_{50}$ values $(17.0 \mu \mathrm{M}->100 \mu \mathrm{M}) .{ }^{53}$ Malonganenones $\mathrm{D}-\mathrm{G}(\mathbf{1 3}$ - 16) were inhibitory to K562 and UT7 tumor cell lines and $1.25 \mu \mathrm{g} / \mathrm{mL}$ caused apoptosis of mammalian cells. Nuttingins A - E (18-22) were also inhibitory to the same tumor cell lines. ${ }^{54}$ Malonganenone I (24) was moderately active against HeLa and K562 cancer cell lines with $\mathrm{IC}_{50}$ values of $10.8 \mu \mathrm{M}$ and $8.7 \mu \mathrm{M}$, respectively. ${ }^{55}$

\subsubsection{Antimalarial activity}

Malonganenones A (10) and C (11) inhibited the growth of the malaria causative species $P$. falciparum inside infected red blood cells with $\mathrm{IC}_{50}$ values of $0.81 \mu \mathrm{M}$ and $5.20 \mu \mathrm{M}$, respectively. ${ }^{36}$ Malonganenone $\mathrm{B}(\mathbf{1 2})$ was poorly active with an $\mathrm{IC}_{50}$ value greater than $50 \mu \mathrm{M}$.

In addition to the antiplasmodial activity, 10 - 12 inhibited the activity of PfHsp70-1 in a malate dehydrogenase aggregation suppression assay in a dose dependent manner. To test compounds for heat shock protein modulation, the model protein malate dehydrogenase was used. This protein is prone to heat-induced aggregation and Hsp70s play a preventative role by chaperoning the proteins. ${ }^{58}$ Compounds active against Hsp70s will result in more aggregated protein in comparison to assays without the compound. The extent of aggregation can be measured by UV-Vis absorbance, in which the aggregates absorb at $360 \mathrm{~nm}$. While $\mathbf{1 0}-\mathbf{1 2}$ were active against PfHsp70-1, they were inactive against a human related Hsp70, ${ }^{36}$ which showed heat shock proteins can be selectively modulated. In addition, $\mathbf{1 0}$ further inhibited the aggregation suppression ability of PfHsp $70-x$ by $20 \%$ at a concentration of $300 \mu \mathrm{M}^{59}$

The function of Hsp70 is dependent on ATP and Hsp40 co-chaperones can greatly enhance the ability of Hsp70 to hydrolyse ATP to ADP, a process called ATPase activity. ${ }^{60}$ Interestingly, 10 strongly inhibited (75\%) the PfHsp40 stimulated ATPase activity of PfHsp70-1 at a concentration of $100 \mu \mathrm{M}$ but had no effect when human Hsp40 was used for stimulation. Moreover, 10 further interrupted the interaction between PfHsp70-X and a human Hsp40 (Hsja1). ${ }^{59}$ 
Malonganenone A (10) displayed the desired properties of an effect Hsp70 inhibitor, inhibition of PfHsp70-1 and PfHsp70-x, but no effect on a human equivalent Hsp70. In addition, 10 was non-toxic towards mammalian cell lines (MDA-231-MB and MCF12A) at $50 \mu \mathrm{M}$, which is more than 50 times the $\mathrm{IC}_{50}$ value against $P$. falciparum $(0.81 \mu \mathrm{M}) .{ }^{59}$

\subsection{Synthesis of malonganenones}

Only the total synthesis of malonganenone $\mathbf{J}(\mathbf{2 5})$ has been reported by the Gundersen group in late September, 2016 (Scheme 1.2). ${ }^{61}$ Malonganenone $\mathbf{J}$ features a 3methylhypoxanthine (27) head group and an $N-7$ geranylgeranyl side chain.

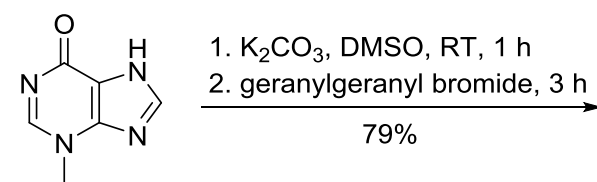

27

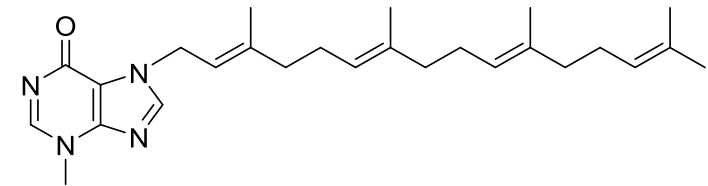

25

Scheme 1.2 Synthesis of malonganenone $\mathbf{J}(\mathbf{2 5}){ }^{61}$

Gundersen's approach made 27 from adenine (28), first alkylating at N-3 with methyl $p$ toluenesulfonate to give the tosyl salt (29). ${ }^{62,63}$ The use of alternative methylating agents such as methyl halides could not be used since they majorly favoured $N-9$ alkylation (70 $-95 \%) .{ }^{64-66}$ Recrystallisation from aqueous ammonia produced 3-methyladenine (30) and deamination with sodium nitrite afforded 27 (Scheme 1.3). ${ }^{67}$ Subsequent alkylation with geranylgeranyl bromide in DMSO primarily afforded 25 in $79 \%$ yield (Scheme 1.2).

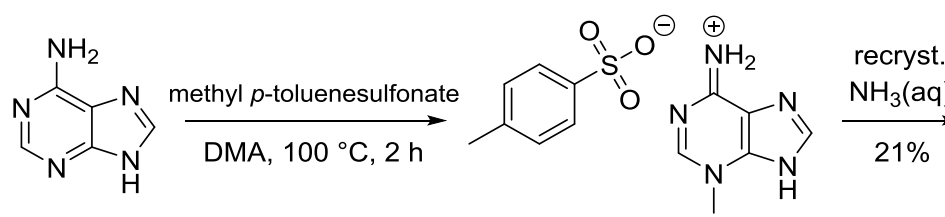

28
29

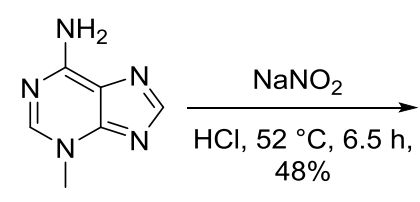

30<smiles>Cn1cnc(=O)c2[nH]cnc21</smiles>

27

Scheme 1.3 Route to head group 27 used in the Gundersen synthesis of malonganenone J. ${ }^{61}$

Another route to 27 has been covered in a single paper (Scheme 1.4), where the target was an intermediate in the total synthesis of another marine natural product, the bromotyrosine aphrocallistin (31) (Figure 1.7) from the Hexactinellida sponge Aphrocallistes beatrix. ${ }^{68}$ 


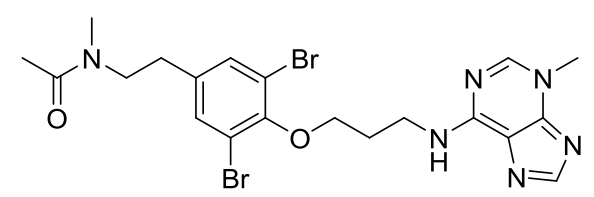

31

Figure 1.7 Aphrocallistin (31), which features a purine-based head group derived from $27 .{ }^{68}$ $\mathrm{N}$-Methylthiourea (32) and ethyl (hydroxyimino)cyanoacetate (33) were first coupled by refluxing with sodium ethoxide in ethanol to form the six-membered ring of nitroso 34 . The nitroso group was then reduced with sodium dithionite to yield diamine $\mathbf{3 5}$ before condensation with trimethyl orthoformate to install the imidazole ring of bicyclic $\mathbf{3 6}$. Finally, desulfurisation with Raney nickel afforded 27. Although both $\mathbf{3 2}$ and $\mathbf{3 3}$ are commercially available, they can be synthesised from $N$-methylthiocyanate $(37)^{69}$ and ethyl cyanoacetate $(\mathbf{3 8}),{ }^{70}$ respectively.

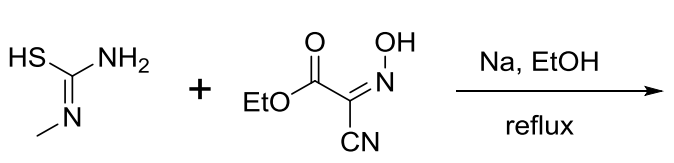

32<smiles>CC([Mg])CON</smiles><smiles>CN=C=S</smiles>

37
33

$\mathrm{NaNO}_{2} \uparrow \begin{array}{r}\mathrm{H}_{2} \mathrm{O}, 0{ }^{\circ} \mathrm{C} \\ 2 \mathrm{~h}, 65 \%\end{array}$<smiles>CCOC(=O)CC[N]</smiles>

38<smiles>Cn1c(S)nc(=O)c(N=O)c1N</smiles>

34 $\mathrm{CH}\left(\mathrm{OCH}_{3}\right)_{3} \mid \begin{gathered}86 \% \text { over three } \\ \text { steps }\end{gathered}$<smiles></smiles>

27

Scheme 1.4 Synthetic route to 27 by Wright et al. ${ }^{68}$ excluding starting material syntheses. ${ }^{69,70}$

\subsection{Research aims}

The aim of this project was to synthesise a library of malonganenone analogues probing both the head group and chain length, for structure-activity relationship (SAR) analysis against $P$. falciparum infected red blood cells.

Malonganenones A (10) and C (12) have identical side chains but the head group of $\mathbf{1 0}$ is based on a purine skeleton whilst the head of $\mathbf{1 2}$ is a simple formamide, yet both had significant antiplasmodial activity against $P$. falciparum. If both have the same mode of action, this could suggest the natural product side chain may not be essential for activity, 
such that a simpler side chain might be used as a substitute. Substitution with a simpler chain is also favoured to avoid the synthetic challenge of the original $\alpha, \beta$-unsaturated ketone side chain (39). However, a simplified analogue of malonganenone B, which substituted the side chain with a methyl group, was completely inactive in the same assays against PfHsp70-1, whereas the activity of $\mathbf{1 1}$ was dose-dependent. ${ }^{36}$ Therefore, the side chain must play some role in the bioactivity of the malonganenones, but it is feasible that the $\mathrm{C}_{20}$ chain (39) just aids in crossing hydrophobic membranes. Therefore, the chain length was probed using the terpenoids geranyl (40), farnesyl (41) and geranylgeranyl (42) isoprenoids which are based on 10, 15, and 20 carbons, respectively (Figure 1.8).
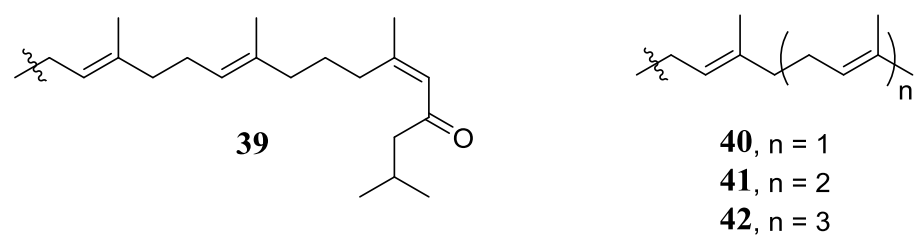

Figure 1.8 The natural product side chain (39) of malonganenones $\mathrm{A}-\mathrm{C}$ and the terpenoids used as substitutes to probe chain length.

Analogues of 10 were accessible through alkylation of purine-based head groups (Scheme 1.5). To probe the SAR of the natural product side chain, the head group must remain the same. The head group of $\mathbf{1 0}$ is 3-methylhypoxanthine (27), which has been synthesised as previously discussed, that could be alkylated with the three side chains mentioned. Purine analogues such as adenine (28), 6-chloropurine (43) and 6-(dimethylamino)purine (44) and the related purinones, xanthine (45), 3-methylxanthine (46), theophylline (47), allopurinol (48) and 1,3-dimethyluric acid (49) could be alkylated to yield further analogues. Interestingly, 47 is the head group of nuttingin A (18) and B (19), the latter has the same side chain as the malonganenones of interest, $10-12$. Other available $N$ heterocyclic head groups such as imidazole (50) and the pyrimidines, uracil (51), thymine (52) and cytosine (53) could be alkylated to furnish further analogues. 


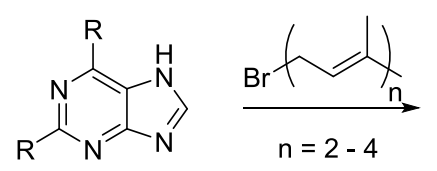<smiles>[R]C1=Nc2nc(CCCCC)nc(n2)C([R])=N1</smiles><smiles>Nc1ncnc2nc[nH]c12</smiles>

28<smiles>Oc1ncnc2[nH]ncc12</smiles>

48<smiles>Clc1ncnc2nc[nH]c12</smiles>

43<smiles>CN(C)c1ncnc2nc[nH]c12</smiles>

44<smiles>O=c1[nH]c(=O)c2[nH]cnc2[nH]1</smiles>

45<smiles>O=c1cc[nH]c(=O)[nH]1</smiles>

51<smiles>Cn1c(=O)[nH]c(=O)c2[nH]cnc21</smiles>

46<smiles>Cc1c[nH]c(=O)[nH]c1=O</smiles>

52<smiles>Cn1c(=O)c2[nH]cnc2n(C)c1=O</smiles>

47

50<smiles>c1c[nH]cn1</smiles>

Scheme 1.5 Proposed route to malonganenone A analogues with various head groups.

Malonganenone C (12) was moderately antiplasmodial $(5.2 \mu \mathrm{M})$ and is much simpler in terms of the head group compared to $\mathbf{1 0}$. Therefore, analogues would be easily accessible to provide more compounds for the library. Analogues of $\mathbf{1 2}$ could be made by formylation of terpenoid amines, this would also probe the SAR of the natural product side chain since the natural product head group of $\mathbf{1 2}$ is a formamide. Closely related analogues could be made by acetylation of terpenoid amines. In addition, various formamides and acetamides could be alkylated to further probe the SAR of the head group (Scheme 1.6).

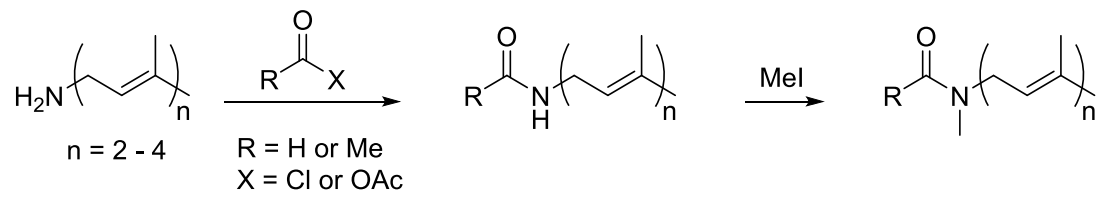

Scheme 1.6 Proposed route to malonganenone C analogues. 


\section{Syntheses}

Malonganenone A exhibited the most desirable antimalarial activity, ${ }^{36,59}$ therefore these analogues were the priority. To first probe the SAR of the natural product terpenoid chain, the natural product head group, 3-methylhypoxanthine (27), was the first target of this project.

\subsection{Synthesis of 3-methylhypoxanthine}

Only the four-step procedure to synthesise 27 was found during literature research. ${ }^{68}$ The same approach was used, beginning from ethyl cyanoacetate (38) to make the ethyl (hydroxyimino)cyanoacetate (33) starting material, ${ }^{70}$ while $N$-methylthiourea (32) was purchased (Scheme 2.1).

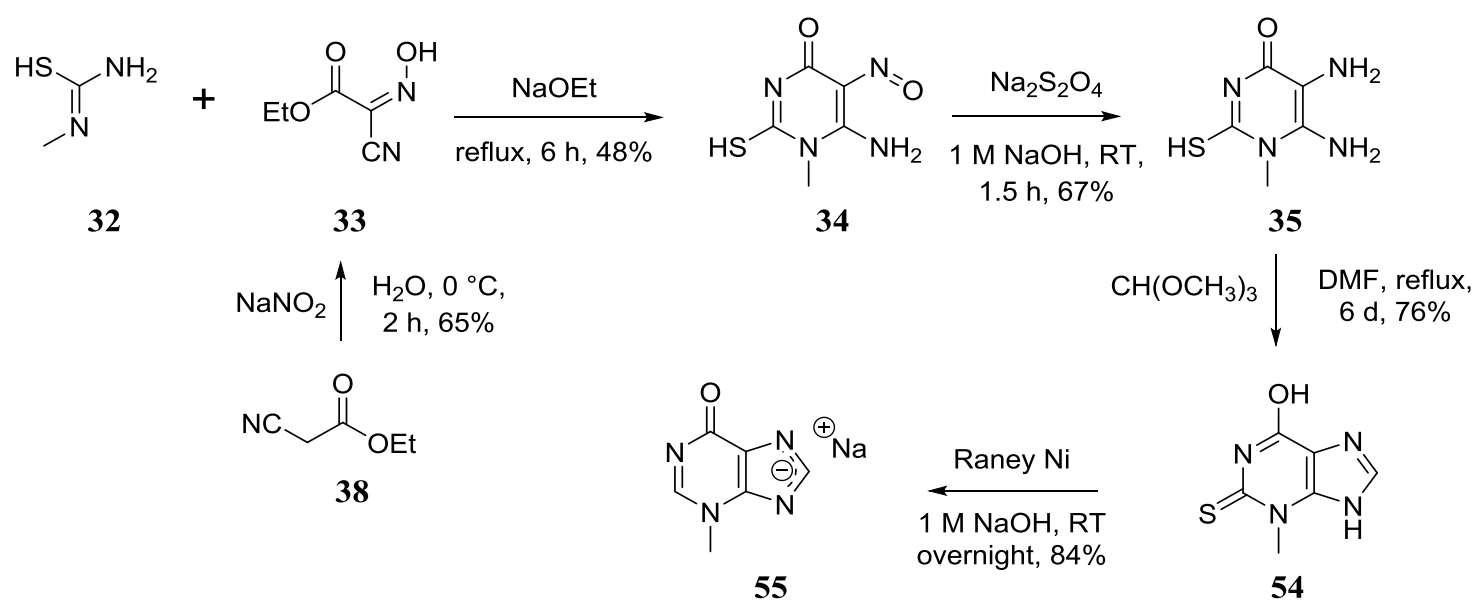

Scheme 2.1 Synthesis of 3-methylhypoxanthine in this work.

The synthesis of $\mathbf{3 3}$ proceeded smoothly in $65 \%$ yield with sufficient purity to continue onto the coupling reaction. Crude $\mathbf{3 3}$ was refluxed with $\mathbf{3 2}$ with freshly prepared $1 \mathrm{M}$ sodium ethoxide. Over time, the yellow precipitate turned red and subsequent acidification by dropwise addition of $1 \mathrm{M} \mathrm{HCl}$ produced a blue-grey precipitate. The precipitate was isolated by filtration and dried in the oven overnight to give nitroso 34 , obtained in $48 \%$ yield, less than the reported $86 \%{ }^{68}$ Nitroso 34 was then reduced with sodium dithionite and diamine $\mathbf{3 5}$ was obtained in $67 \%$ yield, whereas the reported yield was quantitative.

The third step of the route was condensation with trimethyl orthoformate to install the imidazole ring. Diamine 35 was refluxed with trimethyl orthoformate in DMF and the 
resulting precipitate was isolated by filtration and recrystallised from water. Bicyclic product 54 had such poor solubility in boiling water that almost $2 \mathrm{~L}$ was used to recrystallise $1.2 \mathrm{~g}$ of crude $\mathbf{5 4}$. The resulting pale orange precipitate was isolated in $76 \%$ yield, while the reported yield was quantitative. ${ }^{68}$ The difference in yield was likely due to the literature reaction being monitored by LC-MS analysis for complete consumption of starting material, whereas this reaction time was modelled after the literature procedure time, along with monitoring by TLC analysis, which was less accurate than monitoring by LC-MS.

${ }^{1} \mathrm{H}$ NMR analysis of recrystallised 54 revealed the same resonances as reported in the literature ${ }^{68}$ two broad singlets at 13.76 and $12.37 \mathrm{ppm}$ for the exchangeable protons, a singlet at $8.08 \mathrm{ppm}$ for the aromatic proton and lastly, a singlet at $3.72 \mathrm{ppm}$ for the methyl protons. The ${ }^{1} \mathrm{H}$ NMR data reported in the literature ${ }^{68}$ and for the product obtained in this synthesis, disagreed with Wright's proposed lactam structure, 2-mercapto-3methylxanthine (36). Both were obtained in deuterated DMSO, so the solvent did not influence the ratio of tautomers. The resonance at $13.76 \mathrm{ppm}$ corresponded to the exchangeable proton on the nitrogen and the broad singlet at $12.37 \mathrm{ppm}$ was a hydroxyl exchangeable proton. Furthermore, in addition to the desired peaks observed, there were smaller resonances offset by approximately $0.06 \mathrm{ppm}$ for all peaks, excluding the exchangeable proton at $13.76 \mathrm{ppm}$, which suggested a mixture of tautomers. For both tautomers to contain hydroxyl exchangeable protons, the actual structure is based on lactim, rather than lactam, functionality and the tautomerism arises from the imidazole ring, where the proton is either at $N-7$ (54) or $N-9$ (56) (Scheme 2.2).

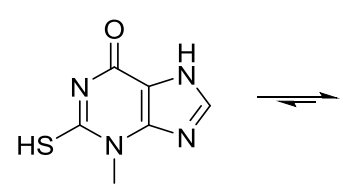

36<smiles>Cn1c(=S)nc(O)c2[nH]cnc21</smiles>

54<smiles>Cn1c(=S)nc(O)c2nc[nH]c21</smiles>

56

Scheme 2.2 Tautomerism of 2-mercapto-3-methylhypoxanthine (36).

Further evidence for the favouring of the lactim tautomers was found in the ${ }^{13} \mathrm{C}$ NMR spectrum, where the major tautomer had a carbon resonance at $174.2 \mathrm{ppm}$, which was suggestive of a thiourea motif. ${ }^{71}$ Comparatively, the ${ }^{1} \mathrm{H}$ NMR spectrum of crude $\mathbf{5 4}$ was for a single tautomer, which suggested the absence of the exchangeable proton in the imidazole ring (Figure 2.1). This is consistent with the basic reaction conditions used, 
therefore crude $\mathbf{5 4}$ was isolated as a salt and recrystallisation protonated the imidazole moiety.

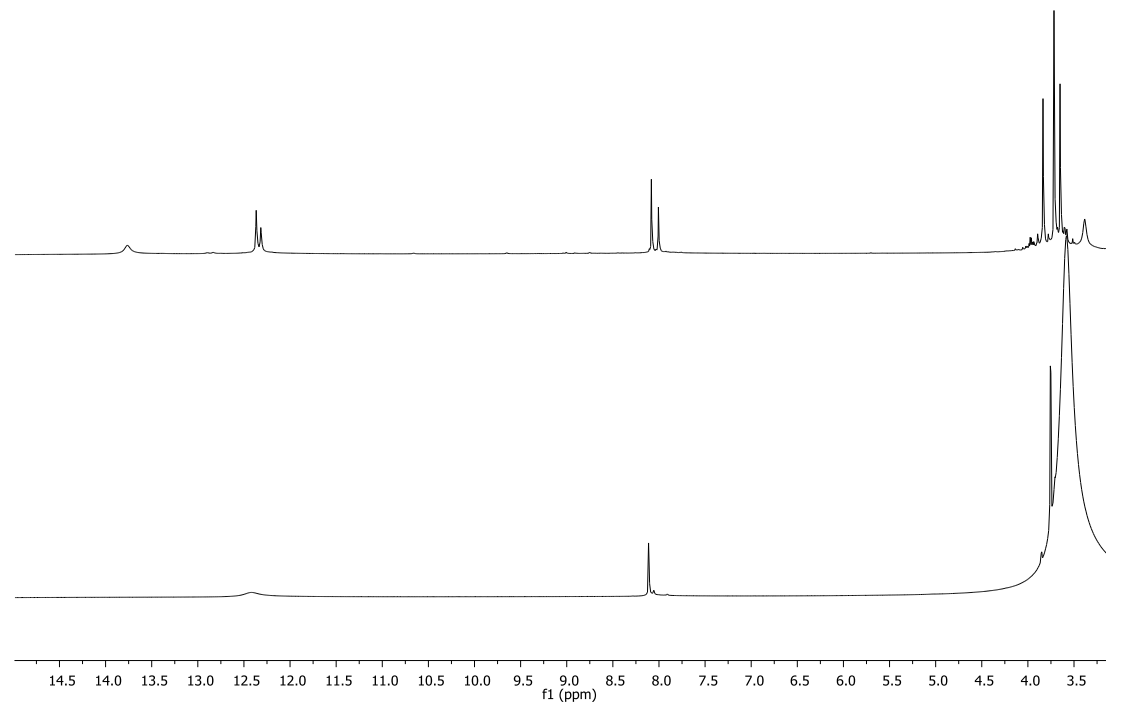

Figure 2.1 ${ }^{1} \mathrm{H}$ NMR spectra (600 MHz, DMSO-d 6 ) of the recrystallised 54 (top) and crude 54 (bottom).

The final step in the route to 3-methylxanthine was desulfurisation with Raney nickel. Raney nickel is a pyrophoric solid and is dangerous when dry; care was taken to ensure the solid was always suspended in water. Fresh, active Raney nickel was prepared by dissolving powdered nickel-aluminium alloy in $2.5 \mathrm{M} \mathrm{NaOH}$ while swirling gently. After much of the bubbling had subsided, the reaction beaker was placed in a desiccator without desiccant overnight. ${ }^{72}$ The spongy black solid was rinsed with water and then propan-2ol three times each, by gently mixing and decanting. Finally, the Raney nickel was suspended in minimal water before the addition of $\mathbf{5 4}$, as a dark orange solution in aqueous $\mathrm{NaOH}$. The reaction was heated in a $40{ }^{\circ} \mathrm{C}$ water bath for several hours with occasional swirling and then left overnight at room temperature. The reaction was filtered and the filtrate solvent was removed under reduced pressure to afford an orange powder. The ${ }^{1} \mathrm{H}$ NMR spectrum of the crude product agreed with the literature, with one methyl and two aromatic resonances at $3.69 \mathrm{ppm}, 7.90 \mathrm{ppm}$ and $7.36 \mathrm{ppm}$, respectively. In addition, there was a resonance at $8.49 \mathrm{ppm}$, which may have been related to starting material or some by-product but the ${ }^{13} \mathrm{C}$ NMR spectrum only presented six resonances, as expected for the desired product. The absence of an imidazole exchangeable proton and therefore tautomers suggested the final product (55) was isolated as a salt, as previously found for crude $\mathbf{5 4}$. 


\subsection{Synthesis of terpenoid bromides}

The terpenoid bromides required are readily available through bromination of appropriate alcohols. Brominating reagents in the literature include carbon tetrabromide with triphenylphosphine, ${ }^{73}$ but overwhelmingly the most common brominating reagent is phosphorus tribromide, as featured in the synthesis of farnesyl bromide and geranylgeranyl bromide. ${ }^{74,75}$ The terpenoid bromides are prone to degradation over time but storage at $-20{ }^{\circ} \mathrm{C}$ slows down this process. ${ }^{76,77}$

The cost of the terpenoid alcohols increase with each additional isoprenoid unit and the use of geranylgeraniol starting material was too expensive for a library of analogues. A significantly cheaper alternative was geranyllinalool, where 10 -fold more was available in comparison to geranylgeraniol for the same cost. However, the product formed was a mixture of geometric isomers at position $2(72: 28 \mathrm{E} / \mathrm{Z}) .{ }^{78,79}$ Using the isomeric mixture for alkylation could potentially yield more analogues per reaction if the geometric products could be separated by chromatography. More analogues would be advantageous for SAR analysis and the influence of alkene geometry could be probed, in addition to head group and chain length. Similarly, isomeric farnesol was cheaper than trans-farnesol and was more appropriate for generating a library of compounds in terms of cost.

Geraniol (57), farnesol (58), and geranyllinalool (59) were reacted with phosphorus tribromide to synthesise the terpenoid bromides (Scheme 2.3, Table 2.1). The reactions proceeded smoothly to give clean crude products in excellent yields, with no trace of starting material by ${ }^{1} \mathrm{H}$ NMR analysis.
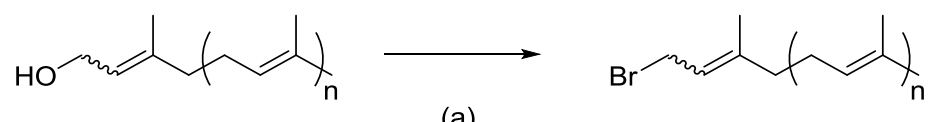

$57, \mathrm{n}=1$

$\mathbf{5 8}, \mathrm{n}=2$

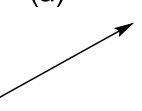

60, $\mathrm{n}=1, \mathrm{E} / \mathrm{Z}$ 1:0

61, $n=2, E / Z$ 8:1

62, $n=3, E / Z 3: 1$

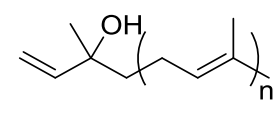

59, $n=3$

Scheme 2.3 Synthesis of terpenoid bromides; (a) Conditions summarised in Table 2.1. 
Table 2.1 Summary of the conditions for terpenoid bromide syntheses.

\begin{tabular}{ccccccc}
\hline Entry & $\mathrm{SM}^{\mathrm{a}}$ & $\mathrm{PBr}_{3}{ }^{\mathrm{b}}$ & Base & Solvent & Time $(\mathrm{h})$ & Yield (\%) \\
\hline 1 & $\mathbf{5 7}$ & 0.46 & - & $\mathrm{Et}_{2} \mathrm{O}$ & 1.5 & 92 \\
2 & $\mathbf{5 8}$ & 0.44 & Pyridine $^{\mathrm{c}}$ & $\mathrm{DCM}$ & 2 & 99 \\
3 & $\mathbf{5 9}$ & 0.41 & - & $\mathrm{Et}_{2} \mathrm{O}$ & 2 & 99 \\
\hline
\end{tabular}

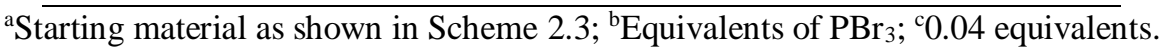

Entries 1 and 3 were based on a procedure from the same paper, ${ }^{80}$ while the procedure of entry 2 was from another source. ${ }^{74}$ The latter included a catalytic amount of pyridine, but this seemed to have no effect on the success of the reaction.

For farnesyl- (61) and geranylgeranyl bromides (62), the ratio of geometric isomers was determined by ${ }^{1} \mathrm{H}$ NMR analysis. The brominated methylene has a slightly different chemical shift for each of the isomers. Although the signals overlap, one peak from each of the doublets was resolved enough for integration and the approximate ratio of the integrals was taken as the $E / Z$ ratio (Figure 2.2). The ratio could also be determined from the ratio of methyl groups closest to the bromine, when the methylene doublets were not well resolved. For farnesyl bromide, the ratio of $E$ and $Z$ isomers was predetermined by the alcohol starting material while the ratio obtained for geranylgeranyl bromide was determined during the reaction, where the more thermodynamically stable $E$ isomer was favoured.
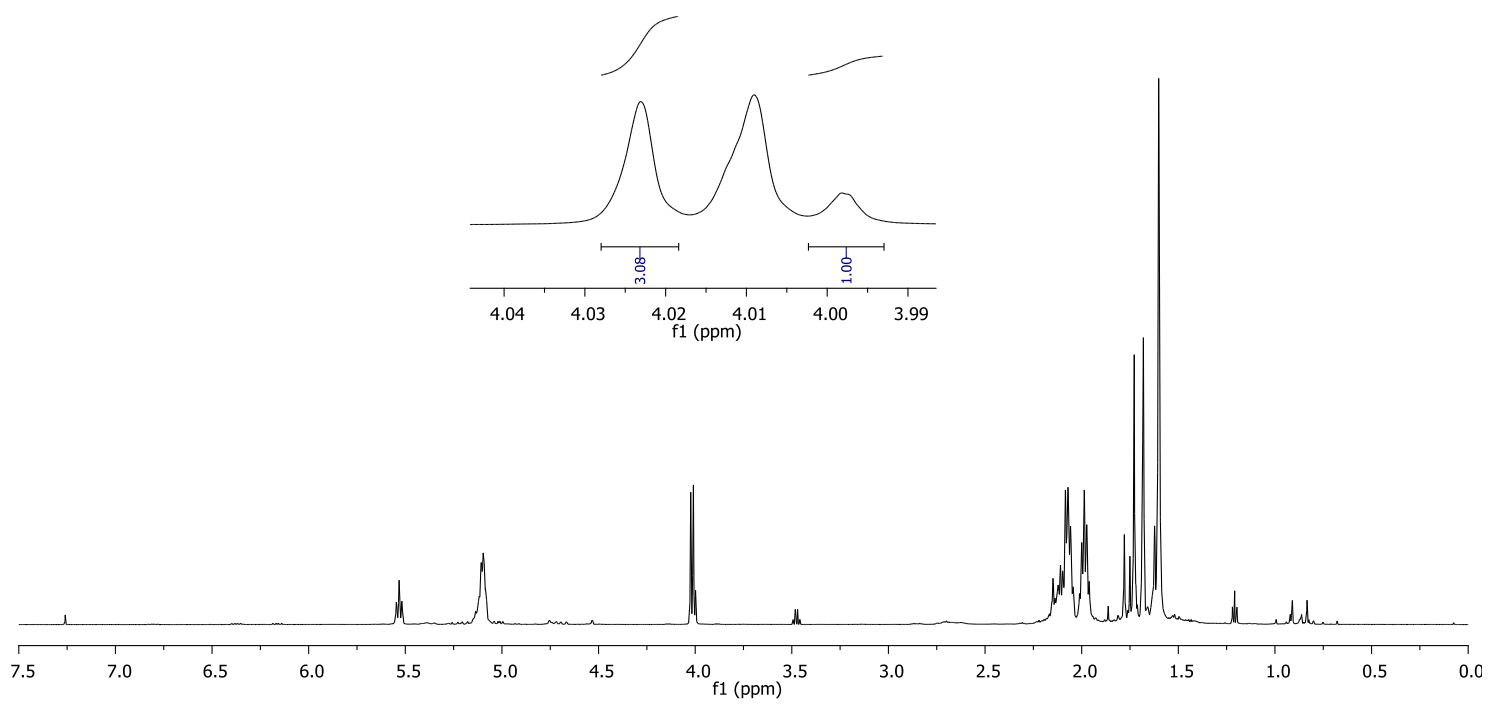

Figure $2.2{ }^{1} \mathrm{H}$ NMR spectrum $\left(600 \mathrm{MHz}, \mathrm{CDCl}_{3}\right)$ of geranylgeranyl bromide (62); inset magnification of the overlapping methylene doublets arising from the $E$ and $Z$ isomers. 


\subsection{Structural elucidation of the terpenoid chains}

All the malonganenone analogues synthesised during the project have terpenoid chains, with three different isoprenoid lengths. Beyond the methylene adjacent to the site of alkylation, the remainder of the chain has proton and carbon chemical shifts conserved across all compounds that have the same chain length. Therefore, the structural elucidation of the terpenoid chain was identical for each compound and the same 2D NMR correlation patterns were observed, which is summarised in this section. Knowledge of the approximate chemical shifts arising from the terpenoid chains before elucidating the structure of unknown compounds was immensely helpful since unique resonances from the head groups were easily identified.

Structures of the chains were solved using a combination of $1 \mathrm{D}$ and $2 \mathrm{D}$ NMR spectroscopy, including ${ }^{1} \mathrm{H}$ and ${ }^{13} \mathrm{C}$ NMR, COSY, HSQC, HMBC and NOESY 2D experiments. Several key correlations observed are shown in Figure 2.3.

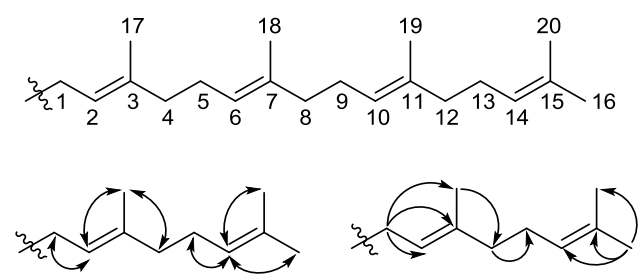

Figure 2.3 Numbering of the geranylgeranyl side chain; Typical COSY and HMBC correlations observed for geranyl side chains shown with double and single headed arrows, respectively.

For the shortest geranyl chain length, beginning at the methylene adjacent to the site of alkylation, which typically appeared as a doublet between $4-5$ ppm, a COSY correlation was observed to the adjacent alkene methine. The newly assigned methine, which had a carbon resonance typically between $115-120 \mathrm{ppm}$ and proton resonance around $4.9 \mathrm{ppm}$, had a COSY correlation through two bonds to the C-3 methyl. A NOESY correlation was also observed between the methylene, adjacent alkene methine and the methyl at C-3. The alkene methine also presented a HMBC correlation to the same C-3 methyl carbon and another $\mathrm{HMBC}$ correlation to the $\mathrm{C}-4$ methylene, which usually resonated at 39.6 ppm. This newly assigned methylene presented a HMBC correlation to the adjacent C-5 methylene, which appeared around $26.2 \mathrm{ppm}$ and these two methylenes were usually overlapping on the ${ }^{1} \mathrm{H}$ NMR spectrum and resonated around $2.1 \mathrm{ppm}$. From the terminal methyl, the quaternary carbon and nearby alkene methine were identified by HMBC correlations. The terminal quaternary carbon usually resonated around $131 \mathrm{ppm}$ while the 
adjacent alkene methine resonated around $123.5 \mathrm{ppm}$ and $5.05 \mathrm{ppm}$ on the ${ }^{13} \mathrm{C}$ and ${ }^{1} \mathrm{H}$ NMR spectra, respectively. Similar evidence was used to assign the protons and carbons for the farnesyl and geranylgeranyl chains. The initial and terminal isoprenoid unit had the same chemical shifts as geranyl, it was only the central isoprenoid units that shifted slightly.

The $2 E$ and $2 Z$ isomers of farnesyl- and geranylgeranyl chains were distinguished by two key ${ }^{13} \mathrm{C}$ NMR signals; the C-3 methyl and C-4 methylene. For the $E$ isomer, the methyl and methylene appeared around 16.5 and $39.5 \mathrm{ppm}$, respectively. For the $Z$ isomer, the methyl appeared more downfield around $23.5 \mathrm{ppm}$ and the methylene was more upfield around $32.2 \mathrm{ppm}$. The significant differences in chemical shift allowed the easy identification of compounds that were isolated as a mixture of geometric isomers since the ${ }^{13} \mathrm{C}$ NMR spectrum had both sets of signals in varying ratios. These patterns were first derived from analysis of the ${ }^{1} \mathrm{H}$ and ${ }^{13} \mathrm{C}$ chemical shifts for the $E$ and $Z$ isomers of geraniol. ${ }^{81}$ The trends were identical, since only the chemical shifts of the first methylene changes significantly with the identity of the adjacent head group.

For some compounds, analysis of the ${ }^{1} \mathrm{H}$ NMR spectrum could also distinguish between the geometric isomers since the chemical shifts in the methylene region changed slightly. The methylenes that were adjacent in the terpenoid chains had similar chemical shifts in the ${ }^{1} \mathrm{H}$ NMR spectra and the signals usually overlapped, H-4/5 in geranyl, as well as $\mathrm{H}-$ $8 / 9$ in farnesyl and H-12/13 in geranylgeranyl since the chemical environments were similar. However, when the alkene geometry was $Z$, the proton chemical environment of the H-4 methylene was different to the H-5 methylene, which resulted in the H-4 methylene resonance appearing more downfield from the H-5 methylene. This effect was easily observed for the geranylgeranyl derivatives, since they have three sets of adjacent methylenes. These displayed four distinct methylene signals for the $Z$ isomer, and only three methylene signals for the $E$ isomer (Figure 2.4). For the $Z$ isomer, the two most downfield methylene signals integrated for two protons each, H-4 and H-5, and the remaining two signals integrated for four protons each since the two later sets of methylenes still have similar chemical environments as the surrounding alkene configurations were still $E$. 

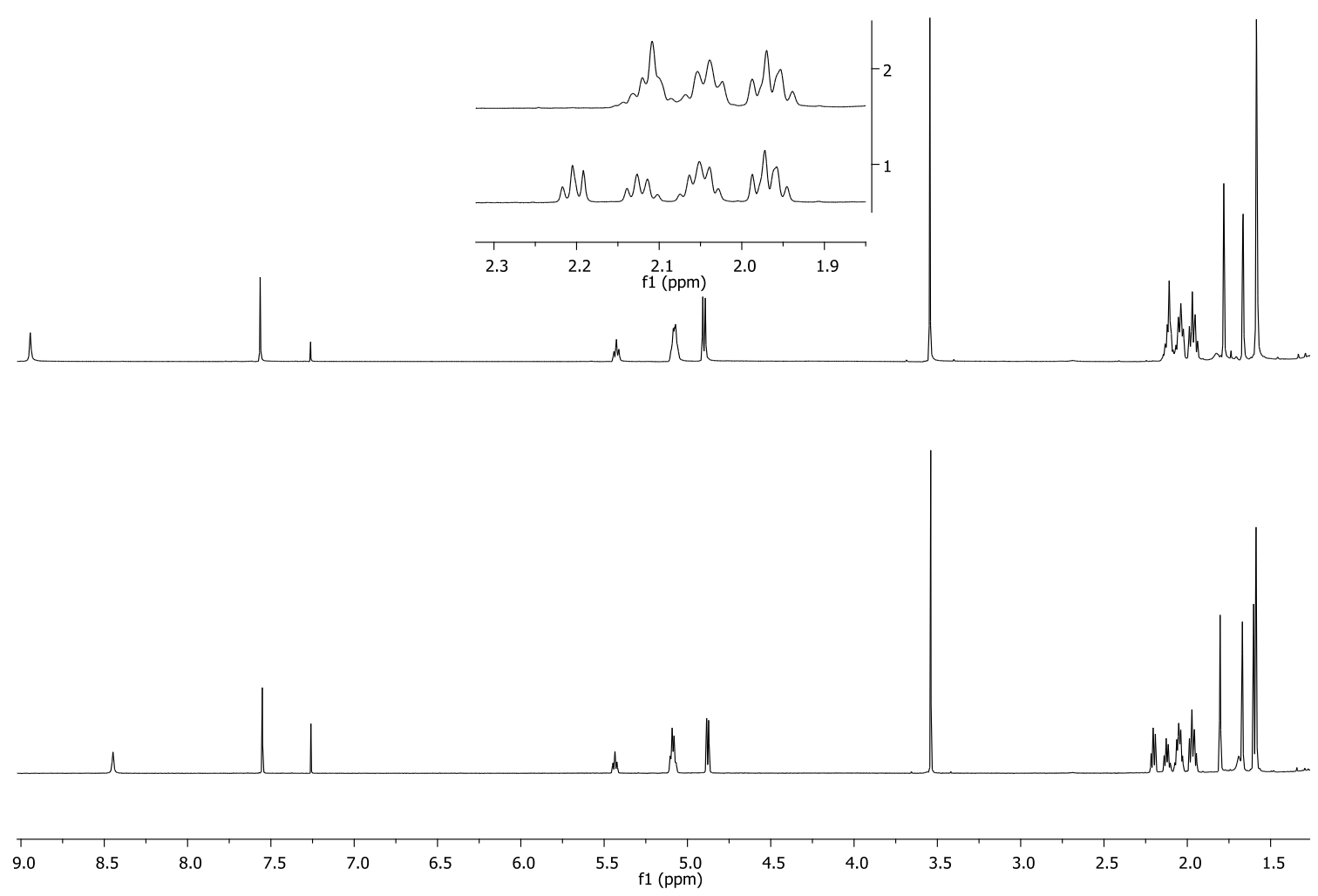<smiles>CC(C)=CCCC(C)=CCCC(C)=CCCC(C)=CCn1cnc2c1c(=O)n(C)c(=O)n2C</smiles>

63

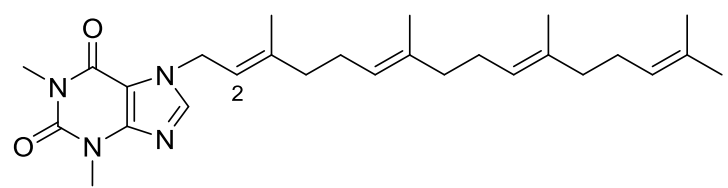

64

Figure 2.4 ${ }^{1} \mathrm{H}$ NMR spectra of geranylgeranyl theophylline (600 MHz, $\left.\mathrm{CDCl}_{3}\right)$; Top $-{ }^{1} \mathrm{H} \mathrm{NMR}$ spectrum of $2 E N-7$ geranylgeranyl theophylline (63); Bottom $-{ }^{1} \mathrm{H}$ NMR spectrum of $2 Z \mathrm{Z}-7$ geranylgeranyl theophylline (64); Inset - expansion of the methylene region.

Not all the carbons on the farnesyl and geranylgeranyl chains could be assigned due to overlapping signals in the 1D and 2D NMR data. Rough assignments could still be made since the chains are comprised of repeating isoprenoid units such that carbons in similar environments were close in chemical shift, for example the C-4, C-8 and C-12 methylenes in a $2 E$ geranylgeranyl chain all appear around $39 \mathrm{ppm}$, while the C-5, C-9 and C-13 methylenes appear around $26 \mathrm{ppm}$. More specific assignments for the methylenes could tentatively be made on the fact that as the terpenoid chain length increased, carbons in similar environments gradually shift downfield as the distance from the head group increased. For the $2 E$ farnesyl chain, the methylenes at C-4 and C-8 resonated around $39.6 \mathrm{ppm}$ and $39.8 \mathrm{ppm}$, respectively, with a difference of $0.2 \mathrm{ppm}$. Following this trend, the C-12 methylene on the geranylgeranyl chain should appear downfield from C-8, which was again, downfield from $\mathrm{C}-4$. 
The same trend of increasingly downfield resonances was observed for the other sets of methylenes and the methines. The only signals that shift upfield further along the chain were the quaternary carbons. C-3 appeared the most downfield, usually between 140 $145 \mathrm{ppm}$, while the terminal C-7 for the geranyl chain appeared around $131 \mathrm{ppm}$. In the farnesyl chain, the middle quaternary carbon (C-7) resonated around $136 \mathrm{ppm}$, while the terminal C-11 resonated around $131 \mathrm{ppm}$. Geranylgeranyl followed the same trends, the first and last quaternary carbons, C-3 and C-15, appeared the most downfield and upfield, respectively, while the two middle signals appear around $135-136 \mathrm{ppm}$. Following the trend of increasingly upfield resonances, the more upfield signal between the two was likely the carbon closer to the end of the chain. Definitive assignments for all compounds could not be made due to overlapping signals in the 1D and 2D NMR data in some cases.

\subsection{Alkylation of 3-methylhypoxanthine}

The alkylation of 3-methylhypoxanthine (27) was the proposed route to generate important side chain analogues of malonganenone A, which have the same head group as the natural product. The starting material, in salt form (55), was used without purification following the literature procedure ${ }^{68}$ in alkylation reactions with the terpenoid bromides (Scheme 2.4, Table 2.2).
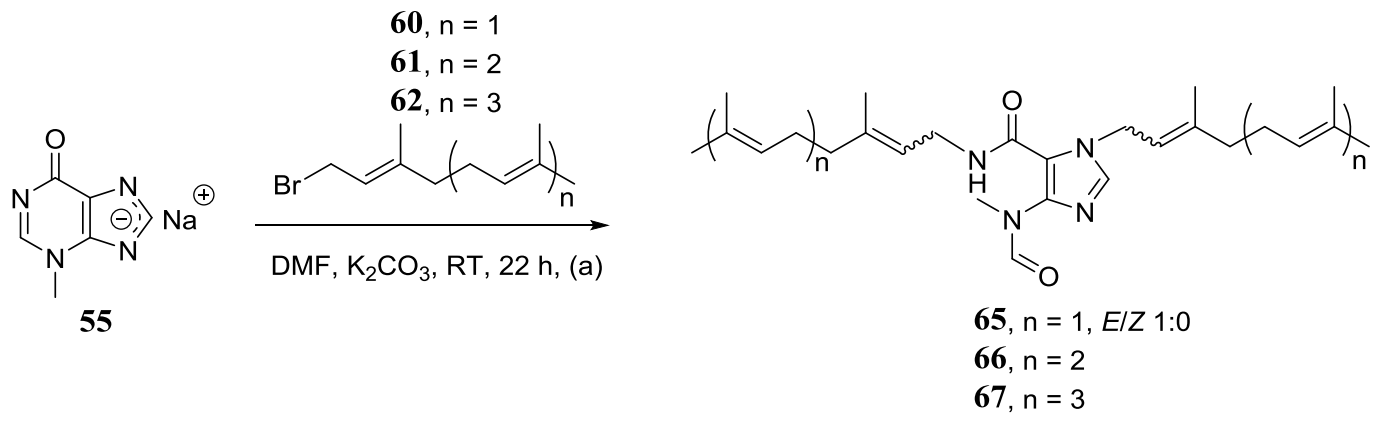

Scheme 2.4 Sodium 3-methylhypoxanthide (55) alkylation; (a) Further conditions summarised in Table 2.2.

Table 2.2 Summary of the conditions for the alkylation of $\mathbf{5 5}$.

\begin{tabular}{cccc}
\hline Entry & T. $^{\mathrm{Br}}{ }^{\mathrm{a}}$ & $\mathrm{T}^{\mathrm{T}} \mathrm{Br}^{\mathrm{b}}$ & Yield $(\%)$ \\
\hline 1 & $\mathbf{6 0}$ & 1.3 & 2 \\
2 & $\mathbf{6 1}$ & 1.3 & 2 \\
3 & $\mathbf{6 2}$ & 1.2 & 3
\end{tabular}

aTerpenoid bromide used, as shown in Scheme 2.4; ${ }^{b}$ Equivalents of terpenoid bromide to $\mathbf{5 5 .}$

Entry 1 summarises the first reaction carried out in this series, the reaction of $\mathbf{5 5}$ with geranyl bromide (60). Only one major product $(\mathbf{6 5})$ was isolated and initially, the ${ }^{1} \mathrm{H}$ NMR 
spectrum appeared too complicated to be a single compound despite the results of TLC analysis. A further attempt at purification by silica gel flash chromatography yielded a compound with the same ${ }^{1} \mathrm{H}$ NMR spectrum. On closer analysis, a doublet at $4.92 \mathrm{ppm}$ and a triplet at $3.99 \mathrm{ppm}$, integrating for two protons each, were indicative of $\mathrm{N}$ methylenes from two geranyl groups. For one of the methylenes to appear as a triplet, it must have been adjacent to another proton in addition to the C-2 methine on the geranyl chain, which could have only been a protonated nitrogen, formed by ring hydrolysis.

Additionally, the methylenes and aromatic peaks had smaller offset peaks, which suggested the product existed as a mixture of rotamers. The presence of rotamers was further supported by an analogue of malonganenone B, also based on an imidazole skeleton with adjacent substituents, which had the same type of signal doubling. ${ }^{56,57}$ The presence of rotamers further explained the complexity of the ${ }^{1} \mathrm{H}$ NMR spectrum of $\mathbf{6 5}$. The same results were obtained for the farnesyl- (entry 2) and geranylgeranyl (entry 3) bromide reactions. The ${ }^{1} \mathrm{H}$ NMR spectral complexity further prevented the estimation of $E / Z$ ratio for the farnesyl- (66) and geranylgeranyl (67) derivatives.

The isolation of hydrolysed products $(\mathbf{6 5}-\mathbf{6 7})$ was consistent with previous findings in the synthesis of malonganenone $\mathbf{J}(\mathbf{2 5}) .{ }^{61}$ Along with the desired $N-7$ geranylgeranylated product 25, Gundersen also isolated dialkylated- (68) and monoalkylated (69) hydrolysed products, in $11 \%$ and $10 \%$ yields, respectively (Figure 2.5 ).

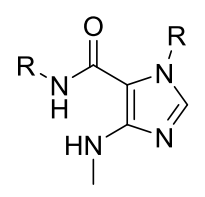

68

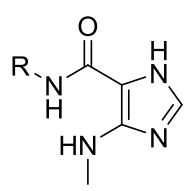

69<smiles>[R]C(C)(C)CC=C(C)CCC=C(C)CCC=C(C)CCC=C(C)C</smiles>

Figure 2.5 Structures of hydrolysed by products isolated during the synthesis of malonganenone J. ${ }^{61}$

Furthermore, in Gundersen's initial optimisation on a model system with a smaller terpenoid, the reaction between geranyl bromide and 27 revealed that when DMF or DMA was used as a solvent, less of the desired $N-7$ alkylated product was formed $(41-82 \%)$, as measured by crude ${ }^{1} \mathrm{H}$ NMR analysis. In addition, tetraalkylammonium salts, such as 70 (Figure 2.6), were formed by reaction of geranyl bromide with the amide solvents, 
which subsequently interfered with purification. Although less of the desired product was formed in DMF, their lowest yield was still a moderate $41 \%$.

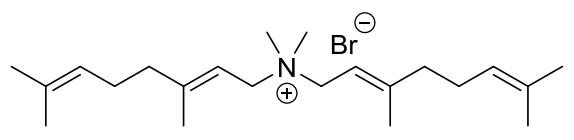

70

Figure 2.6 Tetraalkylammonium salt isolated from the reaction of geranyl bromide and 3methylxanthine in DMF or DMA.

In this thesis work, DMF was used for these reactions but none of the desired $\mathrm{N}-7$ alkylated product was observed by ${ }^{1} \mathrm{H}$ NMR or MS analysis. Since the major product isolated was formed by hydrolysis, this suggested the reaction conditions were not anhydrous. The DMF was the likely source of moisture, especially since the $1 \mathrm{~L}$ bottle used was already opened when this project commenced, so the initial integrity was unknown. Starting material $\mathbf{5 3}$ was freeze dried and the potassium carbonate was stored in a desiccator, so these are less likely to have been the sources of moisture.

Interestingly, alkylation followed by hydrolysis is the proposed mechanism for interconversion of malonganenone $\mathrm{A}$ to nuttingin $\mathrm{F}$ and then malonganenone $\mathrm{B} .{ }^{56} \mathrm{It}$ is no surprise the same facile type of reaction was observed in these syntheses and a possible mechanism is shown in Scheme 2.5. Under basic conditions, any residual water would be deprotonated, so the likely nucleophile was a hydroxide ion.

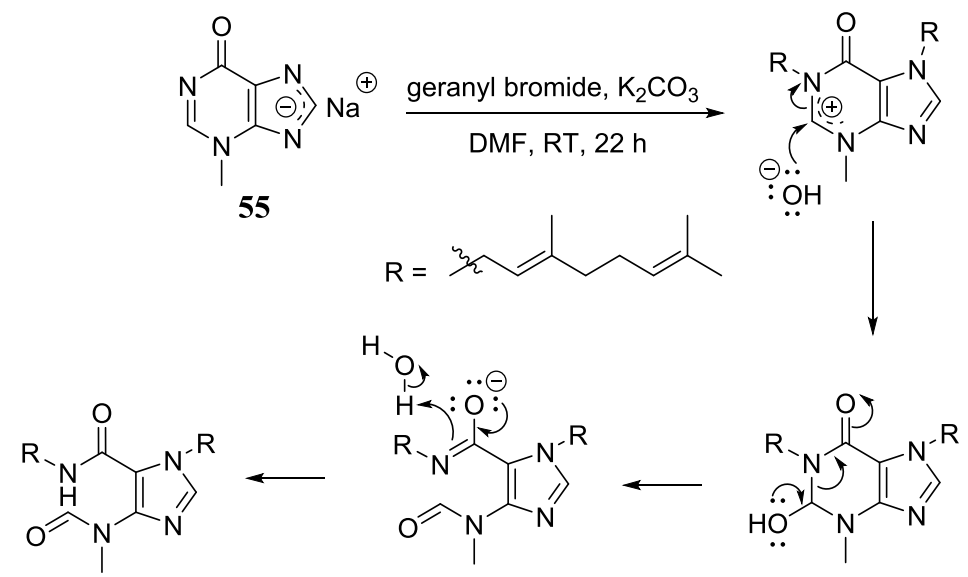

Scheme 2.5 Possible mechanism of hydrolysis for the geranyl derivative of 3methylhypoxanthine. 


\subsection{Alkylation of Purines}

The purines, adenine (28), 6-(dimethylamino)purine (44) and 6-chloropurine (43) were selected for alkylation with the terpenoid bromides.

Previously, terpenoid derivatives of adenine have been synthesised using selective conditions to form the desired products. The reaction of geranylamine with 6-chloro-9(2-tetrahydropyranyl)purine (71), followed by hydrolysis yielded $N$-6 geranyl adenine (72). $N$-6 Farnesyl adenine (73) was formed using the same approach (Scheme 2.6) ${ }^{82}$



71

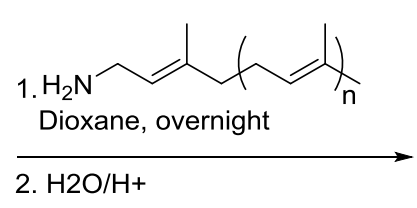

2. $\mathrm{H} 2 \mathrm{O} / \mathrm{H}+$

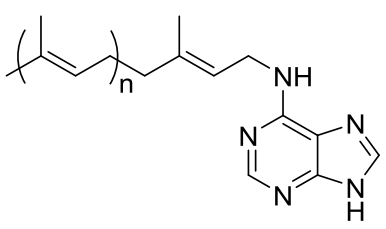

$72, n=2,66 \%$

$\mathbf{7 3}, \mathrm{n}=3,16 \%$

Scheme 2.6 Selective synthesis of $N-6$ terpenoid adenines. ${ }^{82}$

3-Methyladenine (30) has been alkylated with geranylgeranyl bromide, ${ }^{62}$ which yielded an $N$-7 alkylated product and under the same conditions, 9-methyladenine (74) afforded an $N$-1 alkylated product as a salt (75) (Scheme 2.7).<smiles>Cn1cnc(N)c2ncnc1-2</smiles>

30<smiles>Cn1cnc2c(N)ncnc21</smiles>

74 $\underset{\text { DMA }, 50{ }^{\circ} \mathrm{C}, 54 \%}{\stackrel{\text { geranylgeranyl bromide }}{\longrightarrow}}$

DMA, $50{ }^{\circ} \mathrm{C}, 33 \%$<smiles>CC(C)=CCC/C(C)=C/CC/C(C)=C/CC/C(C)=C/Cn1cnc2c1c(=N)ncn2C</smiles><smiles></smiles>

75

Scheme 2.7 Synthesis of geranylgeranyl adenine derivatives. ${ }^{62}$

Only one example of non-selective terpenoid alkylation of adenine (28) was found in the literature. Alkylation of $\mathbf{2 8}$ with three equivalents of geranyl bromide gave a trialkylated product (76), with two geranyl chains at $N-6$ and one at $N-9$ (Scheme 2.8) ${ }^{83}$ The use of less terpenoid bromide could yield monoalkylated products. 

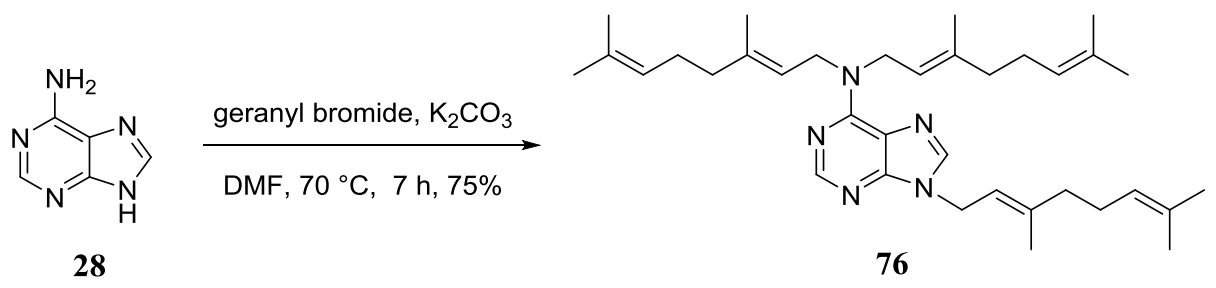

Scheme 2.8 Synthesis of trigeranyled adenine under non-selective conditions. ${ }^{83}$

6-Chloropurine (43) has previously been alkylated with geranylgeranyl bromide in DMF using potassium carbonate as a base to yield both the $N-7$ and $N-9$ geranylgeranylated derivatives in $27 \%$ and $57 \%$ yields, respectively (Scheme 2.9) ${ }^{62}$ Changing the solvent to DMA and adding methylaquacobaloxime resulted in selective alkylation at the N-7 position and the product was isolated in $40 \%$ yield. The selectively synthesised $\mathrm{N}-7$ geranylgeranyl 6-chloropurine was then further reacted with ammonia to convert the C-6 chloro group into an amino group as a means to afford $N-7$ geranylgeranyl adenine. ${ }^{62}$

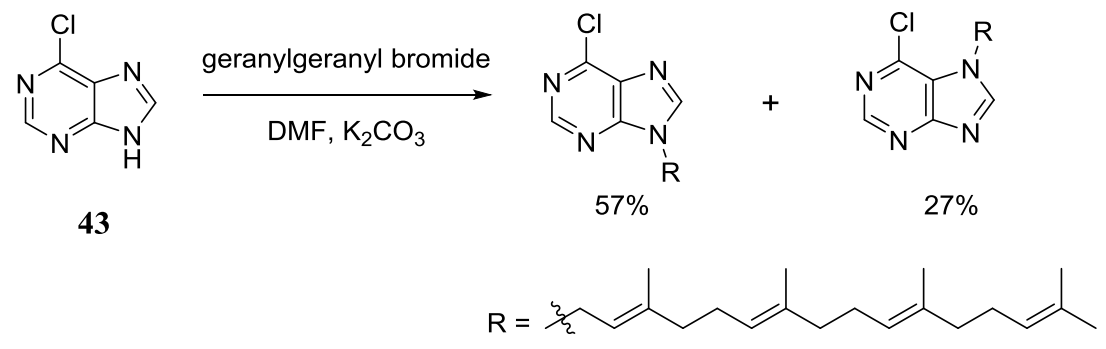

Scheme 2.9 Synthesis of geranylgeranyl derivatives of 6-chloropurine. ${ }^{62}$

Examples of terpenoid derivatives of 6-(dimethylamino)purine (44) were not found in the literature.

For this project, variability in the alkylation position was advantageous since a larger analogue library could better probe the structure-activity relationship of the head group and the potential for more than one regioisomer per reaction was attractive. Therefore, non-selective reaction conditions were used throughout.

The three purine analogues selected were successfully alkylated with the terpenoid bromides and various regioisomers were isolated (Scheme 2.10, Table 2.3). The structures of the purine derivatives were elucidated using $1 \mathrm{D}$ and 2D NMR data. The carbons around the ring were first assigned using several HMBC correlations (Figure 2.7). H-2 and H-8 both presented HMBC correlations to a common carbon that, assuming ${ }^{2-}$ ${ }^{3} J_{\mathrm{CH}}$ were detected, must be C-4. In addition, H-2 and H-8 presented HMBC correlations to C-6 and C-5, respectively. C-6 tended to be more deshielded due to electron 
withdrawing substituents (i.e. $\mathrm{NH}_{2}$ ) while $\mathrm{C}-5$ appeared more upfield, between $110-130$ ppm.

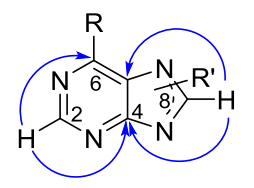

Figure 2.7 Typical observed HMBC correlations used to assign the head group carbon resonances for the purine derivatives.

After assigning the ring carbons, the next step was to identify HMBC correlations from the $\mathrm{N}$-methylene to the head group carbons to determine the position of alkylation. Alkylation at N-7 (77) or N-9 (78) yielded key HMBC correlations from the $N$-methylene to $\mathrm{C}-8$ for both regioisomers but have separate correlations to $\mathrm{C}-4$ or $\mathrm{C}-5$, respectively while alkylation at $\mathrm{N}-3$ (79) presented $\mathrm{HMBC}$ correlations from the $\mathrm{N}$-methylene to $\mathrm{C}-2$ and C-4 (Figure 2.8).

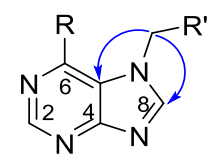

77

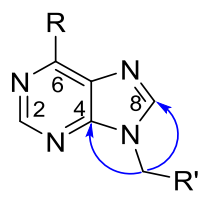

78

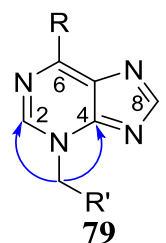

79

Figure 2.8 Observed HMBC correlations for $N-7$ (77), $N-9$ (78) and $N-3$ (79) alkylated purines.

In addition to the use of NMR data for structural elucidation, a single X-ray crystal structure was obtained for $N-3$ geranyl adenine $(\mathbf{8 0})$. This structure confirmed the presented 2D NMR correlations of the compound and greatly aided in the structural elucidation of the other malonganenone A analogues. A large amount of disorder was observed for the geranyl chain, since it can freely rotate once a certain distance from the head group has been reached, around the C-3-C-4 bond (shown as C-8-C-10 in Figure 2.9). 



Figure 2.9 Left - ORTEP diagram of $N-3$ geranyl adenine (80) including $\mathrm{CDCl}_{3}$ with thermal motion drawn at $20 \%$ probability; Right - Depiction of disorder in the geranyl chain.

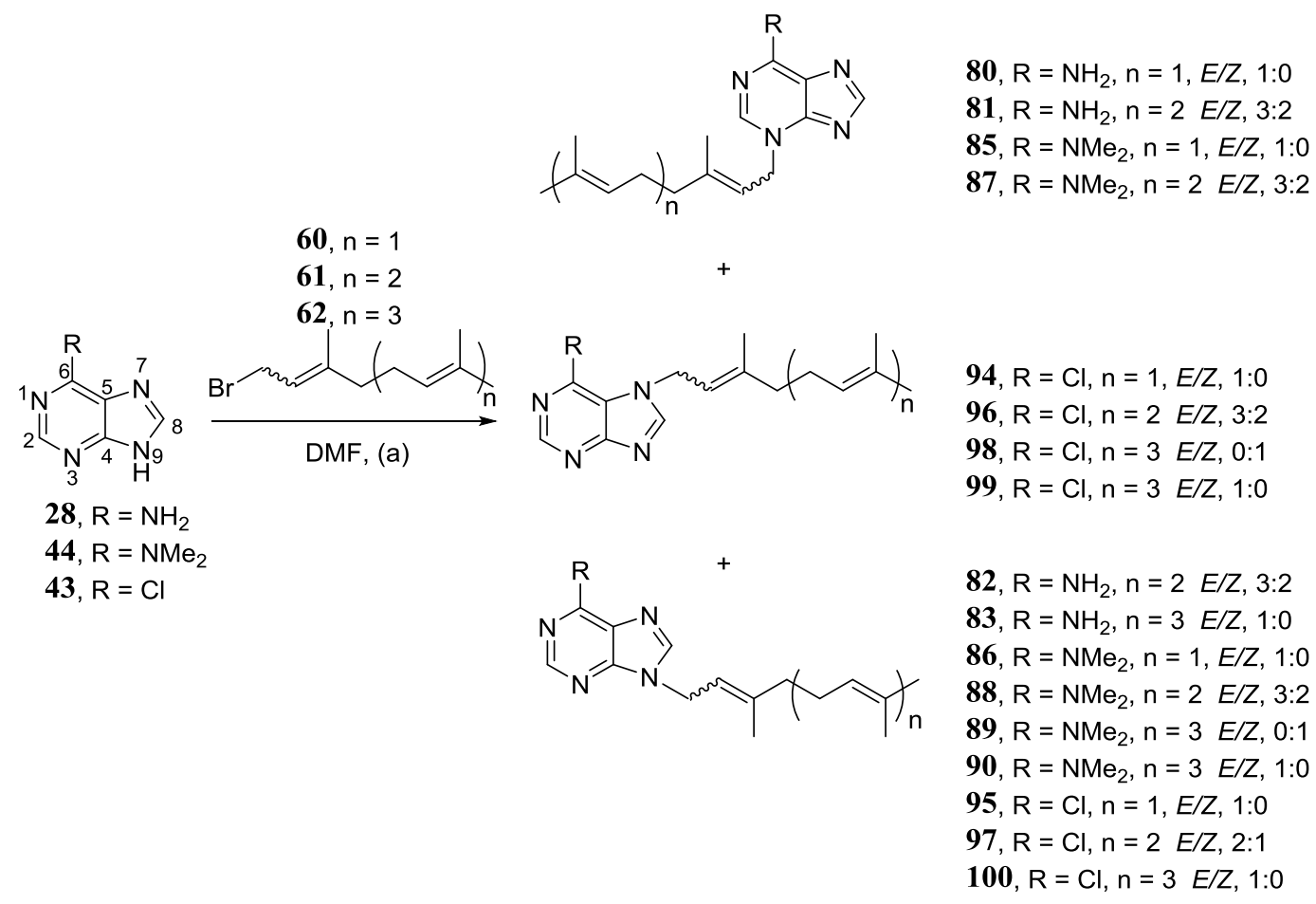

Scheme 2.10 Alkylation of purine-based head groups; (a) Further conditions summarised in Table 2.3. 
Table 2.3 Summary of the conditions for purine alkylations.

\begin{tabular}{cccccccccc}
\hline Entry & Purine $^{\mathrm{a}}$ & $\mathrm{T} . \mathrm{Br}^{\mathrm{b}}$ & $\mathrm{T} . \mathrm{Br}^{\mathrm{c}}$ & $\mathrm{Base}$ & Temp. $\left({ }^{\circ} \mathrm{C}\right)$ & $\mathrm{Time}(\mathrm{h})$ & $\mathrm{N}-3(\%)$ & $\mathrm{N}-7(\%)$ & $\mathrm{N}-9(\%)$ \\
\hline 1 & $\mathbf{2 8}$ & $\mathbf{6 0}$ & 1.2 & $\mathrm{~K}_{2} \mathrm{CO}_{3}$ & $\mathrm{RT}$ & 21 & 19 & - & - \\
2 & $\mathbf{2 8}$ & $\mathbf{6 1}$ & 1.1 & $\mathrm{~K}_{2} \mathrm{CO}_{3}$ & 50 & 27 & 13 & - & 2 \\
3 & $\mathbf{2 8}$ & $\mathbf{6 2}$ & 1.1 & $\mathrm{~K}_{2} \mathrm{CO}_{3}$ & $\mathrm{RT}$ & 27 & - & - & 4 \\
4 & $\mathbf{4 4}$ & $\mathbf{6 0}$ & 2.4 & $\mathrm{Na}_{2} \mathrm{CO}_{3} / \mathrm{K}_{2} \mathrm{CO}_{3}$ & $\mathrm{RT}$ & 48 & 12 & - & 18 \\
5 & $\mathbf{4 4}$ & $\mathbf{6 1}$ & 1.3 & $\mathrm{~K}_{2} \mathrm{CO}_{3}$ & 50 & 21 & 29 & - & 17 \\
6 & $\mathbf{4 4}$ & $\mathbf{6 2}$ & 1.1 & $\mathrm{~K}_{2} \mathrm{CO}_{3}$ & $\mathrm{RT}$ & 44 & $-\mathrm{d}$ & - & 18 \\
7 & $\mathbf{4 3}$ & $\mathbf{6 0}$ & 1.1 & $\mathrm{~K}_{2} \mathrm{CO}_{3}$ & $\mathrm{RT}$ & 21 & - & 20 & 46 \\
8 & $\mathbf{4 3}$ & $\mathbf{6 1}$ & 1.1 & $\mathrm{~K}_{2} \mathrm{CO}_{3}$ & 50 & 24 & - & 21 & 19 \\
9 & $\mathbf{4 3}$ & $\mathbf{6 2}$ & 1.1 & $\mathrm{~K}_{2} \mathrm{CO}_{3}$ & RT & 27 & - & 25 & 15 \\
\hline
\end{tabular}

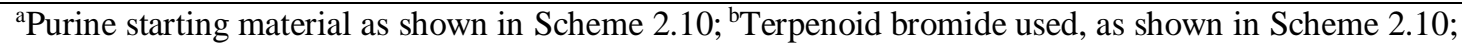
${ }^{c}$ Equivalents of terpenoid bromide to purine; ${ }^{\mathrm{d}}$ This product was isolated, but degraded before characterisation.

Entries 1 - 3 summarise the alkylation of adenine (28) with terpenoid bromides of increasing length. $N-3(\mathbf{8 0}, \mathbf{8 1})$ and $N-9(\mathbf{8 2}, \mathbf{8 3})$ monoalkylated products were isolated, but not for all three reactions since some regioisomers were lost upon purification. The geranyl bromide reaction also produced a minor amount of a digeranyl species (84) (Figure 2.10). No dialkylated species were isolated from the farnesyl- (entry 2) or geranylgeranyl bromide (entry 3) reactions.

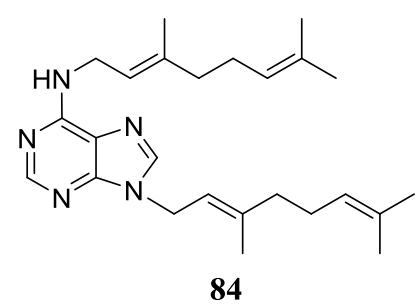

Figure 2.10 Digeranyl adenine.

Entries 4 - 6 summarise the alkylation of 6-(dimethylamino)purine (44). $N-3(\mathbf{8 5}, \mathbf{8 7})$ and $N-9(86,88-90)$ monoalkylated regioisomers were isolated from all three reactions. Interestingly, each ${ }^{1} \mathrm{H}$ NMR spectrum displayed broad signals for the $N$-methyl groups, which suggested slow interconversion between isomeric forms with respect to the NMR time scale. For example, $N-9$ geranyl derivative 86 had an $N$-methyl signal at 3.53 ppm that integrated for six protons while the $N-3$ geranyl derivative 85 had two separate $N$ methyl resonances at $3.92 \mathrm{ppm}$ and $3.33 \mathrm{ppm}$, each integrated for three protons, which indicated they were non-equivalent and some barrier to rotation was present (Figure 2.11). 

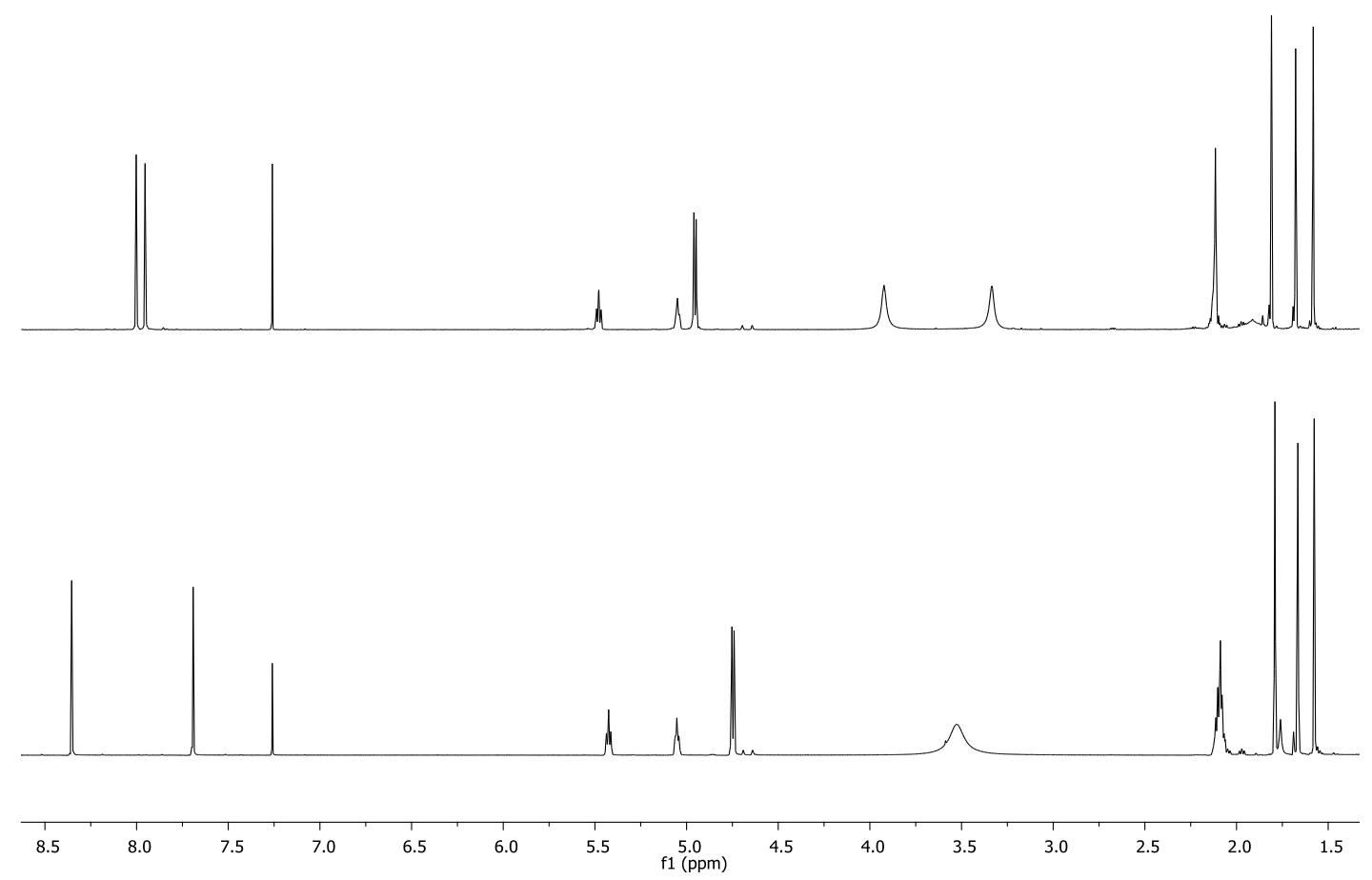

Figure 2.11 ${ }^{1} \mathrm{H}$ NMR spectra (600 $\mathrm{MHz}, \mathrm{CDCl}_{3}$ ) of geranyl 6-(dimethylamino)purine derivatives; top $-N-3$ regioisomer $(\mathbf{8 5})$; bottom $-N-9$ regioisomer $(\mathbf{8 6})$.

The explanation cannot be based on steric hindrance, since any hindering of terpenoid rotation should also prevent alkylation at that position in the first place. Therefore, the broad $N$-methyl resonances observed must a consequence of electronic effects. A study by García-Rubiño and co-workers on alkylation of adenine derivatives, including 44, reported an $N$-3 alkylated product and confirmed the structure with X-ray crystallography. They also observed two broad $N$-methyl resonances and rationalised the non-equivalency arises from resonance hybrid $\mathbf{9 1}$, stabilised by resonance structures 92 and $\mathbf{9 3}$ (Scheme 2.11). ${ }^{84}$ This evidence further supports the proposed $N-3$ alkylated structures.

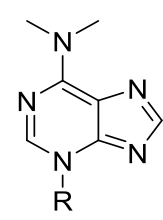

92<smiles></smiles>

91

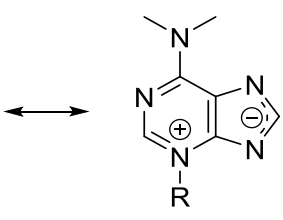

93

Scheme 2.11 Resonance structures of an $N$-3 alkylated derivative of 6-(dimethylamino)purine. ${ }^{84}$

Entries 7 - 9 summarise the alkylation of 6-chloropurine (43), which resulted in the isolation of $N-7(94,96,98,99)$ and $N-9(95,97,100)$ alkylated regioisomers, where the latter was favoured. This is consistent with literature precedent, ${ }^{62}$ the electronegative $C$ 6 chlorine deactivates the pyrimidine ring to prevent alkylation at N-3. 


\subsection{Alkylation of purinones}

The selected purinones, xanthine (45), 3-methylxanthine (46), and theophylline (47) are related by increasing methylation. The other two purinones selected were 1,3dimethyluric acid (49) and 2-mercapto-3-methylhypoxanthine (36), where the latter was an intermediate in the synthesis of 3-methylhypoxanthine (27). This section discusses the alkylation results of $\mathbf{4 5}-\mathbf{4 7}, \mathbf{4 9}$, and $\mathbf{3 6}$, separately.

Reports of the synthesis of terpenoid derivatives of these purinones were not found in the literature. The closest example was the alkylation of xanthine with allyl bromide (Scheme 2.12). ${ }^{85}$ Xanthine was first silylated and then reacted with two equivalents of allyl bromide, producing two diallylated products. The $N-7, N-9$ product (101), isolated as a salt, was favoured over the $N-7, N-3$ product (102) in an approximate 3:1 ratio. The authors rationalised that allyl bromide is highly reactive, but as two equivalents of the alkylating agent were used, double alkylation could be expected. ${ }^{85}$

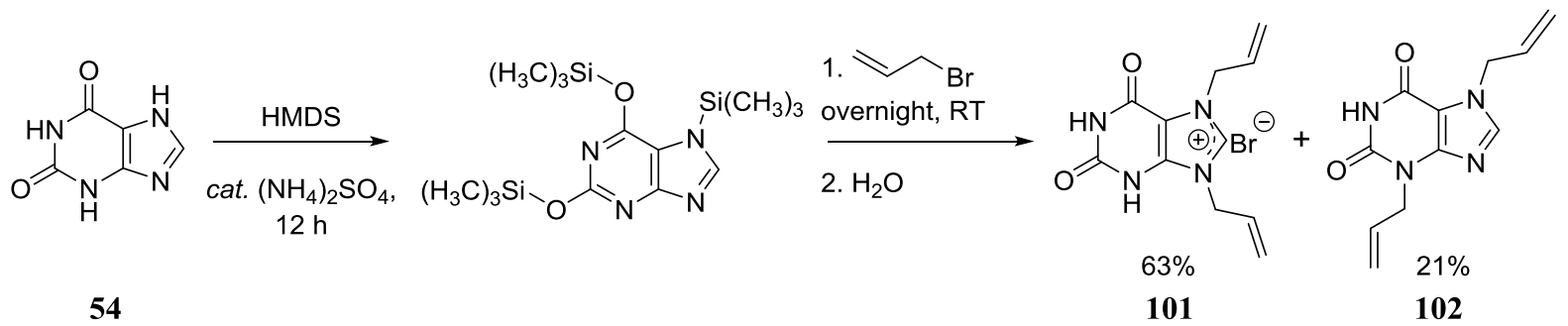

Scheme 2.12 The alkylation of xanthine with allyl bromide. ${ }^{85}$

Purinones $45-47$ were reacted with the terpenoid bromides to give primarily $N-7$ alkylated products (Scheme 2.13, Table 2.4). Xanthine had additional alkylation at N-3; even though only one equivalent of terpenoid bromide was used, no monoalkylated species were isolated.

The structures of the $N-7$ alkylated purinones were elucidated using $1 \mathrm{D}$ and 2D NMR data in the same way as previously discussed for the purines. The ${ }^{13} \mathrm{C}$ resonances of the head group were first determined by HMBC correlations from protons on the head group $(\mathbf{1 0 3}-\mathbf{1 0 5})$ (Figure 2.12). Then, the position of alkylation was determined by the HMBC correlations from the $\mathrm{N}$-methylene to the previously assigned carbons on the head group $(106-108)$. 


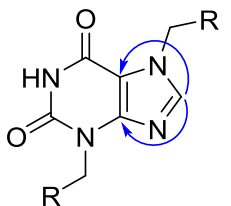

103

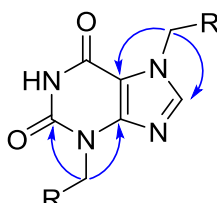

106

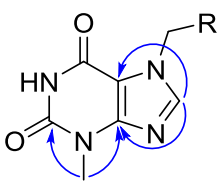

104<smiles>[R]C1CC2CCC(C1)N2CCO</smiles>

107

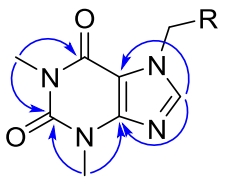

105

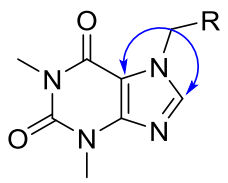

108

Figure 2.12 Typical HMBC correlations observed that were used to assign the ${ }^{13} \mathrm{C}$ resonances of the head group and then to determine position of alkylation of xanthine $(\mathbf{1 0 3}, \mathbf{1 0 6}), 3$ methylxanthine $(\mathbf{1 0 4}, \mathbf{1 0 7})$ and theophylline $(\mathbf{1 0 5}, \mathbf{1 0 8})$ derivatives.

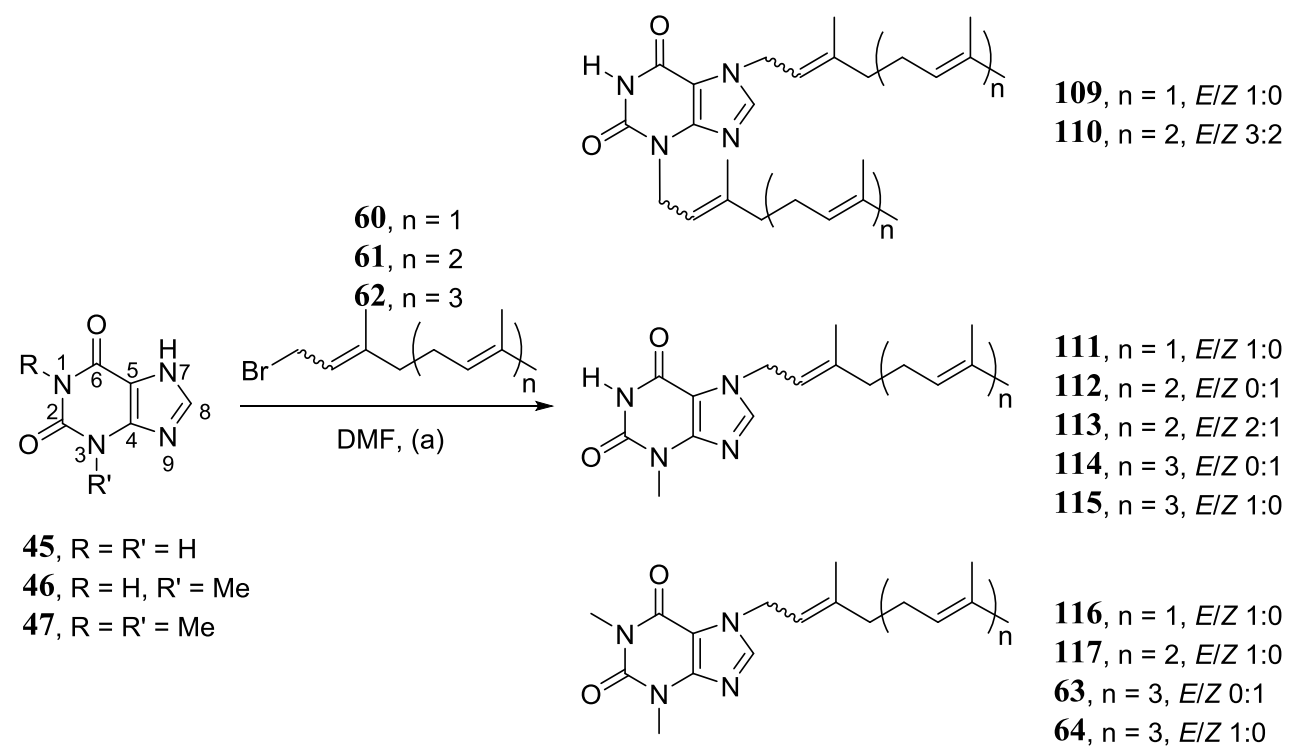

Scheme 2.13 Alkylation of purinone-based head groups; (a) Further reaction conditions in Table 2.4.

Table 2.4 Summary of the conditions for purinone alkylations.

\begin{tabular}{cccccccc}
\hline Entry & Purinone $^{\mathrm{a}}$ & $\mathrm{T} . \mathrm{Br}^{\mathrm{b}}$ & $\mathrm{T} . \mathrm{Br}^{\mathrm{c}}$ & Base & Temp. $\left({ }^{\circ} \mathrm{C}\right)$ & Time $(\mathrm{h})$ & $\mathrm{N}-7(\%)$ \\
\hline 1 & $\mathbf{4 5}$ & $\mathbf{6 0}$ & 1.2 & $\mathrm{~K}_{2} \mathrm{CO}_{3}$ & $\mathrm{RT}$ & 48 & $9^{\mathrm{d}}$ \\
2 & $\mathbf{4 5}$ & $\mathbf{6 1}$ & 1.2 & $\mathrm{~K}_{2} \mathrm{CO}_{3}$ & $\mathrm{RT}$ & 25 & $3^{\mathrm{d}}$ \\
3 & $\mathbf{4 6}$ & $\mathbf{6 0}$ & 2.1 & $\mathrm{Na}_{2} \mathrm{CO}_{3} / \mathrm{K}_{2} \mathrm{CO}_{3}$ & 50 & 48 & 5 \\
4 & $\mathbf{4 6}$ & $\mathbf{6 1}$ & 1.7 & $\mathrm{~K}_{2} \mathrm{CO}_{3}$ & $\mathrm{RT}$ & 21 & 51 \\
5 & $\mathbf{4 6}$ & $\mathbf{6 2}$ & 1.5 & $\mathrm{~K}_{2} \mathrm{CO}_{3}$ & $\mathrm{RT}$ & 44 & 30 \\
6 & $\mathbf{4 7}$ & $\mathbf{6 0}$ & 2.0 & $\mathrm{Na}_{2} \mathrm{CO}_{3} / \mathrm{K}_{2} \mathrm{CO}_{3}$ & 50 & 3 & 45 \\
7 & $\mathbf{4 7}$ & $\mathbf{6 1}$ & 1.1 & $\mathrm{Na}_{2} \mathrm{CO}_{3} / \mathrm{K}_{2} \mathrm{CO}_{3}$ & 80 & 5 & 47 \\
8 & $\mathbf{4 7}$ & $\mathbf{6 2}$ & 1.1 & $\mathrm{~K}_{2} \mathrm{CO}_{3}$ & $\mathrm{RT}$ & 25 & 25 \\
\hline
\end{tabular}

${ }^{a}$ Purinone starting material as shown in Scheme 2.13 ; $^{\mathrm{b}}$ Terpenoid bromide used, as shown in Scheme 2.13; 'Equivalents of terpenoid bromide to purinone; ${ }^{\mathrm{d} I n c l u d e d}$ additional $\mathrm{N}-3$ alkylation.

Entries 1 and 2 summarise the reactions of xanthine (45) with geranyl- and farnesyl bromide, respectively. In both cases, only $N-3, N-7$ dialkylated products $(109,110)$ were isolated. Perhaps less than one equivalent of terpenoid bromide could have yielded monoalkylated derivatives. The reaction with geranylgeranyl bromide was attempted, but unfortunately the digeranylgeranyl product was not isolated. 
Entries 3 - 5 summarise the alkylation of 3-methylxanthine (46) with terpenoids of increasing chain lengths, respectively. All three reactions yielded $N-7$ alkylated derivatives $(111$ - 115), this site was presumably favoured since the N-9 site was sterically hindered by the $N-3$ methyl. Entries $6-8$ summarise the theophylline (47) alkylation reactions, again only $N-7$ alkylated products $(\mathbf{1 1 6}, \mathbf{1 1 7}, \mathbf{6 3}, \mathbf{6 4})$ were isolated.

The lactim tautomer (54) of 2-mercapto-3-methylhypoxanthine (36) was isolated as an intermediate in the synthesis of 3-methylhypoxanthine (27). This head group is a purinone analogue and closely resembles the natural product head group of malonganenone A, therefore it was also alkylated. These reactions proceeded in a cleaner fashion than the reactions with the salt of $\mathbf{2 7}$ and gave the expected products, but still with poor yields (Scheme 2.14, Table 2.5). The site of hydrolysis observed for the 3-methylhypoxanthine derivatives was protected by the thiourea group, so the major products isolated were $N-7$ alkylated (118-121) in all cases. The structures were elucidated using $1 \mathrm{D}$ and $2 \mathrm{D}$ NMR data, using the same HMBC correlations as observed for the 3-methylxanthine derivatives $(\mathbf{1 0 4}, \mathbf{1 0 7})$ (Figure 2.12).

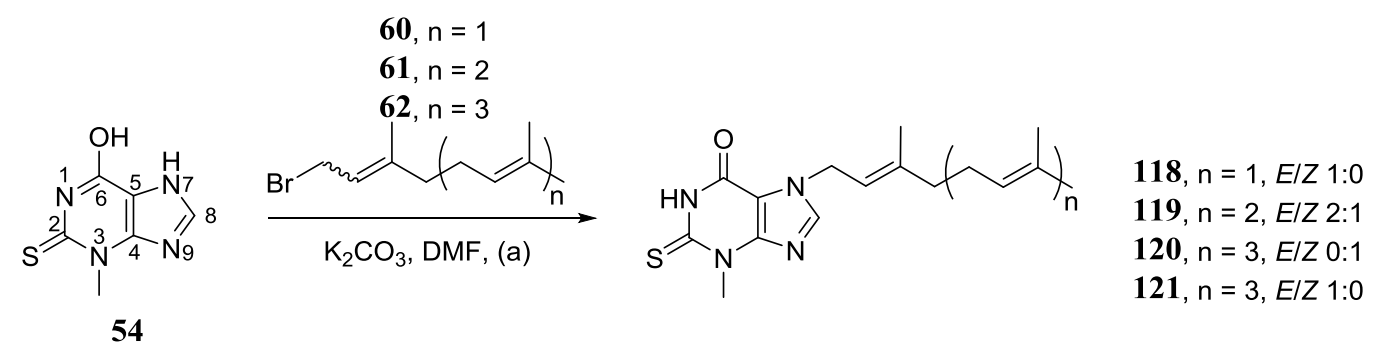

Scheme 2.14 Alkylation of 54; (a) Further reaction conditions summarised in Table 2.5.

Table 2.5 Summary of the conditions for alkylation of 54 .

\begin{tabular}{ccccc}
\hline $\mathrm{T}_{\mathrm{B}} \mathrm{Br}^{\mathrm{a}}$ & $\mathrm{T} . \mathrm{Br}^{\mathrm{b}}$ & Temp. $\left({ }^{\circ} \mathrm{C}\right)$ & Time $(\mathrm{h})$ & $\mathrm{N}-7(\%)$ \\
\hline $\mathbf{6 0}$ & 1.3 & 70 & 30 & 6 \\
$\mathbf{6 1}$ & 1.2 & 50 & 41 & 3 \\
$\mathbf{6 2}$ & 1.1 & $\mathrm{RT}$ & 24 & 5
\end{tabular}

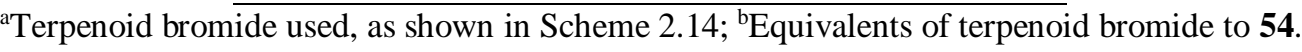

To circumvent hydrolysis of the 3-methylhypoxanthine compounds, perhaps these derivatives could be synthesised first and then desulfurised with Raney nickel. Raney nickel with a low activity could selectively desulfurise rather than hydrogenate alkenes. Highly active Raney nickel could hydrogenate the alkenes of the terpenoid tails, which could also be attractive for generating further analogues. 
The third purinone-based head group was 1,3-dimethyluric acid (49), reports of which have not been previously derivatised with terpenoid chains in the literature. Considering the possible tautomers of $\mathbf{4 9}$ (Figure 2.13), alkylation could occur at four different sites, N-7, N-9, O-6, or O-8, with a chance of dialkylation.

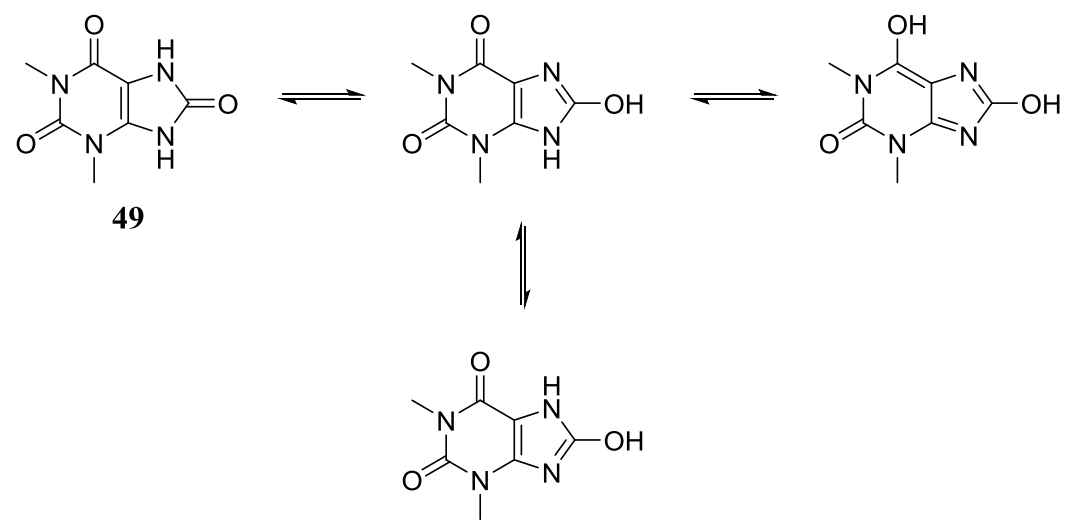

Figure 2.13 Possible tautomers of 49.

However, alkylation resulted in unexpected $C-5$ monoalkylated compounds for each reaction (Scheme 2.15, Table 2.6), which was vastly different to the $\mathrm{N}-7$ alkylated products obtained for the previous purinones. Only a minor amount of $N-9$ alkylated product was isolated from the farnesyl bromide reaction (entry 2). The additional C-8 carbonyl clearly had a large influence on the alkylation pattern.

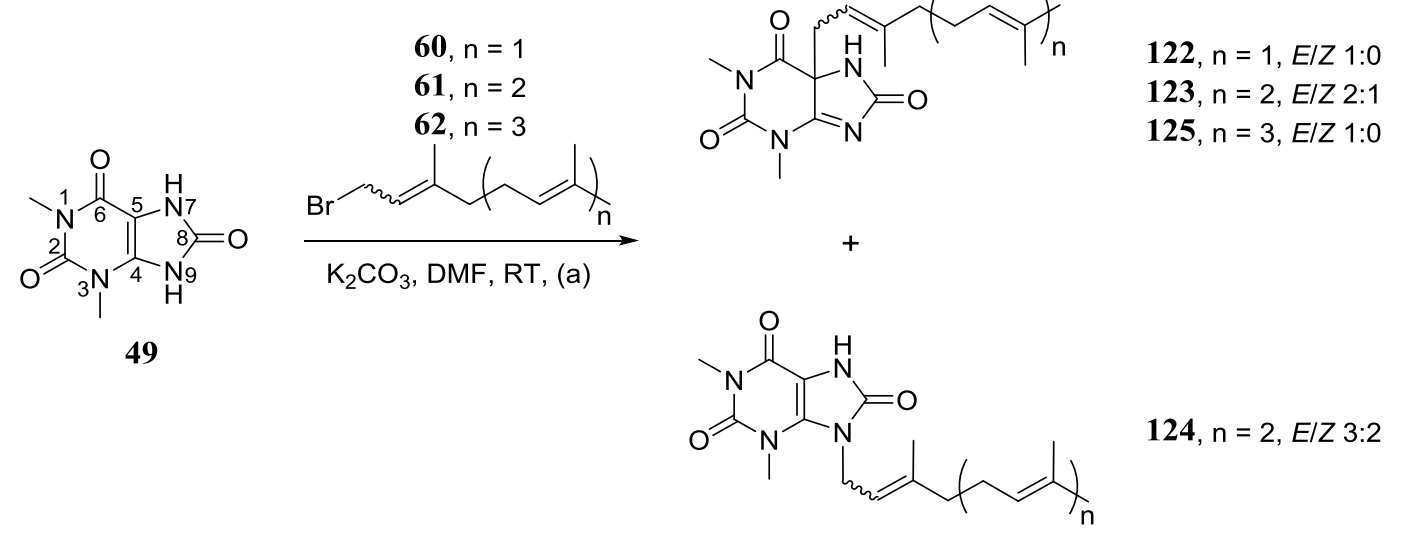

Scheme 2.15 Alkylation of 1,3-dimethyluric acid (49) with terpenoid bromides; (a) Further conditions summarised in Table 2.6. 
Table 2.6 Summary of the conditions for 1,3-dimethyluric acid (49) alkylation.

\begin{tabular}{cccccc}
\hline Entry & $\mathrm{T} \mathrm{Br}^{\mathrm{a}}$ & $\mathrm{T} \mathrm{Br}^{\mathrm{b}}$ & Time $(\mathrm{h})$ & $\mathrm{C}-5(\%)$ & $\mathrm{N}-9(\%)$ \\
\hline 1 & $\mathbf{6 0}$ & 1.1 & 24 & 9 & - \\
2 & $\mathbf{6 1}$ & 0.93 & 19 & 24 & 4 \\
3 & $\mathbf{6 2}$ & 1.0 & 20 & 6 & - \\
\hline
\end{tabular}

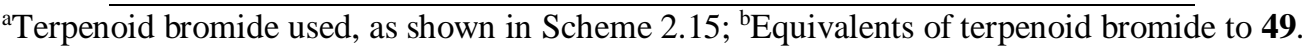

The proposed structure of the $C-5$ farnesylated product $(\mathbf{1 2 3})$ was elucidated using $1 \mathrm{D}$ and $2 \mathrm{D}$ NMR data. ${ }^{1} \mathrm{H}$ NMR analysis revealed the compound was monoalkylated, since it had one set of farnesyl resonances. A monoalkylated formula was confirmed by MS and further analysis of the ${ }^{1} \mathrm{H}$ NMR spectrum revealed one methylene doublet at 2.67 ppm, which had a one bond correlation to a carbon resonating at $40.5 \mathrm{ppm}$. Interestingly, every other purine- and purinone-based analogue synthesised during the project was $N$ or $O$-alkylated and the adjacent terpenoid methylene appeared between $4-5 \mathrm{ppm}$ in the ${ }^{1} \mathrm{H}$ NMR spectrum and between $39-50 \mathrm{ppm}$ in the ${ }^{13} \mathrm{C}$ NMR spectrum. The significantly upfield ${ }^{1} \mathrm{H}$ NMR chemical shift of the methylene suggested the product was not $\mathrm{N}$ - or $\mathrm{O}$ farnesylated.

The structure was elucidated using the method previously described for the purines and purinones, by beginning with the assignment of carbon resonances of the head group. The carbon that the two $N$-methyl groups presented a common HMBC correlation to must be $\mathrm{C}$-2. One $N$-methyl correlated to a carbon resonating at $176.8 \mathrm{ppm}$, while the other correlated to a carbon resonating at $166.4 \mathrm{ppm}$. The more downfield signal was likely the carbonyl carbon, C-6, while the other signal must have been C-4, which allowed the assignment of all four resonances. The remaining downfield carbonyl carbon that resonated at $165.6 \mathrm{ppm}$, was assigned as C-8. After assigning all the carbons associated with the farnesyl chain, process of elimination identified the resonance at $68.2 \mathrm{ppm}$ as $\mathrm{C}$ 5, which was also typically the most upfield shift in a purine ring.

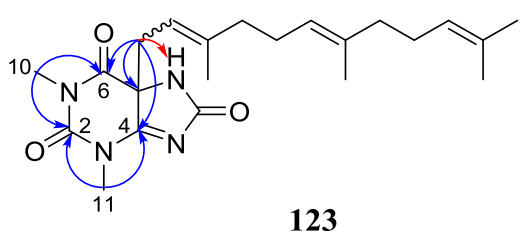

Figure 2.14 Proposed $C$-5 farnesyl derivative (123) of 1,3-dimethyluric acid. HMBC and NOESY correlations are shown as blue and red arrows, respectively.

The farnesyl methylene adjacent to the site of alkylation presented HMBC correlations to C-4, C-5, and C-6. To correlate to three carbons, alkylation must have occurred at C-5, 
which explained the unexpected upfield chemical shift of the methylene. This also explained the chemical shift of C-5, $68.2 \mathrm{ppm}$, which suggested an $\mathrm{sp}^{3}$ hybridised carbon. While this structure proposed (123) suggested a two-bond HMBC correlation to C-5, it was more likely than a four-bond correlation as predicted if alkylation occurred at other sites. In addition, the methylene adjacent to the site of alkylation exhibited a NOESY correlation to the exchangeable proton, which would be plausible if alkylation occurred at C-5. The IR spectrum of $\mathbf{1 2 3}$ also showed three carbonyl stretches at 1695, 1645 and $1612 \mathrm{~cm}^{-1}$, which further ruled out $O$-alkylation.

The structure of the proposed C-5 farnesyl compound (123) was further supported by the other product isolated from the reaction (Table, 2.6 entry 2), which was the $N-9$ farnesyl derivative (124). The $N$-methylene of $\mathbf{1 2 4}$ resonated at $4.66 \mathrm{ppm}$ and $41.6 \mathrm{ppm}$ on the ${ }^{1} \mathrm{H}$ and ${ }^{13} \mathrm{C}$ NMR spectra, respectively, which were typical chemical shifts for $N$-alkylation.

Previous alkylation of $\mathbf{4 9}$ with four equivalents of iodopropane by Callery and co-workers produced a single $N-7, O-8$ dialkylated product (126) (Scheme 2.16). ${ }^{86}$ The $O$-methylene resonated at $4.45 \mathrm{ppm}$ and $72.5 \mathrm{ppm}$ in the ${ }^{1} \mathrm{H}$ and ${ }^{13} \mathrm{C}$ NMR spectra, respectively. This literature evidence further ruled out $O$-alkylation since the methylene chemical shifts of the $C-5$ farnesyl derivative $(\mathbf{1 2 3})$ were significantly different. In addition, Callery's $N$ methylene appeared at $4.07 \mathrm{ppm}$ in the ${ }^{1} \mathrm{H}$ NMR spectrum, while the proposed $C-5$ methylene of $\mathbf{1 2 3}$ in this work appeared significantly more upfield at $2.67 \mathrm{ppm}$.

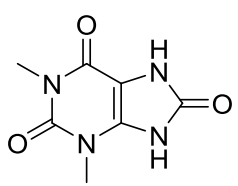

49

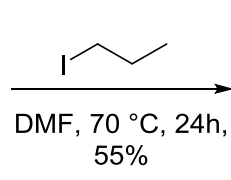

$55 \%$

Scheme 2.16 Alkylation of 1,3-dimethyluric acid with iodopropane. ${ }^{86}$

A possible mechanism to explain the unexpected $C-5$ alkylation is shown in Scheme 2.17. After deprotonation of 49 (predicted $\mathrm{pK}_{\mathrm{a}} 8.16^{81}$ ), the anion could be stabilised by resonance forms that allude to enolate-type reactivity. Therefore, this reaction could potentially be a simple method for generating quaternary carbon-carbon bonds. Naturally, further mechanistic insight would be required. 


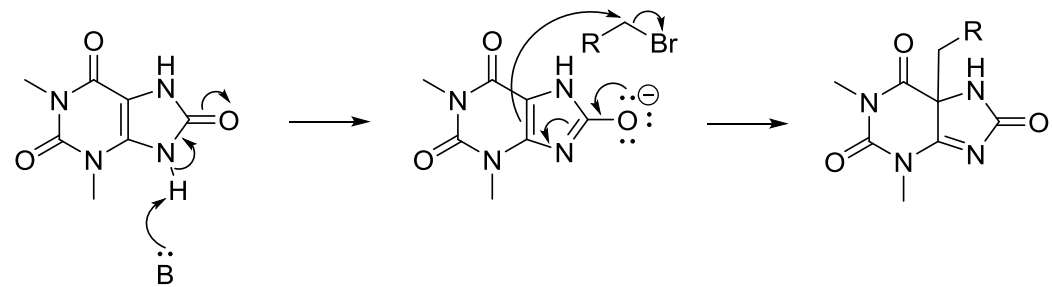

Scheme 2.17 Possible mechanism for $C$-5 alkylation of 1,3-dimethyluric acid (49).

\subsection{Alkylation of pyrimidines}

The pyrimidines selected for alkylation were uracil (51), thymine (52), and cytosine (53). No previous terpenoid alkylation syntheses were found in the literature.

These pyrimidines were alkylated with the terpenoid bromides to yield monoalkylated derivatives (Scheme 2.18, Table 2.7) and the structures were elucidated using 1D and 2D NMR data. The head group carbon resonances were first assigned with several key HMBC correlations $(\mathbf{1 2 7}$ - 129), then the position of alkylation was determined by HMBC correlations from the terpenoid methylene to carbons in the head group (130 132) (Figure 2.15).

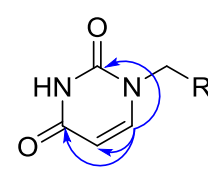

127

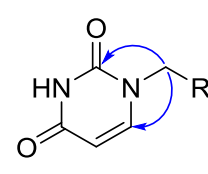

130

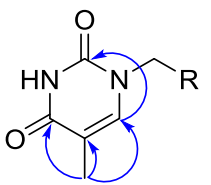

128

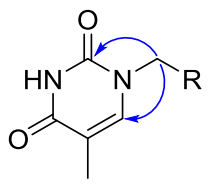

131

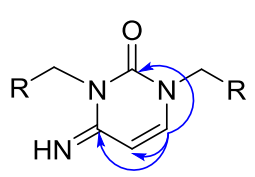

129

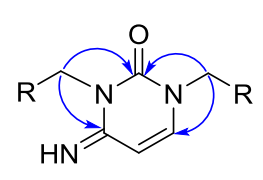

132

Figure 2.15 Typical key HMBC correlations used to assign the head group carbons and alkylation positions of uracil $(\mathbf{1 2 7}, \mathbf{1 3 0})$, thymine $(\mathbf{1 2 8}, \mathbf{1 3 1})$, and cytosine $(\mathbf{1 2 9}, \mathbf{1 3 2})$.
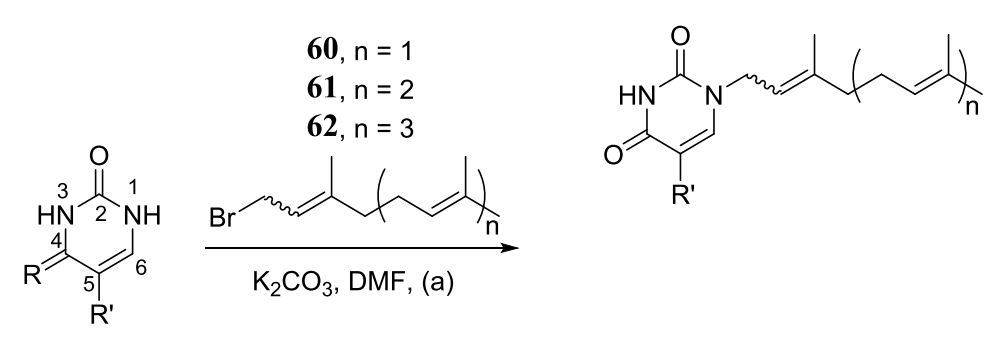

133, $\mathrm{R}^{\prime}=\mathrm{H}, \mathrm{n}=1, E / Z 1: 0$

134, $\mathrm{R}^{\prime}=\mathrm{H}, \mathrm{n}=2, E / Z 2: 1$

135, $\mathrm{R}^{\prime}=\mathrm{H}, \mathrm{n}=3, E / Z$ 0:1

136, $R^{\prime}=H, n=3, E / Z 1: 0$

137, $\mathrm{R}^{\prime}=\mathrm{Me}, \mathrm{n}=1, E / Z 1: 0$

138, $\mathrm{R}^{\prime}=\mathrm{Me}, \mathrm{n}=2, E / Z 3: 2$

139, $R^{\prime}=M e, n=3, E / Z 1: 0$

51, $R=O, R^{\prime}=H$

52, $R=O, R^{\prime}=M e$

53, R $=$ N, R' $=H$

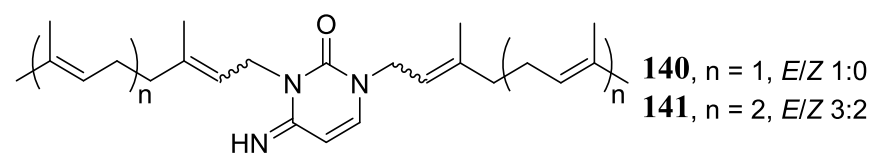

Scheme 2.18 Alkylation of pyrimidine-based head groups; (a) Further conditions summarised in Table 2.7. 
Table 2.7 Summary of the conditions for pyrimidine alkylations.

\begin{tabular}{ccccccc}
\hline Entry & Pyrimidine $^{\mathrm{a}}$ & $\mathrm{T} \mathrm{Br}^{\mathrm{b}}$ & $\mathrm{T} \mathrm{Br}^{\mathrm{c}}$ & Temp. $\left({ }^{\circ} \mathrm{C}\right)$ & Time $(\mathrm{h})$ & $\mathrm{N}-1(\%)$ \\
\hline 1 & $\mathbf{5 1}$ & $\mathbf{6 0}$ & 1.2 & 50 & 21 & 12 \\
2 & $\mathbf{5 1}$ & $\mathbf{6 1}$ & 1.1 & 70 & 24 & 25 \\
3 & $\mathbf{5 1}$ & $\mathbf{6 2}$ & 1.1 & $\mathrm{RT}$ & 48 & 26 \\
4 & $\mathbf{5 2}$ & $\mathbf{6 0}$ & 1.4 & $\mathrm{RT}$ & 20 & 5 \\
5 & $\mathbf{5 2}$ & $\mathbf{6 1}$ & 1.3 & 70 & 24 & 20 \\
6 & $\mathbf{5 2}$ & $\mathbf{6 2}$ & 1.0 & $\mathrm{RT}$ & 24 & 11 \\
7 & $\mathbf{5 3}$ & $\mathbf{6 0}$ & 1.1 & $\mathrm{RT}$ & 70 & $11^{\mathrm{d}}$ \\
8 & $\mathbf{5 3}$ & $\mathbf{6 1}$ & 1.2 & $\mathrm{RT}$ & 25 & $34^{\mathrm{d}}$ \\
\hline
\end{tabular}

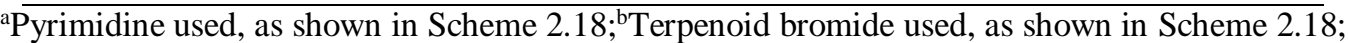

${ }^{\mathrm{c}}$ Equivalents of terpenoid bromide to pyrimidine; ${ }^{\mathrm{d}}$ Included additional $N-3$ alkylation.

Entries 1 - 3 summarise the alkylation of uracil (51), in each case only the $N$-1 alkylated derivatives were isolated $(\mathbf{1 3 3}$ - 136). Entries $4-6$ summarise alkylation of thymine (52) and the same results were obtained as for the uracil derivatives, only $N$-1 alkylated products $(\mathbf{1 3 7} \mathbf{- 1 3 9})$ were isolated.

Entries 7 and 8 summarise the alkylation reactions of cytosine (53) with geranyl- and farnesyl bromides, respectively. Following the previous pyrimidine trends, $N-1$ alkylation occurred, but also in conjunction with $N-3$ alkylation $(140,141)$. The reaction of 53 and geranylgeranyl bromide was attempted, but the $\mathrm{N}-1, \mathrm{~N}-3$ product was not isolated. No monoalkylated derivatives were detected, but they might be formed if less terpenoid bromide was used.

\subsection{Alkylation of other head groups}

\subsubsection{Imidazole}

Geranyl imidazole has previously been synthesised by reaction of imidazole with geranyl bromide in DMF using sodium hydride as a base. ${ }^{87}$ The alkylation of imidazole (50) with the three terpenoid bromides proceeded as expected, producing $\mathrm{N}$-monoalkylated products in each case (Scheme 2.19, Table 2.8). The structures were confirmed using 1D and 2D NMR data in a straightforward manner, key HMBC correlations (142) allowed the assignment of head group carbon resonances (Figure 2.16). The position of alkylation was trivial since the methylene adjacent to the site of alkylation resonated at 4.5 and 44.6 ppm on the ${ }^{1} \mathrm{H}$ and ${ }^{13} \mathrm{C}$ NMR spectra, respectively, which suggested $N$-alkylation as these chemical shifts were conserved across most $N$-alkylated derivatives synthesised in this project. In addition, the ${ }^{1} \mathrm{H}$ NMR data of geranyl imidazole (143) was in excellent agreement with literature. ${ }^{87}$ 


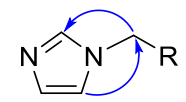

142

Figure 2.16 Typically observed HMBC correlations used in structural elucidation of the imidazole derivatives.

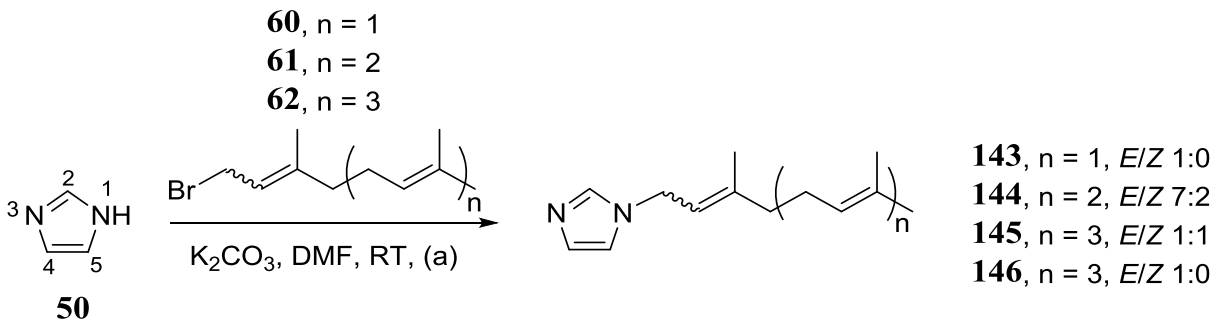

Scheme 2.19 Alkylation of imidazole; (a) Further conditions summarised in Table 2.8.

Table 2.8 Summary of the conditions for imidazole alkylations.

\begin{tabular}{ccccc}
\hline Entry & $\mathrm{T} \mathrm{Br}^{\mathrm{a}}$ & $\mathrm{T}^{\mathrm{B}} \mathrm{Br}^{\mathrm{b}}$ & Time (h) & $\mathrm{N}-1(\%)$ \\
\hline 1 & $\mathbf{6 0}$ & 1.1 & 46 & 32 \\
2 & $\mathbf{6 1}$ & 1.2 & 48 & 8 \\
3 & $\mathbf{6 2}$ & 1.1 & 48 & $42^{\mathrm{c}}$ \\
\hline
\end{tabular}

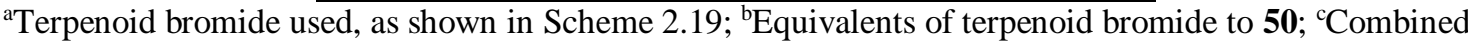
yield of $\mathbf{1 4 5}$ and $\mathbf{1 4 6 .}$

Purification by silica gel flash chromatography was somewhat troublesome as the compounds were prone to streaking. This resulted in the isolation of geometric mixtures for farnesyl imidazole (144) and geranylgeranyl imidazole (145), while geranyl imidazole (143) was solely the $E$ isomer since the geranyl bromide used was also the same configuration. Fortunately, the pure $E$ isomer of geranylgeranyl imidazole (146) was isolated and if the configuration appears to be important in the SAR analysis, then these syntheses can be repeated in the future with purified terpenoid bromides since the geometric isomers are not easily separable.

\subsubsection{Phthalimide}

Originally, the phthalimide derivatives were intended as intermediates for the Gabriel synthesis of primary amines ${ }^{88,89}$ (discussed further in 2.9), since the terpenoid amines would be necessary for the malonganenone $\mathrm{C}$ analogues.

Potassium phthalimide (147) was alkylated with the terpenoid bromides (Scheme 2.20, Table 2.9), but a more appropriate route to the terpenoid amines were found during the project. Therefore, the Gabriel method was abandoned, but geranyl- (148) and farnesyl 
phthalimide (149) were already in hand, so geranylgeranyl phthalimide (150) was synthesised to complete the set and provide further analogues.

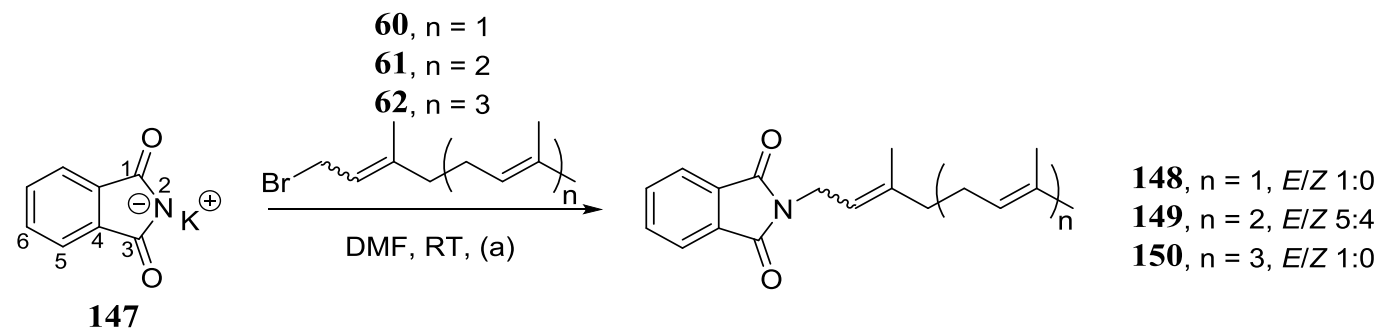

Scheme 2.20 Alkylation of potassium phthalimide; (a) Further conditions summarised in Table 2.9 .

Table 2.9 Summary of the conditions for potassium phthalimide alkylations.

\begin{tabular}{cccccc}
\hline Entry & T. Br & T. Br & Base & Time $(\mathrm{h})$ & $\mathrm{N}-2(\%)$ \\
\hline 1 & $\mathbf{6 0}$ & 0.98 & $\mathrm{Na}_{2} \mathrm{CO}_{3} / \mathrm{K}_{2} \mathrm{CO}_{3}$ & 22 & 24 \\
2 & $\mathbf{6 1}$ & 0.69 & $\mathrm{Na}_{2} \mathrm{CO}_{3} / \mathrm{K}_{2} \mathrm{CO}_{3}$ & 19 & 1 \\
3 & $\mathbf{6 2}$ & 1.1 & $\mathrm{~K}_{2} \mathrm{CO}_{3}$ & 24 & 34 \\
\hline
\end{tabular}

a Terpenoid bromide used, as shown in Scheme 2.20; ${ }^{\mathrm{b}}$ Equivalents of terpenoid bromide to 147.

The alkylation of potassium phthalimide resulted in poor yields for each of the chain lengths, far below literature yields using the same conditions $(60-80 \%) .{ }^{90,91}$ This was partially due to loss of product after multiple rounds of purification, recrystallisation for geranyl phthalimide (148) and silica gel flash chromatography for farnesyl- (149) and geranylgeranyl phthalimide (150). The yield of 149 was particularly poor, which may have been due to degradation of the crude product before purification since there was a significant time between the reaction and subsequent column due to unforeseen circumstances.

\subsubsection{Allopurinol}

Allopurinol (48) is closely related to the other purine-based head groups previously discussed, however, the structural differences of $\mathbf{4 8}$ resulted in markedly different alkylation patterns. Therefore, allopurinol was analysed separately. The syntheses of terpenoid derivatives of $\mathbf{4 8}$ were not found in the literature.

The alkylation of $\mathbf{4 8}$ with the terpenoid bromides resulted in a mixture of mono- and dialkylated derivatives (Scheme 2.21, Table 2.10). The structures were elucidated using 1D and 2D data with the same approach as previously discussed, initial assignments of the carbon resonances of the head group and then determination of the alkylation position. All the allopurinol derivatives displayed the same HMBC correlations used to assign the 
carbon resonances of the head group (151), but differed in the correlations used to distinguish between the regioisomers $(\mathbf{1 5 2}$ - 154) (Figure 2.17).

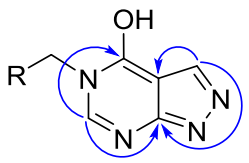

151<smiles>[R]CN1C=C(O)C2=CN=NC2=NCC1</smiles>

152

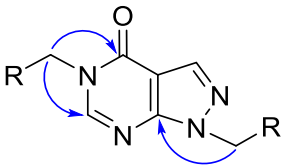

153

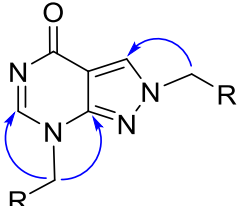

154

Figure 2.17 Key observed HMBC correlations used for structural elucidation of the allopurinol derivatives.

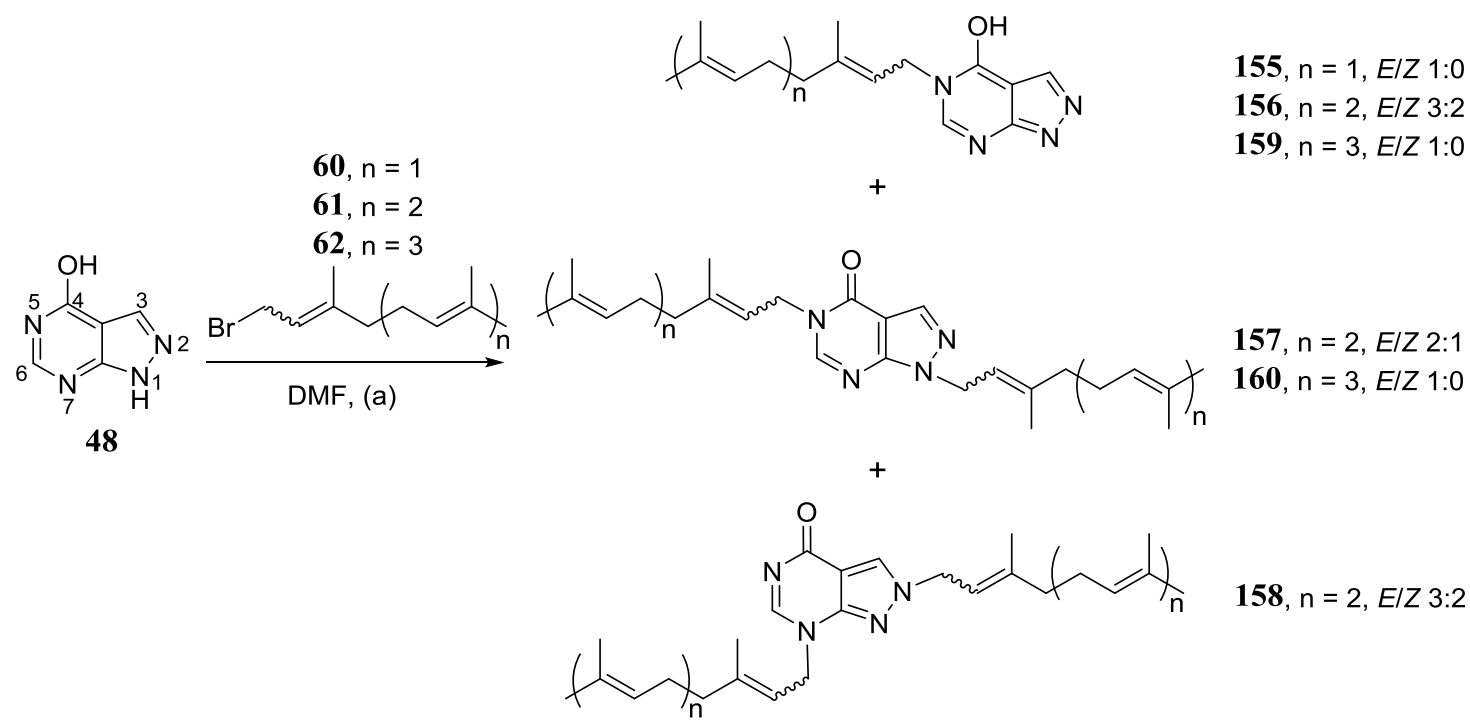

Scheme 2.21 Alkylation of allopurinol; (a) Further conditions summarised in Table 2.10.

Table 2.10 Summary of the conditions for allopurinol alkylations.

\begin{tabular}{ccccccccc}
\hline Entry & $\mathrm{T}^{\mathrm{B} r^{\mathrm{a}}}$ & $\mathrm{T} . \mathrm{Br}{ }^{\mathrm{b}}$ & Base & $\begin{array}{c}\text { Temp. } \\
\left({ }^{\circ} \mathrm{C}\right)\end{array}$ & $\begin{array}{c}\text { Time } \\
(\mathrm{h})\end{array}$ & $\begin{array}{c}\mathrm{N}-5 \\
(\%)\end{array}$ & $\begin{array}{c}\mathrm{N}-1, \mathrm{~N}-5 \\
(\%)\end{array}$ & $\begin{array}{c}\mathrm{N}-2, \mathrm{~N}-7 \\
(\%)\end{array}$ \\
\hline 1 & $\mathbf{6 0}$ & 0.62 & $\mathrm{Na}_{2} \mathrm{CO}_{3} / \mathrm{K}_{2} \mathrm{CO}_{3}$ & $\mathrm{RT}$ & 24 & 2 & - & - \\
2 & $\mathbf{6 1}$ & 1.1 & $\mathrm{~K}_{2} \mathrm{CO}_{3}$ & 70 & 27 & 21 & 12 & 4 \\
3 & $\mathbf{6 2}$ & 1.0 & $\mathrm{~K}_{2} \mathrm{CO}_{3}$ & $\mathrm{RT}$ & 27 & 2 & 3 & - \\
\hline
\end{tabular}

${ }^{a}$ Terpenoid bromide used, as shown in Scheme 2.21 ; ${ }^{b}$ Equivalents of terpenoid bromide to $\mathbf{4 8}$.

The alkylation of allopurinol (48) with geranyl bromide resulted in the isolation of a single product, an $\mathrm{N}-1$ geranylated derivative (155) (entry 1). Monoalkylation was likely favoured since 0.62 equivalents of geranyl bromide was used. Entries 2 and 3 were reactions with farnesyl- and geranylgeranyl bromide, respectively, where they were used in slight excess. This resulted in the formation of dialkylated regioisomers, where alkylation occurred at N-1 and N-5 (157, 160), or N-2 and N-7 (158), in addition to the $N-5$ monoalkylated derivatives $(\mathbf{1 5 6}, \mathbf{1 5 9})$. 
Alkylation at N-5 was unexpected since the C-4 hydroxyl would be expected to sterically hinder the adjacent sites, which was the case for the derivatives of 6-substituted purines. The hydroxyl must have been less sterically hindering than all the C-6 substituents $\left(-\mathrm{NH}_{2}\right.$, $-\mathrm{NMe}_{2}$ and $-\mathrm{Cl}$ ) on the purine-based head groups that were alkylated. Alternatively, the hydroxyl could have been more activating for the N-1 site.

\subsection{Synthesis of terpenoid amines}

The pinnacle intermediate for the malonganenone $\mathrm{C}$ analogues were terpenoid amines. Primary amines can be synthesised using the Gabriel method, conversion of the halogenated starting material to a phthalimide intermediate followed by hydrolysis or hydrazinolysis (Scheme 2.22). ${ }^{88,}{ }^{89}$ First, the phthalimide intermediate must be synthesised, which has previously been achieved by reaction of potassium phthalimide and terpenoid halide in DMF or THF at room temperature. ${ }^{90}$ The use of the terpenoid halides based on geranyl, ${ }^{90}$ farnesyl, ${ }^{91}, 92$ and geranylgeranyl ${ }^{76,93}$ frameworks have already been established in Gabriel syntheses. Alternatively, terpenoid phthalimides could be synthesised in a Mitsunobu reaction between the terpenoid alcohol and phthalimide with diethyl azodicarboxylate in the presence of triphenylphosphine. ${ }^{94-96}$ Cleavage of the phthalimide group with hydrazine hydrate ${ }^{90,95,96}$ or methylamine o7-99 $^{97}$ afforded the primary amine.

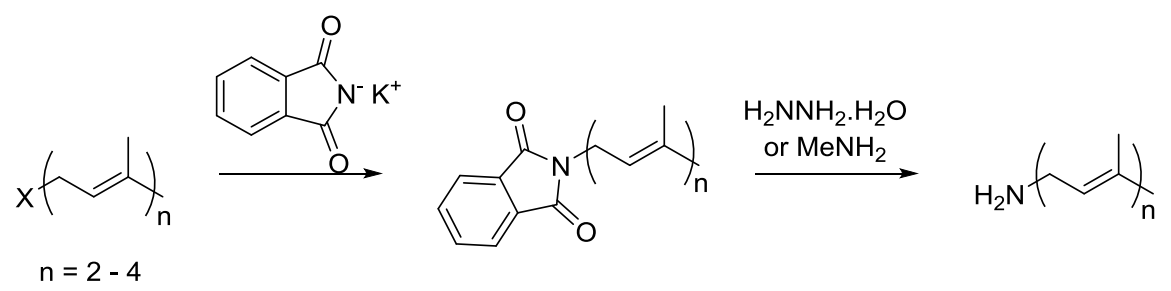

Scheme 2.22 Summary of Gabriel synthesis of primary amines beginning from terpenoid halides. ${ }^{88-93}$

An alternative route to the terpenoid amines involved the reaction of farnesyl bromide with lithium hexamethyldisilazide (LiHMDS), followed by cleavage of the silyl groups to afford farnesylamine. ${ }^{100}$ This route was used as it is advantageous since the cleaved silyl groups are volatile and the crude product was pure enough to avoid chromatography, which was often troublesome for primary amines. Overall, using this methodology geranyl- (161), farnesyl- (162) and geranylgeranyl (163) amines were all made with excellent yields (Scheme 2.23, Table 2.11). 


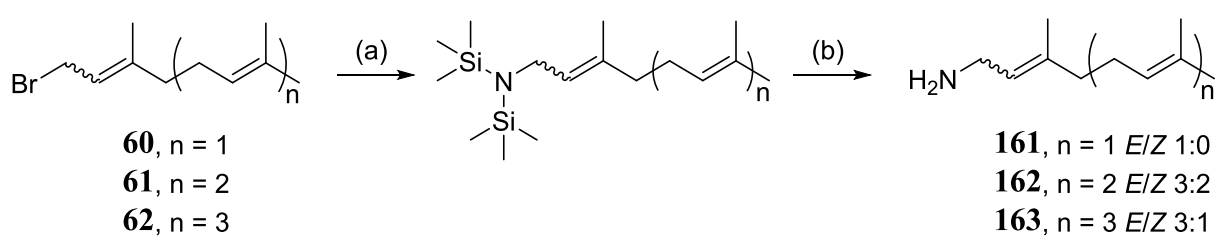

Scheme 2.23 Synthesis of terpenoid primary amines; (a) LiHMDS (1.1 equiv.); (b) $\mathrm{MeOH} / \mathrm{DCM}$; further conditions summarised in Table 2.11.

Table 2.11 Summary of the conditions for terpenoid amine syntheses.

\begin{tabular}{ccccc}
\hline Entry & T. Br $^{\mathrm{a}}$ & ${\text { Time }(\mathrm{h})^{\mathrm{b}}}^{\mathrm{T}}$ & ${\text { Time }(\mathrm{h})^{\mathrm{c}}}^{\mathrm{c}}$ & Yield $(\%)^{(\%)}$ \\
\hline 1 & $\mathbf{6 0}$ & 26 & 22 & 92 \\
2 & $\mathbf{6 1}$ & 26 & 23 & 99.6 \\
3 & $\mathbf{6 2}$ & 23 & 24 & 74 \\
\hline
\end{tabular}

${ }^{\text {a }}$ Terpenoid bromide used, as shown in Scheme 2.23 ; ${ }^{b}$ Reaction time for step (a); ${ }^{c}$ Reaction time for step (b); ${ }^{\mathrm{d}}$ total yield of the crude product over two steps.

\subsection{Formylation and methylation of terpenoid amines}

Formylation of the isoprenoid amines could afford analogues of malonganenone $\mathrm{C}$ (12), which has a simple formamide head group. Formylation of geranylamine (161) has previously been achieved by condensation with formyl chloride with a yield of $83 \% .{ }^{91}$, ${ }^{101}$ An analogue of malonganenone B was successfully formylated in 51\% yield using formic acetic anhydride, where the mixed anhydride was first made by heating excess formic acid with acetic anhydride at $55{ }^{\circ} \mathrm{C}$ for two hours. ${ }^{56}$ The terpenoid formamides could be methylated to furnish more analogues. ${ }^{102}$

The terpenoid amines were formylated using the mixed anhydride approach (Scheme 2.24, Table 2.12). Acetic anhydride and excess formic acid were first heated to promote formation of formic acetic anhydride, before addition of the terpenoid amines. The mixed anhydride was not purified, therefore in the following discussion it refers to a formic acid, acetic anhydride mixture (FAM).

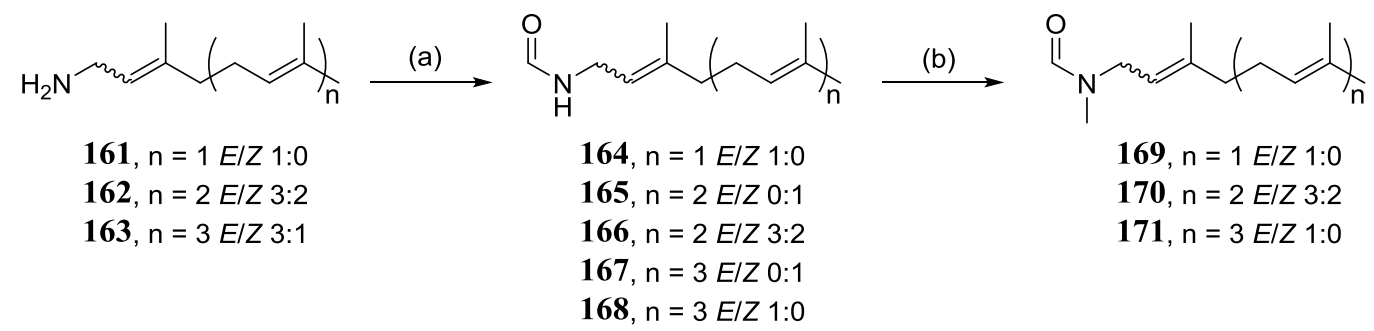

Scheme 2.24 Formylation and subsequent methylation of terpenoid amines; (a) FAM, RT; (b) MeI (3 equiv.), KOH, DMSO, RT; further conditions summarised in Table 2.12. 
Table 2.12 Summary of the conditions for formylation of terpenoid amines.

\begin{tabular}{ccccc}
\hline Entry & SM $^{\mathrm{a}}$ & FAM $^{\mathrm{b}}$ & Time $(\mathrm{h})$ & Yield $(\%)$ \\
\hline 1 & $\mathbf{1 6 1}$ & 2.2 & 3 & 30 \\
2 & $\mathbf{1 6 2}$ & 2.2 & 26 & $6^{\mathrm{c}}$ \\
3 & $\mathbf{1 6 3}$ & 2.7 & 23 & $4^{\mathrm{c}}$ \\
\hline
\end{tabular}

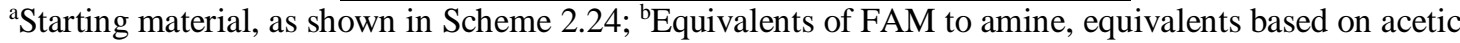
anhydride as the limiting reagent in the formation of formic acetic anhydride; ${ }^{\mathrm{c}} \mathrm{After}$ purification, combined yield of both geometric isomers.

After isolating the farnesyl formamides $(\mathbf{1 6 6}, \mathbf{1 6 7})$ in a such a poor yield (entry 2), an increased equivalent of FAM was used in the geranylgeranyl amine reaction (entry 3 ) in a bid to improve yield, but the outcome was still poor. The best yield was obtained for geranyl formamide (161) (entry 1), which had the shortest reaction time. Although the reactions were monitored by TLC, streaking of the starting material made it difficult to judge the extent of the reaction, so it was unclear whether reaction time played a major role in the success of the reaction without further repetition. In addition, all three crude reaction mixtures had several unidentified high running spots by TLC analysis, which could have been potential by-products or degradation products.

The ${ }^{1} \mathrm{H}$ NMR spectra of the isolated formamide compounds had doubling of all resonances, which indicated a mixture of rotamers. This was consistent with previous ${ }^{1} \mathrm{H}$ NMR data reported for geranyl formamide. ${ }^{103}$

The most abundant isolated terpenoid formamides of each chain length $(\mathbf{1 6 4}, 166$ and 168) were then alkylated with methyl iodide and $\mathrm{KOH}$ in DMSO (Scheme 2.24, Table 2.13) without incident to yield the $N$-methylated terpenoid formamides $(\mathbf{1 6 9}-\mathbf{1 7 1})$.

Table 2.13 Summary of the conditions for terpenoid formamide methylations.

\begin{tabular}{ccccc}
\hline Entry & $\mathrm{SM}^{\mathrm{a}}$ & $\mathrm{KOH}^{\mathrm{b}}$ & Time $(\mathrm{h})$ & Yield $(\%)$ \\
\hline 1 & $\mathbf{1 6 4}$ & 3.9 & 2.5 & 54 \\
2 & $\mathbf{1 6 6}$ & 4.5 & 3 & 56 \\
3 & $\mathbf{1 6 8}$ & 4.3 & 2 & 33 \\
\hline
\end{tabular}

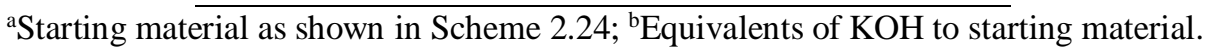

\subsection{Acetylation and methylation of terpenoid amines}

Further malonganenone $\mathrm{C}$ analogues were available by acetylation of the terpenoid amines. Geranylamine acetylation has previously been achieved using acetyl chloride and triethylamine (TEA). ${ }^{91,104}$ Geranylgeranyl acetamide has been synthesised in $92 \%$ yield using the same approach but with $10 \%$ sodium hydroxide in place of TEA. ${ }^{91}$ Alternative 
acetylating agents used in the synthesis of geranyl acetamide include acetic anhydride with catalytic 4-dimethylaminopyridine. ${ }^{92}$ The terpenoid acetamides could then be methylated to furnish more analogues. ${ }^{102}$

The terpenoid amines $(\mathbf{1 6 1} \mathbf{- 1 6 3 )}$ were acetylated using acetyl chloride and TEA to yield the terpenoid acetamides $(\mathbf{1 7 2}-\mathbf{1 7 6})$ smoothly (Scheme 2.25, Table 2.14).

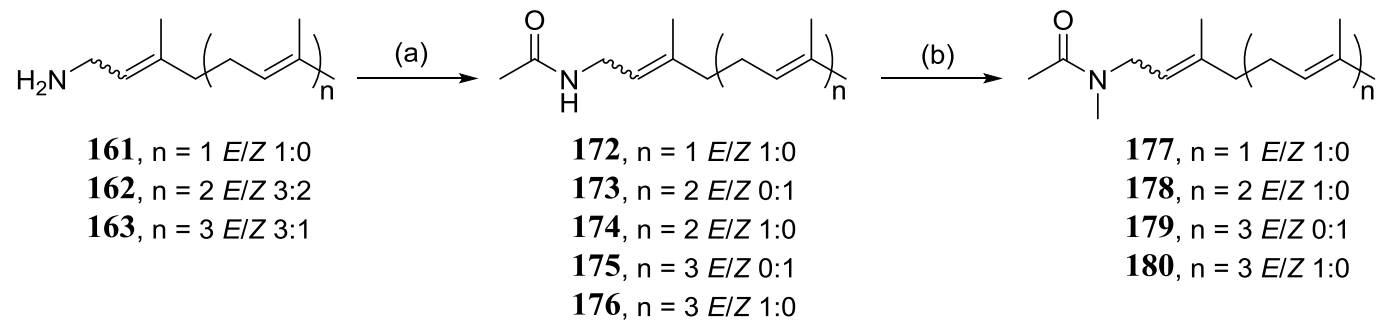

Scheme 2.25 Acetylation and subsequent methylation of terpenoid amines; (a) Acetyl chloride, TEA (3. equiv.), THF, $0{ }^{\circ} \mathrm{C} \rightarrow \mathrm{RT}$. (b) MeI (3 equiv.), $\mathrm{KOH}$, DMSO, RT; further conditions summarised in Table 2.14 and Table 2.15.

Table 2.14 Summary of the conditions for terpenoid amine acetylation.

\begin{tabular}{ccccc}
\hline Entry & $\mathrm{SM}^{\mathrm{a}}$ & $\mathrm{CH}_{3} \mathrm{COCl}^{\mathrm{b}}$ & Time $(\mathrm{h})$ & Yield (\%) \\
\hline 1 & $\mathbf{1 6 1}$ & 1.5 & 5 & 30 \\
2 & $\mathbf{1 6 2}$ & 1.5 & 5.5 & $25^{\mathrm{c}}$ \\
3 & $\mathbf{1 6 3}$ & 1.1 & 4.5 & $31^{\mathrm{c}}$ \\
\hline
\end{tabular}

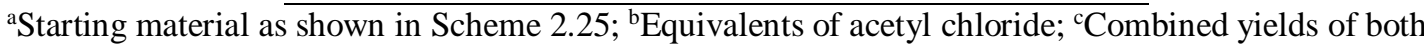
geometric isomers.

The most abundant terpenoid acetamides $(\mathbf{1 7 2}, 174$ - 176) were then methylated with methyl iodide to produce the $N$-methyl terpenoid acetamides $(177-\mathbf{1 8 0})$ (Scheme 2.25, Table 2.15). The methylation of the terpenoid acetamides proceeded cleanly, but the geranyl acetamide reaction (entry 1), had a particularly poor yield of $N$-methylgeranyl acetamide (177). Enough 177 was isolated to obtain a ${ }^{1} \mathrm{H}$ NMR spectrum, but this compound was not characterised further.

Table 2.15 Summary of the conditions for terpenoid acetamide methylations.

\begin{tabular}{ccccc}
\hline Entry & SM $^{\mathrm{a}}$ & $\mathrm{KOH}^{\mathrm{b}}$ & Time $(\mathrm{h})$ & Yield $(\%)$ \\
\hline 1 & $\mathbf{1 7 2}$ & 4.0 & 0.67 & 6 \\
2 & $\mathbf{1 7 4}$ & 4.5 & 2.0 & 53 \\
3 & $\mathbf{1 7 5}$ & 4.0 & 2.9 & 29 \\
4 & $\mathbf{1 7 6}$ & 4.0 & 2.8 & 15 \\
\hline
\end{tabular}

Entry 2 summarises the methylation reaction of farnesyl acetamide (174). The ${ }^{1} \mathrm{H}$ NMR spectrum of the product (178) suggested a mixture of equally abundant rotamers as there 
were two $N$-methylene resonances of equal integration. The presence of rotamers was further confirmed by structural elucidation using 1D and 2D NMR data, each set of rotamer resonances provided equivalent correlations and solved for the same structure. Interestingly, the ${ }^{1} \mathrm{H}$ NMR spectrum of $\mathbf{1 7 4}$ had a single set of resonances, which suggested facile rotation about the amide bond with respect to the NMR time scale. Methylation introduced the presence of bulky $N$-methyl, which impeded free rotation sufficiently to observe the separate rotamer resonances on the ${ }^{1} \mathrm{H}$ NMR spectrum. 


\section{Structure-activity relationship analyses}

The antiparasitic and antibacterial tests were carried out by collaborators at Rhodes University in South Africa and at the University of Otago in New Zealand, respectively.

\subsection{Plasmodium falciparum}

The compounds were first tested in duplicate against $P$. falciparum strain 3D7 infected red blood cells at a single concentration of $20 \mu \mathrm{M}$ and the percentage of viable parasites remaining after treatment was measured. A viability of $100 \%$ would suggest the compound is completely inactive while a viability of $0 \%$ suggests excellent activity at this single concentration. Compounds were then further tested to determine their $\mathrm{IC}_{50}$ at the discretion of the collaborator. Typically, those compounds that reduced viability to less than $20-30 \%$ were put forward for establishing $\mathrm{IC}_{50}$ if they were non-toxic to HeLa cells. Compounds that reduced HeLa cell viability below 50\% were considered generally cytotoxic and set aside. Only two compounds out of 76 tested against HeLa cells, 84 and 140, were significantly cytotoxic (data not included).

Using $\mathrm{IC}_{50}$ values to evaluate SAR gives a more accurate result than using the single concentration results, since the latter single concentration of $20 \mu \mathrm{M}$ can fall at various places on a dose-dependent inhibition curve. For example, if $20 \mu \mathrm{M}$ is at the start of the curve, the compound would appear to have no activity, even though a small increase in concentration could significantly reduce parasite viability. However, only five compounds were tested for $\mathrm{IC}_{50}$ against $P$. falciparum, which was not particularly useful for comprehensive SAR analysis. Therefore, the single concentration data was used to analyse SAR.

The compounds were first categorised into the same classes of head group as seen in the synthetic discussion; purines, purinones, pyrimidines, amides, and lastly, the other head groups and were then subject to SAR analysis. The three major SARs analysed were based on the head groups, terpenoid chain length and terpenoid alkene geometry. The SARs were assessed by comparison of compounds within the same class, alkylated at the same position. Unfortunately, not all the possible regioisomers for each reaction were isolated or tested, therefore, some SARs could not be fully analysed. 


\subsubsection{Purines}

The three purine head groups alkylated were adenine (28), 6-(dimethylamino)purine (44) and 6-chloropurine (43), which differ at the C-6 substituent. This substituent influenced regioselectivity, where 28 and $\mathbf{4 4}$ yielded $N-3$ and $N-9$ alkylated derivatives while $\mathbf{4 3}$ gave $N-7$ and $N-9$ alkylated derivatives (Figure 3.1). Therefore, only $N-9$ alkylated 43 could be compared with the $N-9$ alkylated derivatives of 28 and $\mathbf{4 4}$ to determine the SAR of the C6 substituent. All the purine analogues were tested against P. falciparum at single concentrations $(20 \mu \mathrm{M})$ (Table 3.1).

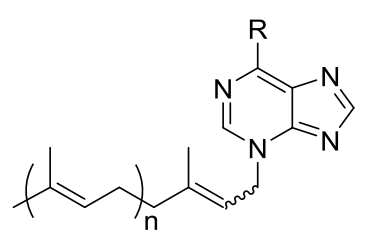

80, $\mathrm{R}=\mathrm{NH}_{2}, \mathrm{n}=1, E / Z, 1: 0$

81, $\mathrm{R}=\mathrm{NH}_{2}, \mathrm{n}=2 E / Z, 3: 2$

85, $\mathrm{R}=\mathrm{NMe}_{2}, \mathrm{n}=1, E / Z, 1: 0$

87, $\mathrm{R}=\mathrm{NMe}_{2}, \mathrm{n}=2 \mathrm{E} / \mathrm{Z}, 3: 2$

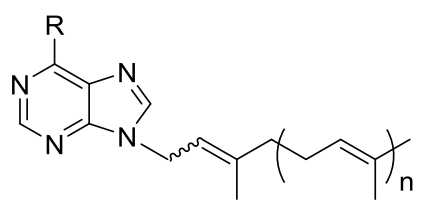

82, $\mathrm{R}=\mathrm{NH}_{2}, \mathrm{n}=2 \quad E / Z, 3: 2$

83, $\mathrm{R}=\mathrm{NH}_{2}, \mathrm{n}=3 \quad E / Z, 1: 0$

86, $\mathrm{R}=\mathrm{NMe}_{2}, \mathrm{n}=1, E / Z, 1: 0$

88, $\mathrm{R}=\mathrm{NMe}_{2}, \mathrm{n}=2 \quad E / Z, 3: 2$

89, $\mathrm{R}=\mathrm{NMe}_{2}, \mathrm{n}=3 \mathrm{E} / \mathrm{Z}, 0: 1$

90, $\mathrm{R}=\mathrm{NMe}_{2}, \mathrm{n}=3 E / Z, 1: 0$

95, $\mathrm{R}=\mathrm{Cl}, \mathrm{n}=1, E / Z, 1: 0$

97, $\mathrm{R}=\mathrm{Cl}, \mathrm{n}=2 E / Z, 2: 1$

100, $\mathrm{R}=\mathrm{Cl}, \mathrm{n}=3 E / Z, 1: 0$

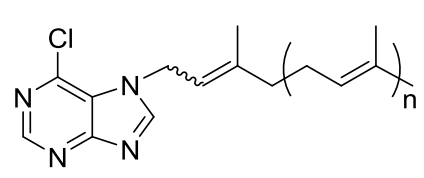

94, $\mathrm{n}=1, E / Z, 1: 0$

96, $\mathrm{n}=2 E / Z, 3: 2$

98, $\mathrm{n}=3 E / Z, 0: 1$

99, $\mathrm{n}=3 E / Z, 1: 0$

Figure 3.1 Purine-based analogues tested against $P$. falciparum.

Table 3.1 The activities of malonganenone A analogues based on adenine (28), 6(dimethylamino)purine (44) and 6-chloropurine (43) against $P$. falciparum.

\begin{tabular}{cccccc}
\hline $\begin{array}{c}\text { Derivatives } \\
\text { of } \mathbf{2 8}\end{array}$ & $\begin{array}{c}\text { Viability } \\
(\%)\end{array}$ & $\begin{array}{c}\text { Derivatives } \\
\text { of } \mathbf{4 4}\end{array}$ & $\begin{array}{c}\text { Viability } \\
(\%)\end{array}$ & $\begin{array}{c}\text { Derivatives } \\
\text { of } \mathbf{4 3}\end{array}$ & $\begin{array}{c}\text { Viability } \\
(\%)\end{array}$ \\
\hline $\mathbf{8 4}$ & -1.4 & $\mathbf{8 6}$ & 83.1 & $\mathbf{9 4}$ & 106.0 \\
$\mathbf{8 0}$ & 76.8 & $\mathbf{8 5}$ & 77.4 & $\mathbf{9 5}$ & 66.2 \\
$\mathbf{8 1}$ & 129.2 & $\mathbf{8 7}$ & 121.2 & $\mathbf{9 6}$ & 86.5 \\
$\mathbf{8 2}$ & 114.2 & $\mathbf{8 8}$ & 93.9 & $\mathbf{9 7}$ & 84.0 \\
$\mathbf{8 3}$ & 96.4 & $\mathbf{8 9}$ & 80.8 & $\mathbf{1 0 0}$ & 83.4 \\
& & $\mathbf{9 0}$ & 91.2 & $\mathbf{9 9}$ & 102.6 \\
& & & & $\mathbf{9 8}$ & 106.0 \\
\hline
\end{tabular}

Tested in duplicated at $20 \mu \mathrm{M}$.

$N$-3: The activity of the $N-3$ alkylated compounds were unaffected when the C-6 substituent changed from an amino to a dimethylamino group as observed for the geranyl derivatives (80 to 85 ) and the farnesyl derivatives (81 to 87) of adenine and 6(dimethylamino)purine, respectively. In addition, increasing the terpenoid chain length from geranyl to farnesyl for both head groups ( $\mathbf{8 0}$ to $\mathbf{8 1}, \mathbf{8 5}$ to $\mathbf{8 7}$ ) appeared to lower activity, with both farnesyl derivatives increasing viability to over $100 \%$. Unfortunately, 
the $N-3$ geranylgeranyl derivatives of $\mathbf{2 8}$ and $\mathbf{4 4}$ were lost during purification but the small trend observed suggests they would not be particularly active.

$N$-7: The $N-7$ alkylated compounds were only formed from 6-chloropurine $(94,96,98$, 99) and only the SAR of the terpenoid chain length and alkene geometry could be assessed, neither of which had substantial influence on activity.

$N$-9: For the $N-9$ alkylated derivatives, activity increased when the C-6 substituent was changed from amino $(\mathbf{8 2}, \mathbf{8 3})$ to dimethylamino $(\mathbf{8 8}-\mathbf{9 0})$, and increased again when the substituent changed to chloro $(\mathbf{9 5}, \mathbf{9 7}, \mathbf{1 0 0})$ for each terpenoid chain length. This could be a result of an increase in the electron withdrawing nature of C-6. Increasing the terpenoid chain length from geranyl to farnesyl had minimal effect on activity for the adenine- (82 to $\mathbf{8 3}$ ) and 6-(dimethylamino)purine (88 to 90 ) derivatives. Conversely, activity slightly decreased for the 6-chloropurine derivatives (95 to 97 to 100) upon increasing chain length. The SAR of alkene geometry could only be analysed by comparison of $\mathbf{8 9}$ and $\mathbf{9 0}$, which were $2 Z$ and $2 E$ geometric isomers of geranylgeranyl 6-(dimethylamino)purine, respectively. The $Z$ geometry of $\mathbf{8 9}$ was slightly more active than the $E$ geometry of $\mathbf{9 0}$.

The only unusual compound isolated for the purine analogues was $N-6, N-9$ digeranyl adenine (84). This compound exhibited the best activity in the single concentration tests (-1.4\% viability), but reduced the percentage of viable HeLa cells to less than $50 \%$ at 20 $\mu \mathrm{M}$, so further tests of $\mathbf{8 4}$ were not pursued since it was generally cytotoxic.

The overall trends for the purine derivatives can be seen in Figure 3.2. Varying the C-6 substituent had minor influence on activity, but no group seemed to be closely associated with activity. Increasing the terpenoid chain length both increased and decreased activity depending on the purine head group. 


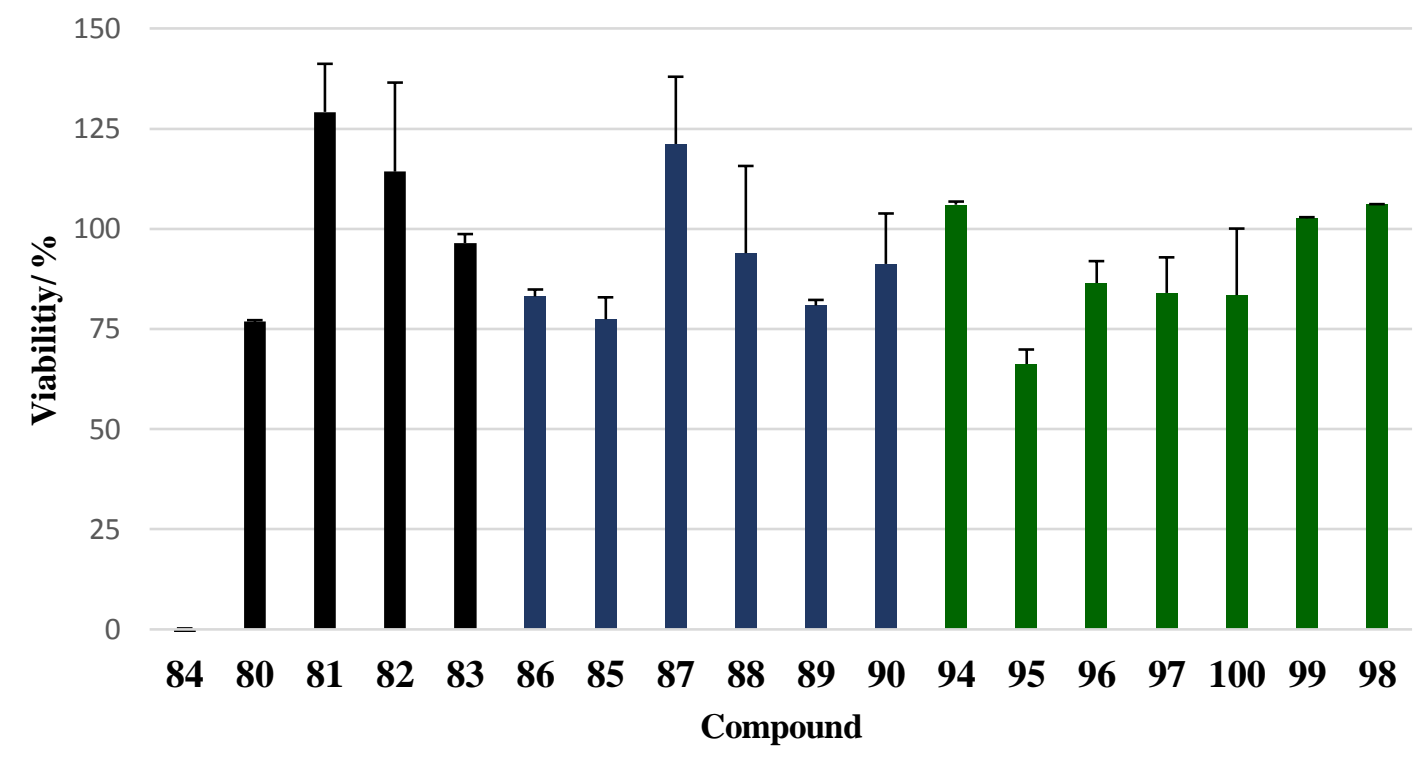

Figure 3.2 Single concentration activities of analogues based on adenine (black), 6(dimethylamino)purine (blue), and 6-chloropurine (green) against P. falciparum.

\subsubsection{Purinones}

The purinone-based head groups were xanthine (45), 2-mercapto-3-methylhypoxanthine (36), 3-methylhypoxanthine (46) and theophylline (47). The purinones $45-47$ are related by methylation, while 36 is akin to $\mathbf{4 6}$ but replaces the C-2 urea with a thiourea. These compounds were all $N-7$ alkylated, therefore it would seem direct comparisons could be made to analyse the SAR of the head groups, but comparisons could only be made relative to 3-methylxanthine since single substitutions of this head group formed the other head groups. In addition to $N-7$ alkylation, the derivatives of $\mathbf{4 5}$ had further alkylation occur at N-3 (Figure 3.3). All purinone derivatives were tested against $P$. falciparum at single concentrations $(20 \mu \mathrm{M})$ (Table 3.2). 
<smiles>CC(C)=CCCC(C)(C)CC=C(C)CCn1cnc2c1c(=O)[nH]c(=S)n2C</smiles>

118, $\mathrm{n}=1, E / Z 1: 0$

119, $\mathrm{n}=2, E / Z 2: 1$

120, $\mathrm{n}=3, E / Z 0: 1$

121, $\mathrm{n}=3, E / Z 1: 0$

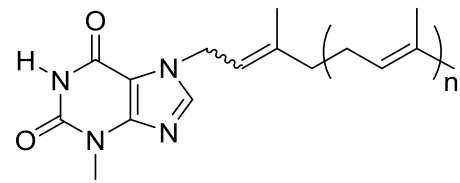

111, $\mathrm{n}=1, E / Z 1: 0$

112, $\mathrm{n}=2, E / Z 0: 1$

113, $\mathrm{n}=2, E / Z$ 2:1

114, $\mathrm{n}=3, E / Z$ 0:1

115, $\mathrm{n}=3, E / Z 1: 0$<smiles>CC(C)=CCCC(C)CCC=C(C)CCC=C(C)CCn1cnc2c1c(=O)[nH]c(=O)n2CC=C(C)C</smiles>

109, $\mathrm{n}=1, E / Z 1: 0$

110, $\mathrm{n}=2, E / Z 3: 2$<smiles>CC(C)=CCCCC(C)=CCn1cnc2c1c(=O)n(C)c(=O)n2C</smiles>

116, $\mathrm{n}=1, E / Z 1: 0$

117, $\mathrm{n}=2, E / Z 1: 0$

63, $\mathrm{n}=3, E / Z$ 0:1

64, $\mathrm{n}=3, E / Z 1: 0$

Figure 3.3 Purinone-based analogues tested against $P$. falciparum.

Table 3.2 The activities of malonganenone A analogues based on xanthine (45), 2-mercapto-3methylxanthine (36), 3-methylxanthine (46) and theophylline (47) against $P$. falciparum.

\begin{tabular}{cccccccc}
\hline $\begin{array}{c}\text { Derivatives } \\
\text { of } \mathbf{3 6}\end{array}$ & $\begin{array}{c}\text { Viability } \\
(\%)\end{array}$ & $\begin{array}{c}\text { Derivatives } \\
\text { of } \mathbf{4 6}\end{array}$ & $\begin{array}{c}\text { Viability } \\
(\%)\end{array}$ & $\begin{array}{c}\text { Derivatives } \\
\text { of } \mathbf{4 5}\end{array}$ & $\begin{array}{c}\text { Viability } \\
(\%)\end{array}$ & $\begin{array}{c}\text { Derivatives } \\
\text { of } \mathbf{4 7}\end{array}$ & $\begin{array}{c}\text { Viability } \\
(\%)\end{array}$ \\
\hline $\mathbf{1 1 8}$ & 61.3 & $\mathbf{1 1 1}$ & 83.1 & $\mathbf{1 0 9}$ & 28.6 & $\mathbf{1 1 6}$ & 122.9 \\
$\mathbf{1 1 9}$ & 71.8 & $\mathbf{1 1 2}$ & 92.3 & $\mathbf{1 1 0}$ & 70.7 & $\mathbf{1 1 7}$ & 100.2 \\
$\mathbf{1 2 1}$ & 119.2 & $\mathbf{1 1 3}$ & 122.6 & & & $\mathbf{6 3}$ & 22.2 \\
$\mathbf{1 2 0}$ & 114.3 & $\mathbf{1 1 4}$ & 109.7 & & & $\mathbf{6 4}$ & 51.6 \\
& & $\mathbf{1 1 5}$ & 122.2 & & & & \\
\hline
\end{tabular}

Tested in duplicated at $20 \mu \mathrm{M}$.

$N-7$ : For geranyl- and farnesyl 3-methyl-2-thioxanthine derivatives (118, 119), substitution of the thiourea with a urea group to form the 3-methylhypoxanthine derivatives $(\mathbf{1 1 1}, \mathbf{1 1 3})$ decreased activity. Activity remained roughly the same when this change was made for the geranylgeranyl derivatives.

From 3-methylxanthine to theophylline, the additional $\mathrm{N}-1$ methyl had a dampening effect on activity for the geranyl- (111 to 116) and farnesyl (112 to 117) derivatives. The opposite effect was observed for geranylgeranyl theophylline (64), which was significantly more active than the geranylgeranyl derivatives of the other two head groups $(114,115,120,121)$. Considering the SAR of the head groups with the smaller chain lengths, the unexpectedly high activity of the geranylgeranyl theophylline derivatives may have been due to the extra isoprenoid unit on the terpenoid chain in conjunction with the additional $N-1$ methyl on the head group. 
Increasing the terpenoid chain length was overall deactivating for the 3-methyl-2thioxanthine- $(\mathbf{1 1 8}-\mathbf{1 2 0})$ and 3-methylxanthine $(\mathbf{1 1 1}-\mathbf{1 1 5})$ derivatives. Conversely, for the theophylline derivatives, increasing terpenoid chain length from geranyl (116) to farnesyl (117) had minimal consequence for activity but adding the third isoprenoid unit to form the geranylgeranyl chain (64) significantly increased activity.

The SAR of alkene geometry was analysed using several sets of geometric isomers. The $2 Z$ isomer of geranylgeranyl theophylline $(\mathbf{6 3})$ displayed twice the activity of the $2 E$ isomer (64). The importance of the geometry around alkene 2 was further supported by the 3-methylxanthine derivatives, where farnesyl- and geranylgeranyl chains with $Z$ geometry $(112,114)$ were more active than their $E$ counterparts $(113,115)$. Alkene geometry had little effect for the geranylgeranyl isomers of the 3-methyl-2-thioxanthine derivatives $(\mathbf{1 2 0}, \mathbf{1 2 1})$.

$N-7, N-3$ : The dialkylated xanthine derivatives and the 3-methylxanthine derivatives have terpenoids or methyls at N-3, respectively. Changing from methyl to geranyl or farnesyl significantly increased activity (111 to 109,113 to 110 ), with a greater increase upon geranyl substitution. Digeranylgeranyl xanthine was not isolated for testing, but it would be expected to have an increased activity compared to geranylgeranyl 3-methylxanthine. Increasing the terpenoid chain length for the xanthine derivatives had a dampening effect on activity, but again, digeranylgeranyl xanthine was not isolated so there is one less data point to support this claim.

The overall SAR of the purinone derivatives is summarised in Figure 3.4, where the activity of the different head groups was closely related to the length of the terpenoid chain. 


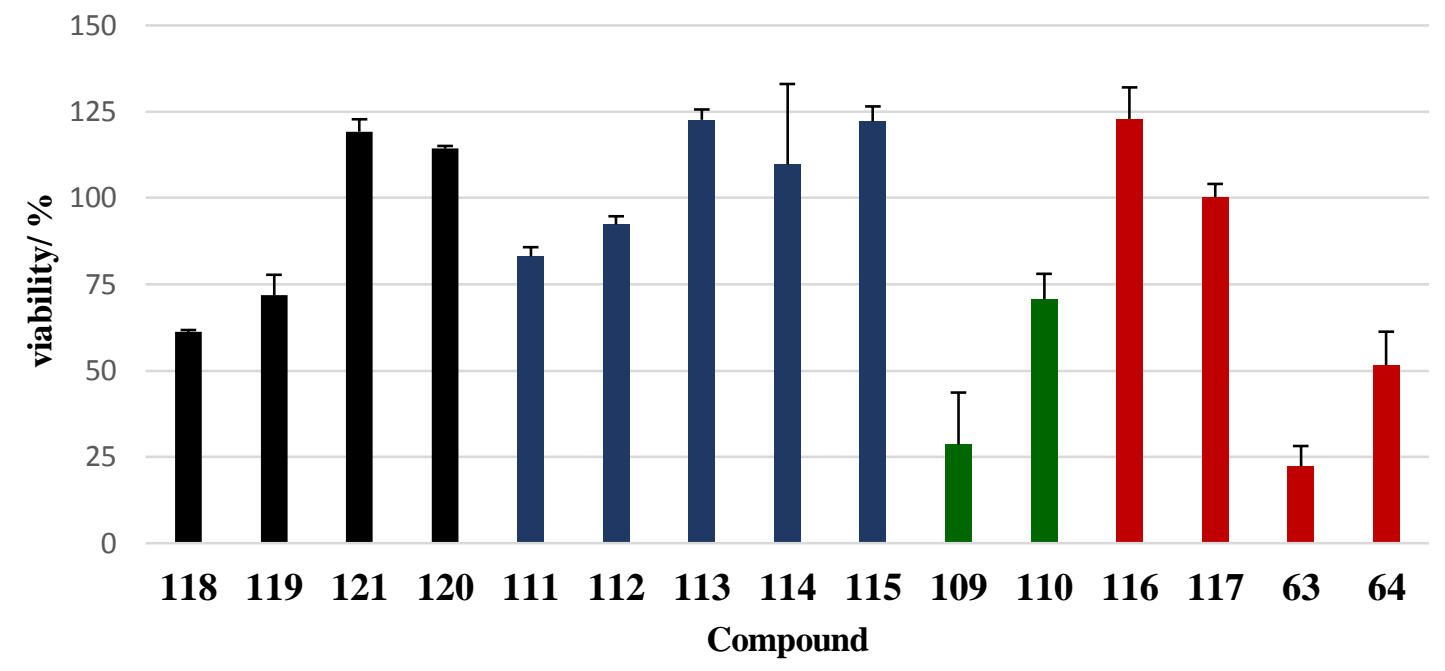

Figure 3.4 Single concentration activities of analogues based on 3-methyl-2-thioxanthine (black), 3-methylxanthine (blue), xanthine (green), and theophylline (red) against $P$. falciparum.

The additional purinone head group was 1,3-dimethyluric acid (49), which displayed an unusual alkylation pattern in comparison to the previous purinones discussed (Figure 3.5). Four of the five submitted analogues were tested against $P$. falciparum at single concentrations $(20 \mu \mathrm{M})$ (Table 3.3).<smiles>CC(C)=CCCC(C)(C)CCC12NC(=O)N=C1N(C)C(=O)N(C)C2=O</smiles>

122, $\mathrm{n}=1, E / Z 1: 0$ $123, \mathrm{n}=2, E / Z 3: 2$

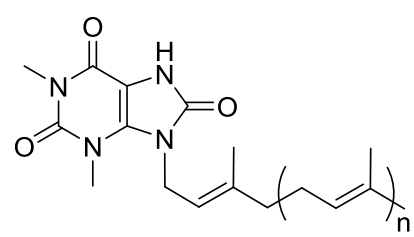

$124, n=2, E / Z 3: 2$

Figure 3.5 1,3-dimethyluric acid derivatives tested against $P$. falciparum.

Table 3.3 Activities of malonganenone A analogues based on 1,3-dimethyluric acid (49) against P. falciparum.

\begin{tabular}{cc}
\hline $\begin{array}{c}\text { Derivatives } \\
\text { of } \mathbf{4 9}\end{array}$ & $\begin{array}{c}\text { Viability } \\
(\%)\end{array}$ \\
\hline $\mathbf{1 2 2}$ & 164.0 \\
$\mathbf{1 2 3}$ & 90.9 \\
$\mathbf{1 2 4}$ & 102.0 \\
$\mathbf{1 2 5}$ & - \\
\hline
\end{tabular}

Tested in duplicated at $20 \mu \mathrm{M}$.

The SAR analysis of these compounds was limited since some regioisomers were missing. When the alkylation position changed from $\mathrm{C}-5$ to $\mathrm{N}-9$, activity minorly 
decreased for the farnesyl derivatives (123 to 124). Increasing the chain length from geranyl to farnesyl for the $C-5$ alkylated derivatives (122 to $\mathbf{1 2 3}$ ) appeared to increase activity, since 122 increased parasite viability to over $100 \%$ and the extra isoprenoid in 123 reduced viability. It would be interesting to further probe the chain length by testing the $C$-5 geranylgeranyl derivative (125) to see if activity could be improved again. Compound 125 was submitted, but not tested by collaborators for unknown reasons. Furthermore, alkylation at C-5 would form a racemate, therefore chiral separation or enantioselective synthesis would need to be used to determine the SAR of the enantiomers.

\subsubsection{Pyrimidines}

The pyrimidines alkylated were uracil (51), thymine (52) and cytosine (53). These differ by a methyl group at position 5 and $\mathbf{5 3}$ has an imine instead of a carbonyl at C-4 as for $\mathbf{5 1}$ and 52. All compounds isolated were $N-1$ alkylated, but the cytosine derivatives had addition alkylation occur at N-3 (Figure 3.6). All the pyrimidine-based analogues, apart from one, were tested at single concentration against P. falciparum $(20 \mu \mathrm{M})$ (Table 3.4).


Figure 3.6 Pyrimidine-based analogues tested against $P$. falciparum.

Table 3.4 The activities of malonganenone A analogues based on uracil (51), thymine (52), and cytosine (53) against $P$. falciparum.

\begin{tabular}{cccccc}
\hline $\begin{array}{c}\text { Derivatives } \\
\text { of } \mathbf{5 1}\end{array}$ & $\begin{array}{c}\text { Viability } \\
(\%)\end{array}$ & $\begin{array}{c}\text { Derivatives } \\
\text { of } \mathbf{5 2}\end{array}$ & $\begin{array}{c}\text { Viability } \\
(\%)\end{array}$ & $\begin{array}{c}\text { Derivatives } \\
\text { of } \mathbf{5 3}\end{array}$ & $\begin{array}{c}\text { Viability } \\
(\%)\end{array}$ \\
\hline $\mathbf{1 3 3}$ & 102.8 & $\mathbf{1 3 7}$ & 93.4 & $\mathbf{1 4 0}$ & 99.1 \\
$\mathbf{1 3 4}$ & 95.6 & $\mathbf{1 3 8}$ & 90.3 & $\mathbf{1 4 1}$ & 22.7 \\
$\mathbf{1 3 6}$ & - & $\mathbf{1 3 9}$ & 112.9 & & \\
$\mathbf{1 3 5}$ & 90.5 & & & & \\
\hline
\end{tabular}

Tested in duplicated at $20 \mu \mathrm{M}$.

$N$-1: Changing H-5 to a methyl group or increasing the terpenoid chain length had no appreciable effect on activity, as observed for the uracil $(\mathbf{1 3 3}, \mathbf{1 3 4}, \mathbf{1 3 5})$ and thymine $(137$ - 139) derivatives. 
$N$-1,N-3: Neither the N-1 or C-4 substituents influenced activity for geranyl uracil (133) and digeranyl cytosine (140), but difarnesyl cytosine (141) was significantly more active than farnesyl uracil (134). This trend may have been based on terpenoid chain length rather than head group identity.

The SAR of the alkene geometry could not be probed for the pyrimidines as only one isomer was tested for each of the head groups, since the other was lost during purification. The only compounds that could have provided insight into the SAR for alkene geometry in the pyrimidines was geranylgeranyl uracil, both the $E(\mathbf{1 3 6})$ and $Z(\mathbf{1 3 5})$ isomers were submitted for testing but $\mathbf{1 3 6}$ was not tested for unknown reasons.

The general SAR of the pyrimidine derivatives is shown in Figure 3.7, chain length and head group had no effect on activity for the uracil and thymine derivatives while cytosine had a different SAR, since it was dialkylated. Perhaps the SAR would align with the other pyrimidines if the derivatives were monoalkylated instead, this might be achieved by using less than one equivalent of terpenoid bromide.

$20 \mu \mathrm{M}$ Pyrimidines vs. $P$. falciparum

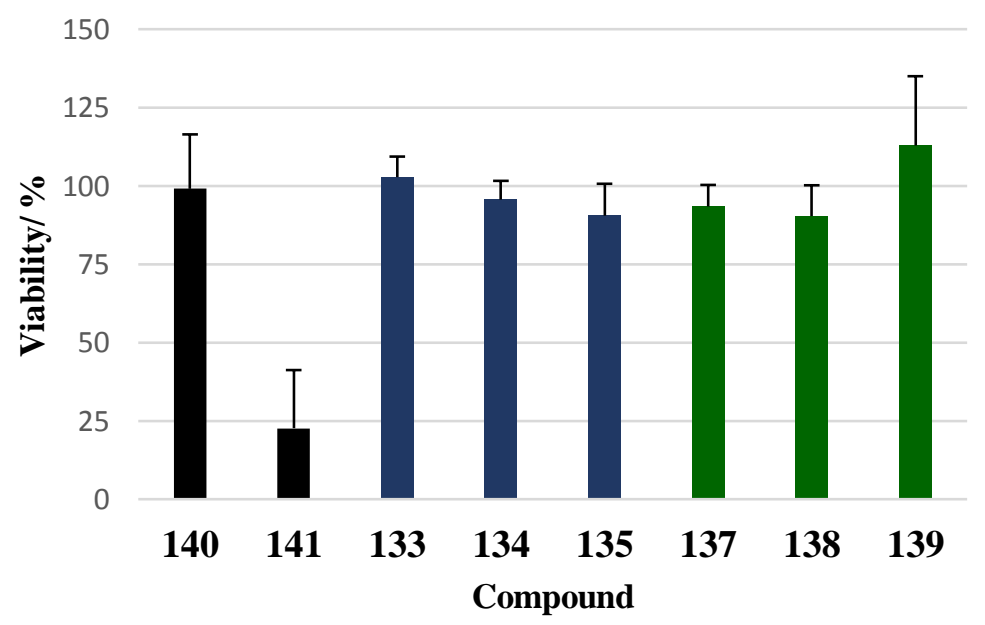

Figure 3.7 Single concentration activities of analogues based on cytosine (black), uracil (blue), and thymine (green) against $P$. falciparum. 


\subsubsection{Other head groups}

The remaining head groups that did not fit in the previous categories are each discussed separately in this section (Figure 3.8). All these derivatives were tested against $P$. falciparum at a single concentration $(20 \mu \mathrm{M})$ (Table 3.5).

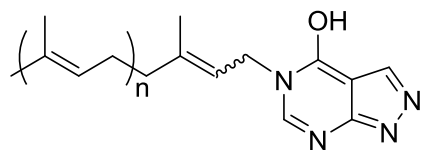

155, $\mathrm{n}=1, E / Z 1: 0$

156, $\mathrm{n}=2, E / Z 3: 2$



158, $\mathrm{n}=2, E / Z 3: 2$<smiles>CCC(C)=CCn1ncc2c(=O)n(CC=C(C)CCCCC=C(C)C)cnc21</smiles>

157, $\mathrm{n}=2, E / Z 2: 1$

160, $\mathrm{n}=3, E / Z 1: 0$<smiles>CC(C)=CCCC(C)(C)C=CCN1C(=O)c2ccccc2C1=O</smiles>

148, $\mathrm{n}=1, E / Z 1: 0$

149, $\mathrm{n}=2, E / Z 5: 4$

$150, \mathrm{n}=3, E / Z 1: 0$<smiles>CC(C)=CCCC(C)C(C)=CCn1ccnc1</smiles>

143, $\mathrm{n}=1, E / Z 1: 0$

144, $\mathrm{n}=2, E / Z 7: 2$

145, $\mathrm{n}=3, E / Z 1: 1$

146, $\mathrm{n}=3, E / Z 1: 0$

Figure 3.8 Further analogues tested against $P$. falciparum.

Table 3.5 The activities of analogues based on allopurinol (52), phthalimide (147) and imidazole (50) against $P$. falciparum.

\begin{tabular}{cccccc}
\hline $\begin{array}{c}\text { Derivatives } \\
\text { of 52 }\end{array}$ & $\begin{array}{c}\text { Viability } \\
(\%)\end{array}$ & $\begin{array}{c}\text { Derivatives } \\
\text { of } \mathbf{1 4 7}\end{array}$ & $\begin{array}{c}\text { Viability } \\
(\%)\end{array}$ & $\begin{array}{c}\text { Derivatives } \\
\text { of } \mathbf{5 0}\end{array}$ & $\begin{array}{c}\text { Viability } \\
(\%)\end{array}$ \\
\hline $\mathbf{1 5 5}$ & 110.6 & $\mathbf{1 4 8}$ & 96.2 & $\mathbf{1 4 3}$ & 40.6 \\
$\mathbf{1 5 7}$ & 78.2 & $\mathbf{1 4 9}$ & 90.9 & $\mathbf{1 4 4}$ & -0.3 \\
$\mathbf{1 5 8}$ & 112.5 & $\mathbf{1 5 0}$ & 109.3 & $\mathbf{1 4 5}$ & 19.7 \\
$\mathbf{1 5 6}$ & 100.1 & & & $\mathbf{1 4 6}$ & 12.5 \\
$\mathbf{1 6 0}$ & 77.1 & & & & \\
\hline
\end{tabular}

Tested in duplicated at $20 \mu \mathrm{M}$.

The allopurinol head group is a mix between the purine and purinone head groups previously discussed, but these analogues are not particularly comparable to either class since the alkylation pattern was quite different. $N-1$ monoalkylated allopurinol and two types of dialkylated compounds were isolated from the various reactions. The only SAR analysis possible for the allopurinol compounds was terpenoid chain length and alkene geometry. Since the geometric isomers were not separated, only chain length could be analysed. Unfortunately, not all the possible regioisomers were isolated for each chain length, since the reaction conditions were slightly different and some regioisomers were lost upon purification. $N-1$ geranyl- (155) and $N-1$ farnesyl allopurinol (156) were inactive. $N-1, N-5$ difarnesyl allopurinol (157) was weakly active and changing the sites 
of alkylation to $N-2$ and $N-7$ (158) decreased activity. In addition, increasing the terpenoid chain length for the $N-1, N-5$ dialkylated compound from farnesyl to geranylgeranyl (157 to 160) had no effect. The activities of the allopurinol compounds were poor, which means repeating these syntheses to isolate all possible regioisomers is less important.

The phthalimide derivatives $(\mathbf{1 4 8}$ - 150) were inactive and increasing the terpenoid chain length had no appreciable effect on activity.

The activity of the imidazole derivatives varied with terpenoid chain length. Increasing the length from geranyl to farnesyl (143 to 144) significantly increased activity. An additional isoprenoid unit to form the geranylgeranyl derivatives $(\mathbf{1 4 5}, \mathbf{1 4 6})$ appeared to decrease activity. In addition, the $E$ isomer (146) of the geranylgeranyl derivative was more active than the 1:1 mixture of $E$ and $Z$ isomers (145).

The SAR analyses discussed are visually summarised in Figure 3.9, while these head groups are not directly comparable, chain length and extent of alkylation influenced activity.

\section{$20 \mu \mathrm{M}$ other head groups vs. P. falciparum}

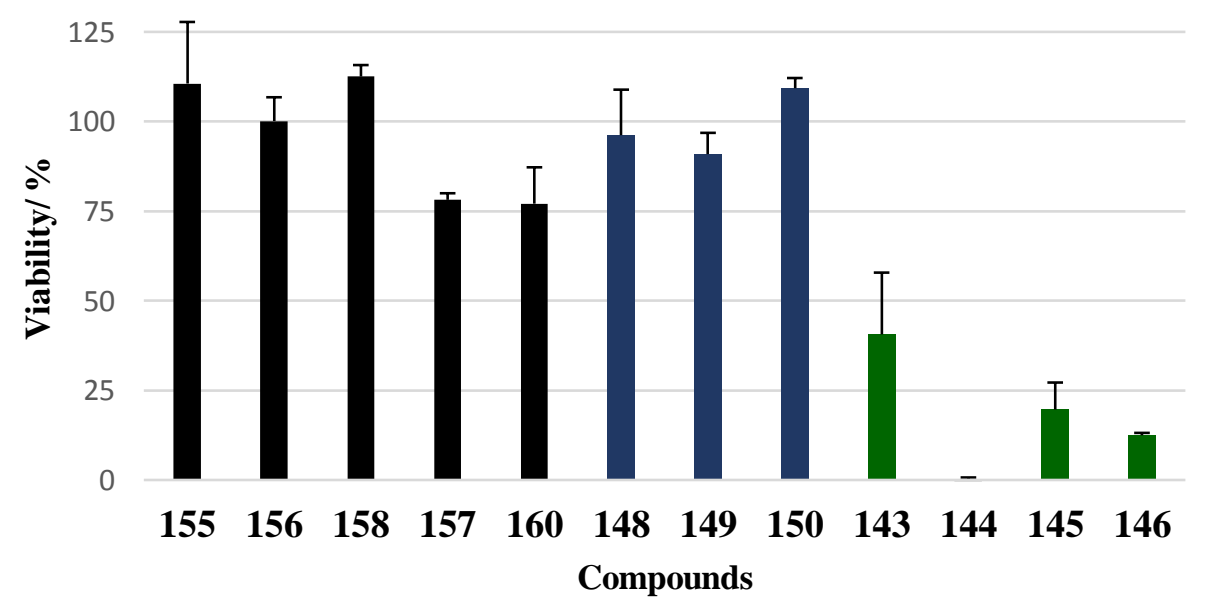

Figure 3.9 Single concentration activities of analogues against $P$. falciparum. Head groups distinguished by colour, allopurinol (black), phthalimide (blue) and imidazole (green). 


\subsubsection{Amides}

The malonganenone $\mathrm{C}$ analogues were based on simple amides with or without additional methylation (Figure 3.10). All submitted analogues were tested against P. falciparum at single concentrations $(20 \mu \mathrm{M})$ (Table 3.6).

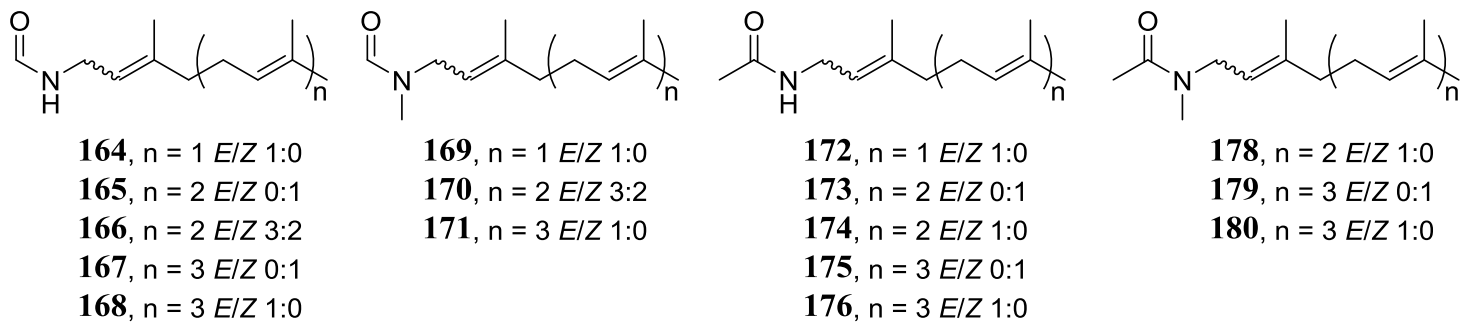

Figure 3.10 Amide-based analogues tested against $P$. falciparum.

Table 3.6 The activities of amide-based analogues against $P$. falciparum.

\begin{tabular}{cccccccc}
\hline Formamides & $\begin{array}{c}\text { Viability } \\
(\%)\end{array}$ & $\begin{array}{c}N \text {-methyl } \\
\text { formamides }\end{array}$ & $\begin{array}{c}\text { Viability } \\
(\%)\end{array}$ & Acetamides & $\begin{array}{c}\text { Viability } \\
(\%)\end{array}$ & $\begin{array}{c}N \text {-methyl } \\
\text { acetamides }\end{array}$ & $\begin{array}{c}\text { Viability } \\
(\%)\end{array}$ \\
\hline $\mathbf{1 6 4}$ & 111.7 & $\mathbf{1 6 9}$ & 100.5 & $\mathbf{1 7 2}$ & 132.5 & - & - \\
$\mathbf{1 6 5}$ & 120.7 & - & - & $\mathbf{1 7 3}$ & 106.5 & - & - \\
$\mathbf{1 6 6}$ & 123.4 & $\mathbf{1 7 0}$ & 103.2 & $\mathbf{1 7 4}$ & 94.7 & $\mathbf{1 7 8}$ & 122.1 \\
$\mathbf{1 6 7}$ & 84.9 & - & - & $\mathbf{1 7 5}$ & 75.7 & $\mathbf{1 7 9}$ & 85.3 \\
$\mathbf{1 6 8}$ & 114.3 & $\mathbf{1 7 1}$ & 58.9 & $\mathbf{1 7 6}$ & 126.5 & $\mathbf{1 8 0}$ & 54.2 \\
\hline
\end{tabular}

Tested in duplicated at $20 \mu \mathrm{M}$.

Changing the formamide to an acetamide had minimal effect on activity for the geranyl derivatives (164 to 172). The same change for the farnesyl- and $2 Z$ geranylgeranyl derivatives increased activity $(\mathbf{1 6 5}, \mathbf{1 6 6}, 167$ to $173, \mathbf{1 7 4}, \mathbf{1 7 5})$.

Methylation of geranyl- and farnesyl formamides appeared to minorly increase activity since viability was over $100 \%$ pre-methylation $(164,166$ to 169,170$)$. Methylation of geranylgeranyl formamide significantly increased activity (168 to 171). Methylation of $2 E$ farnesyl- and $2 Z$ geranylgeranyl acetamides decreased activity $(\mathbf{1 7 4}, \mathbf{1 7 5}$ to $\mathbf{1 7 8}, \mathbf{1 7 9})$, but greatly increased activity for the $2 E$ geranylgeranyl derivative (176 to $\mathbf{1 8 0}$ ).

Increasing the terpenoid chain length for the formamides $(164-168)$ mostly had no effect on activity, but the $2 Z$ isomer of geranylgeranyl formamide (167) was more active than the other derivatives. This SAR was more likely from the alkene geometry than terpenoid chain length. For the $\mathrm{N}$-methylformamide derivatives, increasing the terpenoid chain length from geranyl (169) to farnesyl (170) had no effect, while a further increase to geranylgeranyl (171) increased activity almost two-fold. For the acetamides, increasing 
terpenoid chain length had minimal effect for the $E$ isomers (172 to 174 to $\mathbf{1 7 6}$ ), while the change from farnesyl to geranylgeranyl increased activity of the $\mathrm{Z}$ isomers (173 to 175). For the $N$-methylacetamides, changing from farnesyl to geranylgeranyl increased activity for the $E$ isomers (179 to $\mathbf{1 8 0})$.

The SAR of alkene geometry depended on chain length, where no effect was observed for the farnesyl derivatives, but some influence was observed for the geranylgeranyl derivatives. The $Z$ isomers $(167, \mathbf{1 7 5})$ were more active than the $E$ isomers $(\mathbf{1 6 8}, \mathbf{1 7 6})$ of the geranylgeranyl derivatives of formamide and acetamide, while the opposite relationship was observed for the $N$-methylacetamides $(\mathbf{1 7 9}, \mathbf{1 8 0})$.

The overarching trends for the SAR of the amide-based analogues is readily seen in Figure 3.11, activity increased with terpenoid chain length.

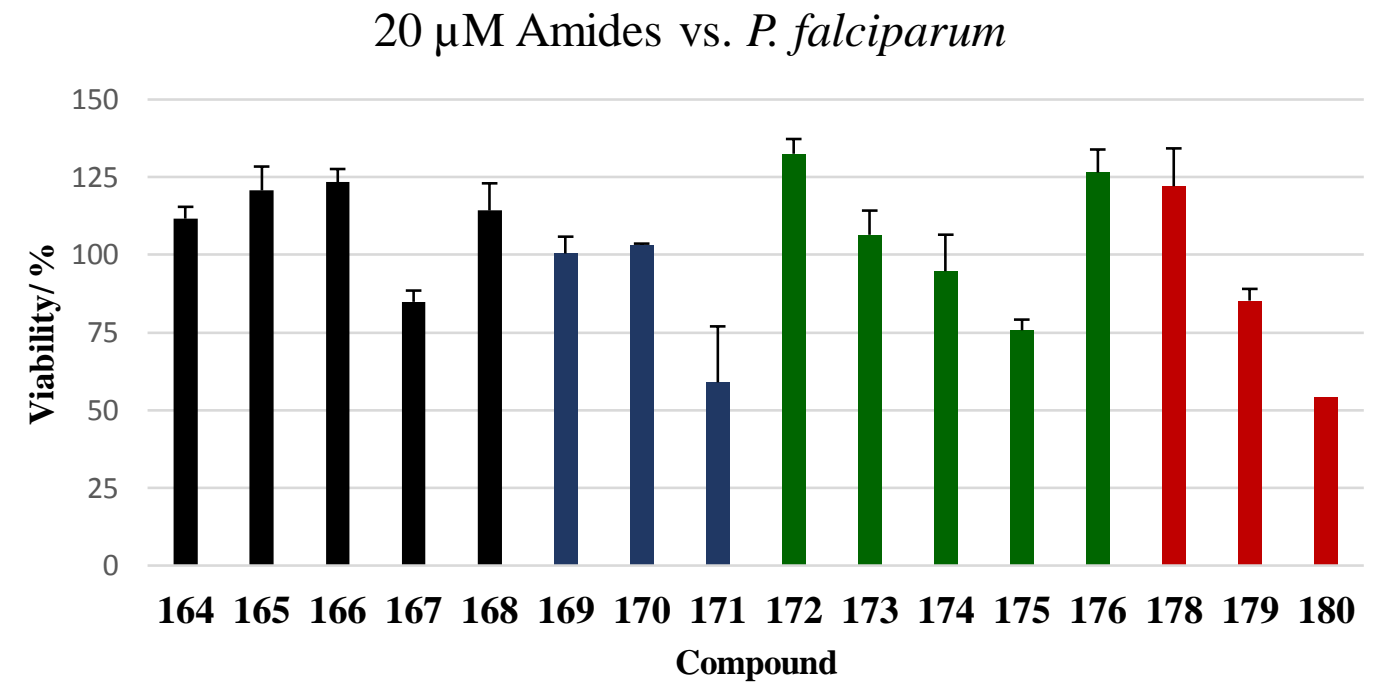

Figure 3.11 Single concentration activities of analogues based on formamide (black), $\mathrm{N}$ methylformamide (blue), acetamide (green), and $N$-methylacetamide (red) against $P$. falciparum. 
Lead compounds that reduced parasite viability to $<20-30 \%$ were further assessed for $\mathrm{IC}_{50}$ (Table 3.7). No clear SAR was observed across the four compounds for which $\mathrm{IC}_{50}$ values were obtained, but the presence of three imidazole based compounds suggests this head group was important for activity.

Table 3.7 $\mathrm{IC}_{50}$ values for select malonganenone A analogues.

145

${ }^{a}$ The $\mathrm{IC}_{50}$ curve was not suitable. The drug standard chloroquine has an $\mathrm{IC}_{50}$ value in the range $0.01-0.05 \mu \mathrm{M}$.

For the imidazole derivatives, increasing the terpenoid chain length from farnesyl (144) to geranylgeranyl $(\mathbf{1 4 5}, \mathbf{1 4 6})$ increased activity. In addition, the compound with the best activity was geranylgeranyl imidazole (145) as a 1:1 mixture of $E / Z$ about the alkene at position 2, while $2 E$ geranylgeranyl imidazole (146) had the next best activity. These $\mathrm{IC}_{50}$ values are close, which would be expected for such similar compounds as $\mathbf{1 4 5}$ contains approximately half of $\mathbf{1 4 6}$. The other half of the geometric mixture was suggested to be more active since the $\mathrm{IC}_{50}$ value is lower than just the $2 E$ isomer alone. It would be of interest to test just the $2 Z$ derivative as an increased activity compared to both $\mathbf{1 4 5}$ and 
146 would be expected. Since the $Z$ isomer was not separable from the $E$ isomer, the geranylgeranyl bromide starting material would simply need purification beforehand.

The SAR of the imidazole derivatives derived from the single concentration data and $\mathrm{IC}_{50}$ values are not completely in agreement. For both sets, activity increased on lengthening the terpenoid chain from geranyl to farnesyl, but the change from farnesyl to geranylgeranyl had opposite trends for activity. In addition, the SAR of alkene geometry was opposite. Therefore, the SARs derived for all other compounds from the single concentration inhibition data are tentative at best.

It is interesting to note that the single concentration test against $P$. falciparum does not translate well with the $\mathrm{IC}_{50}$ values. The most active compound at a single concentration, farnesyl imidazole (144), which reduced parasite viability to $-0.3 \%$, had the highest $\mathrm{IC}_{50}$ value obtained. Isomeric geranylgeranyl imidazole (145), which only reduced parasite viability to $19.4 \%$ in the single concentration assay, had the best $\mathrm{IC}_{50}$ value. This seems to undermine the requirement of reducing to at least $>30 \%$ P. falciparum viability, but it is the uncertainty of the single concentration tests that must be considered. Each test was carried out in duplicate and some had large uncertainty. For example, difarnesylated cytosine (141), appeared to have met the inhibition requirement since the viability was $22.7 \%$ but the standard deviation for this result was $18.6 \%$, which could render this compound outside of the desired range. This compound was examined in an $\mathrm{IC}_{50}$ test, but no curve was obtained as $12 \%$ of cells were still viable at the maximum concentration of $100 \mu \mathrm{M}$, which further solidifies the significance of a large uncertainty and the true viability is likely more than $30 \%$ after the single concentration test. A few other compounds also had large uncertainties, which potentially ruled them out of testing for $\mathrm{IC}_{50}$. This was the case for geranyl imidazole (143), in which the viability was $40.6 \pm$ $17.2 \%$, where subtracting the standard deviation would lower the viability to $23.4 \%$. It is a shame that this compound was not tested for $\mathrm{IC}_{50}$ since the other imidazole compounds were tested, it may have further solidified the significance of the imidazole head group in terms of SAR and further supported the SAR of the terpenoid chain length. Nevertheless, the imidazole head group is significant and increasing terpenoid chain length increased activity, and the $Z$ isomer was more active than the $E$ isomer.

Imidazole derivatives were initially thought of as malonganenone A analogues, but these are more correctly malonganenone B analogues, since the latter is an $N-1$ alkylated 4,5- 
disubstituted imidazole, with an $\mathrm{IC}_{50}$ value greater than $50 \mu \mathrm{M}$. Removing the amide substituents on 4 and 5, and substituting the natural product tail with geranylgeranyl to reduce the structure to a loose skeleton greatly increased activity against $P$. falciparum. The most active analogue in this project was geranylgeranyl imidazole (145), with an $\mathrm{IC}_{50}$ value of $8.4 \mu \mathrm{M}$, which was close to the $\mathrm{IC}_{50}$ of malonganenone $\mathrm{C}(\mathbf{1 2})$. The clear advantage of $\mathbf{1 4 5}$ over the malonganenones, was that it could be isolated from a simple one step reaction and bypassed the synthesis of the unusual side chain. In addition, the imidazole head group is easily obtained from commercial sources.

In the same assay against $P$. falciparum infected red blood cells, malonganenone A (10) and $\mathrm{C}$ (12) had $\mathrm{IC}_{50}$ values of $0.81 \mu \mathrm{M}$ and $5.2 \mu \mathrm{M}$, respectively. The SAR of the natural product side chain could not be determined directly, since the natural product head group derivatives were not tested. The malonganenone A head group based alkylations did not yield the desired products, while the malonganenone $\mathrm{C}$ head group based analogues did not have their $\mathrm{IC}_{50}$ values determined since the single concentration activities were too low. The overall inactivity of the malonganenone $\mathrm{C}$ terpenoid formamide analogues suggested the natural product chain was important for activity but as previously discussed, the single concentration activities did not translate well with the corresponding $\mathrm{IC}_{50}$ values. Therefore, no substantial conclusive SAR of the natural product chain can be derived without the $\mathrm{IC}_{50}$ values of the derivatives that share the same natural product head group.

\subsection{Trypanosoma brucei}

Due to unforeseen circumstances, the compounds were significantly delayed by chemical couriers providing reagents for testing against $P$. falciparum. While waiting, our collaborators tested the compounds against the parasite Trypanosoma brucei, which is responsible for African sleeping sickness. T. brucei infection is similar to P. falciparum infection, it is carried by an insect, the Glossina tsetse fly, and the parasites rampantly multiply in the blood and can eventually cross the blood-brain barrier to cause neurological defects and death if left untreated. ${ }^{105}$ Although the malonganenone analogues synthesised during this project were targeted at P. falciparum, they are significantly more active against T. brucei. P. falciparum testing is against parasites within red blood cells while T. brucei is tested directly against the parasite, which could mean the higher activities observed are more truly representative of antiparasitic activity. 
For P. falciparum testing, the compounds must first deal with cell entry to access the parasite, but this is also a good model for an actual malaria infection.

The compounds were tested at a single concentration of $20 \mu \mathrm{M}$ against cultures of $T$. bruce $i$ and the percentage of viable parasites remaining after treatment was assessed. Compounds which reduced viability to $<10-20 \%$ were further tested for $\mathrm{IC}_{50}$. A total of 51 compounds were further assessed for $\mathrm{IC}_{50}$, which means quality $\mathrm{SARs}$ could be primarily derived from this data rather than the single concentration inhibition data. In some cases, where an entire set of compounds was not tested for $\mathrm{IC}_{50}$, the single concentration data was used to tentatively analyse the SAR. 


\subsubsection{Purines}

All the purine derivatives (Figure 3.12) were tested against $T$. brucei at single concentrations $(20 \mu \mathrm{M})$ (Table 3.8) and select compounds further had $\mathrm{IC}_{50}$ values determined (Table 3.9).

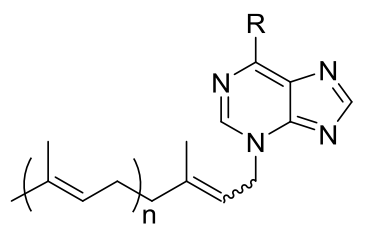

80, $\mathrm{R}=\mathrm{NH}_{2}, \mathrm{n}=1, E / Z, 1: 0$

81, $\mathrm{R}=\mathrm{NH}_{2}, \mathrm{n}=2 E / Z, 3: 2$

85, $\mathrm{R}=\mathrm{NMe}_{2}, \mathrm{n}=1, E / Z, 1: 0$

87, $\mathrm{R}=\mathrm{NMe}_{2}, \mathrm{n}=2 \mathrm{E} / \mathrm{Z}, 3: 2$



82, $\mathrm{R}=\mathrm{NH}_{2}, \mathrm{n}=2 \quad E / Z, 3: 2$

83, $\mathrm{R}=\mathrm{NH}_{2}, \mathrm{n}=3 \mathrm{E} / \mathrm{Z}, 1: 0$

86, $\mathrm{R}=\mathrm{NMe}_{2}, \mathrm{n}=1, E / Z, 1: 0$

88, $\mathrm{R}=\mathrm{NMe}_{2}, \mathrm{n}=2 E / Z, 3: 2$

89, $\mathrm{R}=\mathrm{NMe}_{2}, \mathrm{n}=3 \quad E / Z, 0: 1$

90, $\mathrm{R}=\mathrm{NMe}_{2}, \mathrm{n}=3 \mathrm{E} / Z, 1: 0$

95, $\mathrm{R}=\mathrm{Cl}, \mathrm{n}=1, E / Z, 1: 0$

97, $\mathrm{R}=\mathrm{Cl}, \mathrm{n}=2 \mathrm{E} / \mathrm{Z}, 2: 1$

100, $\mathrm{R}=\mathrm{Cl}, \mathrm{n}=3 E / Z, 1: 0$<smiles>CC(C)=CCCC(C)=CCn1cnc2ncnc(Cl)c21</smiles>

94, $\mathrm{R}=\mathrm{Cl}, \mathrm{n}=1, E / Z, 1: 0$

96, $\mathrm{R}=\mathrm{Cl}, \mathrm{n}=2 E / Z, 3: 2$

98, $\mathrm{R}=\mathrm{Cl}, \mathrm{n}=3 \quad E / Z, 0: 1$

99, $\mathrm{R}=\mathrm{Cl}, \mathrm{n}=3 E / Z, 1: 0$

Figure 3.12 Purine-based analogues tested against T. brucei.

Table 3.8 The activities of malonganenone A analogues based on adenine (28), 6(dimethylamino)purine (44), and 6-chloropurine (43) against T. brucei.

\begin{tabular}{cccccc}
\hline $\begin{array}{c}\text { Derivatives } \\
\text { of } \mathbf{2 8}\end{array}$ & $\begin{array}{c}\text { Viability } \\
(\%)\end{array}$ & $\begin{array}{c}\text { Derivatives } \\
\text { of } \mathbf{4 4}\end{array}$ & $\begin{array}{c}\text { Viability } \\
(\%)\end{array}$ & $\begin{array}{c}\text { Derivatives } \\
\text { of } \mathbf{4 3}\end{array}$ & $\begin{array}{c}\text { Viability } \\
(\%)\end{array}$ \\
\hline $\mathbf{8 4}$ & 0.5 & $\mathbf{8 6}$ & 2.8 & $\mathbf{9 4}$ & 5.3 \\
$\mathbf{8 0}$ & 89.9 & $\mathbf{8 5}$ & 67.8 & $\mathbf{9 5}$ & -0.02 \\
$\mathbf{8 1}$ & 6.0 & $\mathbf{8 7}$ & 0.7 & $\mathbf{9 6}$ & -1.7 \\
$\mathbf{8 2}$ & 16.6 & $\mathbf{8 8}$ & 0.8 & $\mathbf{9 7}$ & 0.2 \\
$\mathbf{8 3}$ & 6.1 & $\mathbf{8 9}$ & 6.3 & $\mathbf{1 0 0}$ & 5.7 \\
& & $\mathbf{9 0}$ & 6.5 & $\mathbf{9 9}$ & 5.4 \\
& & & & $\mathbf{9 8}$ & 5.7 \\
\hline
\end{tabular}

Tested in duplicated at $20 \mu \mathrm{M}$.

Table 3.9 The $\mathrm{IC}_{50}$ values of malonganenone A analogues based on adenine (28), 6(dimethylamino)purine (44), and 6-chloropurine (43) against T. brucei.

\begin{tabular}{cccccc}
\hline $\begin{array}{c}\text { Derivatives } \\
\text { of } \mathbf{2 8}\end{array}$ & $\mathrm{IC}_{50} / \mu \mathrm{M}$ & $\begin{array}{c}\text { Derivatives } \\
\text { of } \mathbf{4 4}\end{array}$ & $\mathrm{IC}_{50} / \mu \mathrm{M}$ & $\begin{array}{c}\text { Derivatives } \\
\text { of } \mathbf{4 3}\end{array}$ & $\mathrm{IC}_{50} / \mu \mathrm{M}$ \\
\hline $\mathbf{8 4}$ & $-^{\mathrm{a}}$ & $\mathbf{8 6}$ & 28.4 & $\mathbf{9 4}$ & 11.0 \\
$\mathbf{8 0}$ & - & $\mathbf{8 5}$ & - & $\mathbf{9 5}$ & 12.2 \\
$\mathbf{8 1}$ & 12.7 & $\mathbf{8 7}$ & 14.0 & $\mathbf{9 6}$ & 9.3 \\
$\mathbf{8 2}$ & 47.7 & $\mathbf{8 8}$ & 9.5 & $\mathbf{9 7}$ & 12.9 \\
$\mathbf{8 3}$ & 13.4 & $\mathbf{8 9}$ & 8.7 & $\mathbf{1 0 0}$ & 6.8 \\
& & $\mathbf{9 0}$ & 9.2 & $\mathbf{9 9}$ & 11.0 \\
& & & & $\mathbf{9 8}$ & 19.1 \\
\hline
\end{tabular}

${ }^{a}$ Generally cytotoxic against HeLa cells ( $>50 \%$ inhibition at $\left.20 \mu \mathrm{M}\right)$. The drug standard pentamidine has an $\mathrm{IC}_{50}$ value in the range $0.001-0.05 \mu \mathrm{M}$. 
$N-3$ : In regards to the $N-3$ farnesyl derivatives of adenine (81) and 6(dimethylamino)purine (87), changing the purine C-6 substituent from an amino group to a dimethylamino group slightly decreased activity. The $N-3$ geranylgeranyl derivatives of adenine and 6-(dimethylamino)purine were not isolated, but it would be interesting to see if the same SAR could be observed.

$N$-9: Analysis of the $N-9$ farnesyl derivatives for all three purine head groups showed that when the C-6 substituent changed from amino to dimethylamino (82 to 88 ) activity increased, while changing from dimethylamino to chloro ( 88 to 97 ) activity decreased slightly. The $N-9$ geranylgeranyl derivatives increased activity after the substitution of amino to dimethylamino (83 to $\mathbf{9 0}$ ) and then increased again on the change from dimethylamino to chloro (90 to 100). Increasing the terpenoid chain length from farnesyl to geranylgeranyl significantly increased activity for the adenine derivatives ( 82 to 83 ). Activity also increased for each added isoprenoid for the 6-dimethylamino derivatives $(\mathbf{8 6}-\mathbf{9 0})$, with the greatest increase in activity from geranyl $(\mathbf{8 6})$ to farnesyl $(\mathbf{8 8})$ and a slight increase for an additional isoprenoid unit to form the geranylgeranyl derivative (90). Alkene geometry had a minor effect on activity for the $E$ (99) and $Z$ (98) isomers of geranylgeranyl 6-(dimethylamino)purine, where the $Z$ isomer was slightly more active. Increasing the terpenoid chain length from geranyl to farnesyl had minimal effect on activity for the 6-chloropurine derivatives (95 to 97), but an additional isoprenoid unit to form the geranylgeranyl derivative (100), increased activity almost two-fold.

$\mathbf{N - 7}$ : Increasing the terpenoid chain length for the 6-chloropurine derivatives $(\mathbf{9 4}, 96,98$, 99) overall had minimal effect on activity, but a decrease in activity was observed for the geranylgeranyl derivative with $Z$ geometry (98). This may have been a consequence of alkene geometry rather than chain length, since the $E(\mathbf{9 9})$ isomer was slightly more active than the $Z(\mathbf{9 8})$ isomer of the geranylgeranyl derivatives.

The overarching trends for the purine derivatives against $T$. brucei are summarised in Figure 3.13, the C-6 substituent of the head group had a minor influence activity. The terpenoid chain length had various effects on activity, depending on the C-6 substituent. 


\section{Purines vs. T. brucei}

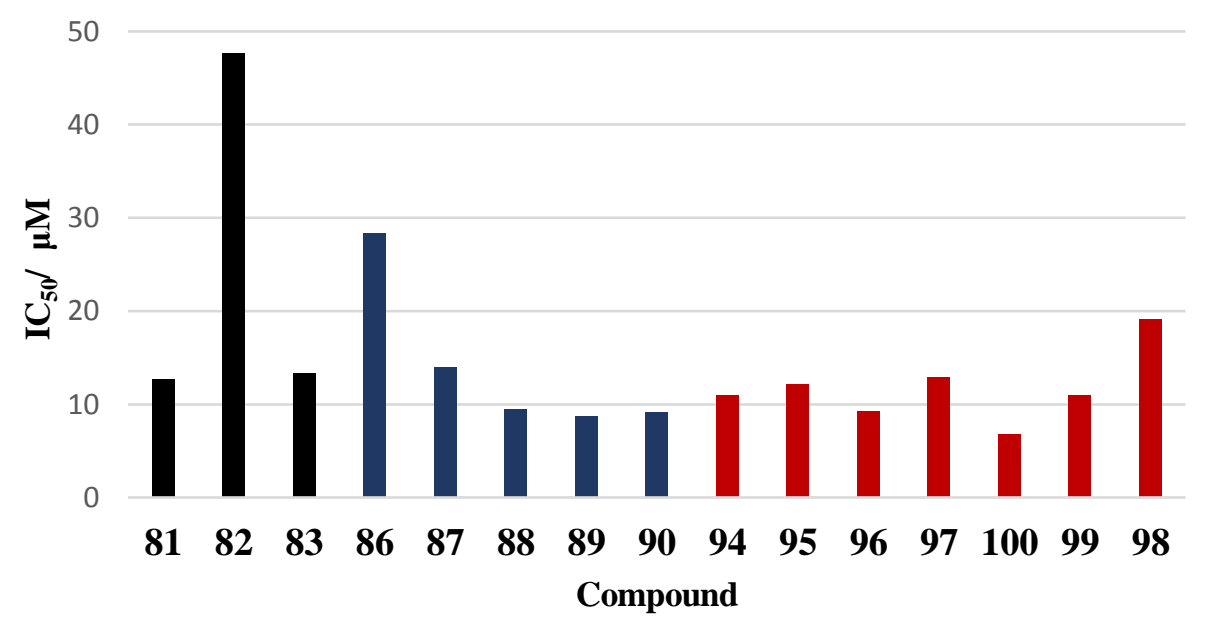

Figure 3.13 $\mathrm{IC}_{50}$ values of analogues based on adenine (black), 6-(dimethylamino)purine (blue), and 6-chloropurine (red) against T. brucei.

\subsubsection{Purinones}

All the purinone derivatives (Figure 3.14) were tested against $T$. brucei at single concentrations $(20 \mu \mathrm{M})$ (Table 3.10) and select compounds further had $\mathrm{IC}_{50}$ values determined (Table 3.11).<smiles>CC(C)=CCCC(C)=CCn1cnc2c1c(=O)[nH]c(=S)n2C</smiles><smiles>C=C(C)CCCC(C)=CCn1cnc2c1c(=O)[nH]c(=O)n2C</smiles><smiles>CC(C)=CCCC(C)=CCn1cnc2c1c(=O)n(C)c(=O)n2C</smiles>

$$
\begin{aligned}
& \text { 118, } \mathrm{n}=1, E / Z 1: 0 \\
& 119, \mathrm{n}=2, E / Z 2: 1 \\
& \mathbf{1 2 0}, \mathrm{n}=3, E / Z \text { 0:1 }
\end{aligned}
$$$$
\text { 111, } \mathrm{n}=1, E / Z 1: 0
$$$$
\text { 112, } \mathrm{n}=2, E / Z \text { 0:1 }
$$$$
\text { 113, } \mathrm{n}=2, E / Z 2: 1
$$$$
\text { 114, } \mathrm{n}=3, E / Z \text { 0:1 }
$$$$
\text { 115, } \mathrm{n}=3, E / Z 1: 0
$$$$
\text { 116, } \mathrm{n}=1, E / Z 1: 0
$$$$
\text { 117, } \mathrm{n}=2, E / Z 1: 0
$$$$
\text { 63, } \mathrm{n}=3, E / Z \text { 0:1 }
$$$$
\text { 64, } \mathrm{n}=3, E / Z 1: 0
$$

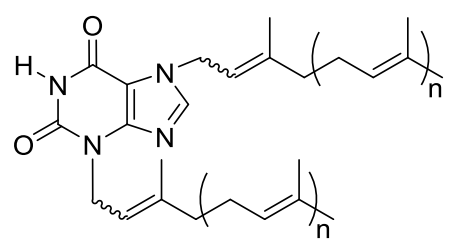

109, $\mathrm{n}=1, E / Z 1: 0$

110, $\mathrm{n}=2, E / Z 3: 2$

Figure 3.14 Purinone-based analogues tested against T. brucei. 
Table 3.10 The activities of malonganenone A analogues based on 2-mercapto-3methylhypoxanthine (36), 3-methylxanthine (46), xanthine (45), and theophylline (47) against T. brucei.

\begin{tabular}{cccccccc}
\hline $\begin{array}{c}\text { Derivatives } \\
\text { of 36 }\end{array}$ & $\begin{array}{c}\text { Viability } \\
(\%)\end{array}$ & $\begin{array}{c}\text { Derivatives } \\
\text { of } \mathbf{4 6}\end{array}$ & $\begin{array}{c}\text { Viability } \\
(\%)\end{array}$ & $\begin{array}{c}\text { Derivatives } \\
\text { of } \mathbf{4 5}\end{array}$ & $\begin{array}{c}\text { Viability } \\
(\%)\end{array}$ & $\begin{array}{c}\text { Derivatives } \\
\text { of } \mathbf{4 7}\end{array}$ & $\begin{array}{c}\text { Viability } \\
(\%)\end{array}$ \\
\hline $\mathbf{1 1 8}$ & 102.1 & $\mathbf{1 1 1}$ & 3.6 & $\mathbf{1 0 9}$ & 0.9 & $\mathbf{1 1 6}$ & 106.8 \\
$\mathbf{1 1 9}$ & 60.4 & $\mathbf{1 1 2}$ & 6.0 & $\mathbf{1 1 0}$ & 0.1 & $\mathbf{1 1 7}$ & 26.1 \\
$\mathbf{1 2 1}$ & 40.1 & $\mathbf{1 1 3}$ & 1.3 & & & $\mathbf{6 3}$ & 6.2 \\
$\mathbf{1 2 0}$ & 56.4 & $\mathbf{1 1 4}$ & 6.4 & & & $\mathbf{6 4}$ & 6.1 \\
& & $\mathbf{1 1 5}$ & 6.2 & & & & \\
\hline
\end{tabular}

Tested in duplicated at $20 \mu \mathrm{M}$.

Table 3.11 $\mathrm{IC}_{50}$ values of purinone-based malonganenone A analogues based on 3methylxanthine (46), xanthine (45), and theophylline (47) against $T$. brucei.

\begin{tabular}{cccccc}
\hline $\begin{array}{c}\text { Derivatives } \\
\text { of } \mathbf{4 6}\end{array}$ & $\mathrm{IC}_{50} / \mu \mathrm{M}$ & $\begin{array}{c}\text { Derivatives } \\
\text { of } \mathbf{4 5}\end{array}$ & $\mathrm{IC}_{50} / \mu \mathrm{M}$ & $\begin{array}{c}\text { Derivatives } \\
\text { of } \mathbf{4 7}\end{array}$ & $\mathrm{IC}_{50} / \mu \mathrm{M}$ \\
\hline $\mathbf{1 1 1}$ & 18.9 & $\mathbf{1 0 9}$ & 2.0 & $\mathbf{1 1 6}$ & \\
$\mathbf{1 1 2}$ & 4.6 & $\mathbf{1 1 0}$ & 1.2 & $\mathbf{1 1 7}$ & \\
$\mathbf{1 1 3}$ & 1.9 & & & $\mathbf{6 3}$ & 5.2 \\
$\mathbf{1 1 4}$ & 5.9 & & & $\mathbf{6 4}$ & 21.6 \\
$\mathbf{1 1 5}$ & 10.2 & & & & \\
\hline
\end{tabular}

The drug standard pentamidine has an $\mathrm{IC}_{50}$ value in the range $0.001-0.05 \mu \mathrm{M}$.

$N$-7: None of the 3-methyl-2-thioxanthine derivatives were sufficiently active at $20 \mu \mathrm{M}$ to warrant $\mathrm{IC}_{50}$ determination. However, comparing the single concentration activities of the 3-methyl-2-thioxanthine- $(\mathbf{1 1 8}$ - 121) and 3-methylxanthine $(\mathbf{1 1 1}$ - 115) derivatives (Table 3.10), substitution of the C-2 thiourea with a urea group significantly increased activity for all three terpenoid chain lengths.

Returning to $\mathrm{IC}_{50}$ based SAR analysis, $\mathrm{N}-1$ methylation of the $\mathrm{N}-7$ geranylgeranyl 3methylxanthine derivatives $(\mathbf{1 1 4}, \mathbf{1 1 5})$, to form the theophylline derivatives $(\mathbf{6 3}, \mathbf{6 4})$, had opposing effects on activity for the two geometric isomers. Activity of the $Z$ isomer (114 to 63) was slightly increased upon $N$-1 methylation, while activity decreased for the $E$ isomer (115 to 64), which suggested significant importance of alkene geometry. The SAR of the alkene geometry was further analysed by comparison of the geranylgeranyl isomers of 3-methylxanthine $(\mathbf{1 1 4}, \mathbf{1 1 5})$ and theophylline $(\mathbf{6 3}, \mathbf{6 4})$, where the $Z$ isomers were more active than the $E$ isomers. Conversely, for farnesyl 3-methylxanthine, the $E$ isomer (113) was slightly more active than the $Z$ isomer (112). Increasing the terpenoid chain length of the $E$ isomers from geranyl to farnesyl increased activity for the 3-methylxanthine derivatives (111 to 113), but increasing the chain length further to geranylgeranyl (115) 
decreased activity. Lengthening the terpenoid chain of the $Z$ isomers from farnesyl to geranylgeranyl (112 to $\mathbf{1 1 4}$ ) had no appreciable effect on activity for the of 3methylxanthine derivatives.

$N-3, N-7$ : When $N-3$ farnesyl- (113) and geranylgeranyl (115) 3-methylxanthine was substituted with a terpenoid chain to form the xanthine derivatives $(\mathbf{1 0 9}, \mathbf{1 1 0})$, activity increased. Increasing the chain length from geranyl to farnesyl increased activity of the xanthine derivatives (109 to $\mathbf{1 1 0})$.

The overall trends for the active purinone-based analogues is seen in Figure 3.15. Small changes to the head group influenced activity, as well as changing the terpenoid chain length. In addition, dialkylation improved activity.

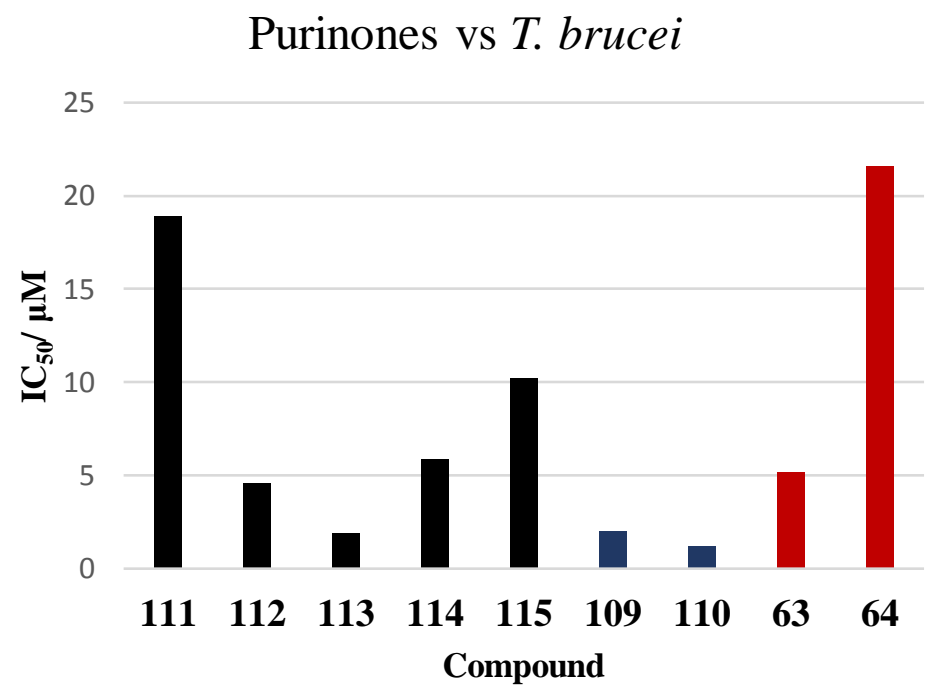

Figure 3.15 $\mathrm{IC}_{50}$ values of analogues based on 3-methylxanthine (black), xanthine (blue), and theophylline (red) against $T$. brucei.

\subsubsection{Pyrimidines}

All the pyrimidine derivatives (Figure 3.16) were tested against T. brucei at single concentrations $(20 \mu \mathrm{M})$ (Table 3.12) and select compounds further had $\mathrm{IC}_{50}$ values determined (Table 3.13). 
<smiles></smiles>

133, $\mathrm{n}=1, E / Z 1: 0$

134, $\mathrm{n}=2, E / Z 2: 1$

$135, \mathrm{n}=3, E / Z 0: 1$<smiles>CC(C)=CCCC(C)=CCn1cc(C)c(=O)[nH]c1=O</smiles>

137, $\mathrm{n}=1, E / Z 1: 0$

$138, \mathrm{n}=2, E / Z 3: 2$

139, $\mathrm{n}=3, E / Z$ 0:1<smiles>C=C(C)/C=C/CC(C)(C)/C=C(\C)Cn1ccc(=N)n(C/C=C(\C)C(C)CCC=C(C)C)c1=O</smiles>

140, $\mathrm{n}=1, E / Z 1: 0$

$141, n=2, E / Z 3: 2$

Figure 3.16 Pyrimidine-based analogues tested against $T$. brucei.

Table 3.12 The activities of malonganenone A analogues based on uracil (51), thymine (52), and cytosine (53) against $T$. brucei.

\begin{tabular}{cccccc}
\hline $\begin{array}{c}\text { Derivatives } \\
\text { of } \mathbf{5 1}\end{array}$ & $\begin{array}{c}\text { Viability } \\
(\%)\end{array}$ & $\begin{array}{c}\text { Derivatives } \\
\text { of } \mathbf{5 2}\end{array}$ & $\begin{array}{c}\text { Viability } \\
(\%)\end{array}$ & $\begin{array}{c}\text { Derivatives } \\
\text { of } \mathbf{5 3}\end{array}$ & $\begin{array}{c}\text { Viability } \\
(\%)\end{array}$ \\
\hline $\mathbf{1 3 3}$ & 102.0 & $\mathbf{1 3 7}$ & 94.1 & $\mathbf{1 4 0}$ & 5.7 \\
$\mathbf{1 3 4}$ & 1.3 & $\mathbf{1 3 8}$ & 105.5 & $\mathbf{1 4 1}$ & -0.1 \\
$\mathbf{1 3 6}$ & - & $\mathbf{1 3 9}$ & 5.4 & & \\
$\mathbf{1 3 5}$ & 6.3 & & & & \\
\hline
\end{tabular}

Tested in duplicated at $20 \mu \mathrm{M}$.

Table 3.13 The $\mathrm{IC}_{50}$ values of malonganenone A analogues based on uracil (51), thymine (52), and cytosine (53) against $T$. brucei.

\begin{tabular}{cccccc}
\hline $\begin{array}{c}\text { Derivatives } \\
\text { of } \mathbf{5 1}\end{array}$ & $\mathrm{IC}_{50} / \mu \mathrm{M}$ & $\begin{array}{c}\text { Derivatives } \\
\text { of } \mathbf{5 2}\end{array}$ & $\mathrm{IC}_{50} / \mu \mathrm{M}$ & $\begin{array}{c}\text { Derivatives } \\
\text { of } \mathbf{5 3}\end{array}$ & $\mathrm{IC}_{50} / \mu \mathrm{M}$ \\
\hline $\mathbf{1 3 3}$ & - & $\mathbf{1 3 7}$ & - & $\mathbf{1 4 0}$ & $-^{\mathrm{a}}$ \\
$\mathbf{1 3 4}$ & 16.5 & $\mathbf{1 3 8}$ & - & $\mathbf{1 4 1}$ & 2.0 \\
$\mathbf{1 3 6}$ & - & $\mathbf{1 3 9}$ & 15.8 & & \\
$\mathbf{1 3 5}$ & 6.2 & & & & \\
\hline
\end{tabular}

${ }^{a}$ Generally cytotoxic against HeLa cells ( $>50 \%$ inhibition at $\left.20 \mu \mathrm{M}\right)$. The drug standard pentamidine has an $\mathrm{IC}_{50}$ value in the range $0.001-0.05 \mu \mathrm{M}$.

$N$-1: Substitution of H-5 for a methyl decreased activity for the geranylgeranyl derivatives of uracil and thymine (135 to $\mathbf{1 3 9}$ ). Increasing the terpenoid chain length from farnesyl to geranylgeranyl increased activity for the uracil derivatives $(\mathbf{1 3 3}-\mathbf{1 3 5})$.

$N-1, N-3$ : Substitution of the C-4 oxo for an imine and the $\mathrm{N}-3 \mathrm{H}$ for another terpenoid chain increased activity for farnesyl derivatives of uracil and cytosine (134 to $\mathbf{1 4 1}$ ).

A brief visual summary is provided in Figure 3.17, where the head group, chain length, and extent of alkylation influenced activity. 


\section{Pyrimidines vs. T. brucei}



Figure 3.17 $\mathrm{IC}_{50}$ values of analogues based on uracil (black), thymine (blue) and cytosine (green) against $T$. brucei.

\subsubsection{Other head groups}

All the derivatives based on other compounds (Figure 3.18) were tested against T. brucei at single concentrations $(20 \mu \mathrm{M})$ (Table 3.14) and select compounds further had $\mathrm{IC}_{50}$ values determined (Table 3.15).

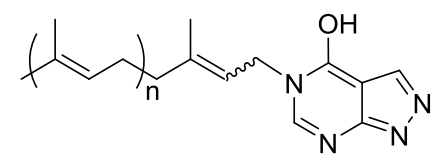

$155, \mathrm{n}=1, E / Z 1: 0$

$156, n=2, E / Z 3: 2$

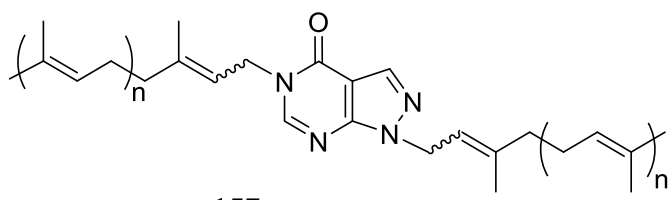

157, $\mathrm{n}=2, E / Z 2: 1$

$160, \mathrm{n}=3, E / Z 1: 0$<smiles>[R16]CCn1cnc(=O)c2cn(C/C=C(\C)C(C)=CCCC(C)(C)CC=C(C)C)nc21</smiles>

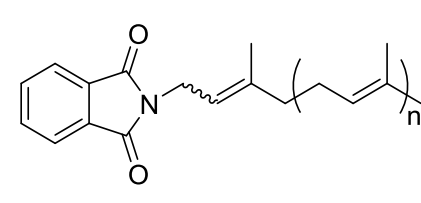

148, $\mathrm{n}=1, E / Z 1: 0$

$149, \mathrm{n}=2, E / Z 5: 4$

150, $\mathrm{n}=3, E / Z 1: 0$<smiles>CC(C)=CCCC(C)=CCn1ccnc1</smiles>

143, $\mathrm{n}=1, E / Z 1: 0$

144, $\mathrm{n}=2, E / Z 7: 2$

$145, \mathrm{n}=3, E / Z 1: 1$

146, $\mathrm{n}=3, E / Z 1: 0$

Figure 3.18 Further analogues tested against T. brucei. 
Table 3.14 The activities of analogues based on allopurinol (52), phthalimide (147), and imidazole (50) against T. brucei.

\begin{tabular}{cccccc}
\hline $\begin{array}{c}\text { Derivatives } \\
\text { of } \mathbf{5 2}\end{array}$ & $\begin{array}{c}\text { Viability } \\
(\%)\end{array}$ & $\begin{array}{c}\text { Derivatives } \\
\text { of } \mathbf{1 4 7}\end{array}$ & $\begin{array}{c}\text { Viability } \\
(\%)\end{array}$ & $\begin{array}{c}\text { Derivatives } \\
\text { of } \mathbf{5 0}\end{array}$ & $\begin{array}{c}\text { Viability } \\
(\%)\end{array}$ \\
\hline $\mathbf{1 5 5}$ & 101.0 & $\mathbf{1 4 8}$ & 105.7 & $\mathbf{1 4 3}$ & 107.5 \\
$\mathbf{1 5 7}$ & 0.9 & $\mathbf{1 4 9}$ & 6.4 & $\mathbf{1 4 4}$ & 0.6 \\
$\mathbf{1 5 8}$ & 0.5 & $\mathbf{1 5 0}$ & 6.2 & $\mathbf{1 4 5}$ & 5.2 \\
$\mathbf{1 5 6}$ & 0.3 & & & $\mathbf{1 4 6}$ & 5.3 \\
$\mathbf{1 6 0}$ & 5.7 & & & & \\
\hline
\end{tabular}

Tested in duplicated at $20 \mu \mathrm{M}$.

Table 3.15 The $\mathrm{IC}_{50}$ values of analogues based on allopurinol (52), phthalimide (147) and imidazole (50) against $T$. brucei.

\begin{tabular}{cccccc}
\hline $\begin{array}{c}\text { Derivatives } \\
\text { of } \mathbf{5 2}\end{array}$ & $\mathrm{IC}_{50} / \mu \mathrm{M}$ & $\begin{array}{c}\text { Derivatives } \\
\text { of } \mathbf{1 4 7}\end{array}$ & $\mathrm{IC}_{50} / \mu \mathrm{M}$ & $\begin{array}{c}\text { Derivatives } \\
\text { of } \mathbf{5 0}\end{array}$ & $\mathrm{IC}_{50} / \mu \mathrm{M}$ \\
\hline $\mathbf{1 5 5}$ & - & $\mathbf{1 4 8}$ & - & $\mathbf{1 4 3}$ & - \\
$\mathbf{1 5 7}$ & 1.2 & $\mathbf{1 4 9}$ & 32.2 & $\mathbf{1 4 4}$ & 26.8 \\
$\mathbf{1 5 8}$ & 5.5 & $\mathbf{1 5 0}$ & 9.2 & $\mathbf{1 4 5}$ & 3.3 \\
$\mathbf{1 5 6}$ & 16.7 & & & $\mathbf{1 4 6}$ & 3.4 \\
$\mathbf{1 6 0}$ & 2.1 & & & & \\
\hline
\end{tabular}

The drug standard pentamidine has an $\mathrm{IC}_{50}$ value in the range $0.001-0.05 \mu \mathrm{M}$.

The difarnesyl allopurinol derivatives $(157,158,159)$ were more active than $N-1$ monofarnesyl allopurinol (155). $N-1, N-5$ difarnesyl allopurinol (157) was more active than $N-2, N-7$ difarnesyl allopurinol (158). Increasing the terpenoid chain length from farnesyl to geranylgeranyl increased activity for the $N-1, N-5$ derivatives (157 to 160).

Activity increased for the phthalimide derivatives when the terpenoid chain was lengthened from farnesyl (149) to geranylgeranyl (150).

The same trend was observed for the imidazole derivatives, increasing the terpenoid chain from farnesyl (144) to geranylgeranyl (146) increased activity. In addition, the alkene geometry had a minor effect on activity, where the 1:1 mixture of $E$ and $Z$ isomers (145) was slightly more active than just the $E$ isomer (146). This suggested the $Z$ isomer was more active, therefore it would be desirable to synthesise just the $Z$ isomer of geranylgeranyl imidazole to improve activity further.

The overarching structure-activity relationship against $T$. brucei was that increasing the terpenoid chain length increased activity. The structures of the head groups had varying effects on activity, but no general trends could be derived. 


\subsubsection{Amides}

All the amide derivatives (Figure 3.19) were tested against $T$. brucei at single concentrations $(20 \mu \mathrm{M})$ (Table 3.16) and select compounds further had $\mathrm{IC}_{50}$ values determined (Table 3.17).

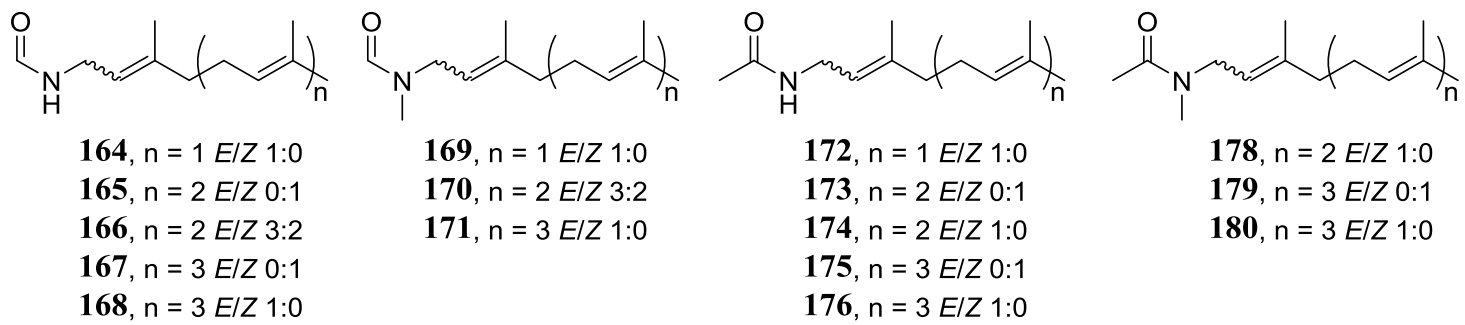

Figure 3.19 Amide-based malonganenone $\mathrm{C}$ analogues tested against $T$. brucei.

Table 3.16 The activities of amide-based malonganenone $\mathrm{C}$ analogues against $T$. brucei.

\begin{tabular}{cccccccc}
\hline Formamides & $\begin{array}{c}\text { Viability } \\
(\%)\end{array}$ & $\begin{array}{c}N \text {-methyl } \\
\text { formamides }\end{array}$ & $\begin{array}{c}\text { Viability } \\
(\%)\end{array}$ & Acetamides & $\begin{array}{c}\text { Viability } \\
(\%)\end{array}$ & $\begin{array}{c}N \text {-methyl } \\
\text { acetamides }\end{array}$ & $\begin{array}{c}\text { Viability } \\
(\%)\end{array}$ \\
\hline $\mathbf{1 6 4}$ & 71.9 & $\mathbf{1 6 9}$ & 75.7 & $\mathbf{1 7 2}$ & 88.9 & - & - \\
$\mathbf{1 6 5}$ & 6.5 & - & - & $\mathbf{1 7 3}$ & 6.5 & - & - \\
$\mathbf{1 6 6}$ & 93.5 & $\mathbf{1 7 0}$ & 79.6 & $\mathbf{1 7 4}$ & 12.8 & $\mathbf{1 7 8}$ & 51.1 \\
$\mathbf{1 6 7}$ & 7.0 & - & - & $\mathbf{1 7 5}$ & 6.1 & $\mathbf{1 7 9}$ & 5.8 \\
$\mathbf{1 6 8}$ & 6.7 & $\mathbf{1 7 1}$ & 5.4 & $\mathbf{1 7 6}$ & 6.8 & $\mathbf{1 8 0}$ & 5.4 \\
\hline
\end{tabular}

Tested in duplicated at $20 \mu \mathrm{M}$.

Table 3.17 The $\mathrm{IC}_{50}$ values of amide-based malonganenone $\mathrm{C}$ analogues against $T$. brucei.

\begin{tabular}{cccccccc}
\hline Formamides & $\begin{array}{c}\mathrm{IC}_{50} / \\
\mu \mathrm{M}\end{array}$ & $\begin{array}{c}N \text {-methyl } \\
\text { formamides }\end{array}$ & $\begin{array}{c}\mathrm{IC}_{50} / \\
\mu \mathrm{M}\end{array}$ & Acetamides & $\begin{array}{c}\mathrm{IC}_{50} / \\
\mu \mathrm{M}\end{array}$ & $\begin{array}{c}N \text {-methyl } \\
\text { acetamides }\end{array}$ & $\begin{array}{c}\mathrm{IC}_{50} / \\
\mu \mathrm{M}\end{array}$ \\
\hline $\mathbf{1 6 4}$ & - & $\mathbf{1 6 9}$ & - & $\mathbf{1 7 2}$ & & - & - \\
$\mathbf{1 6 5}$ & 27.3 & - & - & $\mathbf{1 7 3}$ & 4.5 & - & - \\
$\mathbf{1 6 6}$ & - & $\mathbf{1 7 0}$ & - & $\mathbf{1 7 4}$ & 21.5 & $\mathbf{1 7 8}$ & - \\
$\mathbf{1 6 7}$ & 11.0 & - & - & $\mathbf{1 7 5}$ & 2.2 & $\mathbf{1 7 9}$ & - \\
$\mathbf{1 6 8}$ & 41.8 & $\mathbf{1 7 1}$ & 41.2 & $\mathbf{1 7 6}$ & 3.1 & $\mathbf{1 8 0}$ & 38.4 \\
\hline
\end{tabular}

The drug standard pentamidine has an $\mathrm{IC}_{50}$ value in the range $0.001-0.05 \mu \mathrm{M}$.

Substituting the formamides $(165,167,168)$ for acetamides $(173,175,176)$ increased activity for all three terpenoid chain lengths. Methylation of geranylgeranyl formamide (168 to 171) had no effect on activity, while methylation of geranylgeranyl acetamide (176 to 180) significantly decreased activity. Increasing the terpenoid chain length from farnesyl to geranylgeranyl increased activity for both the formamides (165 to 167) and acetamides (173 to 175,174 to 176$)$.

In addition, the $Z$ isomer (167) was significantly more active than the $E$ isomer (168) for geranylgeranyl formamide. The same trend was observed for the tested acetamides, a 
greater difference in activity was observed between the $Z(\mathbf{1 7 3})$ and $E(\mathbf{1 7 4})$ isomers of farnesyl acetamide, while the difference was smaller for the $Z(\mathbf{1 7 5})$ and $E(\mathbf{1 7 6})$ isomers of geranylgeranyl acetamide.

A visual summary of the trends observed for the amide analogues is shown in Figure 3.20, small changes to the head group, as well as terpenoid chain length, influenced activity.

Amides vs. T. brucei

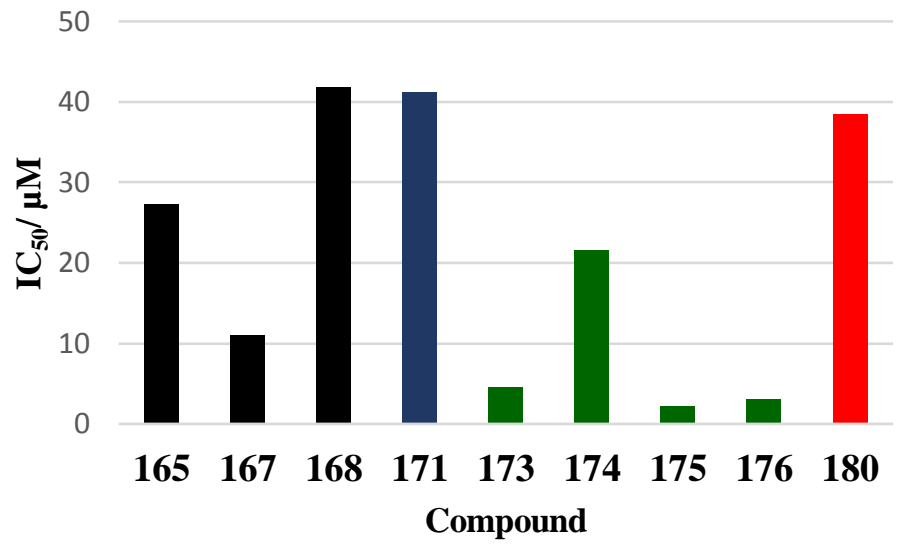

Figure 3.20 $\mathrm{IC}_{50}$ values of analogues based on formamide (black), $N$-methylformamide (blue), acetamide (green), and $N$-methylacetamide (red) against $T$. brucei. 
The overall trends observed for the compounds active against $T$. brucei are shown in Figure 3.21. The purines appeared to be generally less active overall, while the terpenoid chain length had a more important role for the other head groups, as activity varied with length.

Analogues vs. T. brucei

60

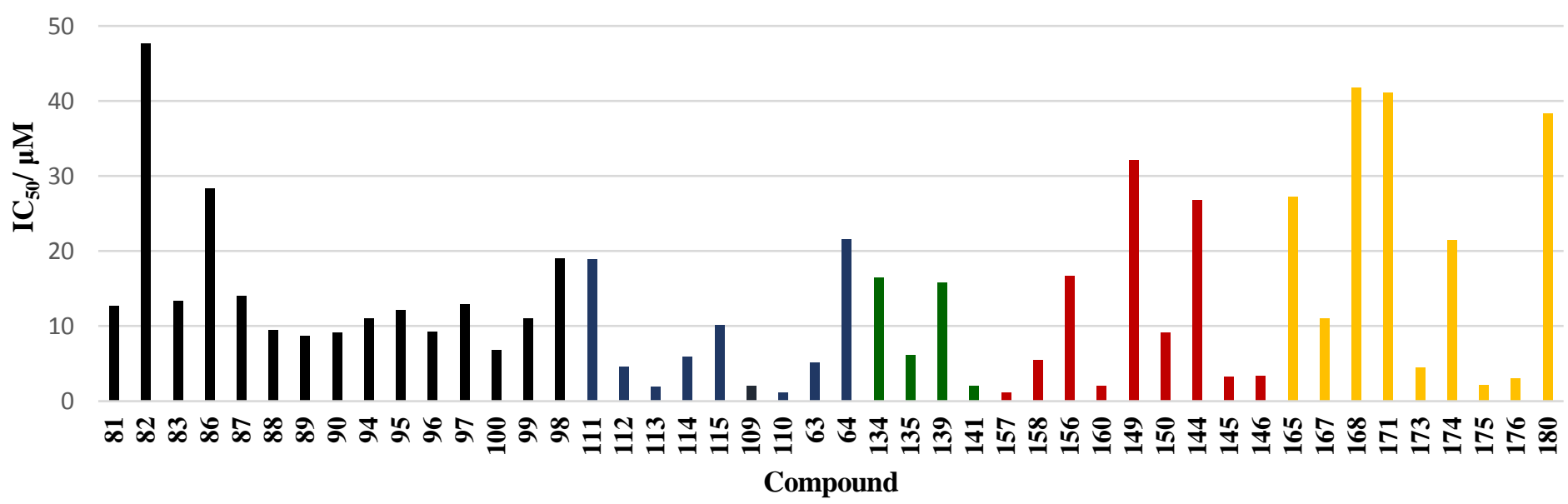

Figure 3.21 $\mathrm{IC}_{50}$ values of analogues based on purines (black), purinones (blue), pyrimidines (green), other head groups (red), and amides (yellow) against $T$. brucei. 


\subsection{Antibacterial activity}

The compounds were further tested against various bacteria to assess off target activity Minimum inhibitory concentrations up to $512 \mu \mathrm{M}$ were determined against two Grampositive bacteria Staphylococcus aureus and Streptococcus uberis and Gram-negative Escherichia coli. Various compounds were active against S. aureus and S. uberis (Figure 3.22, Table 3.18), with more activity shown against the latter species while no inhibition was observed against $E$. coli up to $512 \mu \mathrm{M}$ for all the tested compounds. 


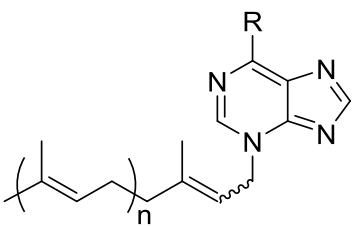

81, $\mathrm{R}=\mathrm{NH}_{2}, \mathrm{n}=2 \quad E / Z, 3: 2$

85, $\mathrm{R}=\mathrm{NMe}_{2}, \mathrm{n}=1, E / Z, 1: 0$

87, $\mathrm{R}=\mathrm{NMe}_{2}, \mathrm{n}=2 E / Z, 3: 2$<smiles>[R]c1ncnc2c1ncn2C/C=C(/C)C(C)(C)CC=C(C)C</smiles>

82, $\mathrm{R}=\mathrm{NH}_{2}, \mathrm{n}=2 \quad E / Z, 3: 2$

83, $\mathrm{R}=\mathrm{NH}_{2}, \mathrm{n}=3 \quad E / Z, 1: 0$

86, $\mathrm{R}=\mathrm{NMe}_{2}, \mathrm{n}=1, E / Z, 1: 0$

88, $\mathrm{R}=\mathrm{NMe}_{2}, \mathrm{n}=2 E / Z, 3: 2$

87, $\mathrm{R}=\mathrm{Cl}, \mathrm{n}=2 \quad E / Z, 2: 1$

100, $\mathrm{R}=\mathrm{Cl}, \mathrm{n}=3 \mathrm{E} / \mathrm{Z}, 1: 0$<smiles>CC(C)=CCCC(C)(C)CC=CCn1cnc2ncnc(Cl)c21</smiles>

94, $\mathrm{R}=\mathrm{Cl}, \mathrm{n}=1, E / Z, 1: 0$

99, $\mathrm{R}=\mathrm{Cl}, \mathrm{n}=3 E / Z, 1: 0$

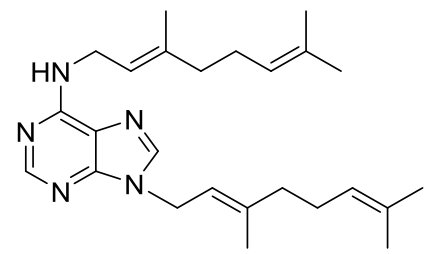

84<smiles>[R]n1c(=O)c2c(ncn2C/C=C(\C)C(C)(C)CC=C(C)C)n(C)c1=O</smiles>

112, $\mathrm{R}=\mathrm{H}, E / Z$ 0:1

117, $\mathrm{R}=\mathrm{Me}, E / Z$ 1:0<smiles>[R]c1cn(C/C=C(\C)CCC=C(C)C)c(=O)[nH]c1=O</smiles>

135, $\mathrm{R}=\mathrm{H}, E / Z 0: 1$

136, $\mathrm{R}=\mathrm{H}, E / Z 1: 0$

139, $\mathrm{R}=\mathrm{Me}, E / Z$ 1:0<smiles>CC(C)=CCCC(C)=CCn1ccnc1</smiles>

$143, \mathrm{n}=1, E / Z 1: 0$

144, $\mathrm{n}=2, E / Z 7: 2$

145, $\mathrm{n}=3, E / Z 1: 1$

146, $\mathrm{n}=3, E / Z 1: 0$<smiles>CC(C)=CCCC(C)=CCN1C(=O)c2ccccc2C1=O</smiles>

149, $\mathrm{n}=2, E / Z 5: 4$

150, $\mathrm{n}=3, E / Z 1: 0$<smiles>CC(C)=CCC/C(C)=C/Cn1ccc(=N)n(C/C=C(\C)CCC=C(C)C)c1=O</smiles>

140<smiles>C=C(C)C=CCC(C)(C)CCNC=O</smiles>

165, $\mathrm{n}=2 E / Z$ 0:1

$166, \mathrm{n}=2 E / Z 3: 2$

167, $\mathrm{n}=3 E / Z 0: 1$

168, $\mathrm{n}=3 E / Z 1: 0$<smiles>CC(C)=CCCC(C)=CCCN(C)C=O</smiles>

170, $\mathrm{n}=2 E / Z 3: 2$

171, $\mathrm{n}=3 E / Z 1: 0$<smiles>CC(=O)NCC=C(C)CCC=C(C)C</smiles>

173, $\mathrm{n}=2 E / Z 0: 1$

$174, \mathrm{n}=2 E / Z 1: 0$

175, $\mathrm{n}=3 E / Z$ 0:1

176, $\mathrm{n}=3 E / Z 1: 0$<smiles>CC(=O)CCCC(C)=CCN(C)C(C)=O</smiles>

178, $\mathrm{n}=2 E / Z 1: 0$

179, $\mathrm{n}=3 E / Z 0: 1$

180, $\mathrm{n}=3 E / Z 1: 0$<smiles>CC(C)=CCC/C(C)=C/CNC(=O)c1c(N(C)C=O)ncn1C/C=C(\C)CCC=C(C)C</smiles>

Figure 3.22 Compounds active against $S$. uberis and $S$. aureus. 
Table 3.18 MIC of compounds active against S. uberis and S. aureus, hyphens represent no inhibition observed up to $512 \mu \mathrm{M}$.

\begin{tabular}{|c|c|c|c|}
\hline $\begin{array}{c}\text { Analogue } \\
\text { Class }\end{array}$ & Compound & $\begin{array}{l}\text { S. uberis } \\
\mathrm{MIC} / \mu \mathrm{M}\end{array}$ & $\begin{array}{l}\text { S. aureus } \\
\mathrm{MIC} / \mu \mathrm{M}\end{array}$ \\
\hline \multirow{12}{*}{ Purines } & 65 & $8-32$ & - \\
\hline & 84 & 64 & 64 \\
\hline & 82 & $64-128$ & - \\
\hline & 81 & 125 & - \\
\hline & 83 & 256 & - \\
\hline & 86 & 256 & - \\
\hline & 85 & 512 & - \\
\hline & 87 & 128 & 256 \\
\hline & 94 & 256 & - \\
\hline & 96 & 128 & - \\
\hline & 100 & 256 & - \\
\hline & 99 & $32-256$ & - \\
\hline \multirow{2}{*}{ Purinones } & 112 & 256 & - \\
\hline & 117 & 512 & - \\
\hline \multirow{4}{*}{ Pyrimidines } & 136 & 16 & - \\
\hline & 135 & $256-512$ & - \\
\hline & 139 & 256 & - \\
\hline & 140 & 16 & 32 \\
\hline \multirow{8}{*}{$\begin{array}{l}\text { Other head } \\
\text { groups }\end{array}$} & 160 & 256 & - \\
\hline & 156 & 512 & - \\
\hline & 143 & 512 & - \\
\hline & 144 & 64 & 256 \\
\hline & 145 & $16-32$ & 128 \\
\hline & 146 & 16 & 128 \\
\hline & 149 & 16 & - \\
\hline & 150 & 256 & - \\
\hline \multirow{14}{*}{ Amides } & 165 & 128 & \\
\hline & 166 & 64 & $128-256$ \\
\hline & 167 & $32-256$ & - \\
\hline & 168 & $16-64$ & - \\
\hline & 173 & 128 & - \\
\hline & 174 & 64 & - \\
\hline & 175 & 128 & - \\
\hline & 176 & $32-128$ & - \\
\hline & 169 & 256 & - \\
\hline & 170 & 64 & 256 \\
\hline & 171 & 32 & - \\
\hline & 178 & 64 & 256 \\
\hline & 179 & 16 & - \\
\hline & 180 & $16-32$ & - \\
\hline
\end{tabular}

Tested in duplicate. MIC values reported as a range were tested in triplicate.

Not many of the compounds were active against $S$. aureus. The SAR of the compounds that were active did not yield any particularly important features for activity. 
Interestingly, MICs were obtained for the three imidazole derivatives $(\mathbf{1 4 3}-\mathbf{1 4 6})$, which were also significantly active against both $P$. falciparum and $T$. brucei. The same trends were observed for the activity against $S$. aureus, increasing the terpenoid chain length from farnesyl (144) to geranylgeranyl (145) increased activity. The activities of the 1:1 mixture of geometric isomers (145) and the $E$ isomer (146) of geranylgeranyl imidazole were in the same concentration bracket, which is expected since they are closely related. The $Z$ isomer has previously been proposed to be more active than the $E$ isomer, therefore it would be interesting to see if the pure $Z$ isomer has a MIC in a lower concentration bracket.

The overall SAR of the compounds against S. uberis favoured the derivatives based on smaller head groups. This trend was readily observed in Figure 3.23, where the simple amides (yellow) were mostly more active than the larger cyclic- and bicyclic head groups. In addition, increasing the terpenoid chain length generally increased activity. This trend was further supported by the inactivity of the shortest geranyl terpenoid chain length for most of the analogues.

\section{Analogues vs. $S$ uberis}

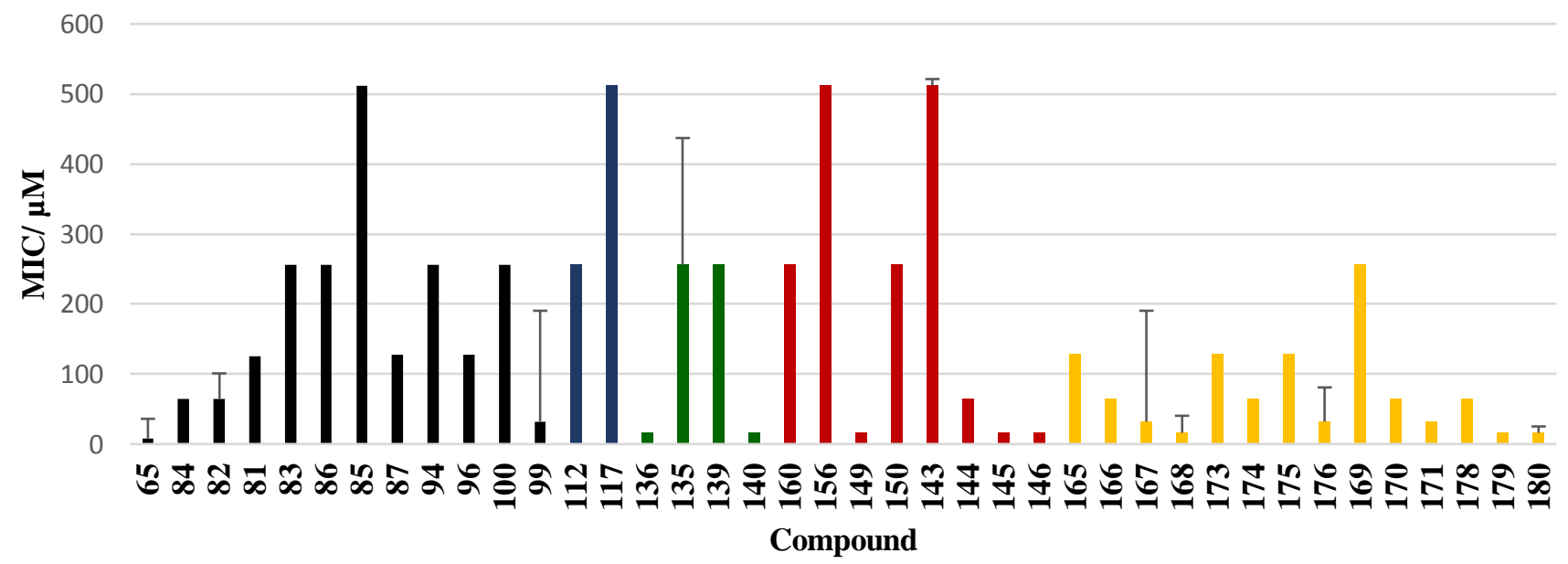

Figure 3.23 MIC values ( $\mu \mathrm{M}$ ) of analogues based on purines (black), purinones (blue), pyrimidines (green), other head groups (red), and amides (yellow) against $S$. uberis. 


\section{Future work}

To fully probe the SAR of the natural product side chain, an analogue of malonganenone A with the same head group and a simpler terpenoid chain must be synthesised. The natural product head group of malonganenone A, 3-methylhypoxanthine (27), was successfully produced in this work. However, the subsequent alkylation reactions did not produce the desired $\mathrm{N}-7$ monoalkylated derivatives due to hydrolysis. Therefore, the alkylation of 27 should be repeated using the same conditions that were successful for the Gundersen group, ${ }^{61}$ which included synthesising 27 using a different route to the one used in this work.

The aim of this project was to synthesis an expansive library of malonganenone analogues. Therefore, work was solely focused towards isolating new analogues, rather than reaction optimisation. This resulted in poor yields for most compounds, therefore future work should include optimising the alkylation reactions of the lead compounds.

Further investigation into the 1,3-dimethyluric acid alkylations should be undertaken to assess the potential uses of the reaction for forming quaternary carbon-carbon bonds.

The compounds were tested against $P$. falciparum infected red blood cells, but initially they were intended for testing against $P$. falciparum heat shock proteins 70-1 and 70-x. Therefore, the library should be tested against these heat shock proteins to assess if they exert their bioactivity through inhibition of these proteins, to yield mode of action information. In addition, the compounds were markedly more active against $T$. brucei, it would also be of interest to test the compounds mode of action within this species.

The structure-activity relationship analyses resulted in the identification of a promising lead compound, geranylgeranyl imidazole, which was active against all test species, $P$. falciparum, T. brucei, S. aureus and S. uberis, except E. coli. This compound was isolated and tested, both as a 1:1 mixture of $E$ and $Z$ isomers at position 2 of the geranylgeranyl chain and as the geometrically pure $E$ isomer. The former was more active, which suggested the $Z$ isomer should be the most bioactive, therefore, the geometrically pure $Z$ isomer of geranylgeranyl imidazole should be synthesised. The geranylgeranyl bromide starting material would simply need purification beforehand, since the geometric isomers were not easily separable by chromatography. 


\section{Conclusion}

A variety of $\mathrm{N}$-heterocyclic head groups were alkylated with a series of three terpenoids of increasing chain length, geranyl, farnesyl and geranylgeranyl moieties to generate malonganenone A analogues. In addition, these amine functionalised terpenoids were formylated or acetylated and methylated to form malonganenone $\mathrm{C}$ analogues. Over 80 analogues were synthesised, of which, 57 are novel compounds. The use of non-selective conditions allowed for the chromatographic isolation of multiple regioisomers from a single reaction, where yield was sacrificed to efficiently generate the library of analogues. Structure-activity relationships against $P$. falciparum. and $T$. brucei, the parasites responsible for malaria and African sleeping sickness, respectively, were analysed. Although no overall trends were derived, smaller trends within the different types of analogues were identified and this resulted in the identification of the lead compound, $2 Z$ geranylgeranyl imidazole. 


\section{Experimental}

All alkylation reactions were carried out under an inert atmosphere ( $\mathrm{Ar}$ or $\left.\mathrm{N}_{2}\right)$ delivered through a manifold using oven or vacuum-dried glassware using standard syringe techniques and dry solvents. Dry DCM and $\mathrm{Et}_{2} \mathrm{O}$ were obtained from a Puresolv. system (Innovative Technology). Triethylamine was distilled from $\mathrm{CaH}_{2}$. Methyl iodide was run through a plug of activated alumina prior to use. All other solvents and reagents were used as received from commercial suppliers. Purification by silica gel flash chromatography used silica gel 60 (40 - 63 micron). Thin-layer chromatography was carried on Macherey-Nagel, POLYGRAM® Sil G/UV254 plates, and were visualised with iodine stain. NMR spectra were recorded using Varian Inova instruments operating at 300 or 500 or $600 \mathrm{MHz}$ for proton and 125 or $150 \mathrm{MHz}$ for carbon. 2D NMR data was obtained using a Varian DirectDrive spectrometer equipped with a triple resonance $\mathrm{HCN}$ cryogenic probe. IR spectra were obtained using an ALPHA FT-IR spectrometer (Bruker). MS data and tandem MS data was collected on an Agilent 6530 Q-TOF LC/MS high-resolution mass spectrometer.

Ethyl (hydroxyimino)cyanoacetate (33); Ethyl cyanoacetate $(38.1 \mathrm{mmol}, 4.72 \mathrm{~mL})$ and sodium nitrite ( $39.0 \mathrm{mmol}, 2.72 \mathrm{~g}$ ) were stirred in $\mathrm{H}_{2} \mathrm{O}(8 \mathrm{~mL})$ on an ice bath. Acetic acid (39.5 mmol, $2.37 \mathrm{~mL}$ ) was added dropwise over 10 minutes to form a bright yellow solution. After 2 hours, the solidified reaction mixture was dissolved in EA and toluene $(1: 1,45 \mathrm{~mL})$, concentrated to a third of the volume under reduced pressure, and extracted with EA $(3 \times 20 \mathrm{~mL})$. The combined extracts were washed with brine $(1 \times 80 \mathrm{~mL})$ and dried over anhydrous $\mathrm{MgSO}_{4}$ to afford 33 as fine pale-yellow crystals (4.08 g, 65\%):

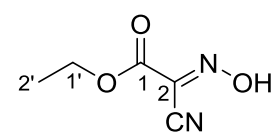

${ }^{1} \mathrm{H}$ NMR (600 MHz, $\left.\mathrm{CDCl}_{3}\right): \delta 4.45\left(\mathrm{q}, J=7 \mathrm{~Hz}, 2 \mathrm{H}, \mathrm{CH}_{2}\right), 1.41\left(\mathrm{t}, J=7.3 \mathrm{~Hz}, 3 \mathrm{H}, \mathrm{CH}_{3}\right)$; ${ }^{13} \mathrm{C} \mathrm{NMR}\left(150 \mathrm{MHz}, \mathrm{CDCl}_{3}\right): \delta 158.6(\mathrm{C}, \mathrm{C}-1), 126.8$ (C, C-2), $107.5(\mathrm{C}, \mathrm{C}-3), 64.1\left(\mathrm{CH}_{2}\right.$, C-1'), $14.1\left(\mathrm{CH}_{3}, \mathrm{C}-2\right.$ ')

\section{6-Amino-2-mercapto-1-methyl-5-nitrosopyrimidin-4(1H)-one (34);}

$\mathrm{N}$-Methylthiourea (30.0 mmol, $2.71 \mathrm{~g})$ in 2-methoxyethanol $(35 \mathrm{~mL})$ was added to a solution of ethyl (hydroxyimino)cyanoacetate $(28.5 \mathrm{mmol}, 4.1 \mathrm{~g})$ in $1 \mathrm{M}$ sodium ethoxide, 
freshly prepared by dissolving sodium metal $(1.31 \mathrm{~g})$ in ethanol $(53 \mathrm{~mL})$, and refluxed for 6 hours. The reaction was cooled on an ice bath and $\mathrm{HCl}(1 \mathrm{M}, 300 \mathrm{~mL})$ was added dropwise over 1 hour, the mixture was filtered and dried in the oven overnight to afford 34 as a blue-grey solid (2.54 g, $48 \%)$ :



${ }^{1} \mathrm{H}$ NMR (600 MHz, $\mathrm{CDCl}_{3}$ ): $\delta 13.08$ (br s, 1H, NH), 3.64 (s, 3H, $\left.\mathrm{NCH}_{3}\right) ;{ }^{13} \mathrm{C} \mathrm{NMR} \mathrm{(150}$ MHz, DMSO-d 6 ): $\delta 177.9$ (C, C-2), 157.9 (C, C-6), 145.6 (C, C-6), 140.0 (C, C-5), 34.3 $\left(\mathrm{CH}_{3}, \mathrm{NCH}_{3}\right)$.

5,6-Diamino-2-mercapto-1-methylpyrimidin-4(1H)-one (35); 6-Amino-2-mercapto1-methyl-5-nitrosopyrimidin-4(1H)-one (13.4 mmol, $2.54 \mathrm{~g}$ ) was added to $\mathrm{NaOH}(1 \mathrm{M}$, $50 \mathrm{~mL}$ ) to form a dark red solution. Sodium dithionite (49.4 mmol, $8.65 \mathrm{~g}$ ) was added and stirred for 1 hour. Small additions $(6 \times 0.2 \mathrm{~g})$ of sodium dithionite were added over the course of 6 hours and the reaction was stirred overnight. The precipitate was isolated by vacuum filtration and washed with $\mathrm{H}_{2} \mathrm{O}$ to afford 35 as an orange powder (1.56 g, 67\%):

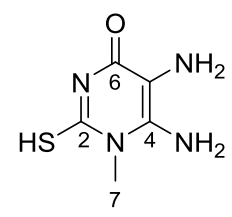

${ }^{1} \mathrm{H}$ NMR (600 MHz, DMSO-d 6 ): $\delta 6.22$ (br s, 2H, NH $\left.2-4\right), 3.74$ (s, 3H, H-7); ${ }^{13} \mathrm{C}$ NMR (150 MHz, DMSO-d6): $\delta 169.4$ (C, C-6), 156.2 (C, C-2), 142.7 (C, C-4), 104.2 (C, C-5), $36.2\left(\mathrm{CH}_{3}, \mathrm{C}-7\right)$; HRESIMS $\mathrm{m} / z$ : $[\mathrm{M}+\mathrm{H}]^{+}$Calcd for $\mathrm{C}_{5} \mathrm{H}_{8} \mathrm{~N}_{4} \mathrm{OS}$ 173.0492; Found $173.0488(\Delta=1.82 \mathrm{ppm})$.

6-Hydroxy-3-methyl-3,9-dihydro-2H-purine-2-thione (56); 5,6-Diamino-2-mercapto1-methylpyrimidin-4(1H)-one (9.1 mmol, $1.607 \mathrm{~g})$ and trimethyl orthoformate (136.4 mmol, $14.9 \mathrm{~mL})$ were refluxed in DMF (10 mL) for 6 days. The solvent was removed under reduced pressure and the residue was recrystallised from $\mathrm{H}_{2} \mathrm{O}$ to afford $\mathbf{5 6}$ as a light orange powder $(1.29 \mathrm{~g}, 76 \%)$ : 


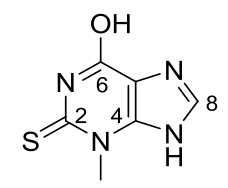

${ }^{1} \mathrm{H}$ NMR (600 MHz, DMSO-d6): $\delta 13.76$ (s, 1H, NH), 12.37 (s, 1H, OH), 8.08 (s, 1H, H8), $3.71\left(\mathrm{~s}, 3 \mathrm{H}, \mathrm{NCH}_{3}\right) ;{ }^{13} \mathrm{C} \mathrm{NMR}\left(150 \mathrm{MHz}, \mathrm{DMSO}-\mathrm{d}_{6}\right): \delta 174.0(\mathrm{C}, \mathrm{C}-2), 152.8(\mathrm{C}, \mathrm{C}-$ 6), 149.9 (C, C-4), 141.5 (C, C-8), 110.8 (C, C-5), $35.2\left(\mathrm{CH}_{3}, \mathrm{NCH}_{3}\right)$; HRESIMS m/z: $[\mathrm{M}+\mathrm{H}]^{+}$Calcd for $\mathrm{C}_{6} \mathrm{H}_{7} \mathrm{~N}_{4} \mathrm{OS}$ 183.0335; Found 183.0344 ( $\left.\Delta=-4.66 \mathrm{ppm}\right)$.

3-Methyl-3,7-dihydro-6H-purin-6-one (55); Nickel-aluminium alloy (1.50 g) was dissolved slowly in $\mathrm{NaOH}(2.5 \mathrm{M}, 10 \mathrm{~mL})$ with gentle swirling over the course of one hour. After which, the beaker was placed in a desiccator without desiccant and left overnight. The solution was decanted and the solid washed thoroughly with water three times before use. Raney Nickel (approx. $1.13 \mathrm{~g}$ ) was washed with propan-2-ol three times and suspended in minimal $\mathrm{H}_{2} \mathrm{O}$. A solution of 3,7-dihydro-2-mercapto-3-methyl-6Hpurin-6-one (4.3 mmol, $0.79 \mathrm{~g})$ in $\mathrm{NaOH}(1 \mathrm{M}, 5 \mathrm{~mL})$ was added and then heated to 50 ${ }^{\circ} \mathrm{C}$ in a water bath. The reaction was swirled occasionally over 30 minutes and then the water bath was removed and left overnight. The mixture was filtered over a pad of celite, and the filtrate was dried under reduced pressure to afford $\mathbf{5 5}$ as a dark orange powder $(0.72 \mathrm{~g}, 84 \%)$ :

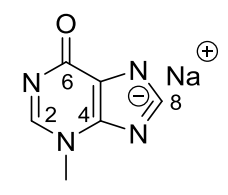

${ }^{1} \mathrm{H}$ NMR (600 MHz, $\mathrm{CDCl}_{3}$ ): $\delta 7.90$ (s, 1H, H-2), 7.36 (s, 1H, H-8), 3.69 (s, 3H, NCH 3 ); ${ }^{13} \mathrm{C}$ NMR (150 MHz, $\mathrm{CDCl}_{3}$ ): $\delta 166.9$ (C, C-4), 149.3 (C, C-6), 148.0 (CH, C-2), 144.5 $(\mathrm{CH}, \mathrm{C}-8), 124.7$ (C, C-5), $35.1\left(\mathrm{CH}_{3}, \mathrm{NCH}_{3}\right)$; HRESIMS $m / z:[\mathrm{M}+\mathrm{H}]^{+}$Calcd for $\mathrm{C}_{6} \mathrm{H}_{7} \mathrm{~N}_{4} \mathrm{O}$ 151.0614; Found 151.0612 ( $\left.\Delta=1.60 \mathrm{ppm}\right)$.

Geranyl bromide; To a solution of geraniol (22.8 mmol, $3.52 \mathrm{~g}, 4.00 \mathrm{~mL})$ in $\mathrm{Et}_{2} \mathrm{O}(60$ $\mathrm{mL})$, was added $\mathrm{PBr}_{3}(10.6 \mathrm{mmol}, 2.88 \mathrm{~g}, 1.00 \mathrm{~mL})$ dropwise over 7 minutes. The reaction was stirred for 90 minutes, then poured onto ice-cold $\mathrm{H}_{2} \mathrm{O}$ and extracted with PE $(3 \times 75$ $\mathrm{mL})$. The combined extracts were washed with $\mathrm{NaHCO}_{3}(1 \times 100 \mathrm{~mL})$, then brine $(1 \times$ $100 \mathrm{~mL}$ ) and dried over anhydrous $\mathrm{MgSO}_{4}$. The solvent was removed under reduced pressure to afford $\mathbf{6 0}$ as a thin, pale-yellow oil (4.95 g, 92\%): 


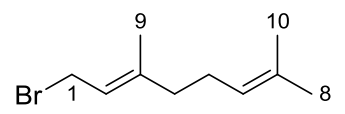

(E)-1-Bromo-3,7-dimethylocta-2,6-diene (60); ${ }^{1} \mathrm{H} \mathrm{NMR}\left(600 \mathrm{MHz}, \mathrm{CDCl}_{3}\right): \delta 5.53(\mathrm{t}$, $J=8.4 \mathrm{~Hz}, 1 \mathrm{H}, \mathrm{H}-2), 5.09-5.04$ (m, 1H, H-6), 4.03 (d, $J=8.5 \mathrm{~Hz}, 2 \mathrm{H}, \mathrm{H}-1), 2.13-2.04$ (complex m, 4H, H-4 and H-5), 1.73 (s, J=4.5 Hz, 3H, H-9), 1.68 (s, 3H, H-10), 1.60 (s, $3 \mathrm{H}, \mathrm{H}-8) ;{ }^{13} \mathrm{C}$ NMR (150 MHz, $\mathrm{CDCl}_{3}$ ): $\delta 143.8$ (C, C-3), 132.2 (C, C-7), 123.7 (CH, C6), $120.6(\mathrm{CH}, \mathrm{C}-2), 39.7\left(\mathrm{CH}_{2}, \mathrm{H}-4\right), 29.9\left(\mathrm{CH}_{2}, \mathrm{C}-1\right), 26.3\left(\mathrm{CH}_{2}, \mathrm{C}-5\right), 25.8\left(\mathrm{CH}_{3}, \mathrm{C}-\right.$ 10), $17.9\left(\mathrm{CH}_{3}, \mathrm{C}-8\right), 16.1\left(\mathrm{CH}_{3}, \mathrm{C}-9\right)$.

Farnesyl bromide; Farnesol (19.9 mmol, 4.44 g, $5.00 \mathrm{~mL})$ and pyridine $(0.800 \mathrm{mmol}$, $63.3 \mathrm{mg}, 64.8 \mu \mathrm{L})$ in dry DCM $(40 \mathrm{~mL})$ were stirred on an ice-salt bath for 15 minutes before dropwise addition of $\mathrm{PBr}_{3}(8.76 \mathrm{mmol}, 2.37 \mathrm{~g}, 824 \mu \mathrm{L})$ over 20 minutes. The reaction was stirred in the absence of light for two hours, then poured onto $\mathrm{NaOH}(2.5 \mathrm{M}$, $60 \mathrm{~mL})$ and extracted with $\mathrm{Et}_{2} \mathrm{O}(3 \times 50 \mathrm{~mL})$. The combined extracts were washed with $\mathrm{H}_{2} \mathrm{O}(2 \times 30 \mathrm{~mL})$, then brine $(1 \times 30 \mathrm{~mL})$ and dried over anhydrous $\mathrm{MgSO}_{4}$. The solvent was removed under reduced pressure to yield $\mathbf{6 1}$ as a pale-yellow oil $(5.61 \mathrm{~g}, 99 \%)$ :

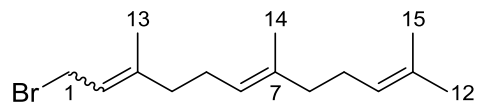

(6E)-1-Bromo-3,7,11-trimethyldodeca-2,6,10-triene (61); $E / Z$ 8:1, NMR data for the major $E$ isomer: ${ }^{1} \mathrm{H}$ NMR (600 MHz, $\left.\mathrm{CDCl}_{3}\right): \delta 5.53(\mathrm{t}, J=8.5 \mathrm{~Hz}, 1 \mathrm{H}, \mathrm{H}-2), 5.11-5.05$ (complex m, 2H, H-6 and H-10), 4.02 (d, $J=8.4$ Hz, 2H, H-1), 2.17 - 1.95 (complex m, $8 \mathrm{H}, 4 \times \mathrm{CH}_{2}$ ), 1.73 (s, 3H, H-13), 1.68 (s, 3H, H-15), 1.60 (s, 6H, H-12 and H-14); ${ }^{13} \mathrm{C}$ NMR (150 MHz, $\left.\mathrm{CDCl}_{3}\right): \delta 143.8$ (C, C-3), 135.8 (C, C-7), 131.5 (C, C-11), $124.4(\mathrm{CH}$, C-10), 123.5 (CH, C-6), 120.7 (CH, C-2), $39.8\left(\mathrm{CH}_{2}, \mathrm{C}-8\right), 39.70\left(\mathrm{CH}_{2}, \mathrm{C}-4\right), 29.9\left(\mathrm{CH}_{2}\right.$, C-1), $26.8\left(\mathrm{CH}_{2}, \mathrm{C}-9\right), 26.2\left(\mathrm{CH}_{2}, \mathrm{C}-4\right), 25.9\left(\mathrm{CH}_{3}, \mathrm{C}-15\right), 17.9\left(\mathrm{CH}_{3}, \mathrm{C}-12\right), 16.2\left(\mathrm{CH}_{3}\right.$, $\mathrm{C}-13$ or $\mathrm{C}-14), 16.1\left(\mathrm{CH}_{3}, \mathrm{C}-13\right.$ or $\left.\mathrm{C}-14\right)$.

Geranylgeranyl bromide; Geranyllinalool (7.6 mmol, $2.21 \mathrm{~g}, 2.5 \mathrm{~mL})$ in $\mathrm{Et}_{2} \mathrm{O}(15$ $\mathrm{mL}$ ) was stirred on an ice bath for 10 minutes before dropwise addition of $\mathrm{PBr}_{3}$ (3.1 mmol, $84.5 \mathrm{mg}, 293 \mu \mathrm{L}$ ) over 10 minutes. The reaction was stirred for two hours in the absence of light, then $\mathrm{MeOH}(1 \mathrm{~mL})$ was added slowly and the mixture was poured onto $\mathrm{H}_{2} \mathrm{O}(10$ $\mathrm{mL})$. The mixture was washed with $\mathrm{H}_{2} \mathrm{O}(2 \times 10 \mathrm{~mL})$, then brine $(1 \times 10 \mathrm{~mL})$ and dried over anhydrous $\mathrm{MgSO}_{4}$. The solvent was removed under reduced pressure to afford $\mathbf{6 2}$ as a thin pale-yellow oil (2.66 g, 99\%): 




(6E,10E)-1-Bromo-3,7,11,15-tetramethylhexadeca-2,6,10,14-tetraene (62); $E: Z$ 3:1, NMR data for the major isomer: ${ }^{1} \mathrm{H}$ NMR $\left(600 \mathrm{MHz}, \mathrm{CDCl}_{3}\right): \delta 5.53(\mathrm{t}, J=8.4 \mathrm{~Hz}, 1 \mathrm{H}$, H-2), 5.13 - 5.07 (complex m, 3H, H-6, H-10 and H-14), 4.02 (d, J = 8.4 Hz, 2H, H-1), 2.17 - 2.03 (complex m, 8H, $4 \times \mathrm{CH}_{2}$ ), 2.03 - 1.93 (complex m, 4H, $2 \times \mathrm{CH}_{2}$ ), 1.73 (s, $3 \mathrm{H}, \mathrm{H}-17), 1.68$ (s, 3H, H-20), $1.60\left(\mathrm{~s}, 9 \mathrm{H}, 3 \times \mathrm{CH}_{3}\right) ;{ }^{13} \mathrm{C} \mathrm{NMR}\left(150 \mathrm{MHz}, \mathrm{CDCl}_{3}\right): \delta$ 143.6 (C, C-3), 135.7 (C, C-7), 135.0 (C, C-11), 131.3 (C, C-15), 124.5 (CH, C-14), 124.3 (CH, C-10), 123.5 (CH, C-6), 120.7 (CH, C-2), $39.9\left(\mathrm{CH}_{2}, \mathrm{C}-12\right), 39.8\left(\mathrm{CH}_{2}, \mathrm{C}-8\right), 39.7$ $\left(\mathrm{CH}_{2}, \mathrm{C}-4\right), 29.7\left(\mathrm{CH}_{2}, \mathrm{C}-1\right), 26.9\left(\mathrm{CH}_{2}, \mathrm{C}-13\right), 26.7\left(\mathrm{CH}_{2}, \mathrm{C}-9\right), 26.2\left(\mathrm{CH}_{2}, \mathrm{C}-13\right), 25.8$ $\left(\mathrm{CH}_{3}, \mathrm{C}-20\right), 17.8\left(\mathrm{CH}_{3}, \mathrm{C}-16\right), 16.2\left(\mathrm{CH}_{3}, \mathrm{C}-17\right.$ or $\mathrm{C}-18$ or $\left.\mathrm{C}-19\right), 16.13\left(\mathrm{CH}_{3}, \mathrm{C}-17\right.$ or C-18 or C-19), $16.08\left(\mathrm{CH}_{3}, \mathrm{C}-17\right.$ or $\mathrm{C}-18$ or $\left.\mathrm{C}-19\right)$.

\section{$N, 1-b i s((E)-3,7-D i m e t h y l o c t a-2,6-d i e n-1-y l)-4-(m e t h y l a m i n o)-1 H$-imidazole-5-}

carboxamide (65); Sodium 3-methylhypoxanthinide (0.84 mmol, $144.9 \mathrm{mg}$ ) and $\mathrm{K}_{2} \mathrm{CO}_{3}$ (1.1 mmol, $151.8 \mathrm{mg})$ were stirred in DMF (2 mL) at room temperature for 1.5 hours before dropwise addition of geranyl bromide $(1.1 \mathrm{mmol}, 228 \mathrm{mg}, 208.5 \mu \mathrm{L})$ in DMF (1 $\mathrm{mL})$ over 90 minutes. The reaction was stirred for 22 hours, then poured onto $\mathrm{H}_{2} \mathrm{O}(9 \mathrm{~mL})$ and extracted with EA $(4 \times 3 \mathrm{~mL})$. The combined extracts were washed with $\mathrm{H}_{2} \mathrm{O}(3 \times 3$ $\mathrm{mL})$, then brine $(1 \times 3 \mathrm{~mL})$ and dried over anhydrous $\mathrm{MgSO}_{4}$. The solvent was removed under reduced pressure and the resulting oil was purified by silica gel flash chromatography twice (1:1 EA/PE and 1:3 EA/PE) to afford $\mathbf{6 5}$ as a pale-yellow oil (4.3 $\mathrm{mg}, 2 \%)$ :

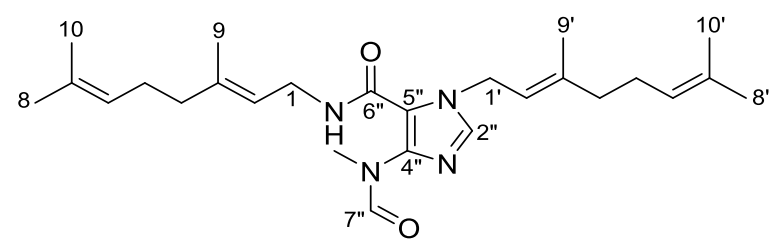

$\mathrm{R}_{f}=0.10(1: 1 \mathrm{EA} / \mathrm{PE}) ;{ }^{1} \mathrm{H} \mathrm{NMR}\left(500 \mathrm{MHz}, \mathrm{CDCl}_{3}\right): \delta 8.34(\mathrm{~s}, 1 \mathrm{H}, \mathrm{H}-7$ '”), 7.57 (t, $J=5.3$ Hz, 1H, NH), 7.45 (s, 1H, H-2”), 5.39 (t, $J=6.7$ Hz, 1H, H-2 or H-2'), $5.14-5.03$ (complex m, 2H, H-6 and H-6'), 4.92 (d, J =7.2 Hz, 2H, H-1'), 3.99 (t, $J=6.2 \mathrm{~Hz}, 3 \mathrm{H}$, H-1), 2.91 (s, 3H, $\mathrm{NCH}_{3}$ ), $2.18-2.07$ (complex m, 4H, $2 \times \mathrm{CH}_{2}$ ), $2.07-1.98$ (m, 4H, 2 $\left.\times \mathrm{CH}_{2}\right), 1.70\left(\mathrm{~s}, 3 \mathrm{H}, \mathrm{CH}_{3}\right), 1.69\left(\mathrm{~s}, 3 \mathrm{H}, \mathrm{CH}_{3}\right), 1.64\left(\mathrm{~s}, 6 \mathrm{H}, 2 \times \mathrm{CH}_{3}\right), 1.61\left(\mathrm{~s}, 6 \mathrm{H}, 2 \times \mathrm{CH}_{3}\right)$; IR (film from $\mathrm{CH}_{2} \mathrm{Cl}_{2}$ ): $v_{\max } 3306,3108,2966,2916,2856,1649 \mathrm{~cm}^{-1}$. 


\section{4-(N-Methylformamido)- $N, 1-b i s((6 E)-3,7,11-t r i m e t h y l d o d e c a-2,6,10-t r i e n-1-y l)-$}

1H-imidazole-5-carboxamide (66); Sodium 3-methylhypoxanthinide (0.84 mmol, 145.2 $\mathrm{mg})$ and $\mathrm{K}_{2} \mathrm{CO}_{3}(1.124 \mathrm{mmol}, 155.3 \mathrm{mg})$ were stirred in $\mathrm{DMF}(2 \mathrm{~mL})$ at room temperature for 1.5 hours before dropwise addition of farnesyl bromide (1.1 mmol, $298.8 \mathrm{mg}, 284 \mu \mathrm{L})$ in DMF ( $1 \mathrm{~mL})$ over two hours. The reaction was stirred for 22 hours, then poured onto $\mathrm{H}_{2} \mathrm{O}(9 \mathrm{~mL})$ and extracted with EA $(4 \times 3 \mathrm{~mL})$. The combined extracts were washed with $\mathrm{H}_{2} \mathrm{O}(3 \times 3 \mathrm{~mL})$, then brine $(1 \times 3 \mathrm{~mL})$ and dried over anhydrous $\mathrm{MgSO}_{4}$. The solvent was removed under reduced pressure and the residue was purified by silica gel flash chromatography twice (1:1 EA/PE and 1:3 EA/PE) to afford 66 as a pale-yellow oil (7.1 $\mathrm{mg}, 2 \%)$ :

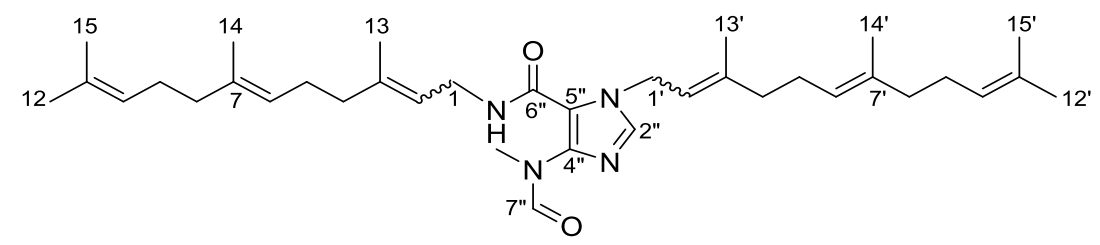

${ }^{1} \mathrm{H}$ NMR (500 MHz, $\mathrm{CDCl}_{3}$ ): $\delta 8.34$ (s, 1H, H-7"), 7.57 (t, J=5.2 Hz, 1H, NH), 7.45 (s, 1H, H-2”), 5.40 (t, $J=7.0 \mathrm{~Hz}, 1 \mathrm{H}, \mathrm{H}-2$ or H-2'), 5.21 (t, $J=9.2 \mathrm{~Hz}, 1 \mathrm{H}, \mathrm{H}-2$ or H-4), 5.16 - 5.06 (complex m, 4H, H-6, H-6', H-10 and H-10'), 4.92 (d, J=7.1 Hz, 2H, H-1'), $3.98(\mathrm{t}, J=6.1 \mathrm{~Hz}, 2 \mathrm{H}, \mathrm{H}-1), 3.26\left(\mathrm{~s}, 3 \mathrm{H}, \mathrm{NCH}_{3}\right), 2.22-1.92$ (complex m, $16 \mathrm{H}, 8 \times \mathrm{CH}_{2}$ ), $1.70\left(\mathrm{~s}, 3 \mathrm{H}, \mathrm{CH}_{3}\right), 1.69\left(\mathrm{~s}, 9 \mathrm{H}, 3 \times \mathrm{CH}_{3}\right), 1.64\left(\mathrm{~s}, 3 \mathrm{H}, \mathrm{CH}_{3}\right), 1.61\left(\mathrm{~s}, 9 \mathrm{H}, 3 \times \mathrm{CH}_{3}\right)$.

\section{4-(N-Methylformamido)- $N, 1-b i s((6 E, 10 E)-3,7,11,15$-tetramethylhexadeca-}

2,6,10,14-tetraen-1-yl)-1H-imidazole-5-carboxamide $\quad(67) ; \quad$ Sodium 3methylhypoxanthinide $(0.84 \mathrm{mmol}, 144.5 \mathrm{mg})$ and $\mathrm{K}_{2} \mathrm{CO}_{3}(1.1 \mathrm{mmol}, 153.1 \mathrm{mg})$ were stirred in DMF (2 mL) for 105 minutes before dropwise addition of geranylgeranyl bromide (1.05 mmol, $371 \mathrm{mg}, 362 \mu \mathrm{L})$ in DMF ( $1 \mathrm{~mL})$ over two hours. The reaction was stirred for 22 hours and then $\mathrm{H}_{2} \mathrm{O}(9 \mathrm{~mL})$ was added. The mixture was extracted with EA $(3 \times 3 \mathrm{~mL})$ and the combined extracts were washed with $\mathrm{H}_{2} \mathrm{O}(3 \times 3 \mathrm{~mL})$, then brine $(1 \times$ $3 \mathrm{~mL}$ ) and dried over anhydrous $\mathrm{MgSO}_{4}$. The solvent was removed under reduced pressure and the resulting residue was purified by silica gel flash chromatography twice (1:1 EA/PE and 1:3 EA/PE) to afford 67 as a colourless oil $(9.3 \mathrm{mg}, 3 \%)$ : 


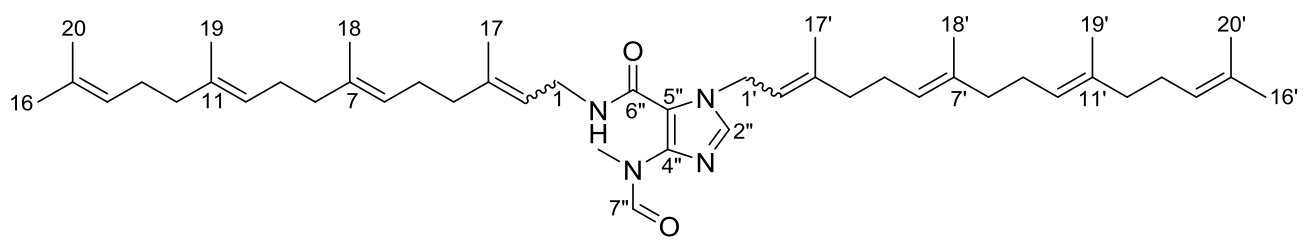

${ }^{1} \mathrm{H}$ NMR (500 MHz, CDCl 3 ): $\delta 8.34$ (s, 1H, H-7”), 7.44 (s, 1H, H-2”), 5.40 (t, J=6.9 Hz, 1H, H-2 or H-2'), 5.21 (m, 1H, H-2 or H-2'), 5.11 (complex m, 6H, $6 \times \mathrm{CH}), 4.92$ (d, $J=$ $7.1 \mathrm{~Hz}, 2 \mathrm{H}, \mathrm{H}-1$ ), 4.00 - 3.96 (m, 2H, H-2), 3.26 (s, 3H, NCH 3 ), 2.20 - 1.92 (complex m, $\left.24 \mathrm{H}, 12 \times \mathrm{CH}_{2}\right), 1.69\left(\mathrm{~s}, 12 \mathrm{H}, 4 \times \mathrm{CH}_{3}\right), 1.61\left(\mathrm{~s}, 18 \mathrm{H}, 6 \times \mathrm{CH}_{3}\right)$; IR (film from $\mathrm{CH}_{2} \mathrm{Cl}_{2}$ ): $v_{\max } 3293,2966,2915,2863,1654 \mathrm{~cm}^{-1}$.

Geranyl adenine; Adenine (1.00 mmol, $134.7 \mathrm{mg}$ ) and $\mathrm{K}_{2} \mathrm{CO}_{3}(1.31 \mathrm{mmol}, 181.3 \mathrm{mg})$ were stirred in DMF $(2 \mathrm{~mL})$ at room temperature for 10 minutes before dropwise addition of geranyl bromide $(1.2 \mathrm{mmol}, 250.6 \mathrm{mg}, 238.2 \mu \mathrm{L})$. The reaction was stirred for 21 hours, then poured onto $\mathrm{H}_{2} \mathrm{O}(6 \mathrm{~mL})$ and extracted with EA $(3 \times 2 \mathrm{~mL})$. The combined extracts were washed with $\mathrm{H}_{2} \mathrm{O}(3 \times 2 \mathrm{~mL})$, then brine $(1 \times 2 \mathrm{~mL})$ and dried over anhydrous $\mathrm{MgSO}_{4}$. The dried residue was purified by silica gel flash chromatography (5\% $\mathrm{MeOH}$ in EA) to yield $\mathbf{8 0}$ as pale-yellow crystals (51.9 $\mathrm{mg}, 19 \%)$ :

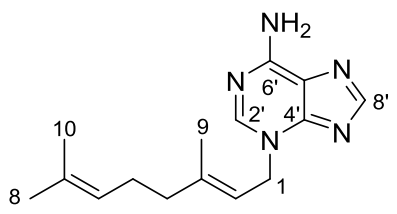

(E)-3-(3,7-Dimethylocta-2,6-dien-1-yl)-3H-purin-6-amine (80); $\mathrm{R}_{f}=0.80(5 \% \mathrm{MeOH}$ in EA); ${ }^{1} \mathrm{H}$ NMR $\left(500 \mathrm{MHz}, \mathrm{CDCl}_{3}\right): \delta 8.06\left(\mathrm{~s}, 1 \mathrm{H}, \mathrm{H}-8^{\prime}\right), 8.02(\mathrm{~s}, 1 \mathrm{H}, \mathrm{H}-2$ '), $5.49(\mathrm{t}, J=$ $7.3 \mathrm{~Hz}, 1 \mathrm{H}, \mathrm{H}-2$ ), 5.04 (br s, 2H, NH ), 5.01 (d, $J=7.3 \mathrm{~Hz}, 2 \mathrm{H}, \mathrm{H}-1$ ), 2.12 (br s, 4H, H4 and $\mathrm{H}-5$ ), 1.83 (s, 3H, H-9), 1.66 (s, 3H, H-10), 1.57 (s, 3H, H-8); ${ }^{13} \mathrm{C}$ NMR (150 MHz, $\left.\mathrm{CDCl}_{3}\right): \delta 154.3$ (C, C-6') $153.9\left(\mathrm{CH}, \mathrm{C}-8^{\prime}\right), 150.9$ (C, C-4'), 145.0 (C, C-3), 141.7 (CH, C-2'), 132.5 (C, C-7), 123.4 (CH, C-6), 120.8 (C, C-5'), 116.2 (CH, C-2), $47.4\left(\mathrm{CH}_{2}, \mathrm{C}-\right.$ 1), $39.6\left(\mathrm{CH}_{2}, \mathrm{C}-4\right), 26.2\left(\mathrm{CH}_{2}, \mathrm{C}-5\right), 25.8\left(\mathrm{CH}_{3}, \mathrm{C}-10\right), 17.9\left(\mathrm{CH}_{3}, \mathrm{C}-8\right), 16.8\left(\mathrm{CH}_{3}, \mathrm{C}-\right.$ 9); IR (film from $\mathrm{CH}_{2} \mathrm{Cl}_{2}$ ): $v_{\max } 3231,3067,2966,2912,2853 \mathrm{~cm}^{-1}$; HRESIMS m/z: $[\mathrm{M}+\mathrm{H}]^{+}$Calcd for $\mathrm{C}_{15} \mathrm{H}_{22} \mathrm{~N}_{5}$ 272.1870; Found 272.1875 ( $\left.\Delta=-2.01 \mathrm{ppm}\right)$; HRESIMS/MS $(40 \mathrm{eV}) \mathrm{m} / \mathrm{z}(\%): 136.0612$ (100), 81.0700 (17). 


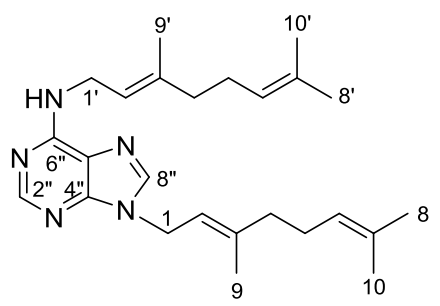

N,9-bis((E)-3,7-Dimethylocta-2,6-dien-1-yl)-9H-purin-6-amine (84); $\mathrm{R}_{f}=0.04(10 \%$ $\mathrm{MeOH} / \mathrm{EA}) ;{ }^{1} \mathrm{H}$ NMR (600 MHz, $\mathrm{CDCl}_{3}$ ): $\delta 7.54$ (s, 2H, H-8" and H-2"), 5.47 (t, $J=7.3$ Hz, 1H, H-2 or H-2'), 5.35 (t, $J=7.6 \mathrm{~Hz}, 1 \mathrm{H}, \mathrm{H}-2$ or H-2'), 5.15 (d, $J=7.3 \mathrm{~Hz}, 2 \mathrm{H}, \mathrm{H}-1$ or H-1'), 5.08 - 5.00 (complex m, 2H, H-6 and H-6'), 4.60 (d, J=7.1 Hz, 1H, H-1 or H1'), 2.15 - 2.03 (complex m, 8H, $4 \times \mathrm{CH}_{2}$ ), 1.78 (s, 3H, H-9 or H-9'), 1.77 (s, 3H, (s, 3H, H-9 or H-9'), 1.67 (s, H-10 or H-10')), 1.65 (s, 3H, H-10 or H-10'), 1.58 (s, 3H, H-8 or H-8'), 1.57 (s, 3H, H-8 or H-8'); ${ }^{13}$ C NMR (150 MHz, CDCl 3 ): $\delta 155.2$ (C, C-6”), 153.3 (CH, C-2”), 144.9 (C, C-3 or C-3'), 144.6 (C, C-3 or C-3'), 132.4 (C, C-7 or C-7'), 132.4 (C, C-7 or C-7'), 123.7 (CH, C-6 or C-6'), 123.4 (CH, C-6 or C-6'), $117.0(\mathrm{CH}, \mathrm{C}-2$ or C-2'), 116.4 (C, C-2 or C-2'), 112.6 (C, C-5’), $39.63\left(\mathrm{CH}_{2}, \mathrm{C}-4\right.$ or C-4'), $39.60\left(\mathrm{CH}_{2}, \mathrm{C}-\right.$ 4 or C-4'), $26.23\left(\mathrm{CH}_{2}, \mathrm{C}-5\right.$ or C-5'), $26.22\left(\mathrm{CH}_{2}, \mathrm{C}-5\right.$ or C-5'), $25.9\left(\mathrm{CH}_{3}, \mathrm{C}-10\right.$ or C10 '), $25.8\left(\mathrm{CH}_{3}, \mathrm{C}-10\right.$ or C-10'), $17.88\left(\mathrm{CH}_{3}, \mathrm{C}-8\right.$ or C-8'), $17.85\left(\mathrm{CH}_{3}, \mathrm{C}-8\right.$ or C-8'), 16.79 (CH3, C-9 or C-9'), 16.76 (CH3, C-9 or C-9'); IR (film from $\mathrm{CH}_{2} \mathrm{Cl}_{2}$ ): v $v_{\max } 2966$, $2916,2855,1629 \mathrm{~cm}^{-1}$.

Farnesyl adenine; Adenine $(0.51 \mathrm{mmol}, 68.3 \mathrm{mg})$ and $\mathrm{K}_{2} \mathrm{CO}_{3}(0.52 \mathrm{mmol}, 71.9 \mathrm{mg})$ were stirred in DMF $(2 \mathrm{~mL})$ at $50{ }^{\circ} \mathrm{C}$ for 10 minutes before dropwise addition of farnesyl bromide $(0.55 \mathrm{mmol}, 157.0 \mathrm{mg}, 149.2 \mu \mathrm{L})$. The reaction was stirred for 27 hours, then filtered and $\mathrm{H}_{2} \mathrm{O}(6 \mathrm{~mL})$ was added to the filtrate. The mixture was stored in the fridge for approximately 2 days until precipitate formed. The solid was isolated by filtration and then purified by silica gel flash chromatography twice $(5 \% \mathrm{MeOH}$ in EA and EA) to afford the $N-3$ farnesylated product $\mathbf{8 1}(22.4 \mathrm{mg}, 13.1 \%)$ as pale yellow crystals and the $\mathrm{N}-9$ farnesylated product 82 as a white powder (3.6 $\mathrm{mg}, 2 \%)$ : 


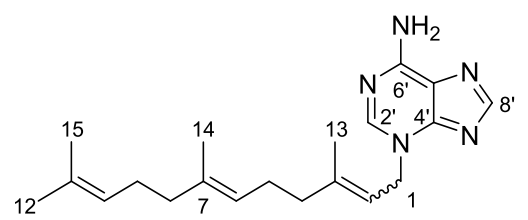

3-((6E)-3,7,11-Trimethyldodeca-2,6,10-trien-1-yl)-3H-purin-6-amine (81); $\mathrm{R}_{f}=0.17$ (5\% MeOH/EA); 3:2 E/Z, NMR data for major isomer: ${ }^{1} \mathrm{H} \mathrm{NMR}\left(600 \mathrm{MHz}, \mathrm{CDCl}_{3}\right): \delta$ 8.05 (s, 1H, H-8'), 8.00 (s, 1H, H-2'), 5.51 - 5.45 (m, 1H, H-2), 5.10 - 5.03 (m, 2H, H-6 and H-10), 5.01 (d, $J=7.3 \mathrm{~Hz}, 2 \mathrm{H}, \mathrm{H}-1), 2.15-2.09$ (complex m, 4H, $2 \times \mathrm{CH}_{2}$ ), $2.05-$ 1.98 (m, 2H, $\left.\mathrm{CH}_{2}\right), 1.98-1.92\left(\mathrm{~m}, 2 \mathrm{H}, \mathrm{CH}_{2}\right), 1.83$ (s, 3H, H-13), 1.65 (s, 3H, $\mathrm{CH}_{3}$ ), 1.57 (s, 6H, $\left.2 \times \mathrm{CH}_{3}\right) ;{ }^{13} \mathrm{C} \mathrm{NMR}\left(150 \mathrm{MHz}, \mathrm{CDCl}_{3}\right): \delta 154.5$ (C, C-6'), $154.1(\mathrm{CH}, \mathrm{C}-8$ '), 150.9 (C, C-4'), 144.9 (C, C-3), 141.6 (CH, C-2'), 136.1 (C, C-7), 131.5 (C, C-11), 124.3 (CH, C-10), 123.3 (CH, C-6), 121.1 (C, C-5'), 116.2 (C, C-2), $47.4\left(\mathrm{CH}_{2}, \mathrm{C}-1\right), 39.8\left(\mathrm{CH}_{2}, \mathrm{C}-\right.$ 8), $39.6\left(\mathrm{CH}_{2}, \mathrm{C}-4\right), 26.8\left(\mathrm{CH}_{2}, \mathrm{C}-9\right), 26.2\left(\mathrm{CH}_{2}, \mathrm{C}-5\right), 25.8\left(\mathrm{CH}_{3}, \mathrm{C}-15\right), 17.8\left(\mathrm{CH}_{3}, \mathrm{C}-\right.$ 12), 16.9( $\left.\mathrm{CH}_{3}, \mathrm{C}-13\right), 16.2\left(\mathrm{CH}_{3}, \mathrm{C}-14\right)$; IR (film from $\left.\mathrm{CH}_{2} \mathrm{Cl}_{2}\right): v_{\max } 3231,3065,2965$, $2915,2855,1704 \mathrm{~cm}^{-1}$.

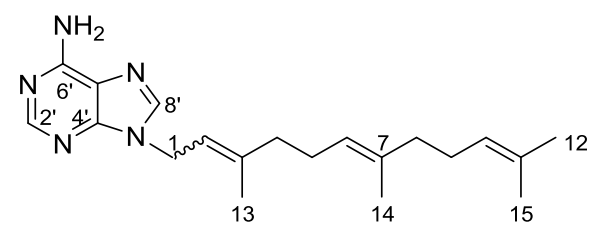

9-((6E)-3,7,11-Trimethyldodeca-2,6,10-trien-1-yl)-9H-purin-6-amine $(82) ; \mathrm{R}_{f}=0.30$ (EA); 3:2 E/Z, NMR data for major isomer: ${ }^{1} \mathrm{H}$ NMR (500 MHz, $\left.\mathrm{CDCl}_{3}\right): \delta 8.38(\mathrm{~s}, 1 \mathrm{H}$, H-2'), 7.78 (s, 1H, H-8'), 5.59 (br s, 2H, NH ( $^{2}, 5.45$ (t, J = 7.1 Hz, 1H, H-2), 5.13 - 5.03 (complex m, 2H, H-6 and H-10), 4.78 (d, $J=7.1 \mathrm{~Hz}, 2 \mathrm{H}, \mathrm{H}-1$ ), $2.19-2.08$ (complex m, $4 \mathrm{H}, 2 \times \mathrm{CH}_{2}$ ), $2.08-1.92$ (complex m, 4H, $2 \times \mathrm{CH}_{2}$ ), 1.81 (s, 3H, H-13), 1.67 (s, 6H, 2 $\left.\times \mathrm{CH}_{3}\right), 1.59\left(\mathrm{~s}, 3 \mathrm{H}, \mathrm{CH}_{3}\right)$; HRESIMS $m / z:[\mathrm{M}+\mathrm{H}]^{+}$Calcd for $\mathrm{C}_{20} \mathrm{H}_{30} \mathrm{~N}_{5}$ 340.2496; Found 340.2501 ( $\Delta=-1.58 \mathrm{ppm})$; HRESIMS/MS (40 eV) $m / z$ (\%): 136.0613 (100), 119.0346 (1).

Geranylgeranyl adenine; Adenine ( $0.69 \mathrm{mmol}, 93.8 \mathrm{mg})$ and $\mathrm{K}_{2} \mathrm{CO}_{3}(0.78 \mathrm{mmol}$, $108.0 \mathrm{mg}$ ) were stirred in DMF $(1 \mathrm{~mL})$ at room temperature for 20 minutes before dropwise addition of geranylgeranyl bromide ( $0.73 \mathrm{mmol}, 259 \mathrm{mg}, 253 \mu \mathrm{L})$ over one minute. The reaction was stirred for 27 hours and then poured onto $\mathrm{H}_{2} \mathrm{O}(3 \mathrm{~mL})$. The aqueous mixture was extracted with EA $(3 \times 2 \mathrm{~mL})$ and the combined extracts were washed with $\mathrm{H}_{2} \mathrm{O}(3 \times 2 \mathrm{~mL})$, then brine $(1 \times 2 \mathrm{~mL})$ and dried over anhydrous $\mathrm{MgSO}_{4}$. 
The solvent was removed under reduced pressure and the resulting residue was purified by silica gel flash chromatography (5\% $\mathrm{MeOH} / \mathrm{EA})$ to afford $\mathbf{8 3}$ as pale-yellow crystals (9.9 mg, 4\%):

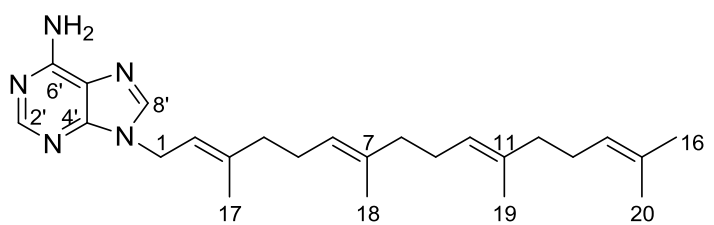

9-((2E,6E,10E)-3,7,11,15-Tetramethylhexadeca-2,6,10,14-tetraen-1-yl)-9H-purin-6amine (83); ${ }^{1} \mathrm{H}$ NMR (500 MHz, $\left.\mathrm{CDCl}_{3}\right): \delta 8.37$ (s, 1H, H-2'), 7.77 (s, 1H, H-8'), 5.77 (br s, 2H, NH $\mathrm{N}_{2}$ ), 5.44 (t, $J=7.2 \mathrm{~Hz}, 1 \mathrm{H}, \mathrm{H}-2$ ), 5.11 - 5.05 (complex m, 3H, H-6, H-10 and $\mathrm{H}-14$ ), 4.77 (d, $J=7.2 \mathrm{~Hz}, 2 \mathrm{H}, \mathrm{H}-1$ ), $2.16-2.08$ (complex m, 4H, $2 \times \mathrm{CH}_{2}$ ), $2.08-$ 2.01 (complex m, 4H, $2 \times \mathrm{CH}_{2}$ ), $2.01-1.92$ (complex m, 4H, $\left.2 \times \mathrm{CH}_{2}\right), 1.81(\mathrm{~s}, 3 \mathrm{H}, \mathrm{H}-$ 17), 1.67 (s, 3H, C-20), 1.59 (s, 9H, $\left.3 \times \mathrm{CH}_{3}\right) ;{ }^{13} \mathrm{C} \mathrm{NMR}\left(150 \mathrm{MHz}, \mathrm{CDCl}_{3}\right): \delta 155.5(\mathrm{C}$, C-6'), 153.0 (CH, C-2'), 143.0 (C, C-3), 140.1 (CH, C-8'), 135.9 (C, C-7), 135.2 (C, C11), 131.4 (C, C-15), 124.5 (CH, C-14), 124.2 (CH, C-10), 123.5 (CH, C-6), 119.7 (C, C5'), $117.5(\mathrm{CH}, \mathrm{C}-2), 41.3\left(\mathrm{CH}_{2}, \mathrm{C}-1\right), 39.9\left(\mathrm{CH}_{2}, \mathrm{C}-12\right), 39.8\left(\mathrm{CH}_{2}, \mathrm{C}-8\right), 39.6\left(\mathrm{CH}_{2}, \mathrm{C}-\right.$ 4), $26.9\left(\mathrm{CH}_{2}, \mathrm{C}-13\right), 26.7\left(\mathrm{CH}_{2}, \mathrm{C}-9\right), 26.3\left(\mathrm{CH}_{2}, \mathrm{C}-5\right), 25.8\left(\mathrm{CH}_{3}, \mathrm{C}-20\right), 17.8\left(\mathrm{CH}_{3}, \mathrm{C}-\right.$ 16), $16.7\left(\mathrm{CH}_{3}, \mathrm{C}-17\right), 16.2\left(\mathrm{CH}_{3}, \mathrm{C}-18\right.$ or $\left.\mathrm{C}-19\right), 16.1\left(\mathrm{CH}_{3}, \mathrm{C}-18\right.$ or $\left.\mathrm{C}-19\right)$; IR (film from $\left.\mathrm{CH}_{2} \mathrm{Cl}_{2}\right): v_{\max } 3468,3324,3153,3051,29692918 \mathrm{~cm}^{-1}$; HRESIMS m/z: $[\mathrm{M}+\mathrm{H}]^{+} \mathrm{Calcd}$ for $\mathrm{C}_{25} \mathrm{H}_{38} \mathrm{~N}_{5}$ 408.3122; Found 408.3129 ( $\Delta=-1.82 \mathrm{ppm}$ ); HRESIMS/MS (40 eV) $\mathrm{m} / \mathrm{z}$ (\%): $136.0614(100)$.

Geranyl 6-(dimethylamino)purine; 6-(Dimethylamino)purine (0.17 mmol, $28.3 \mathrm{mg})$ and $\mathrm{Na}_{2} \mathrm{CO}_{3}-\mathrm{K}_{2} \mathrm{CO}_{3}(1: 1,108 \mathrm{mg})$ were stirred in DMF $(3 \mathrm{~mL})$ before dropwise addition of geranyl bromide $(0.42 \mathrm{mmol}, 90.8 \mathrm{mg}, 83 \mu \mathrm{L})$ over 3 minutes. The reaction was stirred for 2 days and then dried under reduced pressure. The residue was semi-purified by silica gel flash chromatography (EA) into two fractions, which were purified again, separately, by silica gel flash chromatography (1:2 EA/PE or $5 \% \mathrm{MeOH} / \mathrm{EA})$ to yield the $N-3$ geranylated product $85(6.3 \mathrm{mg}, 12 \%)$ and the $N-9$ geranylated product $86(9.2 \mathrm{mg}, 18 \%)$ as white powders: 


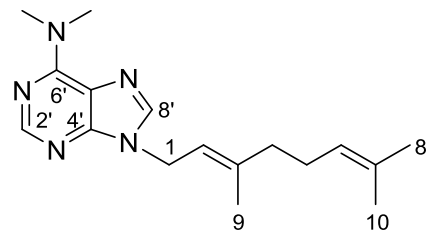

(E)-9-(3,7-Dimethylocta-2,6-dien-1-yl)- $N, N$-dimethyl-9H-purin-6-amine (86); $\mathrm{R}_{f}=$ 0.12 (1:2 EA/PE); ${ }^{1} \mathrm{H}$ NMR (600 MHz, $\mathrm{CDCl}_{3}$ ): $\delta 8.35$ (s, 1H, H-2'), 7.69 (s, 1H, H-8'), 5.43 (t, $J=7.1 \mathrm{~Hz}, 1 \mathrm{H}, \mathrm{H}-2), 5.05$ (t, $J=6.1 \mathrm{~Hz}, 1 \mathrm{H}, \mathrm{H}-6), 4.75$ (d, $J=7.1 \mathrm{~Hz}, 2 \mathrm{H}, \mathrm{H}-1)$, 3.53 (br s, 6H, $2 \times \mathrm{NCH}_{3}$ ), $2.15-2.04$ (complex m, 4H, H-4 and H-5), 1.79 (s, 3H, H-9), 1.67 (s, 3H, H-10), 1.58 (s, 3H, H-8); ${ }^{13} \mathrm{C}$ NMR (150 MHz, CDCl 3 ): $\delta 155.1$ (C, C-6'), 152.5 (C, C-2'), 150.5 (C, C-4'), 142.5 (C, C-3), 137.9 (CH, C-8'), 132.2 (C, C-7), 123.7 (CH, C-6), 120.3 (C, C-5'), 117.9 (CH, C-2), $41.1\left(\mathrm{CH}_{2}, \mathrm{C}-1\right), 39.6\left(\mathrm{CH}_{2}, \mathrm{C}-4\right), 38.7$ $\left(\mathrm{CH}_{3}, 2 \times \mathrm{NCH}_{3}\right), 26.3\left(\mathrm{CH}_{2}, \mathrm{C}-5\right), 25.8\left(\mathrm{CH}_{3}, \mathrm{C}-10\right), 17.9\left(\mathrm{CH}_{3}, \mathrm{C}-8\right), 16.6\left(\mathrm{CH}_{3}, \mathrm{C}-9\right)$; IR (film from $\mathrm{CH}_{2} \mathrm{Cl}_{2}$ ): $v_{\max }$ 2963, 2919, $1637 \mathrm{~cm}^{-1}$; HRESIMS m/z: [M+H] $]^{+}$Calcd for $\mathrm{C}_{17} \mathrm{H}_{26} \mathrm{~N}_{5} 300.2183$; Found $300.2189(\Delta=-1.99 \mathrm{ppm})$.



(E)-3-(3,7-Dimethylocta-2,6-dien-1-yl)- $N, N$-dimethyl-3H-purin-6-amine (85); $\mathrm{R}_{f}=$ $0.21(5 \% \mathrm{MeOH} / \mathrm{EA}) ;{ }^{1} \mathrm{H}$ NMR (600 MHz, $\left.\mathrm{CDCl}_{3}\right): \delta 8.00$ (s, 1H, H-8'), 7.95 (s, 1H, H2'), 5.48 (t, $J=6.9 \mathrm{~Hz}, 1 \mathrm{H}, \mathrm{H}-2), 5.07-5.02$ (m, 1H, H-6), 4.95 (d, J = 7.1 Hz, 2H, H1), 3.92 (br s, 3H, $\mathrm{NCH}_{3 \mathrm{a}}$ or $\mathrm{NCH}_{3 \mathrm{~b}}$ ), 3.34 (br s, 3H, $\mathrm{NCH}_{3 \mathrm{a}}$ or $\mathrm{NCH}_{3 \mathrm{~b}}$ ), $2.17-2.08$ (complex m, 4H, H-4 and H-5), 1.81 (s, 3H, H-9), 1.68 (s, 3H, H-10), 1.58 (s, 3H, H-8); ${ }^{13} \mathrm{C} \mathrm{NMR}\left(150 \mathrm{MHz}, \mathrm{CDCl}_{3}\right.$ ): $\delta 153.4$ (C, C-6'), 152.6 (C, C-8'), 150.7 (C, C-4'), 144.4 (C, C-3), 140.3 (CH, C-2'), 132.4 (C, C-7), 123.6 (CH, C-6), $116.6(\mathrm{CH}, \mathrm{C}-2), 46.9\left(\mathrm{CH}_{2}\right.$, C-1), $39.9\left(\mathrm{CH}_{3}, \mathrm{NCH}_{3 \mathrm{a}}\right.$ or $\left.\mathrm{NCH}_{3 \mathrm{~b}}\right), 39.6\left(\mathrm{CH}_{2}, \mathrm{C}-4\right), 38.1\left(\mathrm{CH}_{3}, \mathrm{NCH}_{3 \mathrm{a}}\right.$ or $\left.\mathrm{NCH}_{3 \mathrm{~b}}\right), 26.3$ $\left(\mathrm{CH}_{2}, \mathrm{C}-5\right), 25.8\left(\mathrm{CH}_{3}, \mathrm{C}-10\right), 17.9\left(\mathrm{CH}_{3}, \mathrm{C}-8\right), 16.7\left(\mathrm{CH}_{3}, \mathrm{C}-9\right)$; IR (film from $\left.\mathrm{CH}_{2} \mathrm{Cl}_{2}\right)$ : $v_{\max } 3077,2964,2922,1607 \mathrm{~cm}^{-1}$; HRESIMS $m / z:[\mathrm{M}+\mathrm{H}]^{+}$Calcd for $\mathrm{C}_{17} \mathrm{H}_{26} \mathrm{~N}_{5} 300.2183$; Found $300.2184(\Delta=-0.55 \mathrm{ppm})$; HRESIMS/MS (40 eV) $\mathrm{m} / z$ (\%): 164.0914 (100).

Farnesyl 6-(dimethylamino)purine; 6-(Dimethylamino)purine (0.088 mmol, 14.4 $\mathrm{mg})$ and $\mathrm{K}_{2} \mathrm{CO}_{3}(0.16 \mathrm{mmol}, 22.3 \mathrm{mg})$ were stirred in $\mathrm{DMF}(1 \mathrm{~mL})$ at $50{ }^{\circ} \mathrm{C}$ for 10 minutes before dropwise addition of farnesyl bromide $(0.11 \mathrm{mmol}, 31.6 \mathrm{mg}, 30 \mu \mathrm{L})$. The reaction was stirred for 21 hours, then filtered and $\mathrm{H}_{2} \mathrm{O}(5 \mathrm{~mL})$ was added. The aqueous mixture 
was extracted with EA $(3 \times 5 \mathrm{~mL})$ and the combined extracts were washed with $\mathrm{H}_{2} \mathrm{O}(3$ $\times 5 \mathrm{~mL})$, then brine $(1 \times 5 \mathrm{~mL})$ and dried over anhydrous $\mathrm{MgSO}_{4}$. The dried residue was purified by silica gel flash chromatography (1:1 EA/PE, then 10\% MeOH/EA) to afford the $N-3$ farnesylated product $87(9.5 \mathrm{mg}, 29 \%)$ and $N-9$ farnesylated product $88(5.6 \mathrm{mg}$, $17 \%)$ as white powders:

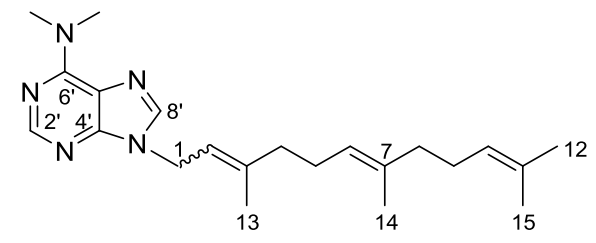

$N, N$-Dimethyl-9-((6E)-3,7,11-trimethyldodeca-2,6,10-trien-1-yl)-9H-purin-6-amine (88); $\mathrm{R}_{f}=0.29(1: 1 \mathrm{EA} / \mathrm{PE}) ; 3: 2 \mathrm{E} / \mathrm{Z}, \mathrm{NMR}$ data for major isomer: ${ }^{1} \mathrm{H} \mathrm{NMR}(500 \mathrm{MHz}$, $\mathrm{CDCl}_{3}$ ): $\delta 8.36$ (s, 1H, H-2'), 7.70 (s, 1H, H-8'), 5.44 (t, J=7.1 Hz, 1H, H-2), $5.11-5.03$ (complex m, 2H, H-6 and H-10), 4.75 (d, $J=7.1 \mathrm{~Hz}, 2 \mathrm{H}, \mathrm{H}-1$ ), 3.53 (br s, $6 \mathrm{H}, 2 \times \mathrm{NCH}_{3}$ ), $2.16-2.06$ (complex m, 4H, $\left.2 \times \mathrm{CH}_{2}\right), 2.06-1.99\left(\mathrm{~m}, 2 \mathrm{H}, \mathrm{CH}_{2}\right), 1.99-1.92(\mathrm{~m}, 2 \mathrm{H}$, $\mathrm{CH}_{2}$ ), 1.81 (s, 3H, H-13), 1.68 (s, 3H, H-15), 1.58 (s, 6H, H-12 and H-14); ${ }^{13} \mathrm{C}$ NMR (150 $\mathrm{MHz} \mathrm{CDCl}_{3}$ ): $\delta 155.1$ (C, C-6'), 152.5 (CH, C-2'), 150.5 (C, C-4'), 142.5 (C, C-3), 137.89 (CH, C-8'), 135.9 (C, C-7), 131.5 (C, C-11), 124.4 (CH, C-10), 117.9 (CH, C-2), $41.2\left(\mathrm{CH}_{2}, \mathrm{C}-1\right), 39.8\left(\mathrm{CH}_{2}, \mathrm{C}-8\right), 39.6\left(\mathrm{CH}_{2}, \mathrm{C}-4\right), 38.7\left(\mathrm{CH}_{3}, 2 \times \mathrm{NCH}_{3}\right), 26.8\left(\mathrm{CH}_{2}, \mathrm{C}-\right.$ 9), $26.3\left(\mathrm{CH}_{2}, \mathrm{C}-5\right), 25.9\left(\mathrm{CH}_{3}, \mathrm{C}-15\right), 17.8\left(\mathrm{CH}_{3}, \mathrm{C}-12\right), 16.7\left(\mathrm{CH}_{3}, \mathrm{C}-13\right), 16.2\left(\mathrm{CH}_{3}\right.$, C-14); IR (film from $\mathrm{CH}_{2} \mathrm{Cl}_{2}$ ): $v_{\max } 3051,2961,2917,2856,1589 \mathrm{~cm}^{-1}$; HRESIMS m/z: $[\mathrm{M}+\mathrm{H}]^{+}$Calcd for $\mathrm{C}_{22} \mathrm{H}_{34} \mathrm{~N}_{5}$ 368.2809; Found 368.2817 ( $\Delta=-2.24 \mathrm{ppm}$ ); HRESIMS/MS (40 eV) $\mathrm{m} / \mathrm{z}(\%): 164.0894$ (100).

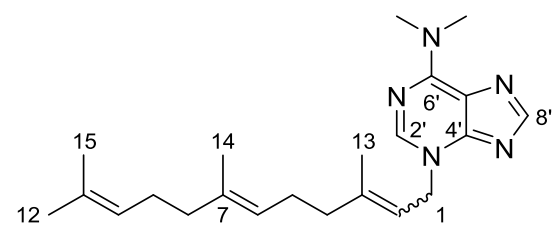

\section{$N, N$-Dimethyl-3-((6E)-3,7,11-trimethyldodeca-2,6,10-trien-1-yl)-3H-purin-6-amine}

(87); $\mathrm{R}_{f}=0.25(10 \% \mathrm{MeOH} / \mathrm{EA}) ; 3: 2 \mathrm{E} / \mathrm{Z}, \mathrm{NMR}$ data for major isomer: ${ }^{1} \mathrm{H}$ NMR (600 MHz, $\mathrm{CDCl}_{3}$ ): $\delta 8.01$ (s, 1H, H-8'), 7.95 (s, 1H, H-2'), 5.48 (t, J = 7.3 Hz, 1H, H-2), 5.09 - 5.03 (complex m, 2H, H-6 and H-10), 4.96 (d, $J=7.3 \mathrm{~Hz}, 2 \mathrm{H}, \mathrm{H}-1$ ), 3.92 (br s, 3H, $\mathrm{NCH}_{3 \mathrm{a}}$ or $\mathrm{NCH}_{3 \mathrm{~b}}$ ), 3.33 (br s, 3H, $\mathrm{NCH}_{3 \mathrm{a}}$ or $\mathrm{NCH}_{3 \mathrm{~b}}$ ), 2.17 - 2.08 (complex m, 4H, H-4 and H-5), $2.05-1.99$ (m, 2H, H-9), $1.99-1.94$ (m, 2H, H-8), 1.82 (s, 3H, H-13), 1.66 (s, $3 \mathrm{H}, \mathrm{H}-15), 1.58$ (s, 6H, H-12 and H-14); ${ }^{13} \mathrm{C} \mathrm{NMR} \mathrm{(150} \mathrm{MHz,} \mathrm{CDCl}_{3}$ ): $\delta 153.4$ (C, C-6'), 
152.4 (CH, C-8'), 150.5 (C, C-4'), 144.5 (C, C-3), 140.4 (CH, C-2'), 136.1 (C, C-7), 131.5 (C, C-11), 124.4 (CH, C-6), 123.3 (CH, C-10), 116.5 (CH, C-2), $46.9\left(\mathrm{CH}_{2}, \mathrm{C}-1\right)$, $39.9\left(\mathrm{CH}_{3}, \mathrm{NCH}_{3 \mathrm{a}}\right.$ or $\left.\mathrm{NCH}_{3 \mathrm{~b}}\right), 39.8\left(\mathrm{CH}_{2}, \mathrm{C}-8\right), 39.6\left(\mathrm{CH}_{2}, \mathrm{C}-4\right), 38.1\left(\mathrm{CH}_{3}, \mathrm{NCH}_{3 \mathrm{a}}\right.$ or $\left.\mathrm{NCH}_{3 \mathrm{~b}}\right)$, $26.8\left(\mathrm{CH}_{2}, \mathrm{C}-9\right), 26.2\left(\mathrm{CH}_{2}, \mathrm{C}-5\right), 25.8\left(\mathrm{CH}_{3}, \mathrm{C}-15\right), 17.8\left(\mathrm{CH}_{3}, \mathrm{C}-12\right), 16.8$ $\left(\mathrm{CH}_{3}, \mathrm{C}-13\right), 16.2\left(\mathrm{CH}_{3}, \mathrm{C}-14\right)$; IR (film from $\left.\mathrm{CH}_{2} \mathrm{Cl}_{2}\right): v_{\max } 2963,2924,2856,1608 \mathrm{~cm}^{-}$ 1; HRESIMS $m / z$ : $[\mathrm{M}+\mathrm{H}]^{+}$Calcd for $\mathrm{C}_{22} \mathrm{H}_{34} \mathrm{~N}_{5}$ 368.2809; Found $368.2818(\Delta=-2.42$ ppm); HRESIMS/MS (40 eV) m/z (\%): 164.0932 (100), 81.0704 (14).

Geranylgeranyl 6-(dimethylamino)purine; 6-(Dimethylamino)purine (0.14 mmol, $23.4 \mathrm{mg})$ and $\mathrm{K}_{2} \mathrm{CO}_{3}(0.16 \mathrm{mmol}, 22.7 \mathrm{mg})$ were stirred in DMF (1 mL) at room temperature for 15 minutes before dropwise addition of geranylgeranyl bromide $(0.15$ mmol, $51.5 \mathrm{mg}, 50.2 \mu \mathrm{L})$. The reaction was stirred for 44 hours, then poured onto $\mathrm{H}_{2} \mathrm{O}(3$ $\mathrm{mL})$ and extracted with EA $(3 \times 2 \mathrm{~mL})$. The combined extracts were washed with $\mathrm{H}_{2} \mathrm{O}(3$ $\times 2 \mathrm{~mL})$, then brine $(1 \times 2 \mathrm{~mL})$ and dried over anhydrous $\mathrm{MgSO}_{4}$. The solvent was removed under reduced pressure and the residue was purified by silica gel flash chromatography (1:2 EA/PE) to afford 89 and $\mathbf{9 0}$, the $2 Z(4.5 \mathrm{mg})$ and $2 E(6.7 \mathrm{mg})$ geometric isomers of $N-9$ geranylgeranyl 6-(dimethylamino)purine, both as white solids with a combined yield of $18 \%$ :

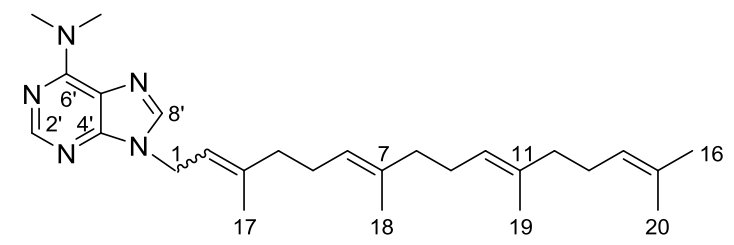

\section{$N, N$-Dimethyl-9-((2Z,6E,10E)-3,7,11,15-tetramethylhexadeca-2,6,10,14-tetraen-1-}

yl)-9H-purin-6-amine (89); $\mathrm{R}_{f}=0.21(1: 2 \mathrm{EA} / \mathrm{PE}) ;{ }^{1} \mathrm{H} \mathrm{NMR}\left(500 \mathrm{MHz}, \mathrm{CDCl}_{3}\right): \delta 8.35$ (s, 1H, H-2'), 7.70 (s, 1H, H-8'), 5.43 (t, $J=7.1 \mathrm{~Hz}, 1 \mathrm{H}, \mathrm{H}-2), 5.15-5.04$ (complex m, $3 \mathrm{H}, \mathrm{H}-6, \mathrm{H}-10$ and H-13), 4.75 (d, $J=7.1 \mathrm{~Hz}, 2 \mathrm{H}, \mathrm{H}-1$ ), 3.53 (br s, $6 \mathrm{H}, 2 \times \mathrm{NCH}_{3}$ ), 2.27 - $2.20\left(\mathrm{~m}, 2 \mathrm{H}, \mathrm{CH}_{2}\right), 2.18-2.10\left(\mathrm{~m}, 2 \mathrm{H}, \mathrm{CH}_{2}\right), 2.10-2.01$ (complex m, 4H, $2 \times \mathrm{CH}_{2}$ ), 2.01 - 1.91 (complex m, 4H, $2 \times \mathrm{CH}_{2}$ ), 1.79 (s, 3H, H-17), 1.67 (s, 3H, H-20), 1.61 (s, $\left.3 \mathrm{H}, \mathrm{CH}_{3}\right), 1.59$ (s, 6H, $\left.2 \times \mathrm{CH}_{3}\right) ;{ }^{13} \mathrm{C} \mathrm{NMR}\left(150 \mathrm{MHz}, \mathrm{CDCl}_{3}\right): \delta 155.1$ (C, C-6'), 152.5 (CH, C-2'), 150.5 (C, C-4'), 142.4 (C, C-3), 137.9 (CH, C-8'), 136.3 (C, C-7), 135.2 (C, C-11), 131.4 (C, C-15), 124.5 (CH, C-14), 124.2 (CH, C-10), 123.3 (CH, C-6), 118.7 $(\mathrm{CH}, \mathrm{C}-2), 41.0\left(\mathrm{CH}_{2}, \mathrm{C}-1\right), 39.9\left(\mathrm{CH}_{2}, \mathrm{C}-12\right), 39.8\left(\mathrm{CH}_{2}, \mathrm{C}-8\right), 32.3\left(\mathrm{CH}_{2}, \mathrm{C}-4\right), 26.9$ $\left(\mathrm{CH}_{2}, \mathrm{C}-13\right), 26.7\left(\mathrm{CH}_{2}, \mathrm{C}-9\right), 26.5\left(\mathrm{CH}_{2}, \mathrm{C}-5\right), 25.9\left(\mathrm{CH}_{3}, \mathrm{C}-20\right), 23.6\left(\mathrm{CH}_{3}, \mathrm{C}-17\right), 17.8$ $\left(\mathrm{CH}_{3}, \mathrm{C}-16\right), 16.20\left(\mathrm{CH}_{3}, \mathrm{C}-18\right.$ or C-19), $16.16\left(\mathrm{CH}_{3}, \mathrm{C}-18\right.$ or $\left.\mathrm{C}-19\right)$; IR (film from 
$\mathrm{CH}_{2} \mathrm{Cl}_{2}$ ): $v_{\max } 3043,2921,2854,1590 \mathrm{~cm}^{-1}$; HRESIMS m/z: [M+H] $]^{+}$Calcd for $\mathrm{C}_{27} \mathrm{H}_{42} \mathrm{~N}_{5}$ 436.3435; Found 436.3430 ( $\Delta=1.06$ ppm); HRESIMS/MS (40 eV) $\mathrm{m} / z(\%): 164.0912$ (100).

$N, N$-Dimethyl-9-((2E,6E,10E)-3,7,11,15-tetramethylhexadeca-2,6,10,14-tetraen-1yl)-9H-purin-6-amine (90); $\mathrm{R}_{f}=0.18(1: 2 \mathrm{EA} / \mathrm{PE}) ;{ }^{1} \mathrm{H} \mathrm{NMR}\left(500 \mathrm{MHz}, \mathrm{CDCl}_{3}\right): \delta 8.36$ (s, 1H, H-2'), 7.70 (s, 1H, H-8'), 5.43 (t, $J=7.0 \mathrm{~Hz}, 1 \mathrm{H}, \mathrm{H}-2), 5.12$ - 5.04 (complex m, 3H, H-6, H-10 and H-14), 4.75 (d, $J=7.1 \mathrm{~Hz}, 2 \mathrm{H}, \mathrm{H}-1$ ), 3.56 (br s, 6H, $2 \times \mathrm{NCH}_{3}$ ), 2.15 - 2.08 (complex m, 4H, $2 \times \mathrm{CH}_{2}$ ), $2.08-2.01$ (complex m, 4H, $2 \times \mathrm{CH}_{2}$ ), $1.99-1.93$ (complex m, 4H, $2 \times \mathrm{CH}_{2}$ ), 1.80 (s, 3H, H-17), 1.67 (s, 3H, $\left.\mathrm{CH}_{3}\right), 1.59$ (s, 3H, $\left.\mathrm{CH}_{3}\right), 1.58$ (s, 6H, $\left.2 \times \mathrm{CH}_{3}\right) ;{ }^{13} \mathrm{C} \mathrm{NMR}\left(150 \mathrm{MHz}, \mathrm{CDCl}_{3}\right): \delta 155.1$ (C, C-6'), $152.5(\mathrm{CH}, \mathrm{C}-2$ ') 150.5 (C, C-4'), 142.5 (C, C-3), 137.9 (CH, C-8'), 135.9 (C, C-7), 135.12 (C, C-11), 131.4 (C, C-15), 124.5 (CH, C-14), 124.2 (CH, C-10), 123.5 (CH, C-6), 117.9 (CH, C-2), 41.1 $\left(\mathrm{CH}_{2}, \mathrm{C}-1\right), 39.9\left(\mathrm{CH}_{2}, \mathrm{C}-12\right), 39.8\left(\mathrm{CH}_{2}, \mathrm{C}-8\right), 39.6\left(\mathrm{CH}_{2}, \mathrm{C}-4\right), 26.9\left(\mathrm{CH}_{2}, \mathrm{C}-13\right), 26.7$ $\left(\mathrm{CH}_{2}, \mathrm{C}-9\right), 26.3\left(\mathrm{CH}_{2}, \mathrm{C}-5\right), 25.8\left(\mathrm{CH}_{3}, \mathrm{C}-20\right), 17.8\left(\mathrm{CH}_{3}, \mathrm{C}-16\right), 16.7\left(\mathrm{CH}_{3}, \mathrm{C}-17\right), 16.2$ $\left(\mathrm{CH}_{3}, \mathrm{C}-18\right.$ or C-19), $16.14\left(\mathrm{CH}_{3}, \mathrm{C}-18\right.$ or C-19); IR (film from $\left.\mathrm{CH}_{2} \mathrm{Cl}_{2}\right): v_{\max } 3104,2962$, 2917, 2855, $1590 \mathrm{~cm}^{-1}$; HRESIMS $\mathrm{m} / z:[\mathrm{M}+\mathrm{H}]^{+}$Calcd for $\mathrm{C}_{27} \mathrm{H}_{42} \mathrm{~N}_{5}$ 436.3435; Found $436.3466(\Delta=-7.15 \mathrm{ppm})$; HRESIMS/MS (40 eV) $\mathrm{m} / \mathrm{z}(\%): 164.0873$ (100).

Geranyl 6-chloropurine; 6-Chloropurine ( $0.30 \mathrm{mmol}, 45.9 \mathrm{mg})$ and $\mathrm{K}_{2} \mathrm{CO}_{3}(0.62$ mmol, $85.6 \mathrm{mg}$ ) were stirred in DMF (1 mL) at room temperature for five minutes before dropwise addition of geranyl bromide $(0.33 \mathrm{mmol}, 71.8 \mathrm{mg}, 65.6 \mu \mathrm{L})$. The reaction was stirred for 21 hours, then poured onto $\mathrm{H}_{2} \mathrm{O}(3 \mathrm{~mL})$ and extracted with $\mathrm{EA}(3 \times 2 \mathrm{~mL})$. The combined extracts were washed with $\mathrm{H}_{2} \mathrm{O}(3 \times 2 \mathrm{~mL})$, then brine $(1 \times 2 \mathrm{~mL})$ and dried over anhydrous $\mathrm{MgSO}_{4}$. The dried, brown residue was purified by silica gel flash chromatography (2:3 EA/PE) to afford 94 and 95, the $N-7$ (17.2 mg, 20\%) and N-9 (39.4 $\mathrm{mg}, 46 \%)$ geranylated regioisomers as colourless oils:

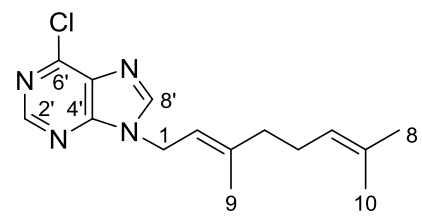

(E)-6-Chloro-9-(3,7-dimethylocta-2,6-dien-1-yl)-9H-purine (95); $\mathbf{R}_{f}=0.48$ (2:3 EA/PE); ${ }^{1} \mathrm{H}$ NMR (300 MHz, $\left.\mathrm{CDCl}_{3}\right): \delta 8.72$ (s, 1H, H-2'), 8.07 (s, 1H, H-8'), 5.42 (t, J $=7.2 \mathrm{~Hz}, 1 \mathrm{H}, \mathrm{H}-2), 5.05-4.97$ (m, 1H, H-6), 4.84 (d, J = $7.3 \mathrm{~Hz}, 2 \mathrm{H}, \mathrm{H}-1), 2.09$ (s, 4H, H-4 and H-5), 1.81 (s, 3H, H-9), 1.64 (s, 3H, H-10), 1.55 (s, 3H, H-8); ${ }^{13} \mathrm{C}$ NMR (150 
MHz, $\mathrm{CDCl}_{3}$ ): $\delta 151.9$ (CH, C-2'), 151.8 (C, C-6'), 150.9 (C, C-4'), 144.8 (CH, C-8'), 144.1 (C, C-3), 132.4 (C, C-5'), 131.8 (C, C-7), 123.4 (CH, C-7), 116.7 (CH, C-2), 41.9 $\left(\mathrm{CH}_{2}, \mathrm{C}-1\right), 39.5\left(\mathrm{CH}_{2}, \mathrm{C}-4\right), 26.1\left(\mathrm{CH}_{2}, \mathrm{C}-5\right), 25.8\left(\mathrm{CH}_{3}, \mathrm{C}-10\right), 17.8\left(\mathrm{CH}_{3}, \mathrm{C}-8\right), 16.7$ $\left(\mathrm{CH}_{3}, \mathrm{C}-9\right.$ ); IR (film from $\mathrm{CH}_{2} \mathrm{Cl}_{2}$ ): $v_{\max } 3064,2966,2916,2855,1556 \mathrm{~cm}^{-1}$; HRESIMS $m / z:[\mathrm{M}+\mathrm{H}]^{+}$Calcd for $\mathrm{C}_{15} \mathrm{H}_{20} \mathrm{ClN}_{4}$ 291.1371; Found 291.1371 ( $\left.\Delta=0.13 \mathrm{ppm}\right)$; HRESIMS/MS (40 eV) m/z (\%): 157.0074 (22), 155.0105 (57), 119.0346 (100).

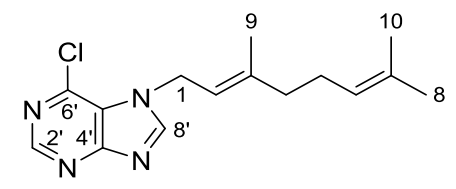

(E)-6-Chloro-7-(3,7-dimethylocta-2,6-dien-1-yl)-7H-purine (94); $\mathbf{R}_{f}=0.16(2: 3$ EA/PE); ${ }^{1} \mathrm{H}$ NMR (300 MHz, $\left.\mathrm{CDCl}_{3}\right): \delta 8.85$ (s, 1H, H-2'), 8.23 (s, 1H, H-8'), 5.43 (t, J $=6.8 \mathrm{~Hz}, 1 \mathrm{H}, \mathrm{H}-2), 5.07(\mathrm{~d}, J=7.0 \mathrm{~Hz}, 2 \mathrm{H}, \mathrm{H}-1), 5.05-5.00(\mathrm{~m}, 1 \mathrm{H}, \mathrm{H}-2), 2.13(\mathrm{~s}, 4 \mathrm{H}$, H-4 and H-5), 1.80 (s, 3H, H-9), 1.66 (s, 3H, H-10), 1.58 (s, 3H, H-8); ${ }^{13} \mathrm{C}$ NMR (150 $\left.\mathrm{MHz}^{\mathrm{CDCl}} \mathrm{CD}_{3}\right): \delta 162.2$ (C, C-6'), 152.5 (CH, C-2'), 148.4 (CH, C-8'), 144.2 (C, C-3), 143.3 (C, C-4'), 132.6 (C, C-7), 123.3 (CH, C-6), 122.7 (C, C-5'), 117.1 (CH, C-2), 45.4 $\left(\mathrm{CH}_{2}, \mathrm{C}-1\right), 39.5\left(\mathrm{CH}_{2}, \mathrm{C}-4\right), 26.1\left(\mathrm{CH}_{2}, \mathrm{C}-5\right), 25.8\left(\mathrm{CH}_{3}, \mathrm{C}-10\right), 17.9\left(\mathrm{CH}_{3}, \mathrm{C}-8\right), 16.8$ $\left(\mathrm{CH}_{3}, \mathrm{C}-9\right)$ ) IR (film from $\mathrm{CH}_{2} \mathrm{Cl}_{2}$ ): $v_{\max }$ 3102, 3065, 2967, 2915, 2854, $1560 \mathrm{~cm}^{-1}$; HRESIMS $m / z:[\mathrm{M}+\mathrm{H}]^{+}$Calcd for $\mathrm{C}_{15} \mathrm{H}_{20} \mathrm{ClN}_{4}$ 291.1371; Found $291.1365(\Delta=2.11$ ppm); HRESIMS/MS (40 eV) m/z (\%): 157.0062 (100), 155.0081 (40).

Farnesyl 6-chloropurine; 6-Chloropurine $(0.31 \mathrm{mmol}, 48.5 \mathrm{mg})$ and $\mathrm{K}_{2} \mathrm{CO}_{3}(0.6$ mmol, $83 \mathrm{mg}$ ) were stirred in DMF $(2 \mathrm{~mL})$ at $50{ }^{\circ} \mathrm{C}$ for 10 minutes before dropwise addition of farnesyl bromide $(0.33 \mathrm{mmol}, 94.0 \mathrm{mg}, 89.6 \mu \mathrm{L})$. The reaction was stirred for 24 hours, then $\mathrm{H}_{2} \mathrm{O}(6 \mathrm{~mL})$ was added and the resulting mixture was extracted with PE (3 $\times 3 \mathrm{~mL}$ ). The combined extracts were dried under reduced pressure and the resulting dark brown oil was purified by silica gel flash chromatography (1:2 and then 1:1 EA/PE) to yield 97 and 96, the $N-9(47.4 \mathrm{mg}, 42.6 \%)$ and $N-7(21.3 \mathrm{mg}, 19 \%)$ farnesylated regioisomers as colourless oils: 


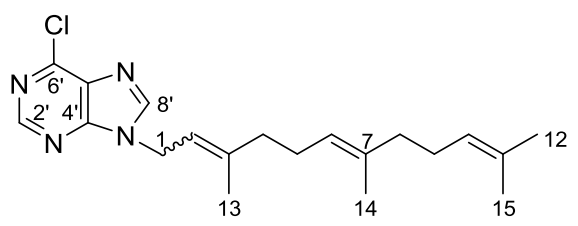

6-Chloro-9-((6E)-3,7,11-trimethyldodeca-2,6,10-trien-1-yl)-9H-purine $(97) ; \mathrm{R}_{f}=$ 0.24 (1:2 EA/PE); 2:1 E/Z, NMR data for major isomer: ${ }^{1} \mathrm{H}$ NMR $\left(600 \mathrm{MHz}, \mathrm{CDCl}_{3}\right): \delta$ 8.72 (s, 1H, H-2'), 8.08 (s, 1H, H-8'), 5.42 (t, $J=7.2 \mathrm{~Hz}, 1 \mathrm{H}, \mathrm{H}-2$ ), 5.06 - 5.00 (complex m, 2H, H-6 and H-10), 4.85 (d, J=7.3 Hz, 2H, H-1), $2.13-2.07$ (complex m, 4H, $2 \times$ $\mathrm{CH}_{2}$ ), $2.02-1.96\left(\mathrm{~m}, 2 \mathrm{H}, \mathrm{CH}_{2}\right), 1.95-1.90$ (m, 2H, $\mathrm{CH}_{2}$ ), 1.82 (s, 3H, H-13), 1.63 (s, $3 \mathrm{H}, \mathrm{H}-15), 1.55$ (s, 6H, H-12 and H-14); ${ }^{13} \mathrm{C} \mathrm{NMR}$ (150 MHz, $\mathrm{CDCl}_{3}$ ): $\delta 152.0(\mathrm{C}, \mathrm{C}-2$ ') , 151.8 (C, C-6'), 151.0 (C, C-4'), 144.9 (C, C-8'), 144.1 (C, C-3), 136.0 (C, C-7), 132.3 (C, C-5'), 131.5 (C, C-11), 124.3 (CH, C-10), 123.3 (CH, C-6), 116.6 (CH, C-2), 41.9 $\left(\mathrm{CH}_{2}, \mathrm{C}-1\right), 39.8\left(\mathrm{CH}_{2}, \mathrm{C}-8\right), 39.5\left(\mathrm{CH}_{2}, \mathrm{C}-4\right), 26.8\left(\mathrm{CH}_{2}, \mathrm{C}-9\right), 26.2\left(\mathrm{CH}_{2}, \mathrm{C}-5\right), 25.8$ $\left(\mathrm{CH}_{3}, \mathrm{C}-15\right), 17.8\left(\mathrm{CH}_{3}, \mathrm{C}-12\right), 16.8\left(\mathrm{CH}_{3}, \mathrm{C}-13\right), 16.2\left(\mathrm{CH}_{3}, \mathrm{C}-14\right)$; IR (film from $\mathrm{CH}_{2} \mathrm{Cl}_{2}$ ): $v_{\max } 3115,2969,2930 \mathrm{~cm}^{-1}$; HRESIMS $\mathrm{m} / z$ : $[\mathrm{M}+\mathrm{H}]^{+}$Calcd for $\mathrm{C}_{20} \mathrm{H}_{28} \mathrm{ClN}_{4}$ 359.1997; Found 359.1993 ( $\Delta=1.13 \mathrm{ppm})$; HRESIMS/MS $m / z$ (\%): 157.0073 (40), 155.0103 (100), 119.0343 (47), 81.0697 (47), 79.0539 (8).

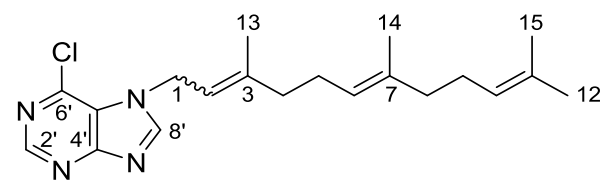

6-Chloro-7-((2E,6E)-3,7,11-trimethyldodeca-2,6,10-trien-1-yl)-9H-purine (96); $\mathrm{R}_{f}=$ 0.20 (1:1 EA/PE); E/Z 3:2, NMR data for major isomer: ${ }^{1} \mathrm{H} \mathrm{NMR}\left(600 \mathrm{MHz}, \mathrm{CDCl}_{3}\right): \delta$ 8.86 (s, 1H, H-2'), 8.23 (s, 1H, H-8'), 5.44 (t, $J=7.0$ Hz, 1H, H-2), 5.08 (d, J = 7.1 Hz, 2H, H-1), 5.07 - 5.04 (complex m, 2H, H-6 and H-10), $2.18-2.09$ (complex m, 4H, $2 \times$ $\mathrm{CH}_{2}$ ), $2.05-1.99$ (m, 2H, $\mathrm{CH}_{2}$ ), 1.98 - 1.93 (m, 2H, $\mathrm{CH}_{2}$ ), 1.82 (s, 3H, H-13), 1.65 (s, $\left.3 \mathrm{H}, \mathrm{CH}_{3}\right), 1.58\left(\mathrm{~s}, 6 \mathrm{H}, 2 \times \mathrm{CH}_{3}\right) ;{ }^{13} \mathrm{C} \mathrm{NMR}\left(150 \mathrm{MHz}, \mathrm{CDCl}_{3}\right): \delta 162.0(\mathrm{C}, \mathrm{C}-6$ '), 152.4 (CH, C-2'), 148.5 (CH, C-8'), 144.2 (C, C-3), 143.3 (C, C-4'), 136.2 (C, C-7), 131.5 (C, C-11), 124.2 (CH, C-10), $123.2(\mathrm{CH}, \mathrm{C}-6), 117.0(\mathrm{CH}, \mathrm{C}-2), 45.4\left(\mathrm{CH}_{2}, \mathrm{C}-1\right), 39.8\left(\mathrm{CH}_{2}\right.$, C-8), $39.5\left(\mathrm{CH}_{2}, \mathrm{C}-4\right), 26.8\left(\mathrm{CH}_{2}, \mathrm{C}-9\right), 26.2\left(\mathrm{CH}_{2}, \mathrm{C}-5\right), 25.8\left(\mathrm{CH}_{3}, \mathrm{C}-15\right), 17.8\left(\mathrm{CH}_{3}\right.$, C-12), $16.9\left(\mathrm{CH}_{3}, \mathrm{C}-13\right), 16.2\left(\mathrm{CH}_{3}, \mathrm{C}-14\right)$; IR (film from $\left.\mathrm{CH}_{2} \mathrm{Cl}_{2}\right): v_{\max } 3053,2981 \mathrm{~cm}^{-}$ 1; HRESIMS $m / z:[\mathrm{M}+\mathrm{H}]^{+}$Calcd for $\mathrm{C}_{20} \mathrm{H}_{28} \mathrm{ClN}_{4}$ 359.1997; Found $359.2002(\Delta=-1.39$ ppm); HRESIMS/MS (40 eV) m/z (\%): 157.0001 (27), 155.0031 (66), 119.0287 (31), 95.0806 (23), 93.0651 (13), 81.0660 (100), 79.0539 (15). 
Geranylgeranyl 6-chloropurine; 6-Chloropurine (0.30 mmol, $45.6 \mathrm{mg})$ and $\mathrm{K}_{2} \mathrm{CO}_{3}$ (0.35 mmol, $48.2 \mathrm{mg}$ ) were stirred in DMF (1 mL) for 15 minutes before dropwise addition of geranylgeranyl bromide $(0.32 \mathrm{mmol}, 111 \mathrm{mg}, 108.6 \mu \mathrm{L})$ over two minutes. The reaction was stirred for 27 hours, then poured onto $\mathrm{H}_{2} \mathrm{O}(3 \mathrm{~mL})$ and extracted with EA $(3 \times 2 \mathrm{~mL})$. The combined extracts were washed with $\mathrm{H}_{2} \mathrm{O}(3 \times 2 \mathrm{~mL})$, then brine $(1$ $\times 2 \mathrm{~mL}$ ) and dried over $\mathrm{MgSO}_{4}$. The solvent was removed under reduced pressure and the residue was purified by silica gel flash chromatography (1:4 and then $2: 3 \mathrm{EA} / \mathrm{PE})$ to yield 98 and 99, the $2 Z(16.8 \mathrm{mg}, 13 \%)$ and $2 E(15.2 \mathrm{mg}, 12 \%)$ isomers of $N-7$ geranylgeranyl 6-chloropurine and $\mathbf{1 0 0}$, the $2 E$ isomer of $N-9$ geranylgeranyl 6chloropurine (19.4 mg, 15\%), all as colourless oils:

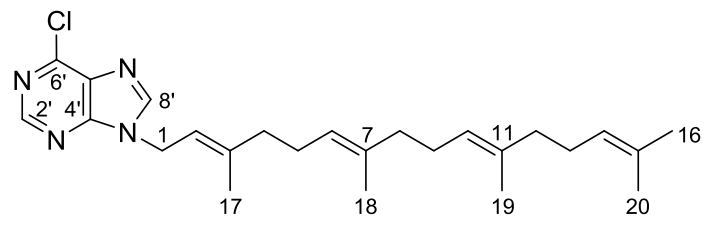

\section{6-Chloro-9-((2E,6E,10E)-3,7,11,15-tetramethylhexadeca-2,6,10,14-tetraen-1-yl)-} $9 H$-purine (100); $\mathrm{R}_{f}=0.14(1: 4 \mathrm{EA} / \mathrm{PE}) ;{ }^{1} \mathrm{H} \mathrm{NMR}\left(500 \mathrm{MHz}, \mathrm{CDCl}_{3}\right): \delta 8.76(\mathrm{~s}, 1 \mathrm{H}, \mathrm{H}$ 2'), 8.09 (s, 1H, H-8'), 5.45 (t, $J=7.3 \mathrm{~Hz}, 1 \mathrm{H}, \mathrm{H}-2$ ), 5.11 - 5.05 (complex m, 3H, H-6, $\mathrm{H}-10$ and $\mathrm{H}-14$ ), 4.87 (d, $J=7.3 \mathrm{~Hz}, 2 \mathrm{H}, \mathrm{H}-1$ ), $2.15-2.10$ (complex m, 4H, $2 \times \mathrm{CH}_{2}$ ), 2.07 - 2.01 (complex m, 4H, $2 \times \mathrm{CH}_{2}$ ), $1.99-1.93$ (complex m, 4H, $2 \times \mathrm{CH}_{2}$ ), 1.84 (s, $3 \mathrm{H}, \mathrm{H}-17), 1.67$ (s, 3H, H-20), 1.59 (s, 9H, $\left.3 \times \mathrm{CH}_{3}\right) ;{ }^{13} \mathrm{C} \mathrm{NMR}\left(150 \mathrm{MHz}, \mathrm{CDCl}_{3}\right): \delta$ 153.3 (C, C-2'), 152.0 (C, C-6'), 151.0 (C, C-4'), 144.9 (C, C-8'), 144.2 (C, C-3), 136.1 (C, C-7), 135.2 (C, C-11), 131.5 (C, C-15), 124.5 (CH, C-14), 124.1 (CH, C-10), 123.3 (CH, C-6), 116.7 (CH, C-2), $41.9\left(\mathrm{CH}_{2}, \mathrm{C}-1\right), 39.9\left(\mathrm{CH}_{2}, \mathrm{C}-12\right), 39.8\left(\mathrm{CH}_{2}, \mathrm{C}-\mathrm{C}-8\right), 39.6$ $\left(\mathrm{CH}_{2}, \mathrm{C}-4\right), 26.9$ (C-13), 26.7 (C-9), 26.2 (C-5), $25.9\left(\mathrm{CH}_{3}, \mathrm{C}-20\right), 17.8\left(\mathrm{CH}_{3}, \mathrm{C}-16\right), 16.8$ $\left(\mathrm{CH}_{3}, \mathrm{C}-17\right), 16.21\left(\mathrm{CH}_{3}, \mathrm{C}-18\right.$ or C-19), $16.16\left(\mathrm{CH}_{3}, \mathrm{C}-18\right.$ or C-19); HRESIMS $m / z$ : $[\mathrm{M}+\mathrm{H}]^{+}$Calcd for $\mathrm{C}_{25} \mathrm{H}_{36} \mathrm{ClN}_{4}$ 427.2623; Found 427.2614 ( $\left.\Delta=2.02 \mathrm{ppm}\right)$; HRESIMS/MS (40 eV) m/z (\%): 157.0068 (39), 155.0098 (100), 119.0334 (21).

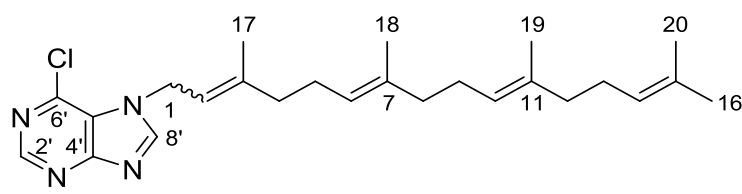

\section{6-Chloro-7-((2E,6E,10E)-3,7,11,15-tetramethylhexadeca-2,6,10,14-tetraen-1-yl)-}

7H-purine (99); $\mathrm{R}_{f}=0.28(2: 3 \mathrm{EA} / \mathrm{PE}) ;{ }^{1} \mathrm{H} \mathrm{NMR}\left(500 \mathrm{MHz}, \mathrm{CDCl}_{3}\right): \delta 8.86(\mathrm{~s}, 1 \mathrm{H}, \mathrm{H}$ 2'), 8.24 (s, 1H, H-8'), 5.44 (t, $J=7.0 \mathrm{~Hz}, 1 \mathrm{H}, \mathrm{H}-2$ ), $5.10-5.03$ (complex m, 5H, H-1, 
H-6, H-10 and H-14), $2.17-2.10$ (complex m, 4H, $2 \times \mathrm{CH}_{2}$ ), 2.08 - 2.01 (complex m, $4 \mathrm{H}, 2 \times \mathrm{CH}_{2}$ ), $2.01-1.92$ (complex m, 4H, $2 \times \mathrm{CH}_{2}$ ), 1.82 (s, 3H, H-17), 1.66 (s, 3H, H20), 1.58 (s, 9H, $\left.3 \times \mathrm{CH}_{3}\right) ;{ }^{13} \mathrm{C}$ NMR (150 MHz, $\left.\mathrm{CDCl}_{3}\right): \delta 162.1$ (C, C-6'), $152.5(\mathrm{CH}$, C-2'), 148.4 (CH, C-8'), 144.3 (C, C-3), 136.2 (C, C-7), 135.2 (C, C-11), 131.4 (C, C15), 124.4 (CH, C-14), 124.11 (CH, C-10), 123.2 (CH, C-6), $117.0(\mathrm{CH}, \mathrm{C}-2), 45.4\left(\mathrm{CH}_{2}\right.$, C-1), $39.8\left(\mathrm{CH}_{2}, \mathrm{C}-12\right), 39.8\left(\mathrm{CH}_{2}, \mathrm{C}-8\right), 39.6\left(\mathrm{CH}_{2}, \mathrm{C}-4\right), 26.9\left(\mathrm{CH}_{2}, \mathrm{C}-13\right), 26.7\left(\mathrm{CH}_{2}\right.$, C-9), $26.2\left(\mathrm{CH}_{2}, \mathrm{C}-5\right), 25.8\left(\mathrm{CH}_{3}, \mathrm{C}-20\right), 17.8\left(\mathrm{CH}_{3}, \mathrm{C}-16\right), 16.9\left(\mathrm{CH}_{3}, \mathrm{C}-17\right), 16.2\left(\mathrm{CH}_{3}\right.$, C-18 or C-19), $16.1\left(\mathrm{CH}_{3}, \mathrm{C}-18\right.$ or C-19); IR (film from $\left.\mathrm{CH}_{2} \mathrm{Cl}_{2}\right)$ : v $v_{\max } 3053,2971,2931$ $\mathrm{cm}^{-1}$.

\section{6-Chloro-7-((2Z,6E,10E)-3,7,11,15-tetramethylhexadeca-2,6,10,14-tetraen-1-yl)-}

7H-purine (98); $\mathrm{R}_{f}=0.21$ (2:3 PE/EA); ${ }^{1} \mathrm{H} \mathrm{NMR}\left(500 \mathrm{MHz}, \mathrm{CDCl}_{3}\right): \delta 8.87(\mathrm{~s}, 1 \mathrm{H}, \mathrm{H}$ 2'), 8.23 (s, 1H, H-8'), 5.45 (t, $J=7.1 \mathrm{~Hz}, 1 \mathrm{H}, \mathrm{H}-2$ ), $5.15-5.08$ (complex m, 3H, H-6, $\mathrm{H}-10$ and H-14), 5.07 (d, J = 7.1 Hz, 2H, H-1), $2.28-2.21\left(\mathrm{~m}, 2 \mathrm{H}, \mathrm{CH}_{2}\right), 2.21-2.13$ (m, $2 \mathrm{H}, \mathrm{CH}_{2}$ ), $2.10-2.02$ (complex m, 4H, $2 \times \mathrm{CH}_{2}$ ), $2.02-1.93$ (complex m, 4H, $2 \times \mathrm{CH}_{2}$ ), 1.84 (s, 3H, H-17), 1.67 (s, 3H, H-20), 1.62 (s, 3H, $\left.\mathrm{CH}_{3}\right), 1.59$ (s, 6H, $\left.2 \times \mathrm{CH}_{3}\right) ;{ }^{13} \mathrm{C} \mathrm{NMR}$ (150 MHz, $\left.\mathrm{CDCl}_{3}\right): \delta 162.1$ (C, C-6'), 152.5 (CH, C-2'), 148.4 (CH, C-8'), 144.1 (C, C3), 136.8 (C, C-7), 135.4 (C, C-11), 131.3 (C, C-15), 124.4 (CH, C-14), 124.1 (CH, C10), 122.8 (CH, C-6), $117.9(\mathrm{CH}, \mathrm{C}-2), 45.2\left(\mathrm{CH}_{2}, \mathrm{C}-1\right), 39.9\left(\mathrm{CH}_{2}, \mathrm{C}-12\right), 39.8\left(\mathrm{CH}_{2}, \mathrm{C}-\right.$ 8), $32.5\left(\mathrm{CH}_{3}, \mathrm{C}-4\right), 26.9\left(\mathrm{CH}_{2}, \mathrm{C}-13\right), 26.7\left(\mathrm{CH}_{2}, \mathrm{C}-9\right), 26.3\left(\mathrm{CH}_{2}, \mathrm{C}-5\right), 25.8\left(\mathrm{CH}_{3}, \mathrm{C}-\right.$ 20), $23.6\left(\mathrm{CH}_{3}, \mathrm{C}-17\right), 17.8\left(\mathrm{CH}_{3}, \mathrm{C}-16\right), 16.18\left(\mathrm{CH}_{3}, \mathrm{C}-18\right.$ or C-19), $16.16\left(\mathrm{CH}_{3}, \mathrm{C}-18\right.$ or C-19); IR (film from $\mathrm{CH}_{2} \mathrm{Cl}_{2}$ ): $v_{\max } 3055,2973,2932 \mathrm{~cm}^{-1}$.

Geranyl xanthine; Xanthine $(2.1 \mathrm{mmol}, 311.5 \mathrm{mg})$ and $\mathrm{K}_{2} \mathrm{CO}_{3}(2.0 \mathrm{mmol}, 272.2 \mathrm{mg})$ were stirred in DMF (3 mL) for 10 minutes before dropwise addition of geranyl bromide ( $2.4 \mathrm{mmol}, 521 \mathrm{mg}, 476 \mu \mathrm{L}$ ). The reaction was stirred for 48 hours, then filtered and $\mathrm{H}_{2} \mathrm{O}$ $(6 \mathrm{~mL})$ was added to the filtrate. The solvents were removed under reduced pressure and the residue was purified by flash chromatography (1:2 EA/PE) to afford 109 as a colourless oil (44.6 mg, 9\%): 


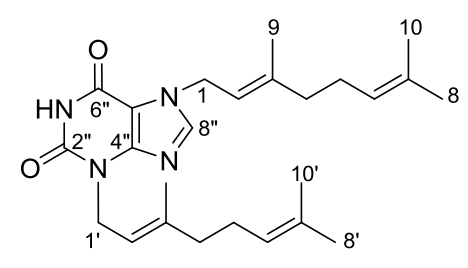

3,7-bis((E)-3,7-Dimethylocta-2,6-dien-1-yl)-3,7-dihydro-1H-purine-2,6-dione (109); $\mathrm{R}_{f}=0.15(1: 2 \mathrm{EA} / \mathrm{PE}) ;{ }^{1} \mathrm{H} \mathrm{NMR}\left(600 \mathrm{MHz}, \mathrm{CDCl}_{3}\right): \delta 8.10$ (br s, $\left.1 \mathrm{H}, \mathrm{NH}\right), 7.55$ (s, $J=$ $\left.2.8 \mathrm{~Hz}, 1 \mathrm{H}, \mathrm{H}-8^{\prime \prime}\right), 5.43$ (t, $\left.J=6.7 \mathrm{~Hz}, 1 \mathrm{H}, \mathrm{H}-2\right), 5.34$ (t, $J=6.4 \mathrm{~Hz}, 1 \mathrm{H}, \mathrm{H}-2$ '), 5.07 5.01 (complex m, 2H, H-6 and H-6'), 4.89 (d, $J=7.3 \mathrm{~Hz}, 2 \mathrm{H}, \mathrm{H}-1$ ), 4.66 (d, J = 6.9 Hz, 2H, H-1'), $2.15-2.09$ (complex m, 4H, $2 \times \mathrm{CH}_{2}$ ), $2.09-2.03\left(\mathrm{~m}, 2 \mathrm{H}, \mathrm{CH}_{2}\right), 2.02-1.96$ (m, 2H, CH2), 1.84 (s, 3H, H-9'), 1.77 (s, 3H, H-9), 1.68 (s, 3H, $\mathrm{CH}_{3}$ ), 1.63 (s, 3H, CH 3 ), 1.59 (s, 3H, $\mathrm{CH}_{3}$ ), 1.56 (s, 3H, $\left.\left.\mathrm{CH}_{3}\right) ;{ }^{13} \mathrm{C} \mathrm{NMR} \mathrm{(150} \mathrm{MHz,} \mathrm{CDCl}_{3}\right): \delta 154.7$ (C, C-6"), 150.62 (C, C-2” or C-4”), 150.58 (C, C-2” or C-4”), 143.8 (C, C-3), 141.1 (C, C-3'), 140.8 (CH, C-8”), 132.4 (C, C-7 or C-7'), 131.8 (C, C-7 or C-7'), 124.0 (CH, C-6 or C6'), 123.6 (CH, C-6 or C-6'), 118.0 (CH, C-2), 117.2 (CH, C-2'), 107.5 (C, C-5”), 44.7 $\left(\mathrm{CH}_{2}, \mathrm{C}-1\right), 40.9\left(\mathrm{CH}_{2}, \mathrm{C}-1^{\prime}\right), 39.7\left(\mathrm{CH}_{2}, \mathrm{C}-4\right.$ ') $39.6\left(\mathrm{CH}_{2}, \mathrm{C}-4\right), 26.5\left(\mathrm{CH}_{2}, \mathrm{C}-5\right.$ or C5'), $26.3\left(\mathrm{CH}_{2}, \mathrm{C}-5\right.$ or C-5'), $25.84\left(\mathrm{CH}_{3}, \mathrm{C}-10\right.$ or C-10'), $25.80\left(\mathrm{CH}_{3}, \mathrm{C}-10\right.$ or C-10'), $17.9\left(\mathrm{CH}_{3}, \mathrm{C}-8\right.$ or C-8'), $17.8\left(\mathrm{CH}_{3}, \mathrm{C}-8\right.$ or C-8'), $16.7\left(\mathrm{CH}_{3}, \mathrm{C}-9^{\prime}\right), 16.6\left(\mathrm{CH}_{3}, \mathrm{C}-9\right)$; IR (film from $\mathrm{CH}_{2} \mathrm{Cl}_{2}$ ): $v_{\max } 3423,3176,3115,3052,2967,2926,1679 \mathrm{~cm}^{-1} ;$ HRESIMS $\mathrm{m} / z$ : $[\mathrm{M}+\mathrm{H}]^{+}$Calcd for $\mathrm{C}_{25} \mathrm{H}_{37} \mathrm{~N}_{4} \mathrm{O}_{2}$ 425.2911; Found 425.2910 ( $\left.\Delta=0.32 \mathrm{ppm}\right)$; HRESIMS/MS (10 eV) m/z (\%): 289.1638 (70), 153.0395 (100).

Farnesyl xanthine; Xanthine ( $2.0 \mathrm{mmol}, 306.3 \mathrm{mg}$ ) and $\mathrm{K}_{2} \mathrm{CO}_{3}(3.04 \mathrm{mmol}, 420.3 \mathrm{mg}$ ) were stirred in DMF (3 mL) for 20 minutes at room temperature before dropwise addition of farnesyl bromide $(2.4 \mathrm{mmol}, 683.4 \mathrm{mg}, 650 \mu \mathrm{L})$ over 15 minutes. The reaction was stirred for 25 hours before pouring onto $\mathrm{H}_{2} \mathrm{O}(12 \mathrm{~mL})$ and extracting with EA $(3 \times 12$ $\mathrm{mL})$. The combined extracts were washed with $\mathrm{H}_{2} \mathrm{O}(3 \times 10 \mathrm{~mL})$, then brine $(1 \times 10 \mathrm{~mL})$ and dried over anhydrous $\mathrm{MgSO}_{4}$. The dried residue was purified by silica gel flash chromatography (1:4 and then 1:2 EA/PE) to afford difarnesylated xanthine as a mixture of $E$ and $Z$ isomers. Further purification by silica gel flash chromatography (1:2 EA/PE) was unsuccessful and $\mathbf{1 1 0}$ was isolated as a colourless oil (19.3 mg, 3\%): 


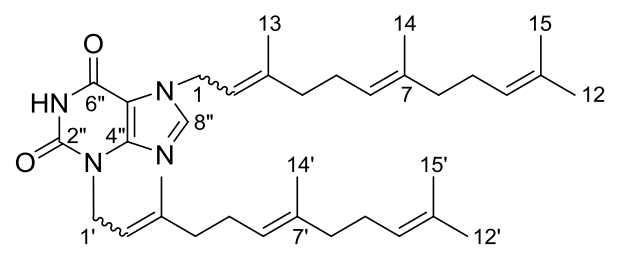

3,7-bis((6E)-3,7,11-Trimethyldodeca-2,6,10-trien-1-yl)-3,7-dihydro-1H-purine-2,6dione (110); $\mathrm{R}_{f}=0.25(1: 2 \mathrm{EA} / \mathrm{PE}) ; 3: 2 \mathrm{E} / \mathrm{Z}$, NMR data for major $2 E, 2{ }^{\prime} E$ isomer: ${ }^{1} \mathrm{H}$ NMR (600 MHz, $\mathrm{CDCl}_{3}$ ): $\delta 8.57$ (br s, 1H, NH), 7.54 (s, 1H, H-8”), 5.43 (t, J=6.6 Hz, 1H, H-2), 5.34 (t, $J=6.8 \mathrm{~Hz}, 1 \mathrm{H}, \mathrm{H}-2$ '), $5.12-5.02$ (complex m, 4H, $4 \times \mathrm{CH}), 4.89$ (d, $J=7.2 \mathrm{~Hz}, 2 \mathrm{H}, \mathrm{H}-1), 4.66$ (d, $J=6.9 \mathrm{~Hz}, 2 \mathrm{H}, \mathrm{H}-1$ '), $2.16-1.89$ (complex m, 16H, $8 \times$ $\mathrm{CH}_{2}$ ), 1.85 (s, 3H, H-9'), 1.78 (s, 3H, H-9), 1.66 (s, 6H, $2 \times \mathrm{CH}_{3}$ ), 1.58 (s, 9H, $3 \times \mathrm{CH}_{3}$ ), 1.55 (s, 3H, $\left.\mathrm{CH}_{3}\right) ;{ }^{13} \mathrm{C}$ NMR (150 MHz, $\left.\mathrm{CDCl}_{3}\right): \delta 154.9$ (C, C-6”), 150.7 (C, C-2" or C4”), 150.6 (C, C-2” or C-4”), 143.8 (C, C-3), 141.1 (C, C-3'), 140.8 (CH, C-8”), 136.0 (C, C-7 or C-7'), 135.4 (C, C-7 or C-7'), 131.5 (C, C-11 or C-11'), 131.4 (C, C-11 or C11'), 124.4 (CH, C-10 or C-10'), 124.3 (CH, C-10 or C-10'), 123.9 (CH, C-6 or C-6'), 123.4 (CH, C-6 or C-6'), 118.0 (CH, C-2), 117.2 (CH, C-2'), 107.5 (C, C-5”), 44.7 ( $\mathrm{CH}_{2}$, C-1), $40.8\left(\mathrm{CH}_{2}, \mathrm{C}-1\right.$ ') $39.79\left(\mathrm{CH}_{2}, \mathrm{C}-8\right.$ or C-8'), $39.78\left(\mathrm{CH}_{2}, \mathrm{C}-8\right.$ or C-8'), $39.7\left(\mathrm{CH}_{2}\right.$, C-4 or C-4'), 39.6 ( $\mathrm{CH}_{2}, \mathrm{C}-4$ or C-4'), $26.8\left(\mathrm{CH}_{2}, \mathrm{C}-9\right.$ or C-9'), $26.8\left(\mathrm{CH}_{2}, \mathrm{C}-9\right.$ or C-9'), $26.4\left(\mathrm{CH}_{2}, \mathrm{C}-5\right.$ or C-5'), $26.3\left(\mathrm{CH}_{2}, \mathrm{C}-5\right.$ or C-5'), $25.8\left(\mathrm{CH}_{3}, \mathrm{H}-15\right.$ or H-15'), $25.8\left(\mathrm{CH}_{3}\right.$, H-15 or H-15'), $17.82\left(\mathrm{CH}_{3}, \mathrm{C}-12\right.$ or C-12'), $17.81\left(\mathrm{CH}_{3}, \mathrm{C}-12\right.$ or C-12'), $16.74\left(\mathrm{CH}_{3}, \mathrm{C}-\right.$ 13 or C-13'), $16.67\left(\mathrm{CH}_{3}, \mathrm{C}-13\right.$ or C-13'), $16.2\left(\mathrm{CH}_{3}, \mathrm{C}-14\right.$ or C-14'), $16.1\left(\mathrm{CH}_{3}, \mathrm{C}-14\right.$ or C-14').

Geranyl 3-methylxanthine; 3-Methylxanthine $(0.17 \mathrm{mmol}, 28.0 \mathrm{mg})$ and $\mathrm{K}_{2} \mathrm{CO}_{3}$ $\mathrm{Na}_{2} \mathrm{CO}_{3}(1: 1,48.6 \mathrm{mg})$ were stirred in $\operatorname{DMF}(2 \mathrm{~mL})$ at $50{ }^{\circ} \mathrm{C}$ before dropwise addition of geranyl bromide $(0.36 \mathrm{mmol}, 77 \mathrm{mg}, 71 \mu \mathrm{L})$. The reaction was stirred for two days, then filtered and concentrated under reduced pressure. The resulting residue was suspended in DCM and filtered again. The filtrate was dried under reduced pressure and the white solid was purified by silica gel flash chromatography (1:9 to 1:0 EA/PE) and finally recrystallised from $\mathrm{PE}$ to afford $\mathbf{1 1 1}$ as an amorphous white powder (16.9 $\mathrm{mg}, \mathbf{5 \%}$ ): 


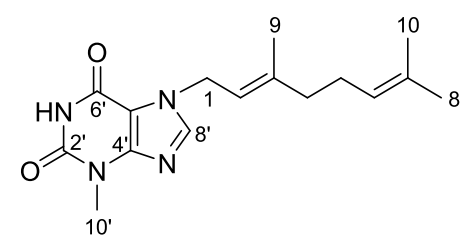

(E)-7-(3,7-Dimethylocta-2,6-dien-1-yl)-3-methyl-3,7-dihydro-1H-purine-2,6-dione (111); ${ }^{1} \mathrm{H}$ NMR (600 MHz, $\left.\mathrm{CDCl}_{3}\right): \delta 8.10$ (s, 1H, NH), 7.55 (s, 1H, H-8'), 5.43 (t, $J=$ $7.3 \mathrm{~Hz}, 1 \mathrm{H}, \mathrm{H}-2), 5.07-5.03$ (m, 1H, H-6), 4.90 (d, J=7.3 Hz, 2H, H-1), 3.55 (s, 3H, H10'), 2.16 - 2.08 (complex m, 4H, H-4 and H-5), 1.78 (s, 3H, H-9), 1.68 (s, 3H, H-10), 1.59 (s, 3H, H-8); ${ }^{13} \mathrm{C}$ NMR (150 MHz, $\left.\mathrm{CDCl}_{3}\right)$ : $\delta 154.5$ (C, C-6'), 151.0 (C, C-2'), 151.0 (C, C-4'), 143.9 (C, C-3), 140.8 (CH, C-8'), 132.4 (C, C-7), 123.5 (CH, H-6), 117.1 (CH, H-2), 107.4 (C, C-5'), $44.8\left(\mathrm{CH}_{2}, \mathrm{C}-1\right), 39.6\left(\mathrm{CH}_{2}, \mathrm{C}-4\right), 29.2\left(\mathrm{CH}_{3}, \mathrm{C}-10\right.$ '), $26.2\left(\mathrm{CH}_{2}\right.$, C-5), $25.9\left(\mathrm{CH}_{3}, \mathrm{C}-10\right), 17.9\left(\mathrm{CH}_{3}, \mathrm{C}-8\right), 16.6\left(\mathrm{CH}_{3}, \mathrm{C}-9\right)$ ) IR (film from $\left.\mathrm{CH}_{2} \mathrm{Cl}_{2}\right): v_{\max }$ 3121, 3021, 2964, 2916, 2826, $1678 \mathrm{~cm}^{-1}$; HRESIMS $m / z$ : $[\mathrm{M}+\mathrm{H}]^{+}$Calcd for $\mathrm{C}_{16} \mathrm{H}_{23} \mathrm{~N}_{4} \mathrm{O}_{2}$ 303.1816; Found $303.1812(\Delta=0.9 \mathrm{ppm})$; HRESIMS/MS (40 eV) $\mathrm{m} / \mathrm{z}(\%): 167.0538$ (100), 149.0431 (8), 124.0487 (17).

Farnesyl 3-methylxanthine; 3-Methylxanthine $(0.20 \mathrm{mmol}, 32.9 \mathrm{mg})$ and $\mathrm{K}_{2} \mathrm{CO}_{3}$ $(0.37 \mathrm{mmol}, 51.2 \mathrm{mg})$ were stirred in DMF $(2 \mathrm{~mL})$ for 5 minutes before dropwise addition of farnesyl bromide $(0.34 \mathrm{mmol}, 98 \mathrm{mg}, 93 \mu \mathrm{L})$. The reaction was stirred for 21 hours, then poured onto $\mathrm{H}_{2} \mathrm{O}(6 \mathrm{~mL})$ and extracted with $\mathrm{EA}(3 \times 6 \mathrm{~mL})$. The combined extracts were washed with $\mathrm{H}_{2} \mathrm{O}(3 \times 10 \mathrm{~mL})$, then brine $(1 \times 10 \mathrm{~mL})$ and dried over anhydrous $\mathrm{MgSO}_{4}$. The solvent was removed under reduced pressure and the residue was purified by silica gel flash chromatography (1:1 EA/PE) to afford 112 and $\mathbf{1 1 3}$, the $2 Z$ (4.6 $\mathrm{mg})$ and $2 E(33.1 \mathrm{mg})$ isomers of $\mathrm{N}-7$ farnesylated 3-methylxanthine as white solids with a combined yield of $51 \%$ :

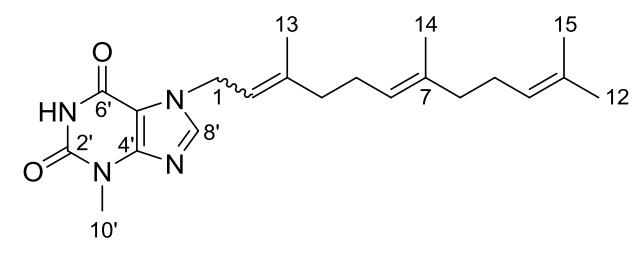

3-Methyl-7-((2Z,6E)-3,7,11-trimethyldodeca-2,6,10-trien-1-yl)-3,7-dihydro-1Hpurine-2,6-dione (112); $\mathrm{R}_{f}=0.20(1: 1 \mathrm{EA} / \mathrm{PE}) ;{ }^{1} \mathrm{H} \mathrm{NMR}\left(600 \mathrm{MHz}, \mathrm{CDCl}_{3}\right): \delta 8.10(\mathrm{~s}$, $1 \mathrm{H}, \mathrm{NH}), 7.55$ (s, 1H, H-8'), 5.44 (t, J=6.9 Hz, 1H, H-2), $5.11-5.05$ (complex m, 2H, H-6 and H-10), 4.88 (d, J=7.4 Hz, 2H, H-1), 3.54 (s, 3H, H-10'), $2.23-2.17$ (m, 2H, H4), $2.15-2.10$ (m, 2H, H-5), $2.07-2.01$ (m, 2H, H-9), $1.99-1.93$ (m, 2H, H-8), 1.81 (s, 
3H, H-13), 1.67 (s, 3H, H-15), 1.60 (s, 3H, H-12), 1.59 (s, 3H, H-14); ${ }^{13} \mathrm{C}$ NMR (150 $\mathrm{MHz}^{\mathrm{CDCl}} \mathrm{CD}_{3}$ ): $\delta 154.5$ (C, C-6'), 151.0 (C, C-2'), 150.9 (C, C-4'), 143.7 (C, C-3), 140.8 (CH, C-8'), 136.5 (C, C-7), 131.6 (C, C-11), 124.3 (CH, C-10), 123.1 (CH, C-6), 118.0 (CH, C-2), 107.4 (C, C-5'), $44.6\left(\mathrm{CH}_{2}, \mathrm{C}-1\right), 39.8\left(\mathrm{CH}_{2}, \mathrm{C}-8\right), 32.2\left(\mathrm{CH}_{2}, \mathrm{C}-4\right), 29.2\left(\mathrm{CH}_{3}\right.$, C-10'), $26.7\left(\mathrm{CH}_{2}, \mathrm{C}-9\right), 26.4\left(\mathrm{CH}_{2}, \mathrm{C}-5\right), 25.9\left(\mathrm{CH}_{3}, \mathrm{C}-15\right), 23.6\left(\mathrm{CH}_{3}, \mathrm{C}-13\right), 17.8\left(\mathrm{CH}_{3}\right.$, C-14), $16.2\left(\mathrm{CH}_{3}, \mathrm{C}-12\right)$; IR (film from $\left.\mathrm{CH}_{2} \mathrm{Cl}_{2}\right): v_{\max } 3400,3162,3035,2969,2930,1683$ $\mathrm{cm}^{-1}$.

\section{3-Methyl-7-((2E,6E)-3,7,11-trimethyldodeca-2,6,10-trien-1-yl)-3,7-dihydro-1 $H$ -}

purine-2,6-dione (113); $\mathrm{R}_{f}=0.18(1: 1, \mathrm{EA} / \mathrm{PE}) ; 2: 1 \mathrm{E} / \mathrm{Z}$, NMR data for major isomer: ${ }^{1} \mathrm{H}$ NMR (600 MHz, $\mathrm{CDCl}_{3}$ ): $\delta 8.89$ (s, 1H, NH), 7.56 (s, 1H, H-8'), 5.42 (t, J = $7.3 \mathrm{~Hz}$, 1H, H-2), 5.08 - 5.04 (complex m, 2H, H-6 and H-10), 4.90 (d, J=7.3 Hz, 2H, H-1), 3.54 (s, 3H, H-10'), 2.16 - 2.07 (complex m, 4H, H-4 and H-5), $2.06-1.99$ (m, 2H, H9), $1.98-1.93$ (m, 2H, H-8), 1.78 (s, 3H, H-13), 1.66 (s, 3H, H-15), 1.58 (s, 3H, H-12); ${ }^{13} \mathrm{C}$ NMR (150 MHz, CDCl 3 ): $\delta 154.9$ (C, C-6'), 151.3 (C, C-2'), 150.9 (C, C-4'), 143.9 (C, C-3), 140.8 (CH, C-8'), 136.0 (C, C-7), 131.5 (C, C-11), 124.3 (CH, C-10), 123.4 (CH, C-6), 117.1 (CH, C-2), 107.5 (C, C-5'), $44.7\left(\mathrm{CH}_{2}, \mathrm{C}-1\right), 39.8\left(\mathrm{CH}_{2}, \mathrm{C}-8\right), 39.6$ $\left(\mathrm{CH}_{2}, \mathrm{C}-4\right), 29.2\left(\mathrm{CH}_{3}, \mathrm{C}-10\right.$ ') $, 26.8\left(\mathrm{CH}_{2}, \mathrm{C}-9\right), 26.2\left(\mathrm{CH}_{2}, \mathrm{C}-5\right), 25.8\left(\mathrm{CH}_{3}, \mathrm{C}-15\right), 17.8$ $\left(\mathrm{CH}_{3}, \mathrm{C}-12\right), 16.7\left(\mathrm{CH}_{3}, \mathrm{C}-13\right), 16.2\left(\mathrm{CH}_{3}, \mathrm{C}-14\right)$; HRESIMS $m / z:[\mathrm{M}+\mathrm{H}]^{+}$Calcd for $\mathrm{C}_{21} \mathrm{H}_{31} \mathrm{~N}_{4} \mathrm{O}_{2}$ 371.2442; Found 371.2445 ( $\Delta=-0.95 \mathrm{ppm}$ ); HRESIMS/MS (40 eV) $\mathrm{m} / \mathrm{z}$ (\%): 167.0552 (100), 124.0506 (87).

Geranylgeranyl 3-methylxanthine; 3-Methylxanthine (0.25 mmol, $40.9 \mathrm{mg})$ and $\mathrm{K}_{2} \mathrm{CO}_{3}(0.38 \mathrm{mmol}, 52.5 \mathrm{mg})$ were stirred in DMF $(1 \mathrm{~mL})$ for 15 minutes before dropwise addition of geranylgeranyl bromide $(0.37 \mathrm{mmol}, 130 \mathrm{mg}, 127 \mu \mathrm{L})$ over 2 minutes. The reaction was stirred for 44 hours, then poured onto $\mathrm{H}_{2} \mathrm{O}(3 \mathrm{~mL})$ and extracted with EA (3 $\times 2 \mathrm{~mL})$. The combined extracts were washed with $\mathrm{H}_{2} \mathrm{O}(3 \times 2 \mathrm{~mL})$, then brine $(1 \times 2$ $\mathrm{mL}$ ) and dried over anhydrous $\mathrm{MgSO}_{4}$. After concentrating under reduced pressure, the residue was purified by silica gel flash chromatography (1:1 EA/PE) to afford 114 and 115 , the $2 Z(10.5 \mathrm{mg})$ and $2 E(22.1 \mathrm{mg}) \mathrm{N}-7$ geranylgeranylated products with a combined yield of $30 \%$ : 


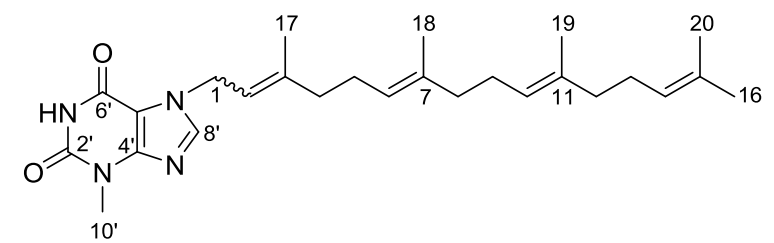

\section{3-Methyl-7-((2Z,6E,10E)-3,7,11,15-tetramethylhexadeca-2,6,10,14-tetraen-1-yl)-}

3,7-dihydro-1H-purine-2,6-dione (114); $\mathrm{R}_{f}=0.20$ (1:1, EA/PE); $1{ }^{1} \mathrm{H}$ NMR (600 MHz, $\left.\mathrm{CDCl}_{3}\right): \delta 8.45(\mathrm{~s}, 1 \mathrm{H}, \mathrm{NH}), 7.55\left(\mathrm{~s}, 1 \mathrm{H}, \mathrm{H}-8^{\prime}\right), 5.44$ (t, J = 7.1 Hz, 1H, H-2), $5.12-5.05$ (complex m, 3H, H-6, H-10 and H-15), 4.88 (d, $J=7.2$ Hz, 2H, H-1), 3.54 (s, 3H, H-10'), $2.20\left(\mathrm{t}, J=7.6 \mathrm{~Hz}, 2 \mathrm{H}, \mathrm{CH}_{2}\right), 2.15-2.09\left(\mathrm{~m}, 2 \mathrm{H}, \mathrm{CH}_{2}\right), 2.08-2.01$ (complex m, 4H, 2 $\left.\times \mathrm{CH}_{2}\right), 2.00-1.93\left(\right.$ complex m, 4H, $\left.2 \times \mathrm{CH}_{2}\right), 1.80(\mathrm{~s}, 3 \mathrm{H}, \mathrm{H}-17), 1.67\left(\mathrm{~s}, 3 \mathrm{H}, \mathrm{CH}_{3}\right)$, $1.60\left(\mathrm{~s}, 3 \mathrm{H}, \mathrm{CH}_{3}\right), 1.59\left(\mathrm{~s}, 6 \mathrm{H}, 2 \times \mathrm{CH}_{3}\right) ;{ }^{13} \mathrm{C} \mathrm{NMR}\left(150 \mathrm{MHz}, \mathrm{CDCl}_{3}\right): \delta 154.6(\mathrm{C}, \mathrm{C}-$ 6'), 151.1 (C, C-2'), 150.9 (C, C-4'), 143.7 (C, C-3), 140.8 (CH, C-8'), 136.5 (C, C-7), 135.3 (C, C-11), 131.4 (C, C-15), 124.5 (CH, C-14), 124.1 (CH, C-6), 123.1 (CH, C-10), 118.0 (CH, C-2), 107.4 (C, C-5'), $44.6\left(\mathrm{CH}_{2}, \mathrm{C}-1\right), 39.9\left(\mathrm{CH}_{2}, \mathrm{C}-12\right), 39.8\left(\mathrm{CH}_{2}, \mathrm{C}-8\right)$, $32.3\left(\mathrm{CH}_{2}, \mathrm{C}-4\right), 29.2\left(\mathrm{CH}_{3}, \mathrm{C}-10\right.$ '), $26.9\left(\mathrm{CH}_{2}, \mathrm{C}-13\right), 26.7\left(\mathrm{CH}_{2}, \mathrm{C}-9\right), 26.5\left(\mathrm{CH}_{2}, \mathrm{C}-5\right)$, $25.8\left(\mathrm{CH}_{3}, \mathrm{C}-20\right), 23.6\left(\mathrm{CH}_{3}, \mathrm{C}-17\right), 17.8\left(\mathrm{CH}_{3}, \mathrm{C}-16\right), 16.2\left(\mathrm{CH}_{3}, \mathrm{C}-18\right.$ or C-19), 16.2 $\left(\mathrm{CH}_{3}, \mathrm{C}-18\right.$ or C-19); IR (film from $\left.\mathrm{CH}_{2} \mathrm{Cl}_{2}\right)$ : $v_{\max } 3458,3159,2968,2924,2852 \mathrm{~cm}^{-1}$; HRESIMS $m / z$ : $[\mathrm{M}+\mathrm{H}]^{+}$Calcd for $\mathrm{C}_{26} \mathrm{H}_{39} \mathrm{~N}_{4} \mathrm{O}_{2} 439.3068$; Found $439.3036(\Delta=7.22$ ppm); HRESIMS/MS (40 eV) m/z (\%): 168.0565 (9), 167.0533 (100), 124.0494 (43).

\section{3-Methyl-7-((2E,6E,10E)-3,7,11,15-tetramethylhexadeca-2,6,10,14-tetraen-1-yl)-}

3,7-dihydro-1H-purine-2,6-dione (115); $\mathrm{R}_{f}=0.12$ (1:1 EA/PE); ${ }^{1} \mathrm{H}$ NMR $(500 \mathrm{MHz}$, $\left.\mathrm{CDCl}_{3}\right): \delta 8.94(\mathrm{~s}, 1 \mathrm{H}, \mathrm{NH}), 7.56\left(\mathrm{~s}, 1 \mathrm{H}, \mathrm{H}-8^{\prime}\right), 5.43$ (t, J=7.3 Hz, 1H, H-2), $5.12-5.04$ (complex m, 3H, H-6, H-10 and H-14), 4.90 (d, J=7.3 Hz, 2H, H-1), 3.54 (s, 3H, H-10'), $2.16-2.08$ (complex m, 4H, $2 \times \mathrm{CH}_{2}$ ), $2.07-2.00$ (complex m, 4H, $2 \times \mathrm{CH}_{2}$ ), $2.00-$ 1.93 (complex m, 4H, $2 \times \mathrm{CH}_{2}$ ), 1.78 (s, 3H, H-17), 1.66 (s, 3H, $\left.\mathrm{CH}_{3}\right), 1.59$ (s, 9H, $3 \times$ $\left.\mathrm{CH}_{3}\right) ;{ }^{13} \mathrm{C}$ NMR (150 MHz, $\mathrm{CDCl}_{3}$ ): $\delta 154.9$ (C, C-6'), 151.3 (C-2'), 150.9 (C-4'), 143.9 (C, C-3), 140.8 (CH, C-8'), 136.0 (C, C-7), 135.2 (C, C-11), 131.41 (C, C-15), 124.5 (CH, C-14), 124.2 (CH, C-6), 123.4 (CH, C-10), 117.1 (CH, C-2), 107.5 (C, C-5'), 44.8 $\left(\mathrm{CH}_{2}, \mathrm{C}-1\right), 39.84\left(\mathrm{CH}_{2}, \mathrm{C}-12\right), 39.79\left(\mathrm{CH}_{2}, \mathrm{C}-9\right), 39.6\left(\mathrm{CH}_{2}, \mathrm{C}-5\right), 29.2\left(\mathrm{CH}_{3}, \mathrm{C}-10\right.$ '), $26.9\left(\mathrm{CH}_{2}, \mathrm{C}-13\right), 26.7\left(\mathrm{CH}_{2}, \mathrm{C}-9\right), 26.3\left(\mathrm{CH}_{2}, \mathrm{C}-5\right), 25.8\left(\mathrm{CH}_{3}, \mathrm{C}-20\right), 17.8\left(\mathrm{CH}_{3}, \mathrm{C}-16\right)$, $16.7\left(\mathrm{CH}_{3}, \mathrm{C}-17\right), 16.2\left(\mathrm{CH}_{3}, \mathrm{C}-18\right.$ or $\left.\mathrm{C}-19\right), 16.1\left(\mathrm{CH}_{3}, \mathrm{C}-18\right.$ or $\left.\mathrm{C}-19\right)$; IR (film from $\left.\mathrm{CH}_{2} \mathrm{Cl}_{2}\right): v_{\max } 3158,3121,3029,2965,2924,2834,1713,1679 \mathrm{~cm}^{-1}$; HRESIMS m/z: 
$[\mathrm{M}+\mathrm{H}]^{+}$Calcd for $\mathrm{C}_{26} \mathrm{H}_{39} \mathrm{~N}_{4} \mathrm{O}_{2}$ 439.3068; Found 439.3035 ( $\Delta=7.37$ ppm); HRESIMS/MS (40 eV) m/z (\%): 168.0459 (9), 167.0437 (100), 124.0412 (39).

Geranyl theophylline; Theophylline hydrate $(2.0 \mathrm{mmol}, 391.3 \mathrm{mg})$ and $\mathrm{K}_{2} \mathrm{CO}_{3}$ $\mathrm{Na}_{2} \mathrm{CO}_{3}(1: 1,244 \mathrm{mg})$ were stirred in $\mathrm{DMF}(3 \mathrm{~mL})$ at $50{ }^{\circ} \mathrm{C}$ for 15 minutes before dropwise addition of geranyl bromide $(4.0 \mathrm{mmol}, 869 \mathrm{mg}, 794 \mu \mathrm{L})$. The reaction was stirred for three hours, after which, $\mathrm{H}_{2} \mathrm{O}(9 \mathrm{~mL})$ was added and the resulting precipitate was isolated by filtration and rinsed with PE. The residue was recrystallised several times from PE to afford $\mathbf{1 1 6}$ as fine white crystals (277.5 $\mathrm{mg}, 45 \%)$ :

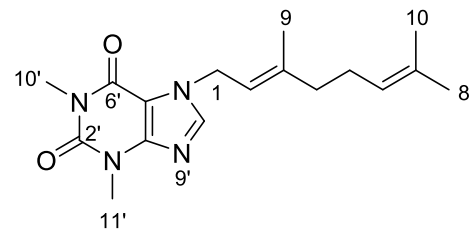

(E)-7-(3,7-Dimethylocta-2,6-dien-1-yl)-1,3-dimethyl-3,7-dihydro-1H-purine-2,6dione (116); ${ }^{1} \mathrm{H} \mathrm{NMR}\left(600 \mathrm{MHz}, \mathrm{CDCl}_{3}\right): \delta 7.53$ (s, 1H, H-8'), 5.43 (t, J = $7.6 \mathrm{~Hz}, 1 \mathrm{H}$, H-2), 5.05 (t, $J=6.2 \mathrm{~Hz}, 1 \mathrm{H}, \mathrm{H}-6), 4.93$ (d, $J=7.3 \mathrm{~Hz}, 2 \mathrm{H}, \mathrm{H}-1), 3.59$ (s, 3H, H-11'), 3.42 (s, 3H, H-10'), 2.15 - 2.07 (complex m, 4H, H-4 and H-5), 1.78 (s, 3H, H-9), 1.68 (s, 3H, H-10), 1.59 (s, 3H, H-8); ${ }^{13} \mathrm{C}$ NMR (150 MHz, CDCl $): \delta 155.5$ (C, C-6'), 151.9 (C, C-2'), 149.0 (C, C-4'), 143.5 (C, C-3), 140.3 (CH, C-8'), 132.4 (C, C-7), 123.6 (CH, C-6), 117.5 (CH, C-2), 107.2 (C, C-5'), $44.7\left(\mathrm{CH}_{2}, \mathrm{C}-1\right), 39.6\left(\mathrm{CH}_{2}, \mathrm{C}-4\right), 29.9\left(\mathrm{CH}_{3}, \mathrm{C}-\right.$ $\left.11^{\prime}\right), 28.1\left(\mathrm{CH}_{3}, \mathrm{C}-10\right.$ '), $26.3\left(\mathrm{CH}_{2}, \mathrm{C}-5\right), 25.9\left(\mathrm{CH}_{3}, \mathrm{C}-10\right), 17.9\left(\mathrm{CH}_{3}, \mathrm{C}-8\right), 16.6\left(\mathrm{CH}_{3}\right.$, C-9); IR (neat): $v_{\max } 3098,2964,2926,2855,1695,1645 \mathrm{~cm}^{-1}$; m.p. $83.3-84.8{ }^{\circ} \mathrm{C}$.

Farnesyl theophylline; Theophylline hydrate (1.85 mmol, $0.37 \mathrm{~g}$ ) and $\mathrm{K}_{2} \mathrm{CO}_{3}-\mathrm{Na}_{2} \mathrm{CO}_{3}$ $(1: 1,0.17 \mathrm{~g})$ were stirred in DMF $(2 \mathrm{~mL})$ at $80{ }^{\circ} \mathrm{C}$ before dropwise addition of farnesyl bromide $(2.0 \mathrm{mmol}, 570.5 \mathrm{mg}, 794 \mu \mathrm{L})$. The reaction was stirred for five hours and then filtered. The solvent was removed under reduced pressure, then the residue was dissolved in hot PE and filtered. The filtrate was dried under reduced pressure and then recrystallised from PE to afford $\mathbf{1 1 7}$ as a crystalline white powder (333.1 mg, 47\%): 


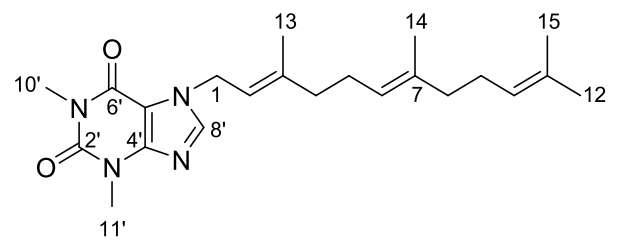

1,3-Dimethyl-7-((2E,6E)-3,7,11-trimethyldodeca-2,6,10-trien-1-yl)-3,7-dihydro-1Hpurine-2,6-dione (117); ${ }^{1} \mathrm{H}$ NMR (600 MHz, $\mathrm{CDCl}_{3}$ ): $\delta 7.53$ (s, 1H, H-8'), 5.43 (t, $J=$ $7.3 \mathrm{~Hz}, 1 \mathrm{H}, \mathrm{H}-2$ ) , $5.09-5.05$ (complex m, 2H, H-6 and H-10), 4.93 (d, $J=7.2 \mathrm{~Hz}, 2 \mathrm{H}$, H-1), 3.58 (s, 3H, H-11'), 3.41 (s, 3H, H-10'), $2.16-2.07$ (complex m, 4H, H-4 and H5), 2.03 (m, 2H, H-9), $1.99-1.93$ (m, 2H, H-8), 1.79 (s, 3H, H-13), 1.67 (s, 1H, H-15), 1.60 (s, 3H, H-12), 1.59 (s, 3H, H-14); ${ }^{13} \mathrm{C}$ NMR (150 MHz, $\mathrm{CDCl}_{3}$ ): $\delta 155.5$ (C, C-6'), 151.9 (C, C-2'), 149.0 (C, C-4'), 143.5 (C, C-3), 140.3 (CH, C-8'), 136.0 (C, C-7), 131.6 (C, C-11), 124.3 (CH, C-10), 123.4 (CH, C-6), 117.5 (CH, C-2), 107.2 (C, C-5'), 44.7 $\left(\mathrm{CH}_{2}, \mathrm{C}-1\right), 39.8\left(\mathrm{CH}_{2}, \mathrm{C}-8\right), 39.6\left(\mathrm{CH}_{2}, \mathrm{C}-4\right), 29.9\left(\mathrm{CH}_{3}, \mathrm{C}-11\right.$ ') $), 28.1\left(\mathrm{CH}_{3}, \mathrm{C}-10^{\prime}\right), 26.8$ $\left(\mathrm{CH}_{2}, \mathrm{C}-9\right), 26.3\left(\mathrm{CH}_{2}, \mathrm{C}-5\right), 25.9\left(\mathrm{CH}_{3}, \mathrm{C}-15\right), 17.8\left(\mathrm{CH}_{3}, \mathrm{C}-12\right), 16.7\left(\mathrm{CH}_{3}, \mathrm{C}-13\right), 16.2$ $\left(\mathrm{CH}_{3}, \mathrm{C}-14\right)$ ); IR (film from $\mathrm{CH}_{2} \mathrm{Cl}_{2}$ ): $v_{\max } 3097,2695,2922,1695,1646 \mathrm{~cm}^{-1}$; HRESIMS $m / z:[\mathrm{M}+\mathrm{H}]^{+}$Calcd for $\mathrm{C}_{22} \mathrm{H}_{33} \mathrm{~N}_{4} \mathrm{O}_{2}$ 385.2598; Found $385.2604(\Delta=-1.53 \mathrm{ppm})$; HRESIMS/MS (40 eV) $\mathrm{m} / \mathrm{z}(\%): 181.0718$ (100), 124.0506 (73).

Geranylgeranyl theophylline; Theophylline hydrate $(0.30 \mathrm{mmol}, 59.1 \mathrm{mg})$ and $\mathrm{K}_{2} \mathrm{CO}_{3}(0.34 \mathrm{mmol}, 46.5 \mathrm{mg})$ were stirred in DMF $(1 \mathrm{~mL})$ at room temperature for 5 minutes before dropwise addition of geranylgeranyl bromide $(0.32 \mathrm{mmol}, 111 \mathrm{mg}, 108.6$ $\mu \mathrm{L})$. The reaction was stirred for 25 hours and then $\mathrm{H}_{2} \mathrm{O}(3 \mathrm{~mL})$ was added. The reaction mixture was extracted with EA $(3 \times 2 \mathrm{~mL})$ and the combined extracts were washed with $\mathrm{H}_{2} \mathrm{O}(3 \times 2 \mathrm{~mL})$, then brine $(1 \times 2 \mathrm{~mL})$ and dried over anhydrous $\mathrm{MgSO}_{4}$. The dried residue was purified by silica gel flash chromatography (2:1 and then 3:2 EA/PE) to afford 63 and 64 , the $2 Z(13.1 \mathrm{mg})$ and $2 E(21.1 \mathrm{mg}) N-7$ geranylgeranylated products as white solids, with a combined yield of $25 \%$ : 


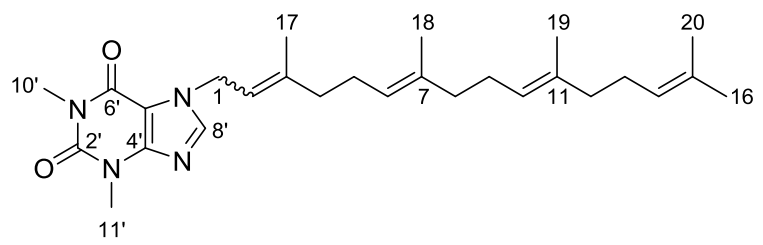

\section{1,3-Dimethyl-7-((2Z,6E,10E)-3,7,11,15-tetramethylhexadeca-2,6,10,14-tetraen-1-}

yl)-3,7-dihydro-1H-purine-2,6-dione (63); $\mathrm{R}_{f}=0.16$ (1:2 EA/PE); ${ }^{1} \mathrm{H}$ NMR $(500 \mathrm{MHz}$, $\mathrm{CDCl}_{3}$ ): $\delta 7.52(\mathrm{~s}, 1 \mathrm{H}, \mathrm{H}-8$ '), 5.44 (t, $J=7.1 \mathrm{~Hz}, 1 \mathrm{H}, \mathrm{H}-2), 5.15-5.01$ (complex m, 3H, H-6, H-10 and H-14), 4.91 (d, J=7.2 Hz, 2H, H1), 3.58 (s, 3H, H-11'), 3.41 (s, 3H, H10'), 2.21 (t, $J=7.6 \mathrm{~Hz}, 2 \mathrm{H}, \mathrm{CH}_{2}$ ), $2.15-2.10$ (m, 2H, $\mathrm{CH}_{2}$ ), $2.08-2.02$ (complex m, $4 \mathrm{H}, 2 \times \mathrm{CH}_{2}$ ), $2.00-1.94$ (complex m, 4H, $2 \times \mathrm{CH}_{2}$ ), 1.80 (s, 3H, H-17), 1.67 (s, 3H, H20), 1.60 (s, 3H, $\left.\mathrm{CH}_{3}\right), 1.59$ (s, 6H, $\left.2 \times \mathrm{CH}_{3}\right) ;{ }^{13} \mathrm{C} \mathrm{NMR}\left(150 \mathrm{MHz}, \mathrm{CDCl}_{3}\right): \delta 155.4(\mathrm{C}$, C-6’), 151.9 (C, C-2'), 148.9 (C, C-4'), 143.3 (C, C-3), 140.3 (CH, C-8'), 136.4 (C, C7), 135.3 (C, C-11), 131.4 (C, C-15), 124.5 (CH, C-14), 124.1 (CH, C-10), 123.1 (CH, C6), 118.4 (CH, C-2), 107.2 (C, C-5'), $44.5\left(\mathrm{CH}_{2}, \mathrm{C}-1\right), 39.9\left(\mathrm{CH}_{2}, \mathrm{C}-12\right), 39.8\left(\mathrm{CH}_{2}, \mathrm{C}-\right.$ 8), $32.3\left(\mathrm{CH}_{2}, \mathrm{C}-4\right), 29.9\left(\mathrm{CH}_{3}, \mathrm{C}-11\right.$ '), $28.1\left(\mathrm{CH}_{3}, \mathrm{C}-10\right.$ ') $, 26.9\left(\mathrm{CH}_{2}, \mathrm{C}-13\right), 26.7\left(\mathrm{CH}_{2}\right.$, C-9), $26.5\left(\mathrm{CH}_{2}, \mathrm{C}-5\right), 25.9\left(\mathrm{CH}_{3}, \mathrm{C}-20\right), 23.6\left(\mathrm{CH}_{3}, \mathrm{C}-17\right), 17.8\left(\mathrm{CH}_{3}, \mathrm{C}-16\right), 16.21\left(\mathrm{CH}_{3}\right.$, C-18 or C-19), $16.15\left(\mathrm{CH}_{3}, \mathrm{C}-18\right.$ or C-19); IR (film from $\mathrm{CH}_{2} \mathrm{Cl}_{2}$ ): $v_{\max } 3111,2917,2853$, 1704, $1658 \mathrm{~cm}^{-1}$; HRESIMS m/z: $[\mathrm{M}+\mathrm{H}]^{+}$Calcd for $\mathrm{C}_{27} \mathrm{H}_{41} \mathrm{~N}_{4} \mathrm{O}_{2}$ 453.3224; Found $453.3215(\Delta=1.97 \mathrm{ppm})$; HRESIMS/MS (40 eV) $\mathrm{m} / z$ (\%): 181.0700 (100), 124.0496 (36).

\section{1,3-Dimethyl-7-((2E,6E,10E)-3,7,11,15-tetramethylhexadeca-2,6,10,14-tetraen-1-}

yl)-3,7-dihydro-1H-purine-2,6-dione (64); $\mathrm{R}_{f}=0.20$ (2:3 EA/PE); ${ }^{1} \mathrm{H}$ NMR $(500 \mathrm{MHz}$, $\mathrm{CDCl}_{3}$ ): $\delta 7.52(\mathrm{~s}, 1 \mathrm{H}, \mathrm{H}-8$ '), $5.43(\mathrm{t}, J=7.1 \mathrm{~Hz}, 1 \mathrm{H}, \mathrm{H}-2), 5.12-5.04$ (complex m, 3H, H-6, H-10 and H-14), 4.92 (d, J = 7.2 Hz, 2H, H-1), 3.58 (s, 3H, H-11'), 3.40 (s, 3H, H10'), 2.15 - 2.07 (complex m, 4H, $2 \times \mathrm{CH}_{2}$ ), 2.07 - 2.01 (complex m, 4H, $2 \times \mathrm{CH}_{2}$ ), 1.991.93 (complex m, 4H, $2 \times \mathrm{CH}_{2}$ ), 1.78 (s, 3H, CH $3, \mathrm{H}-17$ ), 1.66 (s, 3H, $\left.\mathrm{CH}_{3}\right), 1.58$ (s, 9H, $\left.3 \times \mathrm{CH}_{3}\right) ;{ }^{13} \mathrm{C}$ NMR $\left(150 \mathrm{MHz}, \mathrm{CDCl}_{3}\right): \delta 155.4$ (C, C-6'), 151.8 (C, C-2'), $148.9(\mathrm{C}, \mathrm{C}-$ 4'), 143.5 (C, C-3), 140.3 (CH, C-8'), 136.0 (C, C-7), 135.2 (C, C-11), 131.4 (C, C-15), 124.5 (CH, C-10), 124.2 (CH, C-6), 123.4 (CH, C-14), 117.5 (CH, C-2), 107.2 (C, C-5'), $44.6\left(\mathrm{CH}_{2}, \mathrm{C}-1\right), 39.8\left(\mathrm{CH}_{2}, \mathrm{C}-12\right), 39.8\left(\mathrm{CH}_{2}, \mathrm{C}-8\right), 39.6\left(\mathrm{CH}_{2}, \mathrm{C}-4\right), 29.9\left(\mathrm{CH}_{3}, \mathrm{C}-11\right.$ ') $28.1\left(\mathrm{CH}_{3}, \mathrm{C}-10\right.$ '), $26.9\left(\mathrm{CH}_{2}, \mathrm{C}-13\right), 26.7\left(\mathrm{CH}_{2}, \mathrm{C}-8\right), 26.3\left(\mathrm{CH}_{2}, \mathrm{C}-5\right), 25.8\left(\mathrm{CH}_{3}, \mathrm{C}-\right.$ 20), $17.8\left(\mathrm{CH}_{3}, \mathrm{C}-16\right), 16.7\left(\mathrm{CH}_{3}, \mathrm{C}-17\right), 16.2\left(\mathrm{CH}_{3}, \mathrm{C}-18\right.$ or $\left.\mathrm{C}-19\right), 16.1\left(\mathrm{CH}_{3}, \mathrm{C}-18\right.$ or C-19); IR (film from $\mathrm{CH}_{2} \mathrm{Cl}_{2}$ ): $v_{\max } 3110,2916,2854,1704,1658 \mathrm{~cm}^{-1}$; HRESIMS m/z: 
$[\mathrm{M}+\mathrm{H}]^{+}$Calcd for $\mathrm{C}_{27} \mathrm{H}_{41} \mathrm{~N}_{4} \mathrm{O}_{2}$ 453.3224; Found 453.3205 ( $\Delta=4.11$ ppm); HRESIMS/MS (40 eV) m/z (\%): 181.0693 (100), 124.0489 (31).

Geranyl 3-methyl-2-thioxohypoxanthine; 2-Mercapto-3-methylhypoxanthine (0.30 mmol, $54.7 \mathrm{mg})$ and $\mathrm{K}_{2} \mathrm{CO}_{3}(0.61 \mathrm{mmol}, 84.3 \mathrm{mg})$ were stirred in DMF $(2 \mathrm{~mL})$ at $70{ }^{\circ} \mathrm{C}$ before dropwise addition of geranyl bromide $(0.39 \mathrm{mmol}, 84.9 \mathrm{mg}, 77.6 \mu \mathrm{L})$. The reaction was stirred for 30 hours, then $\mathrm{H}_{2} \mathrm{O}(7 \mathrm{~mL})$ was added and the mixture was filtered. The isolated solid was suspended in boiling PE and filtered again. The resulting solid was dissolved in $\mathrm{MeOH}$ and $\mathrm{DCM}(1: 1,5 \mathrm{~mL})$, which formed a precipitate upon partial evaporation. The yellow solid was isolated by filtration and washed with $\mathrm{MeOH}$ to afford the 118 as an off-white powder $(5.4 \mathrm{mg}, 6 \%)$ :

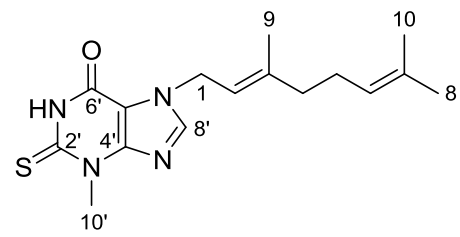

(E)-7-(3,7-Dimethylocta-2,6-dien-1-yl)-3-methyl-2-thioxo-1,2,3,7-tetrahydro-6Hpurin-6-one (118); ${ }^{1} \mathrm{H}$ NMR $\left(600 \mathrm{MHz}, \mathrm{CDCl}_{3}\right): \delta 9.24$ (s, 1H, NH), $7.62(\mathrm{~s}, 1 \mathrm{H}, \mathrm{H}-8$ '), $5.43(\mathrm{t}, J=7.3 \mathrm{~Hz}, 1 \mathrm{H}, \mathrm{H}-2), 5.07-5.03$ (m, 1H, H-6), 4.92 (d, $J=7.3 \mathrm{~Hz}, 2 \mathrm{H}, \mathrm{H}-1)$, 3.93 (s, 3H, H-10'), 2.16 - 2.08 (complex m, 4H, H-4 and H-5), 1.78 (s, 3H, H-9), 1.69 (s, 3H, H-10), 1.60 (s, 3H, H-8); ${ }^{13} \mathrm{C}$ NMR (150 MHz, $\left.\mathrm{CDCl}_{3}\right): \delta 174.3$ (C, C-2'), 152.4 (C, C-6'), 150.9 (C, C-4'), 144.5 (C, C-3), 141.2 (CH, C-8'), 132.5 (C, C-7), 123.5 (CH, C-6), 116.8 (CH, C-2), $110.9(\mathrm{C}, \mathrm{C}-5)$ ') $45.0\left(\mathrm{CH}_{2}, \mathrm{C}-1\right), 39.6\left(\mathrm{CH}_{2}, \mathrm{C}-4\right), 35.5\left(\mathrm{CH}_{3}, \mathrm{C}-\right.$ 10'), $26.2\left(\mathrm{CH}_{2}, \mathrm{C}-5\right), 25.9\left(\mathrm{CH}_{3}, \mathrm{C}-10\right), 17.9\left(\mathrm{CH}_{3}, \mathrm{C}-8\right), 16.7\left(\mathrm{CH}_{3}, \mathrm{C}-9\right)$; IR (neat): $v_{\max }$ 3122, 2964, 2912, 2853, $1708 \mathrm{~cm}^{-1}$; HRESIMS m/z: $[\mathrm{M}+\mathrm{H}]^{+}$Calcd for $\mathrm{C}_{16} \mathrm{H}_{23} \mathrm{~N}_{4} \mathrm{OS}$ 319.1587; Found 319.1591 ( $\Delta=-1.21 \mathrm{ppm})$; HRESIMS/MS (40 eV) $\mathrm{m} / \mathrm{z}(\%): 183.033$ (48), 149.0452 (19), 126.99579 (11), 124.0503 (100), 96.0557 (21), 81.0702 (46).

Farnesyl 3-methyl-2-thioxohypoxanthine; 2-Mercapto-3-methylhypoxanthine (0.32 mmol, $57.8 \mathrm{mg})$ and $\mathrm{K}_{2} \mathrm{CO}_{3}(0.61 \mathrm{mmol}, 84.7 \mathrm{mg})$ were stirred in DMF (2 mL) at $50{ }^{\circ} \mathrm{C}$ for 25 minutes before dropwise addition of farnesyl bromide $(0.39 \mathrm{mmol}, 111 \mathrm{mg}$, 105.8 $\mu \mathrm{L})$. The reaction was stirred for 41 hours, then filtered and $\mathrm{H}_{2} \mathrm{O}(6 \mathrm{~mL})$ was added to the filtrate. The mixture was extracted with PE $(3 \times 3 \mathrm{~mL})$ and the combined extracts were dried under reduced pressure. The residue was recrystallised from PE and then 
further purified by silica gel flash chromatography (1:2 EA/PE) to yield 119 as an off white amorphous powder $(3.3 \mathrm{mg}, 3 \%)$ :

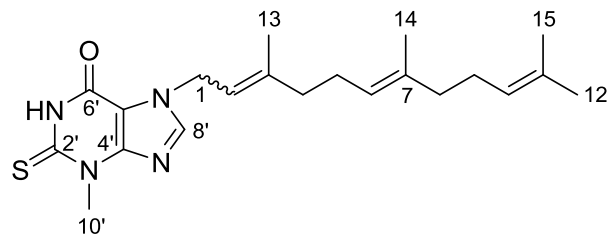

\section{3-Methyl-2-thioxo-7-((6E)-3,7,11-trimethyldodeca-2,6,10-trien-1-yl)-1,2,3,7-}

tetrahydro-6H-purin-6-one (119); $\mathrm{R}_{f}=0.19$ (1:2 EA/PE); 2:1 E/Z, NMR data for major isomer: ${ }^{1} \mathrm{H}$ NMR (600 MHz, $\left.\mathrm{CDCl}_{3}\right): \delta 9.31(\mathrm{~s}, 1 \mathrm{H}, \mathrm{NH}), 7.62(\mathrm{~s}, 1 \mathrm{H}, \mathrm{H}-8$ ') $5.43(\mathrm{t}, J=$ $7.3 \mathrm{~Hz}, 1 \mathrm{H}, \mathrm{H}-2$ ), $5.09-5.05$ (complex m, 2H, H-6 and H-10), 4.92 (d, $J=7.3 \mathrm{~Hz}, 2 \mathrm{H}$, H-1), 3.92 (s, 3H, H-10'), 2.16 - 2.09 (complex m, 4H, $2 \times \mathrm{CH}_{2}$ ), $2.06-2.01$ (complex m, 4H, $2 \times \mathrm{CH}_{2}$ ), 1.78 (s, 3H, H-13), 1.66 (s, 3H, H-16), 1.59 (s, 3H, CH, H-12 or H-14), 1.58 (s, 3H, H-12 or H-14); ${ }^{13} \mathrm{C}$ NMR (150 MHz, $\left.\mathrm{CDCl}_{3}\right)$ : $\delta 174.3$ (C, C-2'), 152.4 (C, C-6’), 150.9 (C, C-4'), 144.5 (C, C-3), 141.1 (CH, C-8'), 136.1 (C, C-7) , 131.6 (C, C11), 124.3 (CH, C-10), 123.3 (CH, C-6), 116.8 (CH, C-2), 110.9 (C, C-5'), $45.0\left(\mathrm{CH}_{2}, \mathrm{C}-\right.$ 1), $39.8\left(\mathrm{CH}_{2}, \mathrm{C}-8\right), 39.6\left(\mathrm{CH}_{2}, \mathrm{C}-8\right), 35.5\left(\mathrm{CH}_{3}, \mathrm{C}-10\right.$ ') $, 26.8\left(\mathrm{CH}_{2}, \mathrm{C}-9\right), 26.2\left(\mathrm{CH}_{2}, \mathrm{C}-\right.$ 5), $25.9\left(\mathrm{CH}_{3}, \mathrm{C}-15\right), 17.8\left(\mathrm{CH}_{3}, \mathrm{C}-12\right), 16.7\left(\mathrm{CH}_{3}, \mathrm{C}-13\right.$ or $\left.\mathrm{C}-14\right), 16.2\left(\mathrm{CH}_{3}, \mathrm{C}-13\right.$ or $\mathrm{C}-$ 14); IR (film from $\mathrm{CH}_{2} \mathrm{Cl}_{2}$ ): $v_{\max } 3116,2922,2854,1691 \mathrm{~cm}^{-1} ; \operatorname{HRESIMS~m/z:~}[\mathrm{M}+\mathrm{H}]^{+}$ Calcd for $\mathrm{C}_{21} \mathrm{H}_{31} \mathrm{~N}_{4} \mathrm{OS} 387.2213$; Found 387.2216 ( $\Delta=-0.68$ ppm); HRESIMS/MS (40 eV) $m / z(\%): 183.0316(100), 149.0436$ (13), 124.0493 (42).

\section{Geranylgeranyl 3-methyl-2-thioxohypoxanthine;}

3-Methyl-2-thioxohypoxanthine (0.30 mmol, $54.7 \mathrm{mg})$ and $\mathrm{K}_{2} \mathrm{CO}_{3}(1.1 \mathrm{mmol}, 150.8 \mathrm{mg})$ were stirred in DMF ( $1 \mathrm{~mL}$ ) for 50 minutes before dropwise addition of geranylgeranyl bromide $(0.32 \mathrm{mmol}, 111.3 \mathrm{mg}, 108.6 \mu \mathrm{L})$ over 3 minutes. The reaction was stirred for 24 hours and then poured onto $\mathrm{H}_{2} \mathrm{O}(3 \mathrm{~mL})$. The mixture was extracted with EA $(3 \times 2$ $\mathrm{mL})$ and the combined extracts were washed with $\mathrm{H}_{2} \mathrm{O}(3 \times 2 \mathrm{~mL})$, then brine $(1 \times 2 \mathrm{~mL})$ and dried over anhydrous $\mathrm{MgSO}_{4}$. The solvent was removed under reduced pressure and the resulting residue was purified by silica gel flash chromatography (1:3 EA/PE) to yield 120 and 121, the $2 Z(3.2 \mathrm{mg})$ and $2 E(3.4 \mathrm{mg}) N-7$ geranylgeranylated products as white powders with a combined yield of $5 \%$ : 


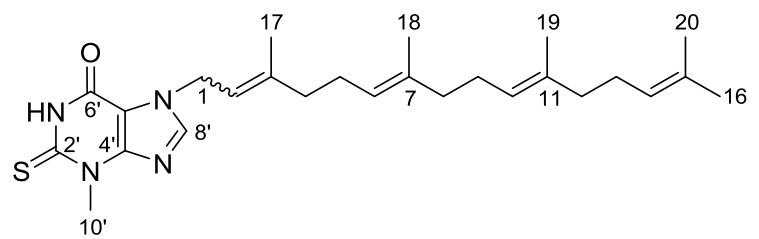

3-Methyl-7-((2Z,6E,10E)-3,7,11,15-tetramethylhexadeca-2,6,10,14-tetraen-1-yl)-2thioxo-1,2,3,7-tetrahydro-6H-purin-6-one (120); $\mathrm{R}_{f}=0.14$ (1:3 EA/PE); ${ }^{1} \mathrm{H}$ NMR (500

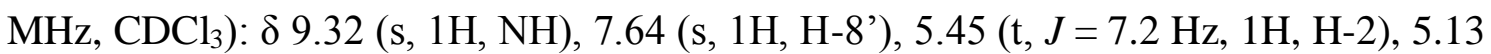
- 5.07 (complex m, 3H, H-6, H-10 and H-14), 4.92 (d, J = 7.3 Hz, 2H, H-1), 3.94 (s, 3H, H-10'), $2.26-2.19$ (m, 2H, CH 2 ), 2.18 - 2.11 (m, 2H, $\mathrm{CH}_{2}$ ), $2.10-2.04$ (complex m, 4H, $2 \times \mathrm{CH}_{2}$ ), $2.02-1.96$ (complex m, 4H, $2 \times \mathrm{CH}_{2}$ ), 1.83 (s, 3H, H-17), 1.69 (s, 3H, H-20), $1.62\left(\mathrm{~s}, 3 \mathrm{H}, \mathrm{CH}_{3}\right), 1.61\left(\mathrm{~s}, 3 \mathrm{H}, \mathrm{CH}_{3}\right), 1.60\left(\mathrm{~s}, 3 \mathrm{H}, \mathrm{CH}_{3}\right) ;{ }^{13} \mathrm{C} \mathrm{NMR}\left(150 \mathrm{MHz}, \mathrm{CDCl}_{3}\right): \delta$ 174.3 (C, C-2'), 152.4 (C, C-6'), 150.9 (C, C-4'), 144.2 (C, C-3), 141.2 (CH, C-8'), 136.6 (C, C-7), 135.3 (C, C-11), 131.5 (C, C-15), 124.5 (CH, C-14), 124.1 (CH, C-10), 123.0 (CH, C-6), 117.7 (CH, C-2), $44.8\left(\mathrm{CH}_{2}, \mathrm{C}-1\right), 39.9\left(\mathrm{CH}_{2}, \mathrm{C}-12\right), 39.8\left(\mathrm{CH}_{2}, \mathrm{C}-8\right), 35.5$ $\left(\mathrm{CH}_{3}, \mathrm{C}-10\right.$ '), $32.3\left(\mathrm{CH}_{2}, \mathrm{C}-4\right), 26.9\left(\mathrm{CH}_{2}, \mathrm{C}-13\right), 26.7\left(\mathrm{CH}_{2}, \mathrm{C}-9\right), 26.4\left(\mathrm{CH}_{2}, \mathrm{C}-5\right), 25.9$ $\left(\mathrm{CH}_{3}, \mathrm{C}-20\right), 23.6\left(\mathrm{CH}_{3}, \mathrm{C}-17\right), 17.8\left(\mathrm{CH}_{3}, \mathrm{C}-16\right), 16.2\left(\mathrm{CH}_{3}, \mathrm{C}-18\right.$ or $\left.\mathrm{C}-19\right), 16.2\left(\mathrm{CH}_{3}\right.$, C-18 or C-19); IR (film from $\mathrm{CH}_{2} \mathrm{Cl}_{2}$ ): $v_{\max } 3205,3118,2965,2917,2855,1696 \mathrm{~cm}^{-1}$; HRESIMS $m / z:[\mathrm{M}+\mathrm{H}]^{+}$Calcd for $\mathrm{C}_{26} \mathrm{H}_{39} \mathrm{~N}_{4} \mathrm{OS} 455.2839$; Found $455.2851(\Delta=-2.68$ ppm); HRESIMS/MS (20 eV) m/z (\%): 183.0339 (100).

\section{3-Methyl-7-((2E,6E,10E)-3,7,11,15-tetramethylhexadeca-2,6,10,14-tetraen-1-yl)-2-}

thioxo-1,2,3,7-tetrahydro-6 $\boldsymbol{H}$-purin-6-one (121); $\mathrm{R}_{f}=0.10(1: 3 \mathrm{EA} / \mathrm{PE}) ;{ }^{1} \mathrm{H} \mathrm{NMR}(500$ MHz, $\mathrm{CDCl}_{3}$ ): $\delta 9.29$ (s, 1H, NH), 7.62 (s, 1H, H-8'), 5.43 (t, J = 7.0 Hz, 1H, H-2), 5.13 - 5.05 (complex m, 3H, H-6, H-10 and H-14), 4.92 (d, J=7.3 Hz, 2H, H-1), 3.92 (s, 3H, H-10'), 2.17 - 2.10 (complex m, 4H, $2 \times \mathrm{CH}_{2}$ ), $2.09-2.02$ (complex m, 4H, $2 \times \mathrm{CH}_{2}$ ), $2.01-1.93$ (complex m, 4H, $2 \times \mathrm{CH}_{2}$ ), 1.79 (s, 3H, H-17), 1.68 (s, 3H, H-20), 1.60-1.58 (complex m, 9H, $\left.3 \times \mathrm{CH}_{3}\right) ;{ }^{13} \mathrm{C}$ NMR $\left(150 \mathrm{MHz}, \mathrm{CDCl}_{3}\right)$ : $\delta 174.3(\mathrm{C}, \mathrm{C}-2$ ') $152.4(\mathrm{C}, \mathrm{C}-$ 6'), 144.5 (C, C-3), 141.1 (CH, C-8'), 136.1 (C, C-7), 135.2 (C, C-11), 131.5 (C, C-15), 124.5 (CH, C-14), 124.2 (CH, C-10), 123.3 (CH, C-6), 116.8 (CH, C-2), $45.0\left(\mathrm{CH}_{2}, \mathrm{C}-\right.$ 1), $39.9\left(\mathrm{CH}_{2}, \mathrm{C}-12\right), 39.8\left(\mathrm{CH}_{2}, \mathrm{C}-8\right), 39.6\left(\mathrm{CH}_{2}, \mathrm{C}-4\right), 35.5\left(\mathrm{CH}_{3}, \mathrm{C}-10\right)$ ') $26.9\left(\mathrm{CH}_{2}, \mathrm{C}-\right.$ 13), $26.7\left(\mathrm{CH}_{2}, \mathrm{C}-9\right), 26.2\left(\mathrm{CH}_{2}, \mathrm{C}-5\right), 25.9\left(\mathrm{CH}_{3}, \mathrm{C}-20\right), 17.8\left(\mathrm{CH}_{3}, \mathrm{C}-16\right), 16.7\left(\mathrm{CH}_{3}\right.$, C-17), $16.2\left(\mathrm{CH}_{3}, \mathrm{C}-18\right.$ or C-19), $16.2\left(\mathrm{CH}_{3}, \mathrm{C}-18\right.$ or C-19); IR (film from $\left.\mathrm{CH}_{2} \mathrm{Cl}_{2}\right): v_{\max }$ 3212, 3117, 2964, 2917, 2853, $1691 \mathrm{~cm}^{-1}$; HRESIMS m/z: [M+H] $]^{+}$Calcd for $\mathrm{C}_{26} \mathrm{H}_{39} \mathrm{~N}_{4} \mathrm{OS}$ 
455.2839; Found 455.2857 ( $\Delta=-3.89 \mathrm{ppm})$; HRESIMS/MS (40 eV) $\mathrm{m} / z(\%): 183.0306$ (100), 124.0487 (13).

Geranyl 1,3-dimethyluric acid; 1,3-Dimethyluric acid (0.12 mmol, $22.6 \mathrm{mg})$ and $\mathrm{K}_{2} \mathrm{CO}_{3}$ (0.119 mmol, $16.5 \mathrm{mg}$ ) were stirred in DMF (2 mL) for 25 minutes before the dropwise addition of geranyl bromide $(0.13 \mathrm{mmol}, 27.6 \mathrm{mg}, 25.2 \mu \mathrm{L})$. The reaction was stirred for 24 hours at room temperature, then poured onto $\mathrm{H}_{2} \mathrm{O}(6 \mathrm{~mL})$ and extracted with EA $(3 \times 2 \mathrm{~mL})$. The combined extracts were washed with $\mathrm{H}_{2} \mathrm{O}(3 \times 2 \mathrm{~mL})$, then brine $(1$ $\times 2 \mathrm{~mL}$ ) and dried over anhydrous $\mathrm{MgSO}_{4}$. The solvent was removed under reduced pressure and the residue was purified by silica gel flash chromatography (1:1 EA/PE) to afford 112 as an amorphous white solid (3.5 mg, 9\%):

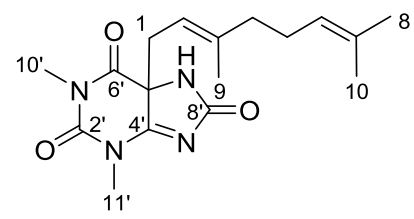

(E)-5-(3,7-Dimethylocta-2,6-dien-1-yl)-1,3-dimethyl-5,7-dihydro-1H-purine-

2,6,8(3H)-trione (122); $\mathrm{R}_{f}=0.23(1: 1 \mathrm{EA} / \mathrm{PE}) ;{ }^{1} \mathrm{H} \mathrm{NMR}\left(600 \mathrm{MHz}, \mathrm{CDCl}_{3}\right): \delta 6.07(\mathrm{~s}$, 1H, NH), $5.06-5.02$ (m, 1H, H-2), 4.95 (t, $J=8.1 \mathrm{~Hz}, 1 \mathrm{H}, \mathrm{H}-1), 3.49$ (s, 3H, H-10'), 3.28 (s, 3H, H-11'), 2.67 (d, $J=8.0 \mathrm{~Hz}, 2 \mathrm{H}, \mathrm{H}-1$ ), $2.12-1.99$ (complex m, 4H, H-4 and H-5), 1.70 (s, 3H, H-9), 1.61 (s, 3H, H-8 or H-10), 1.58 (s, 3H, H-8 or H-10); ${ }^{13} \mathrm{C}$ NMR (150 MHz, $\mathrm{CDCl}_{3}$ ): $\delta 176.9$ (C, C-6’), 166.4 (C, C-4'), 165.4 (C, C-8'), 150.8 (C, C-2’), 145.6 (C, C-3), 132.6 (C, C-7), 123.6 (CH, C-6), 112.8 (CH, C-2), 68.1 (C, C-5'), 40.6 $\left(\mathrm{CH}_{2}, \mathrm{C}-1\right), 39.9\left(\mathrm{CH}_{2}, \mathrm{C}-4\right), 32.0\left(\mathrm{CH}_{3}, \mathrm{C}-10^{\prime}\right), 29.2\left(\mathrm{CH}_{3}, \mathrm{C}-11^{\prime}\right), 26.3\left(\mathrm{CH}_{2}, \mathrm{C}-5\right), 25.8$ $\left(\mathrm{CH}_{3}, \mathrm{C}-10\right), 17.9\left(\mathrm{CH}_{3}, \mathrm{C}-8\right), 16.4\left(\mathrm{CH}_{3}, \mathrm{C}-9\right)$ ); IR (film from $\left.\mathrm{CH}_{2} \mathrm{Cl}_{2}\right)$ : v $v_{\max } 3278,3106$, 2966, 2921, 2857, 1750, 1697, $1609 \mathrm{~cm}^{-1}$; HRESIMS $m / z:[\mathrm{M}+\mathrm{H}]^{+}$Calcd for $\mathrm{C}_{17} \mathrm{H}_{25} \mathrm{~N}_{4} \mathrm{O}_{3}$ 333.1921; Found 333.1921 ( $\Delta=0.19 \mathrm{ppm})$; HRESIMS/MS (40 eV) $\mathrm{m} / \mathrm{z}(\%): 197.0664$ (95), 169.0712 (100), 140.0463 (32), 112.0505 (41).

Farnesyl 1,3-dimethyluric acid; 1,3-Dimethyluric acid $(0.12 \mathrm{mmol}, 23.3 \mathrm{mg})$ and $\mathrm{K}_{2} \mathrm{CO}_{3}(0.12 \mathrm{mmol}, 16.6 \mathrm{mg})$ were stirred in DMF ( $\left.2 \mathrm{~mL}\right)$ for 5 minutes before dropwise addition of farnesyl bromide $(0.11 \mathrm{mmol}, 32.0 \mathrm{mg}, 30.0 \mu \mathrm{L})$. The reaction was stirred for 19 hours at room temperature and then poured onto $\mathrm{H}_{2} \mathrm{O}(6 \mathrm{~mL})$. The mixture was extracted with EA $(3 \times 2 \mathrm{~mL})$ and the combined extracts were washed with $\mathrm{H}_{2} \mathrm{O}(3 \times 2$ $\mathrm{mL})$, then brine $(1 \times 2 \mathrm{~mL})$ and dried over anhydrous $\mathrm{MgSO}_{4}$. The solvent was removed 
under reduced pressure and the remaining residue was purified by silica gel flash chromatography (1:1 EA/PE) to afford 123 and 124, the $C-5(19.2 \mathrm{mg})$ and $N-9(3.3 \mathrm{mg})$ farnesylated products, both as white solids with a combined yield of $28 \%$ :

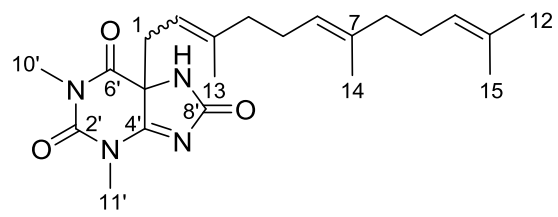

\section{1,3-Dimethyl-5-((6E)-3,7,11-trimethyldodeca-2,6,10-trien-1-yl)-5,7-dihydro-1H-}

purine-2,6,8(3H)-trione (123); 2:1 E/Z NMR data for major isomer: ${ }^{1} \mathrm{H}$ NMR (600 MHz, $\left.\mathrm{CDCl}_{3}\right): \delta 6.39(\mathrm{~s}, 1 \mathrm{H}, \mathrm{NH}), 5.09-5.02$ (complex m, 2H, H-6 and H-10), $4.95(\mathrm{t}, J=7.9$ Hz, 1H, H-2), 3.48 (s, $J=1.4$ Hz, 3H, H-10'), 3.27 (s, $J=1.5$ Hz, 3H, H-11'), 2.68 (d, $J$ $=8.1 \mathrm{~Hz}, 2 \mathrm{H}, \mathrm{H}-1), 2.09-2.00\left(\right.$ complex m, $\left.6 \mathrm{H}, 3 \times \mathrm{CH}_{2}\right), 2.00-1.93\left(\mathrm{~m}, 2 \mathrm{H}, \mathrm{CH}_{2}\right)$, $1.66\left(\mathrm{~s}, 3 \mathrm{H}, \mathrm{CH}_{3}\right), 1.59\left(\mathrm{~s}, 6 \mathrm{H}, 2 \times \mathrm{CH}_{3}\right), 1.58\left(\mathrm{~s}, 3 \mathrm{H}, \mathrm{CH}_{3}\right) ;{ }^{13} \mathrm{C} \mathrm{NMR}\left(150 \mathrm{MHz}, \mathrm{CDCl}_{3}\right)$ : $\delta 176.8$ (C, C-6'), 166.4 (C, C-4'), 165.6 (C, C-8'), 150.9 (C, C-2'), 145.7 (C, C-3), 136.0 (C, C-7), 131.5, (C, C-11) 124.4 (CH, C-10), 123.4 (CH, C-6), 112.7 (CH, C-2), 68.2 (C, C-5'), $40.5\left(\mathrm{CH}_{2}, \mathrm{C}-1\right), 40.0\left(\mathrm{CH}_{2}, \mathrm{C}-8\right), 39.8\left(\mathrm{CH}_{2}, \mathrm{C}-4\right), 32.0\left(\mathrm{CH}_{3}, \mathrm{C}-10\right.$ '), $29.2\left(\mathrm{CH}_{3}\right.$, C-11'), $26.8\left(\mathrm{CH}_{2}, \mathrm{C}-9\right), 26.3\left(\mathrm{CH}_{2}, \mathrm{C}-5\right), 25.8\left(\mathrm{CH}_{3}, \mathrm{C}-15\right), 17.8\left(\mathrm{CH}_{3}, \mathrm{C}-12\right), 16.4\left(\mathrm{CH}_{3}\right.$, C-13 or C-14), $16.2\left(\mathrm{CH}_{3}, \mathrm{C}-13\right.$ or C-14); IR (film from $\left.\mathrm{CH}_{2} \mathrm{Cl}_{2}\right)$ : $v_{\max } 3307,3098,2964$, 2924, 2855, 1695, 1645, $1612 \mathrm{~cm}^{-1}$; HRESIMS m/z: $[\mathrm{M}+\mathrm{H}]^{+}$Calcd for $\mathrm{C}_{22} \mathrm{H}_{33} \mathrm{~N}_{4} \mathrm{O}_{3}$ 401.2547; Found 401.2538 ( $\Delta=2.22 \mathrm{ppm})$; HRESIMS/MS (40 eV) $\mathrm{m} / \mathrm{z}(\%): 197.0639$ (100), 169.0699 (40).

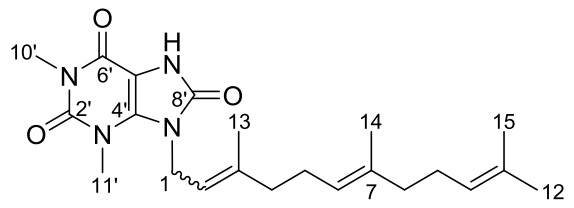

\section{1,3-Dimethyl-9-((6E)-3,7,11-trimethyldodeca-2,6,10-trien-1-yl)-7,9-dihydro-1H-} purine-2,6,8(3H)-trione (124); 3:2 E/Z, NMR data for major isomer: ${ }^{1} \mathrm{H}$ NMR (600 $\mathrm{MHz}_{\mathrm{CDCl}}$ ): $\delta 8.95$ (br s, $\left.1 \mathrm{H}, \mathrm{NH}\right), 5.16-5.11$ (m, 1H, H-2), 5.11 - 5.00 (complex m, 2H, H-6 and H-10), 4.66 (d, $J=5.8 \mathrm{~Hz}, 2 \mathrm{H}, \mathrm{H}-1), 3.67$ (s, 3H, H-11'), 3.40 (d, $J=2.3$ Hz, 3H, H-10'), 2.13 - 2.07 (m, 2H, H-5), 2.07 - 1.98 (complex m, 4H, H-4 and H-9), $1.97-1.91$ (m, 2H, H-8), 1.75 (s, 3H, H-13), 1.67 (s, 3H, H-15), 1.58 (s, 6H, H-12 and H-14); ${ }^{13} \mathrm{C} \mathrm{NMR}\left(150 \mathrm{MHz}, \mathrm{CDCl}_{3}\right.$ ): $\delta 153.2$ (C, C-6'), 151.8 (C, C-8'), 151.0 (C, C-2'), 140.9 (C, C-3), 136.2 (C, C-7), 136.0 (C, C-4'), 131.6 (C, C-11), 124.3 (CH, C-6), 123.3 
(CH, C-10), 119.5 (CH, C-2), 98.4 (C, C-5'), $41.6\left(\mathrm{CH}_{2}, \mathrm{C}-1\right), 39.8\left(\mathrm{CH}_{2}, \mathrm{C}-8\right), 39.4$ $\left(\mathrm{CH}_{2}, \mathrm{C}-4\right), 31.3\left(\mathrm{CH} 3, \mathrm{C}-11^{\prime}\right), 28.6\left(\mathrm{CH}_{3}, \mathrm{C}-10\right.$ ') $, 26.8\left(\mathrm{CH}_{2}, \mathrm{C}-9\right), 26.3\left(\mathrm{CH}_{2}, \mathrm{C}-5\right), 25.9$ $\left(\mathrm{CH}_{3}, \mathrm{H}-15\right), 17.8\left(\mathrm{CH}_{3}, \mathrm{C}-12\right), 17.0\left(\mathrm{CH}_{3}, \mathrm{C}-13\right), 16.2\left(\mathrm{CH}_{3}, \mathrm{C}-14\right)$; IR (film from $\left.\mathrm{CH}_{2} \mathrm{Cl}_{2}\right): v_{\max } 3487,3174,3078,2918,2854,1687,1651 \mathrm{~cm}^{-1}$; HRESIMS m/z: $[\mathrm{M}+\mathrm{H}]^{+}$ Calcd for $\mathrm{C}_{22} \mathrm{H}_{33} \mathrm{~N}_{4} \mathrm{O}_{3}$ 401.2547; Found 401.2551 ( $\Delta=-1.02$ ppm); HRESIMS/MS (40 eV) $m / z(\%): 197.0658$ (100), 169.0707 (57).

Geranylgeranyl 1,3-dimethyluric acid; 1,3-Dimethyluric acid (0.11 mmol, $20.8 \mathrm{mg})$ and $\mathrm{K}_{2} \mathrm{CO}_{3}(0.13 \mathrm{mmol}, 17.6 \mathrm{mg})$ were stirred in DMF $(1 \mathrm{~mL})$ for 15 minutes before dropwise addition of geranylgeranyl bromide $(0.11 \mathrm{mmol}, 37.9 \mathrm{mg}, 37.0 \mu \mathrm{L})$. The reaction was stirred for 20 hours, then poured onto $\mathrm{H}_{2} \mathrm{O}(3 \mathrm{~mL})$ and extracted with EA (3 $\times 2 \mathrm{~mL})$. The combined extracts were washed with $\mathrm{H}_{2} \mathrm{O}(3 \times 2 \mathrm{~mL})$, then brine $(1 \times 2$ $\mathrm{mL}$ ) and dried over anhydrous $\mathrm{MgSO}_{4}$. The solvent was removed under reduced pressure and the residue was purified by silica gel flash chromatography (1:2 EA/PE) to afford $\mathbf{1 2 5}$ as a white powder $(2.8 \mathrm{mg}, 6 \%)$ :



\section{1,3-Dimethyl-5-((2E,6E,10E)-3,7,11,15-tetramethylhexadeca-2,6,10,14-tetraen-1-}

yl)-5,7-dihydro-1 $\boldsymbol{H}$-purine-2,6,8(3H)-trione (125); ${ }^{1} \mathrm{H} \mathrm{NMR}\left(500 \mathrm{MHz}, \mathrm{CDCl}_{3}\right): \delta 5.97$ (s, 1H, NH), $5.12-5.04$ (complex m, 3H, H-6, H-10 and H-14), 4.95 (t, J = 8.0 Hz, 1H, H-2), 3.49 (s, 3H, H-10'), 3.34 (s, 3H, H-11'), 2.67 (d, J = 8.0 Hz, 2H, H-1), 2.11 - 2.02 (complex m, 8H, $4 \times \mathrm{CH}_{2}$ ), $2.02-1.94$ (complex m, 4H, $2 \times \mathrm{CH}_{2}$ ), 1.68 (s, 3H, H-17), $1.61\left(\mathrm{~s}, 3 \mathrm{H}, \mathrm{CH}_{3}\right), 1.60\left(\mathrm{~s}, 3 \mathrm{H}, \mathrm{CH}_{3}\right), 1.58\left(\mathrm{~s}, 6 \mathrm{H}, 2 \times \mathrm{CH}_{3}\right) ;{ }^{13} \mathrm{C} \mathrm{NMR}\left(150 \mathrm{MHz}, \mathrm{CDCl}_{3}\right)$ : $\delta 176.8$ (C, C-6'), 166.4 (C, C-4'), 165.3 (C, C-8'), 150.8 (C, C-2'), 145.8 (C, C-3), 136.2 (C, C-7), 135.2 (C, C-11), 131.5 (C, C-15), 124.5 (CH, C-14), 124.2 (CH, C-10), 123.4 (CH, C-6), 112.7 (CH, C-2), 68.1 (C, C-5'), $40.6\left(\mathrm{CH}_{2}, \mathrm{C}-1\right), 40.0\left(\mathrm{CH}_{2}, \mathrm{C}-12\right), 39.9$ ( $\left.\mathrm{CH}_{2}, \mathrm{C}-8\right), 39.8\left(\mathrm{CH}_{2}, \mathrm{C}-4\right), 32.0\left(\mathrm{CH}_{3}, \mathrm{H}-10^{\prime}\right), 29.2\left(\mathrm{CH}_{3}, \mathrm{H}-11^{\prime}\right), 26.9\left(\mathrm{CH}_{2}, \mathrm{H}-13\right)$, $26.8\left(\mathrm{CH}_{2}, \mathrm{H}-9\right), 26.3\left(\mathrm{CH}_{2}, \mathrm{C}-5\right), 25.9\left(\mathrm{CH}_{3}, \mathrm{C}-20\right), 17.9\left(\mathrm{CH}_{3}, \mathrm{C}-16\right), 16.5\left(\mathrm{CH}_{3}, \mathrm{C}-17\right)$, $16.21\left(\mathrm{CH}_{3}, \mathrm{C}-18\right.$ or $\left.\mathrm{C}-19\right), 16.16\left(\mathrm{CH}_{3}, \mathrm{C}-18\right.$ or $\left.\mathrm{C}-19\right)$; HRESIMS $m / z:[\mathrm{M}+\mathrm{H}]^{+} \mathrm{Calcd}$ for $\mathrm{C}_{27} \mathrm{H}_{41} \mathrm{~N}_{4} \mathrm{O}_{3}$ 469.3173; Found 469.3169 ( $\Delta=0.98 \mathrm{ppm}$ ); HRESIMS/MS (40 eV) $m / z(\%): 197.0660$ (100), 169.0710 (22). 
Geranyl uracil; Uracil (0.53 mmol, $59.9 \mathrm{mg})$ and $\mathrm{K}_{2} \mathrm{CO}_{3}(0.51 \mathrm{mmol}, 68.9 \mathrm{mg})$ were stirred in DMF (2 mL) at $50{ }^{\circ} \mathrm{C}$ for 10 minutes before dropwise addition of geranyl bromide $(0.65 \mathrm{mmol}, 141.1 \mathrm{mg}, 129 \mu \mathrm{L})$. The reaction was stirred for 21 hours and then filtered. $\mathrm{H}_{2} \mathrm{O}(6 \mathrm{~mL})$ was added to the filtrate and then the mixture was stored in the fridge overnight until precipitate formed. The solid was filtered, washed with water and then recrystallised from PE to yield $\mathbf{1 3 3}$ as fine white crystals (15.8 $\mathrm{mg}, 12 \%)$ :

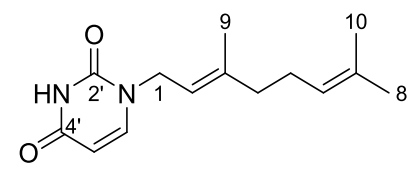

(E)-1-(3,7-Dimethylocta-2,6-dien-1-yl)pyrimidine-2,4(1H,3H)-dione (133); ${ }^{1} \mathrm{H}$ NMR $\left(500 \mathrm{MHz}, \mathrm{CDCl}_{3}\right): \delta 8.42$ (br s, $\left.1 \mathrm{H}, \mathrm{NH}\right), 7.16$ (d, $J=7.9 \mathrm{~Hz}, 1 \mathrm{H}, \mathrm{H}-6$ '), 5.68 (dd, $J=$ 7.9, $\left.2.1 \mathrm{~Hz}, 1 \mathrm{H}, \mathrm{H}-5^{\prime}\right), 5.22$ (t, $\left.J=7.3,1 \mathrm{H}, \mathrm{H}-2\right), 5.04$ (t, $\left.J=6.6 \mathrm{~Hz}, 1 \mathrm{H}, \mathrm{H}-6\right), 4.35$ (d, $J$ $=7.3 \mathrm{~Hz}, 2 \mathrm{H}, \mathrm{H}-1), 2.11$ (complex m, 4H, H-4 and H-5), 1.75 (s, 3H, H-9), 1.68 (s, 3H, H-10), 1.60 (s, 3H, H-8); ${ }^{13} \mathrm{C}$ NMR (150 MHz, $\mathrm{CDCl}_{3}$ ): $\delta 163.4$ (C, C-4'), 150.9 (C, C2'), 143.7 (C, C-3), 143.6 (CH, C-6'), 132.4 (C, C-7), 123.5 (CH, C-6), 117.3 (CH, C-2), $102.2\left(\mathrm{CH}, \mathrm{C}-5\right.$ ') $, 45.2\left(\mathrm{CH}_{2}, \mathrm{C}-1\right), 39.6\left(\mathrm{CH}_{2}, \mathrm{C}-4\right), 26.2\left(\mathrm{CH}_{2}, \mathrm{C}-5\right), 25.9\left(\mathrm{CH}_{3}, \mathrm{C}-10\right)$, $17.9\left(\mathrm{CH}_{3}, \mathrm{C}-8\right), 16.6\left(\mathrm{CH}_{3}, \mathrm{C}-9\right)$; IR (neat): 3121, 2967, 2929, 2808, 1696, $1657 \mathrm{~cm}^{-1}$; m.p. $81.5-83{ }^{\circ} \mathrm{C}$; HRESIMS $m / z$ : $[\mathrm{M}+\mathrm{H}]^{+}$Calcd for $\mathrm{C}_{14} \mathrm{H}_{21} \mathrm{~N}_{2} \mathrm{O}_{2}$ 249.1598; Found 249.1595 ( $\Delta=1.01 \mathrm{ppm})$; HRESIMS/MS (40 eV) $\mathrm{m} / \mathrm{z}$ (\%): 113.0346 (100), 81.0700 (18), $70.0289(7)$.

Farnesyl uracil; Uracil (0.49 mmol, $54.9 \mathrm{mg})$ and $\mathrm{K}_{2} \mathrm{CO}_{3}(0.51 \mathrm{mmol}, 69.9 \mathrm{mg})$ were stirred in DMF $(2 \mathrm{~mL})$ at $70{ }^{\circ} \mathrm{C}$ before dropwise addition of farnesyl bromide $(0.54 \mathrm{mmol}$, $150 \mathrm{mg}, 162.8 \mu \mathrm{L})$. After stirring for 24 hours, the reaction was filtered, $\mathrm{H}_{2} \mathrm{O}(6 \mathrm{~mL})$ was added and the mixture stored in the fridge overnight. The resulting precipitate was isolated by filtration and recrystallised from PE to afford $\mathbf{1 3 4}$ as fine white crystals (38.6 $\mathrm{mg}, 25 \%)$ :

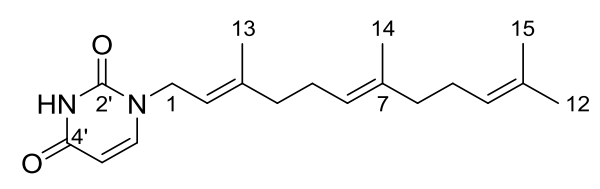

1-((2E,6E)-3,7,11-Trimethyldodeca-2,6,10-trien-1-yl)pyrimidine-2,4(1H,3H)-dione (134); ${ }^{1} \mathrm{H}$ NMR (600 MHz, $\left.\mathrm{CDCl}_{3}\right): \delta 8.46$ (s, $\left.1 \mathrm{H}, \mathrm{NH}\right), 7.16(\mathrm{~d}, J=7.9 \mathrm{~Hz}, 1 \mathrm{H}, \mathrm{H}-6$ '), $5.68\left(\mathrm{dt}, J=7.9,2.0 \mathrm{~Hz}, 1 \mathrm{H}, \mathrm{H}-5^{\prime}\right.$ ), $5.24-5.19$ (m, 1H, H-2), $5.09-5.04$ (complex m, 
2H, H-6 and H-10), 4.34 (d, $J=7.3 \mathrm{~Hz}, 2 \mathrm{H}, \mathrm{H}-1$ ), $2.16-2.01$ (complex m, 6H, $3 \times \mathrm{CH}_{2}$ ), 1.99 - 1.94 (m, 2H, CH 2 ), 1.75 (s, 3H, H-13), 1.68 (s, 3H, H-15), 1.62 (s, 3H, H-12 or H14), 1.59 (s, 3H, H-12 or H-14); IR (film from $\mathrm{CH}_{2} \mathrm{Cl}_{2}$ ): $v_{\max } 3054,2979,2930,1683 \mathrm{~cm}^{-}$ 1; HRESIMS $m / z:[\mathrm{M}+\mathrm{H}]^{+}$Calcd for $\mathrm{C}_{19} \mathrm{H}_{28} \mathrm{~N}_{2} \mathrm{O}_{2} 317.2224$; Found $317.2222(\Delta=0.58$ ppm); HRESIMS/MS m/z (\%): 113.0340 (87), 81.0698 (100).

Geranylgeranyl uracil; Uracil $(0.29 \mathrm{mmol}, 32.7 \mathrm{mg})$ and $\mathrm{K}_{2} \mathrm{CO}_{3}(0.36 \mathrm{mmol}, 50.1 \mathrm{mg})$ were stirred in DMF $(1 \mathrm{~mL})$ for 10 minutes at room temperature before dropwise addition of geranylgeranyl bromide $(0.32 \mathrm{mmol}, 111 \mathrm{mg}, 108.6 \mu \mathrm{L})$. The reaction was stirred for 2 days and then $\mathrm{H}_{2} \mathrm{O}(2 \mathrm{~mL})$ was added. The mixture was extracted with $\mathrm{EA}(3 \times 2 \mathrm{~mL})$ and the combined extracts were washed with $\mathrm{H}_{2} \mathrm{O}(3 \times 2 \mathrm{~mL})$, then brine $(1 \times 2 \mathrm{ml})$ and dried over anhydrous $\mathrm{MgSO}_{4}$. The solvent was removed under reduced pressure and the residue was purified by silica gel flash chromatography (2:3 EA/PE) to yield $\mathbf{1 3 5}$ and 136, the $2 Z(9.4 \mathrm{mg})$ and $2 E(19.2 \mathrm{mg}) \mathrm{N}-1$ geranylgeranylated products as white solids with a combined yield of $26 \%$ :

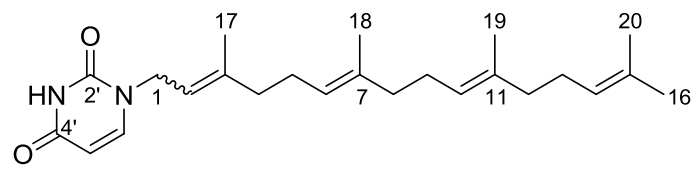

1-((2Z,6E,10E)-3,7,11,15-Tetramethylhexadeca-2,6,10,14-tetraen-1-yl)pyrimidine-

2,4(1H,3H)-dione (135); $\mathrm{R}_{f}=0.23(2: 3 \mathrm{EA} / \mathrm{PE}) ;{ }^{1} \mathrm{H} \mathrm{NMR}\left(500 \mathrm{MHz}, \mathrm{CDCl}_{3}\right): \delta 8.78(\mathrm{~s}$, 1H, NH), 7.15 (dd, $J=7.9,0.8$ Hz, 1H, H-6'), 5.68 (dd, J = 7.9, 1.4 Hz, 1H, H-5'), 5.22 (t, $J=7.2 \mathrm{~Hz}, 1 \mathrm{H}, \mathrm{H}-2$ ), $5.13-5.04$ (complex m, 3H, H-6, H-10 and H-14), 4.33 (d, $J=$ $7.3 \mathrm{~Hz}, 2 \mathrm{H}, \mathrm{H}-1$ ), 2.20 - 2.10 (complex m, 4H, $2 \times \mathrm{CH}_{2}$ ), $2.10-2.02$ (complex m, 4H, 2 $\left.\times \mathrm{CH}_{2}\right), 2.01-1.93\left(\right.$ complex m, 4H, $\left.2 \times \mathrm{CH}_{2}\right), 1.79$ (s, 3H, H-17), 1.68 (s, 3H, H-20), $1.61\left(\mathrm{~s}, 3 \mathrm{H}, \mathrm{CH}_{3}\right), 1.60\left(\mathrm{~s}, 6 \mathrm{H}, 2 \times \mathrm{CH}_{3}\right) ;{ }^{13} \mathrm{C} \mathrm{NMR}\left(150 \mathrm{MHz}, \mathrm{CDCl}_{3}\right): \delta 163.6(\mathrm{C}, \mathrm{C}-$ 4'), 150.9 (C, C-2'), 143.7 (C, C-3), 143.6 (CH, C-6'), 136.5 (C, C-7), 135.3 (C, C-11), 131.5 (C, C-15), 124.5 (CH, C-14), 124.1 (CH, C-10), 123.1 (CH, C-6), 118.1 (CH, C2), $102.2\left(\mathrm{CH}, \mathrm{C}-5\right.$ '), $45.1\left(\mathrm{CH}_{2}, \mathrm{C}-1\right), 39.9\left(2 \times \mathrm{CH}_{2}, \mathrm{C}-8\right.$ and $\left.\mathrm{C}-12\right), 32.2\left(\mathrm{CH}_{2}, \mathrm{C}-4\right)$, $26.9\left(\mathrm{CH}_{2}, \mathrm{C}-13\right), 26.7\left(\mathrm{CH}_{2}, \mathrm{C}-9\right), 26.5\left(\mathrm{CH}_{2}, \mathrm{C}-5\right), 25.9\left(\mathrm{CH}_{3}, \mathrm{C}-20\right), 23.6\left(\mathrm{CH}_{3}, \mathrm{C}-17\right)$, $17.8\left(\mathrm{CH}_{3}, \mathrm{C}-16\right), 16.20\left(\mathrm{CH}_{3}, \mathrm{C}-18\right.$ or $\left.\mathrm{C}-19\right), 16.16\left(\mathrm{CH}_{3}, \mathrm{C}-18\right.$ or $\left.\mathrm{C}-19\right)$; IR (film from $\left.\mathrm{CH}_{2} \mathrm{Cl}_{2}\right): v_{\max } 3425,3197,3054,2970,2930,2875 \mathrm{~cm}^{-1}$; HRESIMS $m / z:[\mathrm{M}+\mathrm{H}]^{+}$Calcd $\mathrm{C}_{24} \mathrm{H}_{37} \mathrm{~N}_{2} \mathrm{O}_{2}$ 385.2850; Found 385.2817 ( $\Delta=8.44 \mathrm{ppm}$ ); HRESIMS/MS $\mathrm{m} / \mathrm{z}(\%)$ : $114.0359(5), 113.0334(100)$. 
1-((2E,6E,10E)-3,7,11,15-Tetramethylhexadeca-2,6,10,14-tetraen-1-yl)pyrimidine-

2,4(1H,3H)-dione (136); $\mathrm{R}_{f}=0.13(2: 3 \mathrm{EA} / \mathrm{PE}) ;{ }^{1} \mathrm{H} \mathrm{NMR}\left(500 \mathrm{MHz}, \mathrm{CDCl}_{3}\right): \delta 9.25$ (s, 1H, NH), 7.15 (d, $J=7.9 \mathrm{~Hz}, 1 \mathrm{H}, \mathrm{H}-6$ '), 5.69 (dd, $J=7.9,1.8 \mathrm{~Hz}, 1 \mathrm{H}, \mathrm{H}-5$ '), 5.22 (t, $J=$ $7.2 \mathrm{~Hz}, 1 \mathrm{H}, \mathrm{H}-2$ ), $5.11-5.04$ (complex m, 3H, H-6, H-10 and H-14), 4.34 (d, J=7.3 Hz, $2 \mathrm{H}, \mathrm{H}-1$ ), 2.15 - 2.01 (complex m, 8H, $4 \times \mathrm{CH}_{2}$ ), $2.00-1.93$ (complex m, 4H, $2 \times \mathrm{CH}_{2}$ ), 1.75 (s, 3H, $\mathrm{CH}_{3}, \mathrm{H}-17$ ), 1.67 (s, 3H, H-20), 1.59 (s, 9H, $\left.3 \times \mathrm{CH}_{3}\right) ;{ }^{13} \mathrm{C} \mathrm{NMR}(150 \mathrm{MHz}$, $\mathrm{CDCl}_{3}$ ): $\delta 163.8$ (C, C-4'), 151.19 (C, C-2'), 143.8 (C, C-3), 143.6 (CH, C-6'), 136.0 (C, C-7), 135.2 (C, C-11), 131.4 (C, C-15), 124.5 (CH, C-14), 124.1 (CH, C-10), 123.4 (CH, C-6), $117.2(\mathrm{CH}, \mathrm{C}-2), 102.3\left(\mathrm{CH}, \mathrm{C}-5\right.$ '), $45.2\left(\mathrm{CH}_{2}, \mathrm{C}-1\right), 39.84\left(\mathrm{CH}_{2}, \mathrm{C}-12\right), 39.80\left(\mathrm{CH}_{2}\right.$, C-8 ), $39.6\left(\mathrm{CH}_{2}, \mathrm{C}-4\right), 26.9\left(\mathrm{CH}_{2}, \mathrm{C}-13\right), 26.7\left(\mathrm{CH}_{2}, \mathrm{C}-9\right), 26.2\left(\mathrm{CH}_{2}, \mathrm{C}-5\right), 25.8\left(\mathrm{CH}_{3}\right.$, C-20), $17.8\left(\mathrm{CH}_{3}, \mathrm{C}-16\right), 16.6\left(\mathrm{CH}_{3}, \mathrm{C}-17\right), 16.2\left(\mathrm{CH}_{3}, \mathrm{C}-18\right.$ or C-19), $16.1\left(\mathrm{CH}_{3}, \mathrm{C}-18\right.$ or C-19); IR (film from $\mathrm{CH}_{2} \mathrm{Cl}_{2}$ ): $v_{\max } 3175,3052,2967,2916,2853,1677 \mathrm{~cm}^{-1}$; HRESIMS $m / z:[\mathrm{M}+\mathrm{H}]^{+}$Calcd $\mathrm{C}_{24} \mathrm{H}_{37} \mathrm{~N}_{2} \mathrm{O}_{2}$ 385.2850, found 385.2834 ( $\Delta=3.98 \mathrm{ppm}$ ); HRESIMS/MS m/z (\%): 114.0369 (6), 113.0341 (100).

Geranyl thymine; Thymine $(0.48 \mathrm{mmol}, 61.0 \mathrm{mg})$ and $\mathrm{K}_{2} \mathrm{CO}_{3}(0.50 \mathrm{mmol}, 69.4 \mathrm{mg})$ were stirred in DMF $(2 \mathrm{~mL})$ at room temperature before dropwise addition of geranyl bromide $(0.65 \mathrm{mmol}, 141.1 \mathrm{mg}, 129 \mu \mathrm{L})$. The reaction was stirred for 20 hours and then filtered. The product was precipitated by addition of $\mathrm{H}_{2} \mathrm{O}(6 \mathrm{~mL})$ and the isolated solid was recrystallised from PE to afford $\mathbf{1 3 7}$ as fine white crystals $(6.8 \mathrm{mg}, \mathbf{5 \%})$ :

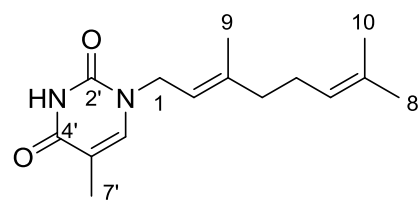

\section{(E)-1-(3,7-Dimethylocta-2,6-dien-1-yl)-5-methylpyrimidine-2,4-(1H,3H)-dione}

(137); ${ }^{1} \mathrm{H}$ NMR (600 MHz, $\left.\mathrm{CDCl}_{3}\right): \delta 8.20$ (br s, $\left.1 \mathrm{H}, \mathrm{NH}\right), 6.95$ (d, J = $1.2 \mathrm{~Hz}, 1 \mathrm{H}, \mathrm{H}-$ 6'), 5.21 (t, $J=7.1 \mathrm{~Hz}, 1 \mathrm{H}, \mathrm{H}-2), 5.05$ (t, $J=6.9 \mathrm{~Hz}, 1 \mathrm{H}, \mathrm{H}-6), 4.32$ (d, $J=7.3 \mathrm{~Hz}, 2 \mathrm{H}$, H-1), 2.14 - 2.05 (complex m, 4H, H-4 and H-5), 1.92 (s, 3H, H-7'), 1.75 (s, 3H, H-9), 1.67 (s, 3H, H-10), 1.60 (s, 3H, H-8); ${ }^{13} \mathrm{C}$ NMR (150 MHz, CDCl 3 ): $\delta 163.9$ (C, C-4'), 150.8 (C, C-2'), 142.9 (C, C-3), 139.7 (CH, C-6'), 132.3 (C, C-7), 123.5 (CH, C-6), 117.7 (CH, C-2), 110.7 (C, C-5'), $45.1\left(\mathrm{CH}_{2}, \mathrm{C}-1\right), 39.6\left(\mathrm{CH}_{2}, \mathrm{C}-4\right), 26.3\left(\mathrm{CH}_{2}, \mathrm{C}-5\right), 25.9\left(\mathrm{CH}_{2}\right.$, C-10), $17.9\left(\mathrm{CH}_{3}, \mathrm{C}-8\right), 16.6\left(\mathrm{CH}_{3}, \mathrm{C}-9\right), 12.6\left(\mathrm{CH}_{3}, \mathrm{C}-7\right.$ '); IR (film from $\left.\mathrm{CH}_{2} \mathrm{Cl}_{2}\right)$ : $v_{\max }$ 3152, 2975, 2919, 2830, 1685, $1645 \mathrm{~cm}^{-1}$; m.p. $81.7-83.3{ }^{\circ} \mathrm{C}$; HRESIMS m/z: $[\mathrm{M}+\mathrm{H}]^{+}$ 
Calcd for $\mathrm{C}_{15} \mathrm{H}_{23} \mathrm{~N}_{2} \mathrm{O}_{2} 263.1754$; Found 263.1752 ( $\left.\Delta=0.9 \mathrm{ppm}\right)$; HRESIMS/MS $m / z(\%)$ : 128.0524 (7), 127.0501 (100), 81.07 (19).

Farnesyl thymine; Thymine $(0.49 \mathrm{mmol}, 62.4 \mathrm{mg})$ and $\mathrm{K}_{2} \mathrm{CO}_{3}(70.5 \mathrm{mg})$ were stirred in DMF (2 mL) at $70{ }^{\circ} \mathrm{C}$ for 15 minutes before dropwise addition of farnesyl bromide $(0.62 \mathrm{mmol}, 176.9 \mathrm{mg}, 162.8 \mu \mathrm{L})$. The reaction was stirred for 24 hours and then filtered. $\mathrm{H}_{2} \mathrm{O}(6 \mathrm{~mL})$ was added to the reaction mixture and stored in the fridge overnight. The resulting precipitate was isolated by filtration and then recrystallised from PE to afford 138 as small white crystals (31.9 mg, 20\%):

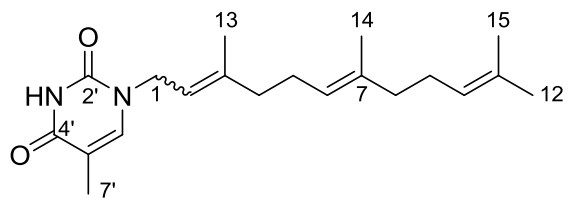

5-Methyl-1-((6E)-3,7,11-trimethyldodeca-2,6,10-trien-1-yl)pyrimidine-2,4(1H,3H)dione (138); 3:2 E/Z, NMR data for major isomer: ${ }^{1} \mathrm{H} \mathrm{NMR}\left(600 \mathrm{MHz}, \mathrm{CDCl}_{3}\right): \delta 8.41$ (br s, 1H, NH), 6.95 (s, 1H, H-6'), 5.21 (m, 1H, H-2), 5.11 - 5.01 (complex m, 2H, H-6 and $\mathrm{H}-10), 4.32$ (d, $J=7.5 \mathrm{~Hz}, 2 \mathrm{H}, \mathrm{H}-1), 2.14-2.02$ (complex m, 6H, $3 \times \mathrm{CH}_{2}$ ), $1.98-$ 1.95 (m, 2H, CH 2 ), 1.91 (s, 3H, H-7'), 1.76 (s, 3H, H-13), 1.67 complex (s, 6H, H-15 and H-14), 1.59 (s, 3H, H-12); ${ }^{13} \mathrm{C}$ NMR (150 MHz, CDCl 3 ): $\delta 164.0$ (C, C-4'), 150.9 (C, C2'), 142.9 (C, C-11), 139.7 (CH, C-6'), 135.9 (C, C-7), 131.6 (C, C-11), 124.3 (CH, C-6 or C-10), 123.4 (CH, C-6 or C-10), 117.7 (CH, C-2), 110.7 (C, C-5'), $45.1\left(\mathrm{CH}_{2}, \mathrm{C}-1\right)$, $39.8\left(\mathrm{CH}_{2}, \mathrm{C}-8\right), 39.6\left(\mathrm{CH}_{2}, \mathrm{C}-4\right), 26.8\left(\mathrm{CH}_{2}, \mathrm{C}-9\right), 26.2\left(\mathrm{CH}_{2}, \mathrm{C}-5\right), 25.9\left(\mathrm{CH}_{3}, \mathrm{C}-15\right)$, $17.8\left(\mathrm{CH}_{3}, \mathrm{C}-12\right), 16.7\left(\mathrm{CH}_{3}, \mathrm{C}-13\right), 16.2\left(\mathrm{CH}_{3}, \mathrm{C}-14\right), 12.6\left(\mathrm{CH}_{3}, \mathrm{C}-7{ }^{\prime}\right) ;{ }^{15} \mathrm{~N}$ NMR (60 $\mathrm{MHz}, \mathrm{CDCl}_{3}$ ): $\delta-226.1\left(\mathrm{~N}-3^{\prime}\right),-246.2\left(\mathrm{~N}-1^{\prime}\right)$; IR (film from $\mathrm{CH}_{2} \mathrm{Cl}_{2}$ ): v $\max , 3177,3052$, $2966,2927,1665 \mathrm{~cm}^{-1}$.

Geranylgeranyl thymine; Thymine $(0.31 \mathrm{mmol}, 38.7 \mathrm{mg})$ and $\mathrm{K}_{2} \mathrm{CO}_{3}(0.36 \mathrm{mmol}$, $49.6 \mathrm{mg}$ ) were stirred in DMF ( $1 \mathrm{~mL})$ at room temperature for 15 minutes before dropwise addition of geranylgeranyl bromide $(0.32 \mathrm{mmol}, 111 \mathrm{mg}, 108.6 \mu \mathrm{L})$. The reaction was stirred for 24 hours and then $\mathrm{H}_{2} \mathrm{O}(3 \mathrm{~mL})$ was added. The mixture was extracted with EA $(3 \times 2 \mathrm{~mL})$ and the combined extracts were washed with $\mathrm{H}_{2} \mathrm{O}(3 \times 2 \mathrm{~mL})$, then brine $(1 \times$ $2 \mathrm{~mL}$ ) and dried over anhydrous $\mathrm{MgSO}_{4}$. The solvent was removed under reduced pressure and the residue was purified by silica gel flash chromatography (2:3 EA/PE) to yield 139 as a waxy solid $(10.1 \mathrm{mg}, 13 \%)$ : 


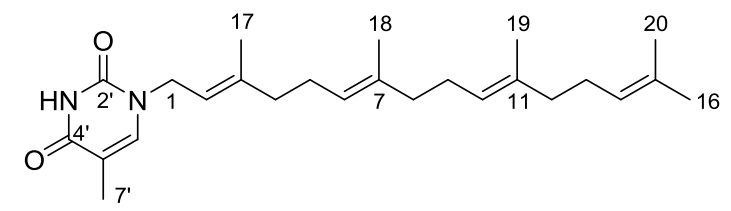

\section{5-Methyl-1-((2E,6E,10E)-3,7,11,15-tetramethylhexadeca-2,6,10,14-tetraen-1-}

yl)pyrimidine-2,4(1H,3H)-dione (139); $\mathrm{R}_{f}=0.22(2: 3 \mathrm{EA} / \mathrm{PE}) ;{ }^{1} \mathrm{H}$ NMR $(500 \mathrm{MHz}$, $\mathrm{CDCl}_{3}$ ): $\delta 8.67$ (br s, $\left.1 \mathrm{H}, \mathrm{NH}\right), 6.95(\mathrm{~d}, J=1.1 \mathrm{~Hz}, 1 \mathrm{H}, \mathrm{H}-6$ '), 5.21 (t, $J=6.7 \mathrm{~Hz}, 1 \mathrm{H}, \mathrm{H}-$ 2), 5.12 - 5.04 (complex m, 3H, H-6, H-10 and H-14), 4.32 (d, J=7.1 Hz, 2H, H-1), 2.16 - 2.02 (complex m, 8H, $4 \times \mathrm{CH}_{2}$ ), $2.01-1.94$ (complex m, 4H, $\left.2 \times \mathrm{CH}_{2}\right), 1.91(\mathrm{~s}, 3 \mathrm{H}, \mathrm{H}-$ 7'), 1.76 (s, 3H, H-17), 1.68 (s, 3H, H-20), 1.60 (s, 6H, $2 \times \mathrm{CH}_{3}$ ), 1.59 (s, 3H, CH 3 ); IR (film from $\mathrm{CH}_{2} \mathrm{Cl}_{2}$ ): $v_{\max } 3427,3176,3043,2968,2925,2855,1668 \mathrm{~cm}^{-1}$.

Geranyl cytosine; Cytosine (1.012 mmol, $112.4 \mathrm{mg}$ ) and $\mathrm{K}_{2} \mathrm{CO}_{3}(1.010 \mathrm{mmol}, 152.0$ $\mathrm{mg}$ ) were stirred in DMF (4 mL) for 25 minutes before dropwise addition of geranyl bromide $(1.098 \mathrm{mmol}, 238.5 \mathrm{mg}, 218.0 \mu \mathrm{L})$. The reaction was stirred for 27 hours at room temperature and then filtered through celite. The filtrate was poured onto $\mathrm{H}_{2} \mathrm{O}(12 \mathrm{~mL})$ and the mixture was extracted with EA $(3 \times 10 \mathrm{~mL})$. The combined extracts were washed with $\mathrm{H}_{2} \mathrm{O}(3 \times 10 \mathrm{~mL})$, then brine $(1 \times 10 \mathrm{~mL})$ and dried over anhydrous $\mathrm{MgSO}_{4}$. The solvent was removed under reduced pressure and the remaining residue was purified by silica gel flash chromatography (1:1 EA/PE) multiple times to afford $\mathbf{1 4 0}$ as a pale-yellow oil (4.5 mg, $2 \%)$ :

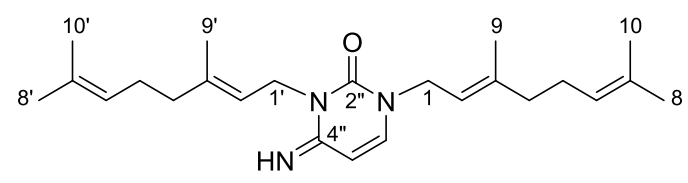

\section{1,3-bis((E)-3,7-Dimethylocta-2,6-dien-1-yl)-4-imino-3,4-dihydropyrimidin-2(1H)-} one (140); $\mathrm{R}_{f}=0.16(1: 1 \mathrm{EA} / \mathrm{PE}) ;{ }^{1} \mathrm{H} \mathrm{NMR}\left(600 \mathrm{MHz}, \mathrm{CDCl}_{3}\right): \delta 6.59(\mathrm{~d}, J=7.9 \mathrm{~Hz}$, 1H, H-6”), 5.53 (d, J=7.9 Hz, 1H, H-5”), 5.23 (t, $J=6.3$ Hz, 1H, H-2'), 5.21 - 5.16 (m, 1H, H-2), 5.09 - 5.02 (complex m, 2H, H-6 and H-6'), 4.62 (d, $J=6.4$ Hz, 2H, H-1'), $4.25(\mathrm{~d}, J=7.2 \mathrm{~Hz}, 2 \mathrm{H}, \mathrm{H}-1), 2.14-2.03$ (complex m, 6H, $3 \times \mathrm{CH}_{2}$ ), $2.01-1.97$ (m, 2H, H-4'), 1.80 (s, 3H, H-9'), 1.71 (s, 3H, H-9), 1.66 (s, 3H, CH $\mathrm{CH}_{3}, 1.65$ (s, 3H, $\mathrm{CH}_{3}$ ), 1.58 (s, $\left.3 \mathrm{H}, \mathrm{CH}_{3}\right), 1.57$ (s, 3H, $\left.\mathrm{CH}_{3}\right) ;{ }^{13} \mathrm{C} \mathrm{NMR}\left(150 \mathrm{MHz}, \mathrm{CDCl}_{3}\right): \delta 158.2(\mathrm{C}, \mathrm{C}-4 ”), 151.3(\mathrm{C}$, C-2”), 142.3 (C, C-3), 139.6 (C, C-3'), 135.2 (CH, C-6”), 132.1 (C, C-7 or C-7'), 131.6 (C, C-7 or C-7'), 124.2 (CH, C-6 or C-6'), 123.7 (CH, C-6 or C-6'), 118.6 (CH, C-2'), 118.3 (CH, C-2), 102.0 (CH, C-5”), $45.7\left(\mathrm{CH}_{2}, \mathrm{C}-1\right), 40.5\left(\mathrm{CH}_{2}, \mathrm{C}-1\right.$ '), $39.8\left(\mathrm{CH}_{2}, \mathrm{C}-4\right.$ '), 
$39.6\left(\mathrm{CH}_{2}, \mathrm{C}-4\right), 26.6\left(\mathrm{CH}_{2}, \mathrm{C}-5\right.$ or C-5'), $26.3\left(\mathrm{CH}_{2}, \mathrm{C}-5\right.$ or C-5'), $25.8\left(\mathrm{CH}_{3}, \mathrm{C}-10\right.$ or C-10'), $25.8\left(\mathrm{CH}_{3}, \mathrm{C}-10\right.$ or C-10'), $17.9\left(\mathrm{CH}_{3}, \mathrm{C}-8\right.$ or C-8'), $17.8\left(\mathrm{CH}_{3}, \mathrm{C}-8\right.$ or C-8'), 16.7 $\left(\mathrm{CH}_{3}, \mathrm{C}-9\right.$ or C-9'), $16.5\left(\mathrm{CH}_{3}, \mathrm{C}-9\right.$ or C-9'); IR (film from $\left.\mathrm{CH}_{2} \mathrm{Cl}_{2}\right)$ : v $v_{\max } 3305,3083$, 2966, 2915, 2855, $1651 \mathrm{~cm}^{-1}$; HRESIMS $m / z$ : $[\mathrm{M}+\mathrm{H}]^{+}$Calcd for $\mathrm{C}_{24} \mathrm{H}_{38} \mathrm{~N}_{3} \mathrm{O} 384.3009$; Found $384.3023(\Delta=-3.61 \mathrm{ppm})$; HRESIMS/MS m/z (20 eV) (\%): 384.3018 (0.1), 248.1764 (100), $113.0529(0.09)$.

Farnesyl cytosine; Cytosine (1.0 mmol, $114.8 \mathrm{mg})$ and $\mathrm{K}_{2} \mathrm{CO}_{3}(1.5 \mathrm{mmol}, 204.4 \mathrm{mg})$ were stirred in DMF (2 mL) for 40 minutes before dropwise addition of farnesyl bromide (1.2 mmol, $341 \mathrm{mg}, 325 \mu \mathrm{L})$. The reaction was stirred for 25 hours at room temperature, then poured onto $\mathrm{H}_{2} \mathrm{O}(6 \mathrm{~mL})$ and extracted with EA $(3 \times 6 \mathrm{~mL})$. The combined extracts were washed with $\mathrm{H}_{2} \mathrm{O}(3 \times 10 \mathrm{~mL})$, then brine $(1 \times 10 \mathrm{~mL})$ and dried over anhydrous $\mathrm{MgSO}_{4}$. The solvent was removed under reduced pressure and the residue was purified by silica gel flash chromatography (1:1 EA/PE) to afford two fractions. These were purified again, separately, by silica gel flash chromatography (1:1 EA/PE and 1:4 EA/PE) to yield $\mathbf{1 4 1}$ as a pale-yellow oil (96.4 $\mathrm{mg}, 31 \%)$ :

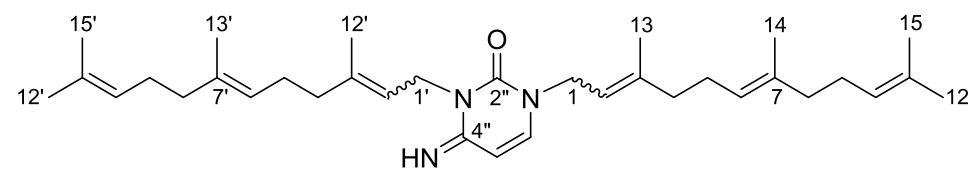

\section{4-Imino-1,3-bis((6E)-3,7,11-trimethyldodeca-2,6,10-trien-1-yl)-3,4-}

dihydropyrimidin-2(1H)-one (141); $\mathrm{R}_{f}=0.19(1: 1 \mathrm{EA} / \mathrm{PE})$; both $3: 2 \mathrm{E} / \mathrm{Z}$, NMR data for major isomer: ${ }^{1} \mathrm{H}$ NMR (600 MHz, $\left.\mathrm{CDCl}_{3}\right): \delta 6.59(\mathrm{dt}, J=7.8,2.6 \mathrm{~Hz}, 1 \mathrm{H}, \mathrm{H}-6$ "), 5.53 (d, $J=5.7 \mathrm{~Hz}, 1 \mathrm{H}, \mathrm{H}-5$ '), 5.24 (t, $\left.J=6.5 \mathrm{~Hz}, 1 \mathrm{H}, \mathrm{H}-2^{\prime}\right), 5.20$ (t, $\left.J=8.5 \mathrm{~Hz}, 1 \mathrm{H}, \mathrm{H}-2\right)$, 5.13 - 5.04 (complex m, 4H, H-6, H-6', H-10, H-10'), 4.63 (d, J = 6.3 Hz, 2H, H-1'), $4.26(\mathrm{~d}, J=7.2 \mathrm{~Hz}, 2 \mathrm{H}, \mathrm{H}-1), 2.15-1.91$ (complex m, 16H, $8 \times \mathrm{CH}_{2}$ ), 1.81 (s, 3H, H12'), 1.72 (s, 3H, H-12), 1.68 (s, 9H, $\left.3 \times \mathrm{CH}_{3}\right), 1.59$ (s, 9H, $\left.3 \times \mathrm{CH}_{3}\right) ;{ }^{13} \mathrm{C}$ NMR (150 MHz, $\mathrm{CDCl}_{3}$ ): $\delta 158.2$ (C, C-4”), 151.4 (C, C-2”), 142.3 (C, C-3), 139.6 (C, C-3'), 135.8 (C, C-7 or C-7'), 135.22 (C, C-7 or C-7'), 131.6 (C, C-11 or C-11'), 131.4 (C, C-11 or C11'), 124.5 (CH, C-10 or C-10'), 124.3 (CH, C-10 or C-10'), 123.6 (CH, C-6 or C-6'), 118.4 (CH, C-2'), 118.4 (CH, C-2), 102.2 (CH, C-5”), $45.7\left(\mathrm{CH}_{2}, \mathrm{C}-1\right), 40.4\left(\mathrm{CH}_{2}, \mathrm{C}-1\right.$ ') $39.84\left(\mathrm{CH}_{2}, \mathrm{C}-8\right.$ or C-8'), $39.83\left(\mathrm{CH}_{2}, \mathrm{C}-8\right.$ or C-8'), $39.77\left(\mathrm{CH}_{2}, \mathrm{C}-4\right.$ or C-4'), 39.65 ( $\mathrm{CH}_{2}, \mathrm{C}-4$ or C-4'), $26.9\left(\mathrm{CH}_{2}, \mathrm{C}-9\right.$ or C-9'), $26.8\left(\mathrm{CH}_{2}, \mathrm{C}-9\right.$ or C-9'), $26.6\left(\mathrm{CH}_{2}, \mathrm{C}-5\right.$ or C-5'), $26.3\left(\mathrm{CH}_{2}, \mathrm{C}-5\right.$ or C-5'), 25.0 (2 $\times \mathrm{CH}_{3}, \mathrm{C}-16$ and C-16'), $17.85\left(2 \times \mathrm{CH}_{3}, \mathrm{C}-12\right.$ and C-12'), $16.7\left(\mathrm{CH}_{3}, \mathrm{C}-12\right.$ or C-12'), $16.6\left(\mathrm{CH}_{3}, \mathrm{C}-12\right.$ or $\left.\mathrm{C}-12{ }^{\prime}\right), 16.2\left(\mathrm{CH}_{3}, \mathrm{C}-14\right.$ or C- 
14'), $16.1\left(\mathrm{CH}_{3}, \mathrm{C}-14\right.$ or C-14'); IR (film from $\left.\mathrm{CH}_{2} \mathrm{Cl}_{2}\right)$ : $v_{\max } 3306,2964,2915,2854 \mathrm{~cm}^{-}$ 1; HRESIMS $m / z:[\mathrm{M}+\mathrm{H}]^{+}$Calcd for $\mathrm{C}_{34} \mathrm{H}_{54} \mathrm{~N}_{3} \mathrm{O} 520.4261$; Found $520.4269(\Delta=-1.47$ ppm); HRESIMS/MS m/z (20 eV) (\%): 112.0509 (100).

Geranyl imidazole; Imidazole $(0.57 \mathrm{mmol}, 38.7 \mathrm{mg})$ and $\mathrm{K}_{2} \mathrm{CO}_{3}(0.66 \mathrm{mmol}, 91.4 \mathrm{mg})$ were stirred in DMF ( $2 \mathrm{~mL}$ ) for 15 minutes at room temperature before dropwise addition of geranyl bromide $(0.60 \mathrm{mmol}, 130 \mathrm{mg}, 119.20 \mu \mathrm{L})$. The reaction was stirred for 46 hours and then $\mathrm{H}_{2} \mathrm{O}(6 \mathrm{~mL})$ was added. The mixture was extracted with $\mathrm{EA}(3 \times 6 \mathrm{~mL})$ and the combined extracts were washed with $\mathrm{H}_{2} \mathrm{O}(3 \times 6 \mathrm{~mL})$, then brine $(1 \times 6 \mathrm{~mL})$ and dried over anhydrous $\mathrm{MgSO}_{4}$. The solvent was removed under reduced pressure and the resulting residue was purified by silica gel flash chromatography (1:1 EA/PE) to afford the $\mathbf{1 4 3}$ as a colourless oil ( $36.7 \mathrm{mg}, 32 \%)$ :

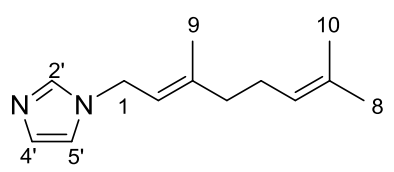

(E)-1-(3,7-Dimethylocta-2,6-dien-1-yl)-1H-imidazole (143); $\mathrm{R}_{f}=0.20(1: 1 \mathrm{EA} / \mathrm{PE}) ;{ }^{1} \mathrm{H}$ NMR (600 MHz, CDCl 3 ): $\delta 7.44$ (s, 1H, H-3'), 7.02 (s, 1H, H-4'), 6.86 (s, 1H, H-5'), 5.33 (t, $J=7.1 \mathrm{~Hz}, 1 \mathrm{H}, \mathrm{H}-2), 5.04$ (t, $J=6.6 \mathrm{~Hz}, 1 \mathrm{H}, \mathrm{H}-6), 4.50$ (d, $J=7.2 \mathrm{~Hz}, 2 \mathrm{H}, \mathrm{H}-1)$, 2.13 - 2.03 (complex m, 4H, H-4 and H-5), 1.72 (s, 3H, H-9), 1.66 (s, 3H, H-10), 1.57 (s, $3 \mathrm{H}, \mathrm{H}-9) ;{ }^{13} \mathrm{C} \mathrm{NMR}\left(120 \mathrm{MHz}, \mathrm{CDCl}_{3}\right.$ ): $\delta 141.7$ (C, C-3), 136.8 (CH, C-2'), 132.2 (C, C7), 129.3 (CH, C-4'), $123.6(\mathrm{CH}, \mathrm{C}-6), 118.7$ (CH, C-5'), $118.6(\mathrm{CH}, \mathrm{C}-2), 44.6\left(\mathrm{CH}_{2}, \mathrm{C}-\right.$ 1), $39.4\left(\mathrm{CH}_{2}, \mathrm{C}-4\right), 26.2\left(\mathrm{CH}_{2}, \mathrm{C}-5\right), 25.8\left(\mathrm{CH}_{3}, \mathrm{C}-10\right), 17.8\left(\mathrm{CH}_{3}, \mathrm{C}-8\right), 16.3\left(\mathrm{CH}_{3}, \mathrm{C}-\right.$ 9); IR (film from $\mathrm{CH}_{2} \mathrm{Cl}_{2}$ ): $v_{\max } 3110,2966,2916,2855 \mathrm{~cm}^{-1}$; HRESIMS $m / z:[\mathrm{M}+\mathrm{H}]^{+}$ Calcd for $\mathrm{C}_{13} \mathrm{H}_{21} \mathrm{~N}_{2}$ 205.1699; Found 205.1700 ( $\Delta=-0.26$ ppm); HRESIMS/MS (40 eV) $\mathrm{m} / \mathrm{z}(\%): 81.0716(21), 79.0559$ (18), 69.0470 (100).

Farnesyl imidazole; Imidazole (0.51 mmol, $34.6 \mathrm{mg})$ and $\mathrm{K}_{2} \mathrm{CO}_{3}(0.65 \mathrm{mmol}, 90.4 \mathrm{mg})$ were stirred in DMF ( $2 \mathrm{~mL}$ ) at room temperature for 10 minutes before dropwise addition of farnesyl bromide $(0.60 \mathrm{mmol}, 0.171 \mathrm{~g}, 162.8 \mu \mathrm{L})$. The reaction was stirred for 48 hours and then $\mathrm{H}_{2} \mathrm{O}(6 \mathrm{~mL})$ was added and the mixture was extracted with EA $(3 \times 6 \mathrm{~mL})$. The combined extracts were washed with $\mathrm{H}_{2} \mathrm{O}(3 \times 6 \mathrm{~mL})$, then brine $(1 \times 6 \mathrm{~mL})$ and dried over anhydrous $\mathrm{MgSO}_{4}$. The solvent was removed under reduced pressure and the resulting residue was purified by silica gel flash chromatography (1:1 EA/PE) to afford 144 as a colourless oil (11.4 mg, 8\%): 


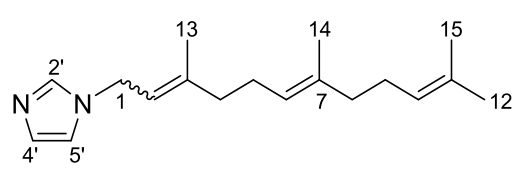

1-((6E)-3,7,11-Trimethyldodeca-2,6,10-trien-1-yl)-1H-imidazole (144); $\mathrm{R}_{f}=0.10(1: 1$ $\mathrm{EA} / \mathrm{PE}) ; 7: 2 \mathrm{E} / \mathrm{Z}, \mathrm{NMR}$ data for major isomer: ${ }^{1} \mathrm{H} \mathrm{NMR}\left(600 \mathrm{MHz}, \mathrm{CDCl}_{3}\right): \delta 7.46(\mathrm{~s}$, 1H, H-2'), 7.04 (s, 1H, H-4'), 6.88 (s, 1H, H-5'), 5.38 - 5.33 (m, 1H, H-2), 5.12 - 5.05 (complex m, 2H, H-6 and H-10), 4.52 (d, $J=7.1 \mathrm{~Hz}, 2 \mathrm{H}, \mathrm{H}-1$ ), $2.19-1.94$ (complex m, $8 \mathrm{H}, 4 \times \mathrm{CH}_{2}$ ), 1.75 (s, 3H, H-9), 1.67 (s, 3H, H-15), 1.60 (s, 3H, $\left.\mathrm{CH}_{3}\right), 1.59$ (s, 3H, CH ); ${ }^{13} \mathrm{C}$ NMR (150 MHz, $\left.\mathrm{CDCl}_{3}\right): \delta 141.9$ (C, C-3) 136.8 (CH, C-2'), 135.9 (C, C-7), 131.5 (C, C-11), 129.2 (CH, C-4'), 124.4 (CH, C-10), 123.5 (CH, C-6), 118.8 (CH, C-5'), 118.6 $(\mathrm{CH}, \mathrm{C}-2), 44.7\left(\mathrm{CH}_{2}, \mathrm{C}-1\right), 39.8\left(\mathrm{CH}_{2}, \mathrm{C}-8\right), 39.5\left(\mathrm{CH}_{2}, \mathrm{C}-4\right), 26.8\left(\mathrm{CH}_{2}, \mathrm{C}-9\right), 26.3$ $\left(\mathrm{CH}_{2}, \mathrm{C}-5\right), 25.8\left(\mathrm{CH}_{3}, \mathrm{C}-15\right), 17.83\left(\mathrm{CH}_{3}, \mathrm{C}-12\right), 16.5\left(\mathrm{CH}_{3}, \mathrm{C}-13\right.$ or $\left.\mathrm{C}-14\right), 16.2\left(\mathrm{CH}_{3}\right.$, C-13 or C-14); IR (film from $\mathrm{CH}_{2} \mathrm{Cl}_{2}$ ): $v_{\max }$ 2965, 2917, $2856 \mathrm{~cm}^{-1}$; HRESIMS m/z: $[\mathrm{M}+\mathrm{H}]^{+}$Calcd for $\mathrm{C}_{18} \mathrm{H}_{29} \mathrm{~N}_{2}$ 273.2325; Found 273.2326 ( $\left.\Delta=-0.39 \mathrm{ppm}\right)$; HRESIMS/MS $m / z$ (\%): 81.0700 (45), 69.0457 (100).

Geranylgeranyl imidazole; Imidazole $(0.30 \mathrm{mmol}, 20.4 \mathrm{mg})$ and $\mathrm{K}_{2} \mathrm{CO}_{3}(0.34 \mathrm{mmol}$, $46.4 \mathrm{mg}$ ) were stirred in DMF (1 mL) for 15 minutes before dropwise addition of geranylgeranyl bromide $(0.32 \mathrm{mmol}, 111 \mathrm{mg}, 108.6 \mu \mathrm{L})$. The reaction was stirred for 2 days, then poured onto $\mathrm{H}_{2} \mathrm{O}(3 \mathrm{~mL})$ and extracted with EA $(4 \times 2 \mathrm{~mL})$. The combined extracts were washed with $\mathrm{H}_{2} \mathrm{O}(3 \times 2 \mathrm{~mL})$, then brine $(1 \times 2 \mathrm{~mL})$ and dried over $\mathrm{MgSO}_{4}$. After concentrating under reduced pressure, the residue was purified by silica gel flash chromatography (1:1 then 2:1 EA/PE) to afford 145 and 146, a 1:1 mixture of $E$ and $Z$ geometric isomers $(26.1 \mathrm{mg}, 26 \%)$ and the pure $E$ isomer $(16.5 \mathrm{mg}, 16 \%)$, both as colourless oils:

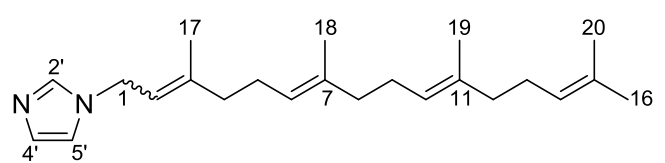

\section{1-((2E,6E,10E)-3,7,11,15-tetramethylhexadeca-2,6,10,14-tetraen-1-yl)-1H-}

imidazole $(145,146) ; \mathrm{R}_{f}=0.18(2: 1 \mathrm{EA} / \mathrm{PE})$; data for major $\mathrm{E}$ isomer: ${ }^{1} \mathrm{H} \mathrm{NMR}(500$ $\mathrm{MHz} \mathrm{CDCl}_{3}$ ): $\delta 7.47$ (s, 1H, H-2'), 7.05 (s, 1H, H-4'), 6.89 (s, 1H, H-5'), 5.36 (t, J = 6.7 $\mathrm{Hz}, 1 \mathrm{H}, \mathrm{H}-2), 5.12-5.05$ (complex m, 3H, H-6, H-10 and H-14), 4.52 (d, J= $7.1 \mathrm{~Hz}, 2 \mathrm{H}$, H-1), 2.17 - 2.01 (complex m, 8H, $4 \times \mathrm{CH}_{2}$ ), $2.01-1.92$ (complex m, 4H, $2 \times \mathrm{CH}_{2}$ ), 1.75 (s, 3H, H-17), 1.67 (s, 3H, H-20), 1.59 (s, 9H, $\left.\left.3 \times \mathrm{CH}_{3}\right) ;{ }^{13} \mathrm{C} \mathrm{NMR} \mathrm{(150} \mathrm{MHz,} \mathrm{CDCl}_{3}\right): \delta$ 
142.0 (C, C-3), 136.8 (CH, C-2'), 135.9 (C, C-11), 135.1 (C, C-7), 131.4 (C, C-15), 129.1 (CH, C-4'), 124.5 (CH, C-14), 124.2 (CH, C-10), 123.5 (CH, C-6), 118.8 (CH, C-5'), $118.5(\mathrm{CH}, \mathrm{C}-2), 44.7\left(\mathrm{CH}_{2}, \mathrm{C}-1\right), 39.9\left(\mathrm{CH}_{2}, \mathrm{C}-12\right), 39.8\left(\mathrm{CH}_{2}, \mathrm{C}-8\right), 39.5\left(\mathrm{CH}_{2}, \mathrm{C}-4\right)$, $26.9\left(\mathrm{CH}_{2}, \mathrm{C}-13\right), 26.7\left(\mathrm{CH}_{2}, \mathrm{C}-9\right), 26.3\left(\mathrm{CH}_{2}, \mathrm{C}-5\right), 25.8\left(\mathrm{CH}_{3}, \mathrm{C}-20\right), 17.8\left(\mathrm{CH}_{3}, \mathrm{C}-16\right)$, $16.5\left(\mathrm{CH}_{3}, \mathrm{C}-17\right), 16.2\left(\mathrm{CH}_{3}, \mathrm{C}-18\right.$ or $\left.\mathrm{C}-19\right), 16.1\left(\mathrm{CH}_{3}, \mathrm{C}-18\right.$ or C-19); IR (film from $\mathrm{CH}_{2} \mathrm{Cl}_{2}$ ): $v_{\max } 3118,2966,2925 \mathrm{~cm}^{-1}$; HRESIMS $\mathrm{m} / \mathrm{z}:[\mathrm{M}+\mathrm{H}]^{+}$Calcd for $\mathrm{C}_{23} \mathrm{H}_{37} \mathrm{~N}_{2}$ 341.2951; Found $341.2934(\Delta=5.19 \mathrm{ppm})$; HRESIMS/MS m/z (\%): 121.1001 (95), 109.1006 (58), 107.0849 (100).

Geranyl phthalimide; Potassium phthalimide (2.6 mmol, $472.8 \mathrm{mg}$ ) and $\mathrm{K}_{2} \mathrm{CO}_{3}$ $\mathrm{Na}_{2} \mathrm{CO}_{3}(1: 1,240 \mathrm{mg})$ were stirred in $\mathrm{DMF}(10 \mathrm{~mL})$ at room temperature before dropwise addition of geranyl bromide $(2.5 \mathrm{mmol}, 543 \mathrm{mg}, 496.4 \mu \mathrm{L})$. The reaction was stirred for 22 hours and then dried under reduced pressure. The reaction mixture was suspended in EA $(30 \mathrm{~mL})$, washed with $\mathrm{H}_{2} \mathrm{O}(3 \times 10 \mathrm{~mL})$ and the organic layer was dried over anhydrous $\mathrm{MgSO}_{4}$. The resulting oil was purified by flash chromatography (1:4 EA/PE) and then recrystallised from PE to afford 148 as small white needles (170.2 $\mathrm{mg}, 24 \%)$ :

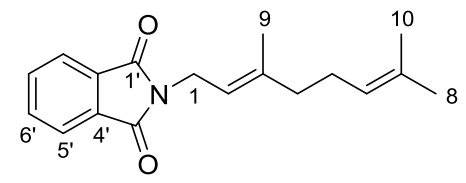

(E)-2-(3,7-Dimethylocta-2,6-dien-1-yl)isoindoline-1,3-dione (148); ${ }^{1} \mathrm{H}$ NMR (600

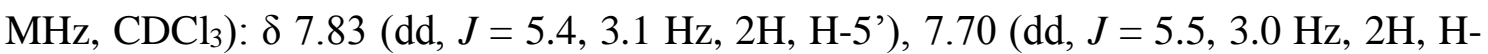
6'), 5.26 (t, J=7.1 Hz, 1H, H-2), 5.04 (tt, 6.9, $1.4 \mathrm{~Hz}, 1 \mathrm{H}, \mathrm{H}-6$ ), 4.28 (d, J=7.2 Hz, 2H, H-1), 2.09 - 2.03 (m, 2H, H-5), 2.01 - 1.97 (m, 2H, H-4), 1.83 (s, 3H, H-9), 1.63 (s, 3H, H-8), 1.56 (s, 3H, H-10); ${ }^{13} \mathrm{C}$ NMR (150 MHz, $\mathrm{CDCl}_{3}$ ): $\delta 168.3$ (C, C-1'), 140.8 (C, C3), 133.9 (CH, C-6’), 132.5 (C, C-4'), 131.9 (C, C-7), 123.9 (CH, C-6), 123.2 (CH, C5'), 118.1 (CH, C-2), $39.6\left(\mathrm{CH}_{2}, \mathrm{C}-4\right), 36.0\left(\mathrm{CH}_{2}, \mathrm{C}-1\right), 26.5\left(\mathrm{CH}_{2}, \mathrm{C}-5\right), 25.8\left(\mathrm{CH}_{3}, \mathrm{C}-\right.$ 10), $17.8\left(\mathrm{CH}_{3}, \mathrm{C}-8\right), 16.5\left(\mathrm{CH}_{3}, \mathrm{C}-9\right)$; IR (film from $\left.\mathrm{CH}_{2} \mathrm{Cl}_{2}\right): v_{\max } 2965,2913,1705 \mathrm{~cm}^{-}$ 1; HRESIMS $m / z:[\mathrm{M}+\mathrm{H}]^{+}$Calcd for $\mathrm{C}_{18} \mathrm{H}_{22} \mathrm{NO}_{2} 284.1645$; Found $284.164(\Delta=1.86$ ppm); HRESIMS/MS (40 eV) m/z (\%): 160.0385 (100), 133.0287 (47), 81.0697 (22).

Farnesyl phthalimide; Potassium phthalimide (2.9 mmol, $541.2 \mathrm{mg}$ ) and $\mathrm{K}_{2} \mathrm{CO}_{3}$ $\mathrm{Na}_{2} \mathrm{CO}_{3}(1: 1,1.9 \mathrm{~g})$ were stirred in DMF $(10 \mathrm{~mL})$ at room temperature. Farnesyl bromide ( $2 \mathrm{mmol}, 570.5 \mathrm{mg}, 300 \mu \mathrm{L}$ ) was added dropwise and then the reaction was stirred for 19 hours. The solvent was removed under reduced pressure and the residue was dissolved in 
EA $(40 \mathrm{~mL})$. The organic phase was washed with $\mathrm{H}_{2} \mathrm{O}(3 \times 10 \mathrm{~mL})$ and then dried over anhydrous $\mathrm{MgSO}_{4}$. The solvent was removed under reduced pressure and the resulting yellow oil was purified by silica gel flash chromatography (1:10 EA/PE) several times to afford 149 as a colourless oil (12.8 $\mathrm{mg}, 2 \%)$ :

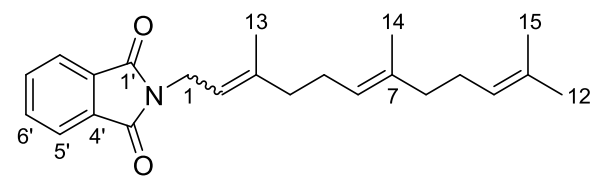

2-((6E)-3,7,11-Trimethyldodeca-2,6,10-trien-1-yl)isoindoline-1,3-dione (149); $\mathrm{R}_{f}=$ 0.23 (1:10 EA/PE); 5:4 E/Z, NMR data for major isomer: ${ }^{1} \mathrm{H} \mathrm{NMR}\left(500 \mathrm{MHz}, \mathrm{CDCl}_{3}\right): \delta$ $7.84-7.81$ (m, 2H, H-5'), 7.71 - 7.68 (m, 2H, H-6'), 5.30 - 5.24 (m, 1H, H-2), 5.11 5.01 (complex m, 2H, H-6 and H-10), 4.27 (d, $J=7.1 \mathrm{~Hz}, 2 \mathrm{H}, \mathrm{H}-1$ ), $2.11-2.03$ ( m, 2H, $\mathrm{CH}_{2}$ ), 2.03 - 1.95 (complex m, 4H, $2 \times \mathrm{CH}_{2}$ ), $1.94-1.88$ (m, 2H, $\mathrm{CH}_{2}$ ), 1.83 (s, 3H, H13), 1.66 (s, 3H, H-15), 1.63 (s, 3H, H-12 or H-14), 1.56 (s, 3H, H-12 or H-14); ${ }^{13} \mathrm{C} \mathrm{NMR}$ (150 MHz, $\mathrm{CDCl}_{3}$ ): $\delta 168.3$ (C, C-1'), 140.8 (C, C-3), 135.5 (C, C-7), 133.9 (CH, C-6'), 132.5 (C, C-4'), 131.4 (C, C-11), 124.5 (CH, C-10), 123.8 (CH, H-6), 123.3 (CH, C-5'), 118.1 (CH, C-2), $39.8\left(\mathrm{CH}_{2}, \mathrm{C}-8\right), 39.6\left(\mathrm{CH}_{2}, \mathrm{C}-8\right), 35.9\left(\mathrm{CH}_{2}, \mathrm{C}-1\right), 26.8\left(\mathrm{CH}_{2}, \mathrm{C}-9\right)$, $26.4\left(\mathrm{CH}_{2}, \mathrm{C}-5\right), 25.8\left(\mathrm{CH}_{3}, \mathrm{C}-15\right), 17.8\left(\mathrm{CH}_{3}, \mathrm{C}-12\right), 16.5\left(\mathrm{CH}_{3}, \mathrm{C}-13\right), 16.1\left(\mathrm{CH}_{3}, \mathrm{C}-\right.$ 14); IR (film from $\mathrm{CH}_{2} \mathrm{Cl}_{2}$ ): $v_{\max } 2964,2917,2854,1710 \mathrm{~cm}^{-1} ; \operatorname{HRESIMS~m/z:~}[\mathrm{M}+\mathrm{H}]^{+}$ Calcd for $\mathrm{C}_{23} \mathrm{H}_{30} \mathrm{NO}_{2}$ 352.2271; Found 352.2257 ( $\Delta=4.01 \mathrm{ppm}$ ); HRESIMS/MS (40 eV) $m / z(\%): 250.9685$ (16), 160.0391(100).

Geranylgeranyl phthalimide; Potassium phthalimide $(0.30 \mathrm{mmol}, 54.8 \mathrm{mg})$ and $\mathrm{K}_{2} \mathrm{CO}_{3}(1.1 \mathrm{mmol}, 155.6 \mathrm{mg})$ were stirred in DMF $(1 \mathrm{~mL})$ for one hour at room temperature before the dropwise addition of geranylgeranyl bromide $(0.32 \mathrm{mmol}, 111$ $\mathrm{mg}, 108.6 \mu \mathrm{L}$ ) over 2 minutes. The reaction was stirred for 24 hours, then poured onto $\mathrm{H}_{2} \mathrm{O}(3 \mathrm{~mL})$ and extracted with EA $(3 \times 2 \mathrm{~mL})$. The combined extracts were washed with $\mathrm{H}_{2} \mathrm{O}(3 \times 2 \mathrm{~mL})$, then brine $(1 \times 2 \mathrm{~mL})$ and dried over anhydrous $\mathrm{MgSO}_{4}$. The solvent was removed under reduced pressure and the residue was purified by silica gel flash chromatography (1:9 EA/PE) to afford $\mathbf{1 5 0}$ as a colourless oil (42.6 $\mathrm{mg}, 34 \%)$ : 


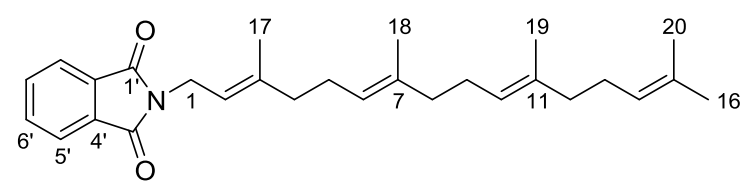

2-((2E,6E,10E)-3,7,11,15-Tetramethylhexadeca-2,6,10,14-tetraen-1-yl)isoindoline-

1,3-dione (150); $\mathrm{R}_{f}=0.31(1: 9 \mathrm{EA} / \mathrm{PE}) ;{ }^{1} \mathrm{H} \mathrm{NMR}\left(500 \mathrm{MHz}, \mathrm{CDCl}_{3}\right): \delta 7.83(\mathrm{dd}, J=5.3$, 3.0 Hz, 1H, H-5'), 7.69 (dd, J = 5.4, 3.0 Hz, 1H, H-6'), 5.27 (t, J= 7.2 Hz, 1H, H-2), 5.13 - 5.02 (complex m, 3H, H-6, H-10 and H-14), 4.28 (d, J = 7.1 Hz, 2H, H-1), $2.11-1.89$ (complex m, 12H, $6 \times \mathrm{CH}_{2}$ ), 1.83 (s, 3H, H-17), 1.67 (s, 3H, H-20), 1.59 (s, 3H, CH 3 ), $1.57\left(\mathrm{~s}, 6 \mathrm{H}, 2 \times \mathrm{CH}_{3}\right) ;{ }^{13} \mathrm{C} \mathrm{NMR}\left(150 \mathrm{MHz}, \mathrm{CDCl}_{3}\right): \delta 168.2(\mathrm{C}, \mathrm{C}-1$ '), $140.8(\mathrm{C}, \mathrm{C}-3)$, 135.4 (C, C-7), 134.9 (C, C-11), 133.9 (CH, C-6'), 132.4 (C, C-4'), 131.3 (C, C-11), 124.5 (CH, C-14), 124.3 (CH, C-10), 123.7 (CH, C-6), 123.2 (CH, C-5'), 118.0 (CH, C-2), 39.8 $\left(\mathrm{CH}_{2}, \mathrm{C}-12\right), 39.7\left(\mathrm{CH}_{2}, \mathrm{C}-8\right), 39.6\left(\mathrm{CH}_{2}, \mathrm{C}-12\right), 35.9\left(\mathrm{CH}_{2}, \mathrm{C}-1\right), 26.8\left(\mathrm{CH}_{2}, \mathrm{C}-13\right), 26.7$ $\left(\mathrm{CH}_{2}, \mathrm{C}-9\right), 26.3\left(\mathrm{CH}_{2}, \mathrm{C}-5\right), 25.8\left(\mathrm{CH}_{3}, \mathrm{C}-20\right), 17.8\left(\mathrm{CH}_{3}, \mathrm{C}-16\right), 16.5\left(\mathrm{CH}_{3}, \mathrm{C}-17\right), 16.10$ $\left(\mathrm{CH}_{3}, \mathrm{C}-18\right.$ or C-19), $16.07\left(\mathrm{CH}_{3}, \mathrm{C}-18\right.$ or C-19); IR (film from $\mathrm{CH}_{2} \mathrm{Cl}_{2}$ ): v $\max 3057,2930$, $1710 \mathrm{~cm}^{-1}$.

Geranyl allopurinol; Allopurinol (0.80 mmol, $109.2 \mathrm{mg})$ and $\mathrm{K}_{2} \mathrm{CO}_{3}-\mathrm{Na}_{2} \mathrm{CO}_{3}$ (1:1, $150.8 \mathrm{mg})$ were stirred in DMF $(10 \mathrm{~mL})$ before dropwise addition of geranyl bromide $(0.50 \mathrm{mmol}, 108 \mathrm{mg}, 99.4 \mu \mathrm{L})$. The reaction was stirred for 24 hours at room temperature and then dried under reduced pressure. The residue was suspended in EA (30 mL) and washed with $\mathrm{H}_{2} \mathrm{O}(3 \times 10 \mathrm{~mL})$, then brine $(1 \times 10 \mathrm{~mL})$ and dried over anhydrous $\mathrm{MgSO}_{4}$. The oily solid was purified by silica gel flash chromatography (1:3 EA/PE) and then recrystallised from $\mathrm{MeOH}$ to afford $\mathbf{1 5 5}$ as an amorphous white powder (4.5 $\mathrm{mg}, \mathbf{2 \%}$ ):

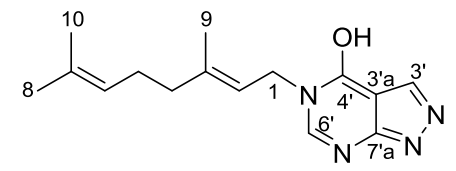

(E)-5-(3,7-Dimethylocta-2,6-dien-1-yl)-5H-pyrazolo[3,4-d]pyrimidin-4-ol $(155) ;{ }^{1} \mathrm{H}$ NMR (600 MHz, $\mathrm{CDCl}_{3}$ ): $\delta 11.32$ (br s, 1H, OH), 8.18 (s, 1H, H-3'), 8.02 (s, 1H, H-6'), $5.34-5.26$ (m, 1H, H-2), 5.07 - 5.02 (m, 1H, H-6), 4.64 (d, J = 7.2 Hz, 2H, H-1), $2.16-$ 2.03 (complex m, 4H, H-4 and H-5), 1.82 (s, 3H, H-9), 1.67 (s, 3H, H-10), 1.59 (s, 3H, $\mathrm{H}-8) ;{ }^{13} \mathrm{C}$ NMR (150 MHz, $\mathrm{CDCl}_{3}$ ): $\delta 157.4$ (C, C-4'), 153.4 (C, C-7'a), 149.4 (CH, C6'), 143.0 (C, C-3), 136.4 (CH, C-3'), 132.3 (C, C-7), 123.6 (CH, C-6), 118.1 (CH, C-2), 105.9 (C, C-3’a), $43.5\left(\mathrm{CH}_{2}, \mathrm{C}-1\right), 39.6\left(\mathrm{CH}_{2}, \mathrm{C}-4\right), 26.3\left(\mathrm{CH}_{2}, \mathrm{C}-5\right), 25.8\left(\mathrm{CH}_{3}, \mathrm{C}-10\right)$, 
$17.9\left(\mathrm{CH}_{3}, \mathrm{C}-8\right), 16.7\left(\mathrm{CH}_{3}, \mathrm{C}-9\right)$ ) IR (film from $\left.\mathrm{CH}_{2} \mathrm{Cl}_{2}\right): v_{\max } 3188,3080,2967,2905$, 2791, 1678, $1568 \mathrm{~cm}^{-1}$; HRESIMS $m / z:[\mathrm{M}+\mathrm{H}]^{+}$Calcd for $\mathrm{C}_{15} \mathrm{H}_{21} \mathrm{~N}_{4} \mathrm{O} 273.1710$; Found 273.1715 ( $\Delta=-1.82 \mathrm{ppm})$; HRESIMS/MS (40 eV) $m / z$ (\%): 137.0454 (100), 110.0349 (39).

Farnesyl allopurinol; Allopurinol $(0.48 \mathrm{mmol}, 65.2 \mathrm{mg})$ and $\mathrm{K}_{2} \mathrm{CO}_{3}$ were stirred in DMF ( $2 \mathrm{~mL})$ at $70{ }^{\circ} \mathrm{C}$ for 10 minutes before dropwise addition of farnesyl bromide $(0.55$ mmol, $157.0 \mathrm{mg}, 149.2 \mu \mathrm{L}$ ). The reaction was stirred for 27 hours, then filtered and $\mathrm{H}_{2} \mathrm{O}$ $(6 \mathrm{~mL})$ was added. The mixture was dried under reduced pressure and purified by silica gel flash chromatography (1:5 and then 1:1 EA/PE) to afford 158 and 157, two difarnesylated derivatives $(6.4 \mathrm{mg}, 4 \%),(17.2 \mathrm{mg}, 12 \%)$ as colourless oils and 156, a monofarnesylated derivative $(33.6,21 \%)$ as a white solid:

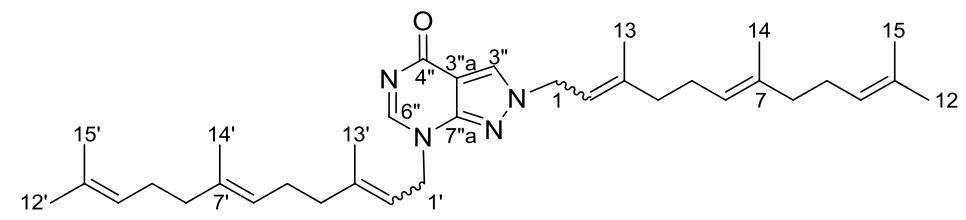

\section{2,7-bis $((6 E)-3,7,11-T r i m e t h y l d o d e c a-2,6,10-t r i e n-1-y l)-2,7-d i h y d r o-4 H$ -}

pyrazolo[3,4-d]pyrimidin-4-one (158); $\mathrm{R}_{f}=0.48$ (1:1 EA/PE); Both 3:2 E/Z, NMR data for major $2 E, 2^{\prime} E$ isomer: ${ }^{1} \mathrm{H} \mathrm{NMR}\left(500 \mathrm{MHz}, \mathrm{CDCl}_{3}\right)$ : $\delta 8.06$ (s, $1 \mathrm{H}, \mathrm{H}-3$ ') $7.95(\mathrm{~s}, 1 \mathrm{H}$, H-6”), 5.51 (t, $J=6.5 \mathrm{~Hz}, 1 \mathrm{H}, \mathrm{H}-2$ ), 5.32 - 5.26 (m, 1H, H-2'), 5.13 - 5.05 (complex m, $4 \mathrm{H}, 4 \times \mathrm{CH}), 4.89$ (d, $J=7.4 \mathrm{~Hz}, 2 \mathrm{H}, \mathrm{H}-1), 4.57$ (d, $J=7.1 \mathrm{~Hz}, 2 \mathrm{H}, \mathrm{H}-1$ '), $2.20-1.93$ (complex m, 16H, $8 \times \mathrm{CH}_{2}$ ), 1.81 (s, 3H, H-13), 1.79 (s, 3H, H-13'), 1.68 (s, 6H, H-15


158.9 (C, C-4”), 158.6 (C, 7”a), 148.5 (CH, C-6”), 144.5 (C, C-3), 142.1 (C, C-3’), 136.0 (C, C-7 or C-7'), 135.8 (C, C-7 or C-7'), 131.7 (C, C-11 or C-11'), 131.4 (C, C-11 or C11'), 127.0 (CH, C-3”), 124.4 (CH, C-10 or C-10'), 124.3 (CH, C-10 or C-10'), 123.5 (C, C-6 or C-6'), 123.4 (C, C-6 or C-6'), 118.5 (CH, H-2'), 116.7 (CH, H-2), 107.1 (C, C3"a), $51.2\left(\mathrm{CH}_{2}, \mathrm{C}-1\right), 43.0\left(\mathrm{CH}_{2}, \mathrm{C}-1^{\prime}\right), 39.77\left(\mathrm{CH}_{2}, \mathrm{C}-8\right.$ or C-8'), $39.76\left(\mathrm{CH}_{2}, \mathrm{C}-8\right.$ or C8'), $39.64\left(\mathrm{CH}_{2}, \mathrm{C}-4\right.$ or C-4'), $39.62\left(\mathrm{CH}_{2}, \mathrm{C}-4\right.$ or C-4'), $26.8\left(\mathrm{CH}_{2}, \mathrm{C}-9\right.$ or C-9'), 26.7 ( $\mathrm{CH}_{2}, \mathrm{C}-9$ or C-9'), $26.4\left(\mathrm{CH}_{2}, \mathrm{C}-5\right.$ or C-5'), $26.3\left(\mathrm{CH}_{2}, \mathrm{C}-5\right.$ or C-5'), $25.8\left(\mathrm{CH}_{3}, \mathrm{C}-15\right.$ and C-15'), $17.82\left(\mathrm{CH}_{3}, \mathrm{C}-12\right.$ or C-12'), $17.81\left(\mathrm{CH}_{3}, \mathrm{C}-12\right.$ or C-12'), $16.8\left(\mathrm{CH}_{3}, \mathrm{C}-13^{\prime}\right)$, $16.7\left(\mathrm{CH}_{3}, \mathrm{C}-13\right), 16.19\left(\mathrm{CH}_{3}, \mathrm{C}-14\right.$ or C-14'), $16.15\left(\mathrm{CH}_{3}, \mathrm{C}-14\right.$ or C-14'); HRESIMS $m / z:[\mathrm{M}+\mathrm{H}]^{+}$Calcd for $\mathrm{C}_{35} \mathrm{H}_{53} \mathrm{~N}_{4} \mathrm{O}$ 545.4214; Found 545.4225 ( $\Delta=-1.97 \mathrm{ppm}$ ); HRESIMS/MS (40 eV) m/z (\%): 137.0451 (100), 81.0699 (30). 




\section{1,5-bis $((6 E)-3,7,11-T r i m e t h y l d o d e c a-2,6,10-t r i e n-1-y l)-1,5-d i h y d r o-4 H$ -}

pyrazolo[3,4-d]pyrimidin-4-one (157); $\mathrm{R}_{f}=0.24$ (1:5 EA/PE); Both 2:1 E/Z, NMR data for major $2 E, 2 E$ ' isomer: ${ }^{1} \mathrm{H} \mathrm{NMR}\left(500 \mathrm{MHz}, \mathrm{CDCl}_{3}\right)$ : $\delta 8.09-8.08(\mathrm{~m}, 1 \mathrm{H}, \mathrm{H}-6 ”), 7.95$ - 7.94 (m, 1H, H-3”), 5.48 - 5.41 (m, 1H, H-2'), 5.34 - 5.28 (m, 1H, H-2), 5.13 - 5.04 (complex m, 4H, H-6, H-6', H-10 and H-10'), 4.94 (d, J = 6.9 Hz, 2H, H-1), 4.61 (d, J= $7.2 \mathrm{~Hz}, 2 \mathrm{H}, \mathrm{H}-1$ '), $2.18-1.99$ (complex m, 14H, $\left.7 \times \mathrm{CH}_{2}\right), 1.99-1.92\left(\mathrm{~m}, 2 \mathrm{H}, \mathrm{CH}_{2}\right)$, 1.85 (s, 3H, H-13), 1.83 (s, 3H, H-13'), 1.68 (s, 6H), 1.60 (s, 6H); ${ }^{13} \mathrm{C}$ NMR (150 MHz, $\mathrm{CDCl}_{3}$ ): $\delta 157.4$ (C, C-4”), 151.0 (C, C-7”a), 148.4 (CH, C-6”), 142.7 (C, C-3'), 141.0 (C, C-3), 135.9 (C, C-7 or C-7'), 135.6 (C, C-7 or C-7'), 135.1 (CH, C-3”), 131.49 (C, C11 or C-11'), 131.46 (C, C-11 or C-11'), 124.42 (CH, C-10 or C-10'), 124.37 (CH, C-10 or C-10'), 123.7 (CH, C-6 or C-6'), 123.5 (CH, C-6 or C-6'), 118.4 (CH, C-2'), 118.3 (CH, C-2), 105.9 (C, C-3”a), $45.4\left(\mathrm{CH}_{2}, \mathrm{C}-1\right), 43.2\left(\mathrm{CH}_{2}, \mathrm{C}-1\right.$ '), $39.80\left(\mathrm{CH}_{2}, \mathrm{C}-8\right.$ or C8'), $39.78\left(\mathrm{CH}_{2}, \mathrm{C}-8\right.$ or C-8'), $39.64\left(\mathrm{CH}_{2}, \mathrm{C}-4\right.$ or C-4'), $39.59\left(\mathrm{CH}_{2}, \mathrm{C}-4\right.$ or C-4'), 26.83 ( $\mathrm{CH}_{2}, \mathrm{C}-9$ or C-9'), $26.81\left(\mathrm{CH}_{2}, \mathrm{C}-9\right.$ or C-9'), $26.34\left(\mathrm{CH}_{2}, \mathrm{C}-5\right.$ or C-5'), $26.30\left(\mathrm{CH}_{2}, \mathrm{C}-\right.$ 5 or C-5'), $25.9\left(\mathrm{CH}_{3}, \mathrm{C}-15\right.$ or C-15'), $25.8\left(\mathrm{CH}_{3}, \mathrm{C}-15\right.$ or C-15'), 17.8 (2 $\times \mathrm{CH}_{3}, \mathrm{H}-16$ and H-16'), $16.74\left(\mathrm{CH}_{3}, \mathrm{C}-17\right), 16.69$ ( $\left.\mathrm{CH}_{3}, \mathrm{C}-17^{\prime}\right), 16.19\left(\mathrm{CH}_{3}, \mathrm{C}-14\right.$ or C-14'), 16.15 $\left(\mathrm{CH}_{3}, \mathrm{C}-14\right.$ or C-14'); IR (film from $\mathrm{CH}_{2} \mathrm{Cl}_{2}$ ): $v_{\max } 3368,2964,2925,2856,1696,1582$ $\mathrm{cm}^{-1}$; HRESIMS $m / z:[\mathrm{M}+\mathrm{H}]^{+}$Calcd for $\mathrm{C}_{35} \mathrm{H}_{52} \mathrm{~N}_{4} \mathrm{O} 545.4214$; Found $545.4223(\Delta=-1.7$ ppm); HRESIMS/MS (40 eV) m/z (\%): 137.0458 (100), 81.702 (12).

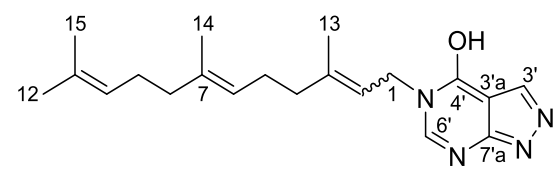

\section{5-((2E,6E)-3,7,11-Trimethyldodeca-2,6,10-trien-1-yl)-5H-pyrazolo[3,4-}

d]pyrimidin-4-ol (156); $\mathrm{R}_{f}=0.16(1: 1 \mathrm{EA} / \mathrm{PE}) ; 3: 2 \mathrm{E} / \mathrm{Z}$, NMR data for major isomer: ${ }^{1} \mathrm{H}$ NMR (600 MHz, $\mathrm{CDCl}_{3}$ ): $\delta 12.64$ (br s, 1H, OH), 8.20 (s, 1H, H-3'), 8.08 (s, 1H, H-6'), $5.34-5.28$ (m, 1H, H-2), $5.09-5.01$ (complex m, 2H, H-6 and H-10), 4.64 (d, $J=7.3$ $\mathrm{Hz}, 2 \mathrm{H}, \mathrm{H}-1), 2.14-2.04$ (complex m, 4H, $2 \times \mathrm{CH}_{2}$ ), $2.04-1.96$ (m, 2H, $\mathrm{CH}_{2}$ ), $1.96-$ 1.92 (m, 2H, $\mathrm{CH}_{2}$ ), 1.82 (s, 3H, H-13), 1.64 (s, 3H, $\left.\mathrm{CH}_{3}\right), 1.57$ (s, 3H, $\left.\mathrm{CH}_{3}\right), 1.56$ (s, 3H, $\left.\mathrm{CH}_{3}\right) ;{ }^{13} \mathrm{C}$ NMR (150 MHz, $\mathrm{CDCl}_{3}$ ): $\delta 157.4$ (C, C-4'), 153.3 (C, C-7'a), 149.4 (CH, C- 
6'), 143.0 (C, C-3), 136.1 (CH, C-3') 135.9 (C, C-7), 131.5 (C, C-11), 124.3 (CH, C-10), 123.4 (CH, C-6), 118.0 (CH, C-2), 105.9 (C, C-3'a), $43.5\left(\mathrm{CH}_{2}, \mathrm{C}-1\right), 39.7\left(\mathrm{CH}_{2}, \mathrm{C}-8\right)$, $39.6\left(\mathrm{CH}_{2}, \mathrm{C}-4\right), 26.8\left(\mathrm{CH}_{2}, \mathrm{C}-9\right), 26.3\left(\mathrm{CH}_{2}, \mathrm{C}-5\right), 25.8\left(\mathrm{CH}_{3}, \mathrm{C}-15\right), 17.8\left(\mathrm{CH}_{3}, \mathrm{C}-12\right)$, $16.7\left(\mathrm{CH}_{3}, \mathrm{C}-13\right.$ or C-14), $16.2\left(\mathrm{CH}_{3}, \mathrm{C}-13\right.$ or C-14); IR (film from $\left.\mathrm{CH}_{2} \mathrm{Cl}_{2}\right): v_{\max } 3188$, 3108, 2967, 2917, $1676 \mathrm{~cm}^{-1}$; HRESIMS $m / z:[\mathrm{M}+\mathrm{H}]^{+}$Calcd for $\mathrm{C}_{20} \mathrm{H}_{29} \mathrm{~N}_{4} \mathrm{O} 341.2336$; Found $341.2340(\Delta=-1.24 \mathrm{ppm})$; HRESIMS/MS (40 eV) $\mathrm{m} / z(\%): 137.0451$ (100), $110.0344(9)$.

Geranylgeranyl allopurinol; Allopurinol $(0.71 \mathrm{mmol}, 96.6 \mathrm{mg})$ and $\mathrm{K}_{2} \mathrm{CO}_{3}(0.81$ mmol, $111.9 \mathrm{mg})$ were stirred in DMF $(1 \mathrm{~mL})$ at room temperature for 25 minutes before dropwise addition of geranylgeranyl bromide $(0.73 \mathrm{mmol}, 259.7 \mathrm{mg}, 253 \mu \mathrm{L})$. The reaction was stirred for 27 hours, then $\mathrm{H}_{2} \mathrm{O}(3 \mathrm{~mL})$ was added and the mixture was extracted with EA $(4 \times 2 \mathrm{~mL})$. The combined extracts were washed with $\mathrm{H}_{2} \mathrm{O}(3 \times 2 \mathrm{~mL})$, then brine $(1 \times 2 \mathrm{~mL})$ and dried over anhydrous $\mathrm{MgSO}_{4}$. The solvent was removed under reduced pressure and the residue purified by silica gel flash chromatography (1:5 and then 1:2 EA/PE) to afford 159, a monoalkylated product $(1.5 \mathrm{mg}, 2 \%)$ as a white solid and 160, a dialkylated product $(6.8 \mathrm{mg}, 3 \%)$ as a colourless oil:

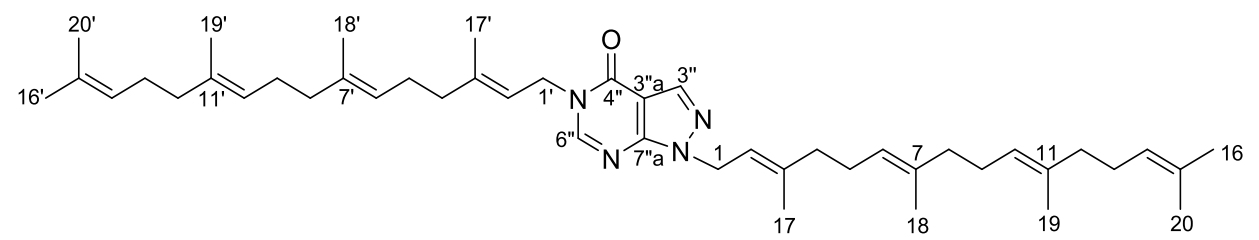

\section{1,5-bis((2E,6E,10E)-3,7,11,15-Tetramethylhexadeca-2,6,10,14-tetraen-1-yl)-1,5-} dihydro-4H-pyrazolo[3,4-d]pyrimidin-4-one (160); ${ }^{1} \mathrm{H}$ NMR $\left(600 \mathrm{MHz}, \mathrm{CDCl}_{3}\right): \delta$ 8.07 (s, 1H, H-3”), 7.93 (s, 1H, H-6”), 5.43 (t, $J=6.8$ Hz, 1H, H-2'), 5.30 (t, $J=7.2 \mathrm{~Hz}$, 1H, H-2), 5.11 - 5.04 (complex m, 6H, H-6, H-6', H-10, H-10', H-14 and H-14'), 4.93 (d, $J=6.9 \mathrm{~Hz}, 2 \mathrm{H}, \mathrm{H}-1), 4.60$ (d, $J=7.3 \mathrm{~Hz}, 2 \mathrm{H}, \mathrm{H}-1$ ') $) 2.14-2.01$ (complex m, 16H, 8 $\times \mathrm{CH}_{2}$ ), 1.99 - 1.93 (complex m, 8H, $4 \times \mathrm{CH}_{2}$ ), 1.83 (s, 3H, H-17), 1.81 (s, 3H, H-17'), 1.67 (s, 6H, H-20 and H-20'), $1.60-1.57$ (complex m, 12H, $\left.4 \times \mathrm{CH}_{3}\right) ;{ }^{13} \mathrm{C}$ NMR (150 MHz, $\left.\mathrm{CDCl}_{3}\right) \delta 157.4$ (C, C-4”), 151.0 (C, C-7”a), 148.4 (CH, C-6”), 142.7 (C, C-3'), 141.1 (C, C-3), 135.9 (C, C-7 or C-7'), 135.6 (C, C-7 or C-7'), 135.1 (2 × C, C-11 and C11') 131.4 (2 × C, C-15 and C-15'), 124.5 (CH, C-14 or C-14'), 124.5 (CH, C-14 or C14'), 124.3 (CH, C-10 or C-10'), 124.2 (CH, C-10 or C-10'), 123.7 (CH, C-6 or C-6'), 123.5 (CH, C-6 or C-6'), 118.4 (CH, C-2'), 118.3 (CH, C-2), 105.9 (C, C-3”a), 45.4 (CH2, C-1), $43.2\left(\mathrm{CH}_{2}, \mathrm{C}-1\right), 39.86\left(\mathrm{CH}_{2}, \mathrm{C}-12\right.$ or C-12'), $39.85\left(\mathrm{CH}_{2}, \mathrm{C}-12\right.$ or C-12'), 39.80 
$\left(\mathrm{CH}_{2}, \mathrm{C}-8\right.$ or C-8'), $39.78\left(\mathrm{CH}_{2}, \mathrm{C}-8\right.$ or C-8'), $39.7\left(\mathrm{CH}_{2}, \mathrm{C}-4\right.$ or C-4'), $39.6\left(\mathrm{CH}_{2}, \mathrm{C}-4\right.$ or C-4'), 26.9 (2 × CH $2, \mathrm{C}-13$ and C-13'), $26.73\left(\mathrm{CH}_{2}, \mathrm{C}-9\right.$ or C-9'), $26.71\left(\mathrm{CH}_{2}, \mathrm{C}-9\right.$ or C9'), $26.38\left(\mathrm{CH}_{2}, \mathrm{C}-5\right.$ or C-5'), $26.35\left(\mathrm{CH}_{2}, \mathrm{C}-5\right.$ or C-5'), $25.9\left(2 \times \mathrm{CH}_{3}, \mathrm{C}-20\right.$ and C-20'), $17.8\left(2 \times \mathrm{CH}_{3}, \mathrm{C}-16\right.$ and C-16'), $16.8\left(\mathrm{CH}_{3}, \mathrm{C}-17\right), 16.7\left(\mathrm{CH}_{3}, \mathrm{C}-17^{\prime}\right), 16.2\left(2 \times \mathrm{CH}_{3}, \mathrm{C}-\right.$ 18 or C-18' or C-19 or C-19'), 16.1 ( $2 \times \mathrm{CH}_{3}, \mathrm{C}-18$ or C-18' or C-19 or C-19') ; IR (film from $\mathrm{CH}_{2} \mathrm{Cl}_{2}$ ): $v_{\max } 3392,2975,2937,1699 \mathrm{~cm}^{-1}$.

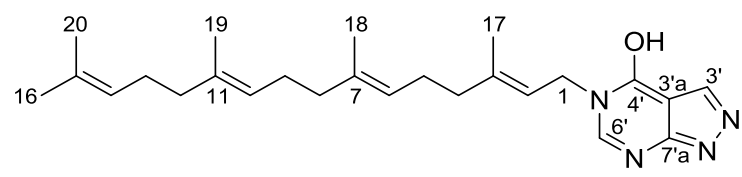

\section{5-((2E,6E,10E)-3,7,11,15-Tetramethylhexadeca-2,6,10,14-tetraen-1-yl)-5H-}

pyrazolo[3,4-d]pyrimidin-4-ol (159); ${ }^{1} \mathrm{H}$ NMR (500 MHz, $\left.\mathrm{CDCl}_{3}\right): \delta 8.16(\mathrm{~s}, 1 \mathrm{H}, \mathrm{H}-3$ '), 7.98 (s, 1H, H-6'), 5.33 - 5.27 (m, 1H, H-2), 5.12 - 5.04 (complex m, 3H, H-6, H-10 and H-14), 4.62 (d, J = 7.2 Hz, 2H, H-1), $2.17-2.00$ (complex m, 8H, $4 \times \mathrm{CH}_{2}$ ), $1.99-1.92$ (complex m, 4H, $2 \times \mathrm{CH}_{2}$ ), 1.82 (s, 3H, H-17), 1.67 (s, 3H, H-20), $1.61-1.52$ (complex m, 9H, $3 \times \mathrm{CH}_{3}$ ); IR (film from $\mathrm{CH}_{2} \mathrm{Cl}_{2}$ ): $v_{\max } 3424,3190,3081,2966,2915,2855,1684$ $\mathrm{cm}^{-1}$; HRESIMS $m / z$ : $[\mathrm{M}+\mathrm{H}]^{+}$Calcd for $\mathrm{C}_{25} \mathrm{H}_{37} \mathrm{~N}_{4} \mathrm{O} 409.2962$; Found $409.2957(\Delta=1.3$ ppm); HRESIMS/MS (40 eV) m/z (\%): 137.0436 (100).

Bis(trimethylsilyl)geranylamine; Geranyl bromide (4.6 mmol, $1.0 \mathrm{~g}, 914 \mu \mathrm{L})$ was added dropwise over five minutes to a stirring solution of LiHMDS (5.2 mmol, $1 \mathrm{M}$ in THF) under nitrogen. The reaction was stirred for 26 hours and then quenched with saturated ammonium chloride solution $(20 \mathrm{~mL})$ on an ice bath. The mixture was extracted with $\mathrm{Et}_{2} \mathrm{O}(3 \times 10 \mathrm{~mL})$ and the combined extracts were dried over anhydrous $\mathrm{MgSO}_{4}$. The solvent was removed under reduced pressure to afford a dark orange oil $(1.1 \mathrm{~g}, 80 \%)$ :



(E)- $N$-(3,7-Dimethylocta-2,6-dien-1-yl)-1,1,1-trimethyl- $N$ -

(trimethylsilyl)silanamine; ${ }^{1} \mathrm{H} \mathrm{NMR}\left(300 \mathrm{MHz}, \mathrm{CDCl}_{3}\right): \delta 5.11(\mathrm{t}, J=6.7 \mathrm{~Hz}, 1 \mathrm{H}, \mathrm{H}-$ 2), 5.01 (t, $J=5.8 \mathrm{~Hz}, 1 \mathrm{H}, \mathrm{H}-6), 3.44$ (d, $J=5.1 \mathrm{~Hz}, 2 \mathrm{H}, \mathrm{H}-1$ ), $2.16-2.04$ (complex m, 2H, H-4 or H-5), 2.03 - 1.93 (m, 2H, H-4 or H-5), 1.69 (s, 3H, H-9), 1.62 (s, 3H, H-8 or $\mathrm{H}-10), 1.58$ (s, 3H, H-8 or H-10), 0.09 (s , $\left.18 \mathrm{H}, 6 \times \mathrm{SiCH}_{3}\right)$. 
Geranylamine; Bis(trimethylsilyl)geranylamine $(3.67 \mathrm{mmol}, 1.09 \mathrm{~g})$ was stirred in $\mathrm{MeOH}(20 \mathrm{~mL})$ and DCM $(2.5 \mathrm{~mL})$ for 22 hours. The solvents were removed under reduced pressure to afford $\mathbf{1 6 1}$ as a dark orange oily solid $(0.52 \mathrm{~g}, 92 \%)$ :

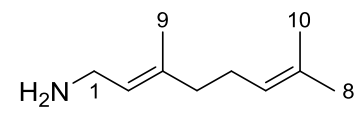

(E)-3,7-Dimethylocta-2,6-dien-1-amine (161); ${ }^{1} \mathrm{H}$ NMR $\left(300 \mathrm{MHz}, \mathrm{CDCl}_{3}\right): \delta 5.28$ (t, $J=6.3 \mathrm{~Hz}, 1 \mathrm{H}, \mathrm{H}-2), 5.11(\mathrm{t}, J=6.6 \mathrm{~Hz}, 1 \mathrm{H}, \mathrm{H}-6), 3.32$ (d, $J=6.7 \mathrm{~Hz}, 2 \mathrm{H}, \mathrm{H}-1), 2.17-$ 2.06 (m, 2H, H-4 of H-5), $2.06-1.97$ (m, 2H, H-4 or H-5), 1.90 (br s, 2H, $\mathrm{NH}_{2}$ ), 1.70 (s, 3H, H-9), 1.66 (s, 3H, H-10), 1.62 (s, 3H, H-8); ${ }^{13} \mathrm{C}$ NMR (150 MHz, $\mathrm{CDCl}_{3}$ ): $\delta 137.2$ (C, C-3), 131.7 (C, C-7), $125.0\left(\mathrm{CH}, \mathrm{C}-2\right.$ or C-6), 124.2 (CH, C-2 or C-6), $39.69\left(\mathrm{CH}_{2}\right.$, C-1 or C-4), $39.6\left(\mathrm{CH}_{2}, \mathrm{C}-1\right.$ or C-4), $26.6\left(\mathrm{CH}_{2}, \mathrm{C}-5\right), 25.8\left(\mathrm{CH}_{3}, \mathrm{C}-10\right), 17.8\left(\mathrm{CH}_{3}, \mathrm{C}-\right.$ 8), $16.3\left(\mathrm{CH}_{3}, \mathrm{C}-9\right)$; HRESIMS $m / z$ : $[\mathrm{M}+\mathrm{H}]^{+}$Calcd for $\mathrm{C}_{10} \mathrm{H}_{20} \mathrm{~N}$ 154.1590; Found $154.1582(\Delta=5.13 \mathrm{ppm})$; HRESIMS/MS $m / z$ (\%): 81.0700 (45), 69.0457 (100).

Bis(trimethylsilyl)farnesylamine; Farnesyl bromide (3.51 mmol, $1.0 \mathrm{~g}, 949 \mu \mathrm{L})$ was added dropwise over five minutes to a stirring solution of LiHMDS (4.00 mmol, $1 \mathrm{M}$ in THF) under nitrogen. The reaction was stirred for 26 hours and then quenched with saturated ammonium chloride solution $(20 \mathrm{~mL})$ on an ice bath. The mixture was extracted with $\mathrm{Et}_{2} \mathrm{O}(3 \times 10 \mathrm{~mL})$ and the combined extracts were dried over anhydrous $\mathrm{MgSO}_{4}$. The solvent was removed under reduced pressure to afford a straw yellow oil (1.07 g, 84\%):

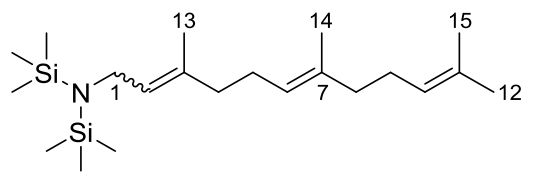

\section{1,1,1-Trimethyl- $N$-((6E)-3,7,11-trimethyldodeca-2,6,10-trien-1-yl)- $N$ -}

(trimethylsilyl)silanamine; ${ }^{1} \mathrm{H} \mathrm{NMR}\left(300 \mathrm{MHz}, \mathrm{CDCl}_{3}\right): \delta 5.16-5.05$ (complex m, $2 \mathrm{H}$, H-6 and H-10), 4.99 (t, $J=5.6$ Hz, 1H, H-2), 3.42 (d, $J=5.1 \mathrm{~Hz}, 2 \mathrm{H}, \mathrm{H}-1), 2.14-1.90$ (complex m, 8H, $4 \times \mathrm{CH}_{2}$ ), 1.68 (s, 3H, H-13), 1.60 (s, 3H, H-15), $1.56\left(\mathrm{~s}, 6 \mathrm{H}, 2 \times \mathrm{CH}_{3}\right.$ ), $0.07\left(\mathrm{~s}, 18 \mathrm{H}, 6 \times \mathrm{SiCH}_{3}\right)$; HRESIMS $\mathrm{m} / z$ : $[\mathrm{M}+\mathrm{H}]^{+}$Calcd for $\mathrm{C}_{15} \mathrm{H}_{28} \mathrm{~N} 222.2216$; Found $222.2200(\Delta=7.32 \mathrm{ppm})$.

Farnesylamine; Bis(trimethylsilyl)farnesylamine $(2.93 \mathrm{mmol}, 1.07 \mathrm{~g})$ was stirred in $\mathrm{MeOH}(20 \mathrm{~mL})$ and DCM $(2.5 \mathrm{~mL})$ for 23 hours. The solvents were removed under reduced pressure to afford $\mathbf{1 6 2}$ as a dark orange oily solid (0.6462 g, 99.6\%): 


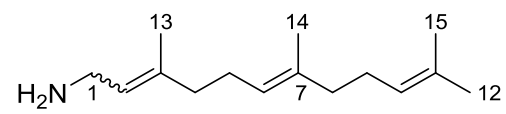

(6E)-3,7,11-Trimethyldodeca-2,6,10-trien-1-amine (162); ${ }^{1} \mathrm{H} \quad \mathrm{NMR} \quad(300 \mathrm{MHz}$, $\left.\mathrm{CDCl}_{3}\right): \delta 5.28(\mathrm{t}, J=6.7 \mathrm{~Hz}, 1 \mathrm{H}, \mathrm{H}-2), 5.17-5.07$ (complex m, 2H, H-6 and H-10), 3.31 $(\mathrm{d}, J=6.7 \mathrm{~Hz}, 2 \mathrm{H}, \mathrm{H}-1), 2.05(\mathrm{t}, J=9.5 \mathrm{~Hz}, 9 \mathrm{H}), 1.70\left(\mathrm{~s}, 6 \mathrm{H}, 2 \times \mathrm{CH}_{3}\right), 1.66\left(\mathrm{~s}, 3 \mathrm{H}, \mathrm{CH}_{3}\right)$, $1.62\left(\mathrm{~s}, 6 \mathrm{H}, 2 \times \mathrm{CH}_{3}\right)$.

Bis(trimethylsilyl)geranylgeranylamine; To a solution of LiHMDS (3.23 mmol, 1 $\mathrm{M}$ in THF) under nitrogen, was added geranylgeranyl bromide (2.83 mmol, $1.00 \mathrm{~g}, 976$ $\mu \mathrm{L}$ ) dropwise over five minutes. The reaction was stirred for 17 hours and then quenched with saturated ammonium chloride solution $(15 \mathrm{~mL})$ while on an ice bath. The mixture was extracted with $\mathrm{Et}_{2} \mathrm{O}(3 \times 10 \mathrm{~mL})$ and the combined extracts were dried over anhydrous $\mathrm{MgSO}_{4}$. The solvent was removed under reduced pressure to afford a light orange oily solid $(1.11 \mathrm{~g}, 90 \%)$ :

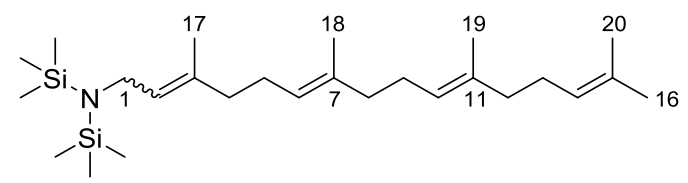

\section{1,1,1-Trimethyl- $N$-((6E,10E)-3,7,11,15-tetramethylhexadeca-2,6,10,14-tetraen-1-} yl)- $N$-(trimethylsilyl)silanamine; ${ }^{1} \mathrm{H} \mathrm{NMR}\left(300 \mathrm{MHz}, \mathrm{CDCl}_{3}\right): \delta 5.19-5.07$ (m, 3H, H6, H-10 and H-14), 5.01 (t, $J=5.9 \mathrm{~Hz}, 1 \mathrm{H}), 3.44(\mathrm{~d}, J=5.2 \mathrm{~Hz}, 1 \mathrm{H}), 2.17-1.93(\mathrm{~m}, 4 \mathrm{H})$, $1.62(\mathrm{~s}, 4 \mathrm{H}), 0.09(\mathrm{~s}, 3 \mathrm{H})$.

Geranylgeranylamine; Bis(trimethylsilyl)geranylgeranylamine $(2.54 \mathrm{mmol}, 1.1 \mathrm{~g})$ was stirred in MeOH (12 mL) and DCM (3 mL) for 24 hours. The solvents were removed under reduced pressure to afford $\mathbf{1 6 3}$ as an orange oily solid $(0.86 \mathrm{~g}, 74 \%)$ :<smiles>CC(C)=CCCC(C)=CCCC(C)=CCCC(C)=CCN</smiles>

$(6 E, 10 E)-3,7,11,15-T e t r a m e t h y l h e x a d e c a-2,6,10,14-t e t r a e n-1-a m i n e ~(163) ; 3: 1 ~ E / Z$, NMR data for major isomer: ${ }^{1} \mathrm{H}$ NMR $\left(500 \mathrm{MHz}, \mathrm{CDCl}_{3}\right): \delta 5.29(\mathrm{t}, J=6.7 \mathrm{~Hz}, 1 \mathrm{H}, \mathrm{H}-$ 2), 5.14 - 5.05 (complex m, 3H, H-6, H-10 and H-14), 3.36 (d, J=6.9 Hz, 2H, H-1), 2.17 - 1.94 (complex m, 12H, $\left.6 \times \mathrm{CH}_{2}\right), 1.68\left(\mathrm{~s}, 3 \mathrm{H}, \mathrm{CH}_{3}\right), 1.66\left(\mathrm{~s}, 3 \mathrm{H}, \mathrm{CH}_{3}\right), 1.60(\mathrm{~s}, 9 \mathrm{H}, 3 \times$ $\left.\mathrm{CH}_{3}\right)$. 
Geranyl formamide; Acetic anhydride (3.6 mmol, $0.336 \mathrm{~g}, 339 \mu \mathrm{L})$ was stirred on an ice bath for 10 minutes under nitrogen before the addition of formic acid (3.9 mmol, 180 $\mathrm{mg}, 147.6 \mu \mathrm{L})$. The ice bath was removed and the reaction was heated at $55{ }^{\circ} \mathrm{C}$ in an oil bath for two and a half hours. Heating was removed and geranylamine (1.6 mmol, 250 $\mathrm{mg}, 3.3 \mathrm{M}$ in formic acid) was added dropwise over 15 minutes and the reaction was stirred for a further three hours. $\mathrm{H}_{2} \mathrm{O}(3 \mathrm{~mL})$ was added and the mixture was extracted with EA $(3 \times 2 \mathrm{~mL})$. The combined extracts were washed with $\mathrm{H}_{2} \mathrm{O}(3 \times 2 \mathrm{~mL})$, then brine $(1 \times 2 \mathrm{~mL})$ and dried over anhydrous $\mathrm{MgSO}_{4}$. The solvent was removed under reduced pressure and the residue was purified by silica gel flash chromatography (2:3 EA/PE) to afford $164(43.3 \mathrm{mg}, 30 \%)$ as a mixture of rotamers:

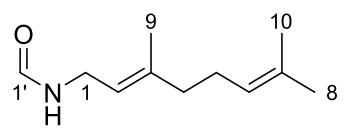

(E)- $\boldsymbol{N}$-(3,7-Dimethylocta-2,6-dien-1-yl)formamide (164); $\mathrm{R}_{f}=0.21$ (2:3 EA/PE); 4:1 rotamers, NMR data for major rotamer: ${ }^{1} \mathrm{H}$ NMR $\left(300 \mathrm{MHz}, \mathrm{CDCl}_{3}\right): \delta 8.16(\mathrm{~s}, 1 \mathrm{H}, \mathrm{H}-$ 1'), 5.46 (br s, 1H, NH), 5.19 (t, $J=6.5 \mathrm{~Hz}, 1 \mathrm{H}, \mathrm{H}-2), 5.06$ (s, 1H, H-6), 3.90 (t, $J=6.2$ Hz, 2H, H-1), 2.15 - 1.95 (complex m, 4H, H-4 and H-5), 1.67 (s, 6H, H-9 and H-10), 1.59 (s, 3H, H-8); ${ }^{13} \mathrm{C}$ NMR (150 MHz, $\mathrm{CDCl}_{3}$ ): $\delta 161.0$ (C, C-1'), 140.7 (C, C-3), 132.0 (C, C-7), 123.9 (CH, C-6), 119.4 (CH, C-2), $39.6\left(\mathrm{CH}_{2}, \mathrm{C}-4\right), 36.2\left(\mathrm{CH}_{2}, \mathrm{C}-1\right), 26.5\left(\mathrm{CH}_{2}\right.$, C-5), $25.8\left(\mathrm{CH}_{3}, \mathrm{C}-10\right), 17.8\left(\mathrm{CH}_{3}, \mathrm{C}-8\right), 16.4\left(\mathrm{CH}_{3}, \mathrm{C}-9\right)$ ) IR (film from $\left.\mathrm{CH}_{2} \mathrm{Cl}_{2}\right): v_{\max }$ 3277, 3045, 2968, 2915, 2856, $1655 \mathrm{~cm}^{-1}$; HRESIMS $m / z$ : $[\mathrm{M}+\mathrm{H}]^{+}$Calcd for $\mathrm{C}_{11} \mathrm{H}_{20} \mathrm{NO}$ 182.1539; Found $182.1528(\Delta=6.09 \mathrm{ppm})$; HRESIMS/MS $(20 \mathrm{eV}) \mathrm{m} / \mathrm{z}(\%): 182.1502$ (7), 137.1316 (100), 109.0999 (15).

Farnesyl formamide; To acetic anhydride $(2.5 \mathrm{mmol}, 254 \mathrm{mg}, 235 \mu \mathrm{L})$ on an ice bath under nitrogen, was added formic acid $(2.7 \mathrm{mmol}, 124 \mathrm{mg}, 102 \mu \mathrm{L})$. The reaction was heated to $55{ }^{\circ} \mathrm{C}$ in an oil bath for two hours, heating was removed and the reaction was cooled to room temperature and farnesylamine $(1.13 \mathrm{mmol}, 250 \mathrm{mg}, 2.82 \mathrm{M}$ in formic acid) was added dropwise over 18 minutes. The reaction was stirred for five hours, then quenched with $\mathrm{H}_{2} \mathrm{O}(3 \mathrm{~mL})$ and the mixture extracted with $\mathrm{EA}(3 \times 2 \mathrm{~mL})$. The combined extracts were washed with $\mathrm{H}_{2} \mathrm{O}(4 \times 3 \mathrm{~mL})$, then brine $(1 \times 2 \mathrm{~mL})$ and dried over anhydrous $\mathrm{MgSO}_{4}$. The solvents were removed under reduced pressure and the residue was purified by silica gel flash chromatography (1:2 EA/PE) to afford $\mathbf{1 6 5}$ and $\mathbf{1 6 6}$, as 
rotameric mixtures of the $2 Z(3.6 \mathrm{mg})$ and $2 E / Z(12.2 \mathrm{mg})$ products as colourless oils with a combined yield of $6 \%$ :

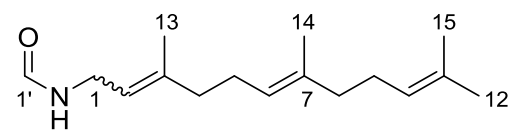

$N$-((2Z,6E)-3,7,11-Trimethyldodeca-2,6,10-trien-1-yl)formamide (165); $\mathrm{R}_{f}=0.18$ (1:2 EA/PE); 3:1 rotamers, NMR data for major rotamer: ${ }^{1} \mathrm{H}$ NMR $\left(300 \mathrm{MHz}, \mathrm{CDCl}_{3}\right): \delta$ 8.14 (s, 1H, H-1'), 5.37 (br s, 1H, NH), 5.21 (t, J=7.3 Hz, 1H, H-2), 5.08 (br s, 2H, H-6 and $\mathrm{H}-10$ ), 3.88 (t, $J=6.3 \mathrm{~Hz}, 2 \mathrm{H}, \mathrm{H}-1$ ), $2.14-1.93$ (complex m, 8H, $4 \times \mathrm{CH}_{2}$ ), 1.72 (s, 3H, H-13), 1.68 (s, 3H, H-15), 1.60 (s, 6H, H-12 and H-14); ${ }^{13} \mathrm{C} \mathrm{NMR} \mathrm{(150} \mathrm{MHz,} \mathrm{CDCl}_{3}$ ): $\delta 160.9$ (C, C-1'), 141.0 (C, C-3), 136.1 (C, C-7), 131.7 (C, C-11), 124.3 (CH, C-10), 123.5 (CH, C-6), 120.2 (CH, C-2), $39.9\left(\mathrm{CH}_{2}, \mathrm{C}-8\right), 36.0\left(\mathrm{CH}_{2}, \mathrm{C}-1\right), 32.0\left(\mathrm{CH}_{2}, \mathrm{C}-4\right)$, $26.8\left(\mathrm{CH}_{2}, \mathrm{C}-5\right.$ or C-9), $26.4\left(\mathrm{CH}_{2}, \mathrm{C}-5\right.$ or C-9), $25.9\left(\mathrm{CH}_{3}, \mathrm{C}-15\right), 23.5\left(\mathrm{CH}_{3}, \mathrm{C}-13\right), 17.9$ $\left(\mathrm{CH}_{3}, \mathrm{C}-12\right), 16.2\left(\mathrm{CH}_{3}, \mathrm{C}-14\right)$; IR (film from $\left.\mathrm{CH}_{2} \mathrm{Cl}_{2}\right): v_{\max } 3024,2964,2919,2855,1656$ $\mathrm{cm}^{-1}$; HRESIMS $m / z$ : $[\mathrm{M}+\mathrm{H}]^{+}$Calcd for $\mathrm{C}_{16} \mathrm{H}_{28} \mathrm{NO} 250.2165$; Found $250.2161(\Delta=1.95$ ppm); HRESIMS/MS (40 eV) m/z (\%): 109.1014 (74), 107.0841 (100).

$N$-((6E)-3,7,11-Trimethyldodeca-2,6,10-trien-1-yl)formamide (166); $\mathrm{R}_{f}=0.14(1: 2$ $\mathrm{EA} / \mathrm{PE}) ; 3: 2 \mathrm{E} / \mathrm{Z}, 7: 2$ rotamers, data for major isomer and rotamer: ${ }^{1} \mathrm{H} \mathrm{NMR}(500 \mathrm{MHz}$, $\mathrm{CDCl}_{3}$ ): $\delta 8.15$ (s, 1H, H-1'), 5.47 (br s, 1H, NH), 5.19 (t, $\left.J=7.1 \mathrm{~Hz}, 1 \mathrm{H}, \mathrm{H}-2\right), 5.13-$ 5.03 (complex m, 2H, H-6 and H-10), 3.90 (t, $J=6.2 \mathrm{~Hz}, 2 \mathrm{H}, \mathrm{H}-1$ ), $2.13-1.92$ (complex $\left.\mathrm{m}, 8 \mathrm{H}, 4 \times \mathrm{CH}_{2}\right), 1.67\left(\mathrm{~s}, 6 \mathrm{H}, 2 \times \mathrm{CH}_{3}\right), 1.59\left(\mathrm{~s}, 6 \mathrm{H}, 2 \times \mathrm{CH}_{3}\right) ;{ }^{13} \mathrm{C} \mathrm{NMR}(150 \mathrm{MHz}$, $\mathrm{CDCl}_{3}$ ): $\delta 161.0(\mathrm{C}, \mathrm{C}-1$ ') 140.7 (C, C-3), 135.6 (C, C-7), 131.5 (C, C-11), $124.4(\mathrm{CH}$, C-10), 123.7 (CH, C-6), 119.4 (CH, C-2), $39.8\left(\mathrm{CH}_{2}, \mathrm{C}-8\right), 39.6\left(\mathrm{CH}_{2}, \mathrm{C}-4\right), 36.2\left(\mathrm{CH}_{2}\right.$, C-1), $26.8\left(\mathrm{CH}_{2}, \mathrm{C}-9\right), 26.4\left(\mathrm{CH}_{2}, \mathrm{C}-5\right), 25.8\left(\mathrm{CH}_{3}, \mathrm{C}-15\right), 17.8\left(\mathrm{CH}_{3}, \mathrm{C}-12\right), 16.4\left(\mathrm{CH}_{3}\right.$, C-13), $16.14\left(\mathrm{CH}_{3}, \mathrm{C}-14\right)$; IR (film from $\left.\mathrm{CH}_{2} \mathrm{Cl}_{2}\right)$ : $v_{\max }$ 3279, 2965, 2916, 2854, $1657 \mathrm{~cm}^{-}$ 1; HRESIMS $m / z$ : $[\mathrm{M}+\mathrm{H}]^{+}$Calcd for $\mathrm{C}_{16} \mathrm{H}_{28} \mathrm{NO} 250.2165$; Found $250.2159(\Delta=2.72$ ppm); HRESIMS/MS (40 eV) m/z (\%): 121.0998 (60), 109.1014 (100).

Geranylgeranyl formamide; Acetic anhydride (2.3 mmol, $233 \mathrm{mg}, 215.5 \mu \mathrm{L})$ was stirred on an ice bath, under nitrogen, before the addition of formic acid (2.5 mmol, 115 $\mathrm{mg}, 94 \mu \mathrm{L})$. The reaction was then heated at $55^{\circ} \mathrm{C}$ for two hours, then cooled to room temperature and geranylgeranylamine $(0.86 \mathrm{mmol}, 250 \mathrm{mg}, 2.15 \mathrm{M}$ in formic acid) was added dropwise over 18 minutes. The reaction was stirred for five hours and then poured onto $\mathrm{H}_{2} \mathrm{O}(3 \mathrm{~mL})$ and extracted with EA $(3 \times 2 \mathrm{~mL})$. The combined extracts were washed 
with $\mathrm{H}_{2} \mathrm{O}(4 \times 3 \mathrm{~mL})$, then brine $(1 \times 3 \mathrm{~mL})$ and dried over anhydrous $\mathrm{MgSO}_{4}$. The solvent was removed under reduced pressure and the residue was purified by silica gel flash chromatography (2:3 EA/PE) to afford $\mathbf{1 6 7}$ and $\mathbf{1 6 8}$, rotameric mixtures of the $2 Z$ (3.8 $\mathrm{mg})$ and $2 E(6.5 \mathrm{mg})$ formylated products as pale-yellow oils with a combined yield of $4 \%$ :

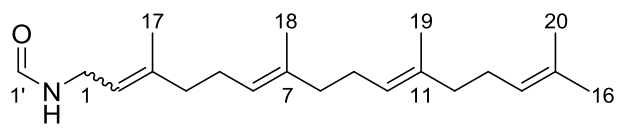

\section{$N$-((2Z,6E,10E)-3,7,11,15-Tetramethylhexadeca-2,6,10,14-tetraen-1-yl)formamide}

(167); $\mathrm{R}_{f}=0.26(2: 3 \mathrm{EA} / \mathrm{PE}) ; 2: 1$ rotamers, NMR data for major rotamer: ${ }^{1} \mathrm{H}$ NMR (300 $\mathrm{MHz} \mathrm{CDCl}_{3}$ ): $\delta 8.14$ (s, 1H, H-1'), 5.28 (br s, 1H, NH), 5.21 (t, $\left.J=8.4 \mathrm{~Hz}, 1 \mathrm{H}, \mathrm{H}-2\right)$, 5.10 (br s, 3H, H-6, H-10 and H-14), 3.88 (t, $J=6.1 \mathrm{~Hz}, 2 \mathrm{H}, \mathrm{H}-1$ ), $2.15-1.90$ (complex m, $\left.12 \mathrm{H}, 6 \times \mathrm{CH}_{2}\right), 1.74(\mathrm{~s}, 3 \mathrm{H}, \mathrm{H}-17), 1.68\left(\mathrm{~s}, 6 \mathrm{H}, 2 \times \mathrm{CH}_{3}\right), 1.60\left(\mathrm{~s}, 6 \mathrm{H}, 2 \times \mathrm{CH}_{3}\right) ;{ }^{13} \mathrm{C}$ NMR (150 MHz, CDCl 3 ): $\delta 160.9$ (C, C-1'), 141.0 (C, C-3), 136.1 (C, C-7), 135.3 (C, C11), 131.5 (C, C-15), 124.5 (CH, C-14), 124.2 (CH, C-10), 123.6 (CH, C-6), 120.2 (CH, C-2), $39.9\left(2 \times \mathrm{CH}_{2}, \mathrm{C}-8\right.$ and $\left.\mathrm{C}-12\right), 36.0\left(\mathrm{CH}_{2}, \mathrm{C}-1\right), 32.1\left(\mathrm{CH}_{2}, \mathrm{C}-4\right), 26.9\left(\mathrm{CH}_{2}, \mathrm{C}-13\right)$, $26.7\left(\mathrm{CH}_{2}, \mathrm{C}-9\right), 26.5\left(\mathrm{CH}_{2}, \mathrm{C}-5\right), 25.9\left(\mathrm{CH}_{3}, \mathrm{C}-20\right), 23.5\left(\mathrm{CH}_{3}, \mathrm{C}-17\right), 17.8\left(\mathrm{CH}_{3}, \mathrm{C}-16\right)$, $16.17\left(\mathrm{CH}_{3}, \mathrm{C}-18\right.$ or C-19), $16.15\left(\mathrm{CH}_{3}, \mathrm{C}-18\right.$ or C-19); IR (film from $\left.\mathrm{CH}_{2} \mathrm{Cl}_{2}\right): v_{\max } 3299$, $3024,2964,2920,2874,1656 \mathrm{~cm}^{-1}$.

\section{$N$-((2E,6E,10E)-3,7,11,15-Tetramethylhexadeca-2,6,10,14-tetraen-1-yl)formamide}

(168); $\mathrm{R}_{f}=0.21$ (2:3 EA/PE); 3:1 rotamers, NMR data for major rotamer: ${ }^{1} \mathrm{H}$ NMR (300 $\mathrm{MHz}, \mathrm{CDCl}_{3}$ ): $\delta 8.16\left(\mathrm{~s}, 1 \mathrm{H}, \mathrm{H}-1^{\prime}\right), 5.41(\mathrm{br} \mathrm{s}, 1 \mathrm{H}, \mathrm{NH}), 5.20(\mathrm{t}, J=6.4 \mathrm{~Hz}, 1 \mathrm{H}, \mathrm{H}-2)$, 5.10 (br s, 3H, H-6, H-10 and H-14), 3.90 (t, $J=6.1 \mathrm{~Hz}, 3 \mathrm{H}, \mathrm{H}-1$ ), $2.16-1.90$ (complex $\left.\mathrm{m}, 12 \mathrm{H}, 6 \times \mathrm{CH}_{2}\right), 1.68\left(\mathrm{~s}, 6 \mathrm{H}, 2 \times \mathrm{CH}_{3}\right), 1.60\left(\mathrm{~s}, 9 \mathrm{H}, 3 \times \mathrm{CH}_{3}\right) ;{ }^{13} \mathrm{C} \mathrm{NMR}(150 \mathrm{MHz}$, $\left.\mathrm{CDCl}_{3}\right): \delta 161.0\left(\mathrm{C}, \mathrm{C}-1^{\prime}\right), 140.8(\mathrm{C}, \mathrm{C}-3), 135.7$ (C, C-7), $135.2(\mathrm{C}, \mathrm{C}-11), 131.5(\mathrm{C}, \mathrm{C}-$ 15), 124.5 (CH, C-14), 124.3 (CH, C-10), 123.8 (CH, C-6), 119.4 (CH, C-2), $39.9\left(\mathrm{CH}_{2}\right.$, C-12), $39.8\left(\mathrm{CH}_{2}, \mathrm{C}-8\right), 39.6\left(\mathrm{CH}_{2}, \mathrm{C}-4\right), 36.2\left(\mathrm{CH}_{2}, \mathrm{C}-1\right), 26.9\left(\mathrm{CH}_{2}, \mathrm{C}-13\right), 26.8\left(\mathrm{CH}_{2}\right.$, C-9), $26.4\left(\mathrm{CH}_{2}, \mathrm{C}-5\right), 25.9\left(\mathrm{CH}_{3}, \mathrm{C}-20\right), 17.8\left(\mathrm{CH}_{3}, \mathrm{C}-16\right), 16.5\left(\mathrm{CH}_{3}, \mathrm{C}-17\right), 16.18\left(\mathrm{CH}_{3}\right.$, C-18 or C-19), $16.16\left(\mathrm{CH}_{3}, \mathrm{C}-18\right.$ or C-19); IR (film from $\mathrm{CH}_{2} \mathrm{Cl}_{2}$ ): $v_{\max } 3293,2966,2915$, 2853, $1660 \mathrm{~cm}^{-1}$; HRESIMS $\mathrm{m} / z$ : $[\mathrm{M}+\mathrm{H}]^{+}$Calcd for $\mathrm{C}_{21} \mathrm{H}_{35} \mathrm{NO}$ 318.2791; Found 318.2784 ( $\Delta=2.37 \mathrm{ppm})$; HRESIMS/MS (20 eV) $\mathrm{m} / \mathrm{z}$ (\%): 121.0997 (59), 109.0998 (82), $107.0846(100)$. 
Geranyl $\boldsymbol{N}$-methylformamide; Freshly powdered $\mathrm{KOH}(0.647 \mathrm{mmol}, 36.3 \mathrm{mg})$ was stirred in dry DMSO $(0.1 \mathrm{~mL})$ for 10 minutes before the addition of geranyl formamide (0.17 mmol, $30.0 \mathrm{mg}, 1.7 \mathrm{M}$ in DMSO), followed immediately by the addition of methyl iodide $(0.5 \mathrm{mmol}, 71.0 \mathrm{mg}, 31.2 \mu \mathrm{L})$. The reaction was stirred for two and a half hours, then poured onto $\mathrm{H}_{2} \mathrm{O}(3 \mathrm{~mL})$ and extracted with DCM $(3 \times 2 \mathrm{~mL})$. The combined extracts were washed with $\mathrm{H}_{2} \mathrm{O}(5 \times 2 \mathrm{~mL})$, then brine $(1 \times 2 \mathrm{~mL})$ and dried over anhydrous $\mathrm{MgSO}_{4}$. The solvent was removed under reduced pressure and the resulting residue was purified by silica gel flash chromatography (1:3 EA/PE) to yield 169 as a colourless oil (17.4 mg, 54\%):

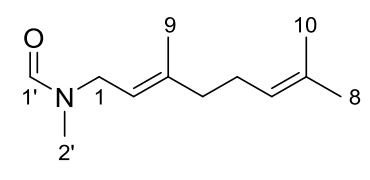

(E)-N-(3,7-Dimethylocta-2,6-dien-1-yl)- $N$-methylformamide (169); $\mathrm{R}_{f}=0.14(1: 3$ $\mathrm{EA} / \mathrm{PE}) ; 3: 2$ rotamers, NMR data for major rotamer: ${ }^{1} \mathrm{H} \mathrm{NMR}\left(500 \mathrm{MHz}, \mathrm{CDCl}_{3}\right): \delta 8.06$ (s, 1H, H-1'), $5.11-5.06$ (m, 1H, H-2), $5.06-5.01$ (m, 1H, H-6), 3.80 (d, J = $7.1 \mathrm{~Hz}$, 2H, H-1), 2.78 (s, 3H, H-2'), 2.13 - 1.99 (complex m, 4H, H-4 and H-5), 1.67 (s, 3H, H9), 1.66 (s, 3H, H-10), 1.58 (s, 3H, H-8); $\left.{ }^{13} \mathrm{C} \mathrm{NMR} \mathrm{(150} \mathrm{MHz,} \mathrm{CDCl}_{3}\right): \delta 162.5$ (C, C-1), 141.3 (C, C-3), 132.1 (C, C-7), 123.7 (CH, C-6), 119.1 (CH, C-2), $47.2\left(\mathrm{CH}_{2}, \mathrm{C}-1\right), 39.7$ $\left(\mathrm{CH}_{2}, \mathrm{C}-4\right), 29.2\left(\mathrm{CH}_{3}, \mathrm{C}-2\right.$ ') $, 26.3\left(\mathrm{CH}_{2}, \mathrm{C}-5\right), 25.8\left(\mathrm{CH}_{3}, \mathrm{C}-10\right), 17.8\left(\mathrm{CH}_{3}, \mathrm{C}-8\right), 16.30$ $\left(\mathrm{CH}_{3}, \mathrm{C}-9\right.$ ); IR (film from $\mathrm{CH}_{2} \mathrm{Cl}_{2}$ ): $v_{\max } 2965,2917,2854,1663 \mathrm{~cm}^{-1}$; HRESIMS m/z: $[\mathrm{M}+\mathrm{H}]^{+}$Calcd for $\mathrm{C}_{12} \mathrm{H}_{22} \mathrm{NO}$ 196.1696; Found 196.1695 ( $\Delta=0.55 \mathrm{ppm}$ ); HRESIMS/MS (20 eV) m/z (\%): 196.1694 (17), 137.1319 (100), 109.1010 (21).

Farnesyl $N$-methylformamide; Farnesyl formamide $(0.040 \mathrm{mmol}, 10 \mathrm{mg})$ was added to freshly powdered $\mathrm{KOH}(0.18 \mathrm{mmol}, 9.9 \mathrm{mg})$ in dry DMSO $(0.1 \mathrm{~mL})$, which was previously stirred for 15 minutes. Immediately following formamide addition, methyl iodide $(0.12 \mathrm{mmol}, 17 \mathrm{mg}, 7.5 \mu \mathrm{L})$ was added and the reaction was stirred for three hours. The reaction was then poured onto $\mathrm{H}_{2} \mathrm{O}(2 \mathrm{~mL})$ and extracted with $\mathrm{DCM}(3 \times 2 \mathrm{~mL})$. The combined extracts were washed with $\mathrm{H}_{2} \mathrm{O}(3 \times 2 \mathrm{~mL})$, then brine $(1 \times 2 \mathrm{~mL})$ and dried over anhydrous $\mathrm{MgSO}_{4}$. The solvent was removed under reduced pressure and the remaining residue was purified by silica gel flash chromatography (1:4 EA/PE) to afford $\mathbf{1 7 0}$ as a colourless oil (5.9 $\mathrm{mg}, 56 \%)$ : 


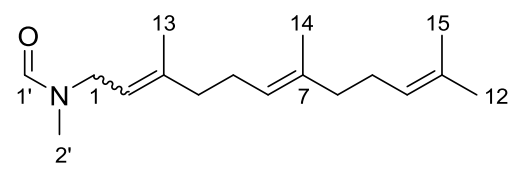

$N$-Methyl- $N$-((6E)-3,7,11-trimethyldodeca-2,6,10-trien-1-yl)formamide $(170) ; \mathrm{R}_{f}=$ 0.10 (1:4 EA/PE); 3:2 E/Z, 3:2 rotamers, NMR data for major isomer and rotamer: ${ }^{1} \mathrm{H}$ NMR (500 MHz, CDCl 3 ): $\delta 8.08$ (s, 1H, H-1'), 5.13 - 5.04 (complex m, 3H, H-2, H-6 and H-10), 3.81 (d, $J=7.0 \mathrm{~Hz}, 2 \mathrm{H}, \mathrm{H}-1$ ), 2.79 (s, 3H, H-2'), $2.14-2.00$ (complex m, 6H, $\left.3 \times \mathrm{CH}_{2}\right), 1.99-1.93\left(\mathrm{~m}, 2 \mathrm{H}, \mathrm{CH}_{2}\right), 1.68$ (s, 3H, H-13), 1.64 (s, 3H, $\left.\mathrm{CH}_{3}, \mathrm{H}-15\right), 1.59$ (s, 6H, H-12 and H-14); ${ }^{13} \mathrm{C}$ NMR (150 MHz, $\left.\mathrm{CDCl}_{3}\right): \delta 162.6$ (C, C-1'), 141.4 (C, C-3), 135.8 (C, C-7), 131.5 (C, C-11), 124.4 (CH, C-10), 123.6 (CH, C-6), 119.0 (CH, C-2), $\left.47.3\left(\mathrm{CH}_{2}, \mathrm{C}-1\right), 39.9\left(\mathrm{CH}_{2}, \mathrm{C}-8\right), 39.7\left(\mathrm{CH}_{2}, \mathrm{C}-4\right), 29.2\left(\mathrm{CH}_{3}, \mathrm{C}-2\right)\right), 26.8\left(\mathrm{CH}_{2}, \mathrm{C}-9\right)$, $26.3\left(\mathrm{CH}_{2}, \mathrm{C}-5\right), 25.9\left(\mathrm{CH}_{3}, \mathrm{C}-15\right), 17.8\left(\mathrm{CH}_{3}, \mathrm{C}-12\right), 16.4\left(\mathrm{CH}_{3}, \mathrm{C}-13\right), 16.2\left(\mathrm{CH}_{3}, \mathrm{C}-\right.$ 14); IR (film from $\mathrm{CH}_{2} \mathrm{Cl}_{2}$ ): $v_{\max } 3495,2963,2916,2853,1677,1665 \mathrm{~cm}^{-1}$; HRESIMS $m / z:[\mathrm{M}+\mathrm{H}]^{+}$Calcd for $\mathrm{C}_{17} \mathrm{H}_{30} \mathrm{NO}$ 264.2322; Found 264.2324 ( $\left.\Delta=-0.78 \mathrm{ppm}\right)$; HRESIMS/MS (40 eV) m/z (\%): 109.1001 (53), 107.085 (100), 105.0694 (58).

Geranylgeranyl $\boldsymbol{N}$-methylformamide; Freshly powdered $\mathrm{KOH}(0.201 \mathrm{mmol}, 11.3$ $\mathrm{mg})$ was stirred in dry DMSO $(0.1 \mathrm{~mL})$ for 15 minutes. $(2 E, 6 E, 10 E)$-Geranylgeranyl formamide (0.047 mmol, $15 \mathrm{mg}, 0.47 \mathrm{M}$ in DMSO) was added, followed immediately by methyl iodide $(0.14 \mathrm{mmol}, 20 \mathrm{mg}, 8.8 \mu \mathrm{L})$ and the reaction was stirred for two hours. Afterward, $\mathrm{H}_{2} \mathrm{O}(2 \mathrm{~mL})$ was added and the mixture was extracted with DCM $(3 \times 2 \mathrm{~mL})$. The combined extracts were washed with $\mathrm{H}_{2} \mathrm{O}(3 \times 2 \mathrm{~mL})$, then brine $(1 \times 2 \mathrm{~mL})$ and dried over anhydrous $\mathrm{MgSO}_{4}$. The solvent was removed under reduced pressure and the resulting residue was purified by silica gel flash chromatography (1:3 EA/PE) to yield 171 as a colourless oil (5.2 $\mathrm{mg}, 33 \%)$ :

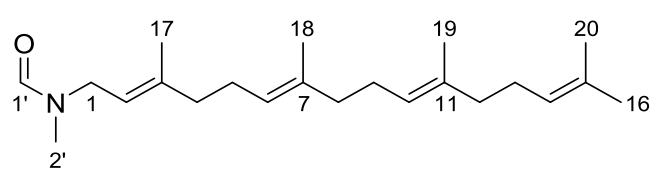

\section{$N$-Methyl- $N$-((2E,6E,10E)-3,7,11,15-tetramethylhexadeca-2,6,10,14-tetraen-1-} yl)formamide (171); $\mathrm{R}_{f}=0.13(1: 3 \mathrm{EA} / \mathrm{PE}) ;{ }^{1} \mathrm{H} \mathrm{NMR}\left(500 \mathrm{MHz}, \mathrm{CDCl}_{3}\right): \delta 8.08(\mathrm{~s}, 1 \mathrm{H}$, H-1'), 5.15 - 5.03 (complex m, 4H, $4 \times \mathrm{CH}$ ), 3.81 (d, J = $7.0 \mathrm{~Hz}, 2 \mathrm{H}, \mathrm{H}-1$ ), 2.79 (s, 3H, H-2'), 2.14 - 2.01 (complex m, 8H, $4 \times \mathrm{CH}_{2}$ ), $2.01-1.88$ (complex m, 4H, $2 \times \mathrm{CH}_{2}$ ), 1.69 (s, 3H, H-17), 1.68 (s, 3H, H-20), 1.61 (s, 3H, $\left.\mathrm{CH}_{3}\right), 1.60\left(\mathrm{~s}, 6 \mathrm{H}, 2 \times \mathrm{CH}_{3}\right) ;{ }^{13} \mathrm{C}$ NMR (150 MHz, $\left.\mathrm{CDCl}_{3}\right): \delta 162.5$ (C, C-1'), 141.4 (C, C-3), 135.8 (C, C-7), $135.2(\mathrm{C}, \mathrm{C}-$ 
11), 131.4 (C, C-15), 124.5 (CH, C-14), 124.2 (CH, C-10), 123.6 (CH, C-6), 119.0 (CH, C-2), $47.3\left(\mathrm{CH}_{2}, \mathrm{C}-1\right), 39.9\left(\mathrm{CH}_{2}, \mathrm{C}-12\right), 39.8\left(\mathrm{CH}_{2}, \mathrm{C}-8\right), 39.7\left(\mathrm{CH}_{2}, \mathrm{C}-4\right), 29.2\left(\mathrm{CH}_{3}\right.$, C-2'), $26.9\left(\mathrm{CH}_{2}, \mathrm{C}-13\right), 26.7\left(\mathrm{CH}_{2}, \mathrm{C}-9\right), 26.4\left(\mathrm{CH}_{2}, \mathrm{C}-5\right), 25.9\left(\mathrm{CH}_{3}, \mathrm{C}-20\right), 17.8\left(\mathrm{CH}_{3}\right.$, C-16), $16.4\left(\mathrm{CH}_{3}, \mathrm{C}-17\right), 16.18\left(\mathrm{CH}_{3}, \mathrm{C}-18\right.$ or C-19), $16.15\left(\mathrm{CH}_{3}, \mathrm{C}-18\right.$ or C-19); IR (film from $\mathrm{CH}_{2} \mathrm{Cl}_{2}$ ): $v_{\max } 2962,2922,2854,1681 \mathrm{~cm}^{-1}$; HRESIMS $\mathrm{m} / z:[\mathrm{M}+\mathrm{H}]^{+}$Calcd for $\mathrm{C}_{22} \mathrm{H}_{38} \mathrm{NO} 332.2948$; Found 322.2955 ( $\Delta=-2.21 \mathrm{ppm}$ ); HRESIMS/MS (40 eV) $\mathrm{m} / \mathrm{z}(\%)$ : 121.1003 (100).

Geranyl acetamide; Dry triethylamine (4.9 mmol, $497 \mathrm{mg}, 681.5 \mu \mathrm{L})$ and geranylamine $(1.6 \mathrm{mmol}, 250.1 \mathrm{mg})$ in dry THF $(15 \mathrm{~mL})$ were stirred on an ice bath for 10 minutes. Acetyl chloride $(2.5 \mathrm{mmol}, 0.192 \mathrm{~g}, 174 \mu \mathrm{L})$ was added and the reaction was stirred for five hours while allowed to warm to room temperature. The reaction was quenched with ice-cold $\mathrm{H}_{2} \mathrm{O}(10 \mathrm{~mL})$ and the mixture was extracted with $\mathrm{EA}(2 \times 10 \mathrm{~mL})$. The combined extracts were washed with $\mathrm{H}_{2} \mathrm{O}(2 \times 10 \mathrm{~mL})$, then brine $(1 \times 10 \mathrm{~mL})$ and dried over anhydrous $\mathrm{MgSO}_{4}$. The solvent was removed under reduced pressure and the resulting residue was purified by silica gel flash chromatography (1:1 EA/PE) to afford 172 as a pale-yellow oil (96.1 $\mathrm{mg}, 30 \%)$ :<smiles>CC(=O)NCC=C(C)CCC=C(C)C</smiles>

(E)- $N$-(3,7-Dimethylocta-2,6-dien-1-yl)acetamide (172); $\mathrm{R}_{f}=0.16(1: 1 \mathrm{EA} / \mathrm{PE}) ;{ }^{1} \mathrm{H}$ NMR (500 MHz, $\mathrm{CDCl}_{3}$ ): $\delta 5.32$ (br s, 1H, NH), 5.19 (td, $\left.J=7.1,1.2 \mathrm{~Hz}, 1 \mathrm{H}, \mathrm{H}-2\right), 5.11$ - 5.04 (m, 1H, H-6), 3.84 (t, $J=6.4 \mathrm{~Hz}, 2 \mathrm{H}, \mathrm{H}-1), 2.12-2.05$ (m, 2H, H-4 or H-5), 2.04 - 1.99 (m, 2H, H-4 or H-5), 1.98 (s, 3H, H-2'), 1.69 (s, 3H, H-9), 1.67 (s, 3H, H-10), 1.60 (s, 3H, H-8); ${ }^{13} \mathrm{C}$ NMR (150 MHz, $\mathrm{CDCl}_{3}$ ): $\delta 169.9$ (C, C-1'), 140.2 (C, C-3), 132.0 (C, C-7), 124.0 (CH, C-6), $119.9(\mathrm{CH}, \mathrm{C}-2), 39.6(\mathrm{CH}, \mathrm{C}-4), 37.8\left(\mathrm{CH}_{2}, \mathrm{C}-1\right), 26.5\left(\mathrm{CH}_{2}, \mathrm{C}-\right.$ 5), $25.9\left(\mathrm{CH}_{3}, \mathrm{C}-10\right), 23.5\left(\mathrm{CH}_{3}, \mathrm{C}-2\right.$ '), $17.9\left(\mathrm{CH}_{3}, \mathrm{C}-8\right), 16.4\left(\mathrm{CH}_{3}, \mathrm{C}-9\right)$; IR (film from $\left.\mathrm{CH}_{2} \mathrm{Cl}_{2}\right): v_{\max }$ 3293, 3081, 2970, 2928, $1649 \mathrm{~cm}^{-1}$; HRESIMS m/z: [M+H] ${ }^{+}$Calcd for $\mathrm{C}_{12} \mathrm{H}_{22} \mathrm{NO}$ 196.1696; Found 196.1708 ( $\left.\Delta=-6.02 \mathrm{ppm}\right)$; HRESIMS/MS (40 eV) $\mathrm{m} / z(\%)$ : 137.1312 (34), 109.0997 (79), 107.0473 (100).

Farnesyl acetamide; Farnesylamine $(1.1 \mathrm{mmol}, 250.1 \mathrm{mg})$ in dry THF $(15 \mathrm{~mL})$ was stirred on ice under nitrogen. Dry triethylamine (3.4 mmol, $342.7 \mathrm{mg}, 472 \mu \mathrm{L})$ was added and stirred for 8 minutes before dropwise addition of acetyl chloride $(1.7 \mathrm{mmol}, 133 \mathrm{mg}$, $120 \mu \mathrm{L}$ ). The reaction was allowed to warm to room temperature whilst stirring for five 
and a half hours. The reaction was then quenched with ice-cold $\mathrm{H}_{2} \mathrm{O}(10 \mathrm{~mL})$ and the mixture was extracted with EA $(2 \times 10 \mathrm{~mL})$. The combined extracts were washed with $\mathrm{H}_{2} \mathrm{O}(2 \times 10 \mathrm{~mL})$, then brine $(1 \times 10 \mathrm{~mL})$ and dried over anhydrous $\mathrm{MgSO}_{4}$. The solvent was removed under reduced pressure and the remaining residue was purified by silica gel flash chromatography (1:1 EA/PE) to afford 173 and 174, the $2 Z(9.9 \mathrm{mg})$ and $2 E(65.1$ $\mathrm{mg}$ ) acetylated products as pale-yellow oils with a combined yield of $25 \%$ :

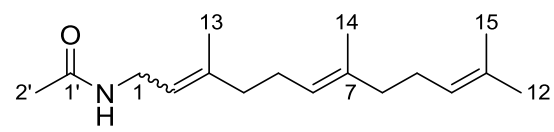

$N$-((2Z,6E)-3,7,11-Trimethyldodeca-2,6,10-trien-1-yl)acetamide (173); $\mathrm{R}_{f}=0.30(1: 1$ $\mathrm{EA} / \mathrm{PE}) ;{ }^{1} \mathrm{H} \mathrm{NMR}\left(500 \mathrm{MHz}, \mathrm{CDCl}_{3}\right): \delta 5.32(\mathrm{br} \mathrm{s}, 1 \mathrm{H}, \mathrm{NH}), 5.20(\mathrm{td}, J=7.2,1.2 \mathrm{~Hz}$, 1H, H-2), 5.12 - 5.04 (complex m, 2H, H-6 and H-10), 3.82 (t, $J=6.5 \mathrm{~Hz}, 2 \mathrm{H}, \mathrm{H}-1$ ), 2.11 - 1.97 (complex m, 8H, $4 \times \mathrm{CH}_{2}$ ), 1.96 (s, 3H, H-2'), 1.72 (s, 3H, H-13), 1.68 (s, 3H, H15), 1.60 (s, 6H, H-12 and H-14); ${ }^{13} \mathrm{C}$ NMR (150 MHz, $\left.\mathrm{CDCl}_{3}\right): \delta 169.9$ (C, C-1'), 140.5 (C, C-3), 135.9 (C, C-7), 131.6 (C, C-11), 124.3 (CH, C-10), 123.6 (CH, C-6), 120.7 (CH, C-2), $39.9\left(\mathrm{CH}_{2}, \mathrm{C}-8\right), 37.5\left(\mathrm{CH}_{2}, \mathrm{C}-1\right), 32.03\left(\mathrm{CH}_{2}, \mathrm{C}-4\right), 26.8\left(\mathrm{CH}_{2}, \mathrm{C}-9\right), 26.5\left(\mathrm{CH}_{2}\right.$, C-5), $25.9\left(\mathrm{CH}_{3}, \mathrm{C}-15\right), 23.5\left(\mathrm{CH}_{3}, \mathrm{C}-1{ }^{\prime}\right), 23.4\left(\mathrm{CH}_{2}, \mathrm{C}-13\right), 17.9\left(\mathrm{CH}_{3}, \mathrm{C}-12\right), 16.2\left(\mathrm{CH}_{3}\right.$, C-14); IR (film from $\mathrm{CH}_{2} \mathrm{Cl}_{2}$ ): $v_{\max } 3293,3086,2967,2927,2857,1653 \mathrm{~cm}^{-1}$; HRESIMS $m / z:[\mathrm{M}+\mathrm{H}]^{+}$Calcd for $\mathrm{C}_{17} \mathrm{H}_{30} \mathrm{NO}$ 264.2322; Found 264.2319 ( $\left.\Delta=1.17 \mathrm{ppm}\right)$; HRESIMS/MS (40 eV) m/z(\%): 109.1008 (95), 107.0850 (100).

$N$-((2E,6E)-3,7,11-Trimethyldodeca-2,6,10-trien-1-yl)acetamide (174); $\mathrm{R}_{f}=0.22(1: 1$ EA/PE); ${ }^{1} \mathrm{H}$ NMR $\left(500 \mathrm{MHz}, \mathrm{CDCl}_{3}\right): \delta 5.32$ (br s, $\left.1 \mathrm{H}, \mathrm{NH}\right), 5.19$ (t, $J=7.1 \mathrm{~Hz}, 1 \mathrm{H}, \mathrm{H}-$ 2), 5.12 - 5.05 (complex m, 2H, H-6 and H-10), 3.84 (t, J=6.4 Hz, 2H, H-1), $2.14-1.98$ (complex m, 8H, $4 \times \mathrm{CH}_{2}$ ), 1.97 (s, 3H, H-2'), 1.69 (s, 3H, H-13), 1.67 (s, 3H, H-15), 1.59 (s, 6H, H-12 and H-14); ${ }^{13} \mathrm{C}$ NMR (150 MHz, CDCl 3 ): $\delta 169.9$ (C, C-1'), 140.3 (C, C-3), 135.6 (C, C-7), 131.5 (C, C-11), 124.4 (CH, C-10), 123.8 (CH, C-6), 119.9 (CH, C2), $39.8\left(\mathrm{CH}_{2}, \mathrm{C}-8\right), 39.6\left(\mathrm{CH}_{2}, \mathrm{C}-4\right), 37.8\left(\mathrm{CH}_{2}, \mathrm{C}-1\right), 26.9\left(\mathrm{CH}_{2}, \mathrm{C}-9\right), 26.4\left(\mathrm{CH}_{2}, \mathrm{C}-5\right)$, $25.9\left(\mathrm{CH}_{3}, \mathrm{C}-15\right), 23.4\left(\mathrm{CH}_{3}, \mathrm{C}-2{ }^{\prime}\right), 17.8\left(\mathrm{CH}_{3}, \mathrm{C}-12\right), 16.4\left(\mathrm{CH}_{3}, \mathrm{C}-13\right), 16.2\left(\mathrm{CH}_{3}, \mathrm{C}-\right.$ 14); IR (film from $\mathrm{CH}_{2} \mathrm{Cl}_{2}$ ): $v_{\max } 3279,3080,2966,2917,2855,1659 \mathrm{~cm}^{-1}$; HRESIMS $m / z:[\mathrm{M}+\mathrm{H}]^{+}$Calcd for $\mathrm{C}_{17} \mathrm{H}_{30} \mathrm{NO}$ 264.2322; Found 264.2318 ( $\left.\Delta=1.36 \mathrm{ppm}\right)$; HRESIMS/MS (40 eV) m/z(\%): 109.1000 (57), 107.0843 (100).

Geranylgeranyl acetamide; To a stirring solution of geranylgeranylamine (1.0 mmol, $300 \mathrm{mg})$ in dry THF $(10 \mathrm{~mL})$ on an ice bath under nitrogen was added dry triethylamine 
(3.16 mmol, $0.3194 \mathrm{~g}, 440 \mu \mathrm{L})$. After stirring for 10 minutes, acetyl chloride (1.1 mmol, $89.4 \mathrm{mg}, 81 \mu \mathrm{L}$ ) was added dropwise and the reaction was stirred for a further four and a half hours while allowed to warm to room temperature. The reaction was then quenched with $\mathrm{H}_{2} \mathrm{O}(10 \mathrm{~mL})$ and extracted with EA $(3 \times 10 \mathrm{~mL})$. The combined extracts were washed with $\mathrm{H}_{2} \mathrm{O}(2 \times 10 \mathrm{~mL})$, then brine $(1 \times 10 \mathrm{~mL})$ and dried over anhydrous $\mathrm{MgSO}_{4}$. The solvent was removed under reduced pressure and the resulting residue was purified by silica gel flash chromatography (1:1 EA/PE) to afford 175 and 176, the $2 Z(22.1 \mathrm{mg})$ and $2 E(95.5 \mathrm{mg})$ acetylated products as pale-yellow oils with a combined yield of $31 \%$ :

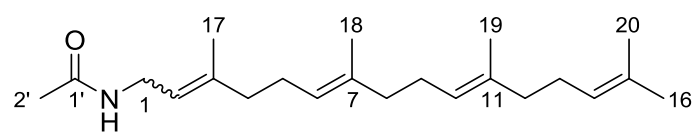

\section{$N$-((2Z,6E,10E)-3,7,11,15-Tetramethylhexadeca-2,6,10,14-tetraen-1-yl)acetamide}

(175); $\mathrm{R}_{f}=0.20(1: 1 \mathrm{EA} / \mathrm{PE}) ;{ }^{1} \mathrm{H} \mathrm{NMR}\left(300 \mathrm{MHz}, \mathrm{CDCl}_{3}\right): \delta 5.38$ (br s, $\left.1 \mathrm{H}, \mathrm{NH}\right), 5.19$ (t, $J=7.2 \mathrm{~Hz}, 1 \mathrm{H}, \mathrm{H}-2), 5.14-5.03$ (complex m, 3H, H-6, H-10 and H-14), 3.81 (t, $J=$ $6.1 \mathrm{~Hz}, 2 \mathrm{H}, \mathrm{H}-1), 2.13$ - 1.96 (complex m, 12H, $6 \times \mathrm{CH}_{2}$ ), 1.95 (s, 3H, H-2'), 1.72 (s, 3H, H-17), 1.67 (s, 3H, H-20), 1.59 (s, 9H, H-16, H-18 and H-19); ${ }^{13} \mathrm{C}$ NMR (150 MHz, $\left.\mathrm{CDCl}_{3}\right): \delta 169.9(\mathrm{C}, \mathrm{C}-1$ ') $, 140.4(\mathrm{C}, \mathrm{C}-3), 136.0$ (C, C-7), 135.2 (C, C-11), $131.4(\mathrm{C}, \mathrm{C}-$ 15), 124.5 (CH, C-14), 124.2 (CH, C-10), 123.6 (CH, C-6), 120.7 (CH, C-2), $39.9\left(\mathrm{CH}_{2}\right.$, C-12), $39.8\left(\mathrm{CH}_{2}, \mathrm{C}-8\right), 37.5\left(\mathrm{CH}_{2}, \mathrm{C}-1\right), 32.1\left(\mathrm{CH}_{2}, \mathrm{C}-4\right), 26.9\left(\mathrm{CH}_{2}, \mathrm{C}-13\right), 26.7\left(\mathrm{CH}_{2}\right.$, C-9), $\left.26.5\left(\mathrm{CH}_{2}, \mathrm{C}-5\right), 25.8\left(\mathrm{CH}_{3}, \mathrm{C}-20\right), 23.5\left(\mathrm{CH}_{3}, \mathrm{C}-17\right), 23.4\left(\mathrm{CH}_{3}, \mathrm{C}-2\right)\right), 17.8\left(\mathrm{CH}_{3}\right.$, C-16), $16.2\left(\mathrm{CH}_{3}, \mathrm{C}-18\right.$ or C-19), $16.1\left(\mathrm{CH}_{3}, \mathrm{C}-18\right.$ or C-19); IR (film from $\left.\mathrm{CH}_{2} \mathrm{Cl}_{2}\right): v_{\max }$ 3277, 3078, 2965, 2916, 2855, $1649 \mathrm{~cm}^{-1}$; HRESIMS $m / z$ : $[\mathrm{M}+\mathrm{H}]^{+}$Calcd for $\mathrm{C}_{22} \mathrm{H}_{38} \mathrm{NO}$ 332.2948; Found $332.2951(\Delta=-0.87 \mathrm{ppm})$; HRESIMS/MS (40 eV) $m / z(\%): 107.0849$ (100).

\section{$N$-((2E,6E,10E)-3,7,11,15-Tetramethylhexadeca-2,6,10,14-tetraen-1-yl)acetamide}

(176); $\mathrm{R}_{f}=0.14(1: 1 \mathrm{EA} / \mathrm{PE}) ;{ }^{1} \mathrm{H} \mathrm{NMR}\left(300 \mathrm{MHz}, \mathrm{CDCl}_{3}\right): \delta 5.32$ (br s, $\left.1 \mathrm{H}, \mathrm{NH}\right), 5.19$ (t, $J=6.8 \mathrm{~Hz}, 1 \mathrm{H}, \mathrm{H}-2), 5.15-5.04$ (complex m, 3H, H-6, H-10 and H-14), 3.84 (t, $J=6.1$ $\mathrm{Hz}, 2 \mathrm{H}, \mathrm{H}-1$ ), 2.15 - 1.98 (complex m, 12H, $6 \times \mathrm{CH}_{2}$ ), 1.67 (s, 6H, $\left.2 \times \mathrm{CH}_{3}\right), 1.60(\mathrm{~s}, 9 \mathrm{H}$, $\left.3 \times \mathrm{CH}_{3}\right) ;{ }^{13} \mathrm{C}$ NMR $\left(150 \mathrm{MHz}, \mathrm{CDCl}_{3}\right): \delta 169.9(\mathrm{C}, \mathrm{C}-1$ ') $, 140.3(\mathrm{C}, \mathrm{C}-3), 135.6(\mathrm{C}, \mathrm{C}-$ 7), 135.2 (C, C-11), 131.5 (C, C-15), 124.5 (CH, C-14), 124.3 (CH, C-10), 123.8 (CH, C6), $119.9(\mathrm{CH}, \mathrm{C}-2), 39.9\left(\mathrm{CH}_{2}, \mathrm{C}-12\right), 39.8\left(\mathrm{CH}_{2}, \mathrm{C}-8\right), 39.6\left(\mathrm{CH}_{2}, \mathrm{C}-4\right), 37.8\left(\mathrm{CH}_{2}, \mathrm{C}-\right.$ 1), $26.9\left(\mathrm{CH}_{2}, \mathrm{C}-13\right), 26.8\left(\mathrm{CH}_{2}, \mathrm{C}-9\right), 26.5\left(\mathrm{CH}_{2}, \mathrm{C}-5\right), 25.9\left(\mathrm{CH}_{3}, \mathrm{C}-20\right), 23.5\left(\mathrm{CH}_{3}, \mathrm{C}-\right.$ 2'), $17.8\left(\mathrm{CH}_{3}, \mathrm{C}-16\right), 16.5\left(\mathrm{CH}_{3}, \mathrm{C}-17\right), 16.19\left(\mathrm{CH}_{3}, \mathrm{C}-18\right.$ or C-19), $16.17\left(\mathrm{CH}_{3}, \mathrm{C}-18\right.$ or 
C-19); IR (film from $\mathrm{CH}_{2} \mathrm{Cl}_{2}$ ): $v_{\max } 3279,3078,2967,2917,2854,1650 \mathrm{~cm}^{-1}$; HRESIMS $m / z:[\mathrm{M}+\mathrm{H}]^{+}$Calcd for $\mathrm{C}_{22} \mathrm{H}_{38} \mathrm{NO}$ 332.2948; Found 332.2934 ( $\left.\Delta=4.2 \mathrm{ppm}\right)$; HRESIMS/MS (20 eV) m/z(\%): 332.3002 (100), 149.1318 (100).

Geranyl $N$-methylacetamide; Freshly powdered $\mathrm{KOH}(0.41 \mathrm{mmol}, 23.2 \mathrm{mg})$ was added to dry DMSO $(0.1 \mathrm{~mL})$ and stirred for seven minutes. Then geranyl acetamide $(0.10$ mmol, $20 \mathrm{mg}, 1 \mathrm{M}$ in dry DMSO) was added, followed immediately by methyl iodide $(0.20 \mathrm{mmol}, 28.7 \mathrm{mg}, 12.6 \mu \mathrm{L})$. The reaction was stirred for 40 minutes, then poured onto $\mathrm{H}_{2} \mathrm{O}(2 \mathrm{~mL})$ and extracted with DCM $(3 \times 2 \mathrm{~mL})$. The combined extracts were washed with $\mathrm{H}_{2} \mathrm{O}(3 \times 2 \mathrm{~mL})$, then brine $(1 \times 2 \mathrm{~mL})$ and dried over $\mathrm{MgSO}_{4}$. The solvent was removed under reduced pressure and the residue was purified by silica gel flash chromatography (1:3 EA/PE) to afford 177 as a colourless oil $(1.3 \mathrm{mg}, 6 \%)$ :

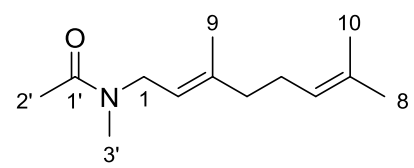

(E)- $N$-(3,7-Dimethylocta-2,6-dien-1-yl)- $N$-methylacetamide (177); ${ }^{1} \mathrm{H}$ NMR (600 $\mathrm{MHz}_{\mathrm{CDCl}}$ ): $\delta 5.14-5.01$ (complex $\mathrm{m}, 2 \mathrm{H}, \mathrm{H}-2$ and H-6), 3.99 (d, $J=6.0 \mathrm{~Hz}, 2 \mathrm{H}, \mathrm{H}-$ 1), 2.89 (s, 3H, H-3'), 2.08 (s, 3H, H-2'), 2.06 - 2.00 (complex m, 4H, H-4 and H-5), 1.67 (s, 3H, H-9), 1.58 (s, 6H, H-8 and H-10); HRESIMS $m / z$ : $[\mathrm{M}+\mathrm{H}]^{+}$Calcd for $\mathrm{C}_{13} \mathrm{H}_{23} \mathrm{NO}$ 210.1852; Found 210.1853 ( $\Delta=-0.44 \mathrm{ppm})$; HRESIMS/MS (20 eV) $\mathrm{m} / z$ (\%): 210.1838 (44), 137.1328 (100), 109.1012 (44).

Farnesyl $N$-methylacetamide; Freshly powdered $\mathrm{KOH}(0.18 \mathrm{mmol}, 9.9 \mathrm{mg})$ was stirred in dry DMSO $(0.1 \mathrm{~mL})$ for 15 minutes before the addition of farnesyl acetamide (0.04 mmol, $10 \mathrm{mg}, 0.4 \mathrm{M}$ in DMSO). Immediately afterward, methyl iodide (0.12 mmol, $17 \mathrm{mg}, 7.5 \mu \mathrm{L}$ ) was added and the reaction was stirred for two hours. The reaction was then poured onto $\mathrm{H}_{2} \mathrm{O}(2 \mathrm{~mL})$ and extracted with DCM $(3 \times 2 \mathrm{~mL})$. The combined extracts were washed with $\mathrm{H}_{2} \mathrm{O}(3 \times 2 \mathrm{~mL})$, then brine $(1 \times 2 \mathrm{~mL})$ and dried over anhydrous $\mathrm{MgSO}_{4}$. The solvent was removed under reduced pressure and the remaining residue was purified by silica gel flash chromatography (1:4 EA/PE) to yield a 1:1 rotameric mixture of $\mathbf{1 7 8}$ as a colourless oil (5.9 mg, 53\%): 


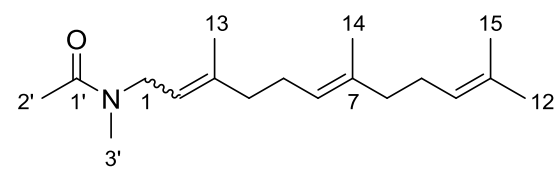

$N$-Methyl- $N$-((2E,6E)-3,7,11-trimethyldodeca-2,6,10-trien-1-yl)acetamide (178); $\mathrm{R}_{f}$ $=0.06$ (1:4 PE/EA); E/Z 2:1, NMR data major isomer and rotamer: ${ }^{1} \mathrm{H}$ NMR $(500 \mathrm{MHz}$, $\left.\mathrm{CDCl}_{3}\right): \delta 5.15-5.06$ (complex m, 3H, H-2, H-6 and H-10), 4.01 (d, J = 7.0 Hz, 2H, H2), 2.91 (s, 3H, H-2'), $2.14-2.10$ (m, 2H, $\mathrm{CH}_{2}$ ), 2.10 (s, 3H, H-3'), 2.07 - 2.02 (complex m, $\left.4 \mathrm{H}, 2 \times \mathrm{CH}_{2}\right), 2.00-1.95\left(\mathrm{~m}, 2 \mathrm{H}, \mathrm{CH}_{2}\right), 1.69\left(\mathrm{~s}, 3 \mathrm{H}, \mathrm{CH}_{3}\right), 1.68\left(\mathrm{~s}, 3 \mathrm{H}, \mathrm{CH}_{3}\right), 1.61$ (s, $\left.6 \mathrm{H}, 2 \times \mathrm{CH}_{3}\right) ;{ }^{13} \mathrm{C} \mathrm{NMR}\left(150 \mathrm{MHz}, \mathrm{CDCl}_{3}\right): \delta 170.3(\mathrm{C}, \mathrm{C}-1$ ') $, 139.6(\mathrm{C}, \mathrm{C}-3), 135.7(\mathrm{C}$, C-7), 131.5 (C, C-11), 124.4 (CH, C-10), 123.6 (CH, C-6), $119.6(\mathrm{CH}, \mathrm{C}-2), 48.7\left(\mathrm{CH}_{2}\right.$, C-1), $\left.39.9\left(\mathrm{CH}_{2}, \mathrm{C}-8\right), 39.6\left(\mathrm{CH}_{2}, \mathrm{C}-4\right), 35.2(\mathrm{CH} 3, \mathrm{C}-3)\right), 26.9\left(\mathrm{CH}_{2}, \mathrm{C}-9\right), 26.4\left(\mathrm{CH}_{2}\right.$, C-5), $25.8\left(\mathrm{CH}_{3}, \mathrm{H}-15\right), 21.6\left(\mathrm{CH}_{3}, \mathrm{C}-2\right), 17.8\left(\mathrm{CH}_{3}, \mathrm{C}-12\right), 16.4\left(\mathrm{CH}_{3}, \mathrm{H}-13\right), 16.2\left(\mathrm{CH}_{3}\right.$, $\mathrm{H}-14)$; HRESIMS $m / z$ : $[\mathrm{M}+\mathrm{H}]^{+}$Calcd for $\mathrm{C}_{18} \mathrm{H}_{32} \mathrm{NO} 278.2478$; Found $278.2482(\Delta=-$ 1.39 ppm); HRESIMS/MS (40 eV) m/z (\%): 121.0993(33), 107.0841 (100).

(2Z)-Geranylgeranyl $N$-methylacetamide; Freshly powdered $\mathrm{KOH}(0.32 \mathrm{mmol}$, $18.0 \mathrm{mg})$ was stirred in dry DMSO $(0.1 \mathrm{~mL})$ for 8 minutes. $(2 Z, 6 E, 10 E)$-Geranylgeranyl acetamide (0.051 mmol, $17.0 \mathrm{mg}, 0.51 \mathrm{M}$ in DMSO) was added, followed immediately by methyl iodide $(0.15 \mathrm{mmol}, 21.8 \mathrm{mg}, 9.6 \mu \mathrm{L})$. The reaction was stirred for three hours, then poured onto $\mathrm{H}_{2} \mathrm{O}(3 \mathrm{~mL})$ and extracted with DCM $(3 \times 2 \mathrm{~mL})$. The combined extracts were washed with $\mathrm{H}_{2} \mathrm{O}(5 \times 2 \mathrm{~mL})$, then brine $(1 \times 2 \mathrm{~mL})$ and dried over anhydrous $\mathrm{MgSO}_{4}$. The solvent was removed under reduced pressure and the resulting residue was purified by silica gel flash chromatography (1:5 EA/PE) to afford 179 as a colourless oil (5.1 mg, 29\%):

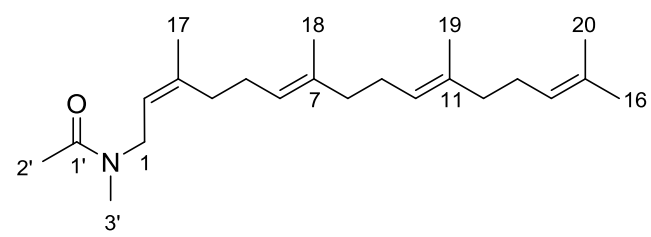

$N$-Methyl- $N$-((2Z,6E,10E)-3,7,11,15-tetramethylhexadeca-2,6,10,14-tetraen-1-

yl)acetamide (179); $\mathrm{R}_{f}=0.04(1: 5 \mathrm{EA} / \mathrm{PE}) ;{ }^{1} \mathrm{H} \mathrm{NMR}\left(500 \mathrm{MHz}, \mathrm{CDCl}_{3}\right): \delta 5.17-5.07$ (complex m, 4H, H-2, H-6, H-10 and H-14), 4.00 (d, J = 7.0 Hz, 2H, H-1), 2.92 (s, 3H, H-3'), 2.14 - 2.10 (complex m, 4H, $2 \times \mathrm{CH}_{2}$ ), 2.10 (s, 3H, H-2'), 2.09 - 2.04 (complex m, 4H, $2 \times \mathrm{CH}_{2}$ ), $2.03-1.97$ (complex m, 4H, $2 \times \mathrm{CH}_{2}$ ), 1.77 (s, 3H, H-17), 1.69 (s, 3H, $\left.\mathrm{CH}_{3}\right), 1.63\left(\mathrm{~s}, 3 \mathrm{H}, \mathrm{CH}_{3}\right), 1.61\left(\mathrm{~s}, 6 \mathrm{H}, 2 \times \mathrm{CH}_{3}\right) ;{ }^{13} \mathrm{C} \mathrm{NMR}\left(150 \mathrm{MHz}, \mathrm{CDCl}_{3}\right): \delta 170.5(\mathrm{C}$, 
C-1'), 139.8 (C, C-3), 136.1 (C, C-7), 135.8 (C, C-11), 131.4 (C, C-15), 124.5 (CH, C14) $124.3(\mathrm{CH}, \mathrm{C}-10), 124.1(\mathrm{CH}, \mathrm{C}-6), 120.3(\mathrm{CH}, \mathrm{C}-2), 48.5\left(\mathrm{CH}_{2}, \mathrm{C}-1\right), 39.9\left(2 \times \mathrm{CH}_{2}\right.$, C-8 and C-12), $35.3\left(\mathrm{CH}_{3}, \mathrm{C}-3\right.$ '), 32.2 ( $\left.\mathrm{CH}_{2}, \mathrm{C}-4\right), 26.9\left(\mathrm{CH}_{2}, \mathrm{C}-13\right), 26.7\left(\mathrm{CH}_{2}, \mathrm{C}-9\right)$, $26.4\left(\mathrm{CH}_{2}, \mathrm{C}-5\right), 25.9\left(\mathrm{CH}_{3}, \mathrm{C}-20\right), 23.5\left(\mathrm{CH}_{3}, \mathrm{C}-17\right), 22.0\left(\mathrm{CH}_{3}, \mathrm{C}-2\right), 17.8\left(\mathrm{CH}_{3}, \mathrm{C}-\right.$ 16), $16.17\left(\mathrm{CH}_{3}, \mathrm{C}-18\right.$ or $\left.\mathrm{C}-19\right), 16.16\left(\mathrm{CH}_{3}, \mathrm{C}-18\right.$ or $\left.\mathrm{C}-19\right)$; IR (film from $\left.\mathrm{CH}_{2} \mathrm{Cl}_{2}\right)$ : $v_{\max }$ 2965, 2915, 2854, $1650 \mathrm{~cm}^{-1}$; HRESIMS m/z: [M+H] ${ }^{+}$Calcd for $\mathrm{C}_{23} \mathrm{H}_{40} \mathrm{NO} 346.3104$; Found $346.3113(\Delta=-2.38 \mathrm{ppm}$ ); HRESIMS/MS (40 eV) $\mathrm{m} / z(\%): 123.1163$ (46), 121.1009 (100).

(2E)-geranylgeranyl $N$-methylacetamide; To dry DMSO $(0.1 \mathrm{~mL})$ was added freshly powdered $\mathrm{KOH}(0.36 \mathrm{mmol}, 20.3 \mathrm{mg})$ and the reaction was stirred for five minutes before the addition of $(2 E, 6 E, 10 E)$-geranylgeranyl acetamide $(0.090 \mathrm{mmol}, 30 \mathrm{mg}, 0.904$ $\mathrm{M}$ in DMSO). Immediately afterward, methyl iodide $(0.27 \mathrm{mmol}, 38.7 \mathrm{mg}, 17.0 \mu \mathrm{L})$ was added and the reaction was stirred for two and a half hours, then poured onto $\mathrm{H}_{2} \mathrm{O}(3 \mathrm{~mL})$ and extracted with DCM $(3 \times 2 \mathrm{~mL})$. The combined extracts were washed with $\mathrm{H}_{2} \mathrm{O}(5 \times$ $2 \mathrm{~mL})$, then brine $(1 \times 2 \mathrm{~mL})$ and dried over anhydrous $\mathrm{MgSO}_{4}$. The solvent was removed under reduced pressure and the residue was purified by silica gel flash chromatography (1:5 EA/PE) to afford $\mathbf{1 8 0}$ as a colourless oil $(4.7 \mathrm{mg}, 15 \%)$ :

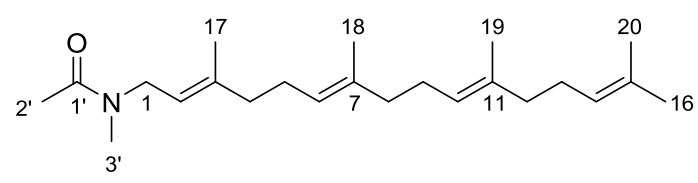

\section{$N$-Methyl- $N$-((2E,6E,10E)-3,7,11,15-tetramethylhexadeca-2,6,10,14-tetraen-1-}

yl)acetamide (180); $\mathrm{R}_{f}=0.05(1: 5 \mathrm{EA} / \mathrm{PE}) ;{ }^{1} \mathrm{H} \mathrm{NMR}\left(500 \mathrm{MHz}, \mathrm{CDCl}_{3}\right): \delta 5.17-5.07$ (complex m, 4H, H-2, H-6, H-10 and H-14)), 4.02 (d, J = $7.0 \mathrm{~Hz}, 2 \mathrm{H}, \mathrm{H}-1), 2.92$ (s, 3H, H-3'), 2.15 - 2.11 (complex m, 4H, $2 \times \mathrm{CH}_{2}$ ), 2.10 (s, 3H, H-2'), 2.08 - 2.04 (complex m, $4 \mathrm{H}, 2 \times \mathrm{CH}_{2}$ ), $2.01-1.96$ (complex m, $4 \mathrm{H}, 2 \times \mathrm{CH}_{2}$ ), 1.69 (s, 6H, $\left.2 \times \mathrm{CH}_{3}\right), 1.64$ (s, $\left.3 \mathrm{H}, \mathrm{CH}_{3}\right), 1.61\left(\mathrm{~s}, 6 \mathrm{H}, 2 \times \mathrm{CH}_{3}\right) ;{ }^{13} \mathrm{C} \mathrm{NMR}\left(150 \mathrm{MHz}, \mathrm{CDCl}_{3}\right): \delta 170.5(\mathrm{C}, \mathrm{C}-1$ '), 139.7 (C, C-3), 135.7 (C, C-7), 135.2 (C, C-11), 131.4 (C, C-15), 124.5 (CH, C-14), 124.2 (CH, C-10), $123.6(\mathrm{CH}, \mathrm{C}-6), 119.4(\mathrm{CH}, \mathrm{C}-2), 48.7\left(\mathrm{CH}_{2}, \mathrm{C}-1\right), 39.9\left(2 \times \mathrm{CH}_{2}, \mathrm{C}-8\right.$ and $\mathrm{C}-$ 12), $39.6\left(\mathrm{CH}_{2}, \mathrm{C}-4\right), 35.2\left(\mathrm{CH}_{3}, \mathrm{C}-3\right.$ ') 26.9 (2 $\times \mathrm{CH}_{2}, \mathrm{C}-9$ and $\left.\mathrm{C}-13\right), 26.4\left(\mathrm{CH}_{2}, \mathrm{C}-5\right)$, $25.9\left(\mathrm{CH}_{3}, \mathrm{C}-20\right), 22.0\left(\mathrm{CH}_{3}, \mathrm{C}-2\right), 17.8\left(\mathrm{CH}_{3}, \mathrm{C}-16\right), 16.4\left(\mathrm{CH}_{3}, \mathrm{C}-17\right), 16.19\left(\mathrm{CH}_{3}, \mathrm{C}-\right.$ 18 or C-19), $16.15\left(\mathrm{CH}_{3}, \mathrm{C}-18\right.$ or C-19); IR (film from $\left.\mathrm{CH}_{2} \mathrm{Cl}_{2}\right): v_{\max } 2965,2916,2854$, $1650 \mathrm{~cm}^{-1}$; HRESIMS $m / z$ : $[\mathrm{M}+\mathrm{H}]^{+}$Calcd for $\mathrm{C}_{23} \mathrm{H}_{40} \mathrm{NO} 346.3104$; Found $346.3109(\Delta$ = -1.29 ppm); HRESIMS/MS (40 eV) m/z (\%):123.1161 (47), 107.0851 (100). 


\section{References}

1. R. Sinden, Cellular microbiology, 2015, 17, 451.

2. W. H. Organisation, World Malaria Report 2014, www.who.int/malaria, (accessed 30/06, 2015).

3. J. Sachs and P. Malaney, Nature, 2002, 415, 680.

4. K. Chotivanich, R. Udomsangpetch, R. McGready, S. Proux, P. Newton, S. Pukrittayakamee, S. Looareesuwan and N. J. White, J. Infect. Dis., 2002, 185, 1538.

5. J. H. Leech, J. W. Barnwell, L. H. Miller and R. J. Howard, J. Exp. Med., 1984, 159, 1567.

6. B. Biggs, R. Anders, H. E. Dillon, K. M. Davern, M. Martin, C. Petersen and G. Brown, J. Immunol., 1992, 149, 2047.

7. X.-z. Su, V. M. Heatwole, S. P. Wertheimer, F. Guinet, J. A. Herrfeldt, D. S. Peterson, J. A. Ravetch and T. E. Wellems, Cell, 1995, 82, 89.

8. M. Aikawa, M. Iseki, J. W. Barnwell, D. Taylor, M. M. Oo and R. J. Howard, Am. J. Trop. Med. Hyg., 1990, 43, 30.

9. D. L. Klayman, Science, 1985, 228, 1049.

10. Q. R. Group, Sci. Sin., 1980, 23, 380.

11. S. R. Meshnick, T. Taylor and S. Kamchonwongpaisan, Microbiol. rev., 1996, 60, 301.

12. D. C. Smith, J. Hist. Med. All. Sci., 1976, 31, 343.

13. F. Loeb, W. Clark, G. Coatney, L. Coggeshall, F. Dieuaide, A. Dochez, E. Hakansson, E. Marshall, C. Marvel and O. McCoy, J. Am. Med. Assoc., 1946, 130, 1069.

14. J. Achan, A. O. Talisuna, A. Erhart, A. Yeka, J. K. Tibenderana, F. N. Baliraine, P. J. Rosenthal and U. D'Alessandro, Malar. J., 2011, 10, 1475.

15. P. B. Bloland, Drug resistance in malaria, World Health Organization Geneva, Switzerland, 2001.

16. N. J. White, F. Nosten, S. Looareesuwan, W. M. Watkins, K. Marsh, R. W. Snow, G. Kokwaro, J. Ouma, T. T. Hien, M. E. Molyneux, T. E. Taylor, C. I. Newbold, T. K. Ruebush, II, M. Danis, B. M. Greenwood, R. M. Anderson and P. Olliaro, Lancet, 353, 1965.

17. R. E. Dickerson and I. Geis, Hemoglobin: Structure, Function, Evolution, and Pathology, Benjamin/Cummings Publishing Company, 1983.

18. S. Kumar and U. Bandyopadhyay, Toxicol. Lett., 2005, 157, 175.

19. C. D. Fitch, Life Sci., 2004, 74, 1957.

20. F. Roberts, C. W. Roberts, J. J. Johnson, D. E. Kyle, T. Krell, J. R. Coggins, G. H. Coombs, W. K. Milhous, S. Tzipori, D. J. P. Ferguson, D. Chakrabarti and R. McLeod, Nature, 1998, 393, 801.

21. J. E. Hyde, Acta Trop., 2005, 94, 191.

22. Y.-L. Hong, Y.-Z. Yang and S. R. Meshnick, Mol. Biochem. Parasitol., 1994, 63, 121.

23. M. Foley and L. Tilley, Pharmacol. Ther., 1998, 79, 55.

24. F. Mockenhaupt, Parasitol. Today, 1995, 11, 248.

25. H. Yang, D. Liu, Y. Yang, K. Huang, Y. Dong, P. Yang, M. Liao and C. Zhang, Southeast Asian J. Trop. Med. Public Health 1997, 28, 460.

26. M. Foley and L. Tilley, Int. J. Parasitol., 1997, 27, 231. 
27. C. H. Sibley, J. E. Hyde, P. F. Sims, C. V. Plowe, J. G. Kublin, E. K. Mberu, A. F. Cowman, P. A. Winstanley, W. M. Watkins and A. M. Nzila, Trends Parasitol., 2001, 17, 570.

28. C. Roper, R. Pearce, B. Bredenkamp, J. Gumede, C. Drakeley, F. Mosha, D. Chandramohan and B. Sharp, Lancet, 2003, 361, 1174.

29. R. J. Maude, W. Pontavornpinyo, S. Saralamba, R. Aguas, S. Yeung, A. M. Dondorp, N. P. Day, N. J. White and L. J. White, Malar. J., 2009, 8, 31.

30. A. M. Dondorp, F. Nosten, P. Yi, D. Das, A. P. Phyo, J. Tarning, K. M. Lwin, F. Ariey, W. Hanpithakpong, S. J. Lee, P. Ringwald, K. Silamut, M. Imwong, K. Chotivanich, P. Lim, T. Herdman, S. S. An, S. Yeung, P. Singhasivanon, N. P. J. Day, N. Lindegardh, D. Socheat and N. J. White, N. Engl. J. Med., 2009, 361, 455.

31. L. Pirkkala and L. Sistonen, eLS, 2001.

32. Z. Li, A. Menoret and P. Srivastava, Curr. Opin. Immunol., 2002, 14, 45.

33. M. J. Gardner, N. Hall, E. Fung, O. White, M. Berriman, R. W. Hyman, J. M. Carlton, A. Pain, K. E. Nelson and S. Bowman, Nature, 2002, 419, 498.

34. P. Acharya, R. Kumar and U. Tatu, Mol. Biochem. Parasitol., 2007, 153, 85.

35. S. R. Pavithra, G. Banumathy, O. Joy, V. Singh and U. Tatu, J. Biol. Chem., 2004, 279, 46692.

36. I. L. Cockburn, E.-R. Pesce, J. M. Pryzborski, M. T. Davies-Coleman, P. G. Clark, R. A. Keyzers, L. L. Stephens and G. L. Blatch, Biol. Chem., 2011, 392, 431.

37. N. J. Patron and R. F. Waller, BioEssays, 2007, 29, 1048.

38. S. Külzer, S. Charnaud, T. Dagan, J. Riedel, P. Mandal, E. R. Pesce, G. L. Blatch, B. S. Crabb, P. R. Gilson and J. M. Przyborski, Cell. Microbiol., 2012, 14, 1784.

39. R. Hatherley, G. L. Blatch and Ö. T. Bishop, J. Biomol. Struct. Dyn., 2014, 32, 1766.

40. J. G. Supko, R. L. Hickman, M. R. Grever and L. Malspeis, Cancer Chemother. Pharmacol., 1995, 36, 305.

41. C. DeBoer, P. Meulman, R. Wnuk and D. Peterson, J. Antibiot., 1970, 23, 442.

42. S. Modi, A. Stopeck, H. Linden, D. Solit, S. Chandarlapaty, N. Rosen, G. D'Andrea, M. Dickler, M. E. Moynahan and S. Sugarman, Clin. Cancer Res., $2011, \mathbf{1 7}, 5132$.

43. T. Mise, G. Funatsu, M. Ishiguro and M. Funatsu, Agric. Biol. Chem., 1977, 41, 2041.

44. F. R. Stermitz and H. Rapoport, J. Am. Chem. Soc., 1961, 83, 4045.

45. D. J. Newman and G. M. Cragg, Journal of Nat. Prod., 2016, 79, 629.

46. R. W. Burg, B. M. Miller, E. E. Baker, J. Birnbaum, S. A. Currie, R. Hartman, Y.L. Kong, R. L. Monaghan, G. Olson and I. Putter, Antimicrob. Agents Chemother., 1979, 15, 361.

47. J. Egerton, D. Ostlind, L. Blair, C. Eary, D. Suhayda, S. Cifelli, R. a. Riek and W. Campbell, Antimicrob. Agents Chemother., 1979, 15, 372.

48. Y. Tu, M. Ni, Y. Zhong, L. Li, S. Cui, M. Zhang, X. Wang and X. Liang, Acta Pharm. Sin., 1981, 16, 366.

49. D. Richardson, SPUMS J., 1999, 29, 173.

50. J. W. Blunt, B. R. Copp, R. A. Keyzers, M. Munro and M. R. Prinsep, Nat. Prod. Rep., 2013, 30, 237.

51. J. W. Blunt, B. R. Copp, R. A. Keyzers, M. H. Munro and M. R. Prinsep, Nat. Prod. Rep., 2015, 32, 116.

52. J. W. Blunt, B. R. Copp, R. A. Keyzers, M. H. Munro and M. R. Prinsep, Nat. Prod. Rep, 2014, 31, 160. 
53. R. A. Keyzers, C. A. Gray, M. H. Schleyer, C. E. Whibley, D. T. Hendricks and M. T. Davies-Coleman, Tetrahedron, 2006, 62, 2200.

54. H. Sorek, A. Rudi, Y. Benayahu, N. Ben-Califa, D. Neumann and Y. Kashman, J. Nat. Prod., 2007, 70, 1104.

55. J.-R. Zhang, P.-L. Li, X.-L. Tang, X. Qi and G.-Q. Li, Chem. Biodivers., 2012, 9, 2218.

56. P. G. Clark, M. Lein and R. A. Keyzers, Org. Biomol. Chem., 2012, 10, 1725.

57. P. G. K. Clark, MSc, Victoria University of Wellington, 2011.

58. A. Shonhai, M. Botha, T. A. de Beer, A. Boshoff and G. L. Blatch, Protein Pept. Lett., 2008, 15, 1117.

59. I. L. Cockburn, A. Boshoff, E.-R. Pesce and G. L. Blatch, Biol. Chem., 2014, 395, 1353.

60. M. Botha, E.-R. Pesce and G. L. Blatch, Int. J. Biochem. \& Cell Biol., 2007, 39, 1781.

61. E. J. Chamgordani, J. Paulsen and L.-L. Gundersen, Tetrahedron Lett. 2016, 57, 4926.

62. A. Vik, E. Hedner, C. Charnock, L. W. Tangen, Ø. Samuelsen, R. Larsson, L. Bohlin and L.-L. Gundersen, Bioorg. Med. Chem., 2007, 15, 4016.

63. J. W. Jones and R. K. Robins, J. Am. Chem. Soc., 1962, 84, 1914.

64. K. K. Ogilvie, S. L. Beaucage and M. F. Gillen, Tetrahedron Lett., 1978, 19, 1663.

65. M. Rasmussen and J. Hope, Australian J. Chem., 1982, 35, 525.

66. W. Drosdziok, C. Lutze, K. Krüger, K. H. Glüsenkamp and M. F. Rajewsky, J. Labelled Comp. Radiopharm., 2003, 46, 815.

67. T. Itaya and H. Matsumoto, Chem. Pharm. Bull., 1985, 33, 2213.

68. A. E. Wright, G. P. Roth, J. K. Hoffman, D. B. Divlianska, D. Pechter, S. H. Sennett, E. A. Guzmán, P. Linley, P. J. McCarthy, T. P. Pitts, S. A. Pomponi and J. K. Reed, J. Nat. Prod., 2009, 72, 1178.

69. M. E. Jung, J.-M. Ku, L. Du, H. Hu and R. A. Gatti, Bioorg. Med. Chem. Lett., 2011, 21, 5842.

70. J.-H. Choi, T. Ohnishi, Y. Yamakawa, S. Takeda, S. Sekiguchi, W. Maruyama, K. Yamashita, T. Suzuki, A. Morita, T. Ikka, R. Motohashi, Y. Kiriiwa, H. Tobina, T. Asai, S. Tokuyama, H. Hirai, N. Yasuda, K. Noguchi, T. Asakawa, S. Sugiyama, T. Kan and H. Kawagishi, Angew. Chem. Int. Ed., 2014, 126, 1578.

71. R. H. Sullivan, P. Nix, E. L. S. Jun and S. L. Parker, Org. Magnetic Res., 1983, 21, 293.

72. A. M. Beigi, M. Teymouri, M. Eslami and M. Farazmand, Analyst, 1999, 124, 767.

73. E. Axelrod, G. Milne and E. E. Van Tamelen, J. Am. Chem. Soc., 1970, 92, 2139.

74. S. J. Roe, M. F. Oldfield, N. Geach and A. Baxter, J. Labelled Comp. Radiopharm., 2013, 56, 485.

75. M. Grinco, V. Kulciţki, N. Ungur, W. Jankowski, T. Chojnacki and P. F. Vlad, Helv. Chim. Acta, 2007, 90, 1223.

76. F. Minutolo, S. Bertini, L. Betti, R. Danesi, G. Gervasi, G. Giannaccini, A. Martinelli, A. M. Papini, E. Peroni and G. Placanica, ChemMedChem, 2006, 1, 218.

77. W. Liu, Y. Zhang, S. Hou and Z. K. Zhao, Tetrahedron Lett., 2013, 54, 6208.

78. K. Yamada, Y. Tahara, M. Toyoda, O. Irino and N. Misaki, (Nisshin Flour Milling Co. Ltd., Gelan Pharmaceutical Co. Ltd), Japan, 4906669, 1990. 
79. A. K. Bakkestuen, L.-L. Gundersen, D. Petersen, B. T. Utenova and A. Vik, Org. \& Biomol. Chem., 2005, 3, 1025.

80. S. A. Snyder and D. S. Treitler, Angew. Chem. Int. Ed., 2009, 48, 7899.

81. D. S. Wishart, C. Knox, A. C. Guo, R. Eisner, N. Young, B. Gautam, D. D. Hau, N. Psychogios, E. Dong, S. Bouatra, R. Mandal, I. Sinelnikov, J. Xia, L. Jia, J. A. Cruz, E. Lim, C. A. Sobsey, S. Shrivastava, P. Huang, P. Liu, L. Fang, J. Peng, R. Fradette, D. Cheng, D. Tzur, M. Clements, A. Lewis, A. De Souza, A. Zuniga, M. Dawe, Y. Xiong, D. Clive, R. Greiner, A. Nazyrova, R. Shaykhutdinov, L. Li, H. J. Vogel and I. Forsythe, Nucleic acids res., 2009, 37, D603.

82. F. Skoog, H. Q. Hamzi, A. M. Szweykowska, N. J. Leonard, K. L. Carraway, T. Fujii, J. P. Helgeson and R. N. Loeppky, Phytochem.y, 1967, 6, 1169.

83. S. Wenyang, L. Zhenhai, L. Ruifeng, C. Qiuxia and H. Shuai, China, CN101023748 A, 2007.

84. M. E. García-Rubiño, M. d. C. Núñez-Carretero, D. Choquesillo-Lazarte, J. M. García-Ruiz, Y. Madrid and J. Campos, RSC Advances, 2014, 4, 22425.

85. C. E. Mueller, D. Shi, M. Manning and J. W. Daly, J. Med. Chem., 1993, 36, 3341.

86. P. S. Callery, M. Stogniew, M. F. Kaiser and R. M. Dennin Jr, Anal.Lett., 1985, 18, 2537.

87. K. Wada, Agric. Biol. Chem., 1978, 42, 787.

88. M. Gibson and R. Bradshaw, Angew. Chem. Int. Ed. , 1968, 7, 919.

89. J. B. Hendrickson, R. Bergeron and D. D. Sternbach, Tetrahedron, 1975, 31, 2517.

90. O. K. Onajole, P. Govender, P. D. v. Helden, H. G. Kruger, G. E. M. Maguire, I. Wiid and T. Govender, Eu. J. Med. Chem., 2010, 45, 2075.

91. S. Matsumoto, M. Doteuchi, T. Mizui and K. Hirai, (Shionogi and Co. Ltd.), Japan, EP0194901 A2, 1986.

92. R. Kothapalli and K. S. Bisht, (University of South Florida), United States, WO2008143847 A1, 2008.

93. F. Minutolo, S. Bertini, L. Betti, R. Danesi, G. Gervasi, G. Giannaccini, C. Papi, G. Placanica, S. Barontini, S. Rapposelli and M. Macchia, Bioorg. Med. Chem. Lett., 2003, 13, 4405.

94. M. Wiecek and K. Kieć-Kononowicz, Acta Pol. Pharm., 2009, 66, 249.

95. M. Więcek, T. Kottke, X. Ligneau, W. Schunack, R. Seifert, H. Stark, J. Handzlik and K. Kieć-Kononowicz, Bioorg. Med. Chem., 2011, 19, 2850.

96. S. Inoue, H. Takaya, K. Tani, S. Otsuka, T. Sato and R. Noyori, J. Am. Chem. Soc., 1990, 112, 4897.

97. C. Lerner, R. Siegrist, E. Schweizer, F. Diederich, V. Gramlich, R. JakobRoetne, G. Zürcher and E. Borroni, Helv. Chim. Acta, 2003, 86, 1045.

98. S. Wolfe and S. Hasan, Can. J. Chem., 1970, 48, 3572.

99. T. Doundoulakis, A. X. Xiang, R. Lira, K. A. Agrios, S. E. Webber, W. Sisson, R. M. Aust, A. M. Shah, R. E. Showalter and J. R. Appleman, Bioorg. Med. Chem. Lett., 2004, 14, 5667.

100. G. M. Coppola and M. Prashad, Synth. comm., 1993, 23, 535.

101. J. Gagnon, M. Drouin and P. D. Harvey, Inorg. Chem., 2001, 40, 6052.

102. R. A. W. Johnstone and M. E. Rose, Tetrahedron, 1979, 35, 2169.

103. W. Li and X.-F. Wu, Chem. A Euro. J., 2015, 21, 14943.

104. M. A. Reed, D. Weaver, S. Sun, A. McLellan and E. Lu, (NeuroQuest Inc.), United States, WO2008143947 A1, 2011.

105. A. Stich, P. M. Abel and S. Krishna, BMJ, 2002, 325, 203. 


\section{Spectra}


Ethyl (hydroxyimino)cyanoacetate (33)

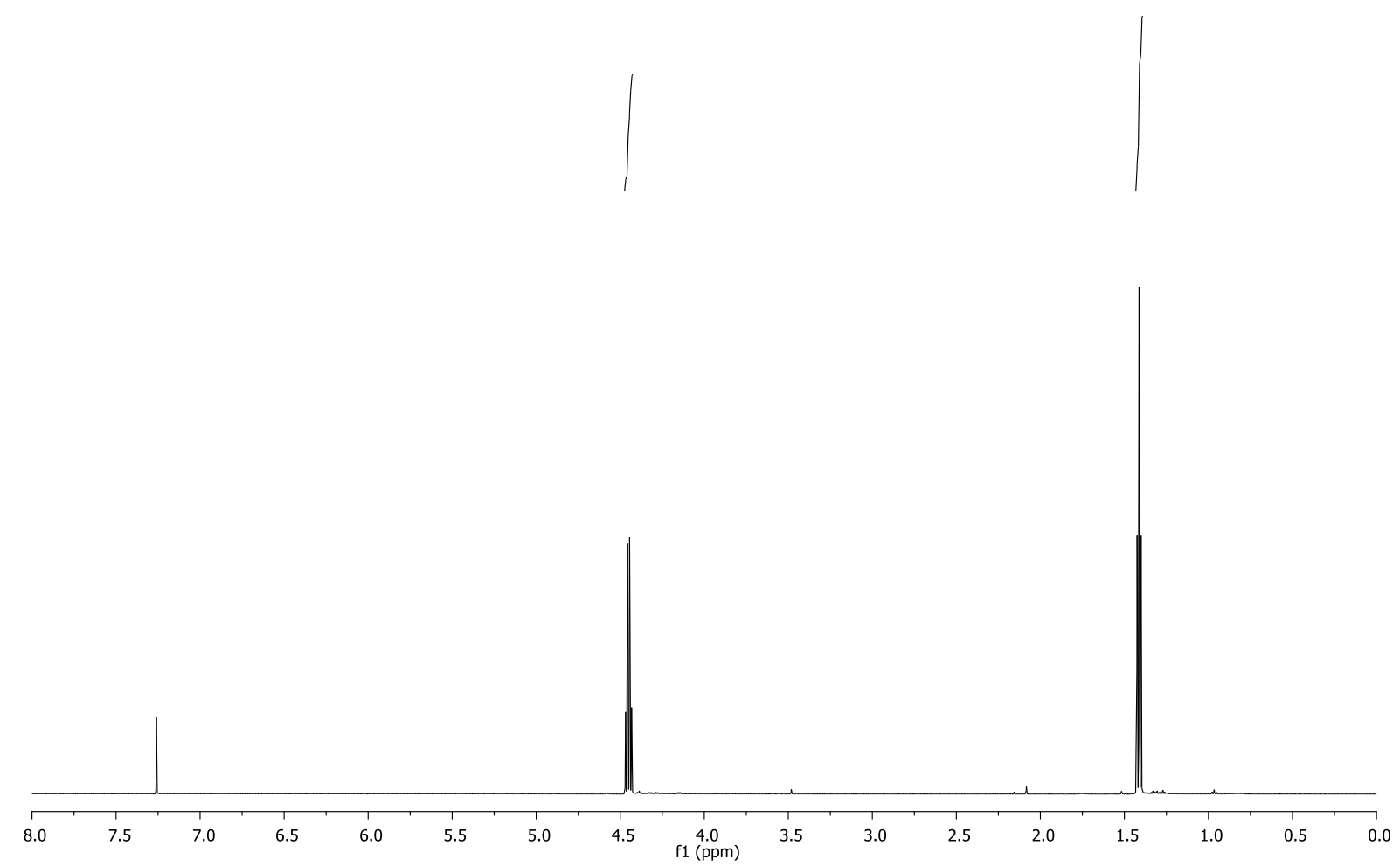

${ }^{1} \mathrm{H}$ NMR spectrum $\left(600 \mathrm{MHz}, \mathrm{CDCl}_{3}\right)$ of 33.

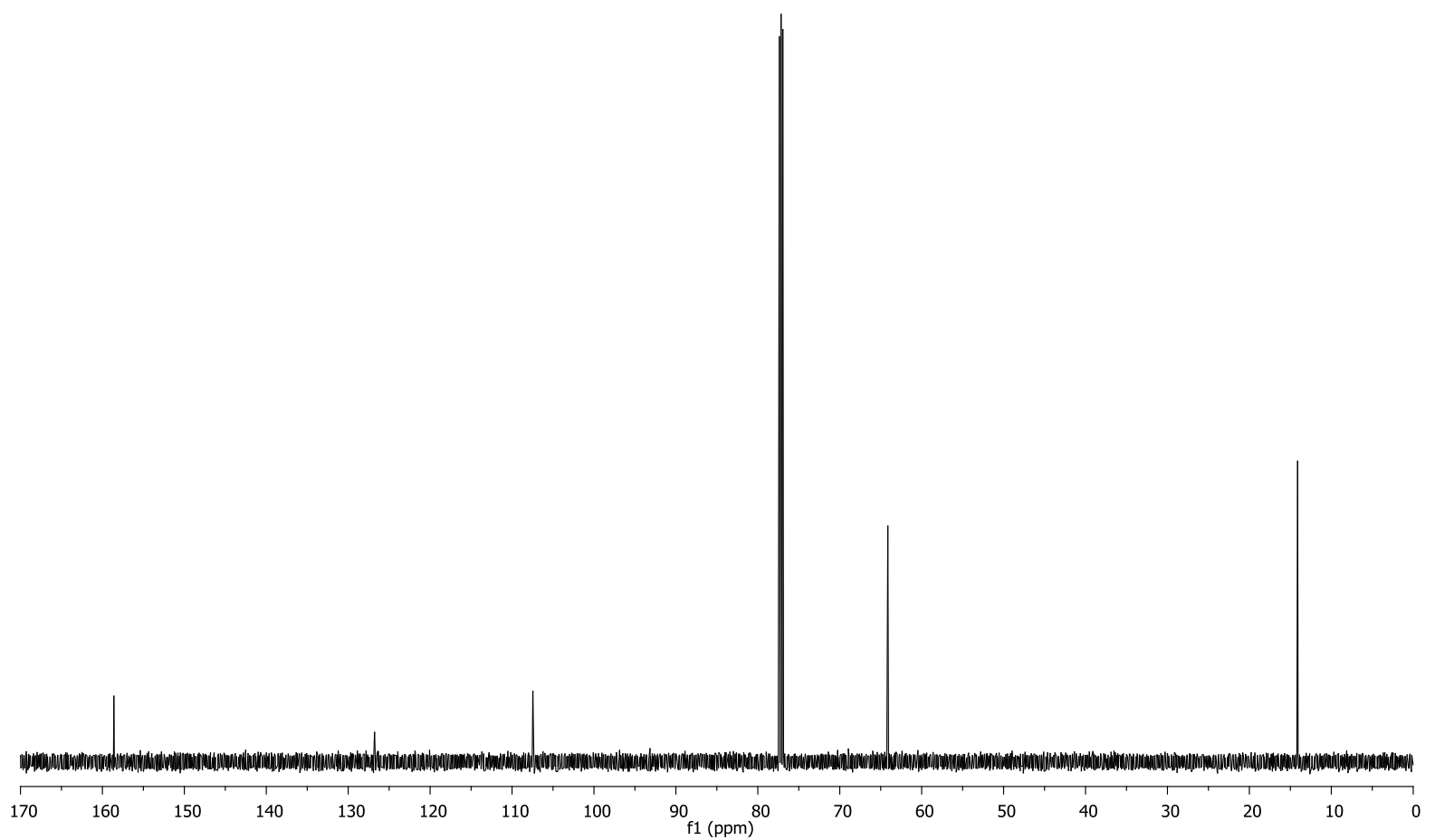

${ }^{13} \mathrm{C}$ NMR spectrum $\left(150 \mathrm{MHz}, \mathrm{CDCl}_{3}\right)$ of $\mathbf{3 3}$. 
6-Amino-2-mercapto-1-methyl-5-nitrosopyrimidin-4(1H)-one (34)

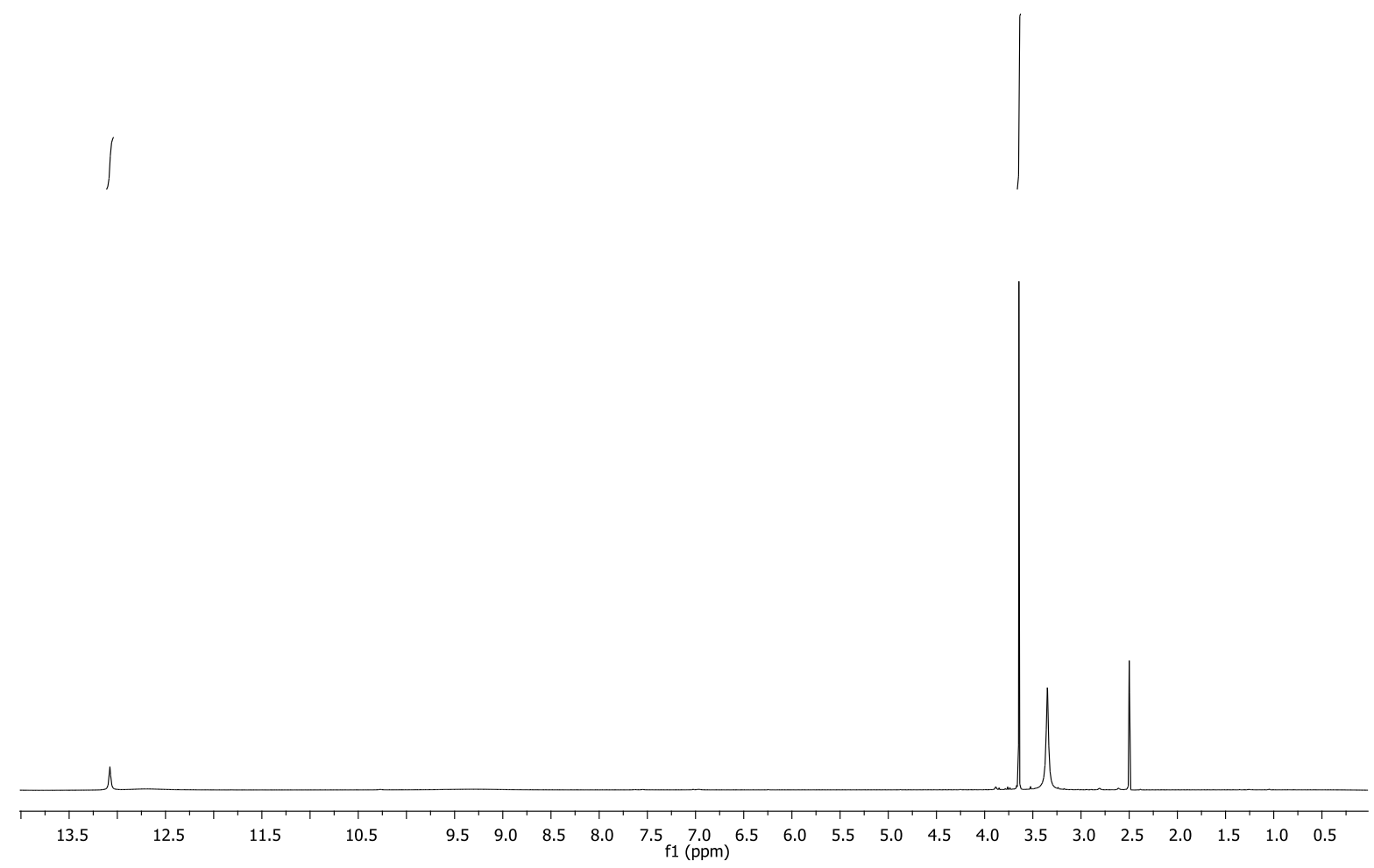

${ }^{1} \mathrm{H}$ NMR spectrum $\left(600 \mathrm{MHz}, \mathrm{DMSO}-\mathrm{d}_{6}\right)$ of $\mathbf{3 4}$.

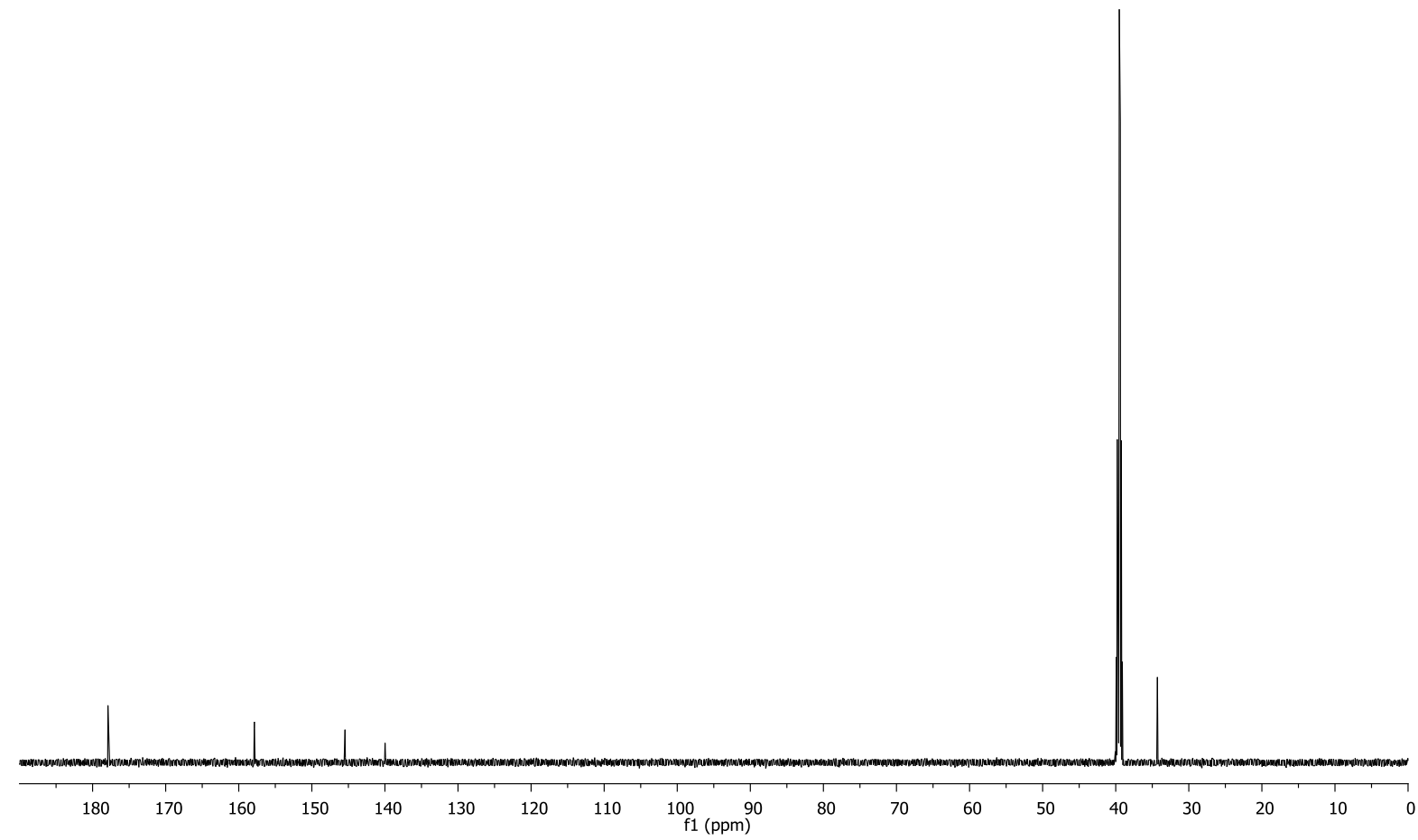

${ }^{13} \mathrm{C}$ NMR spectrum (150 MHz, DMSO-d 6 ) of 34. 
5,6-Diamino-2-mercapto-1-methylpyrimidin-4(1H)-one (35)

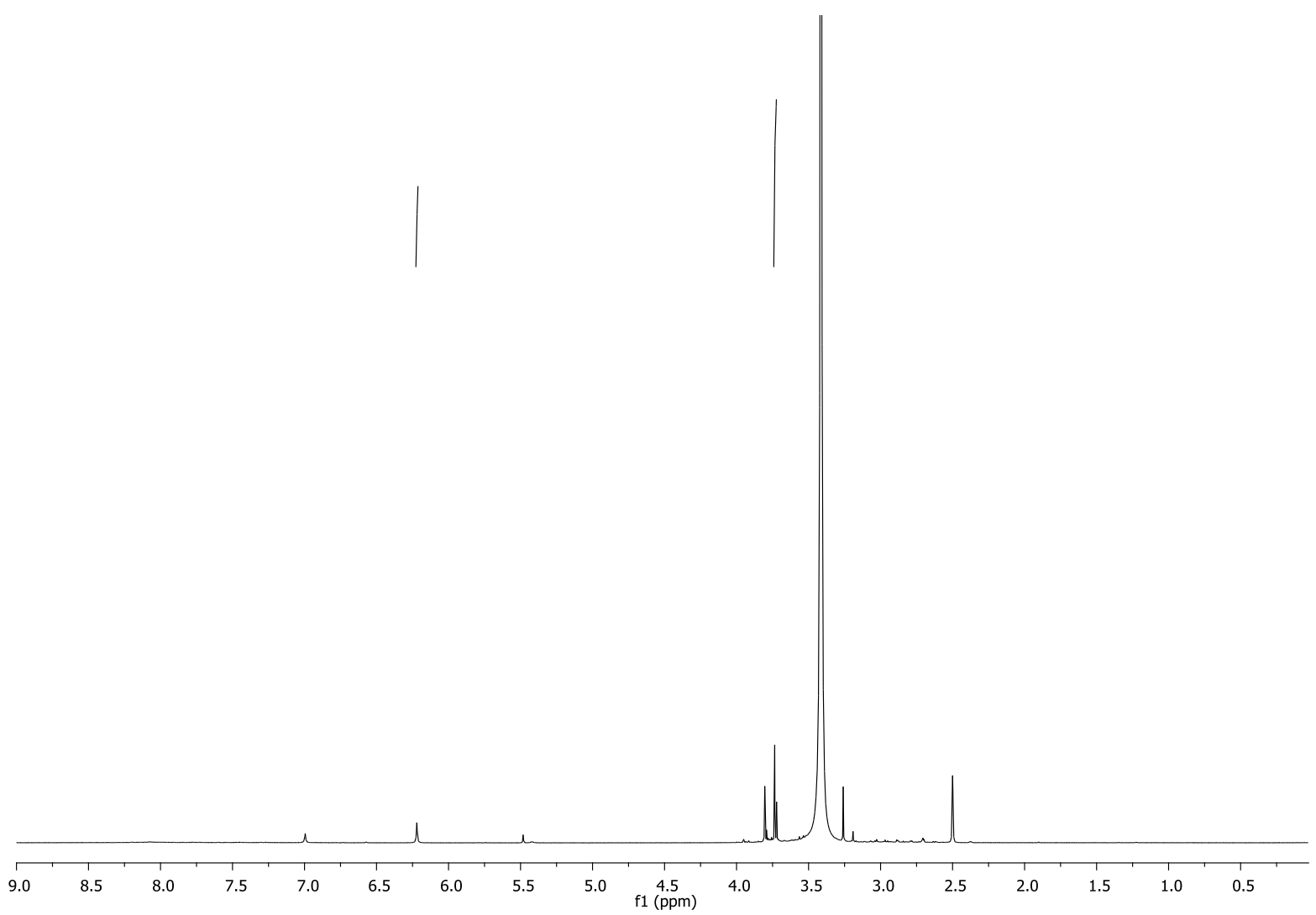

${ }^{1} \mathrm{H}$ NMR spectrum (600 MHz, DMSO-d 6 ) of 35.

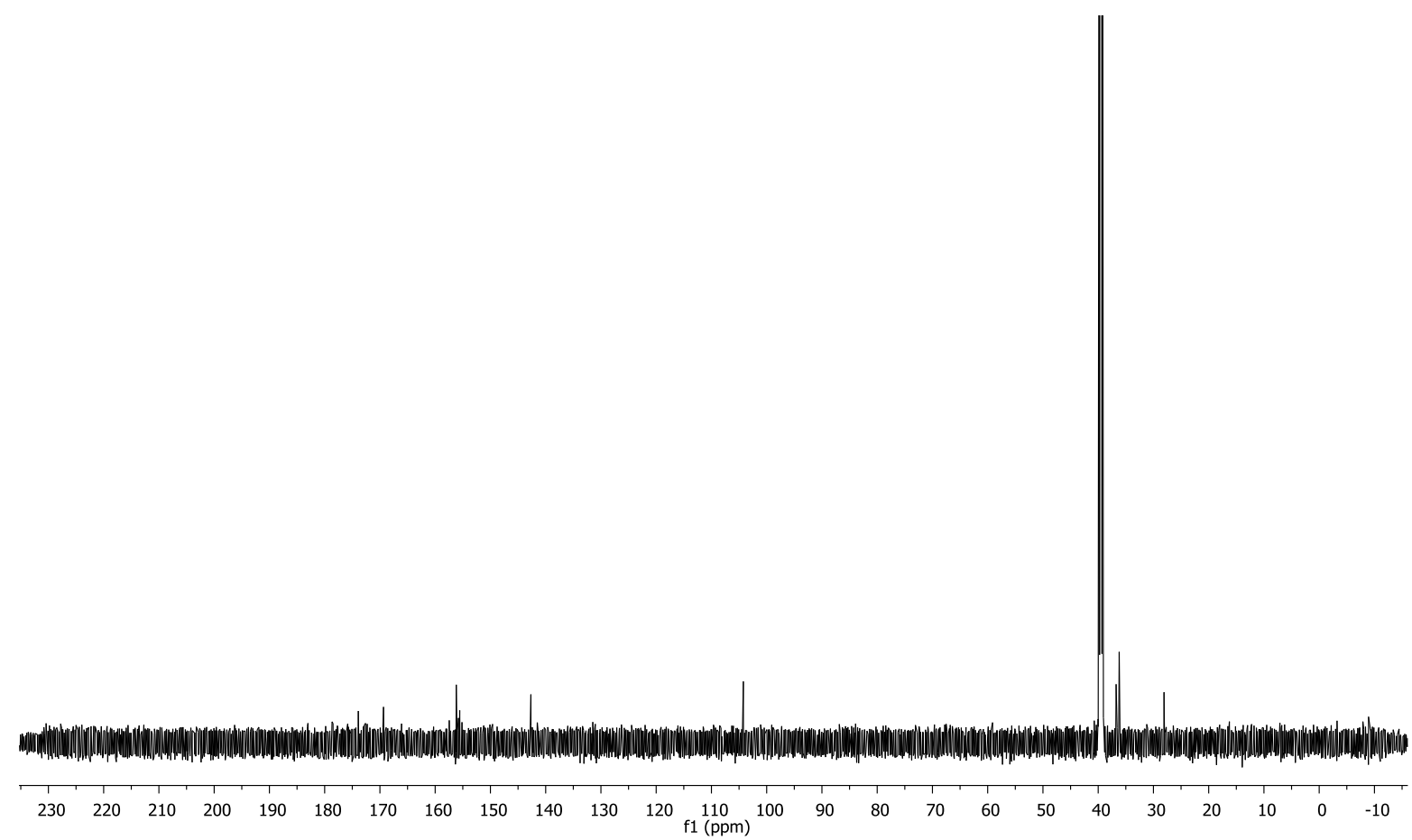

${ }^{13} \mathrm{C}$ NMR spectrum (150MHz, DMSO-d $\left.\mathrm{d}_{6}\right)$ of 35. 
6-Hydroxy-3-methyl-3,9-dihydro-2H-purine-2-thione (56)

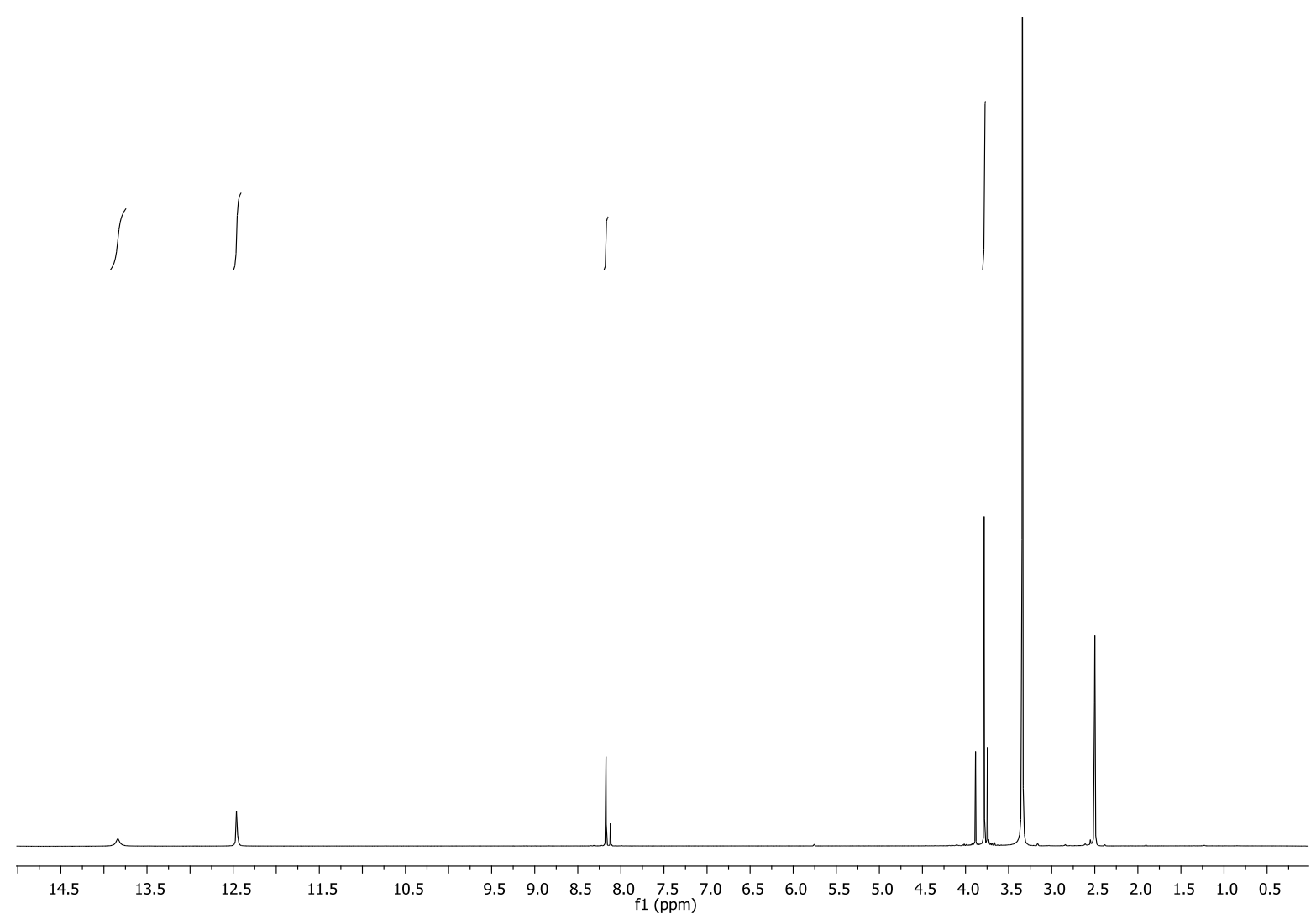

${ }^{1} \mathrm{H}$ NMR spectrum (600 MHz, DMSO-d 6 ) of 56.

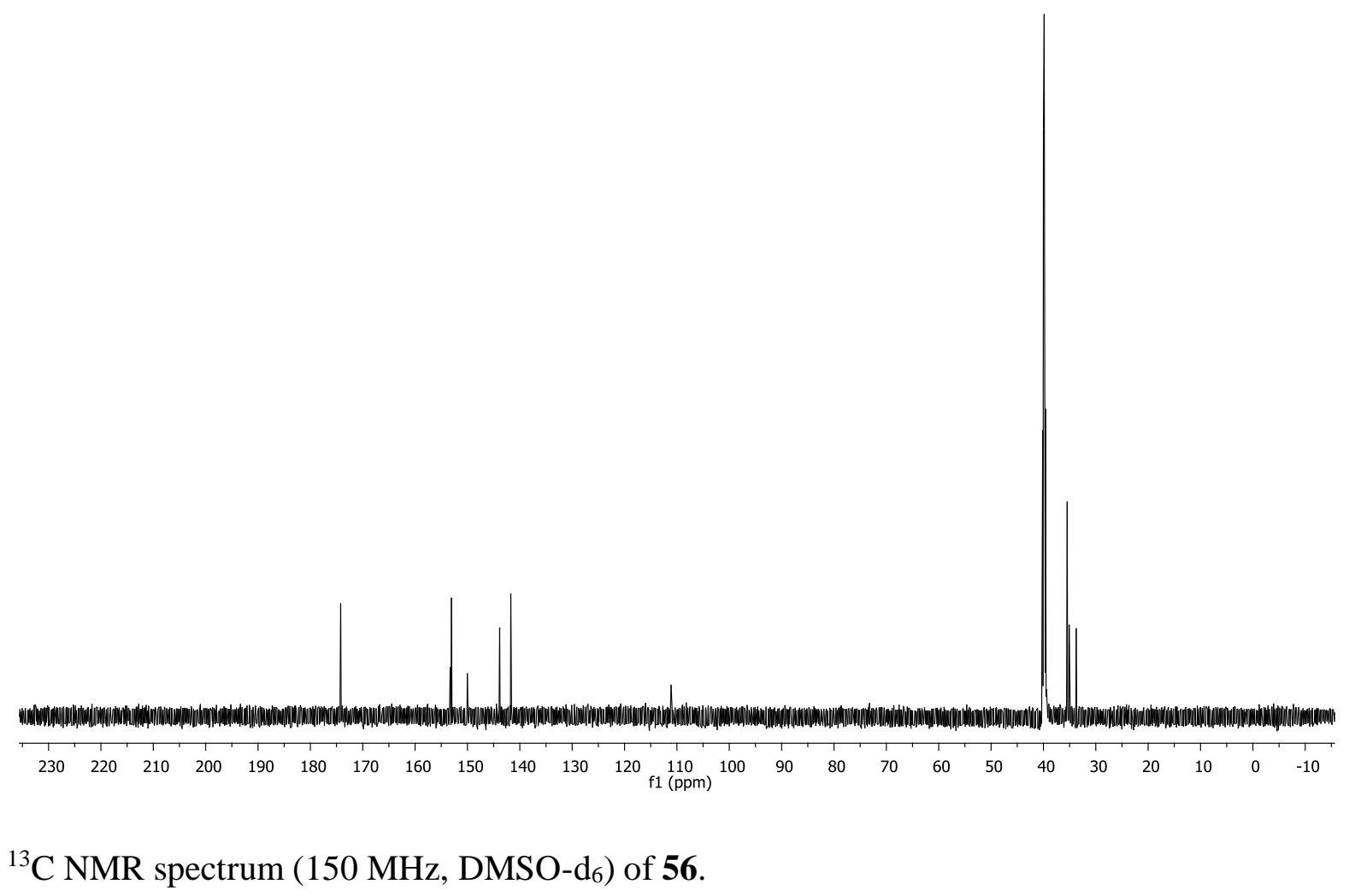


Sodium 3-methyl-6-oxo-3,6-dihydropurin-7-ide (55)

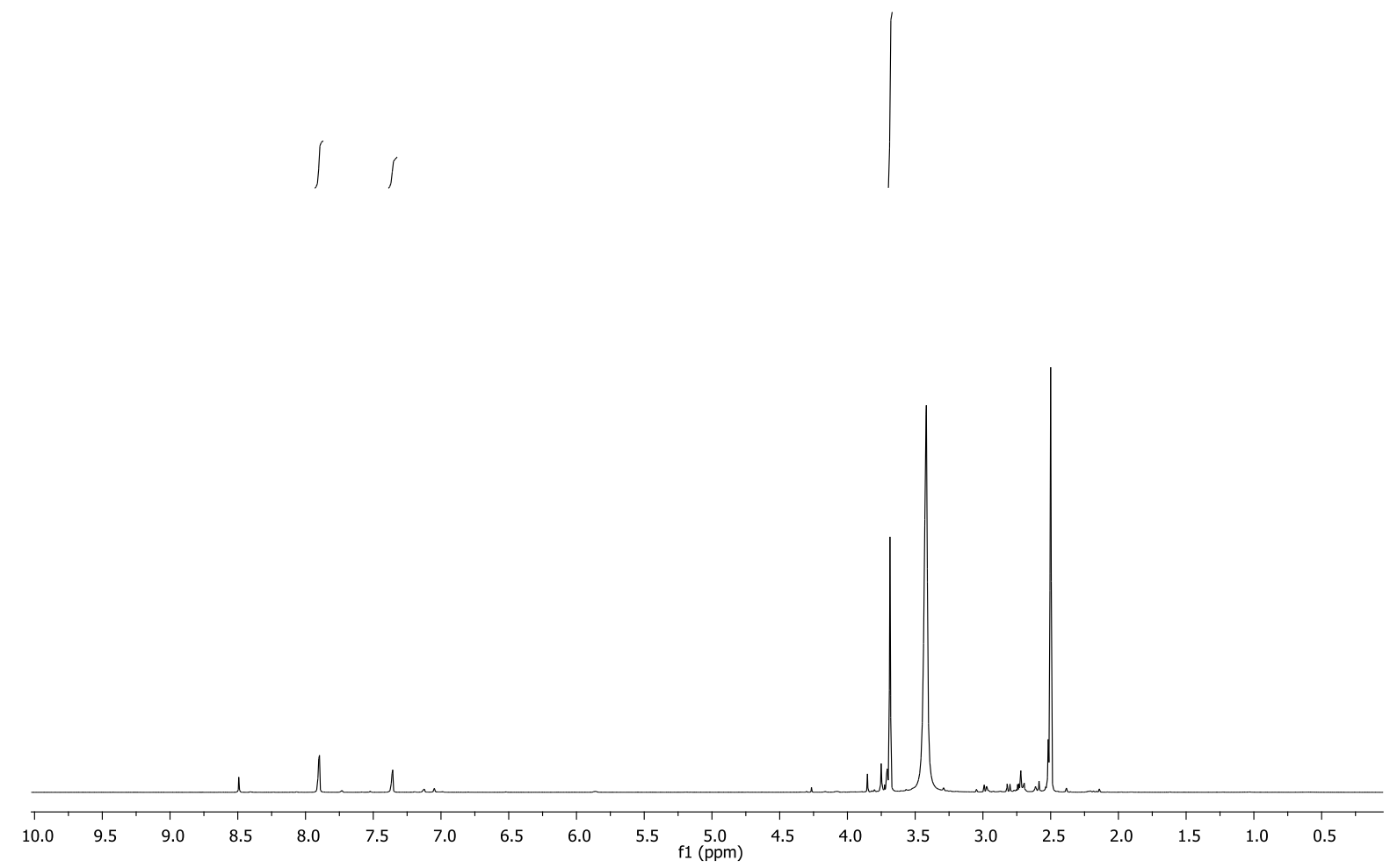

${ }^{1} \mathrm{H}$ NMR spectrum $\left(600 \mathrm{MHz}, \mathrm{DMSO}-\mathrm{d}_{6}\right)$ of 55.

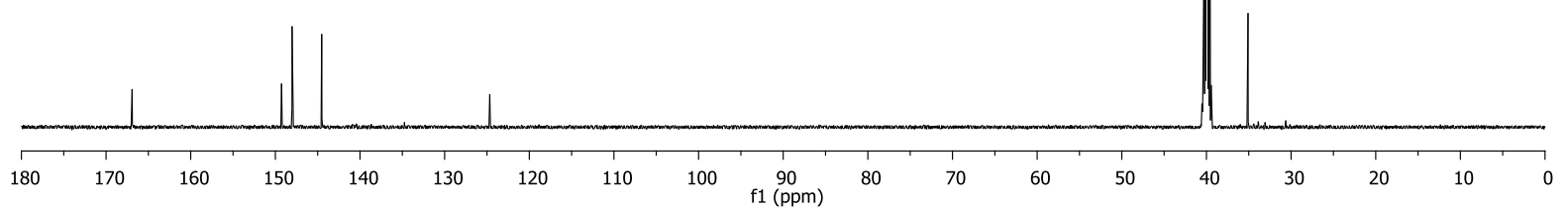

${ }^{13} \mathrm{C}$ NMR spectrum (150 MHz, DMSO-d 6 ) of 55. 
(E)-1-Bromo-3,7-dimethylocta-2,6-diene (60)

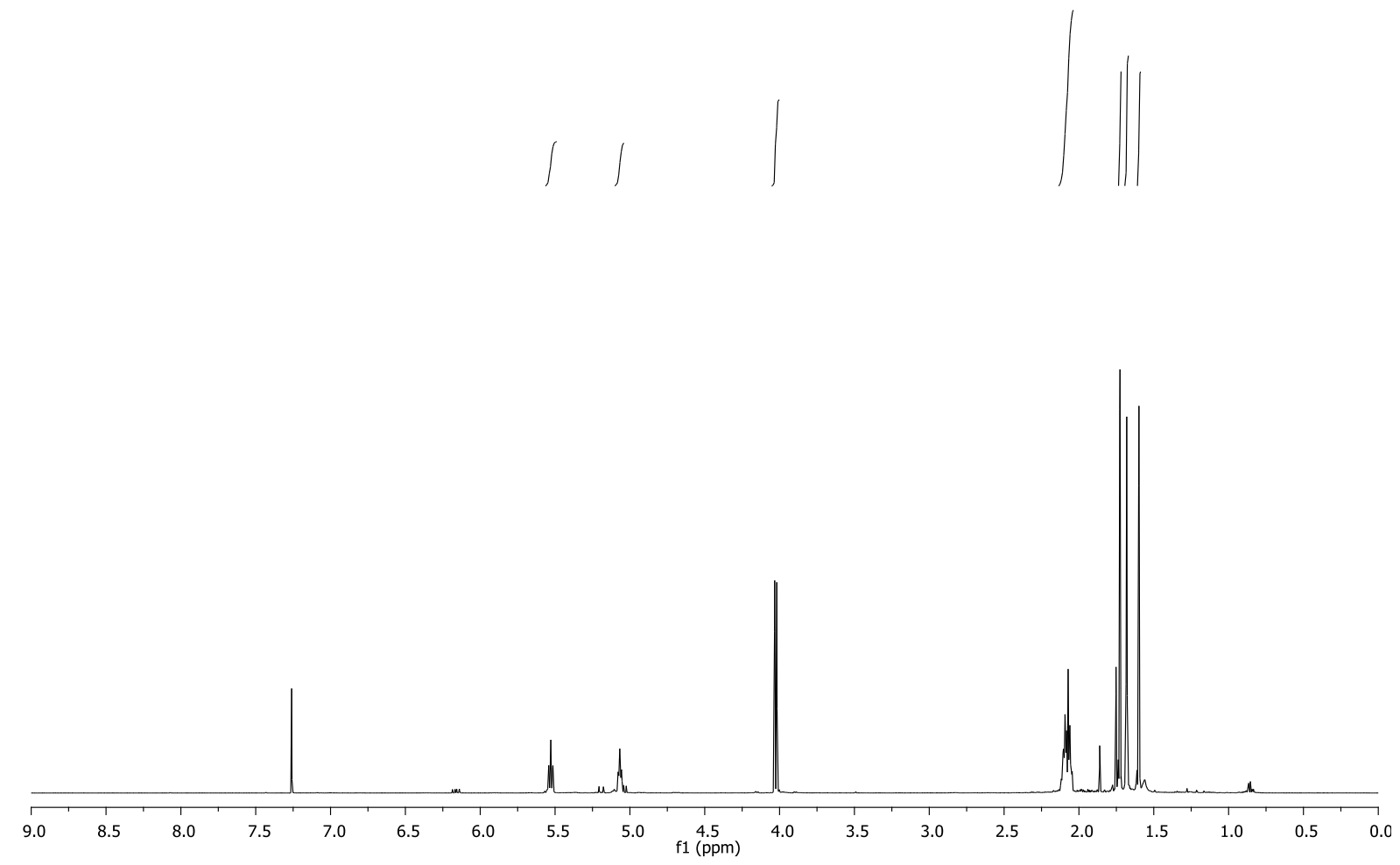

${ }^{1} \mathrm{H}$ NMR spectrum $\left(600 \mathrm{MHz}, \mathrm{CDCl}_{3}\right)$ of $\mathbf{6 0 .}$

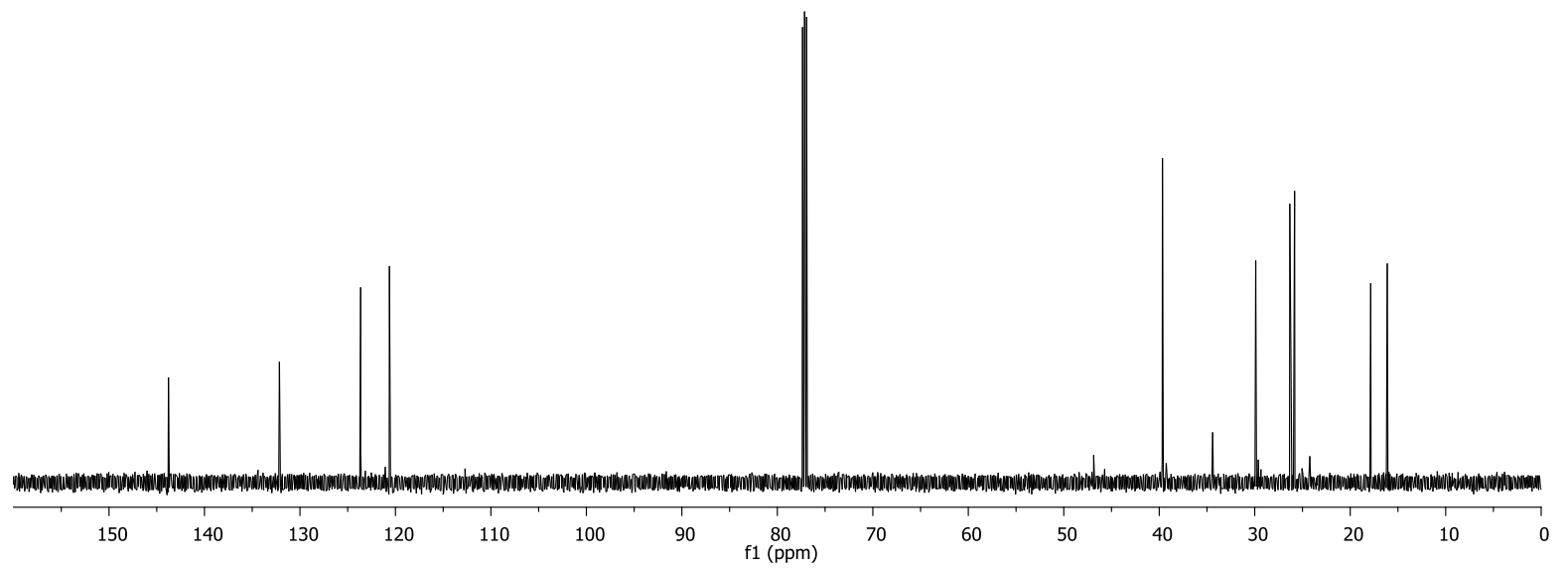

${ }^{13} \mathrm{C}$ NMR spectrum $\left(150 \mathrm{MHz}, \mathrm{CDCl}_{3}\right)$ of $\mathbf{6 0}$. 
(6E)-1-Bromo-3,7,11-trimethyldodeca-2,6,10-triene (61)

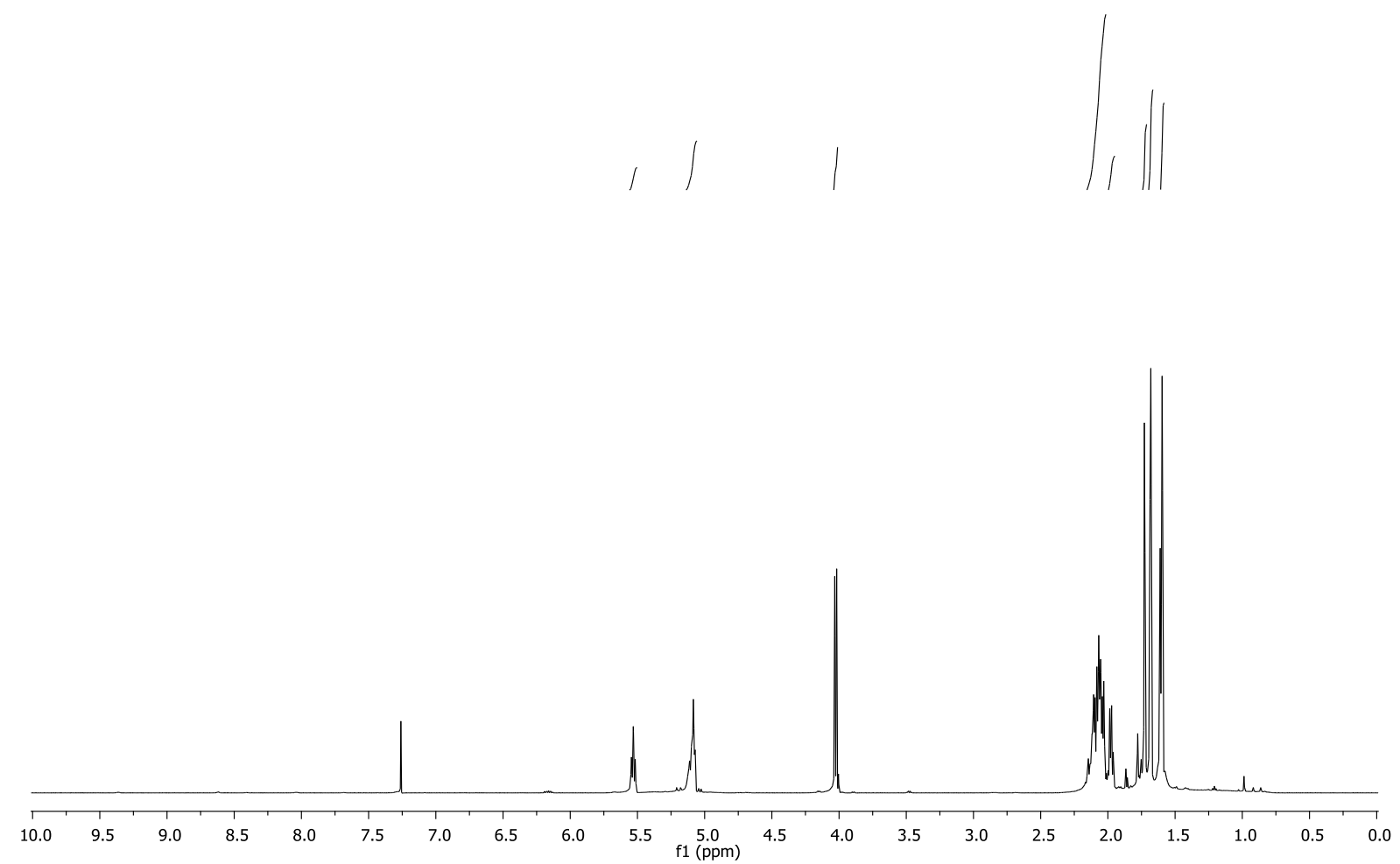

${ }^{1} \mathrm{H}$ NMR spectrum $\left(600 \mathrm{MHz}, \mathrm{CDCl}_{3}\right)$ of $\mathbf{6 1}$.

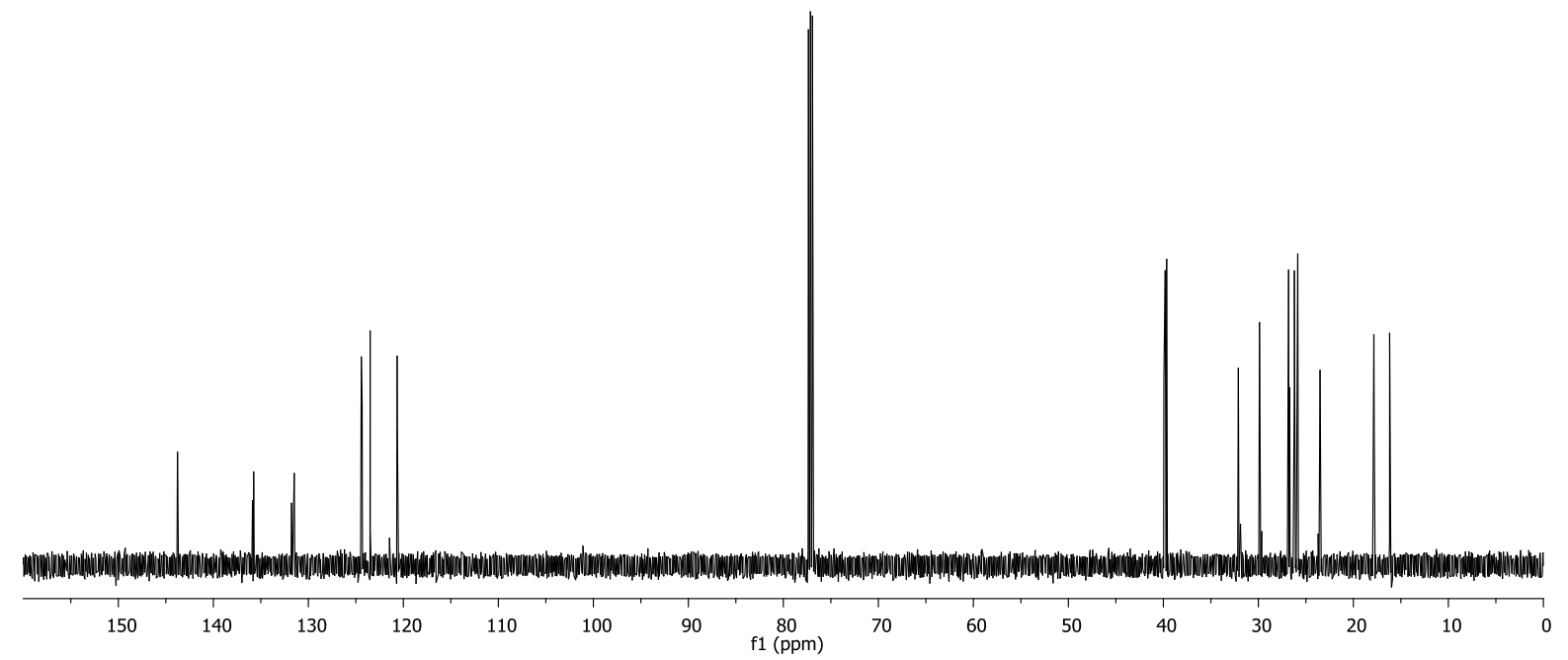

${ }^{13} \mathrm{C}$ NMR spectrum $\left(150 \mathrm{MHz}, \mathrm{CDCl}_{3}\right)$ of $6 \mathbf{1 .}$ 
(6E,10E)-1-Bromo-3,7,11,15-tetramethylhexadeca-2,6,10,14-tetraene (62)

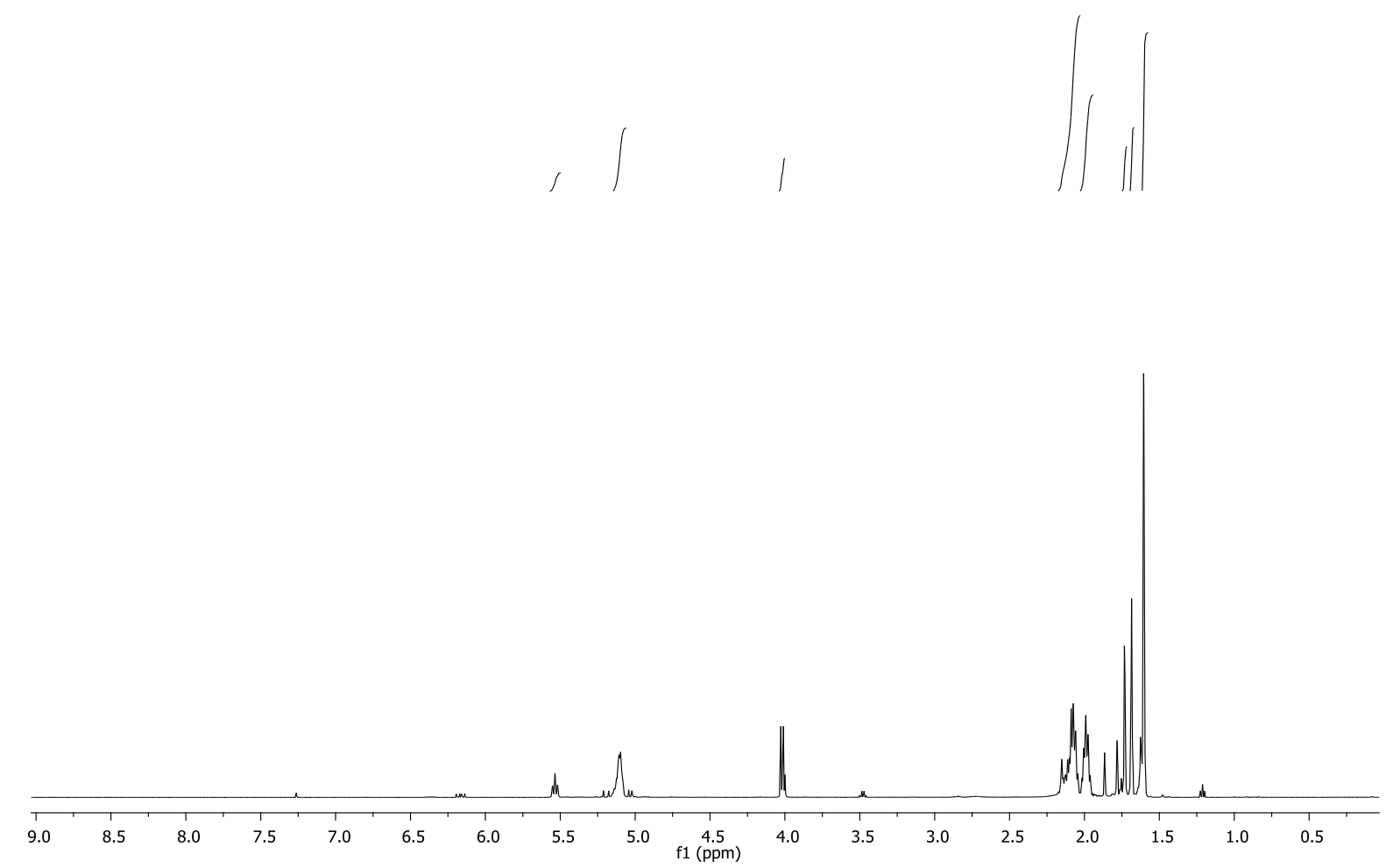

${ }^{1} \mathrm{H}$ NMR spectrum $\left(600 \mathrm{MHz}, \mathrm{CDCl}_{3}\right)$ of 62.

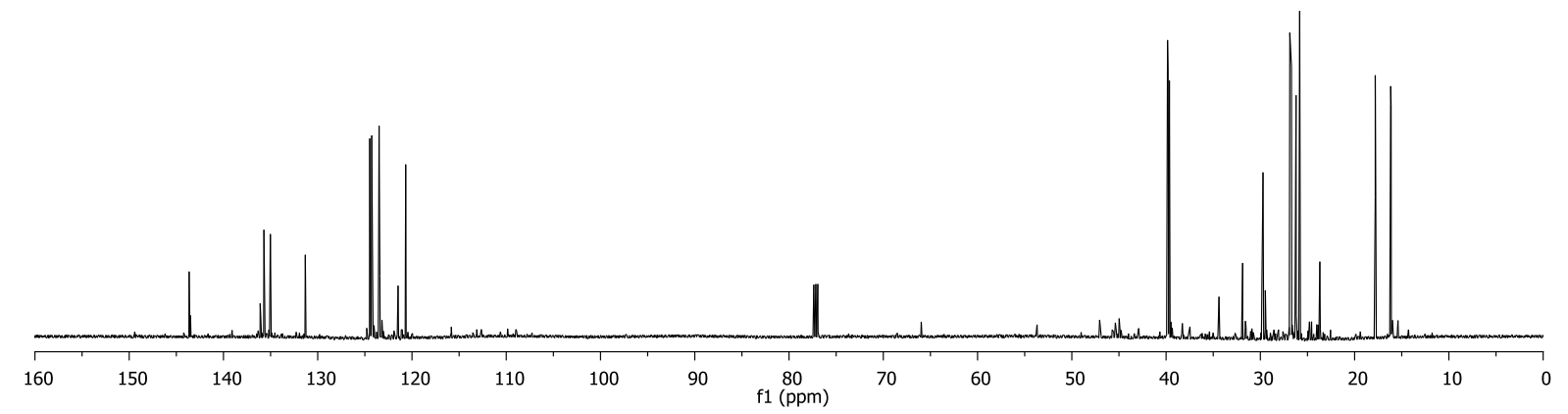

${ }^{13} \mathrm{C} \mathrm{NMR}$ spectrum $\left(150 \mathrm{MHz}, \mathrm{CDCl}_{3}\right)$ of $\mathbf{6 2}$. 
$N, 1-$ bis $((E)-3,7-D i m e t h y l o c t a-f 2,6-d i e n-1-y l)-4-(m e t h y l a m i n o)-1 H$-imidazole-5carboxamide (65)

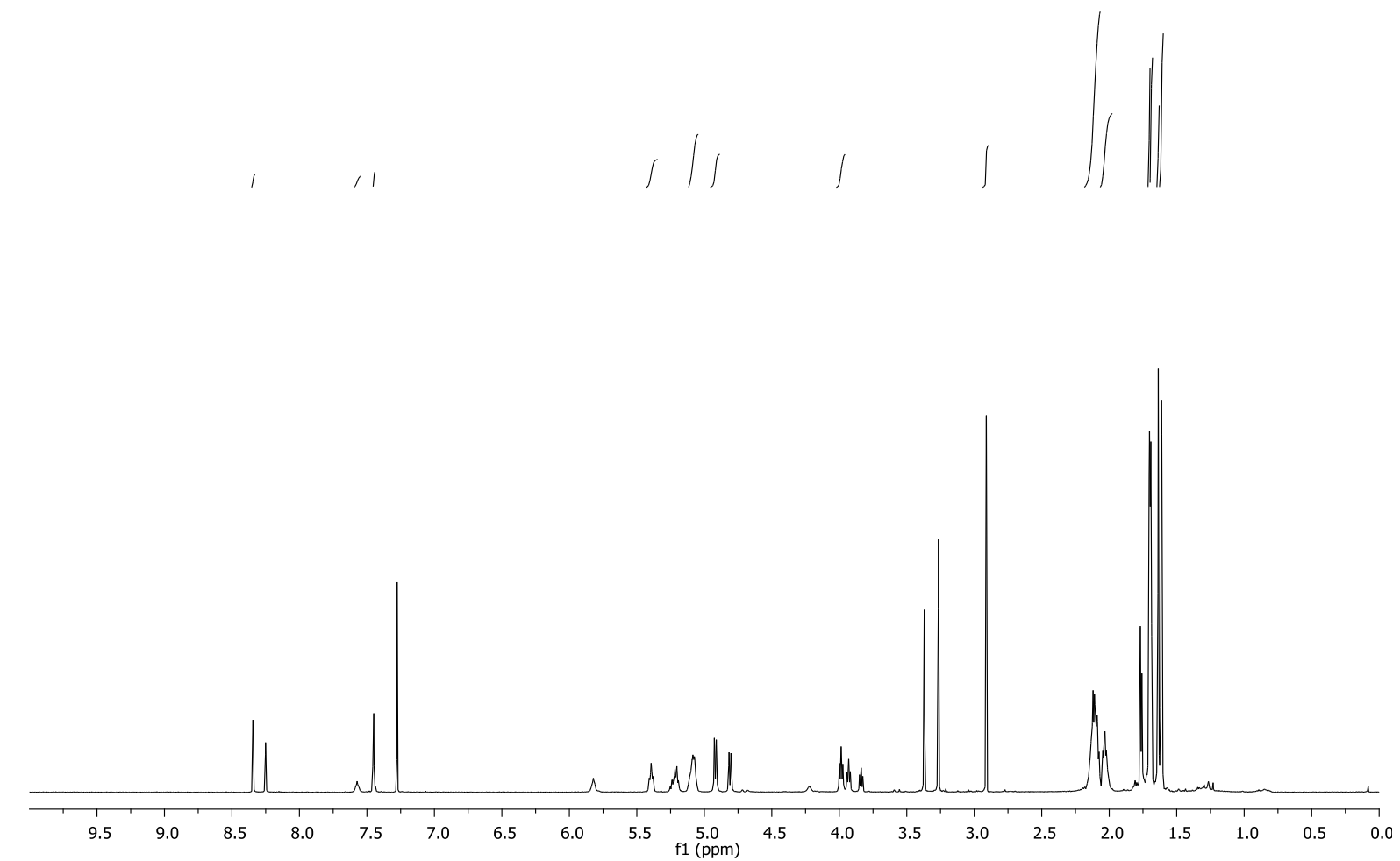

${ }^{1} \mathrm{H}$ NMR spectrum $\left(600 \mathrm{MHz}, \mathrm{CDCl}_{3}\right)$ of $6 \mathbf{5 .}$ 
4-(N-Methylformamido)- $N, 1-$ bis((6E)-3,7,11-trimethyldodeca-2,6,10-trien-1-yl)-1Himidazole-5-carboxamide (66)

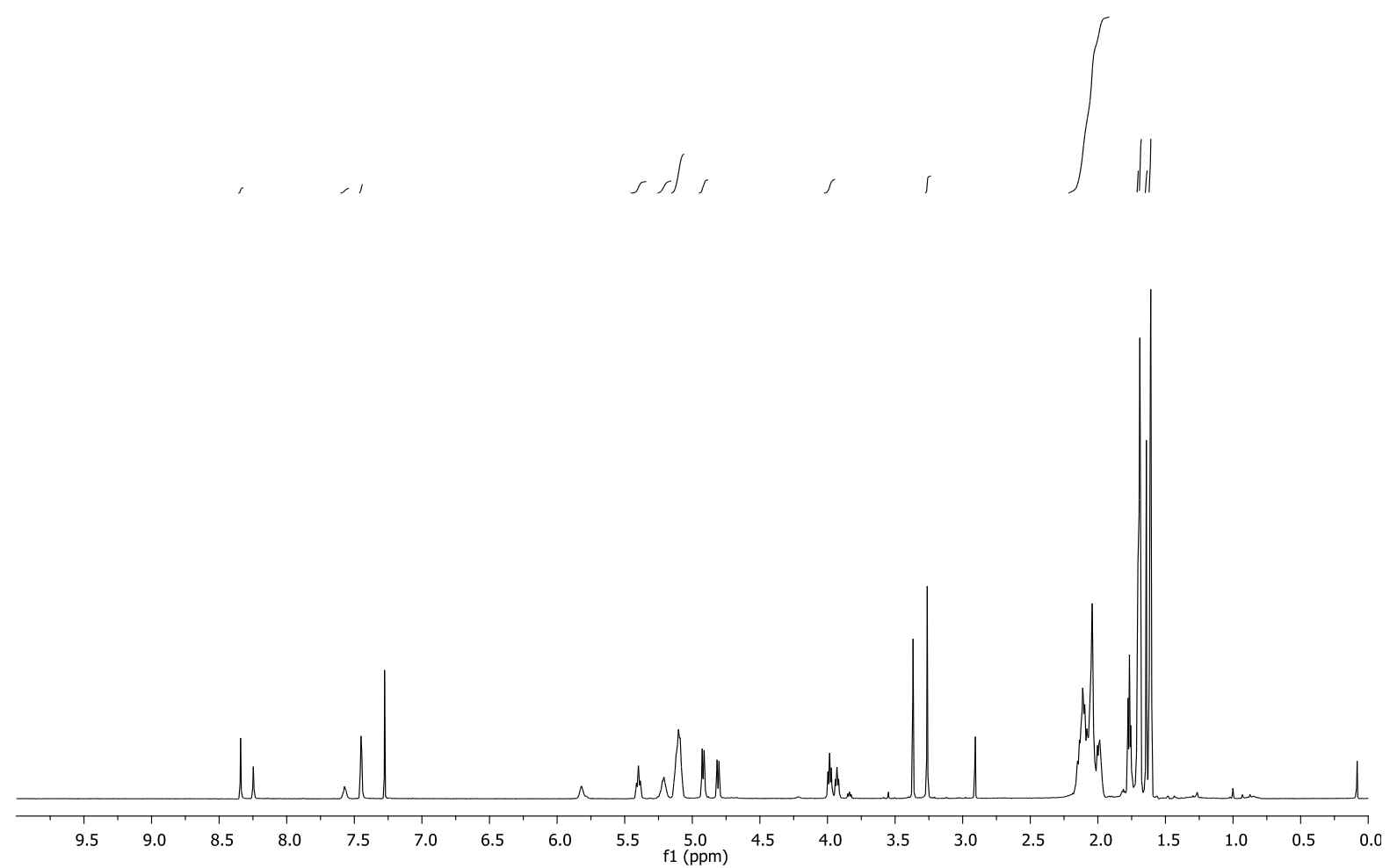

${ }^{1} \mathrm{H}$ NMR spectrum $\left(600 \mathrm{MHz}, \mathrm{CDCl}_{3}\right)$ of $\mathbf{6 6}$. 
4-(N-Methylformamido)- $N, 1$-bis( $(6 E, 10 E)-3,7,11,15$-tetramethylhexadeca-2,6,10,14tetraen-1-yl)-1 $H$-imidazole-5-carboxamide (67)

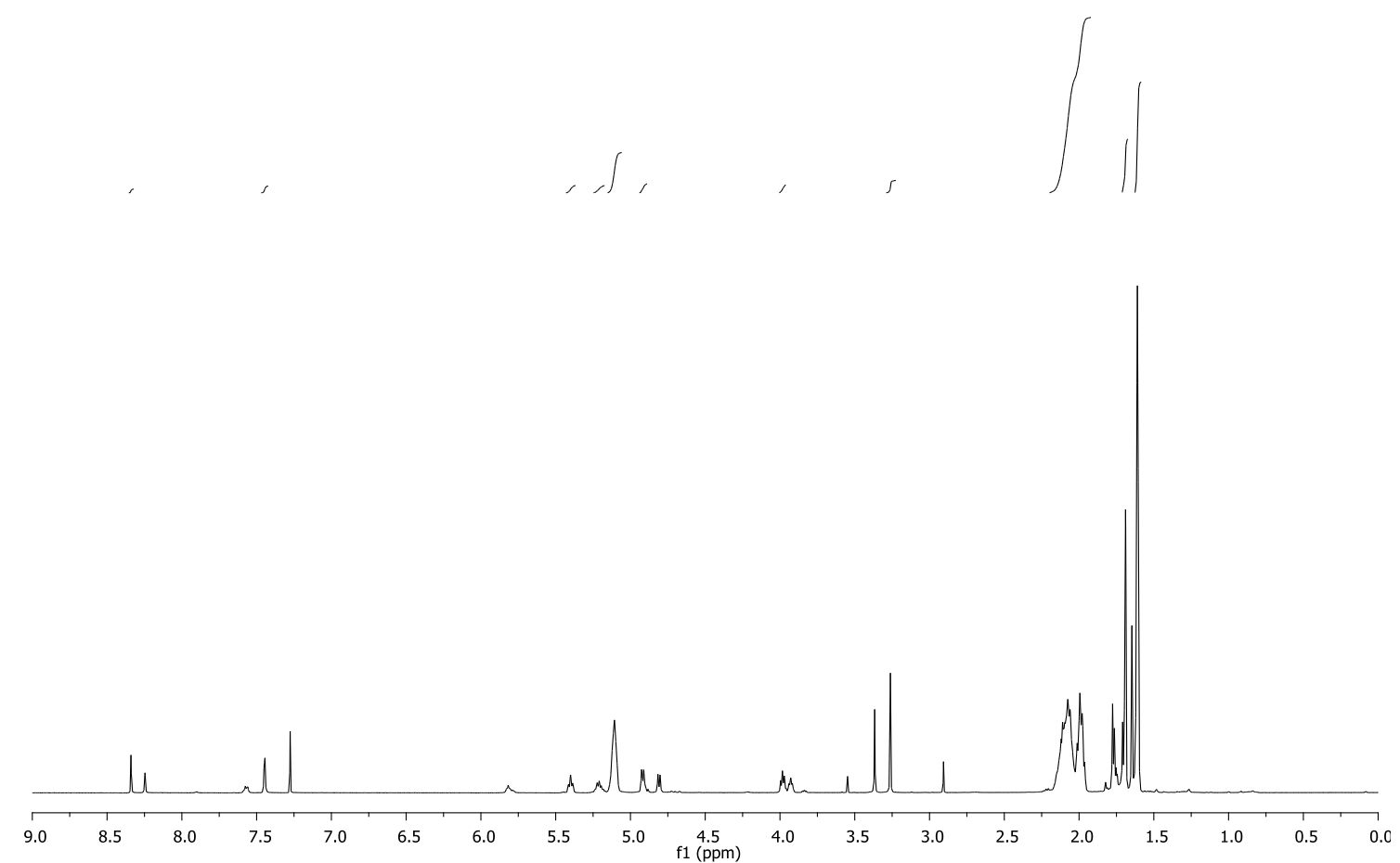

${ }^{1} \mathrm{H}$ NMR spectrum $\left(600 \mathrm{MHz}, \mathrm{CDCl}_{3}\right)$ of 67. 
(E)-3-(3,7-Dimethylocta-2,6-dien-1-yl)-3H-purin-6-amine (80)

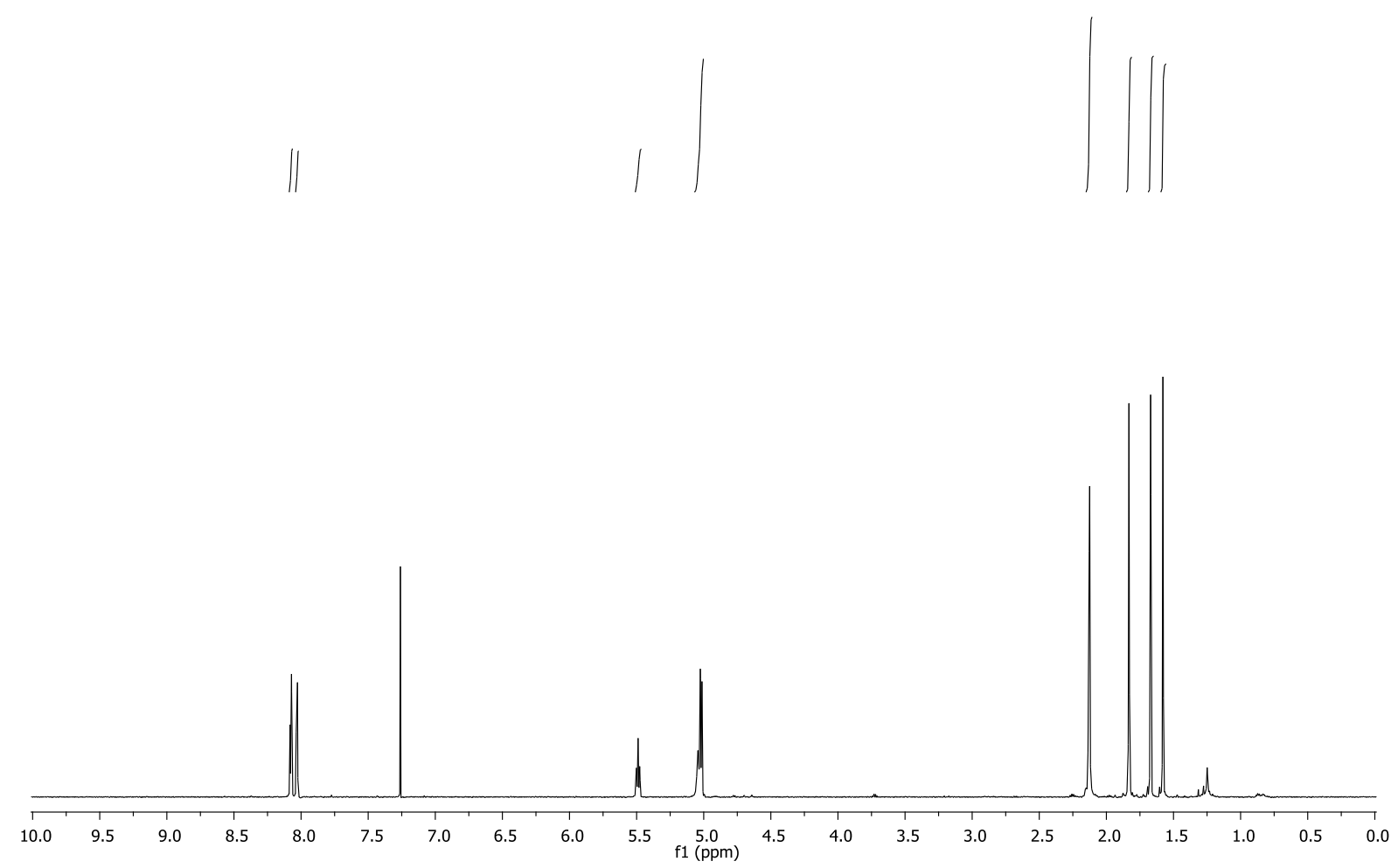

${ }^{1} \mathrm{H}$ NMR spectrum $\left(500 \mathrm{MHz}, \mathrm{CDCl}_{3}\right)$ of $\mathbf{8 0}$.

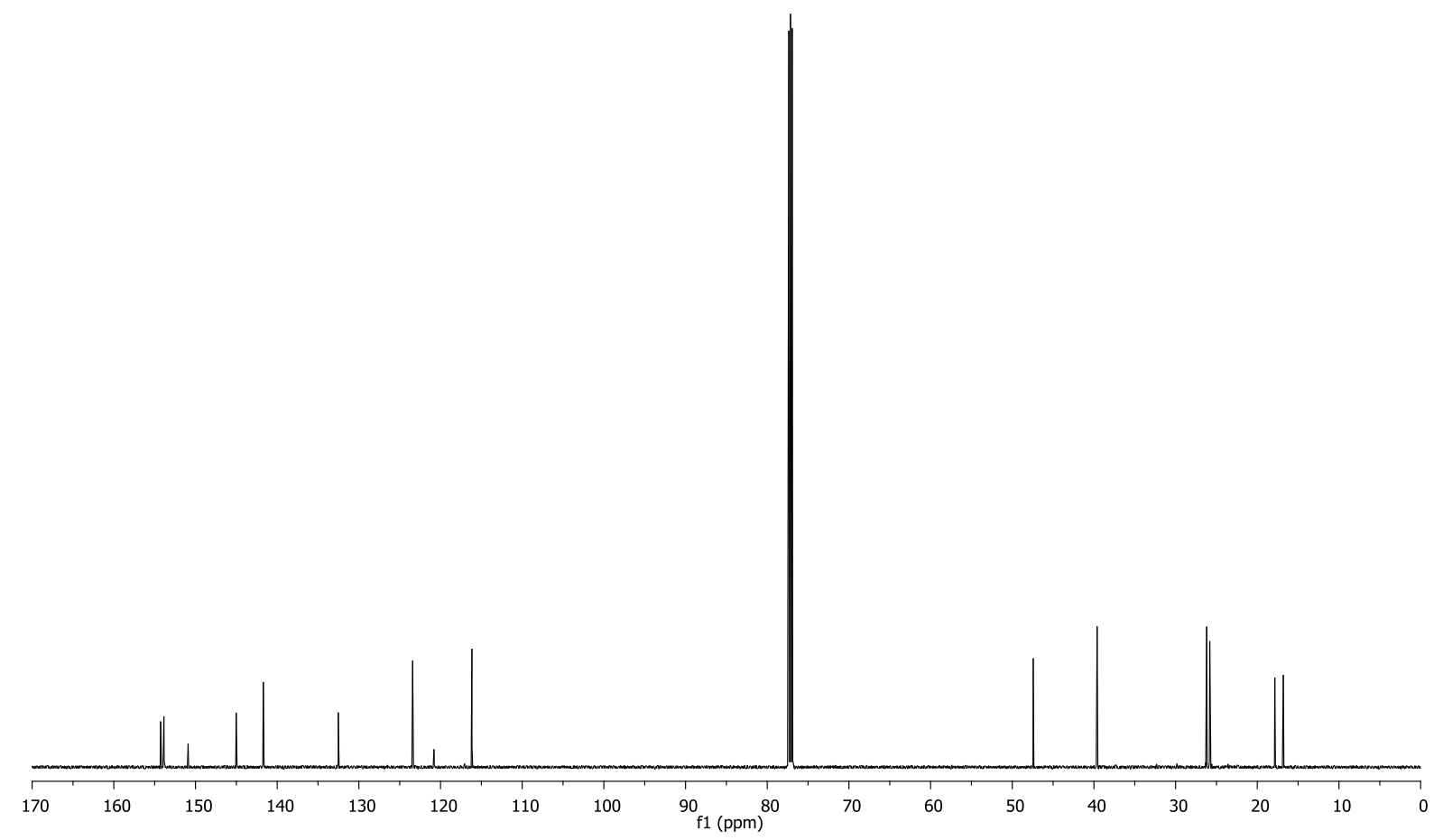

${ }^{13} \mathrm{C}$ NMR spectrum $\left(150 \mathrm{MHz}, \mathrm{CDCl}_{3}\right)$ of $\mathbf{8 0}$. 
N,9-bis((E)-3,7-Dimethylocta-2,6-dien-1-yl)-9H-purin-6-amine (84)

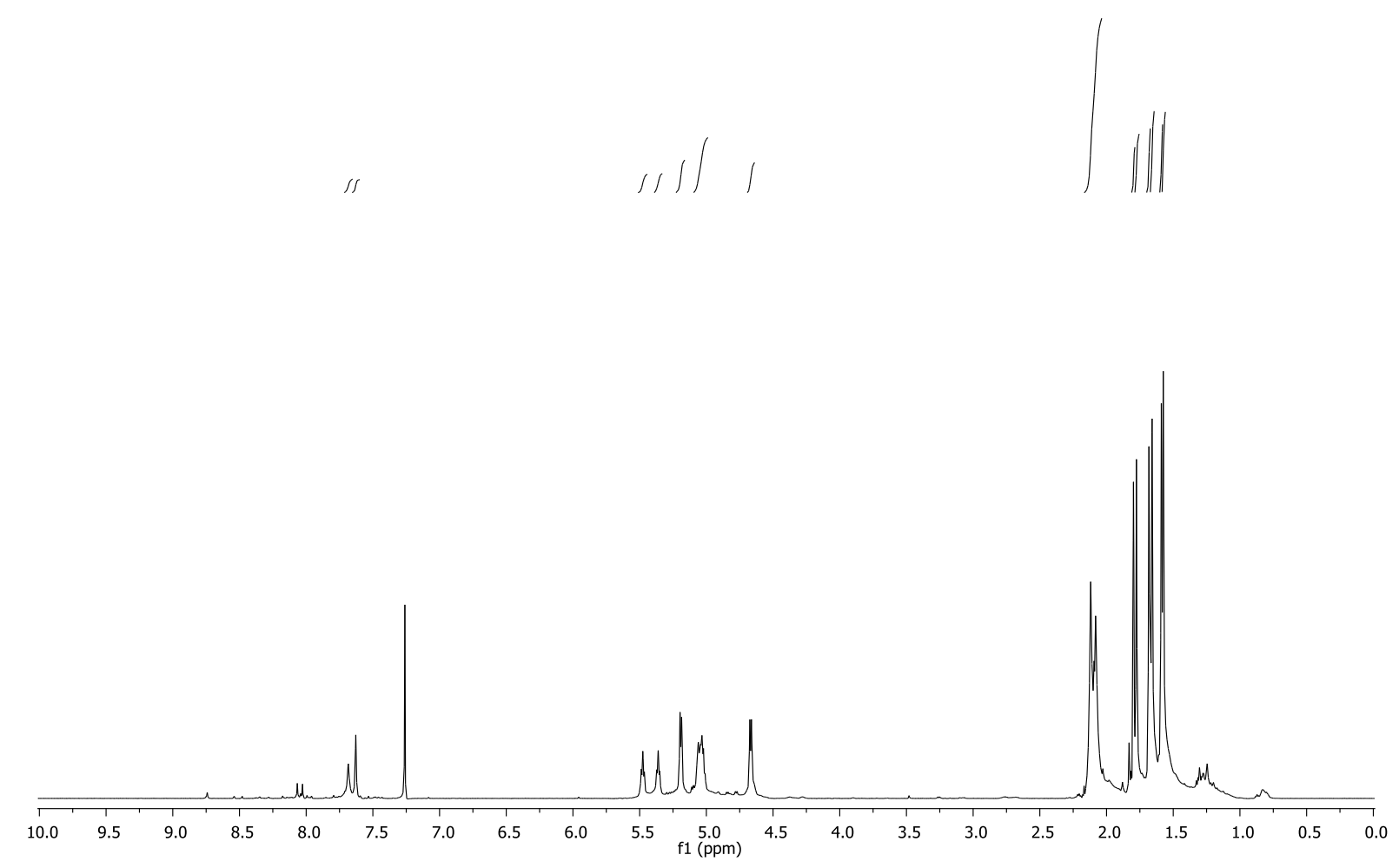

${ }^{1} \mathrm{H}$ NMR spectrum $\left(600 \mathrm{MHz}, \mathrm{CDCl}_{3}\right)$ of $\mathbf{8 4}$.

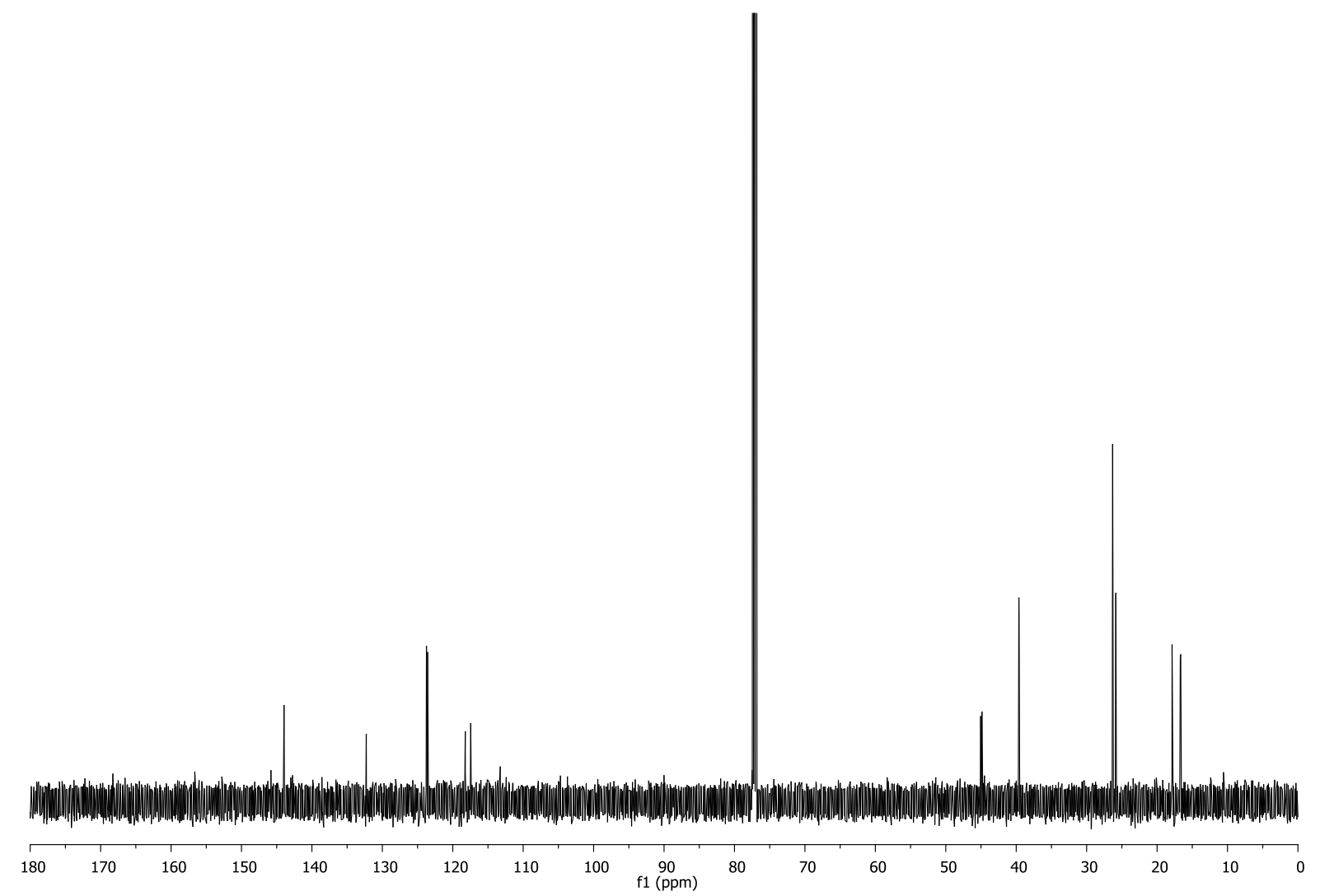

${ }^{13} \mathrm{C}$ NMR spectrum $\left(150 \mathrm{MHz}, \mathrm{CDCl}_{3}\right)$ of $\mathbf{8 4}$. 
3-((6E)-3,7,11-Trimethyldodeca-2,6,10-trien-1-yl)-3H-purin-6-amine (81)

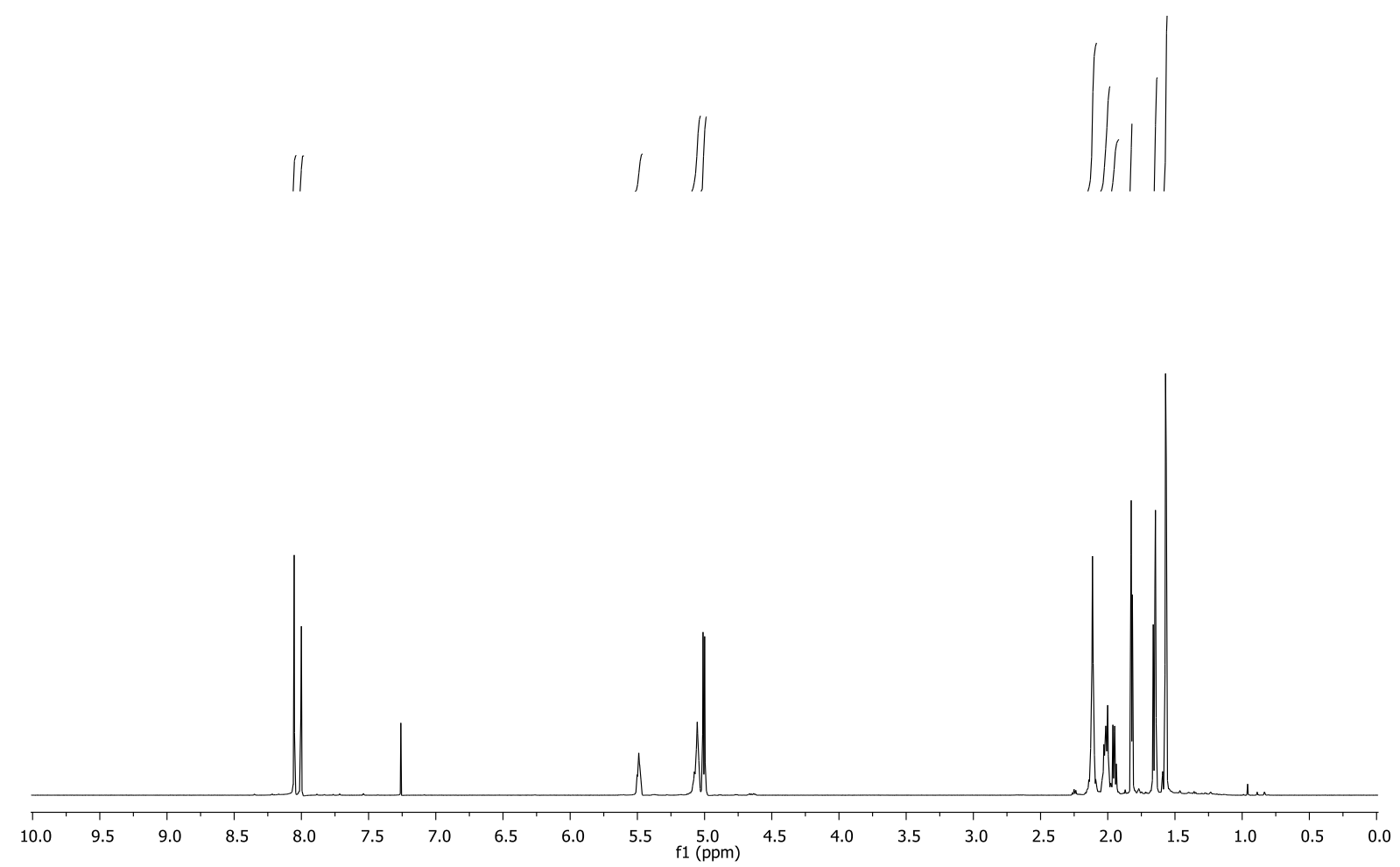

${ }^{1} \mathrm{H}$ NMR spectrum $\left(600 \mathrm{MHz}, \mathrm{CDCl}_{3}\right)$ of $\mathbf{8 1}$.

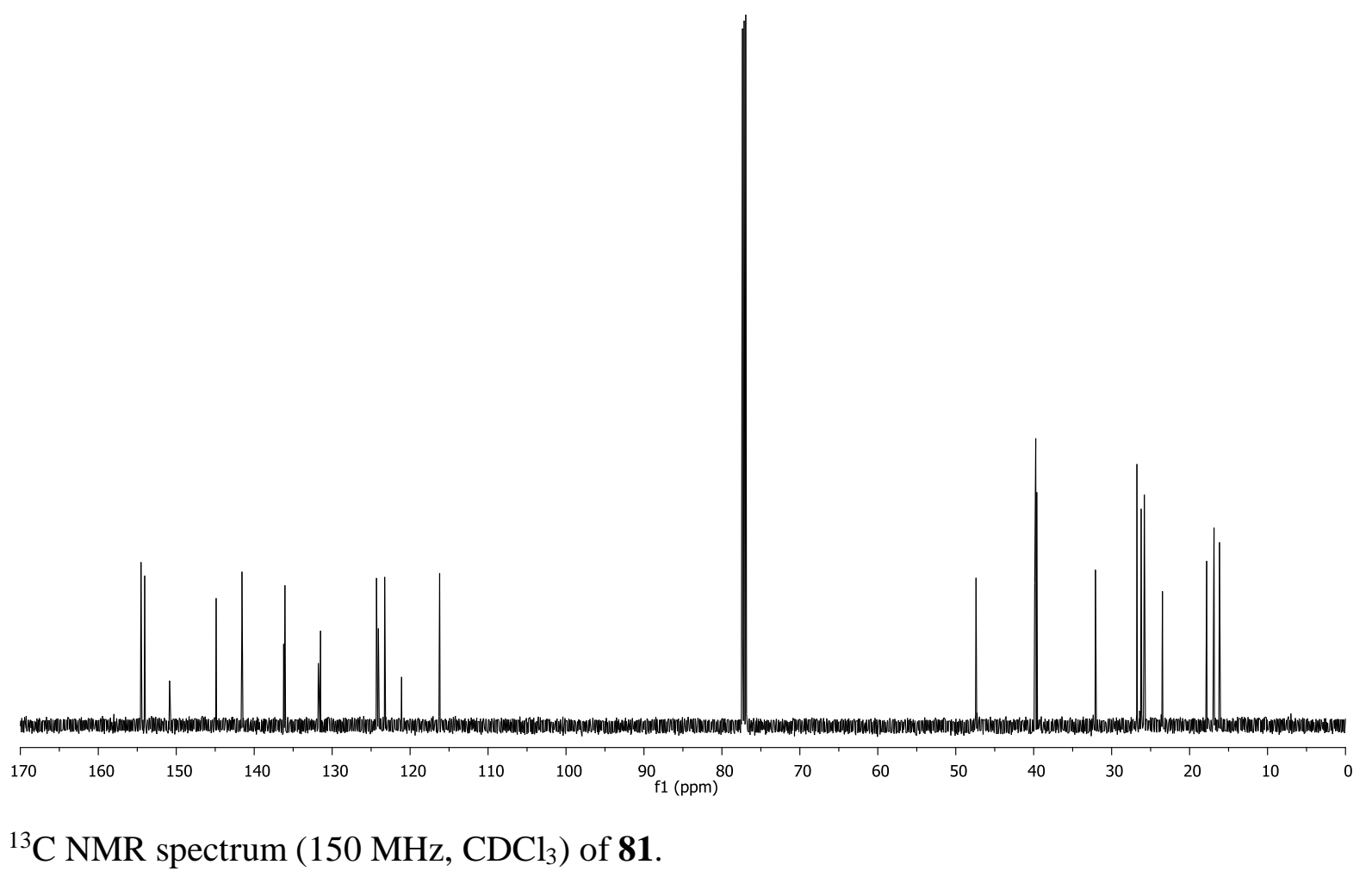


9-((6E)-3,7,11-Trimethyldodeca-2,6,10-trien-1-yl)-9H-purin-6-amine (82)



${ }^{1} \mathrm{H}$ NMR spectrum $\left(500 \mathrm{MHz}, \mathrm{CDCl}_{3}\right)$ of 82 . 
9-((2E,6E,10E)-3,7,11,15-Tetramethylhexadeca-2,6,10,14-tetraen-1-yl)-9H-purin-6amine (83)

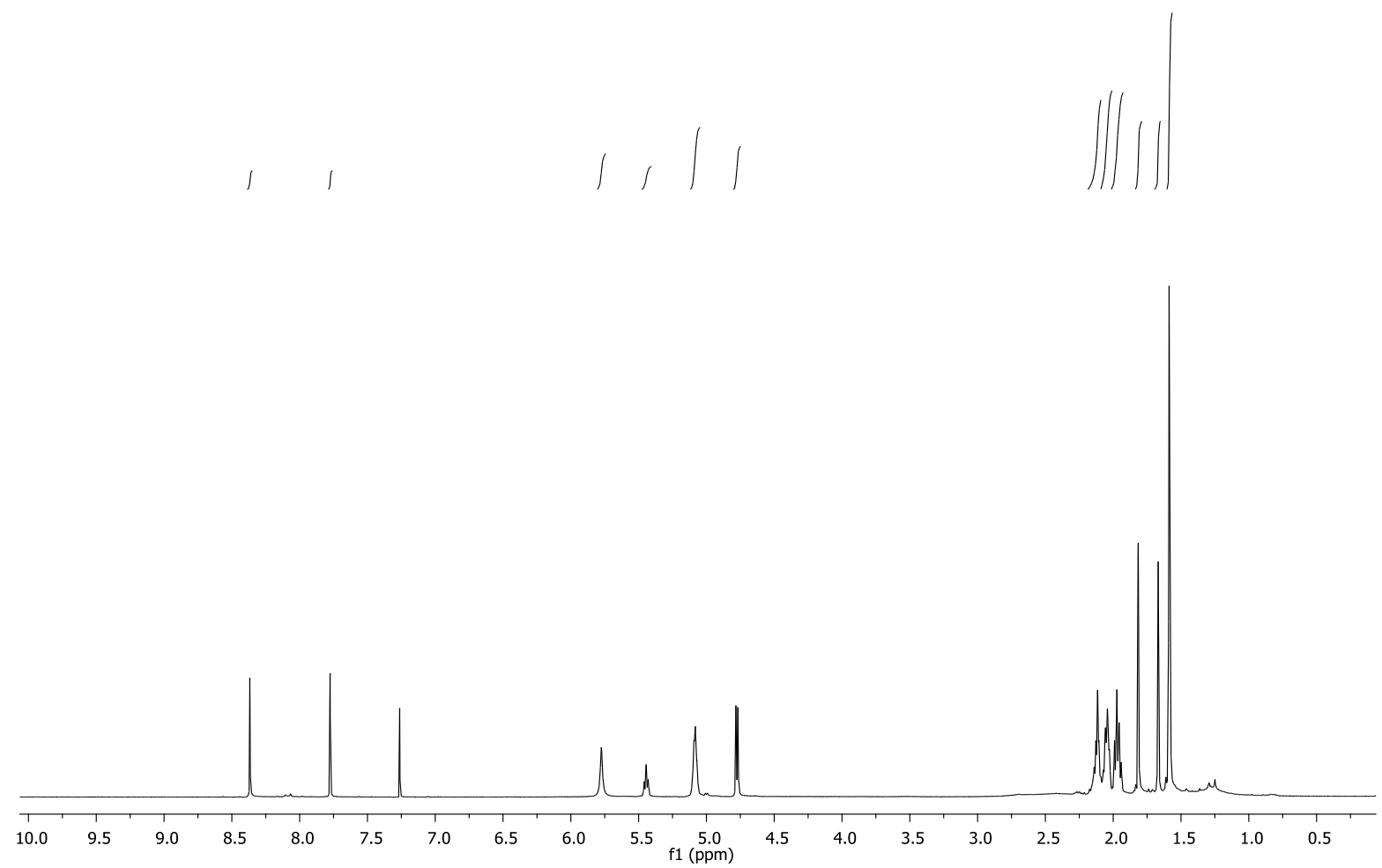

${ }^{1} \mathrm{H}$ NMR spectrum $\left(500 \mathrm{MHz}, \mathrm{CDCl}_{3}\right)$ of $\mathbf{8 3}$.

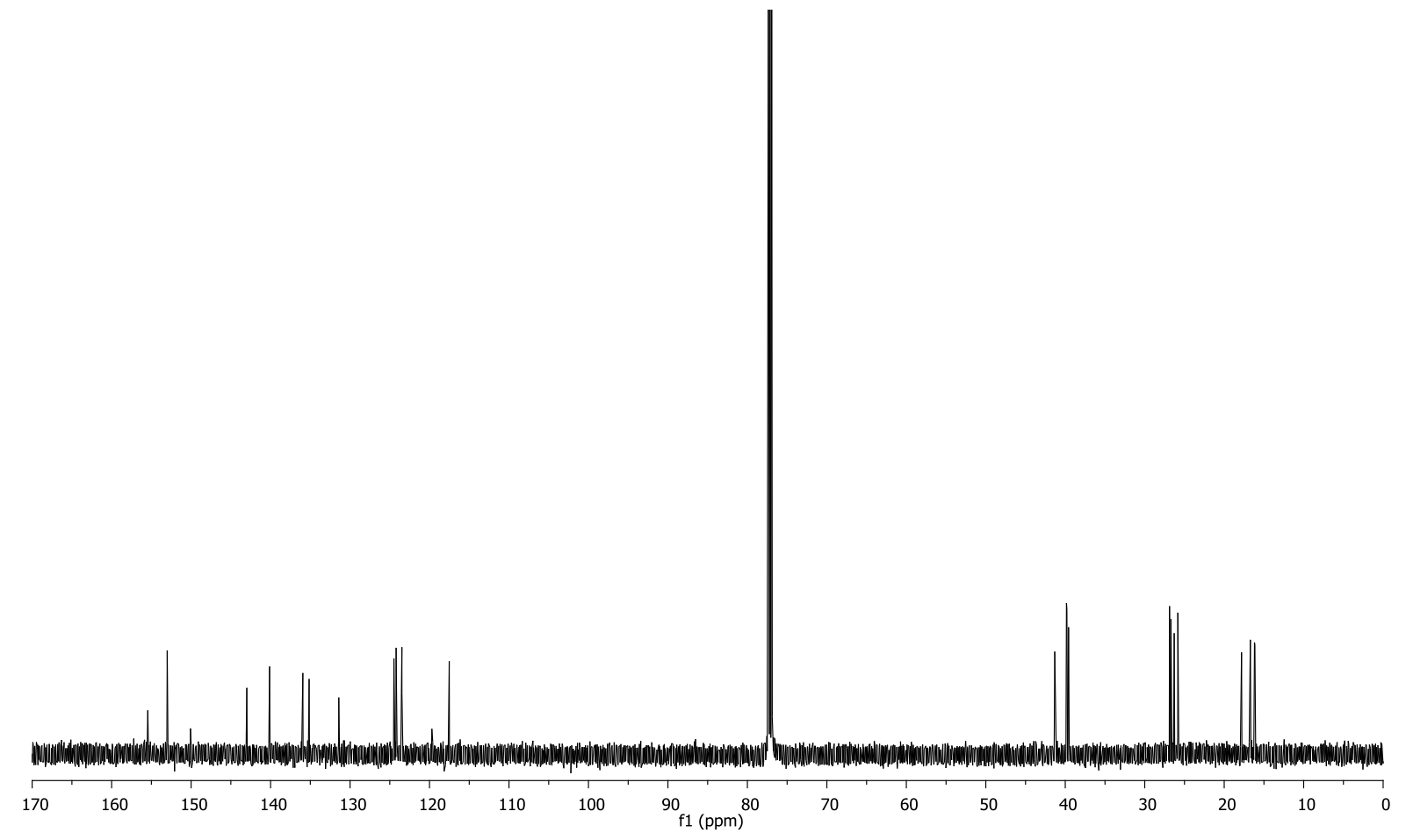

${ }^{13} \mathrm{C}$ NMR spectrum $\left(150 \mathrm{MHz}, \mathrm{CDCl}_{3}\right)$ of 83 . 
(E)-3-(3,7-Dimethylocta-2,6-dien-1-yl)- $N, N$-dimethyl-3H-purin-6-amine (85)



${ }^{1} \mathrm{H}$ NMR spectrum $\left(600 \mathrm{MHz}, \mathrm{CDCl}_{3}\right)$ of $\mathbf{8 5}$.

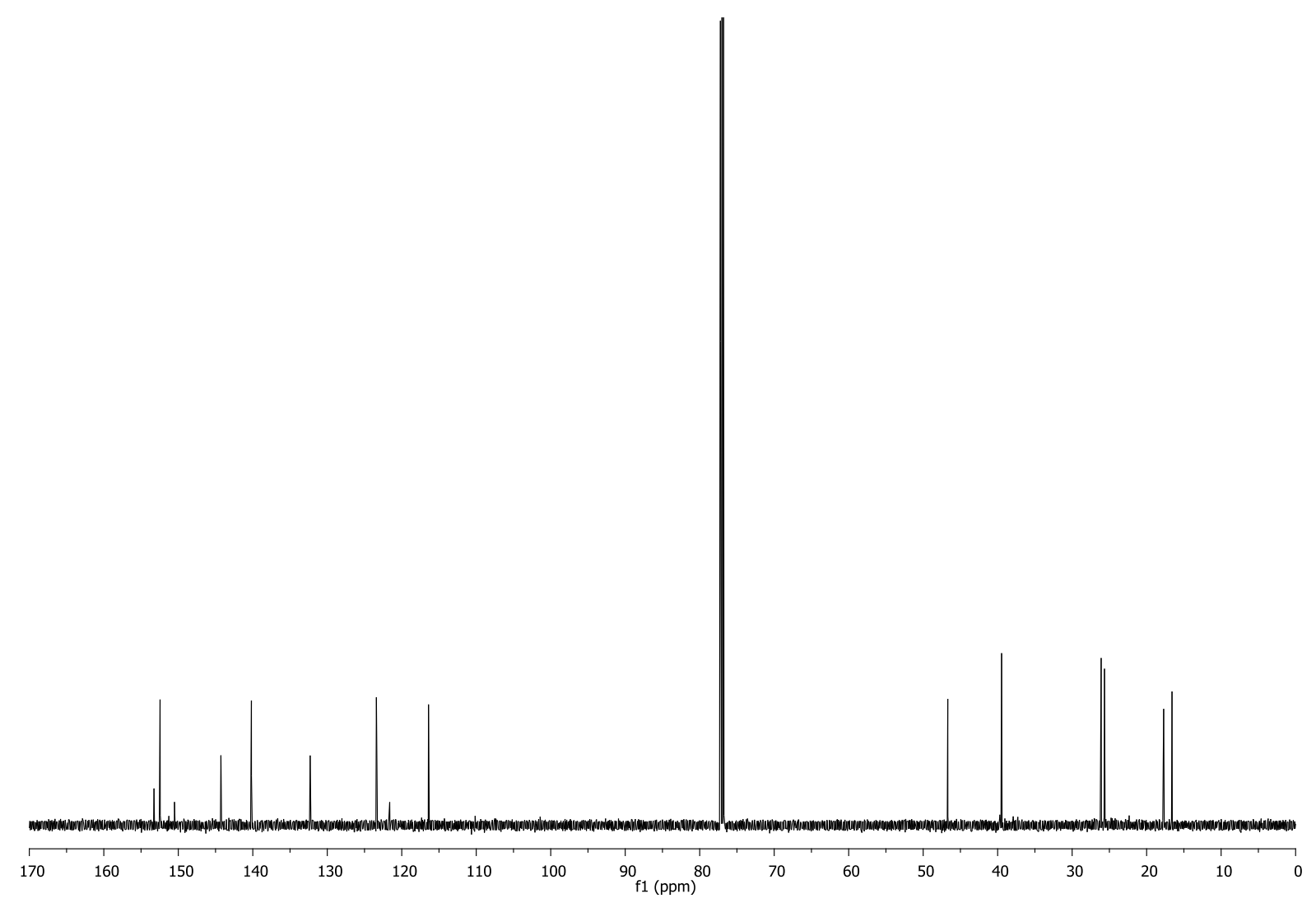

${ }^{13} \mathrm{C}$ NMR spectrum $\left(150 \mathrm{MHz}, \mathrm{CDCl}_{3}\right)$ of 85 . 
(E)-9-(3,7-Dimethylocta-2,6-dien-1-yl)- $N, N$-dimethyl-9H-purin-6-amine (86)

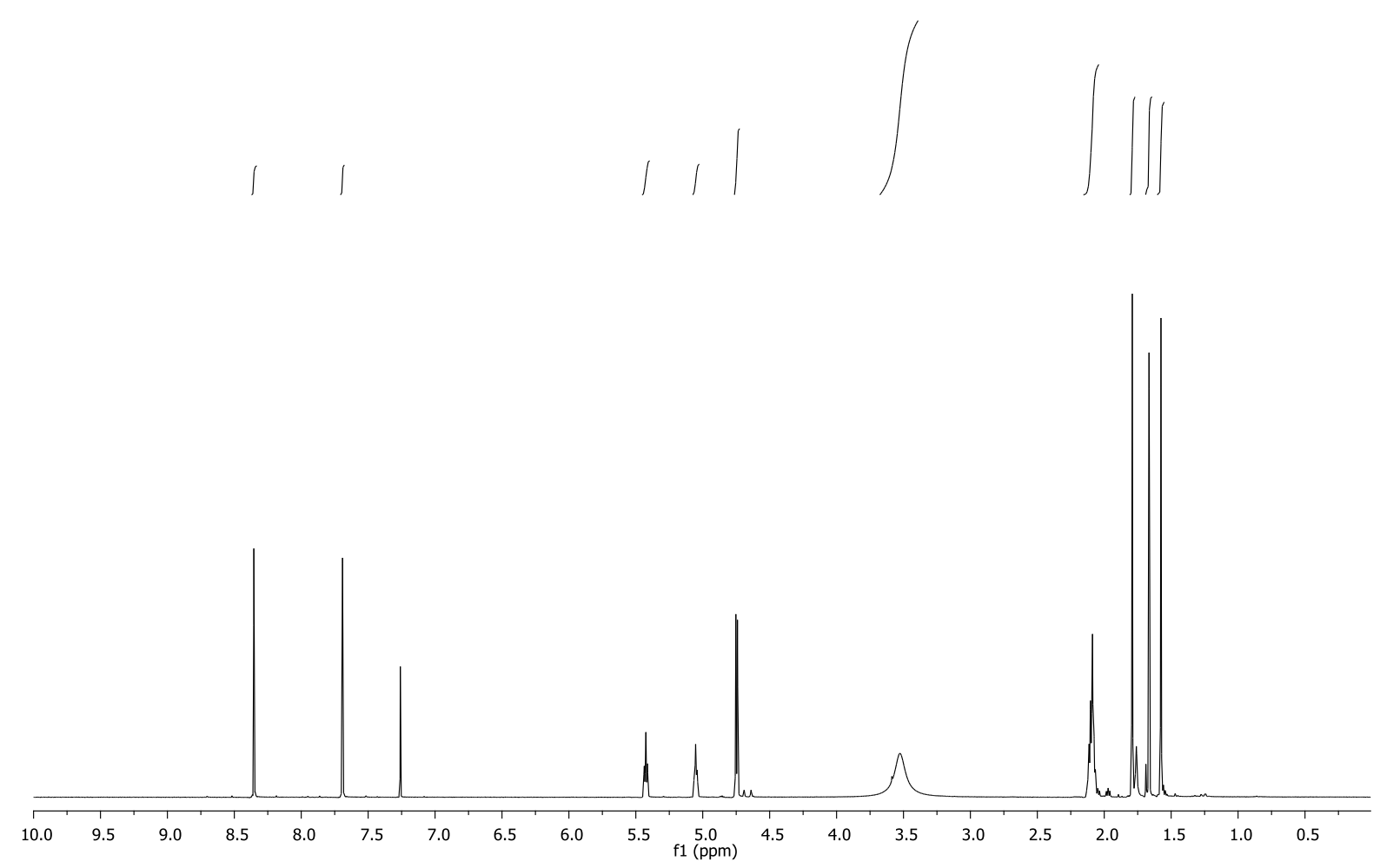

${ }^{1} \mathrm{H}$ NMR spectrum $\left(600 \mathrm{MHz}, \mathrm{CDCl}_{3}\right)$ of $\mathbf{8 6}$.

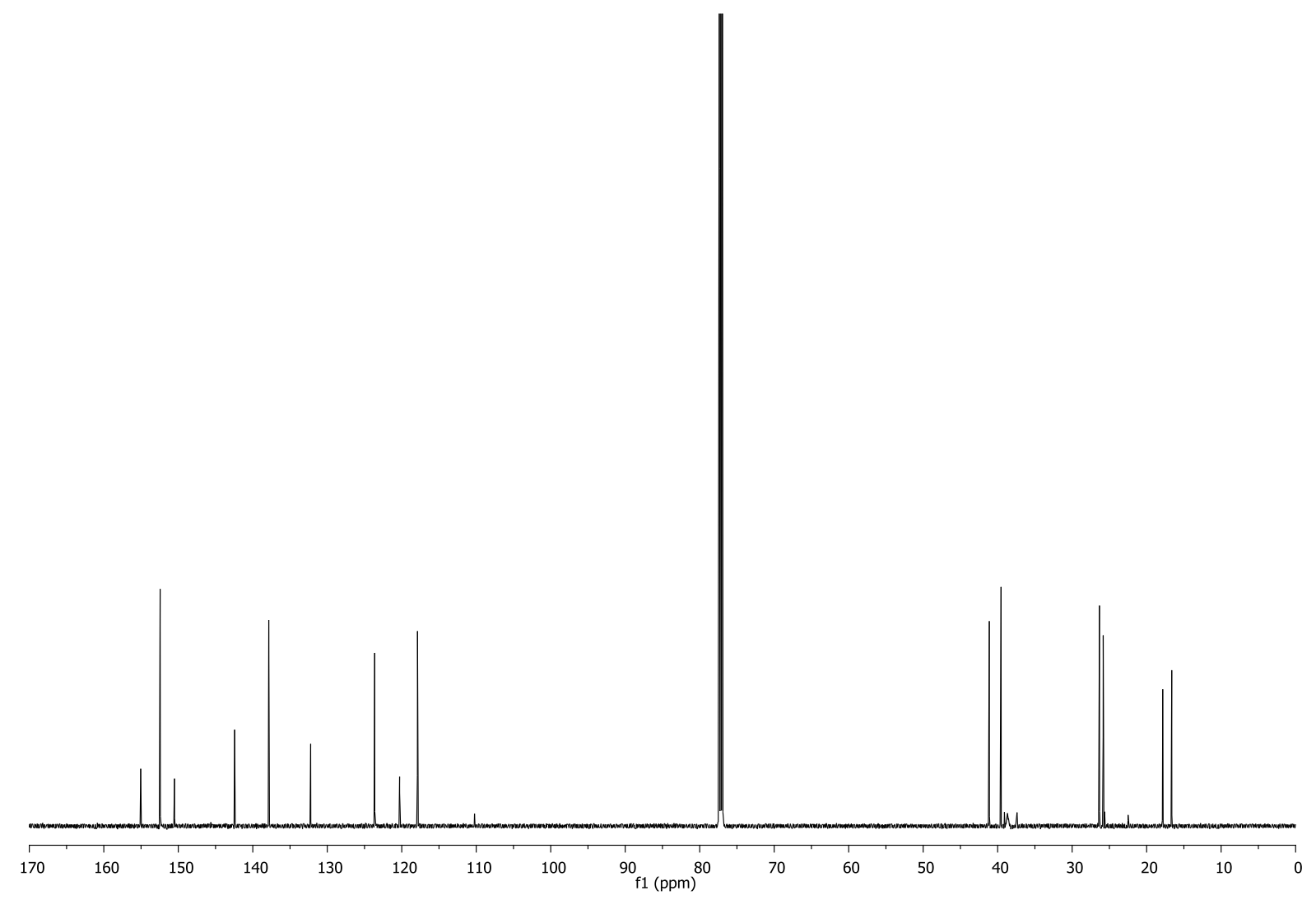

${ }^{13} \mathrm{C}$ NMR spectrum $\left(150 \mathrm{MHz}, \mathrm{CDCl}_{3}\right)$ of $\mathbf{8 6}$. 
$N, N$-Dimethyl-3-((6E)-3,7,11-trimethyldodeca-2,6,10-trien-1-yl)-3H-purin-6-amine (87)

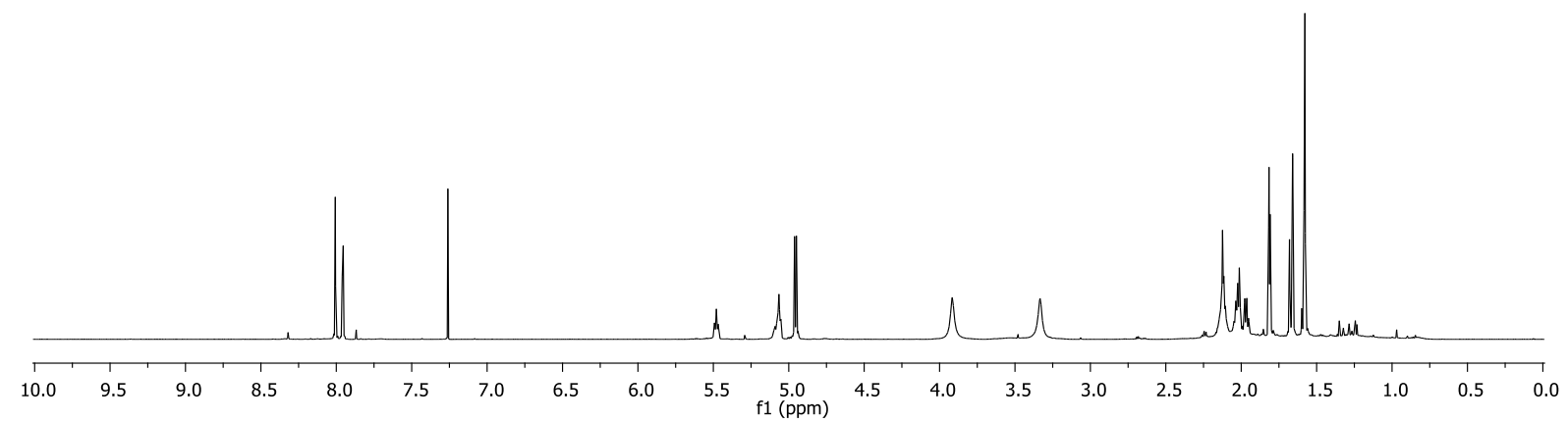

${ }^{1} \mathrm{H}$ NMR spectrum $\left(600 \mathrm{MHz}, \mathrm{CDCl}_{3}\right)$ of 87.

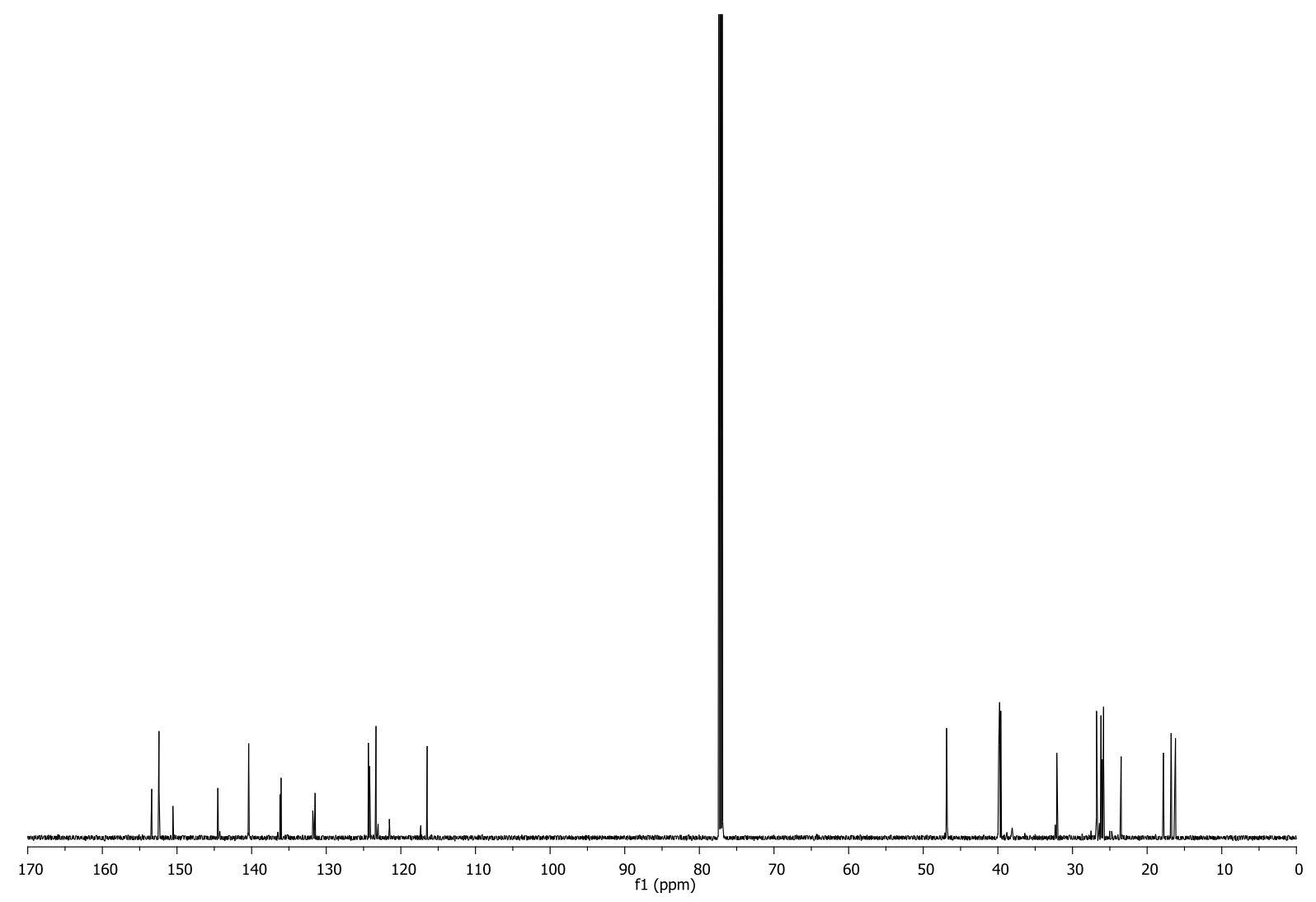

${ }^{13} \mathrm{C}$ NMR spectrum $\left(150 \mathrm{MHz}, \mathrm{CDCl}_{3}\right)$ of 87. 
$N, N$-Dimethyl-9-((6E)-3,7,11-trimethyldodeca-2,6,10-trien-1-yl)-9H-purin-6-amine (88)

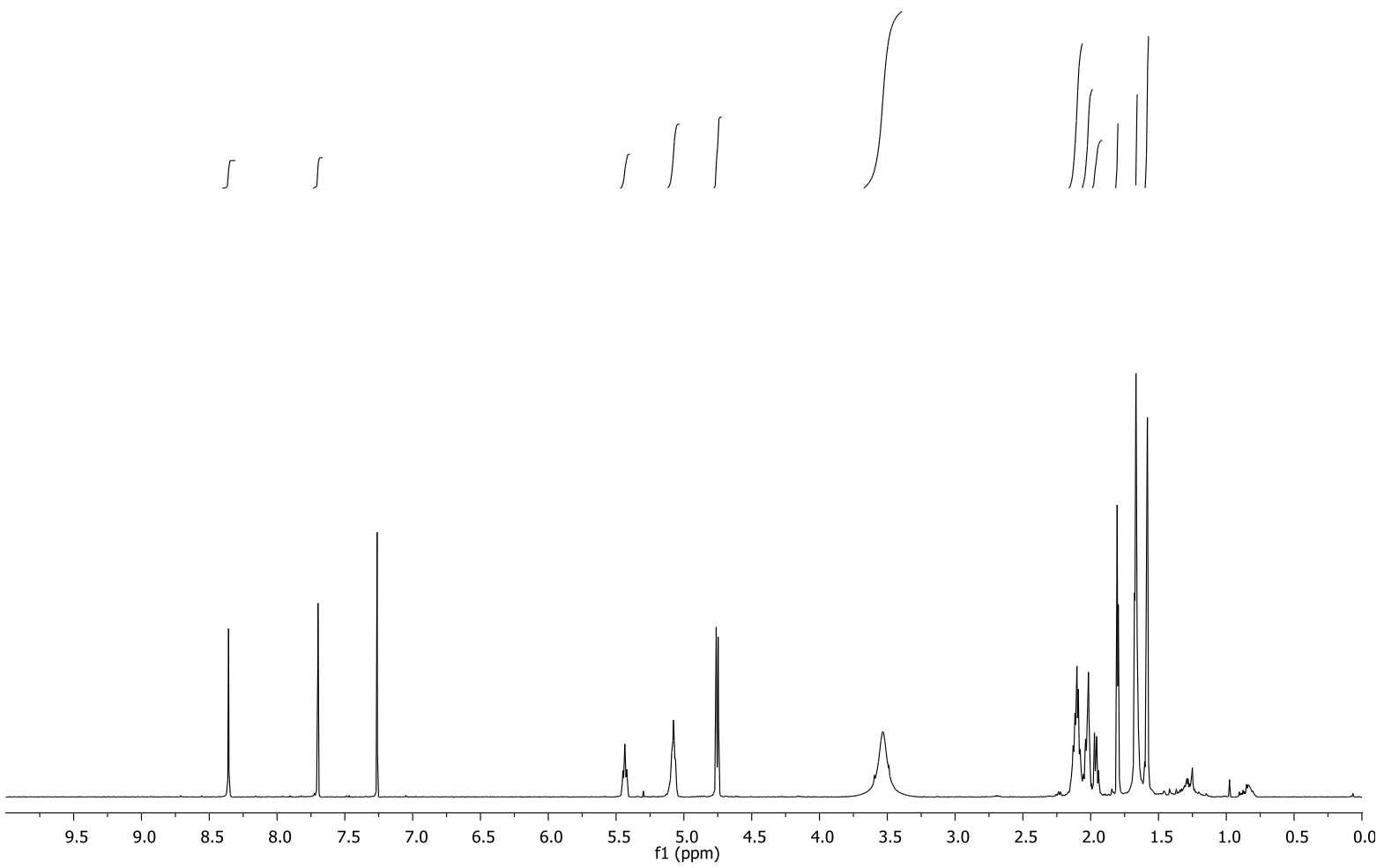

${ }^{1} \mathrm{H}$ NMR spectrum $\left(500 \mathrm{MHz}, \mathrm{CDCl}_{3}\right)$ of $\mathbf{8 8}$.

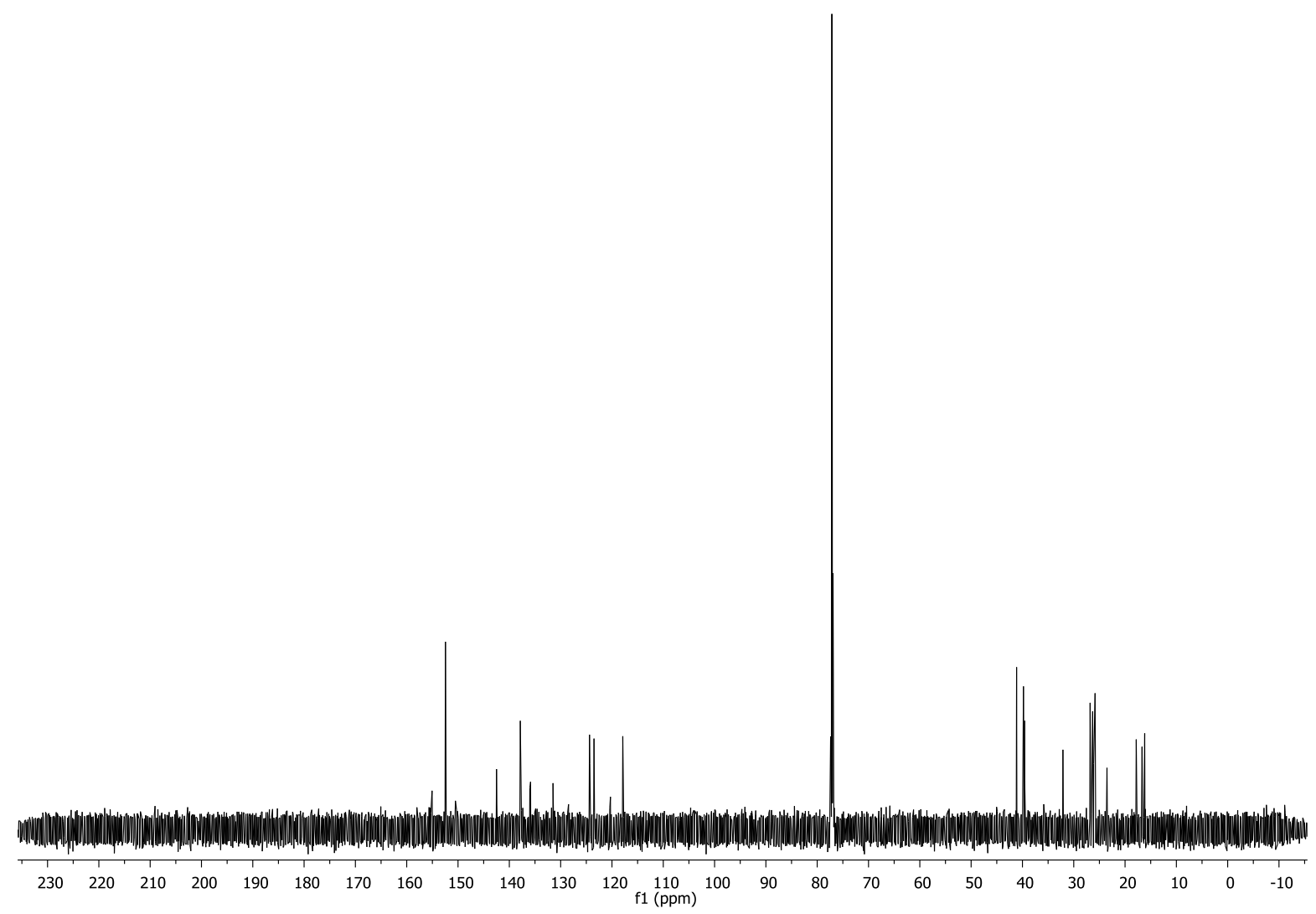

${ }^{13} \mathrm{C}$ NMR spectrum $\left(150 \mathrm{MHz}, \mathrm{CDCl}_{3}\right)$ of $\mathbf{8 8}$. 
$N, N$-Dimethyl-9-((2Z,6E,10E)-3,7,11,15-tetramethylhexadeca-2,6,10,14-tetraen-1-yl)9H-purin-6-amine (89)

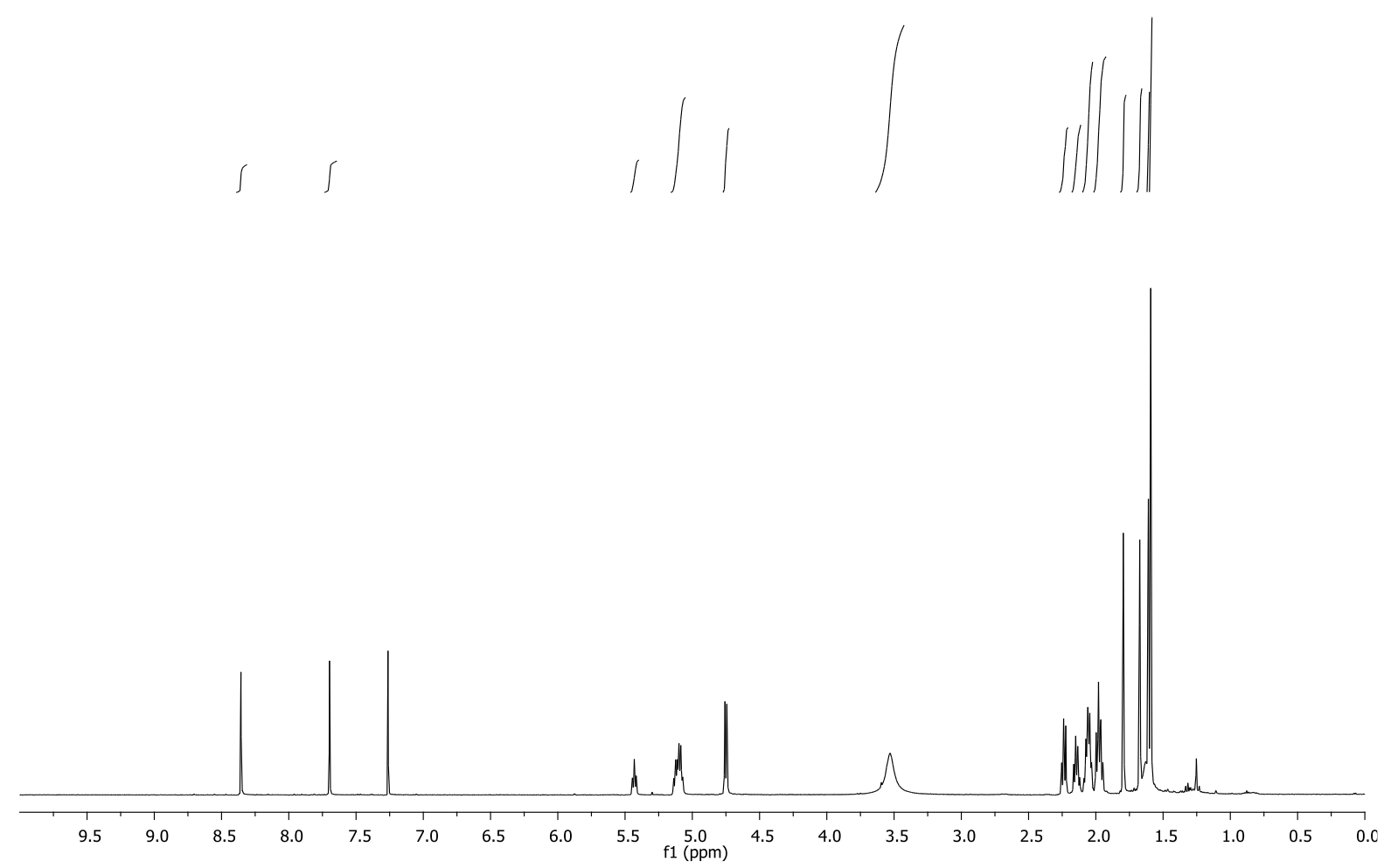

${ }^{1} \mathrm{H}$ NMR spectrum $\left(500 \mathrm{MHz}, \mathrm{CDCl}_{3}\right)$ of 89.

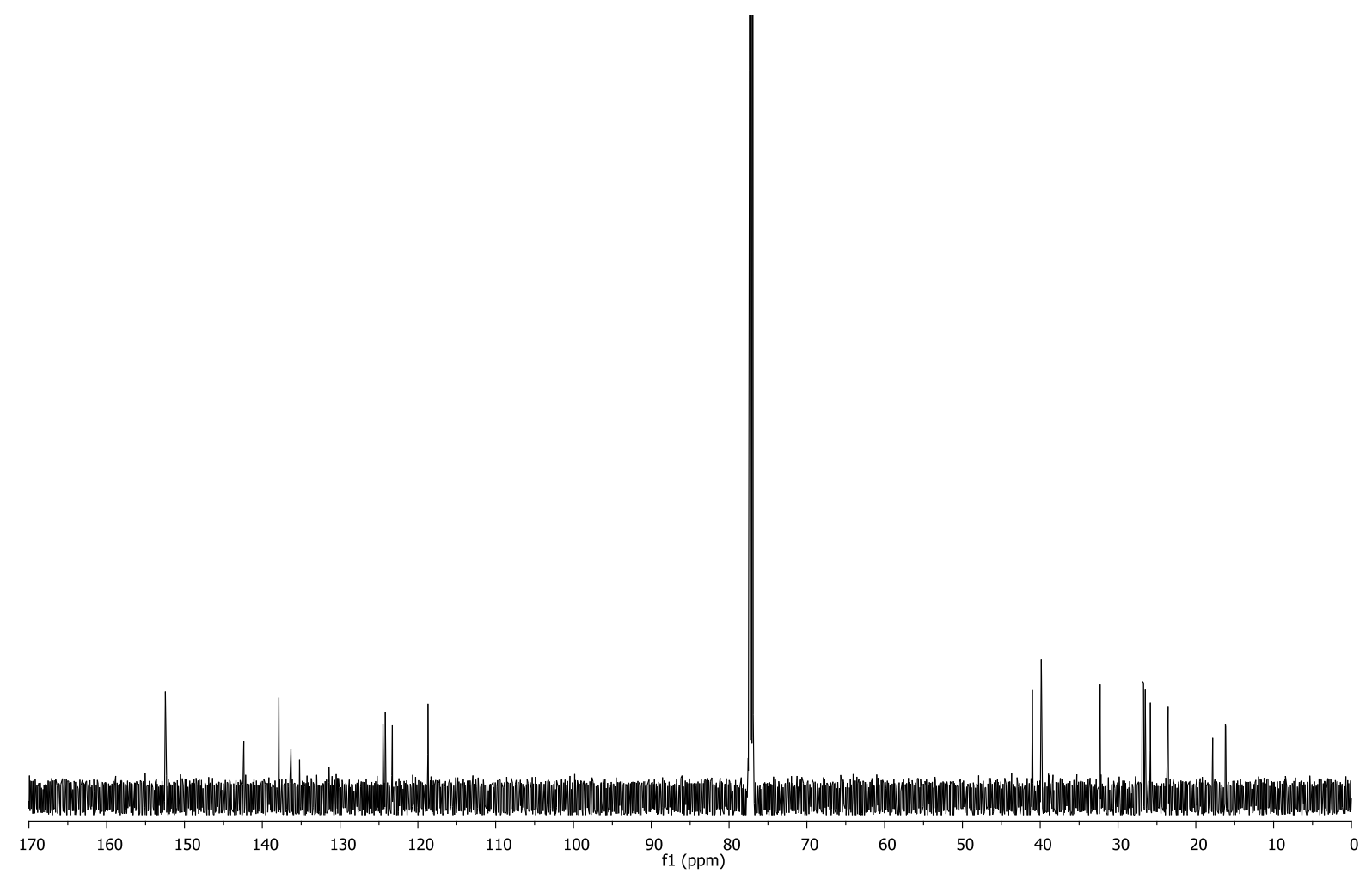

${ }^{13} \mathrm{C}$ NMR spectrum $\left(150 \mathrm{MHz}, \mathrm{CDCl}_{3}\right)$ of 89. 
$N, N$-Dimethyl-9-((2E,6E,10E)-3,7,11,15-tetramethylhexadeca-2,6,10,14-tetraen-1-yl)9H-purin-6-amine (90)

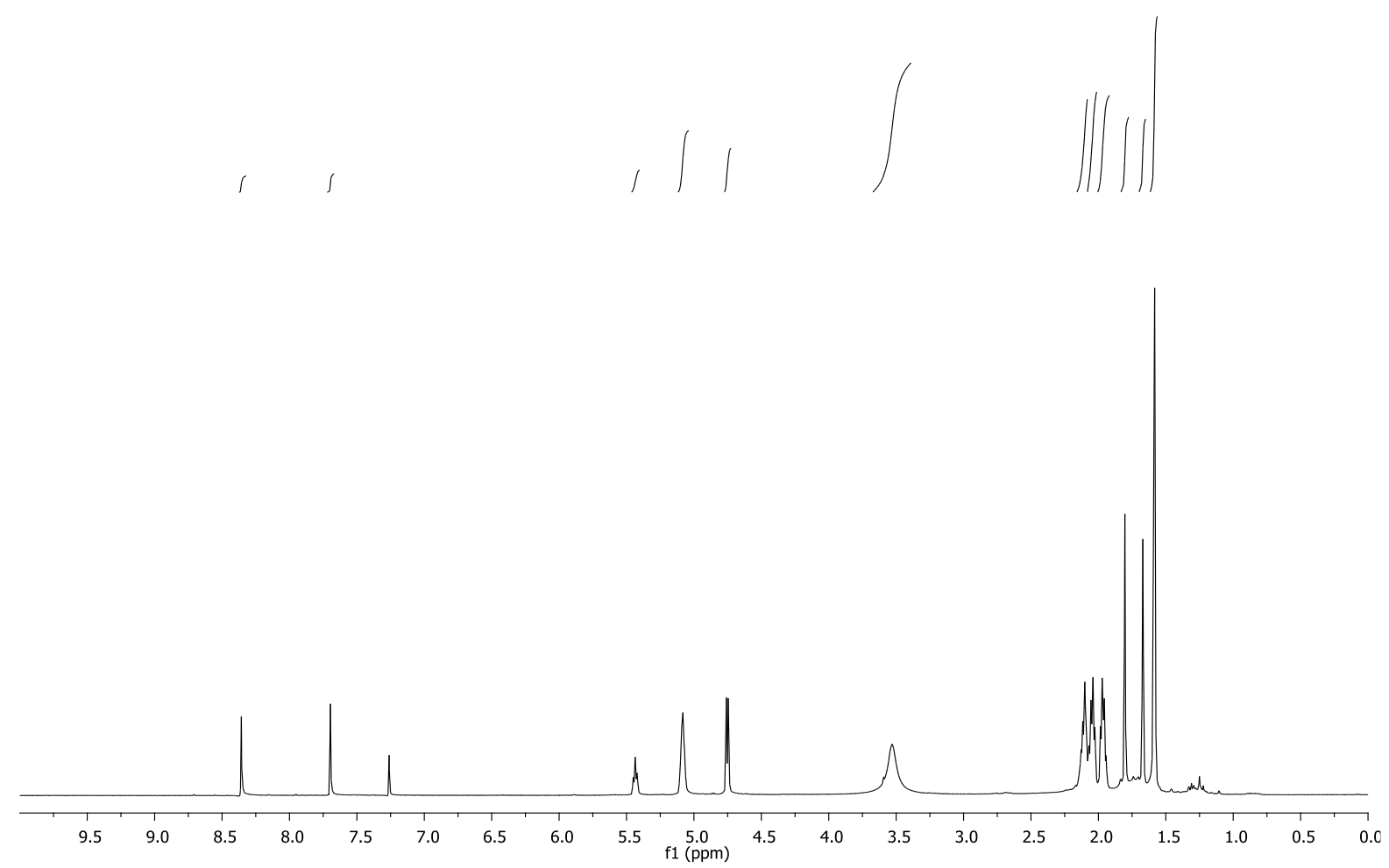

${ }^{1} \mathrm{H}$ NMR spectrum $\left(500 \mathrm{MHz}, \mathrm{CDCl}_{3}\right)$ of 90.

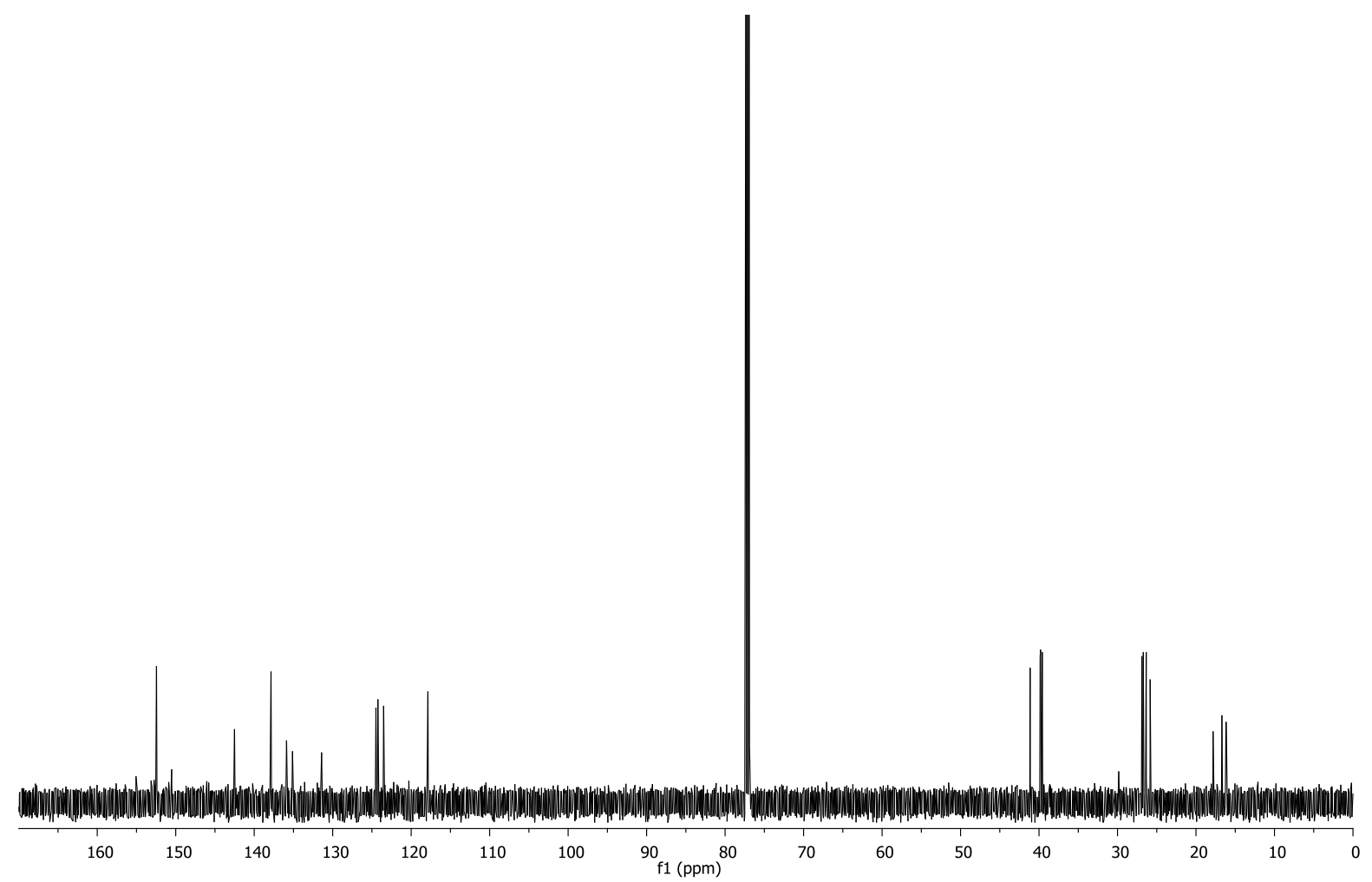

${ }^{13} \mathrm{C}$ NMR spectrum $\left(150 \mathrm{MHz}, \mathrm{CDCl}_{3}\right)$ of 90. 
E)-6-Chloro-7-(3,7-dimethylocta-2,6-dien-1-yl)-7H-purine (94)

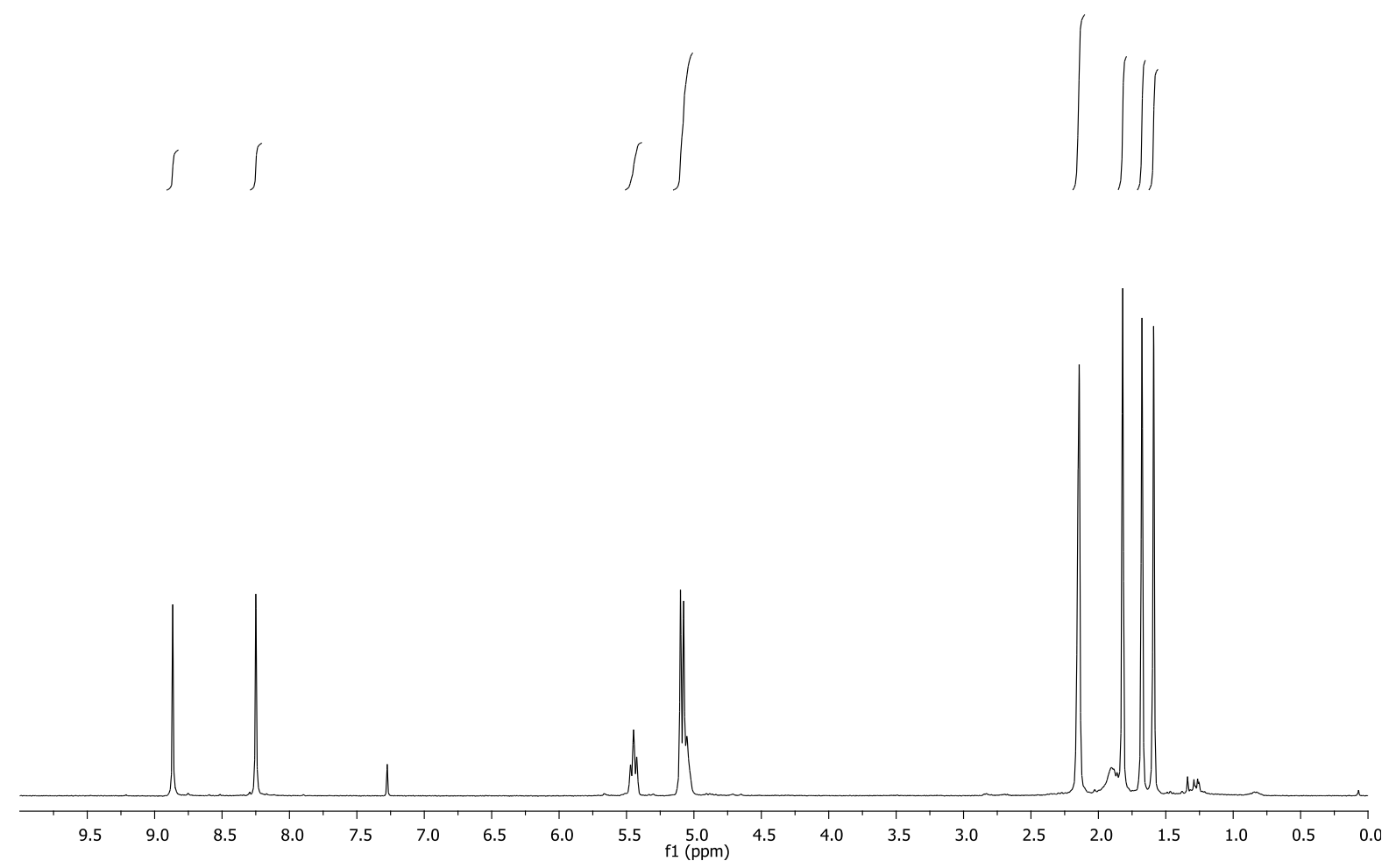

${ }^{1} \mathrm{H}$ NMR spectrum $\left(300 \mathrm{MHz}, \mathrm{CDCl}_{3}\right)$ of 94.

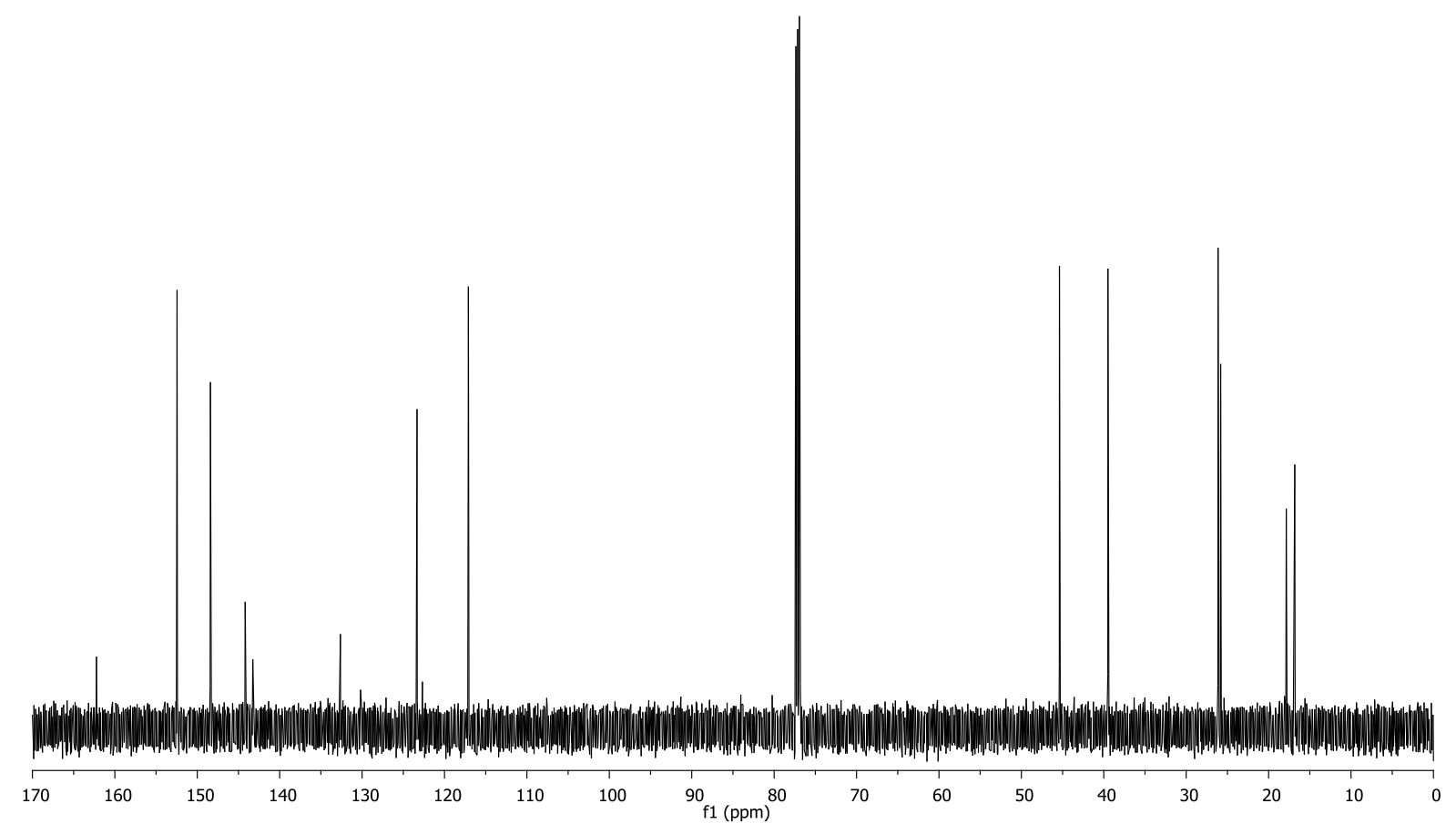

${ }^{13} \mathrm{C}$ NMR spectrum $\left(150 \mathrm{MHz}, \mathrm{CDCl}_{3}\right)$ of 94. 
(E)-6-Chloro-9-(3,7-dimethylocta-2,6-dien-1-yl)-9H-purine (95)

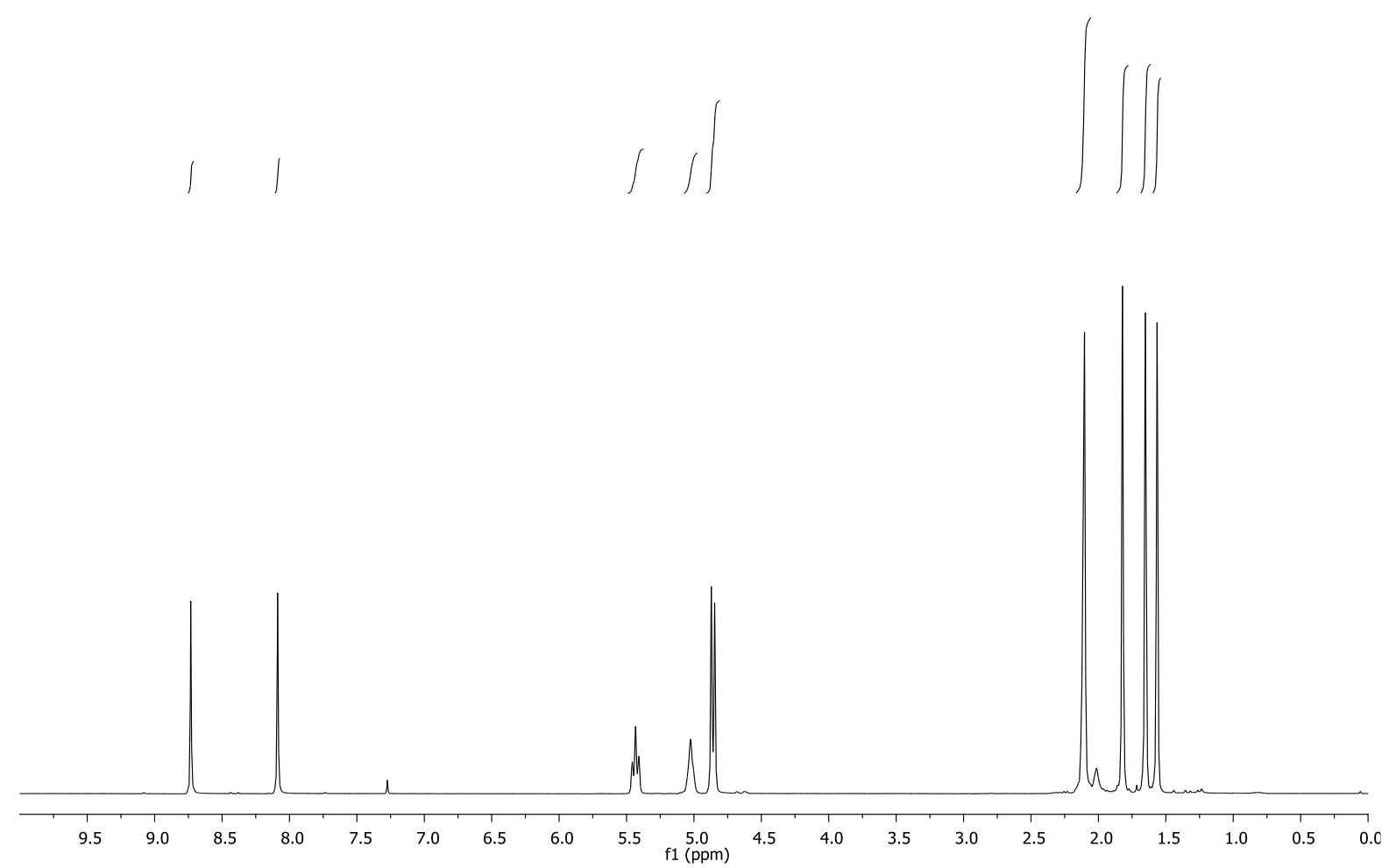

${ }^{1} \mathrm{H}$ NMR spectrum $\left(300 \mathrm{MHz}, \mathrm{CDCl}_{3}\right)$ of 95.

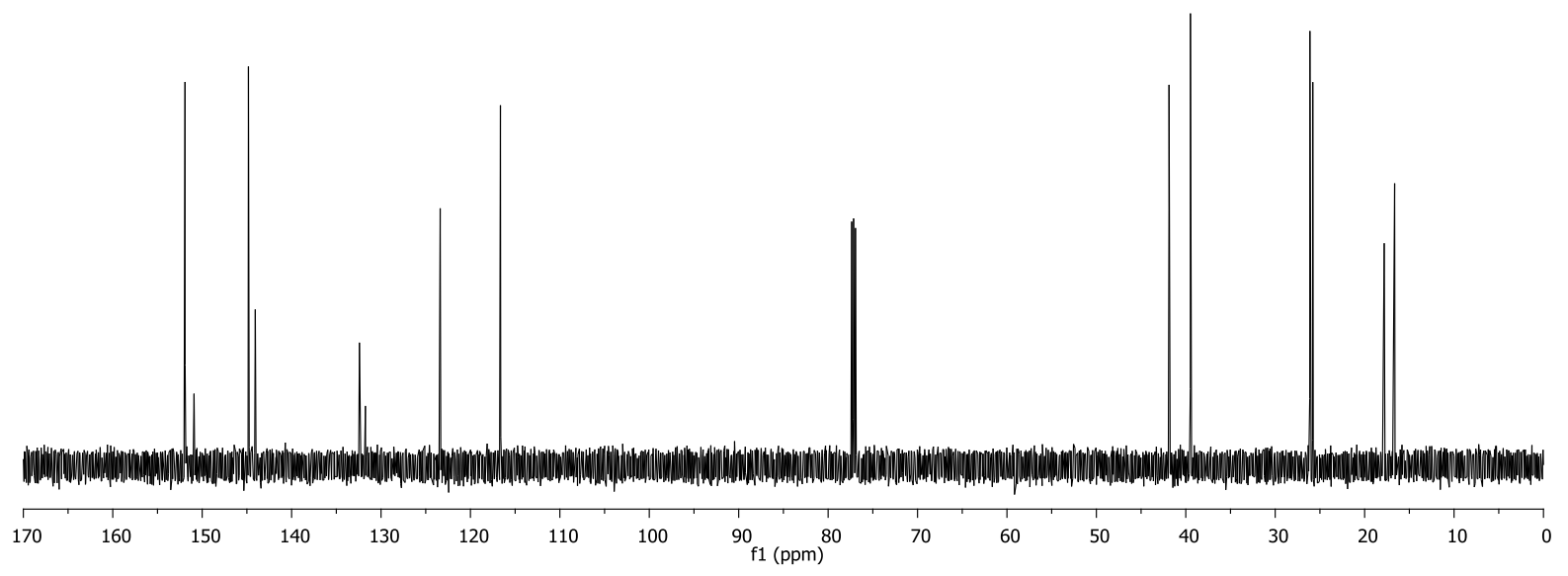

${ }^{13} \mathrm{C}$ NMR spectrum $\left(150 \mathrm{MHz}, \mathrm{CDCl}_{3}\right)$ of 95. 
6-Chloro-7-((2E,6E)-3,7,11-trimethyldodeca-2,6,10-trien-1-yl)-9H-purine (96)

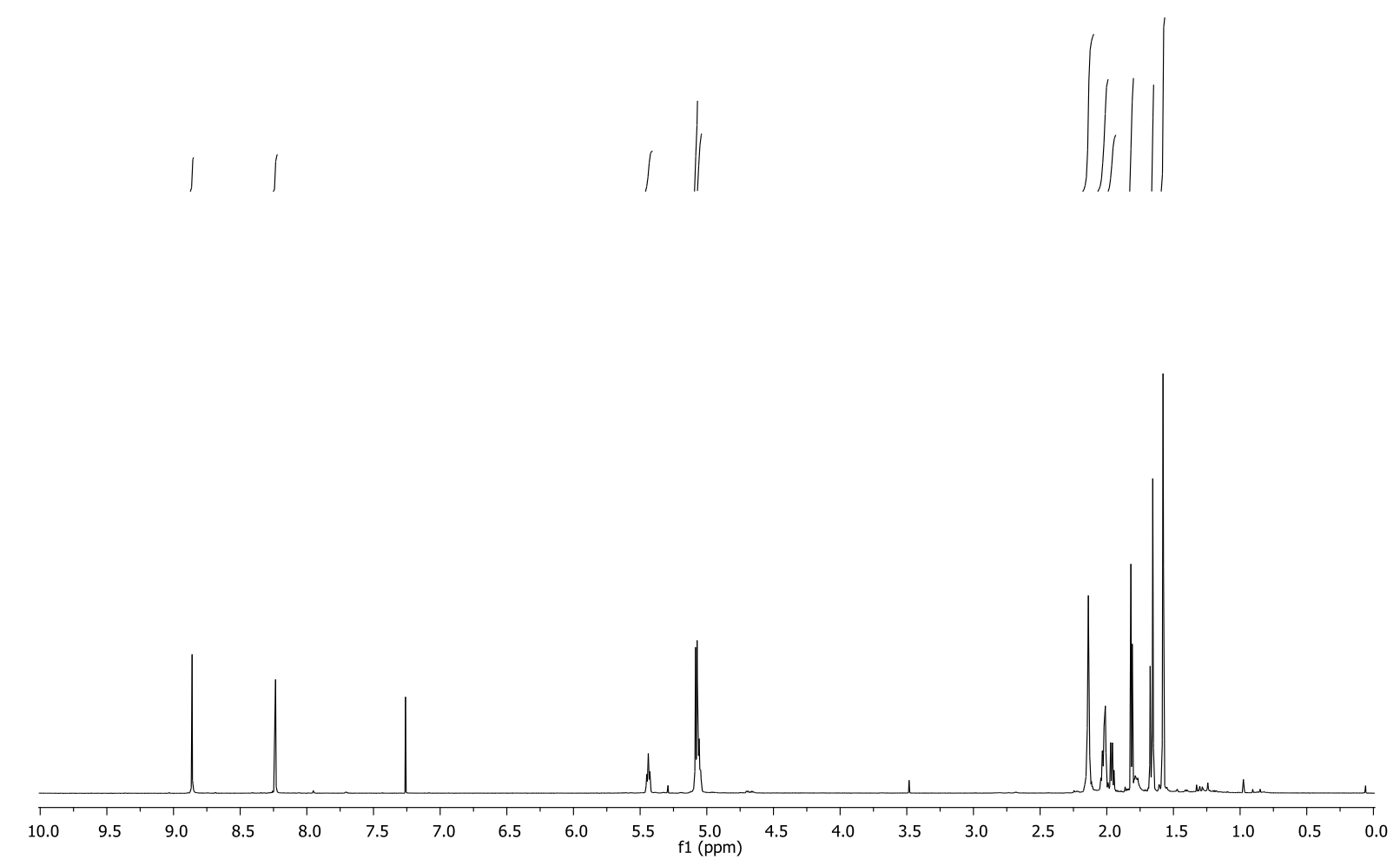

${ }^{1} \mathrm{H}$ NMR spectrum $\left(600 \mathrm{MHz}, \mathrm{CDCl}_{3}\right)$ of 96.

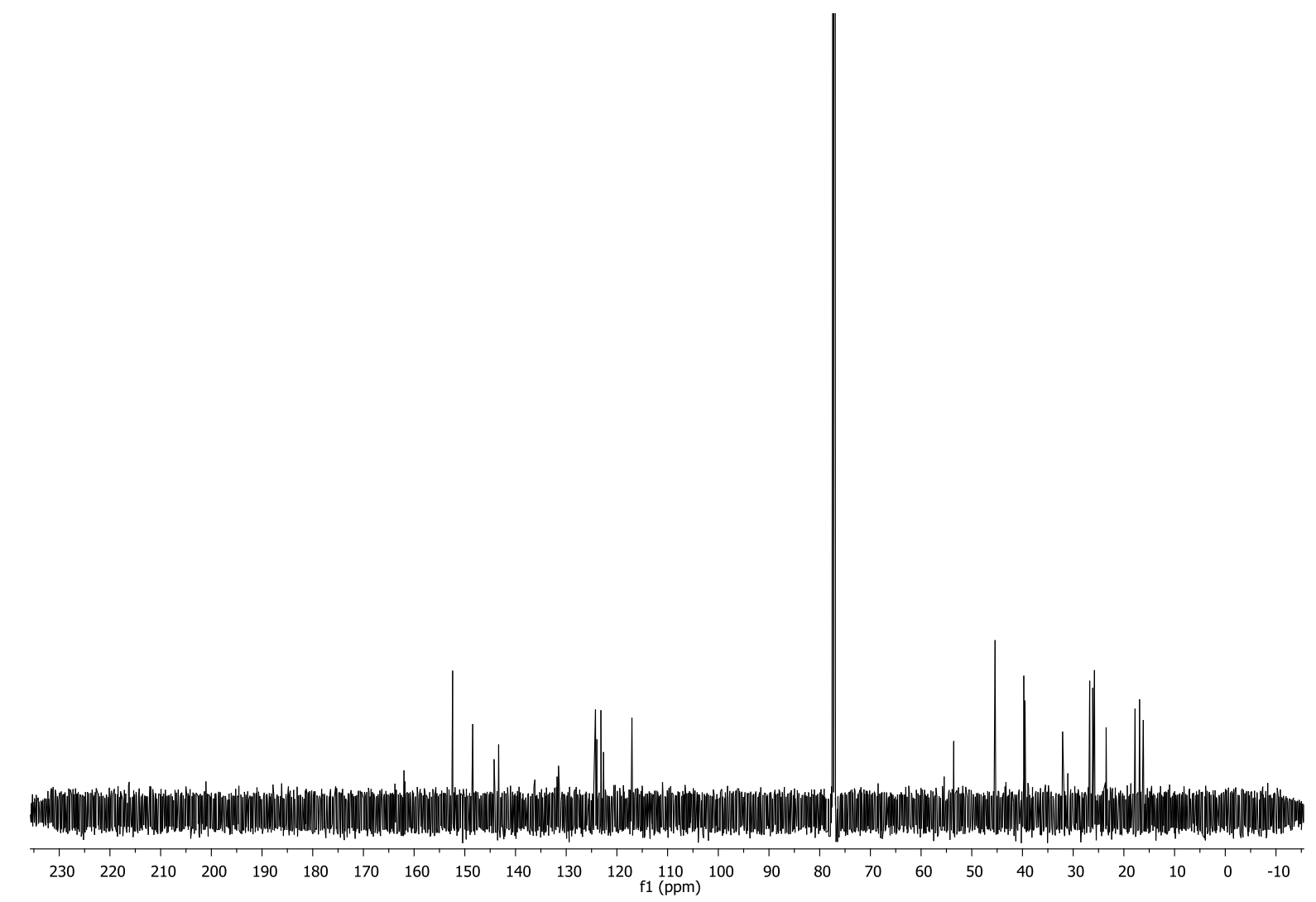

${ }^{13} \mathrm{C}$ NMR spectrum $\left(150 \mathrm{MHz}, \mathrm{CDCl}_{3}\right)$ of 96. 
6-Chloro-9-((6E)-3,7,11-trimethyldodeca-2,6,10-trien-1-yl)-9H-purine (97)

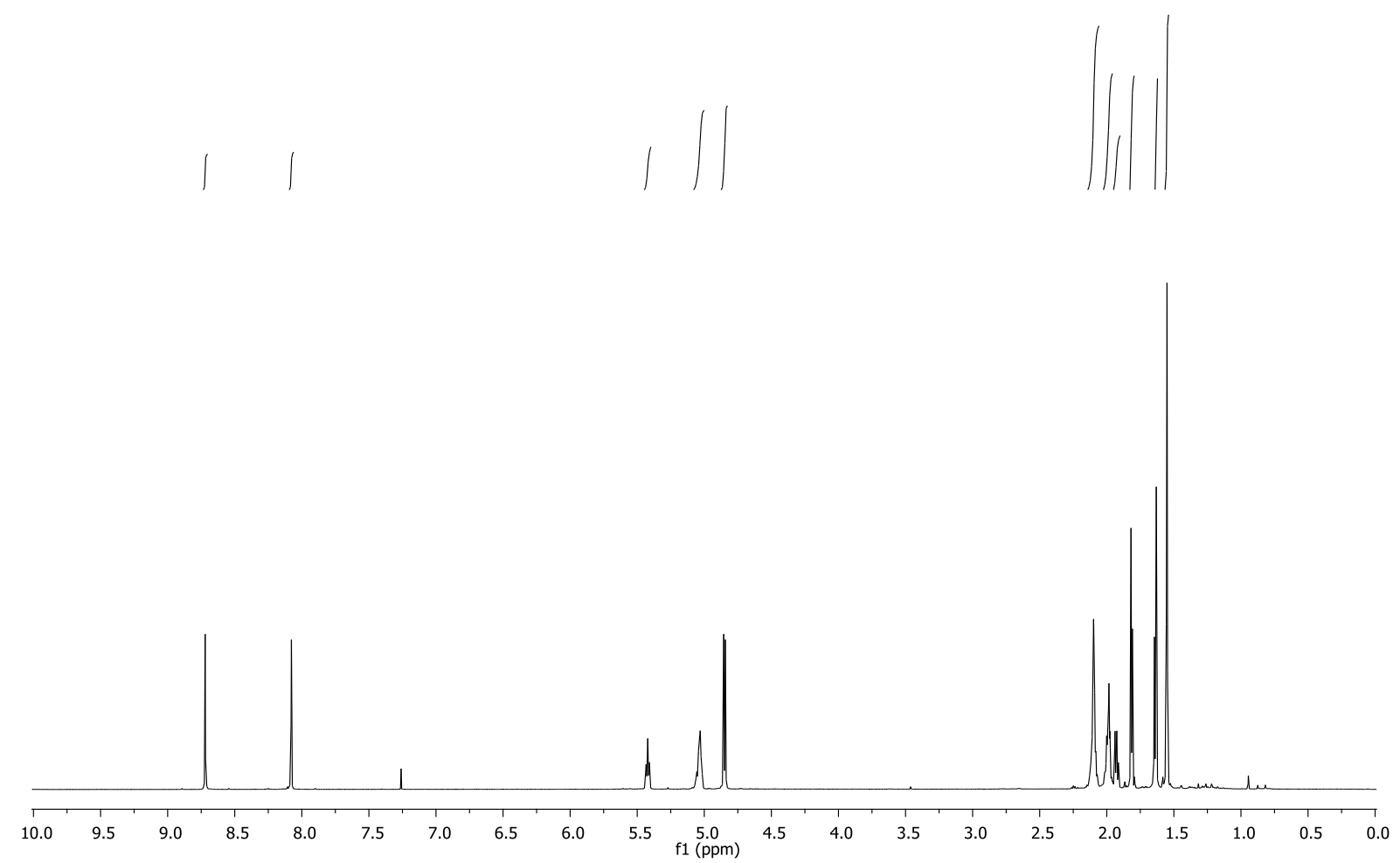

${ }^{1} \mathrm{H}$ NMR spectrum $\left(600 \mathrm{MHz}, \mathrm{CDCl}_{3}\right)$ of 97.

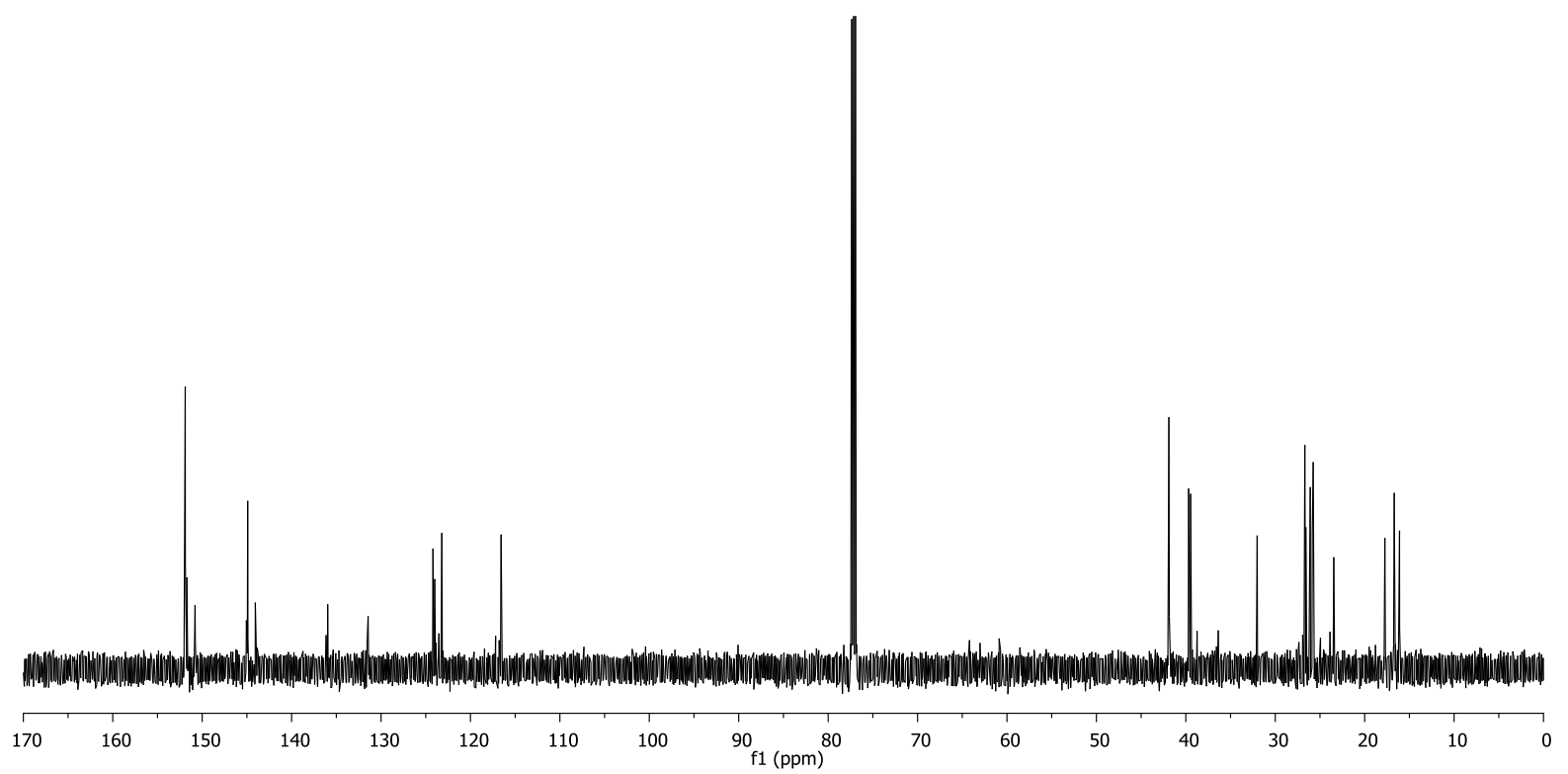

${ }^{13} \mathrm{C}$ NMR spectrum $\left(150 \mathrm{MHz}, \mathrm{CDCl}_{3}\right)$ of 97. 
6-Chloro-7-((2Z,6E,10E)-3,7,11,15-tetramethylhexadeca-2,6,10,14-tetraen-1-yl)-7Hpurine (98)

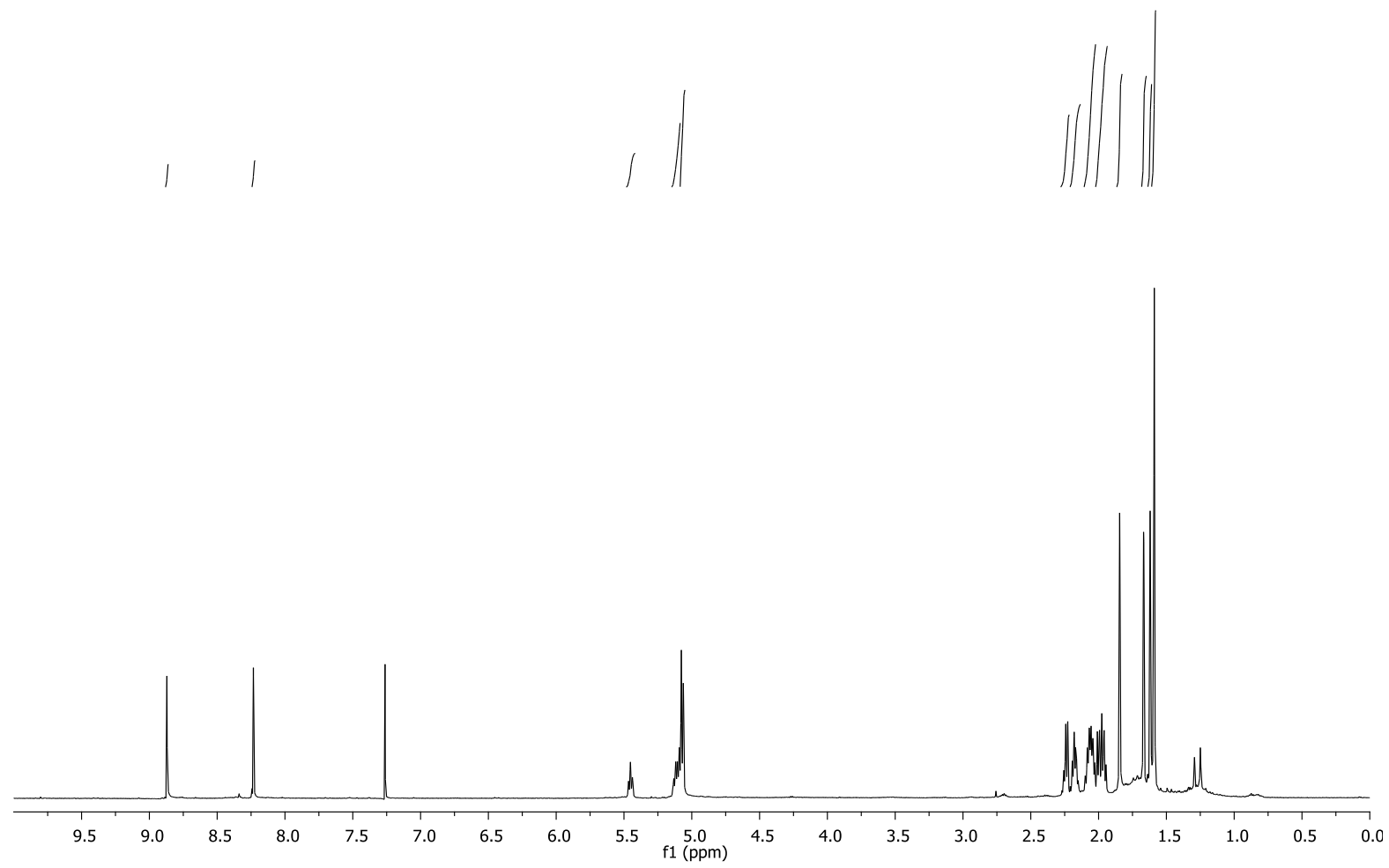

${ }^{1} \mathrm{H}$ NMR spectrum $\left(500 \mathrm{MHz}, \mathrm{CDCl}_{3}\right)$ of 98.

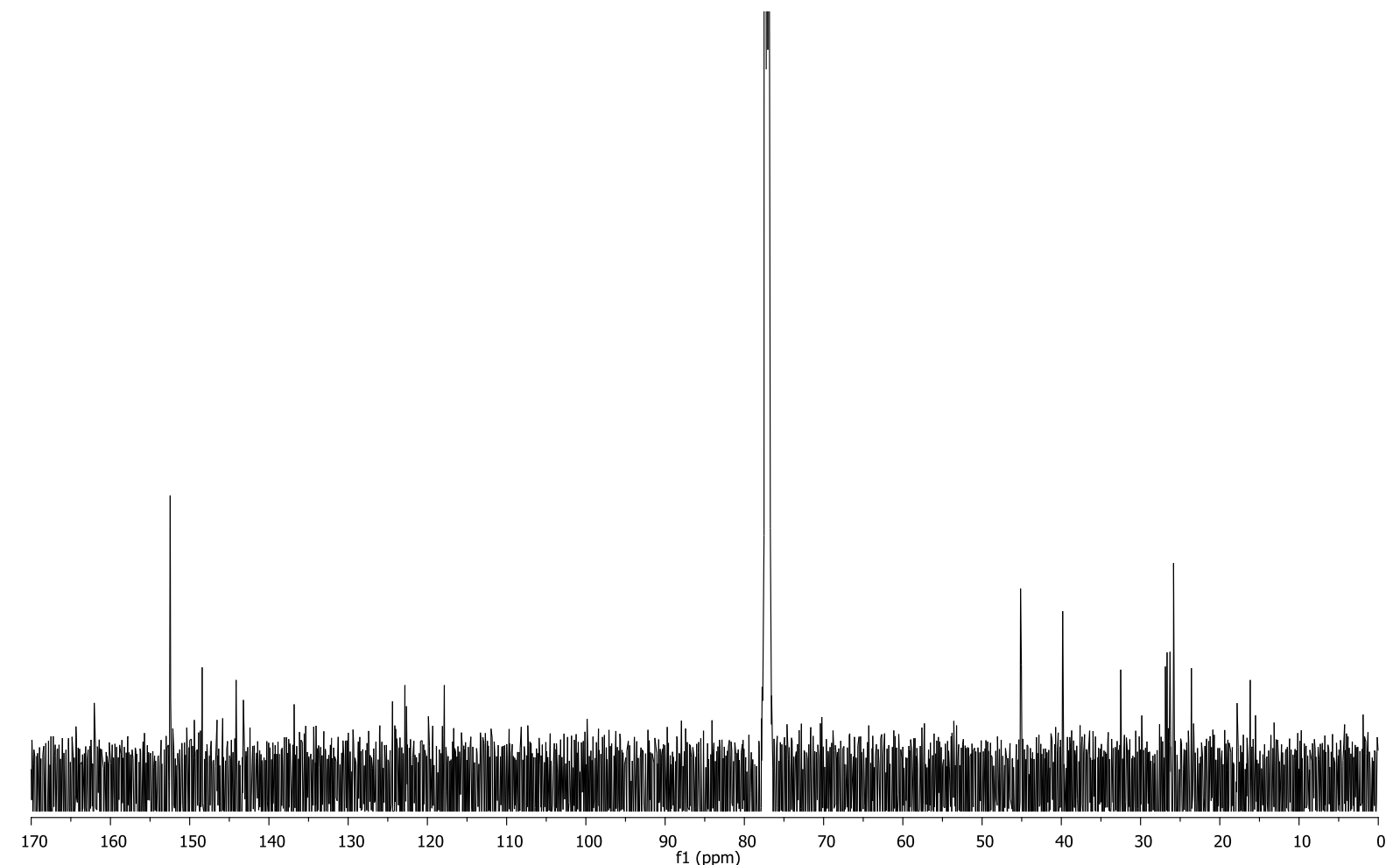

${ }^{13} \mathrm{C}$ NMR spectrum $\left(150 \mathrm{MHz}, \mathrm{CDCl}_{3}\right)$ of $\mathbf{9 8 .}$ 
6-Chloro-7-((2E,6E,10E)-3,7,11,15-tetramethylhexadeca-2,6,10,14-tetraen-1-yl)-7Hpurine (99)

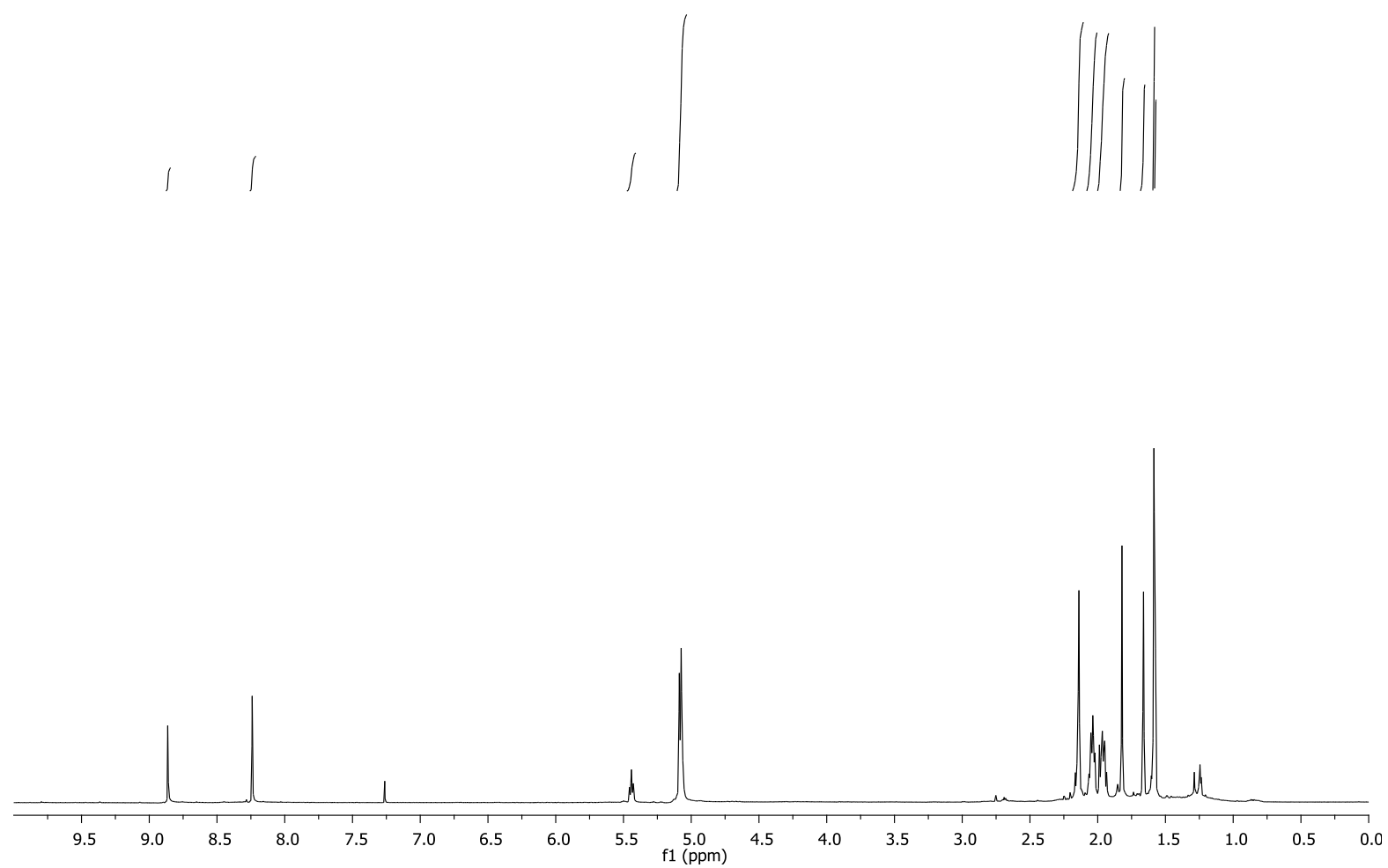

${ }^{1} \mathrm{H}$ NMR spectrum $\left(500 \mathrm{MHz}, \mathrm{CDCl}_{3}\right)$ of 99.



${ }^{13} \mathrm{C}$ NMR spectrum $\left(150 \mathrm{MHz}, \mathrm{CDCl}_{3}\right)$ of 99. 
6-Chloro-9-((2E,6E,10E)-3,7,11,15-tetramethylhexadeca-2,6,10,14-tetraen-1-yl)-9Hpurine (100)

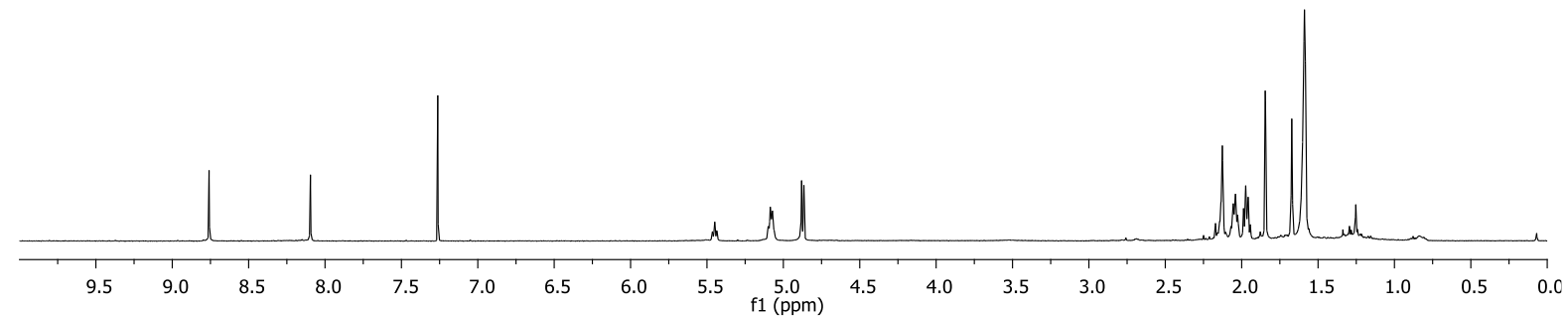

${ }^{1} \mathrm{H}$ NMR spectrum $\left(500 \mathrm{MHz}, \mathrm{CDCl}_{3}\right)$ of $\mathbf{1 0 0}$.

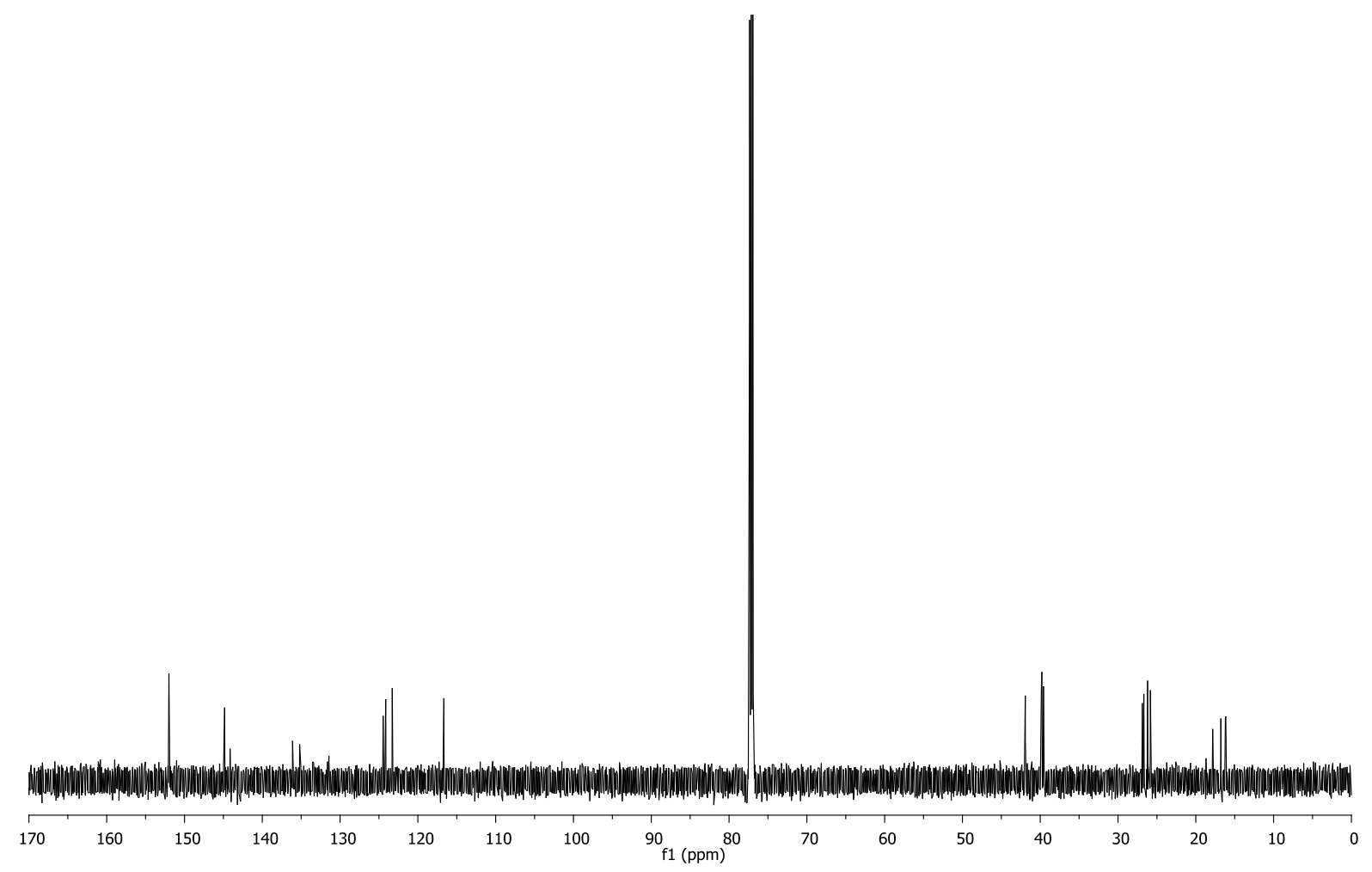

${ }^{13} \mathrm{C}$ NMR spectrum $\left(150 \mathrm{MHz}, \mathrm{CDCl}_{3}\right)$ of $\mathbf{1 0 0}$. 
3,7-bis((E)-3,7-Dimethylocta-2,6-dien-1-yl)-3,7-dihydro-1H-purine-2,6-dione (109)

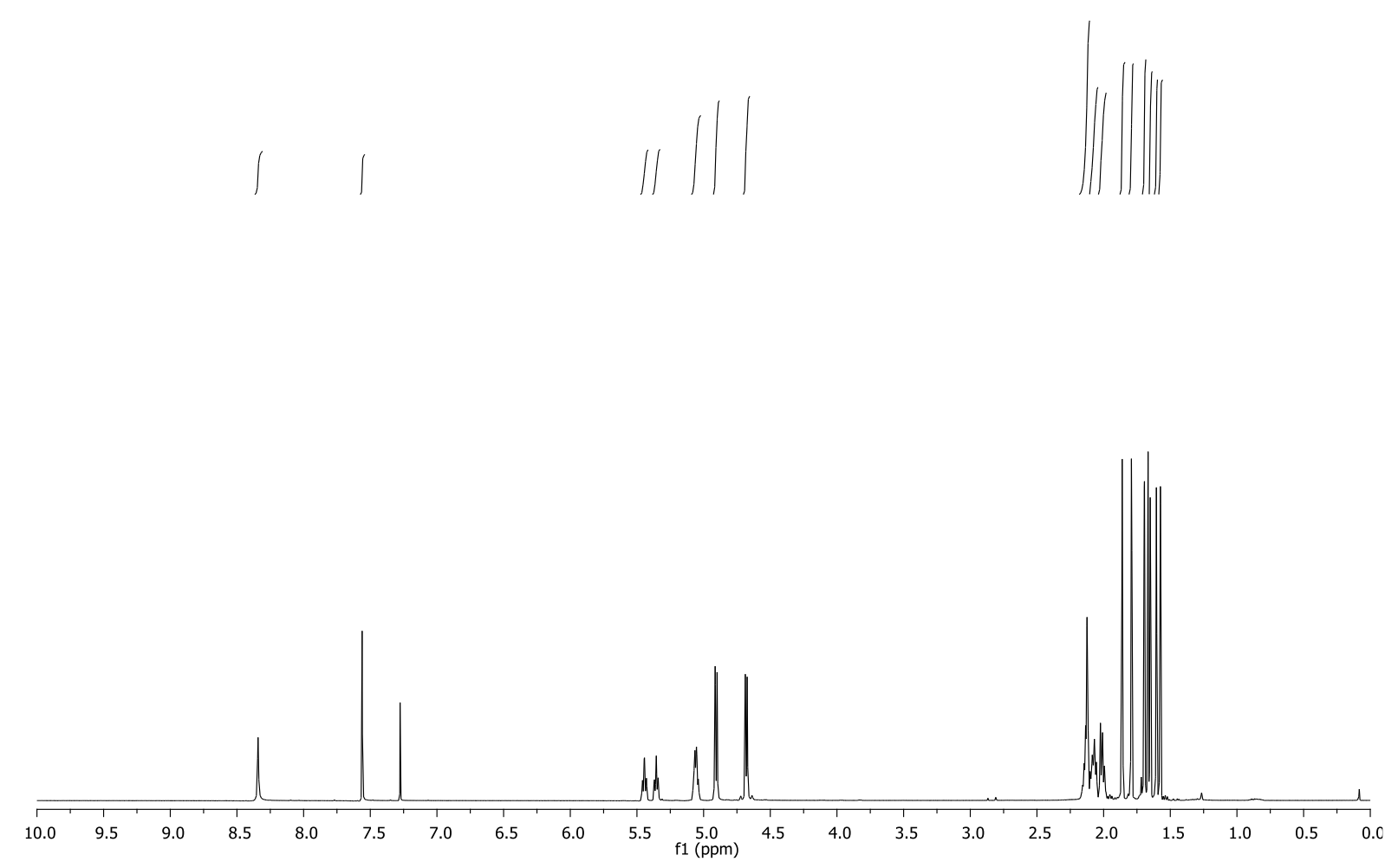

${ }^{1} \mathrm{H}$ NMR spectrum $\left(600 \mathrm{MHz}, \mathrm{CDCl}_{3}\right)$ of $\mathbf{1 0 9}$.

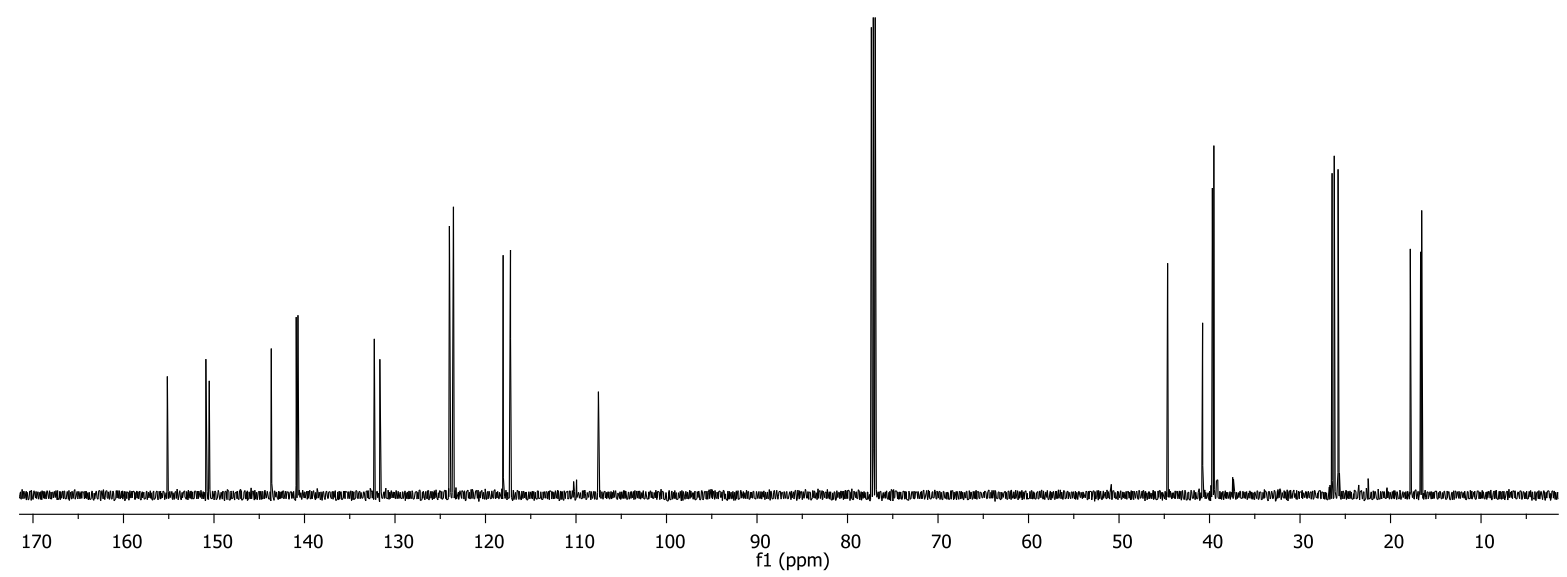

${ }^{13} \mathrm{C}$ NMR spectrum $\left(150 \mathrm{MHz}, \mathrm{CDCl}_{3}\right)$ of $\mathbf{1 0 9}$. 
3,7-bis((6E)-3,7,11-Trimethyldodeca-2,6,10-trien-1-yl)-3,7-dihydro-1H-purine-2,6dione (110)

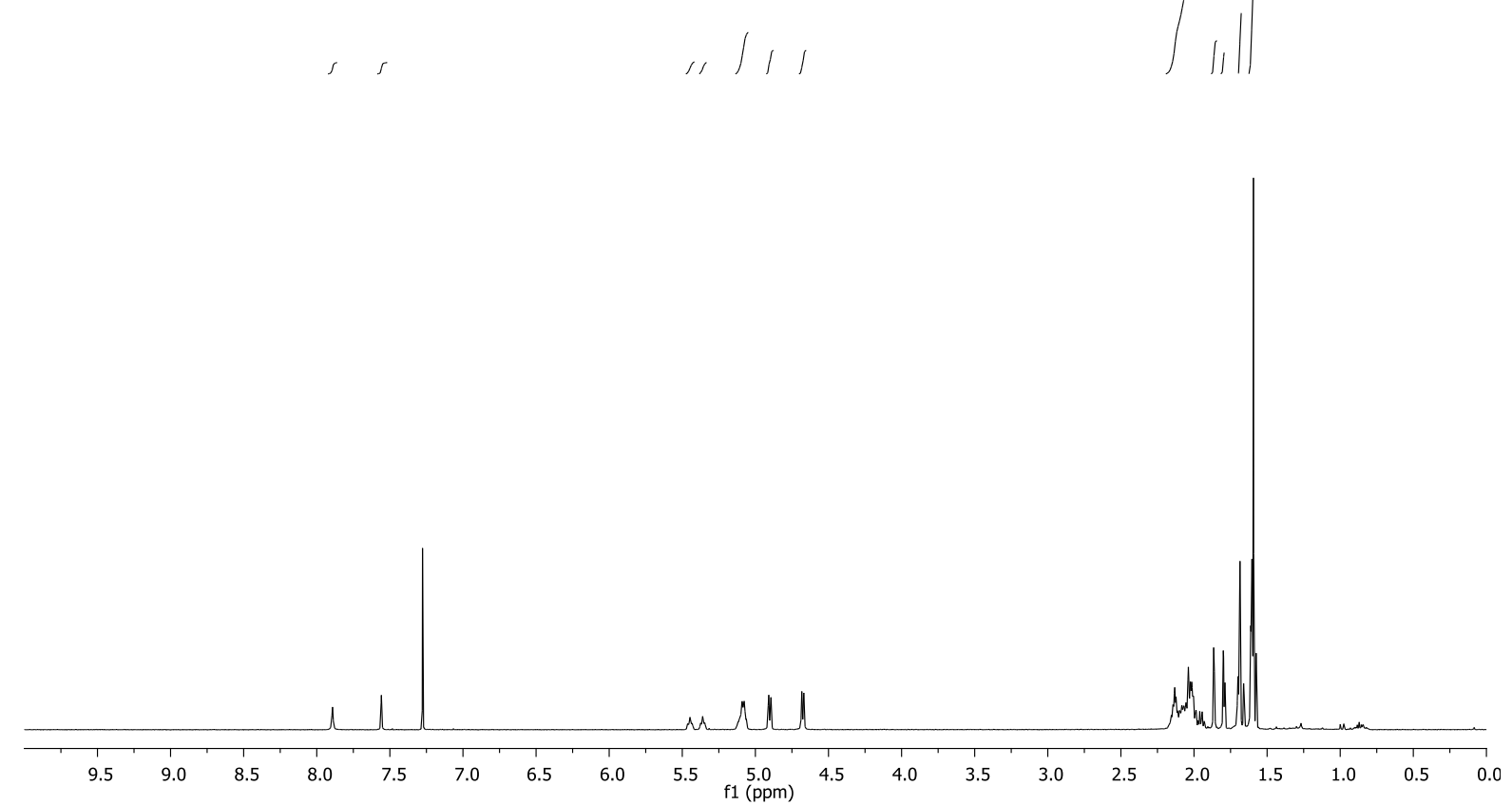

${ }^{1} \mathrm{H}$ NMR spectrum $\left(600 \mathrm{MHz}, \mathrm{CDCl}_{3}\right)$ of $\mathbf{1 1 0}$.

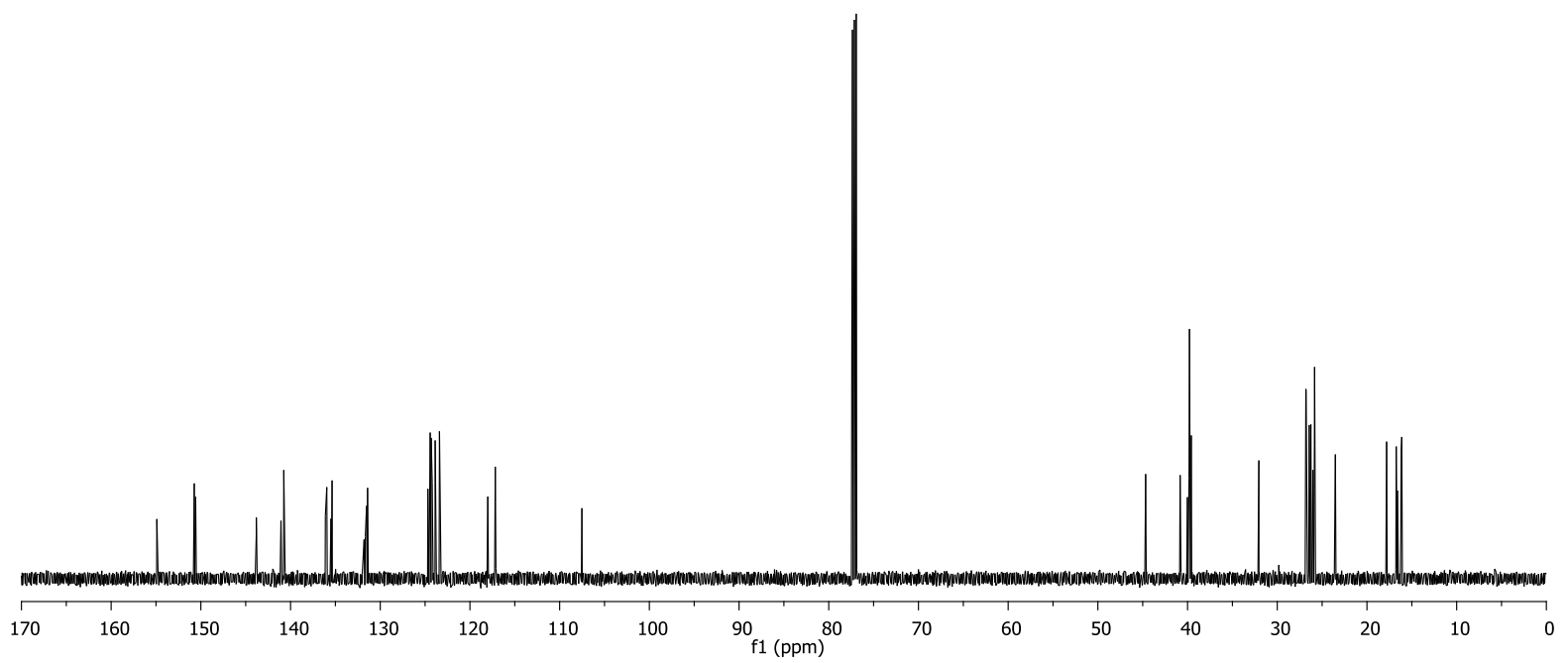

${ }^{13} \mathrm{C}$ NMR spectrum $\left(150 \mathrm{MHz}, \mathrm{CDCl}_{3}\right)$ of $\mathbf{1 1 0}$. 
(E)-7-(3,7-Dimethylocta-2,6-dien-1-yl)-3-methyl-3,7-dihydro-1H-purine-2,6-dione (111)

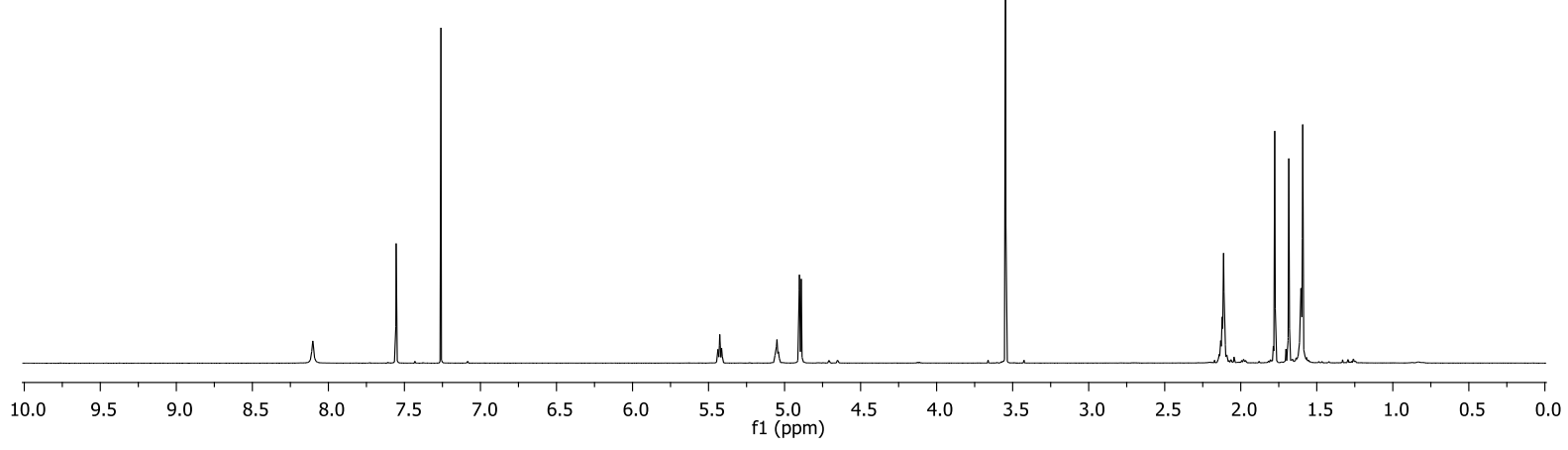

${ }^{1} \mathrm{H}$ NMR spectrum $\left(600 \mathrm{MHz}, \mathrm{CDCl}_{3}\right)$ of $\mathbf{1 1 1}$.

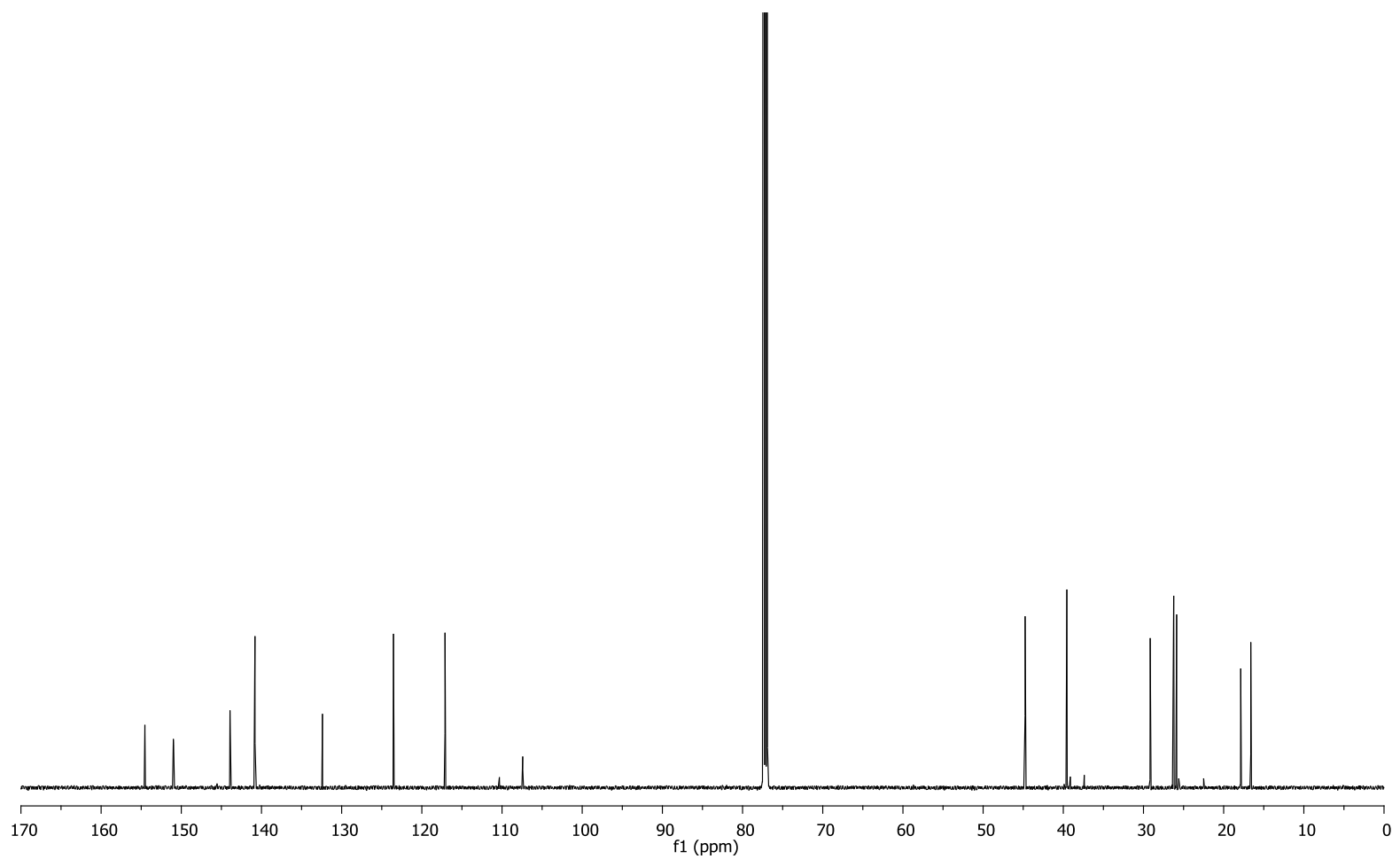

${ }^{13} \mathrm{C}$ NMR spectrum $\left(150 \mathrm{MHz}, \mathrm{CDCl}_{3}\right)$ of $\mathbf{1 1 1}$.

175 
3-Methyl-7-((2Z,6E)-3,7,11-trimethyldodeca-2,6,10-trien-1-yl)-3,7-dihydro-1H-purine2,6-dione (112)

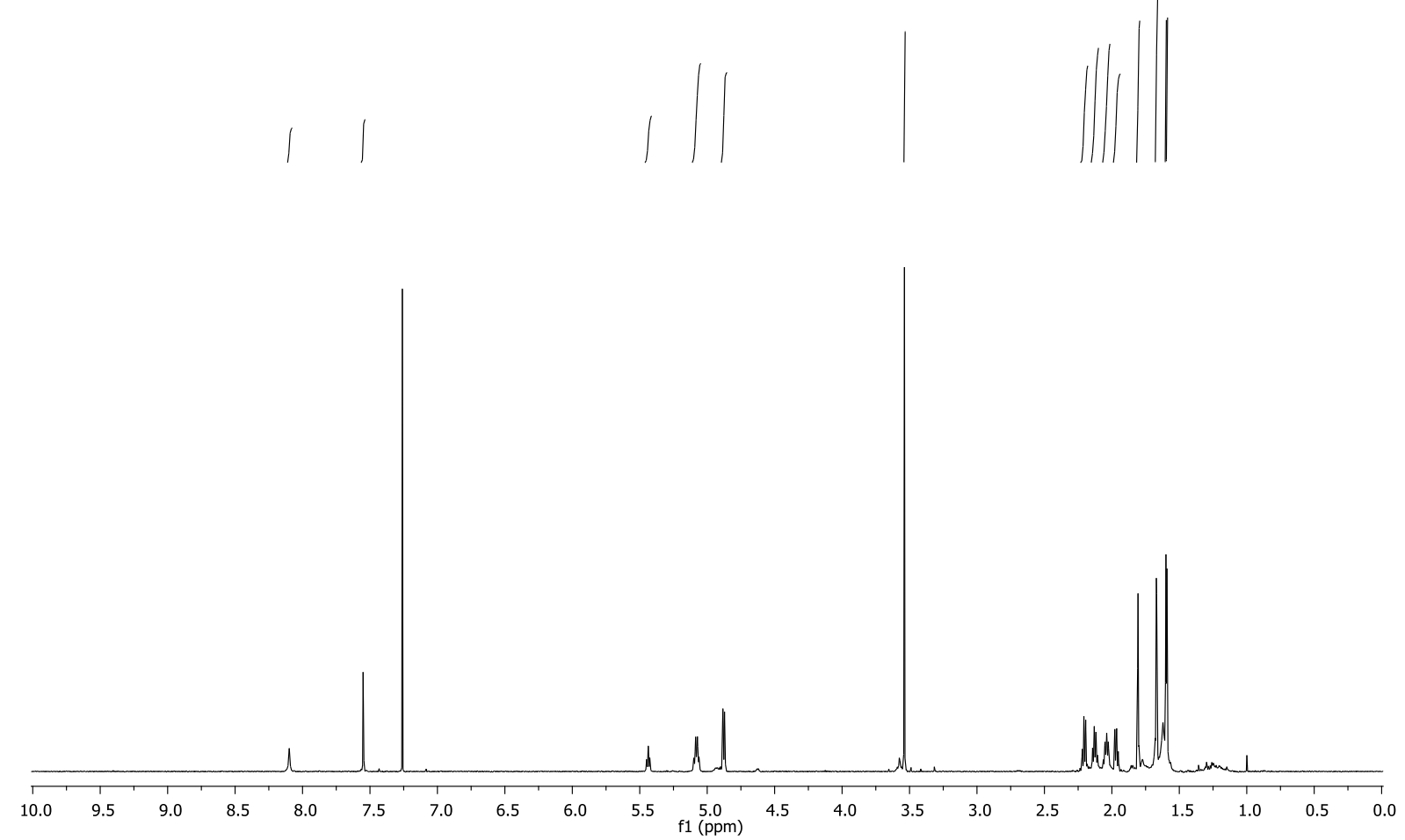

${ }^{1} \mathrm{H}$ NMR spectrum $\left(600 \mathrm{MHz}, \mathrm{CDCl}_{3}\right)$ of $\mathbf{1 1 2}$.

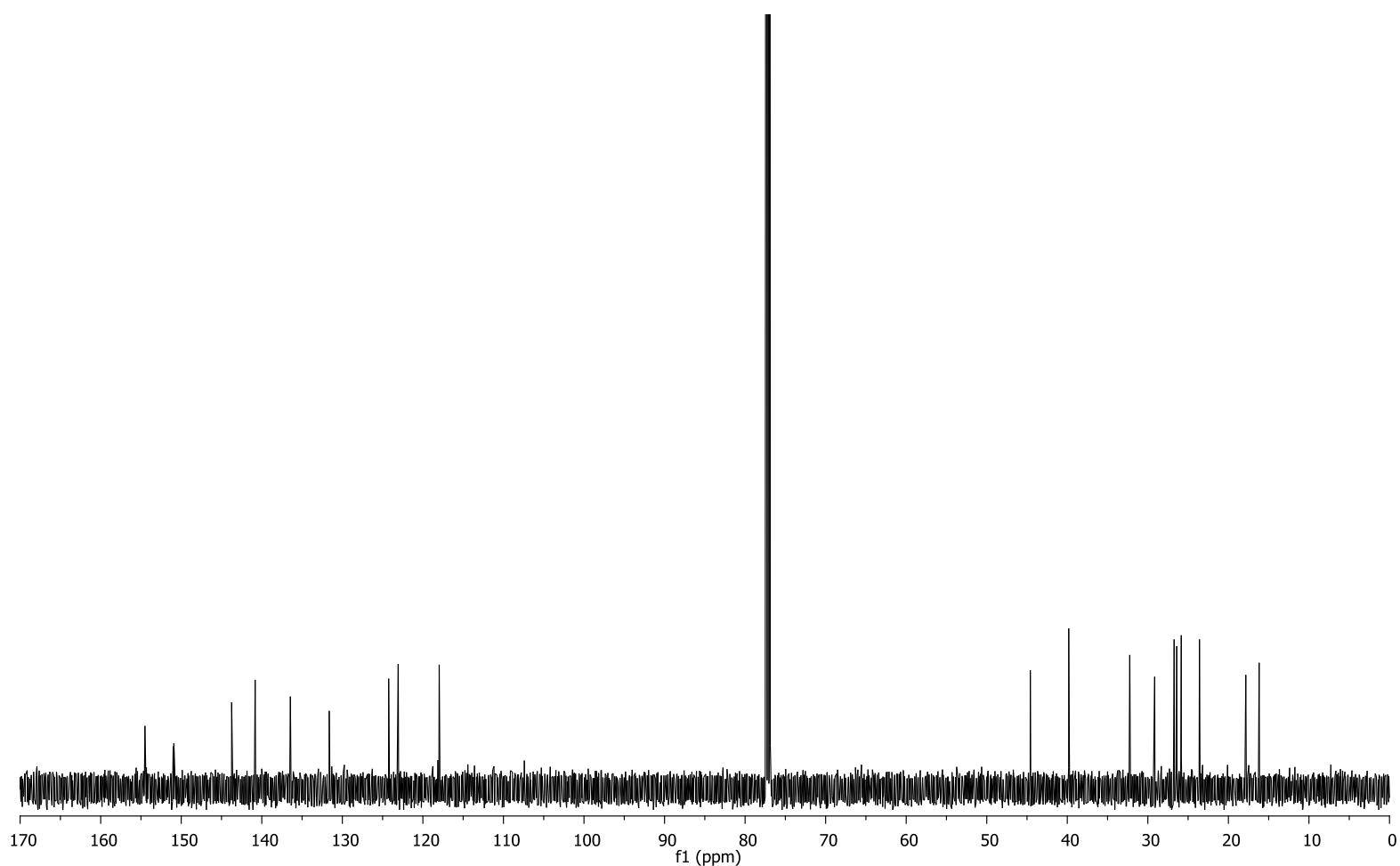

${ }^{13} \mathrm{C}$ NMR spectrum $\left(150 \mathrm{MHz}, \mathrm{CDCl}_{3}\right)$ of $\mathbf{1 1 2}$. 
3-Methyl-7-((2E,6E)-3,7,11-trimethyldodeca-2,6,10-trien-1-yl)-3,7-dihydro-1H-purine2,6-dione (113)

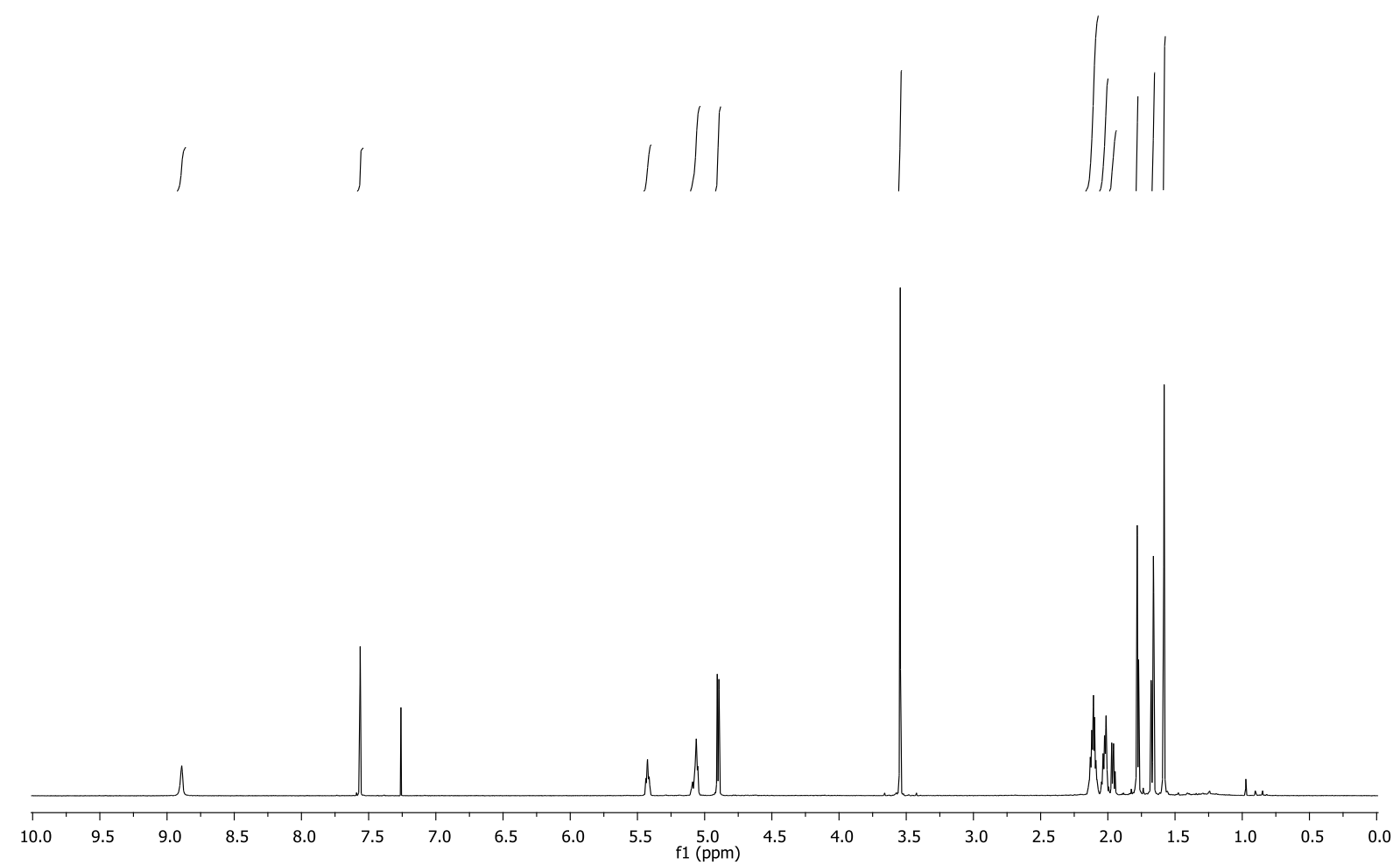

${ }^{1} \mathrm{H}$ NMR spectrum $\left(600 \mathrm{MHz}, \mathrm{CDCl}_{3}\right)$ of $\mathbf{1 1 3}$.

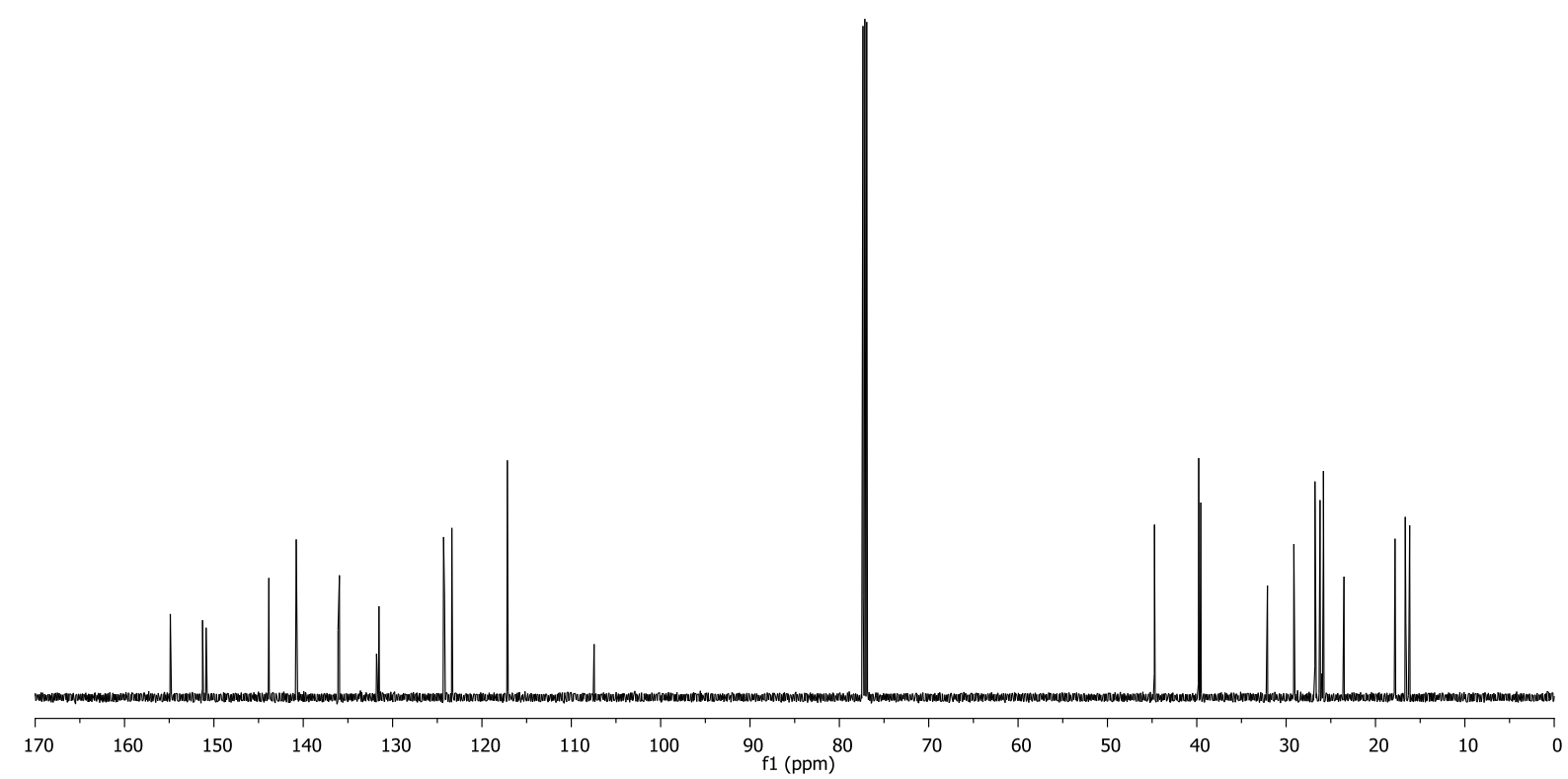

${ }^{13} \mathrm{C}$ NMR spectrum $\left(150 \mathrm{MHz}, \mathrm{CDCl}_{3}\right)$ of $\mathbf{1 1 3}$. 
3-Methyl-7-((2Z,6E,10E)-3,7,11,15-tetramethylhexadeca-2,6,10,14-tetraen-1-yl)-3,7dihydro-1H-purine-2,6-dione (114)

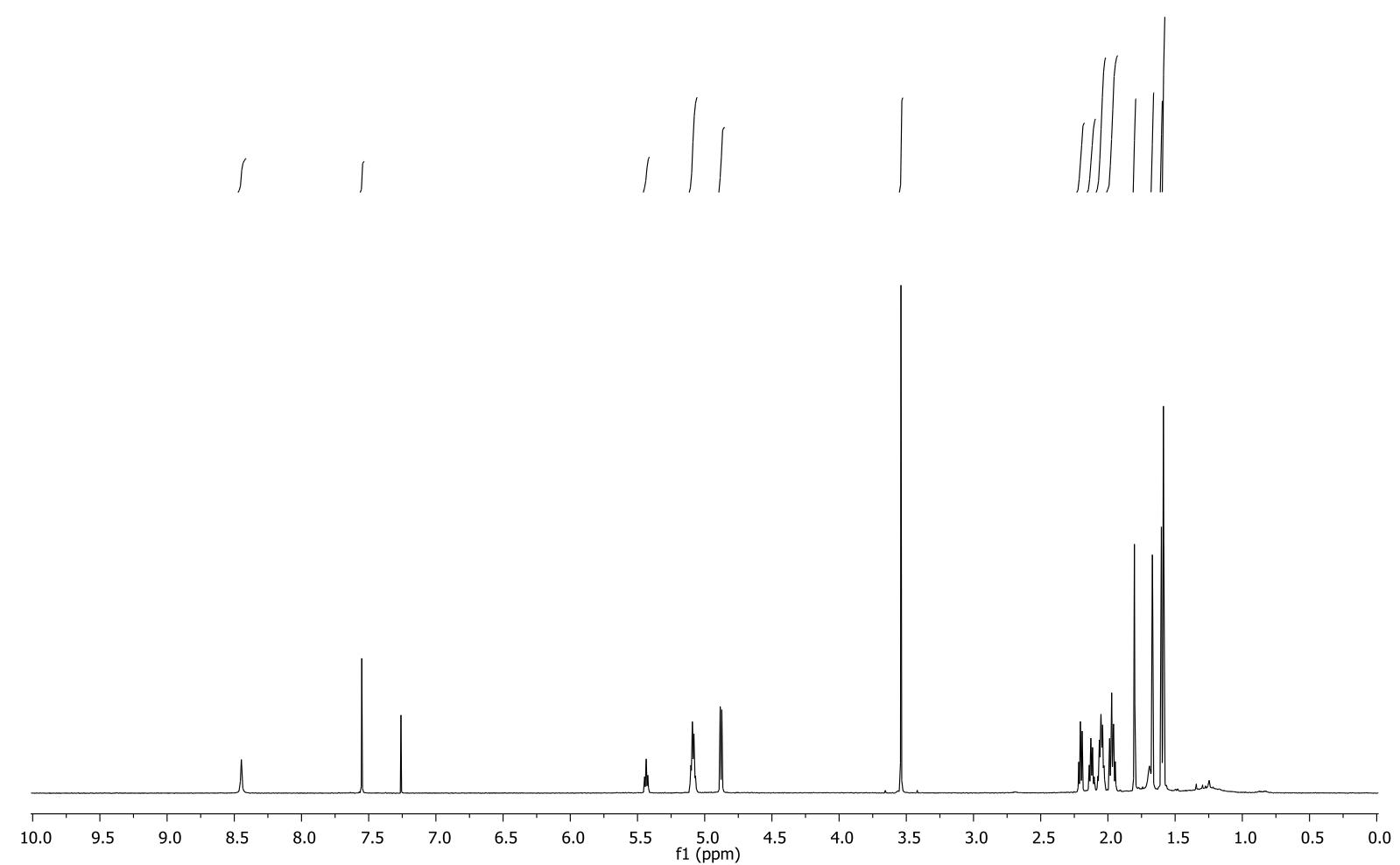

${ }^{1} \mathrm{H}$ NMR spectrum $\left(600 \mathrm{MHz}, \mathrm{CDCl}_{3}\right)$ of $\mathbf{1 1 4}$.

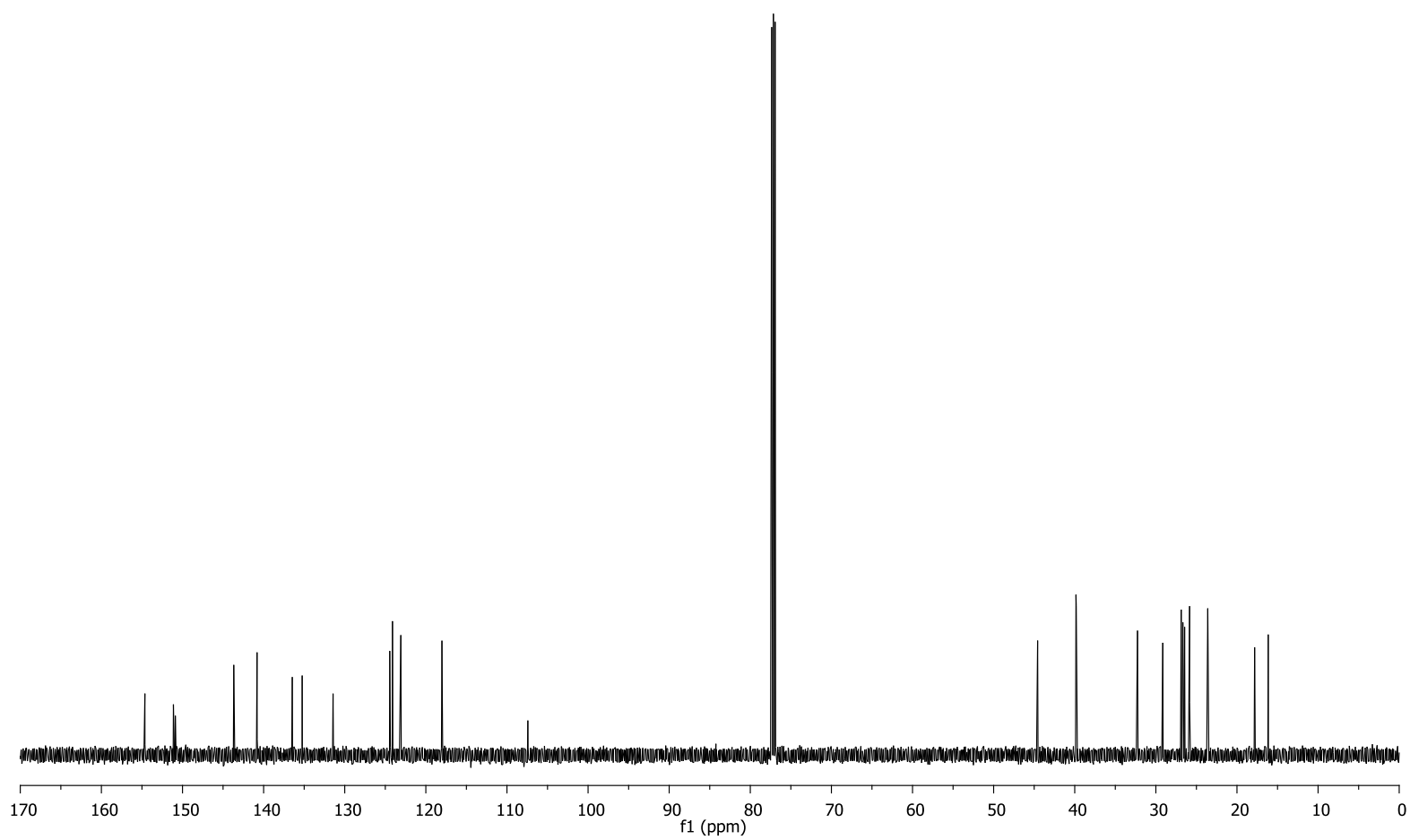

${ }^{13} \mathrm{C}$ NMR spectrum $\left(150 \mathrm{MHz}, \mathrm{CDCl}_{3}\right)$ of $\mathbf{1 1 4}$. 
3-Methyl-7-((2E,6E,10E)-3,7,11,15-tetramethylhexadeca-2,6,10,14-tetraen-1-yl)-3,7dihydro-1H-purine-2,6-dione (115)

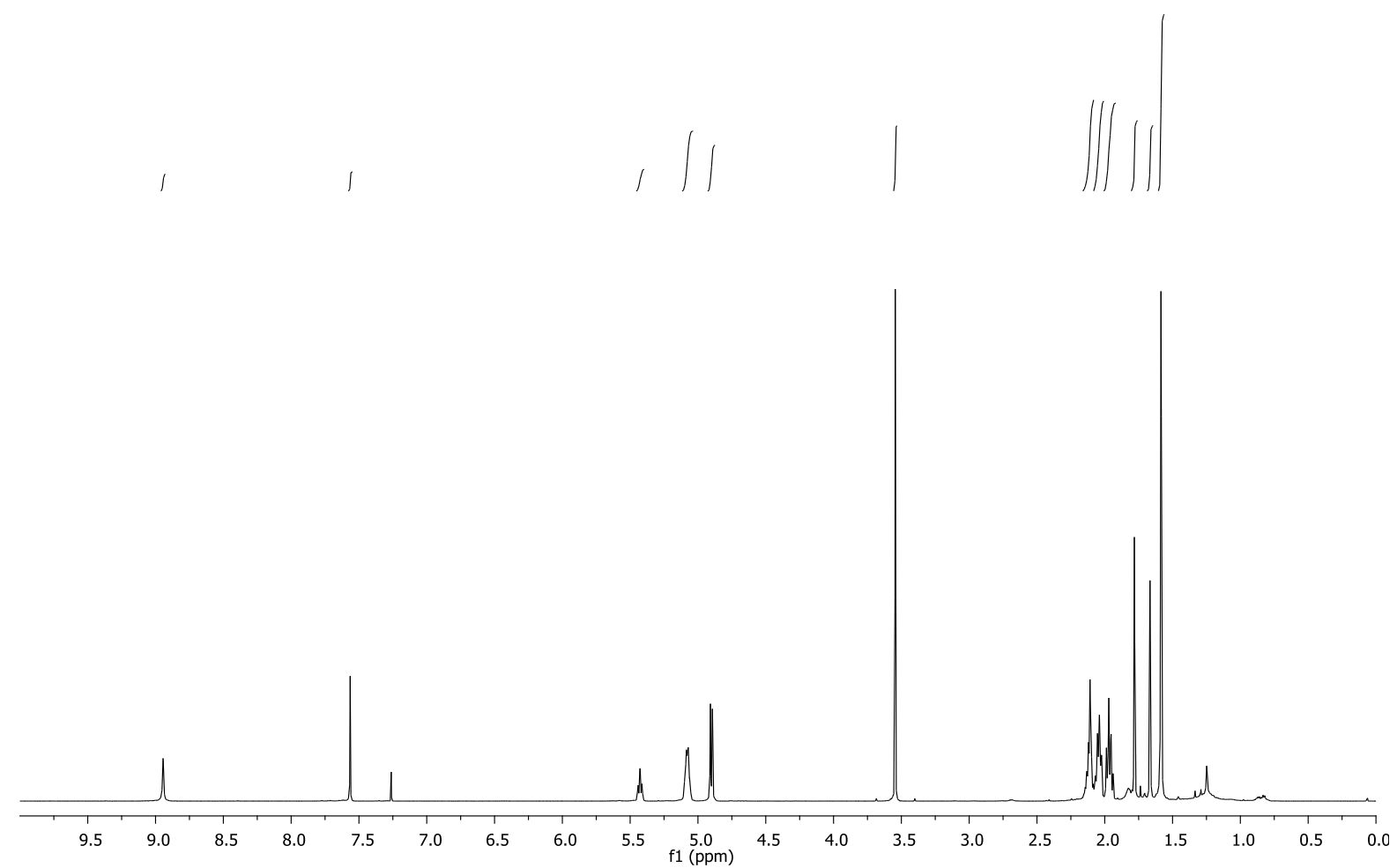

${ }^{1} \mathrm{H}$ NMR spectrum $\left(500 \mathrm{MHz}, \mathrm{CDCl}_{3}\right)$ of $\mathbf{1 1 5}$.

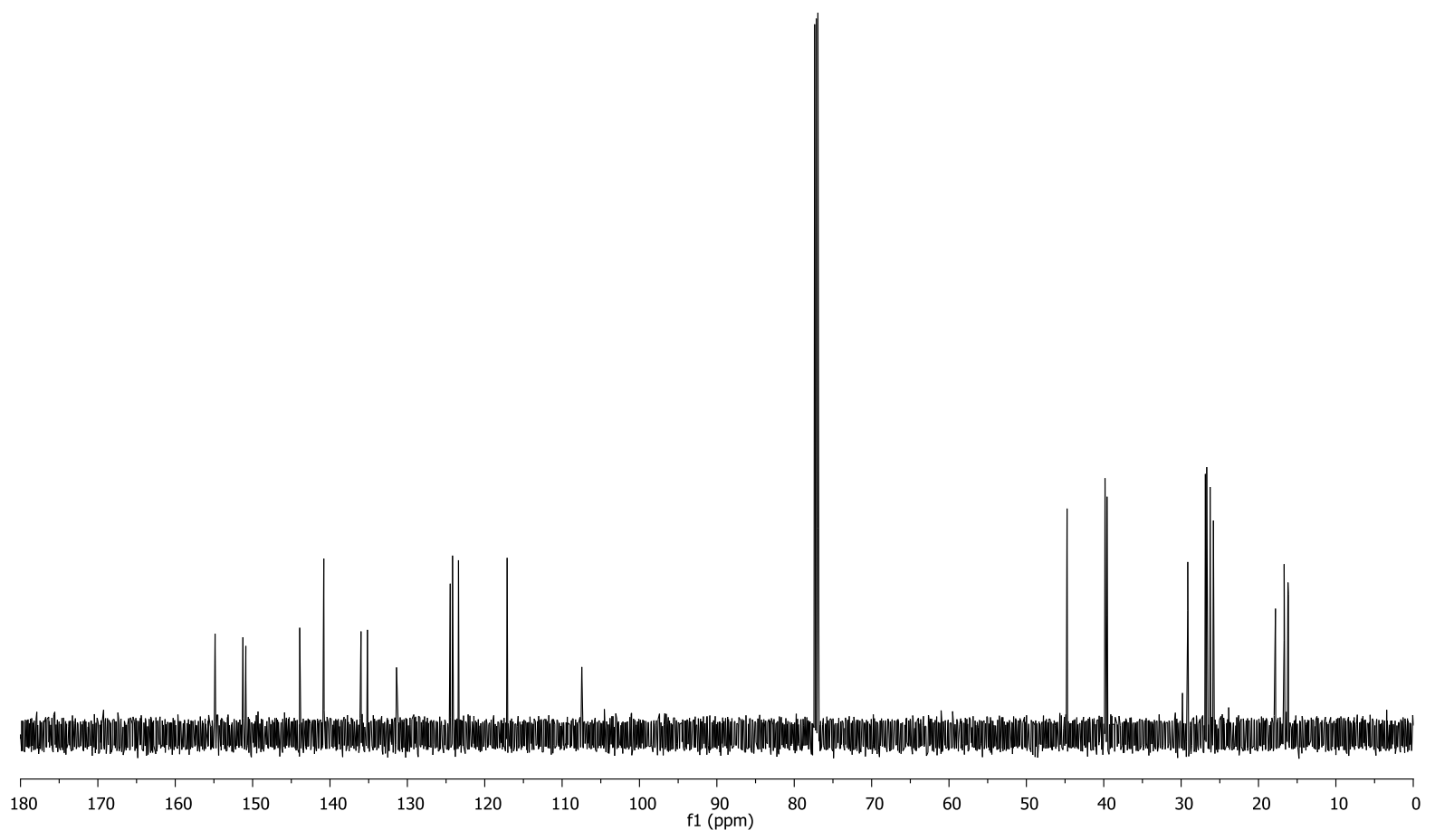

${ }^{13} \mathrm{C}$ NMR spectrum $\left(150 \mathrm{MHz}, \mathrm{CDCl}_{3}\right)$ of $\mathbf{1 1 5}$. 
(E)-7-(3,7-Dimethylocta-2,6-dien-1-yl)-1,3-dimethyl-3,7-dihydro-1H-purine-2,6-dione (116)

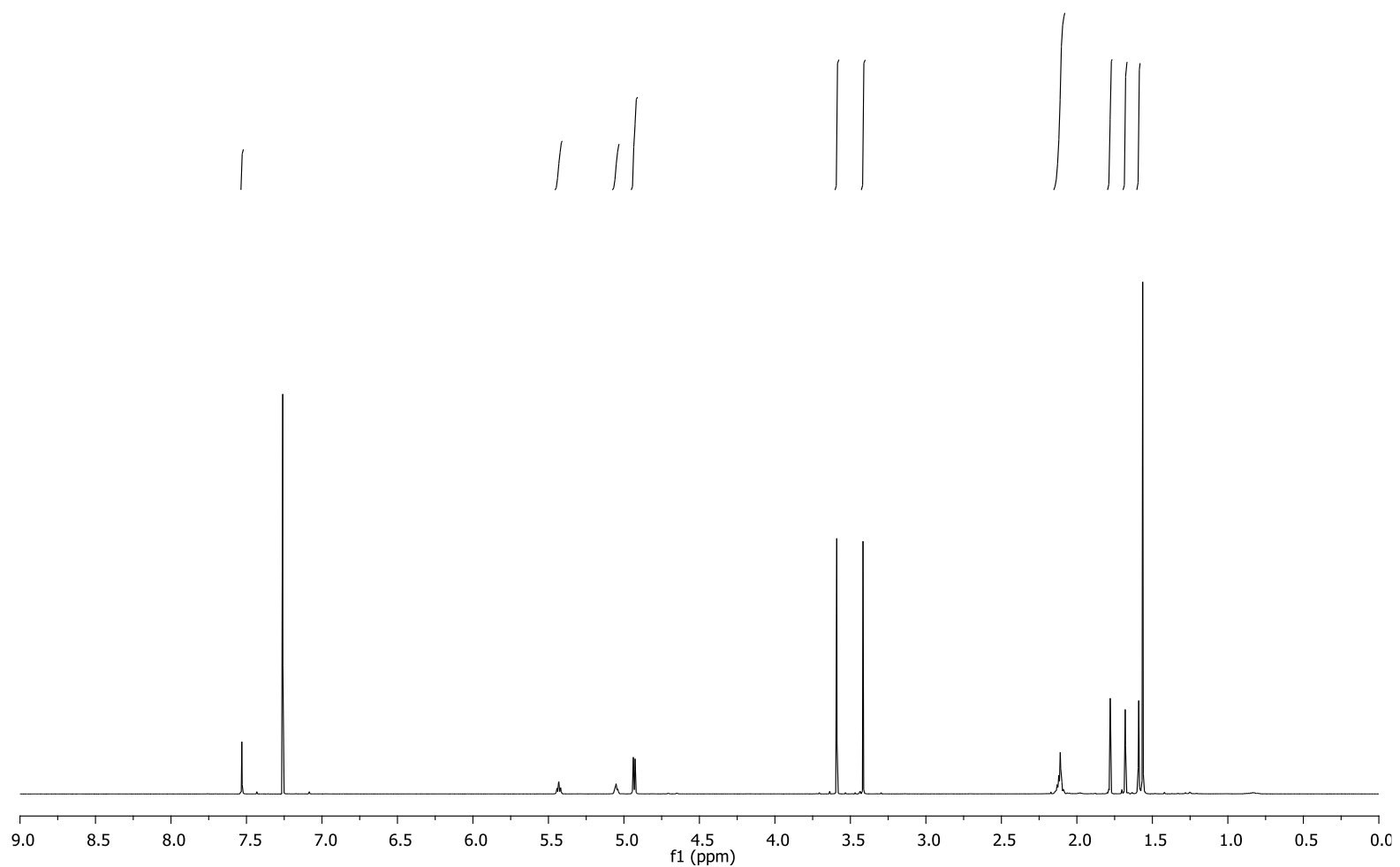

${ }^{1} \mathrm{H}$ NMR spectrum $\left(600 \mathrm{MHz}, \mathrm{CDCl}_{3}\right)$ of $\mathbf{1 1 6}$.

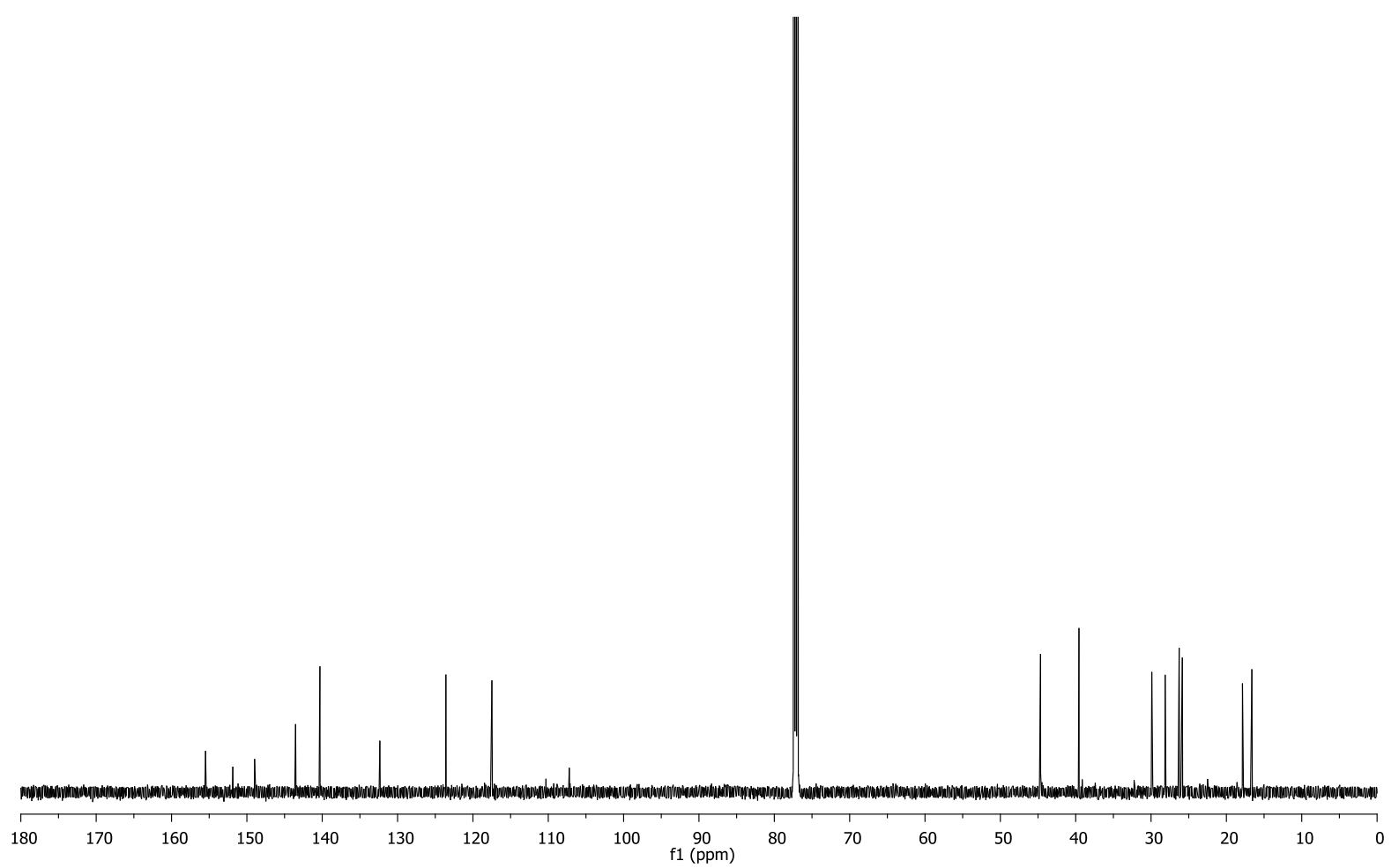

${ }^{13} \mathrm{C}$ NMR spectrum $\left(150 \mathrm{MHz}, \mathrm{CDCl}_{3}\right)$ of $\mathbf{1 1 6}$. 
1,3-Dimethyl-7-((2E,6E)-3,7,11-trimethyldodeca-2,6,10-trien-1-yl)-3,7-dihydro-1Hpurine-2,6-dione (117)

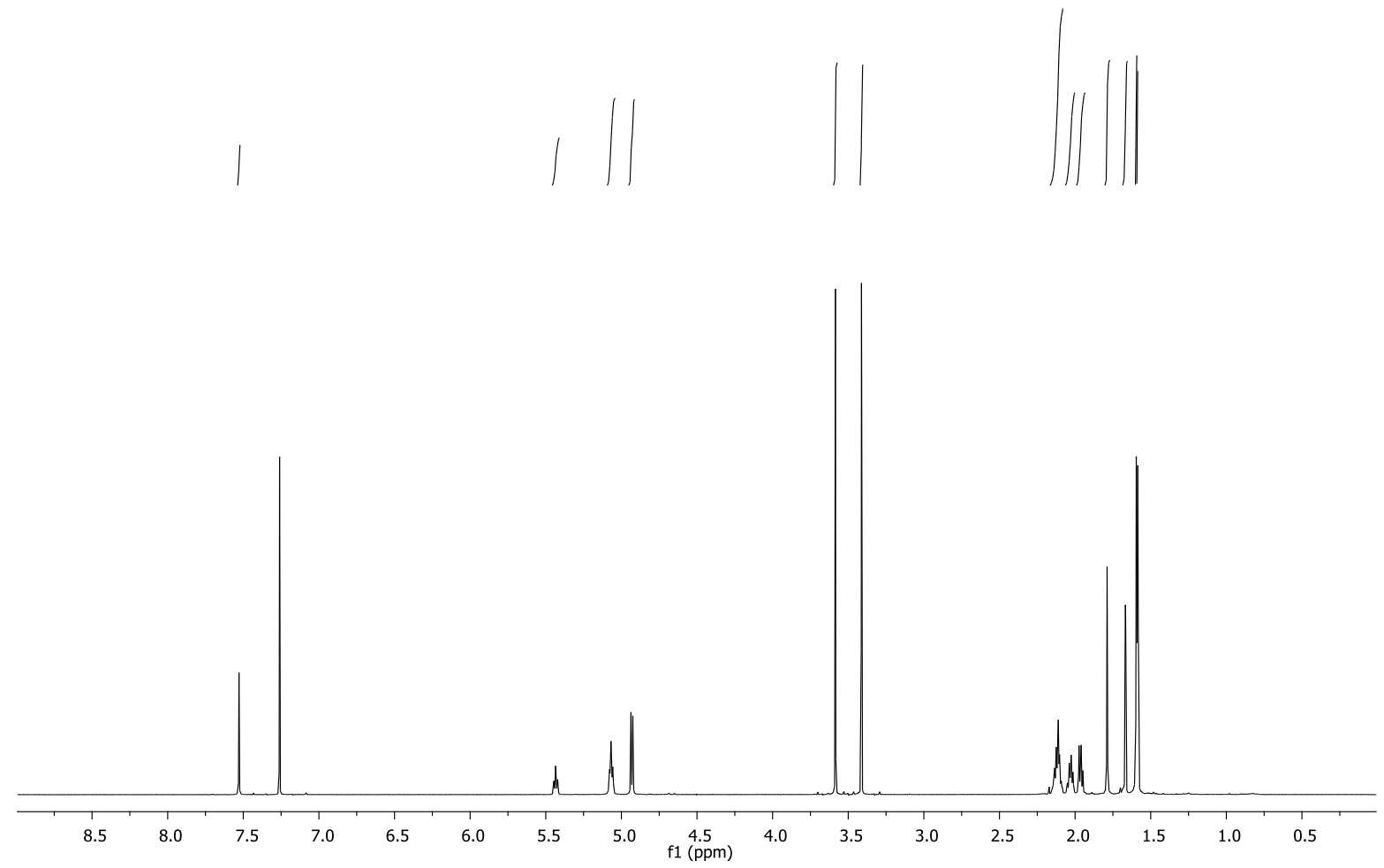

${ }^{1} \mathrm{H}$ NMR spectrum $\left(600 \mathrm{MHz}, \mathrm{CDCl}_{3}\right)$ of 117.

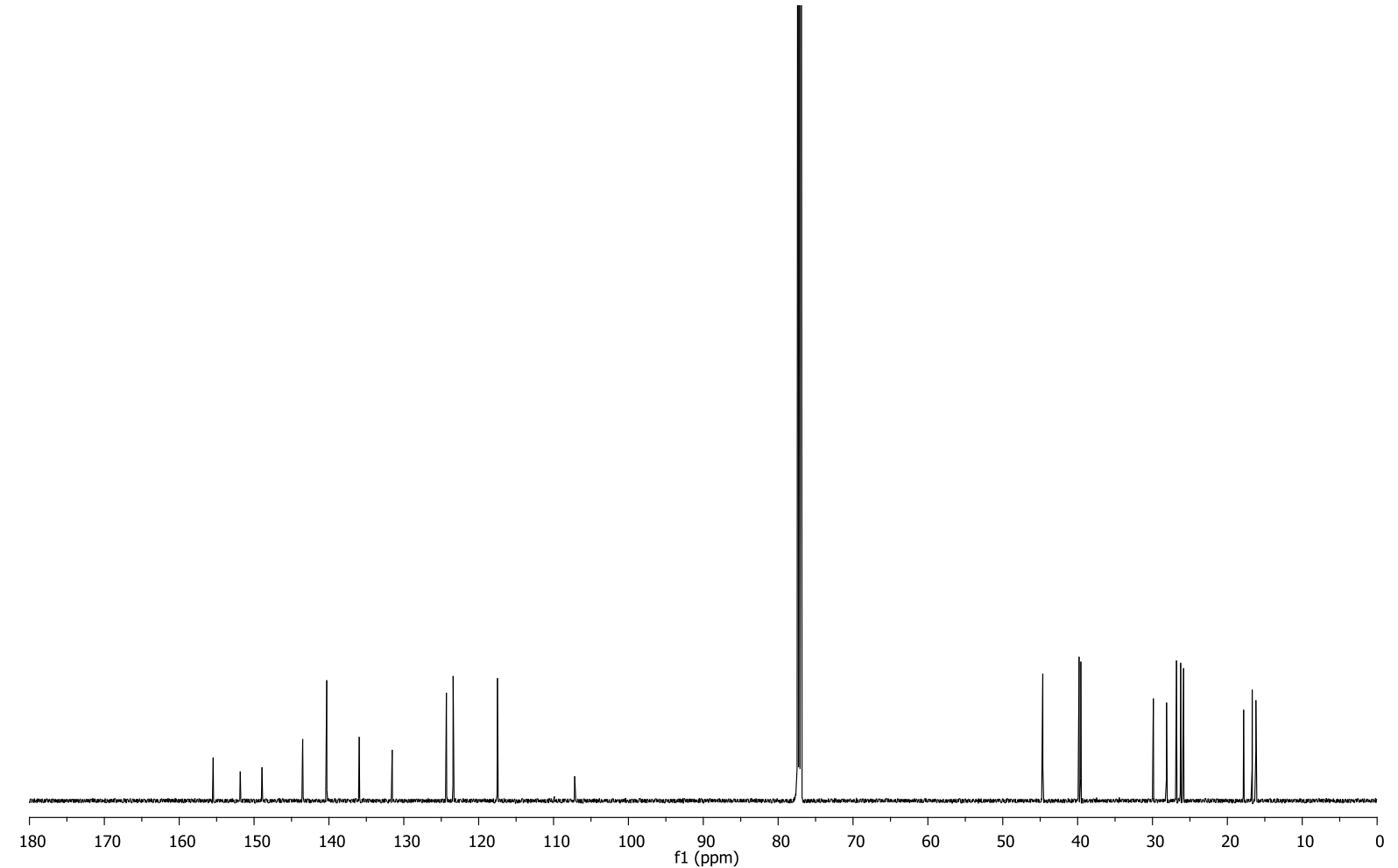

${ }^{13} \mathrm{C}$ NMR spectrum $\left(150 \mathrm{MHz}, \mathrm{CDCl}_{3}\right)$ of $\mathbf{1 1 7}$. 
1,3-Dimethyl-7-((2Z,6E,10E)-3,7,11,15-tetramethylhexadeca-2,6,10,14-tetraen-1-yl)3,7-dihydro-1 $H$-purine-2,6-dione (63)



${ }^{1} \mathrm{H}$ NMR spectrum $\left(500 \mathrm{MHz}, \mathrm{CDCl}_{3}\right)$ of $\mathbf{6 3}$.

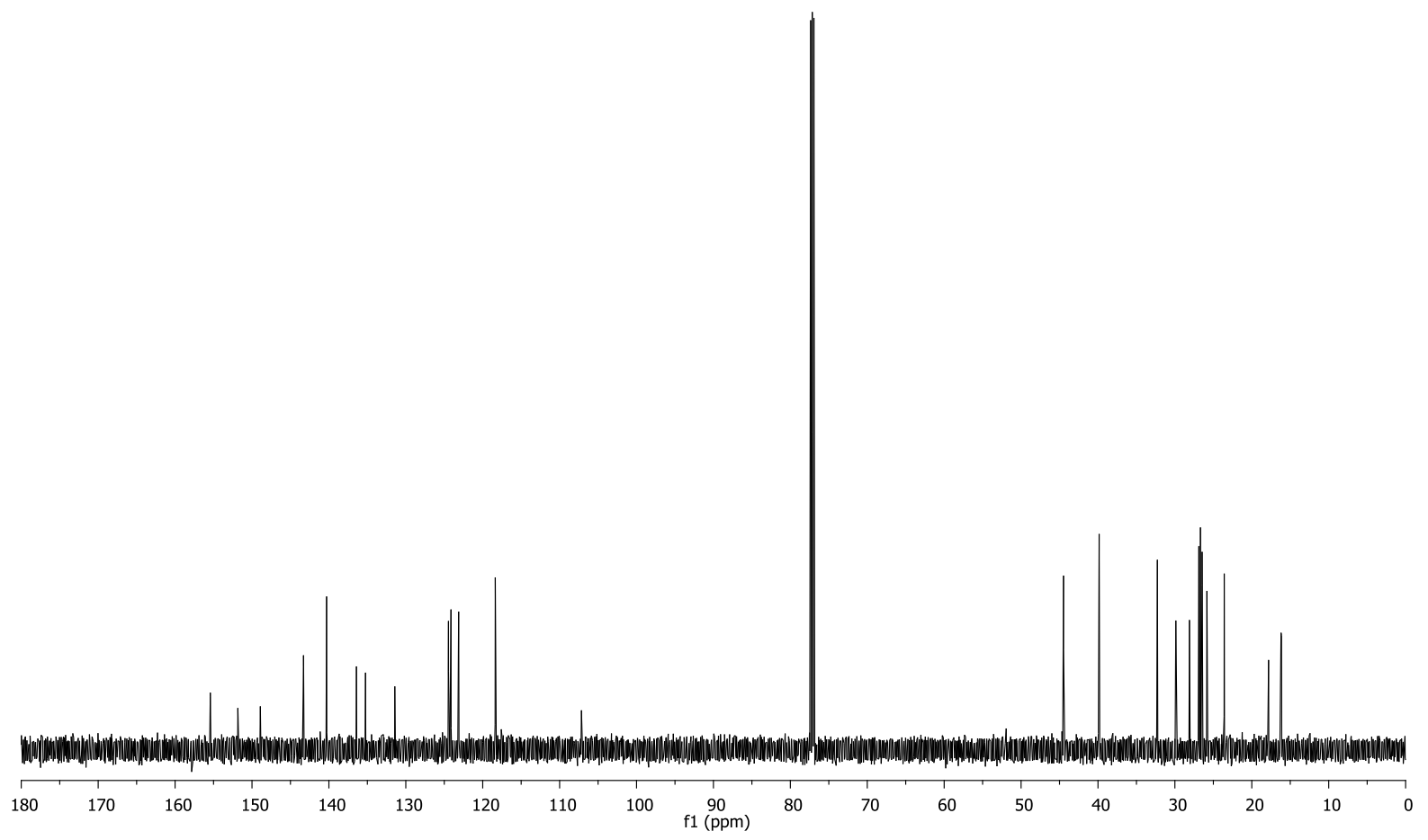

${ }^{13} \mathrm{C}$ NMR spectrum $\left(150 \mathrm{MHz}, \mathrm{CDCl}_{3}\right)$ of 63. 
1,3-Dimethyl-7-((2E,6E,10E)-3,7,11,15-tetramethylhexadeca-2,6,10,14-tetraen-1-yl)3,7-dihydro-1H-purine-2,6-dione (64)

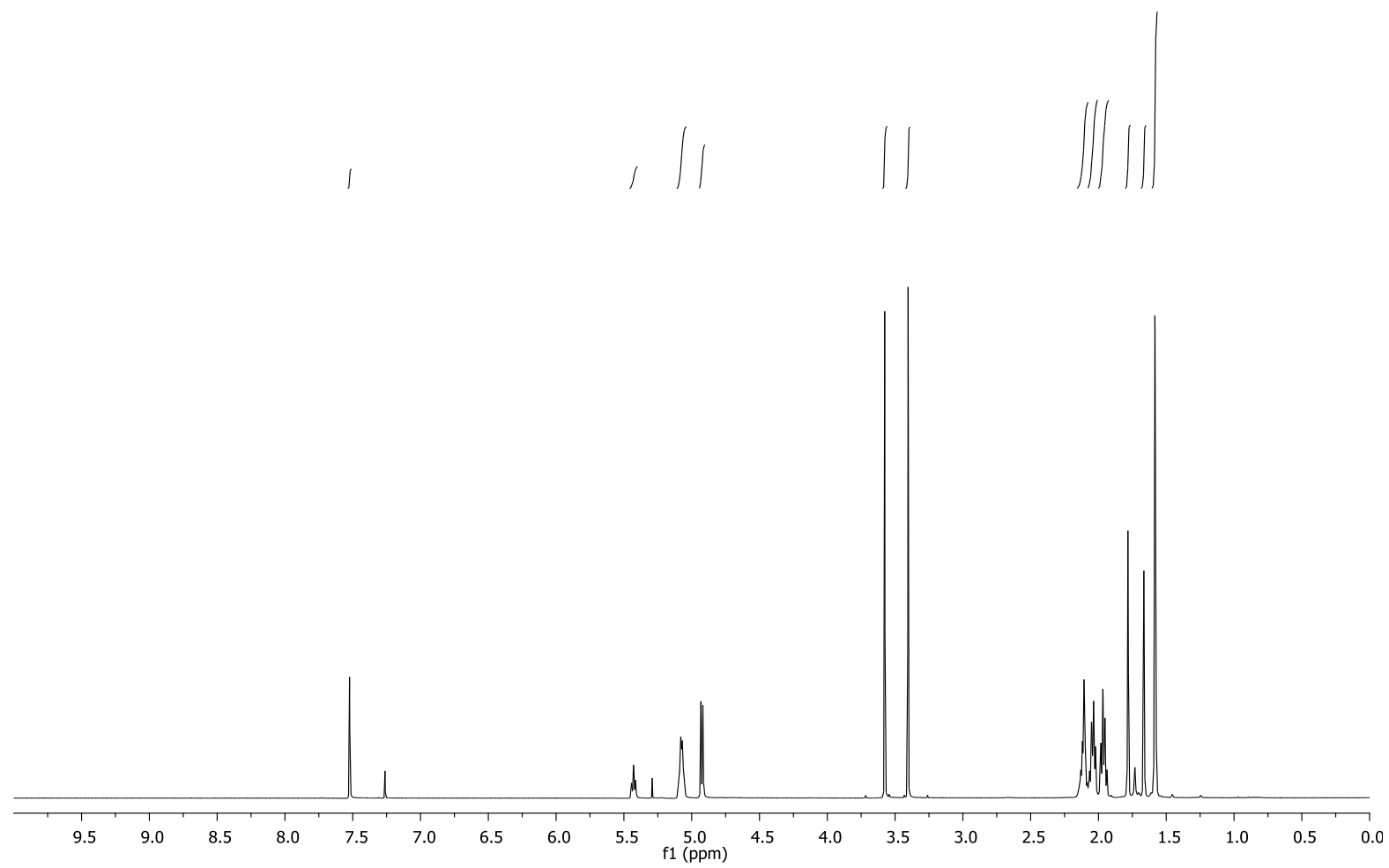

${ }^{1} \mathrm{H}$ NMR spectrum $\left(500 \mathrm{MHz}, \mathrm{CDCl}_{3}\right)$ of 64.

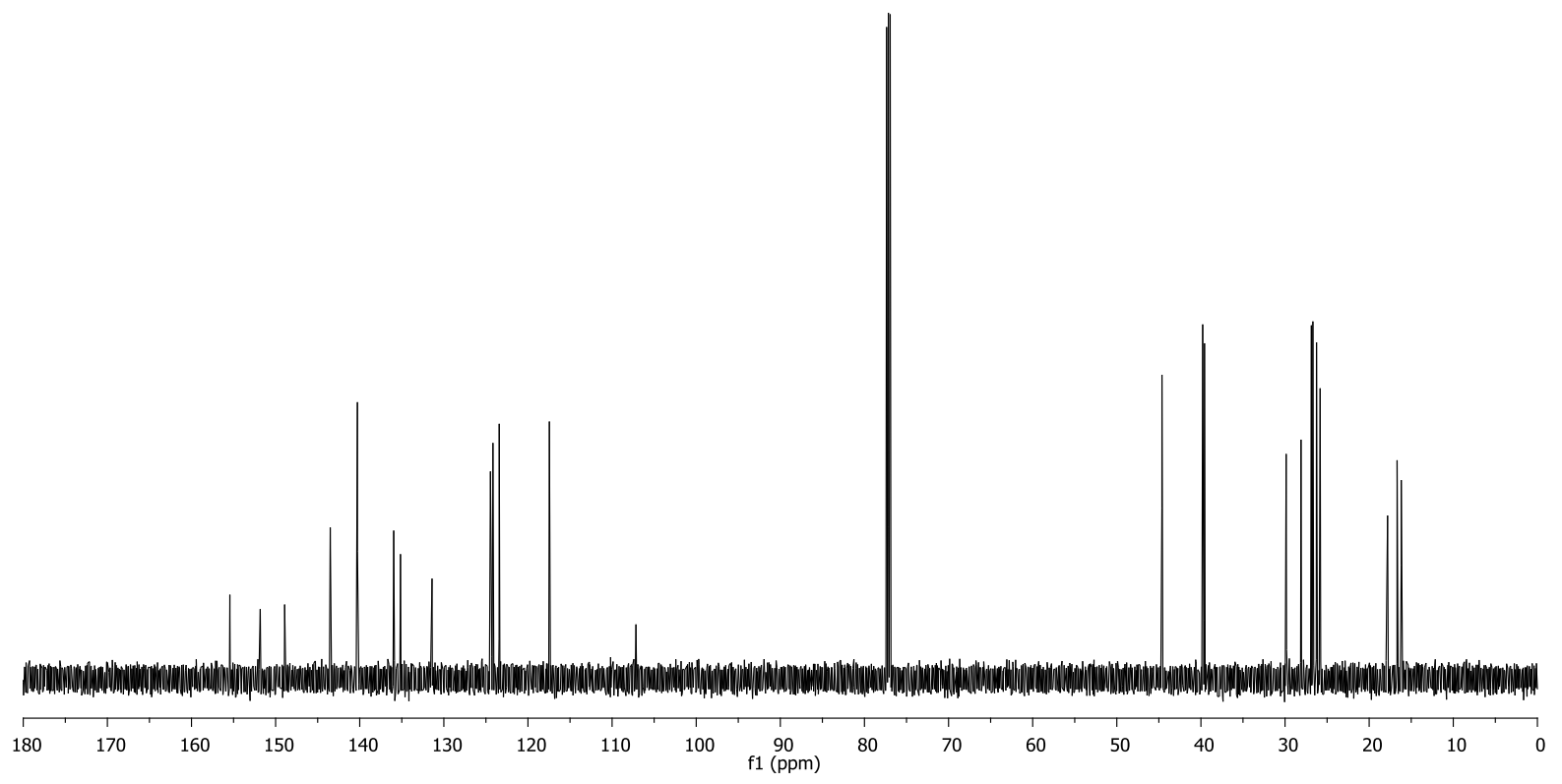

${ }^{13} \mathrm{C}$ NMR spectrum $\left(150 \mathrm{MHz}, \mathrm{CDCl}_{3}\right)$ of 64. 
(E)-7-(3,7-Dimethylocta-2,6-dien-1-yl)-3-methyl-2-thioxo-1,2,3,7-tetrahydro-6H-purin6-one (118)

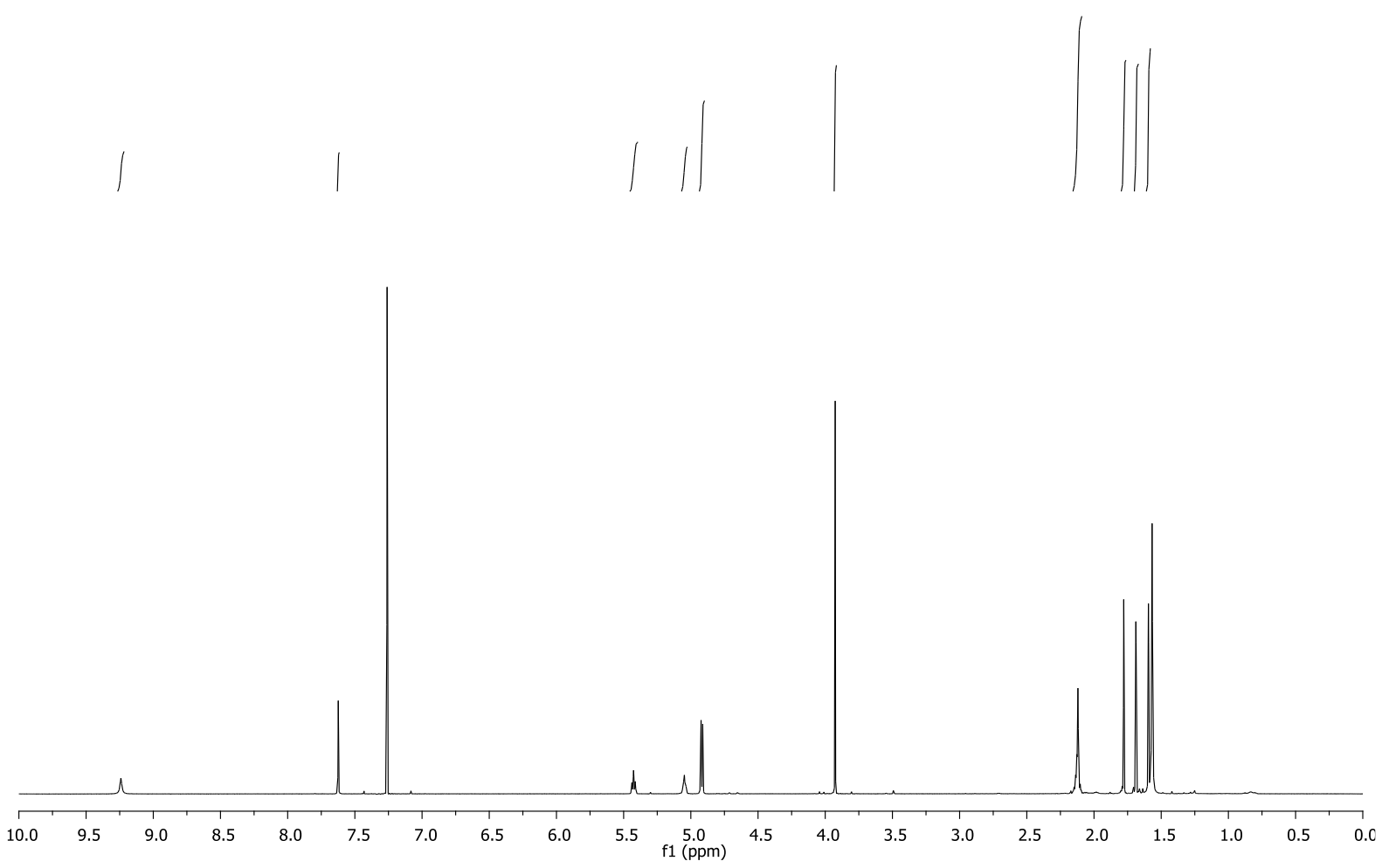

${ }^{1} \mathrm{H}$ NMR spectrum $\left(600 \mathrm{MHz}, \mathrm{CDCl}_{3}\right)$ of $\mathbf{1 1 8}$.

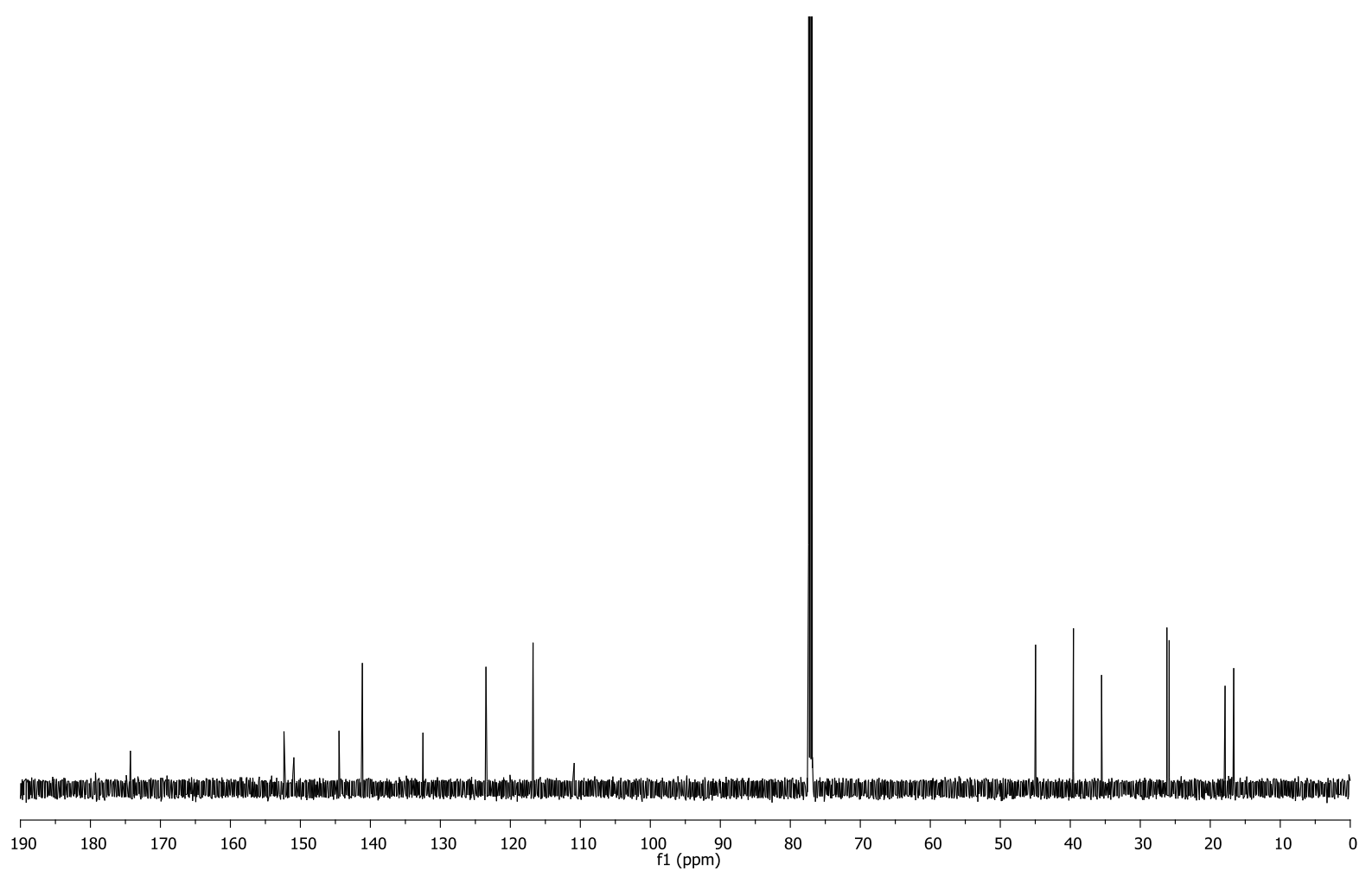

${ }^{13} \mathrm{C}$ NMR spectrum $\left(150 \mathrm{MHz}, \mathrm{CDCl}_{3}\right)$ of $\mathbf{1 1 8 .}$ 
3-Methyl-2-thioxo-7-((2E,6E)-3,7,11-trimethyldodeca-2,6,10-trien-1-yl)-1,2,3,7tetrahydro-6H-purin-6-one (119)



${ }^{1} \mathrm{H}$ NMR spectrum $\left(600 \mathrm{MHz}, \mathrm{CDCl}_{3}\right)$ of 119.



${ }^{13} \mathrm{C}$ NMR spectrum $\left(150 \mathrm{MHz}, \mathrm{CDCl}_{3}\right)$ of $\mathbf{1 1 9}$. 
3-Methyl-7-((2Z,6E,10E)-3,7,11,15-tetramethylhexadeca-2,6,10,14-tetraen-1-yl)-2thioxo-1,2,3,7-tetrahydro-6H-purin-6-one (120)

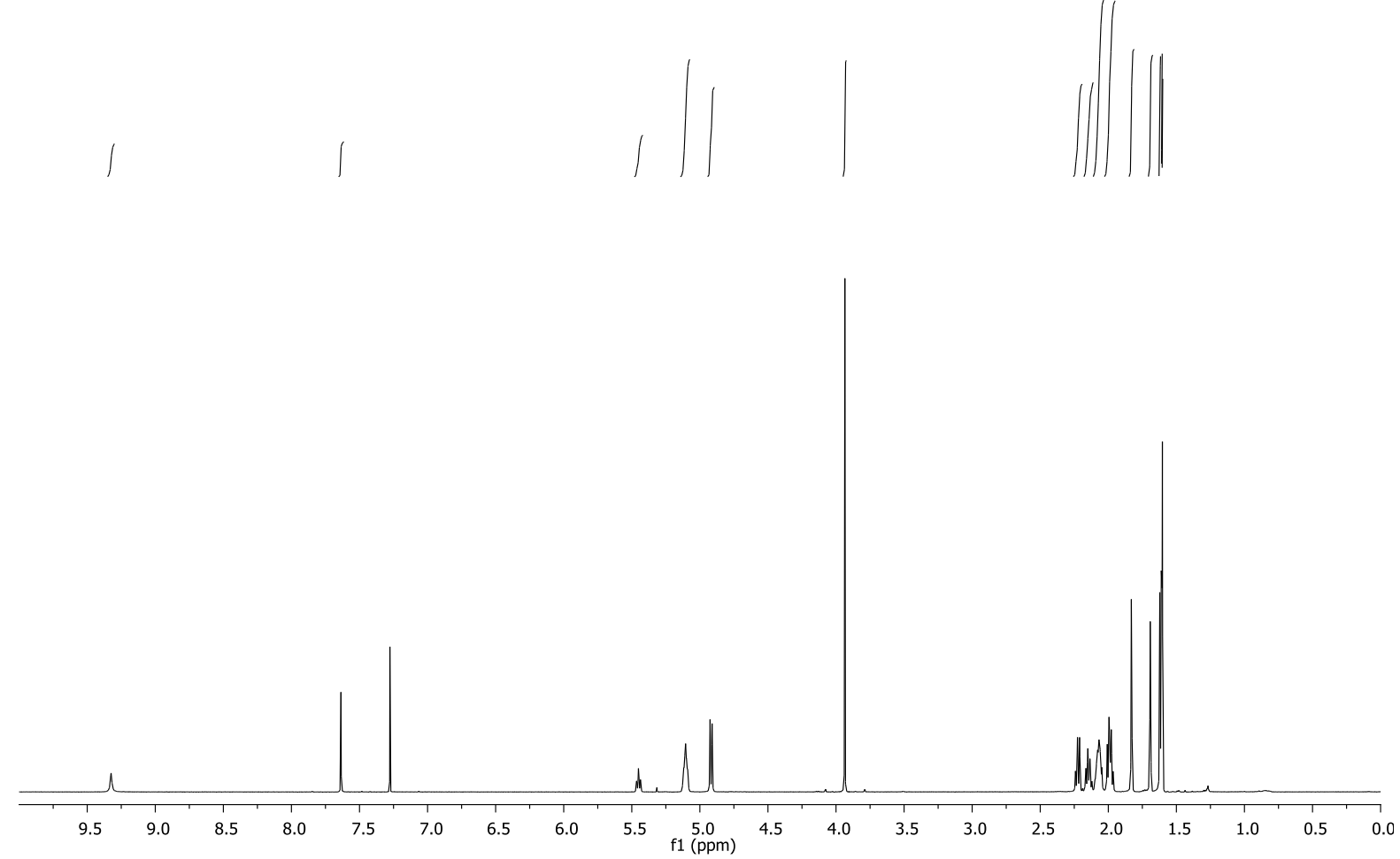

${ }^{1} \mathrm{H}$ NMR spectrum $\left(500 \mathrm{MHz}, \mathrm{CDCl}_{3}\right)$ of $\mathbf{1 2 0 .}$

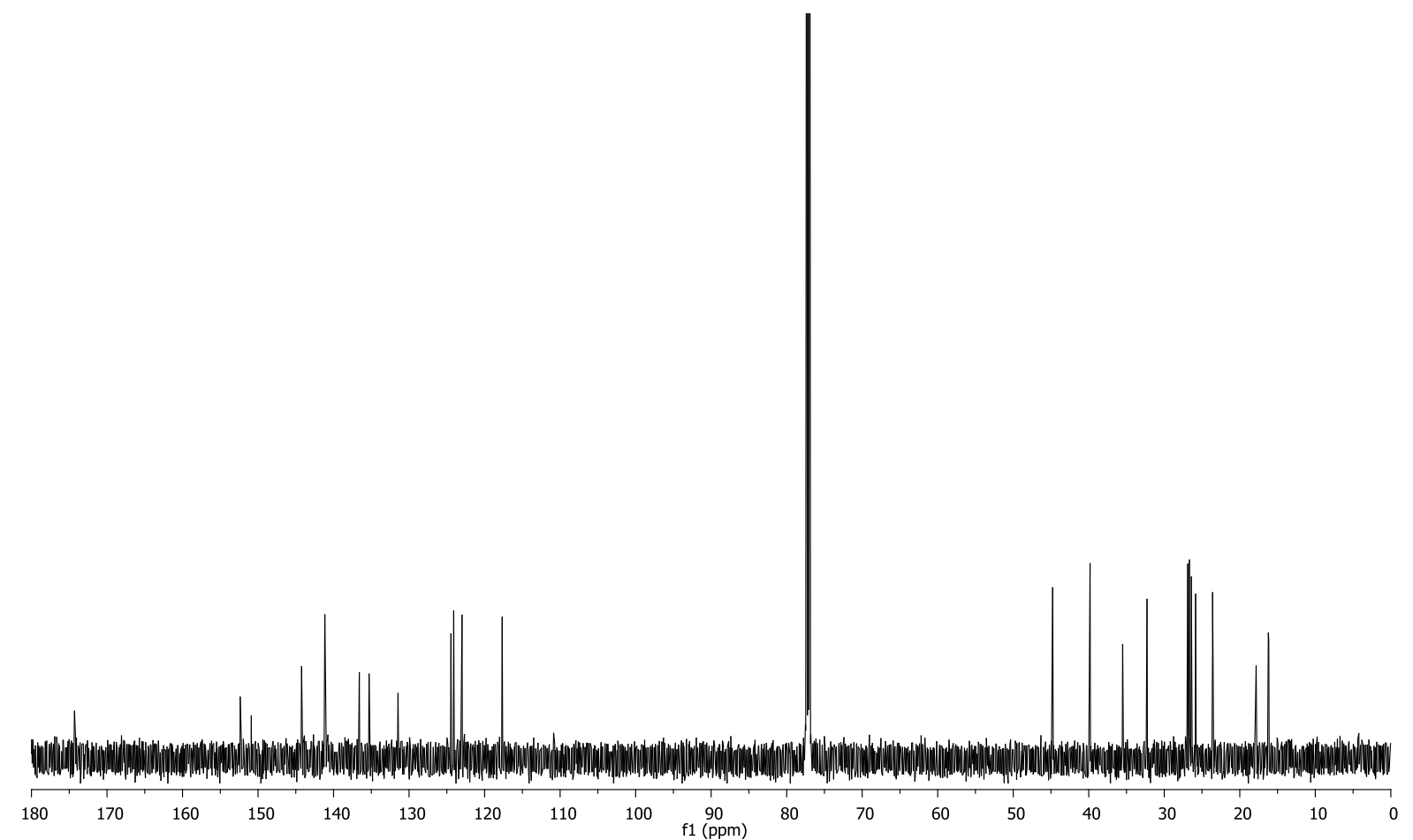

${ }^{13} \mathrm{C}$ NMR spectrum $\left(150 \mathrm{MHz}, \mathrm{CDCl}_{3}\right)$ of $\mathbf{1 2 0}$. 
3-Methyl-7-((2E,6E,10E)-3,7,11,15-tetramethylhexadeca-2,6,10,14-tetraen-1-yl)-2thioxo-1,2,3,7-tetrahydro-6H-purin-6-one (121)

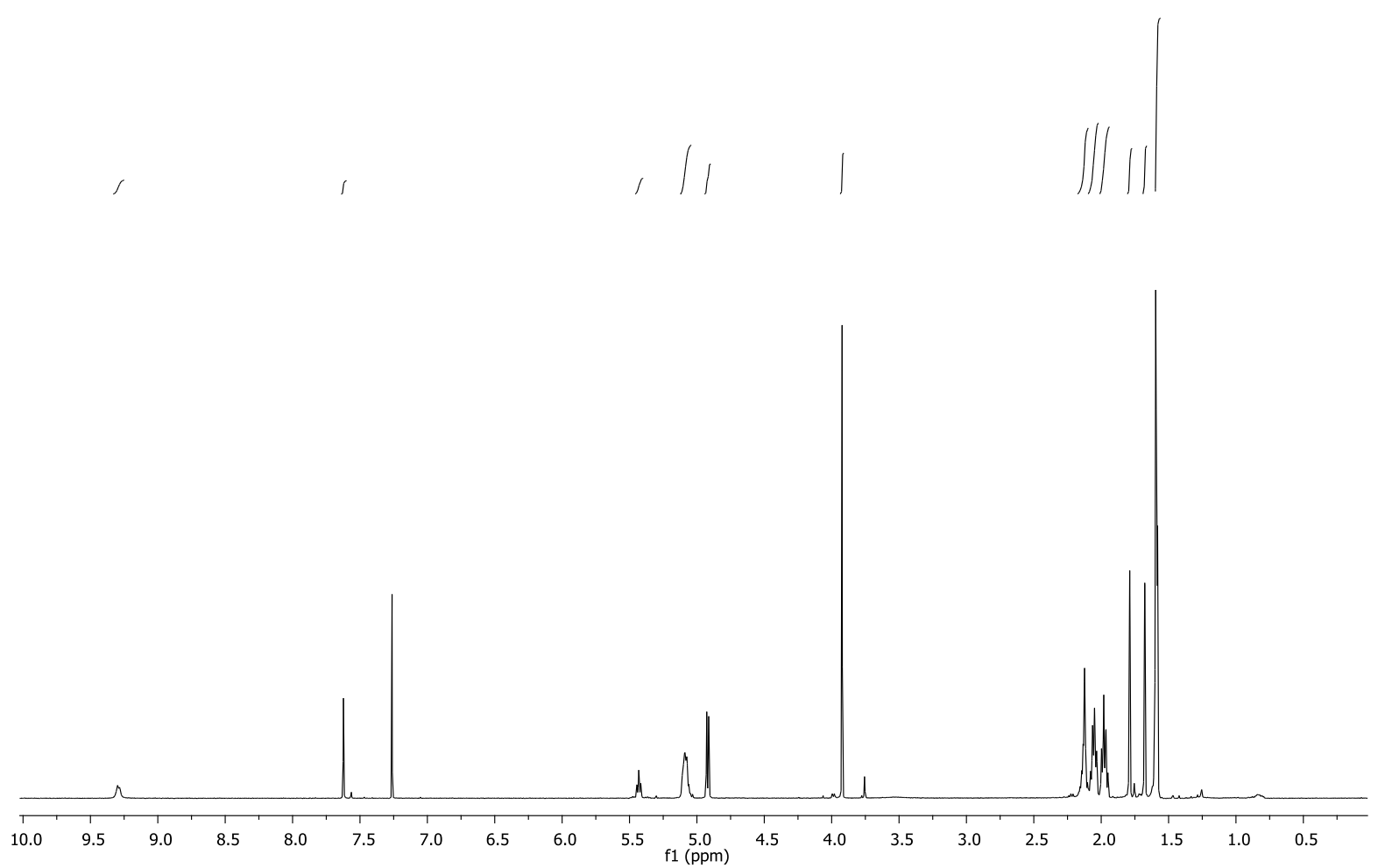

${ }^{1} \mathrm{H}$ NMR spectrum $\left(500 \mathrm{MHz}, \mathrm{CDCl}_{3}\right)$ of $\mathbf{1 2 1}$.

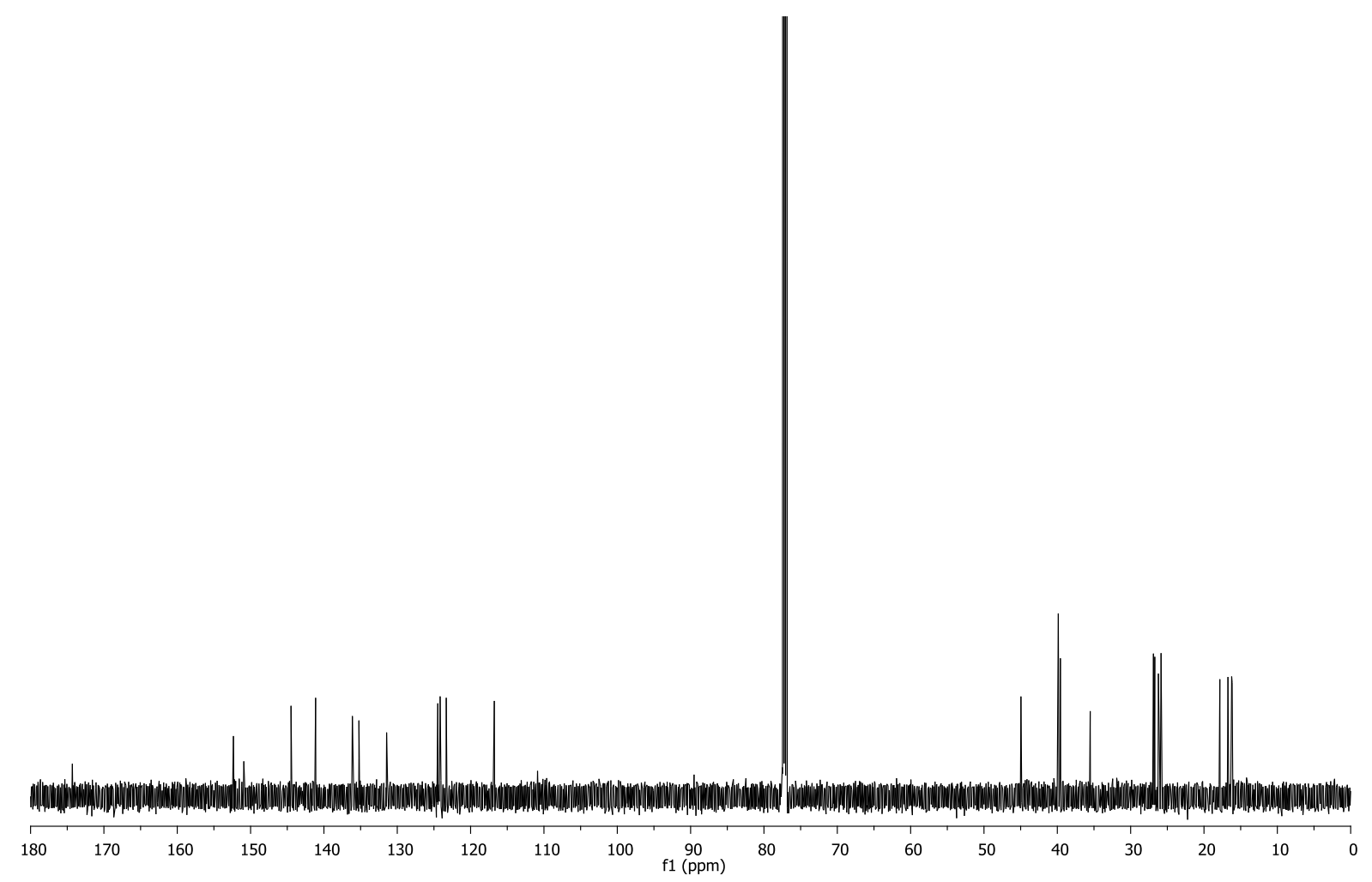

${ }^{13} \mathrm{C}$ NMR spectrum $\left(150 \mathrm{MHz}, \mathrm{CDCl}_{3}\right)$ of $\mathbf{1 2 1}$. 
(E)-5-(3,7-Dimethylocta-2,6-dien-1-yl)-1,3-dimethyl-5,7-dihydro-1 $H$-purine-2,6,8(3H)trione (122)

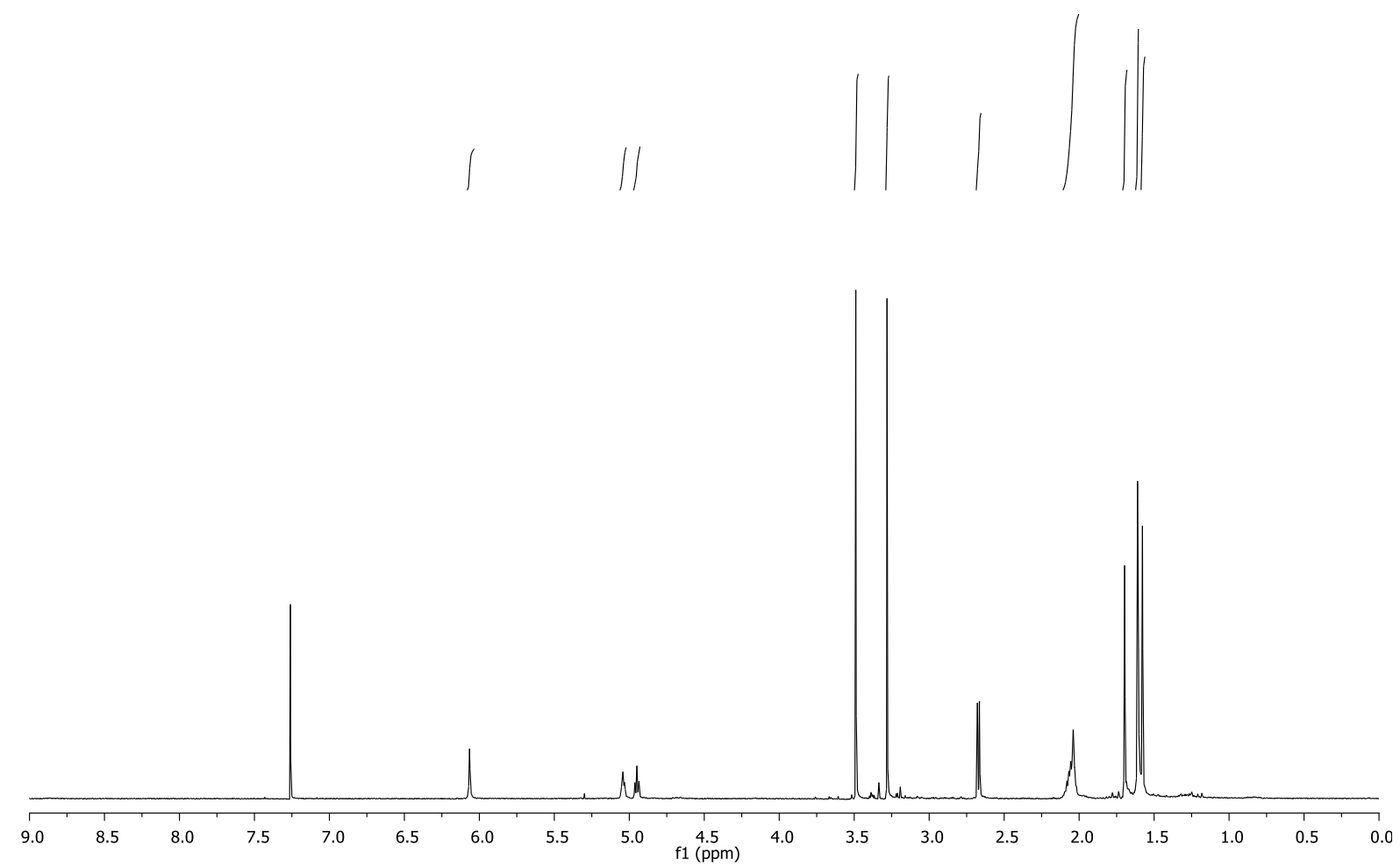

${ }^{1} \mathrm{H}$ NMR spectrum $\left(600 \mathrm{MHz}, \mathrm{CDCl}_{3}\right)$ of 122.

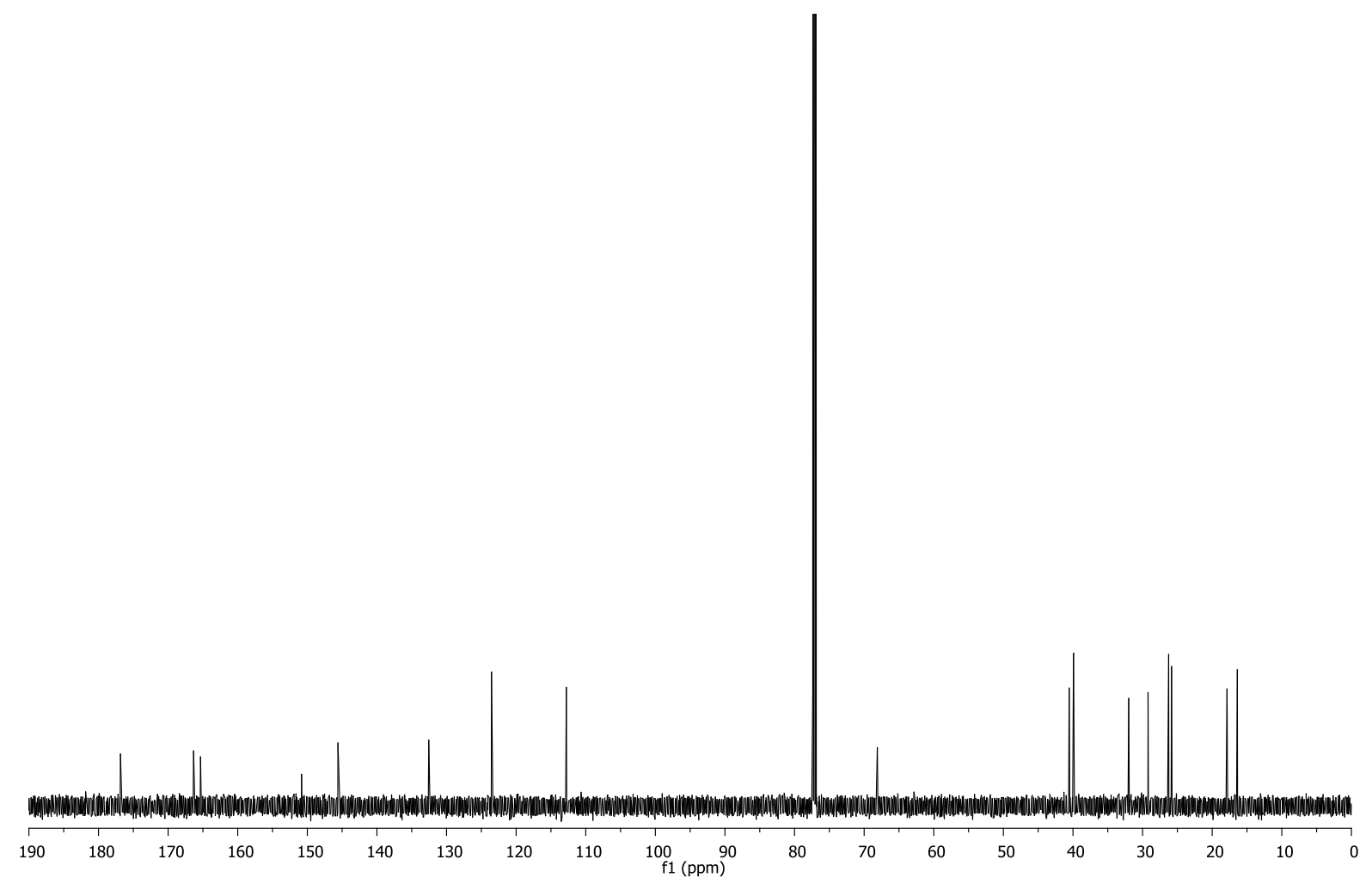

${ }^{13} \mathrm{C}$ NMR spectrum $\left(150 \mathrm{MHz}, \mathrm{CDCl}_{3}\right)$ of $\mathbf{1 2 2}$. 
1,3-Dimethyl-5-((2E,6E)-3,7,11-trimethyldodeca-2,6,10-trien-1-yl)-5,7-dihydro-1Hpurine-2,6,8(3H)-trione (123)

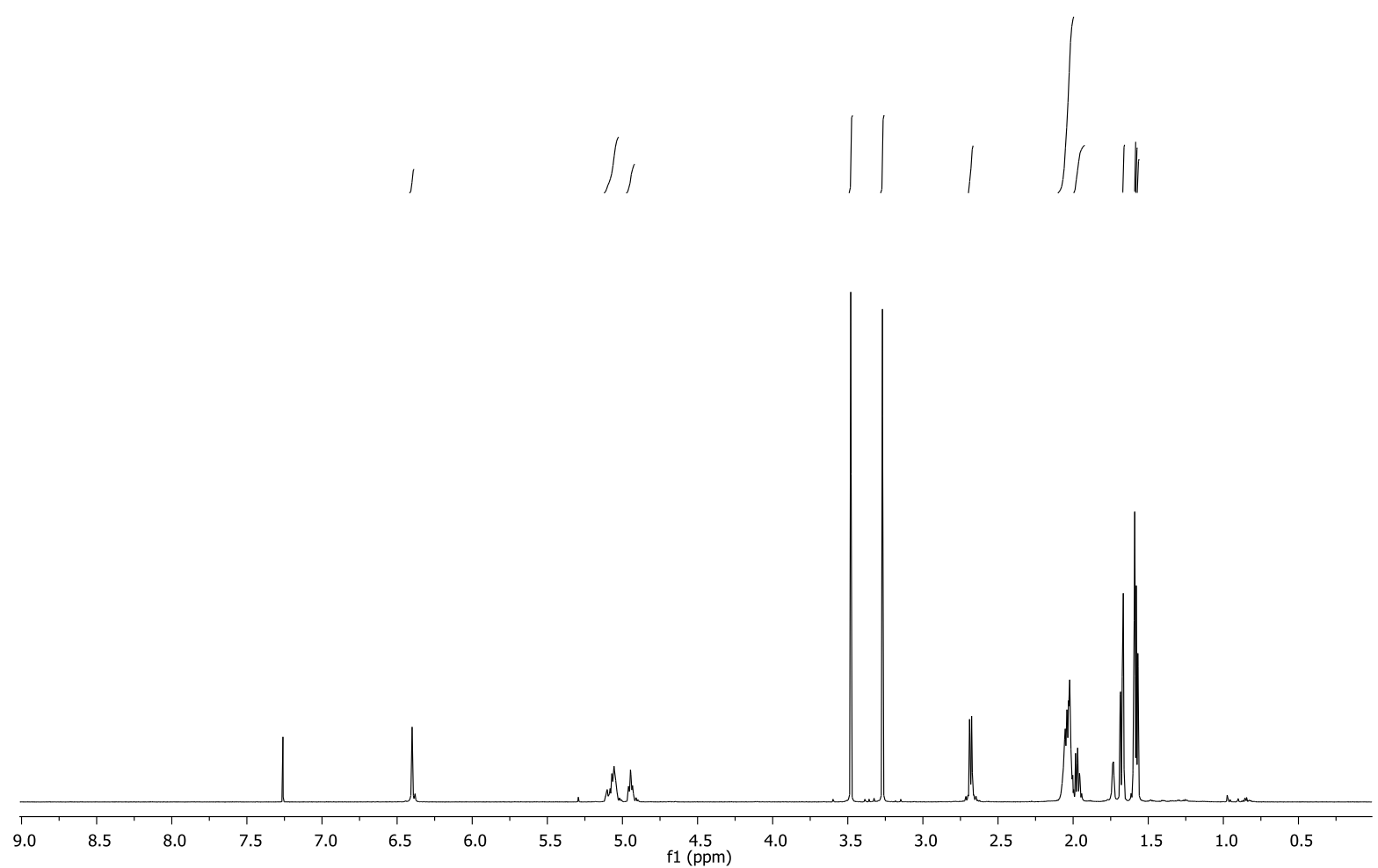

${ }^{1} \mathrm{H}$ NMR spectrum $\left(600 \mathrm{MHz}, \mathrm{CDCl}_{3}\right)$ of $\mathbf{1 2 3}$.

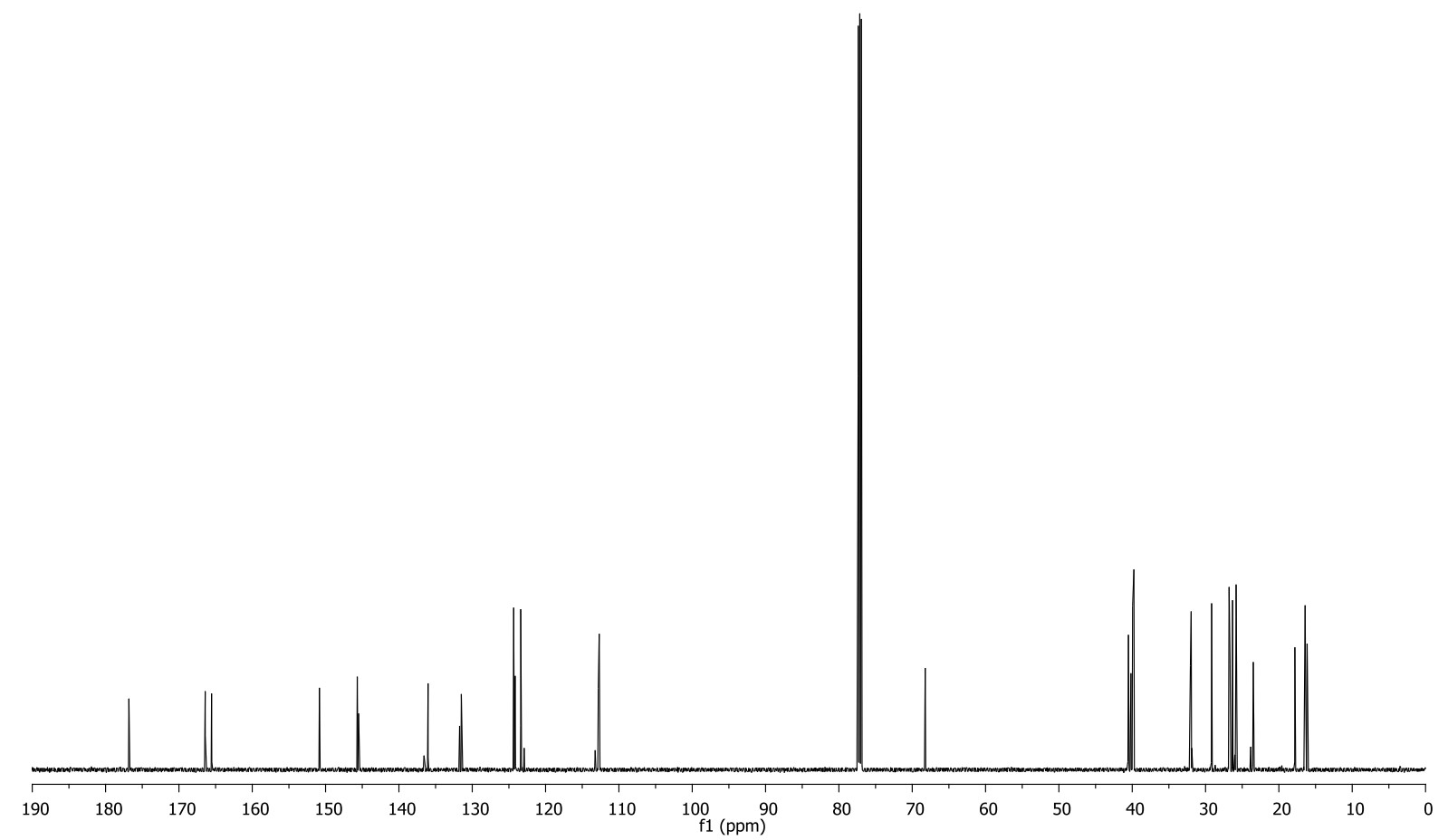

${ }^{13} \mathrm{C}$ NMR spectrum $\left(150 \mathrm{MHz}, \mathrm{CDCl}_{3}\right)$ of $\mathbf{1 2 3}$. 
1,3-Dimethyl-9-((6E)-3,7,11-trimethyldodeca-2,6,10-trien-1-yl)-7,9-dihydro-1H-purine2,6,8(3H)-trione $(\mathbf{1 2 4})$

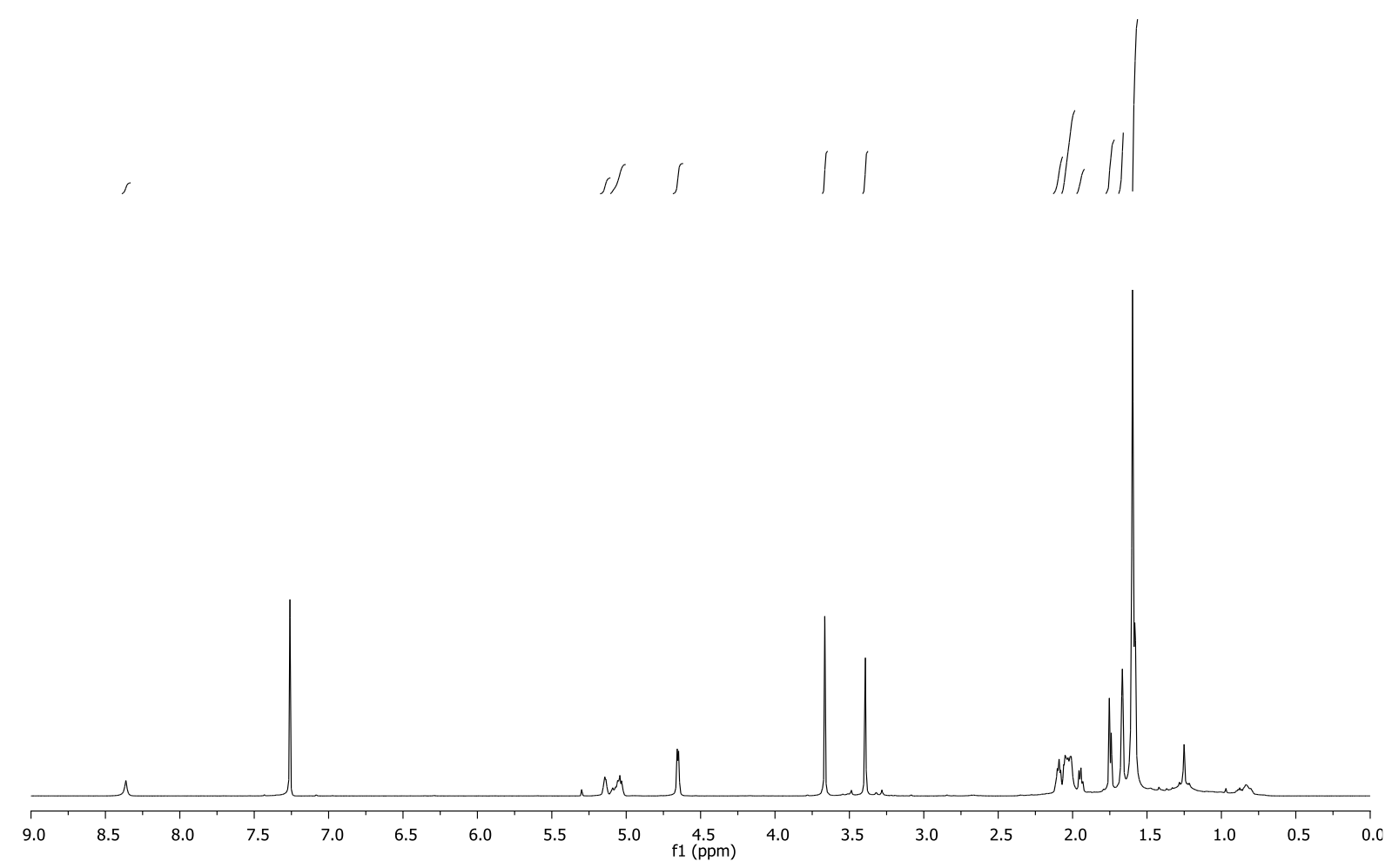

${ }^{1} \mathrm{H}$ NMR spectrum $\left(600 \mathrm{MHz}, \mathrm{CDCl}_{3}\right)$ of $\mathbf{1 2 4}$.



${ }^{13} \mathrm{C}$ NMR spectrum $\left(150 \mathrm{MHz}, \mathrm{CDCl}_{3}\right)$ of $\mathbf{1 2 4}$. 
1,3-Dimethyl-5-((2E,6E,10E)-3,7,11,15-tetramethylhexadeca-2,6,10,14-tetraen-1-yl)5,7-dihydro-1 $H$-purine-2,6,8(3H)-trione (125)

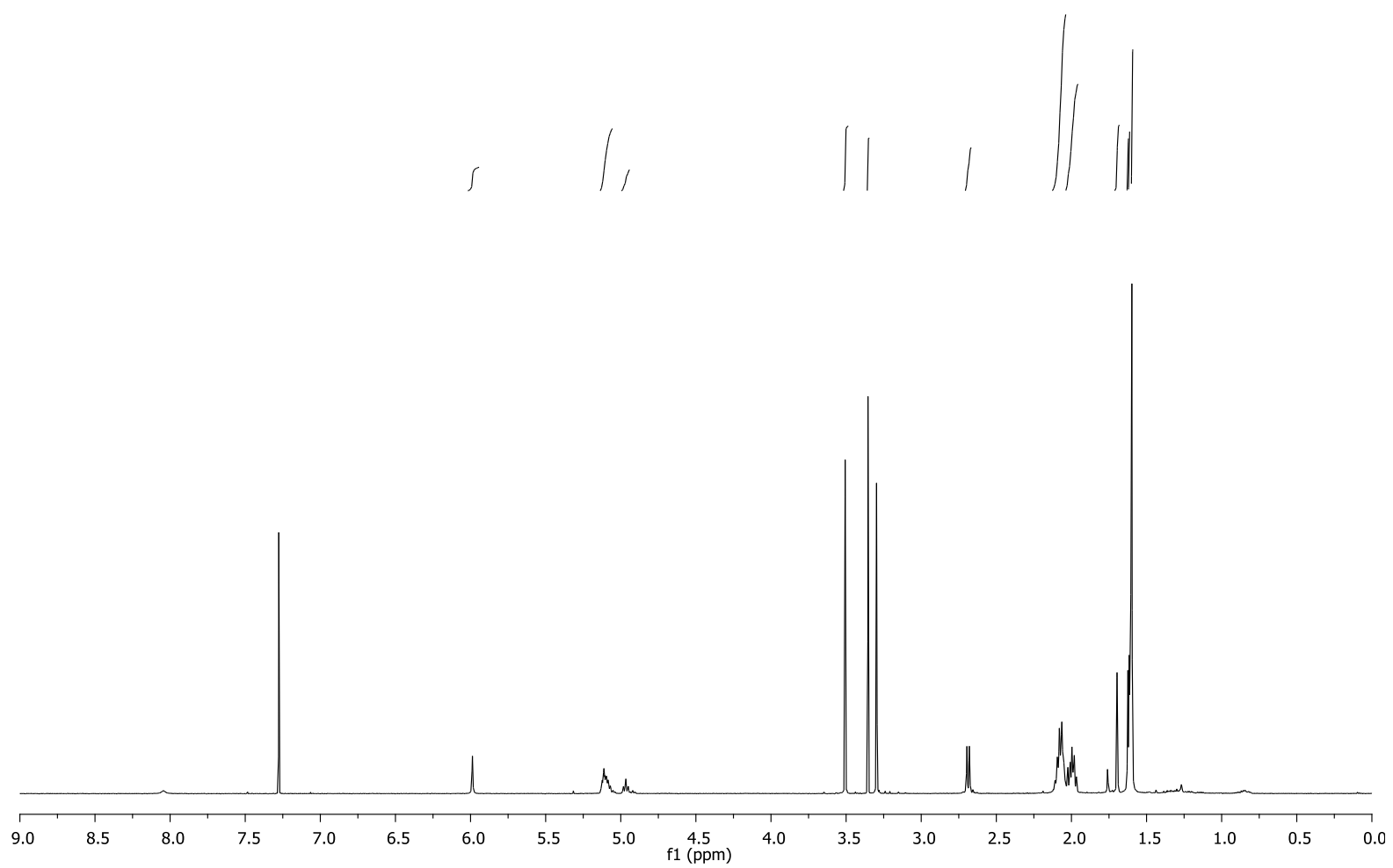

${ }^{1} \mathrm{H}$ NMR spectrum $\left(500 \mathrm{MHz}, \mathrm{CDCl}_{3}\right)$ of $\mathbf{1 2 5}$.

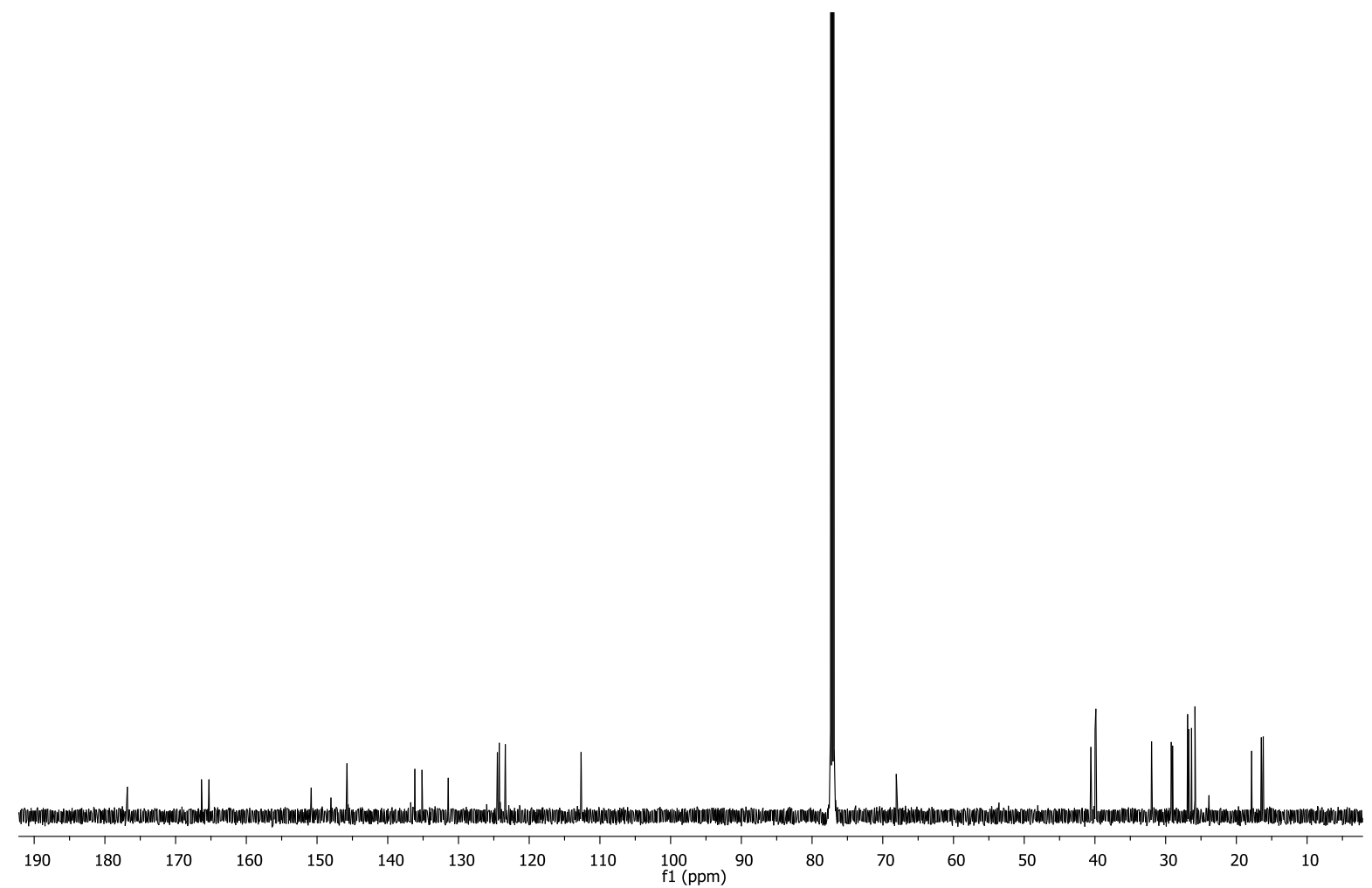

${ }^{13} \mathrm{C}$ NMR spectrum $\left(150 \mathrm{MHz}, \mathrm{CDCl}_{3}\right)$ of $\mathbf{1 2 5}$. 
E)-1-(3,7-Dimethylocta-2,6-dien-1-yl)pyrimidine-2,4(1H,3H)-dione (133)

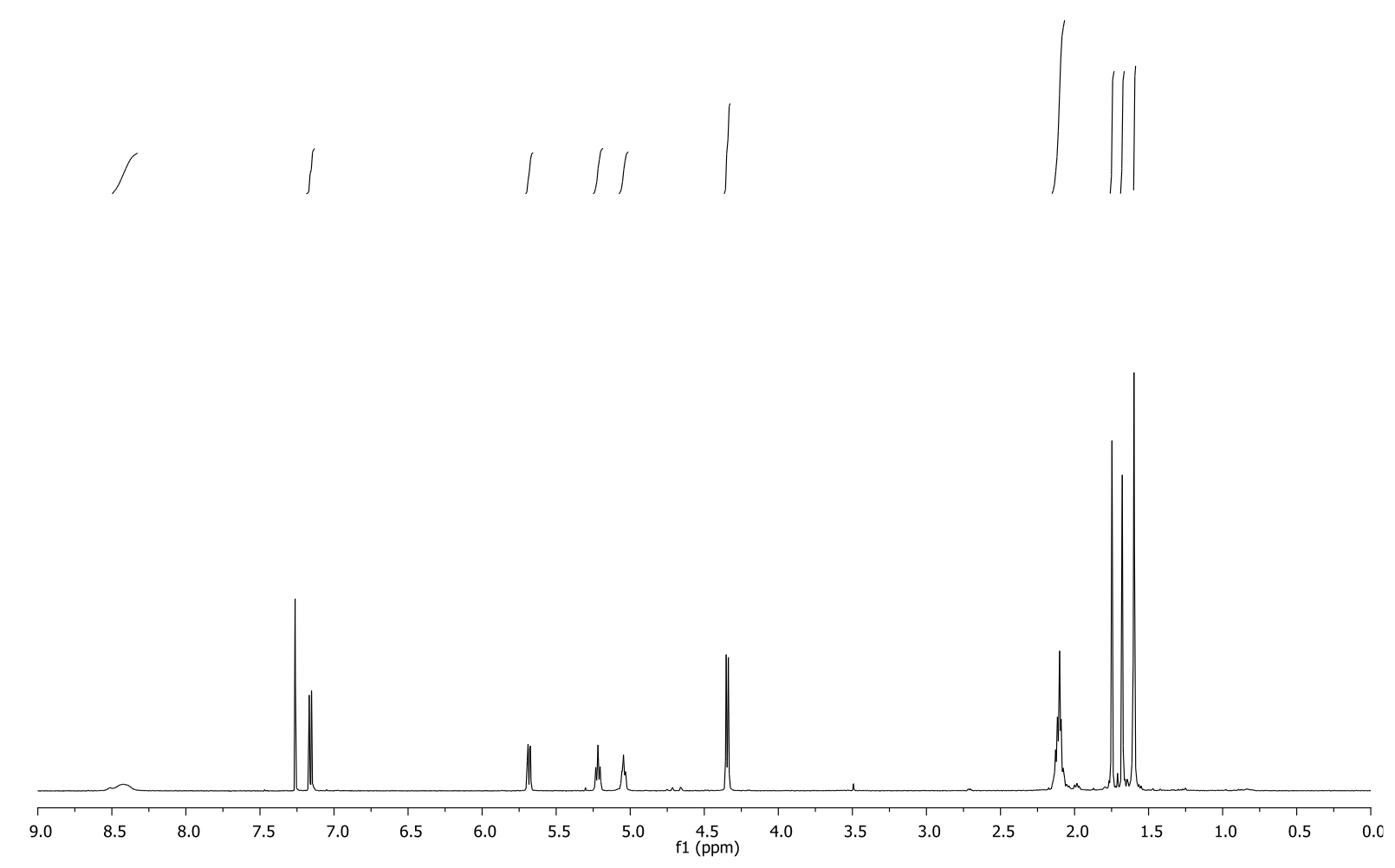

${ }^{1} \mathrm{H}$ NMR spectrum $\left(500 \mathrm{MHz}, \mathrm{CDCl}_{3}\right)$ of 133.

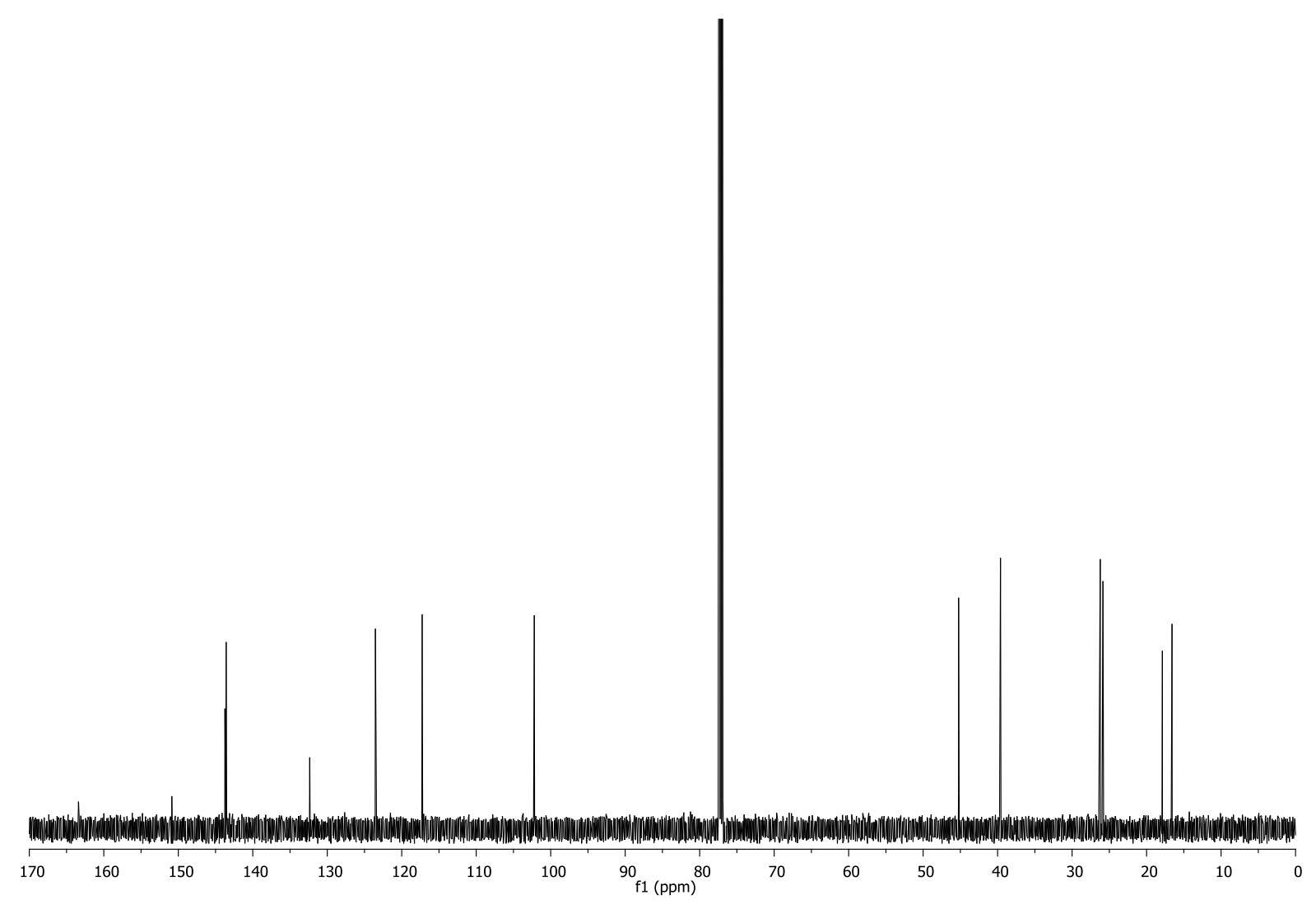

${ }^{13} \mathrm{C}$ NMR spectrum $\left(150 \mathrm{MHz}, \mathrm{CDCl}_{3}\right.$ ) of $\mathbf{1 3 3}$. 
1-((2E,6E)-3,7,11-Trimethyldodeca-2,6,10-trien-1-yl)pyrimidine-2,4(1H,3H)-dione (134)

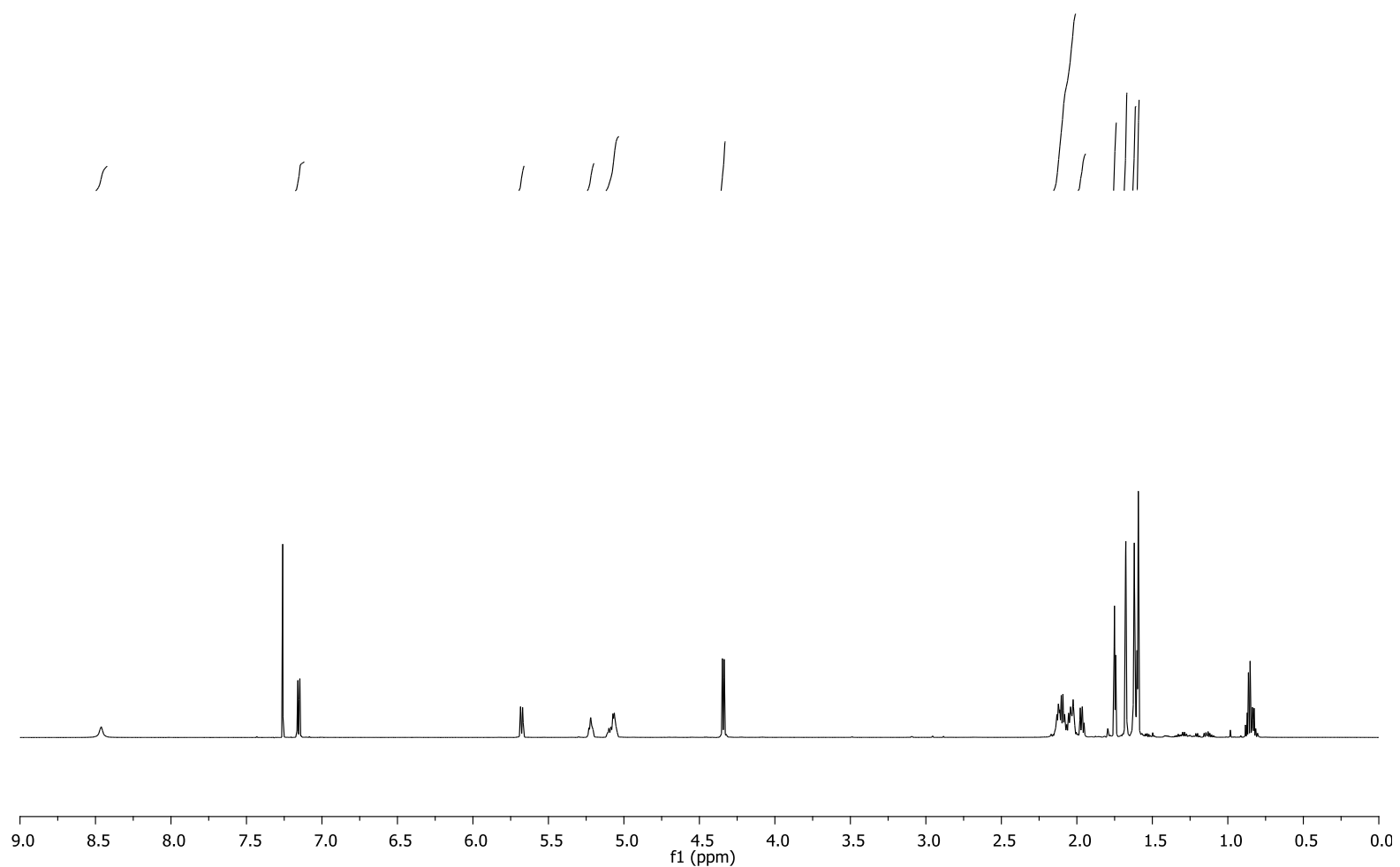

${ }^{1} \mathrm{H}$ NMR spectrum $\left(600 \mathrm{MHz}, \mathrm{CDCl}_{3}\right)$ of 134. 
1-((2Z,6E,10E)-3,7,11,15-Tetramethylhexadeca-2,6,10,14-tetraen-1-yl)pyrimidine2,4(1H,3H)-dione (135)

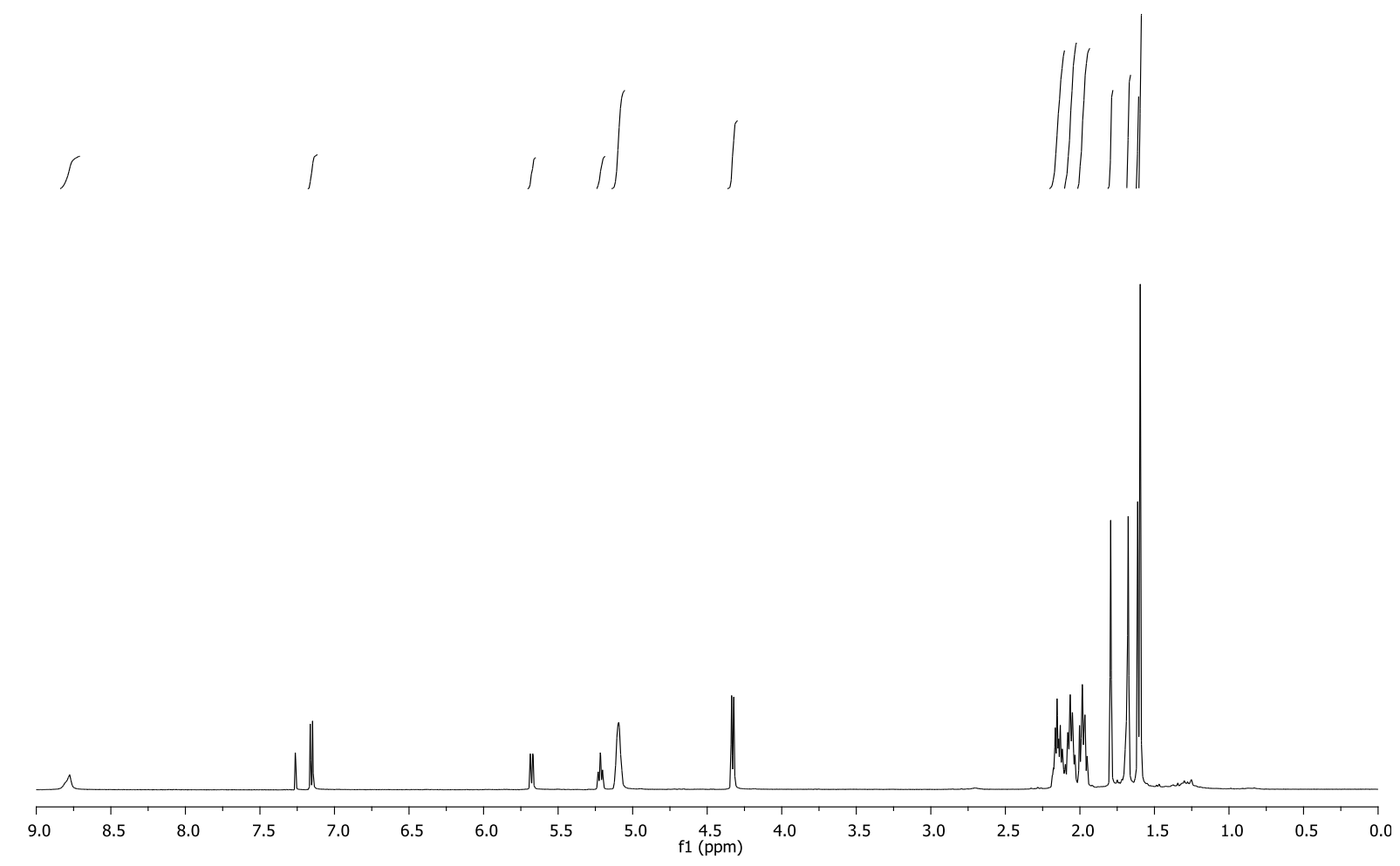

${ }^{1} \mathrm{H}$ NMR spectrum $\left(500 \mathrm{MHz}, \mathrm{CDCl}_{3}\right)$ of 135.

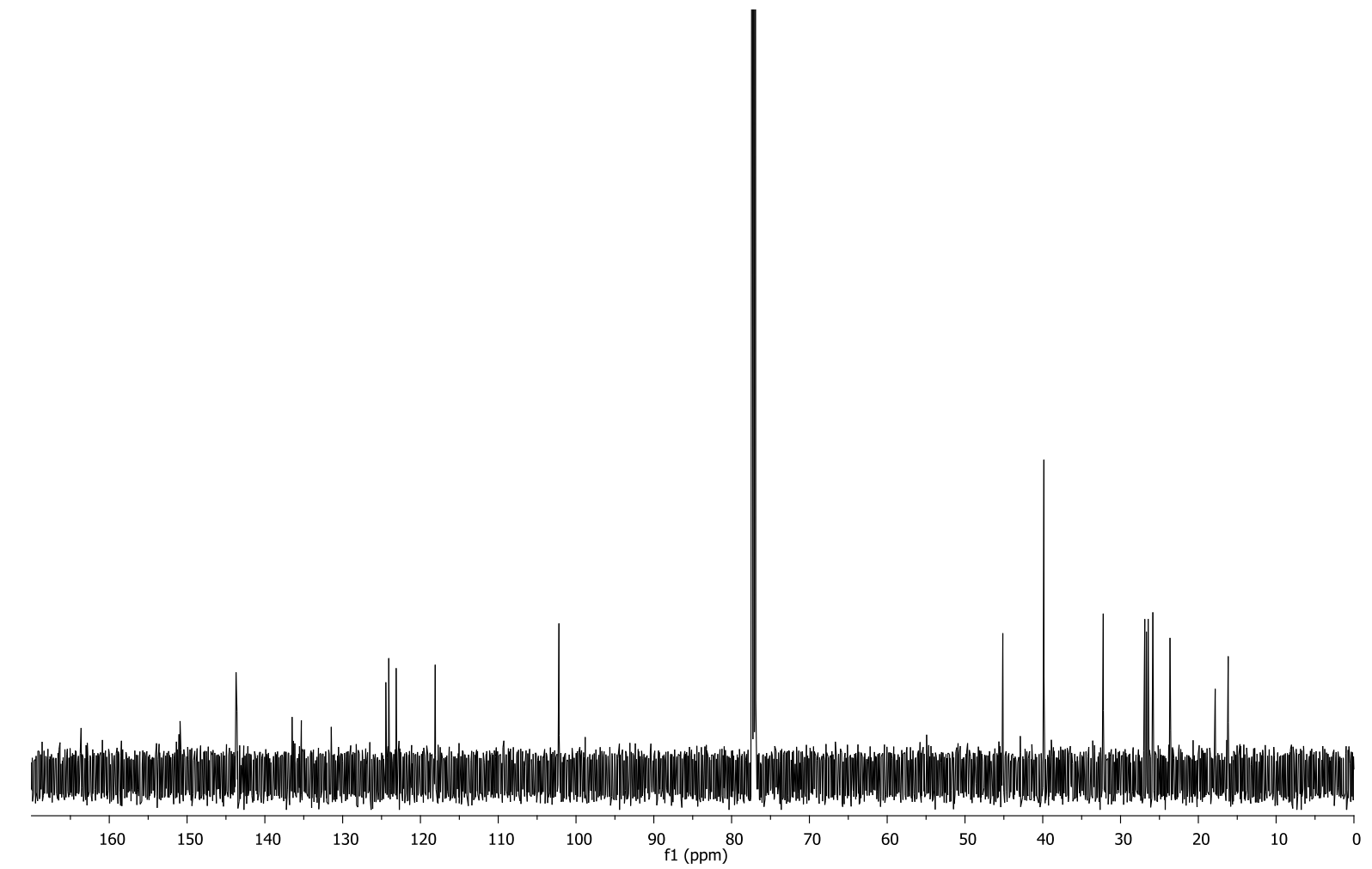

${ }^{13} \mathrm{C}$ NMR spectrum $\left(150 \mathrm{MHz}, \mathrm{CDCl}_{3}\right)$ of $\mathbf{1 3 5}$. 
1-((2E,6E,10E)-3,7,11,15-Tetramethylhexadeca-2,6,10,14-tetraen-1-yl)pyrimidine2,4(1H,3H)-dione (136)

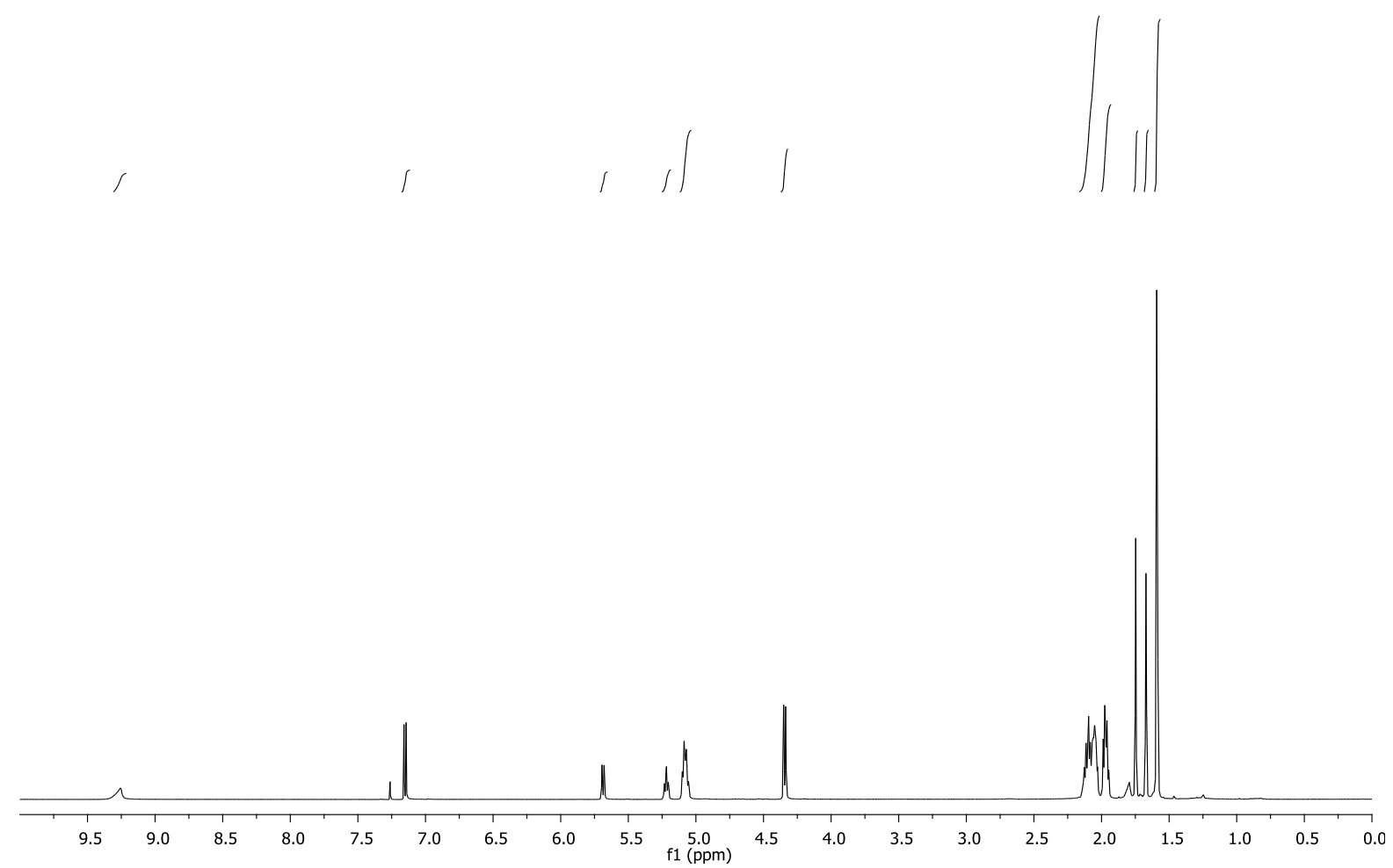

${ }^{1} \mathrm{H}$ NMR spectrum $\left(500 \mathrm{MHz}, \mathrm{CDCl}_{3}\right)$ of $\mathbf{1 3 6}$.

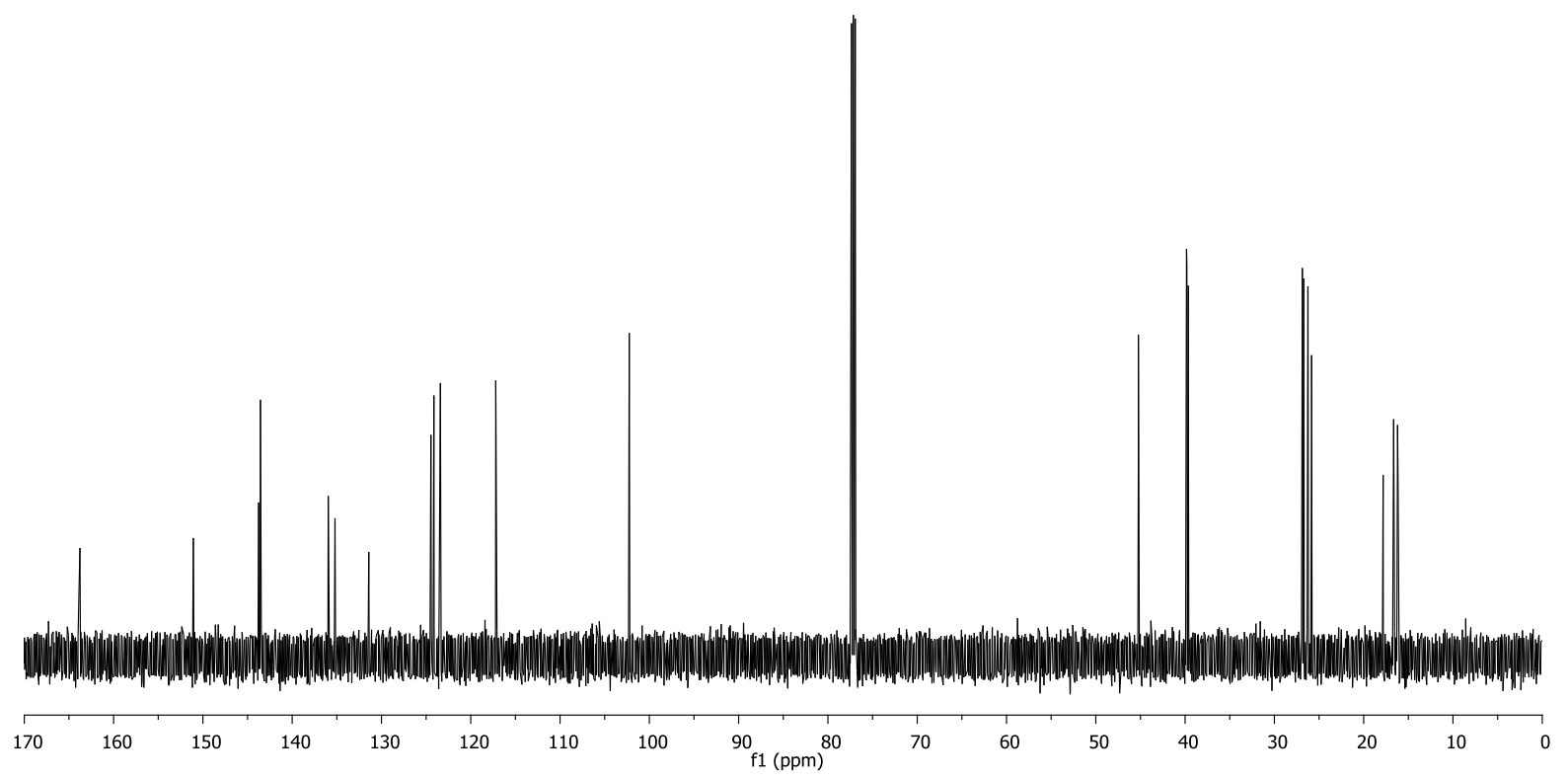

${ }^{13} \mathrm{C}$ NMR spectrum $\left(150 \mathrm{MHz}, \mathrm{CDCl}_{3}\right)$ of $\mathbf{1 3 6}$. 
(E)-1-(3,7-Dimethylocta-2,6-dien-1-yl)-5-methylpyrimidine-2,4-(1H,3H)-dione (137)

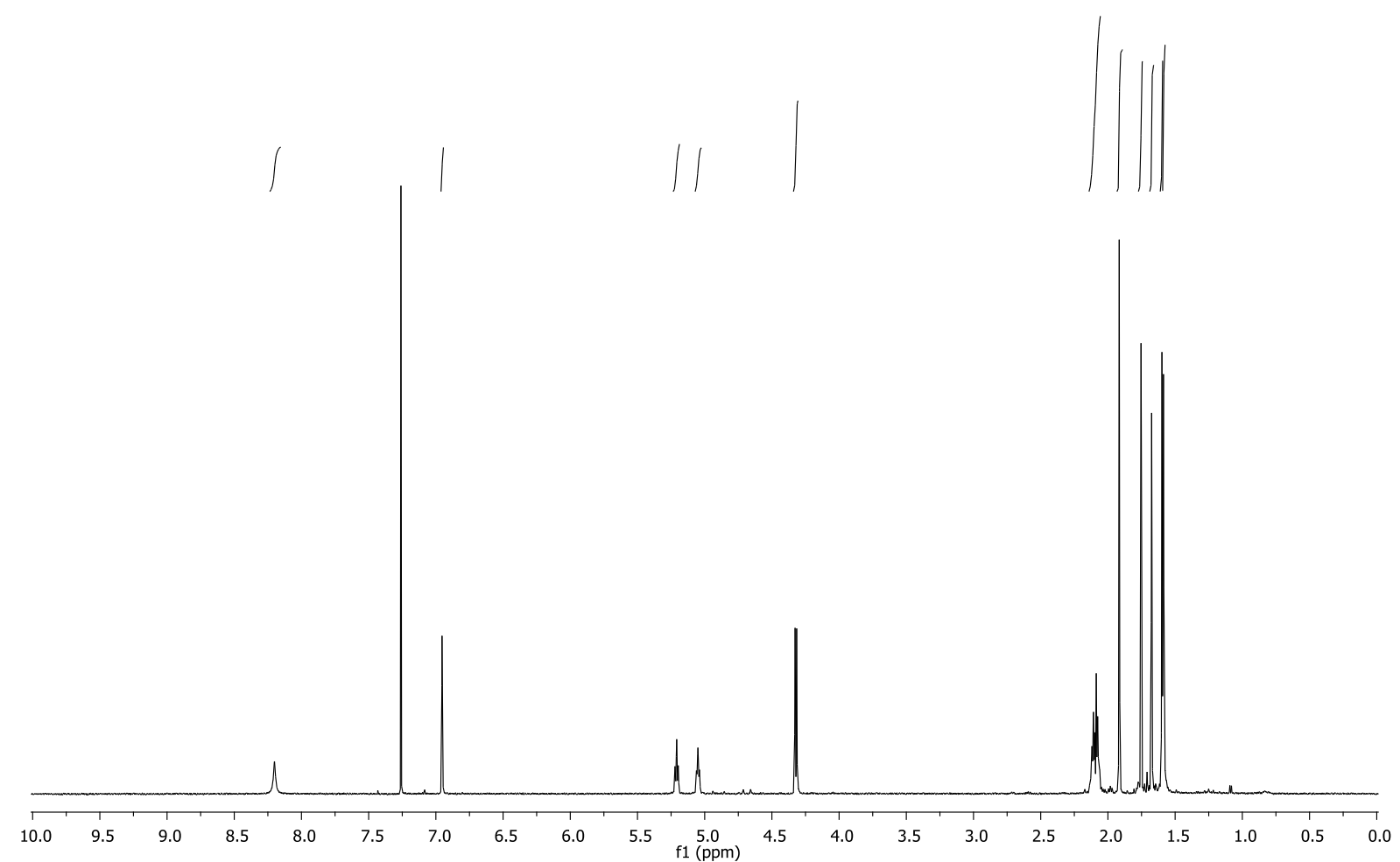

${ }^{1} \mathrm{H}$ NMR spectrum $\left(600 \mathrm{MHz}, \mathrm{CDCl}_{3}\right)$ of 137.

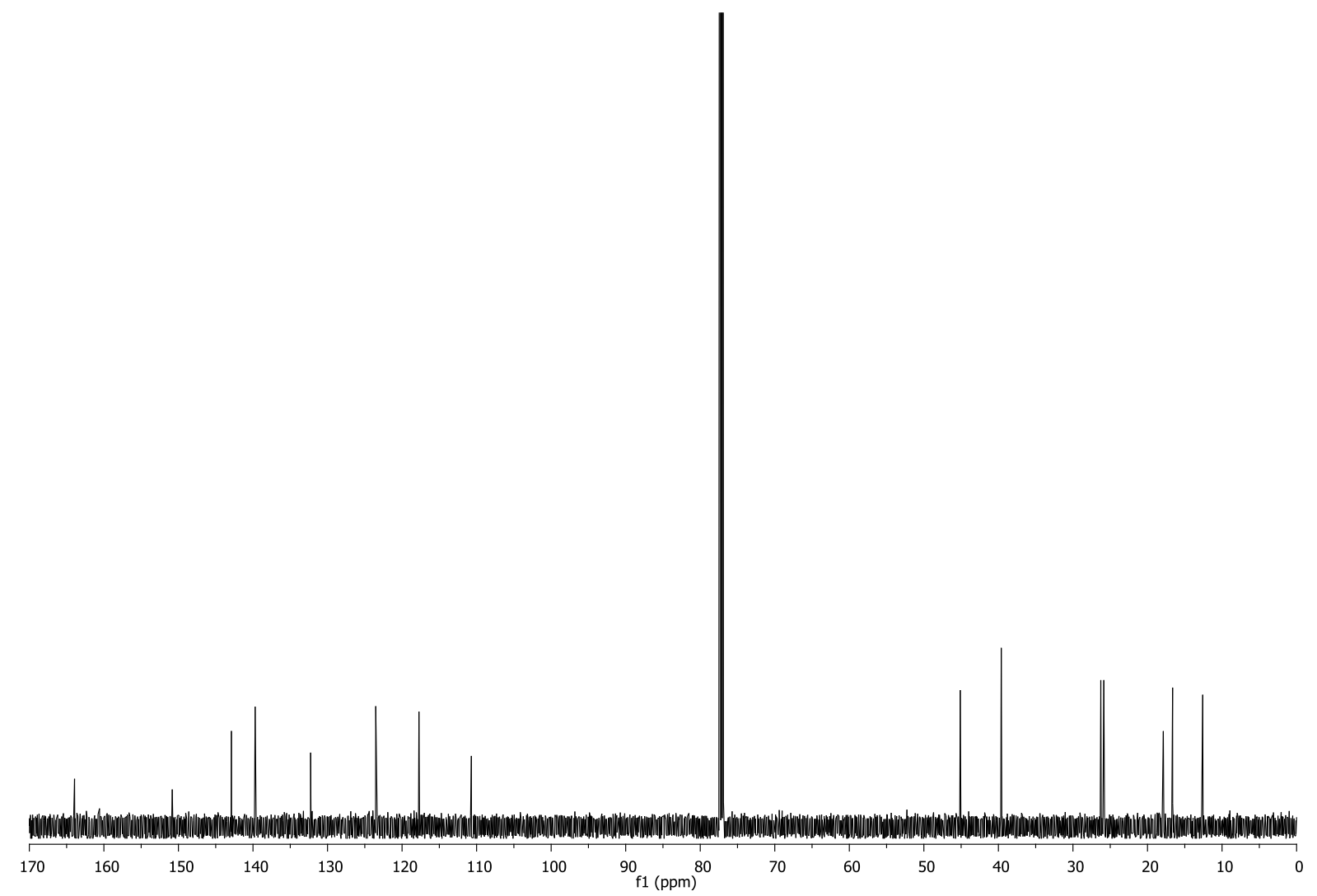

${ }^{13} \mathrm{C}$ NMR spectrum $\left(150 \mathrm{MHz}, \mathrm{CDCl}_{3}\right)$ of 137. 
5-Methyl-1-((6E)-3,7,11-trimethyldodeca-2,6,10-trien-1-yl)pyrimidine-2,4(1H,3H)dione (138)

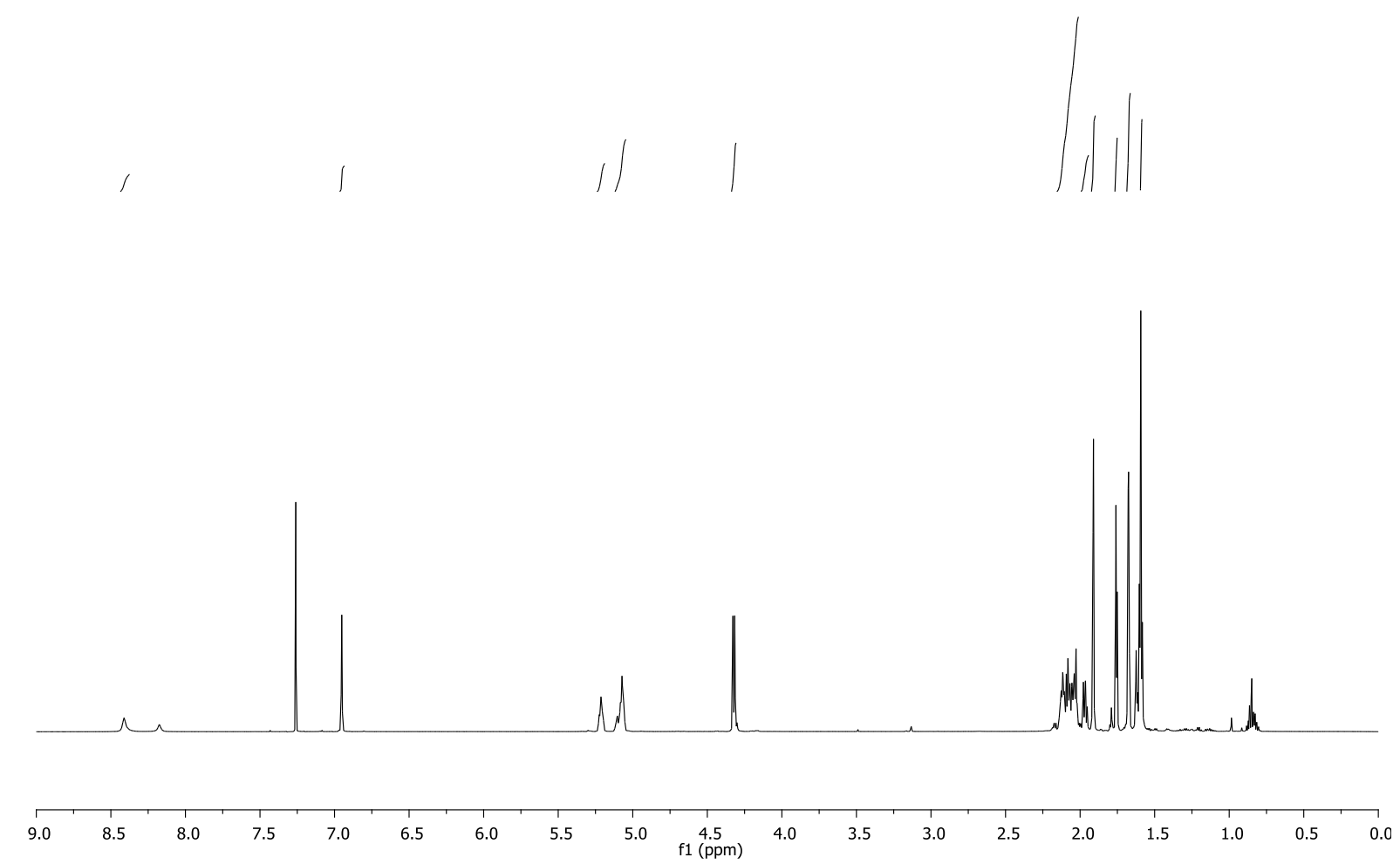

${ }^{1} \mathrm{H}$ NMR spectrum $\left(600 \mathrm{MHz}, \mathrm{CDCl}_{3}\right)$ of $\mathbf{1 3 8}$.

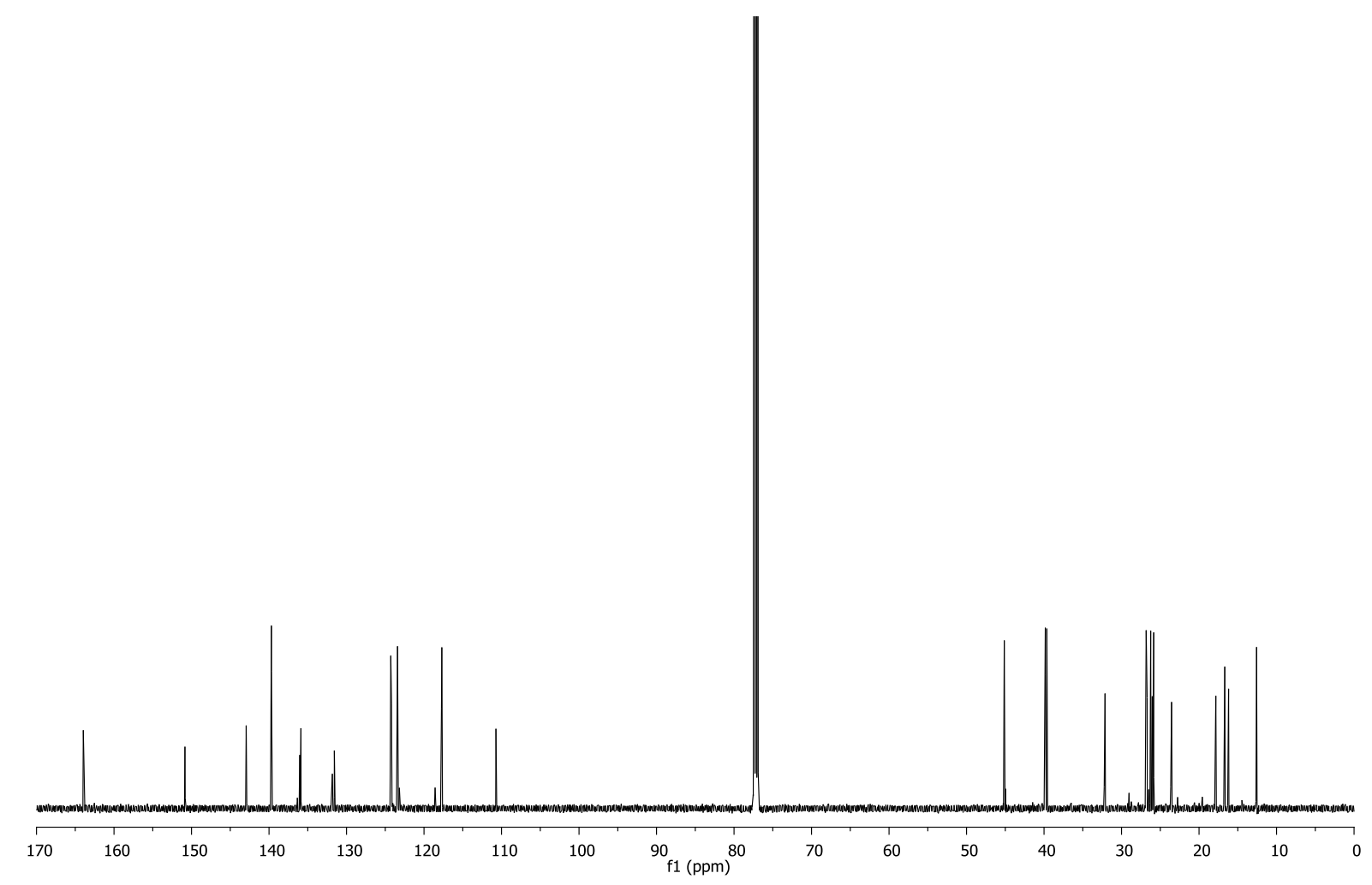

${ }^{13} \mathrm{C}$ NMR spectrum $\left(150 \mathrm{MHz}, \mathrm{CDCl}_{3}\right)$ of $\mathbf{1 3 8}$. 
5-Methyl-1-((2E,6E,10E)-3,7,11,15-tetramethylhexadeca-2,6,10,14-tetraen-1yl)pyrimidine-2,4(1H,3H)-dione (139)

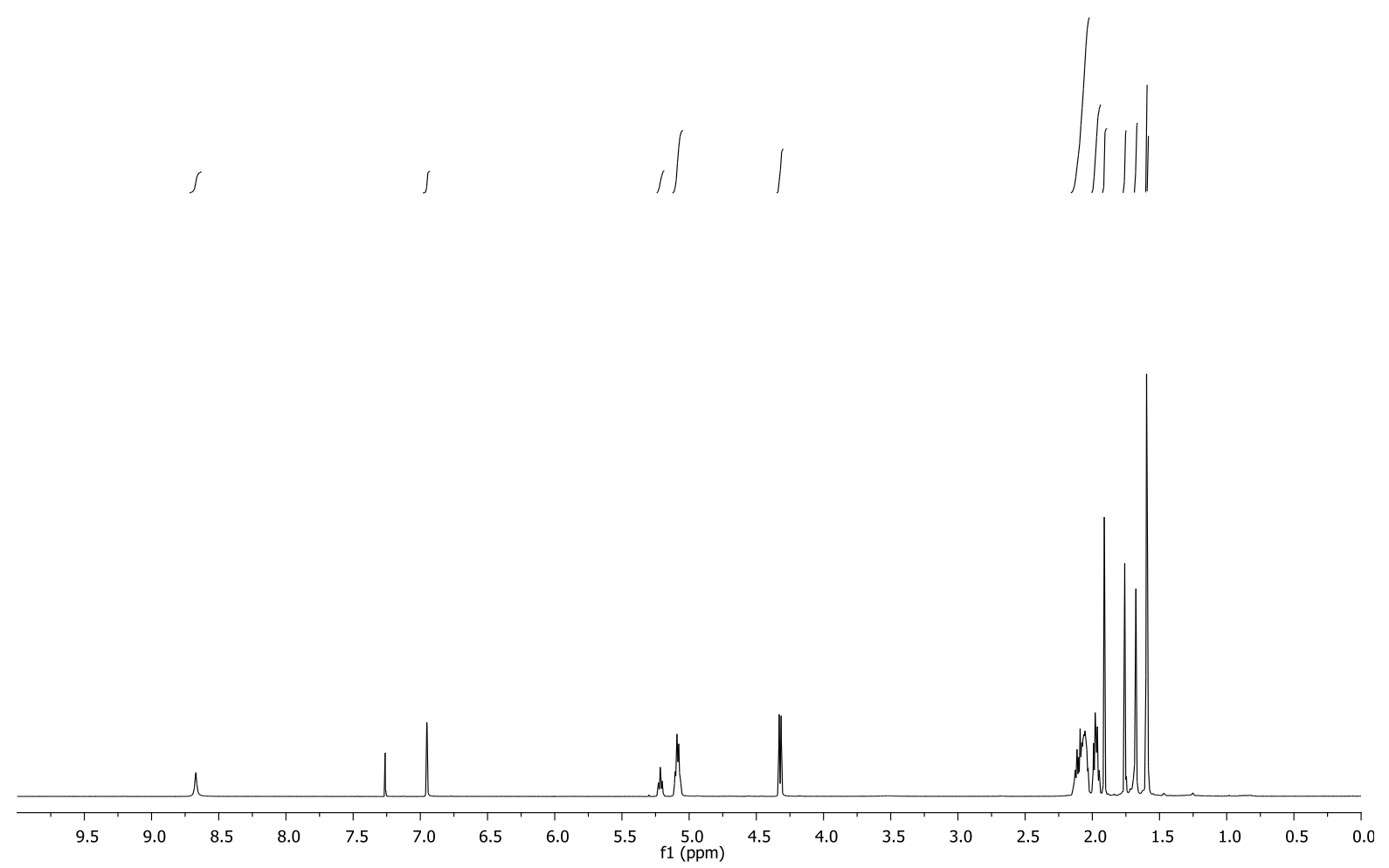

${ }^{1} \mathrm{H}$ NMR spectrum $\left(500 \mathrm{MHz}, \mathrm{CDCl}_{3}\right)$ of 139. 
1,3-bis((E)-3,7-Dimethylocta-2,6-dien-1-yl)-4-imino-3,4-dihydropyrimidin-2(1H)-one (140)

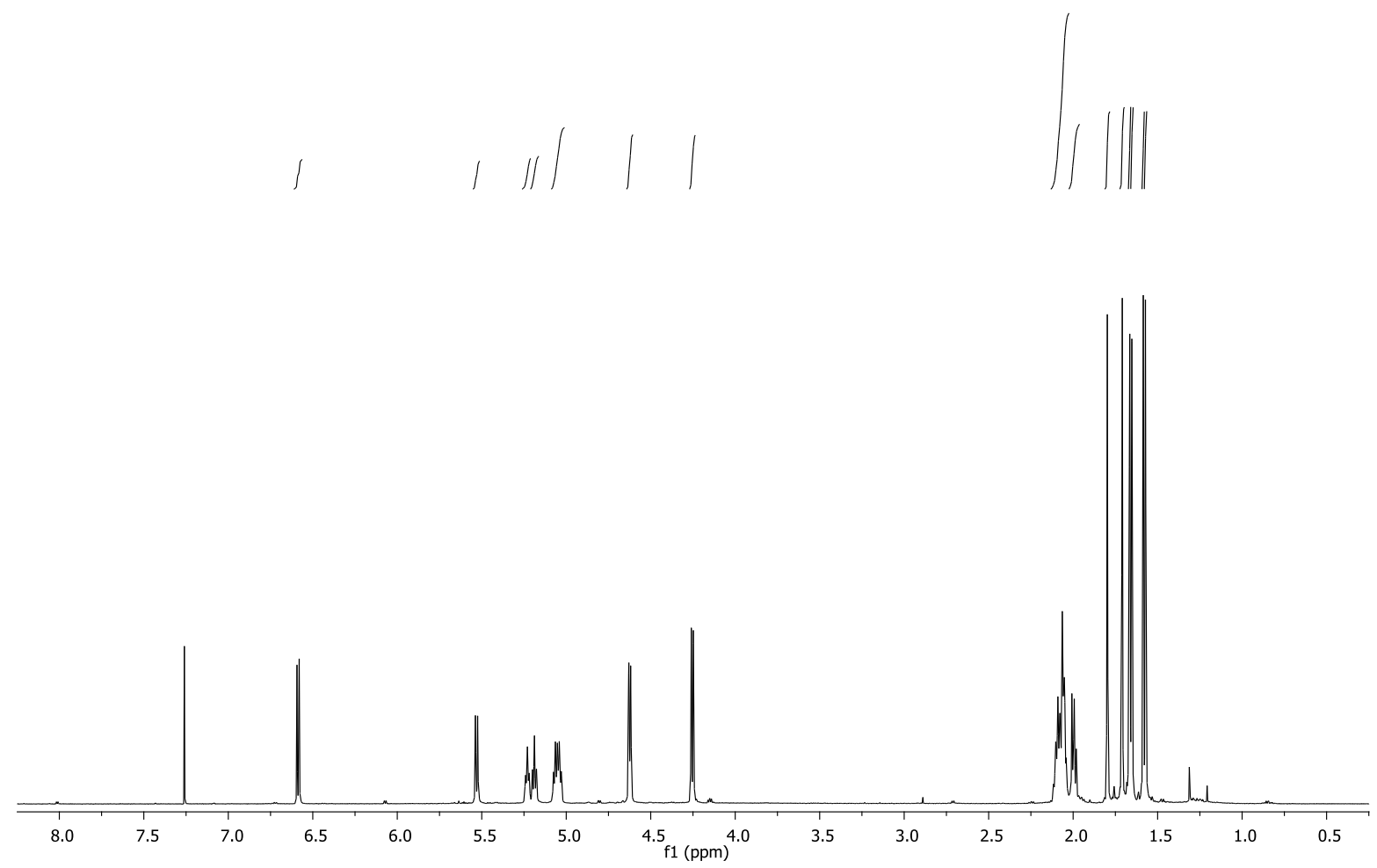

${ }^{1} \mathrm{H}$ NMR spectrum $\left(600 \mathrm{MHz}, \mathrm{CDCl}_{3}\right)$ of $\mathbf{1 4 0}$.

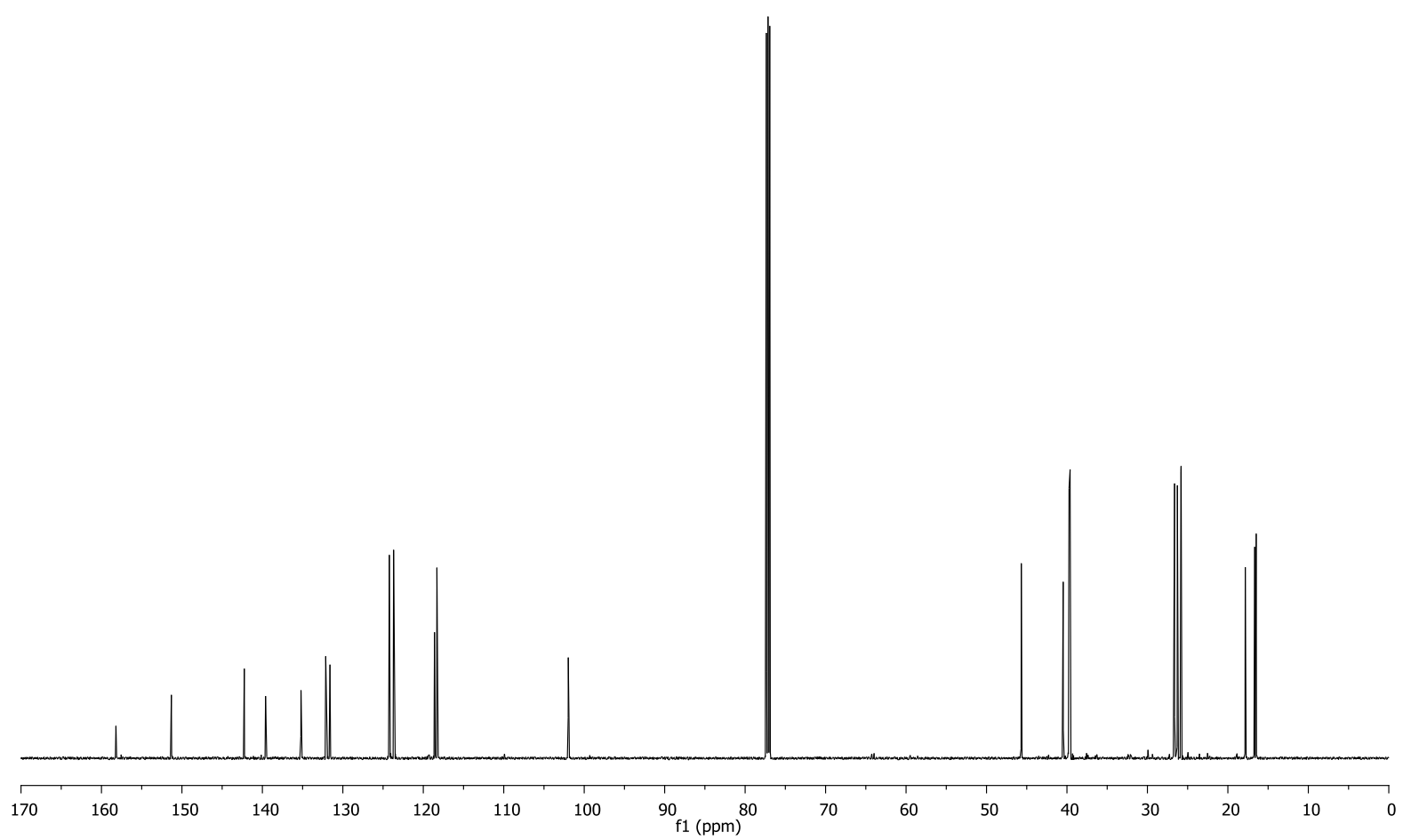

${ }^{13} \mathrm{C}$ NMR spectrum $\left(150 \mathrm{MHz}, \mathrm{CDCl}_{3}\right)$ of $\mathbf{1 4 0 .}$ 
4-Imino-1,3-bis((6E)-3,7,11-trimethyldodeca-2,6,10-trien-1-yl)-3,4-dihydropyrimidin2(1H)-one (141)

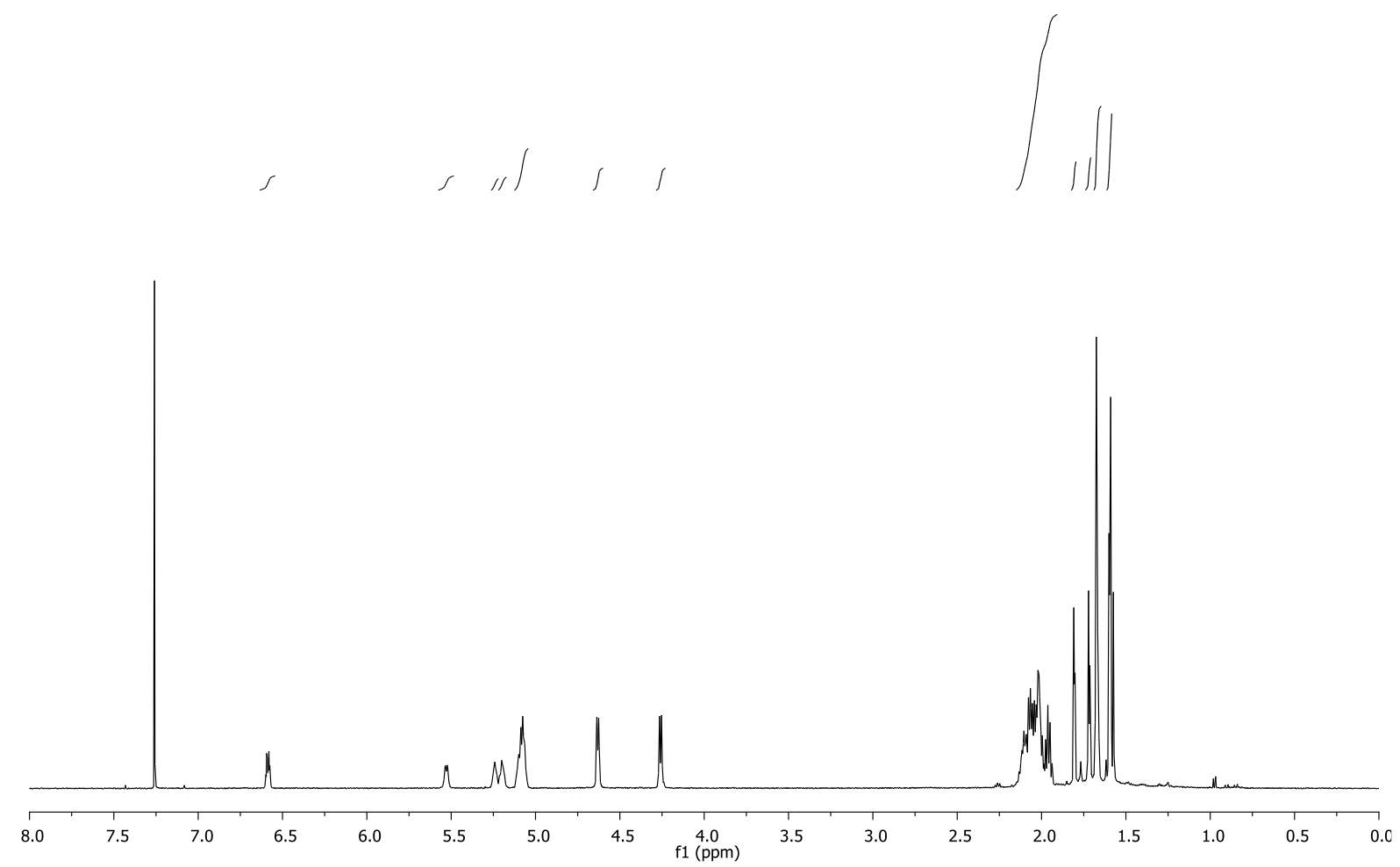

${ }^{1} \mathrm{H}$ NMR spectrum $\left(600 \mathrm{MHz}, \mathrm{CDCl}_{3}\right)$ of $\mathbf{1 4 1}$.

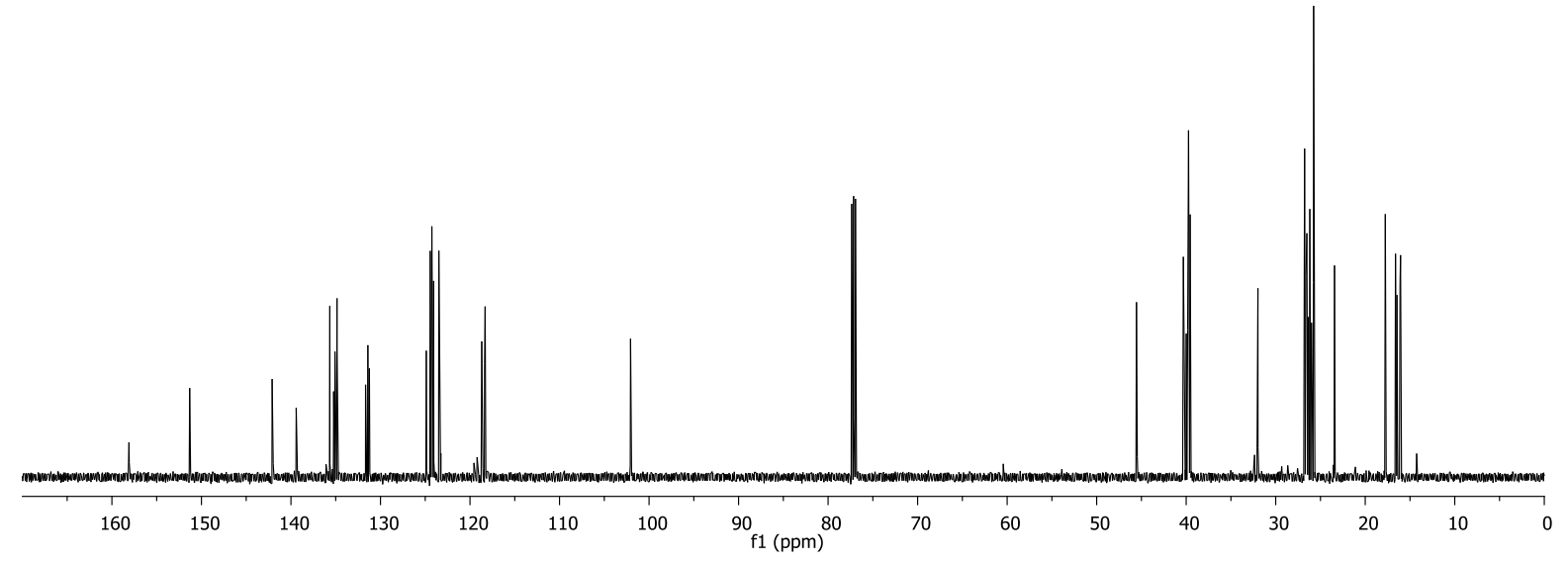

${ }^{13} \mathrm{C}$ NMR spectrum $\left(150 \mathrm{MHz}, \mathrm{CDCl}_{3}\right)$ of 141. 
(E)-1-(3,7-Dimethylocta-2,6-dien-1-yl)-1H-imidazole (143)

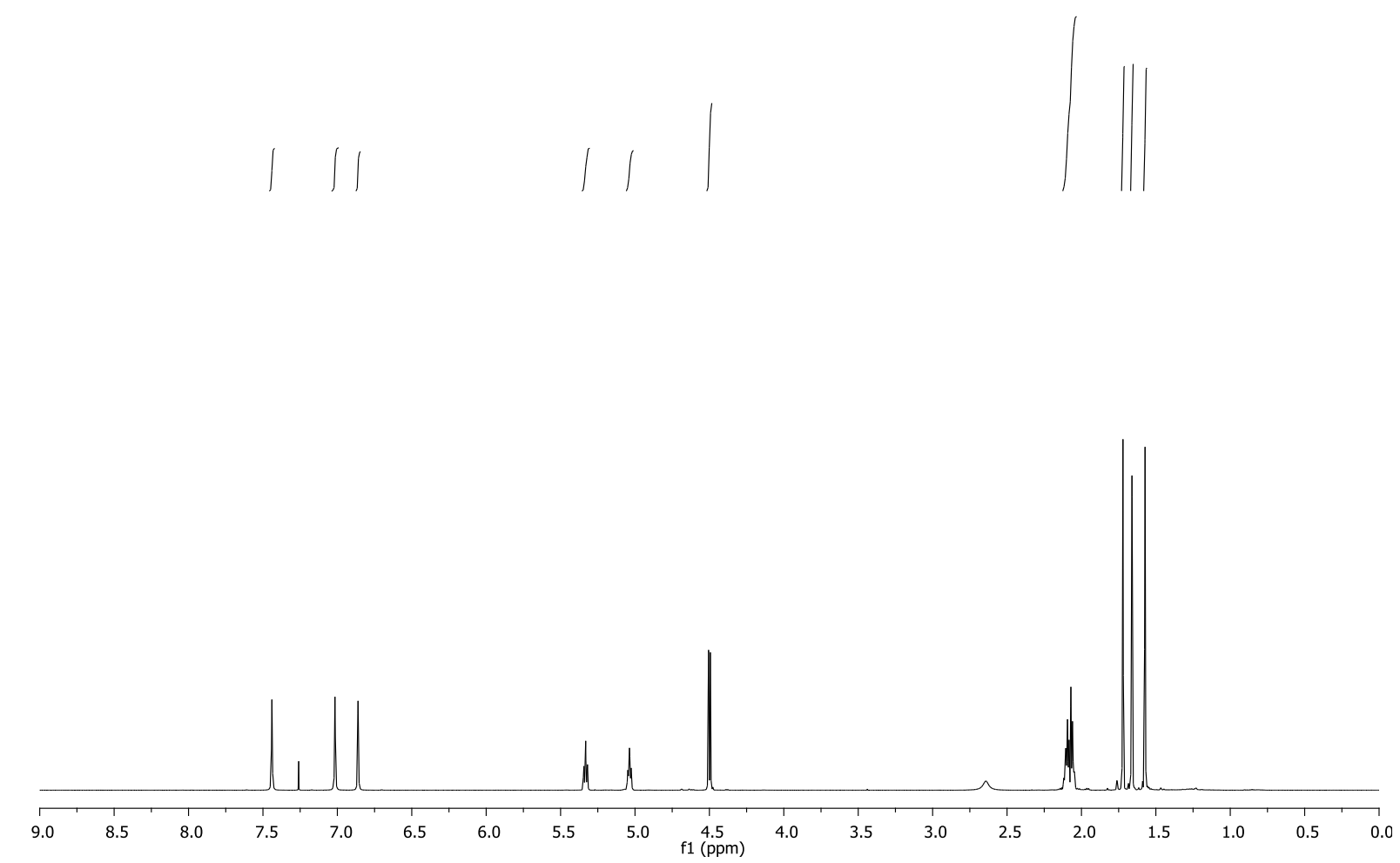

${ }^{1} \mathrm{H}$ NMR spectrum $\left(600 \mathrm{MHz}, \mathrm{CDCl}_{3}\right)$ of $\mathbf{1 4 3}$.

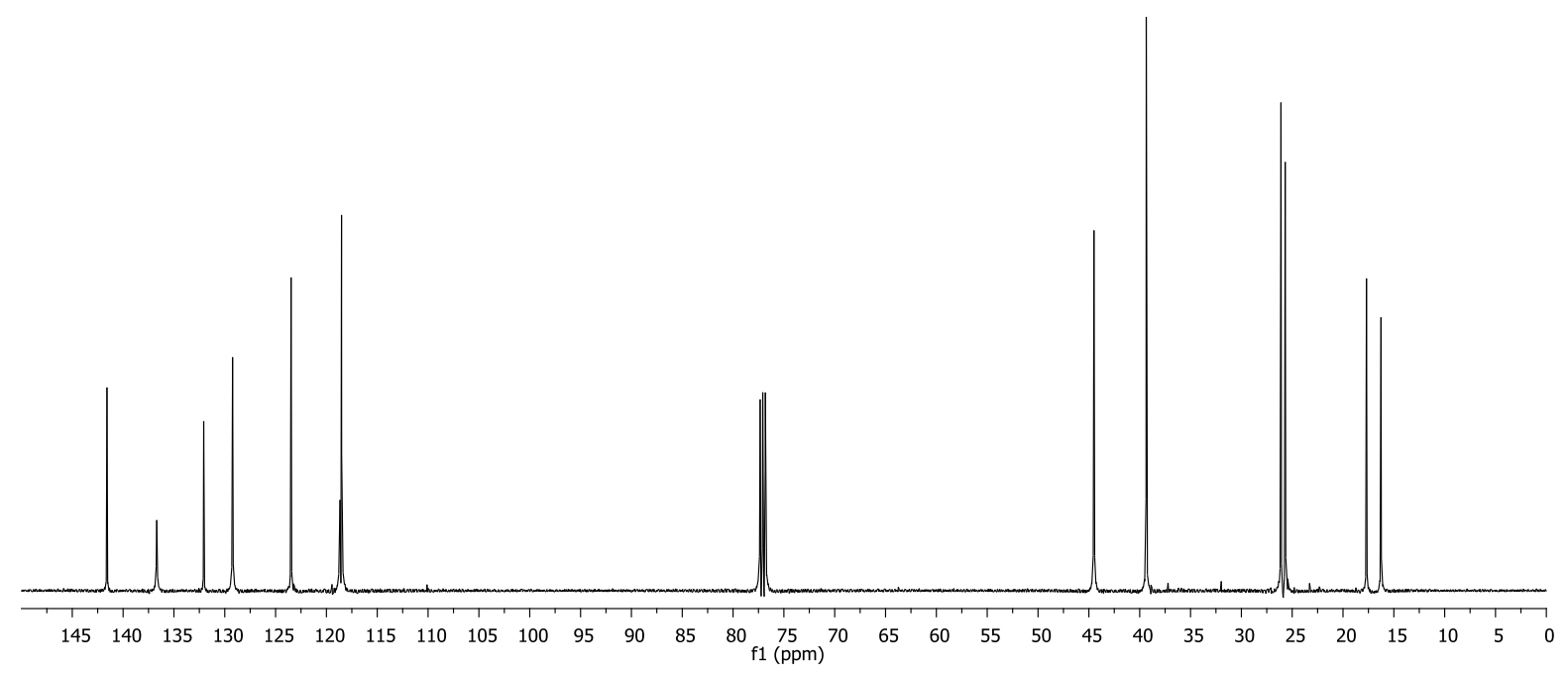

${ }^{13} \mathrm{C}$ NMR spectrum $\left(150 \mathrm{MHz}, \mathrm{CDCl}_{3}\right)$ of 143. 
1-((6E)-3,7,11-Trimethyldodeca-2,6,10-trien-1-yl)-1H-imidazole (144)



${ }^{1} \mathrm{H}$ NMR spectrum $\left(600 \mathrm{MHz}, \mathrm{CDCl}_{3}\right)$ of 144.

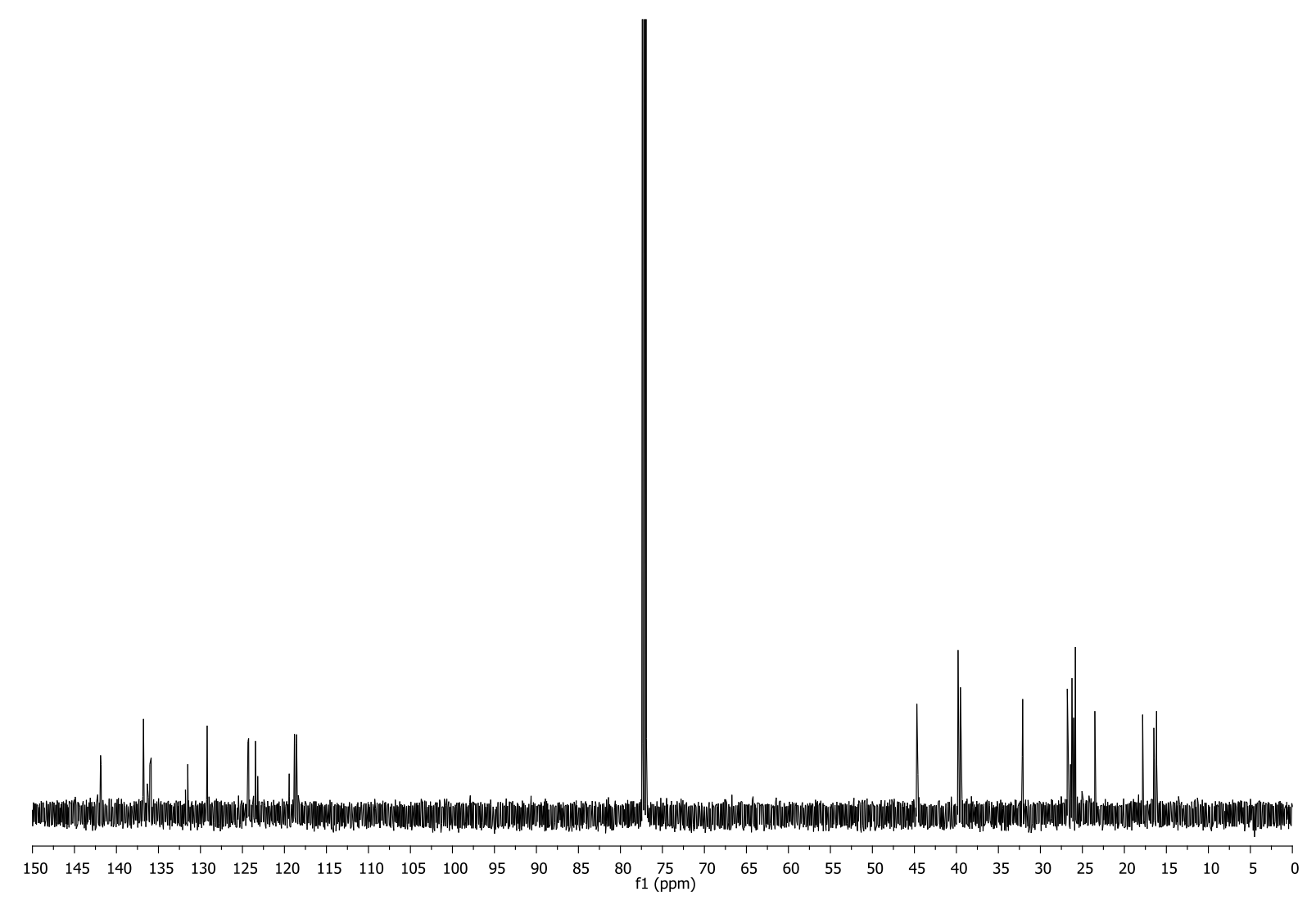

${ }^{13} \mathrm{C}$ NMR spectrum $\left(150 \mathrm{MHz}, \mathrm{CDCl}_{3}\right)$ of $\mathbf{1 4 4}$. 
1-((6E,10E)-3,7,11,15-Tetramethylhexadeca-2,6,10,14-tetraen-1-yl)-1H-imidazole (145)

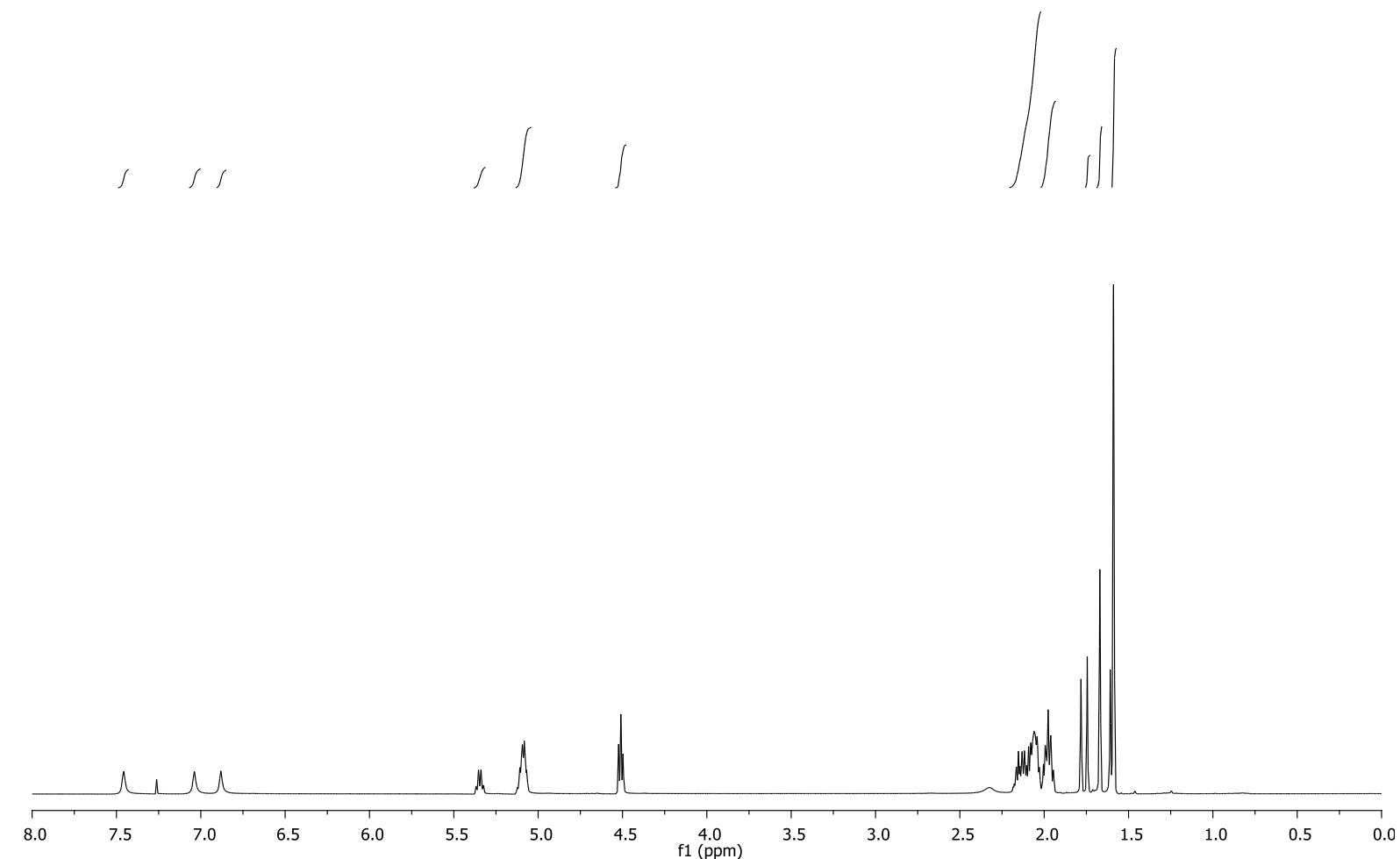

${ }^{1} \mathrm{H}$ NMR spectrum $\left(500 \mathrm{MHz}, \mathrm{CDCl}_{3}\right)$ of $\mathbf{1 4 5}$.

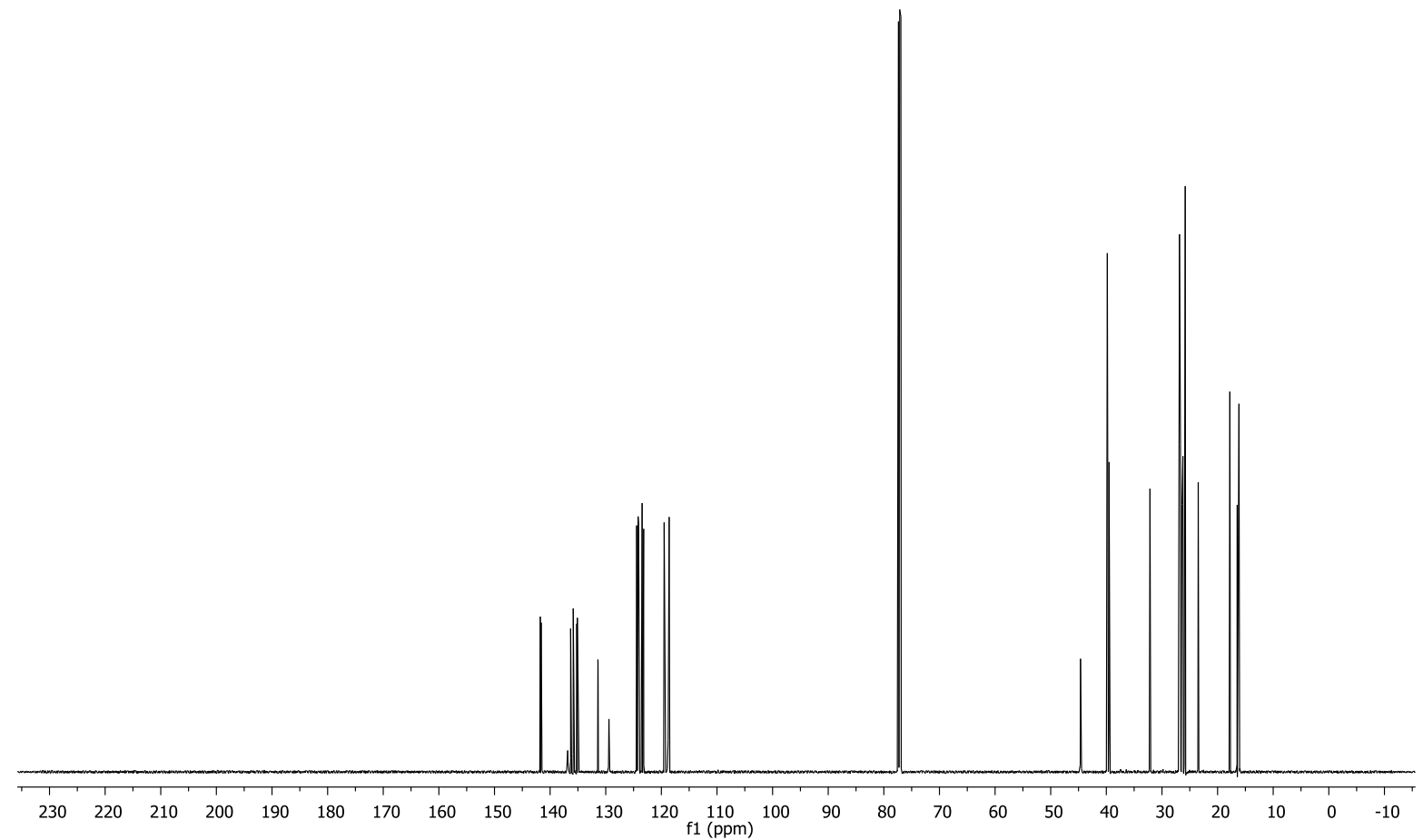

${ }^{13} \mathrm{C}$ NMR spectrum $\left(150 \mathrm{MHz}, \mathrm{CDCl}_{3}\right)$ of $\mathbf{1 4 5}$. 
1-((2E,6E,10E)-3,7,11,15-Tetramethylhexadeca-2,6,10,14-tetraen-1-yl)-1H-imidazole (146)

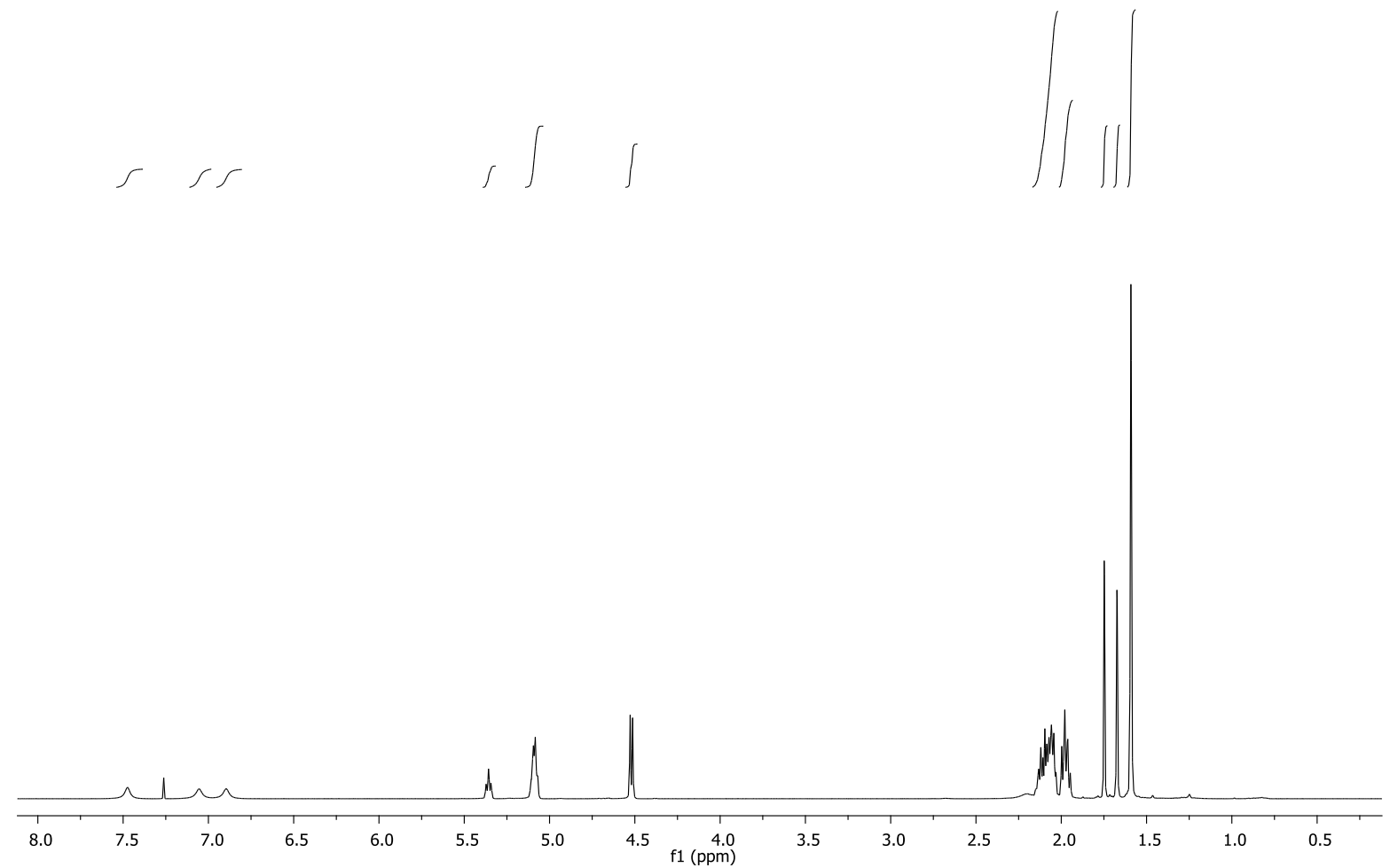

${ }^{1} \mathrm{H}$ NMR spectrum $\left(150 \mathrm{MHz}, \mathrm{CDCl}_{3}\right)$ of 146.

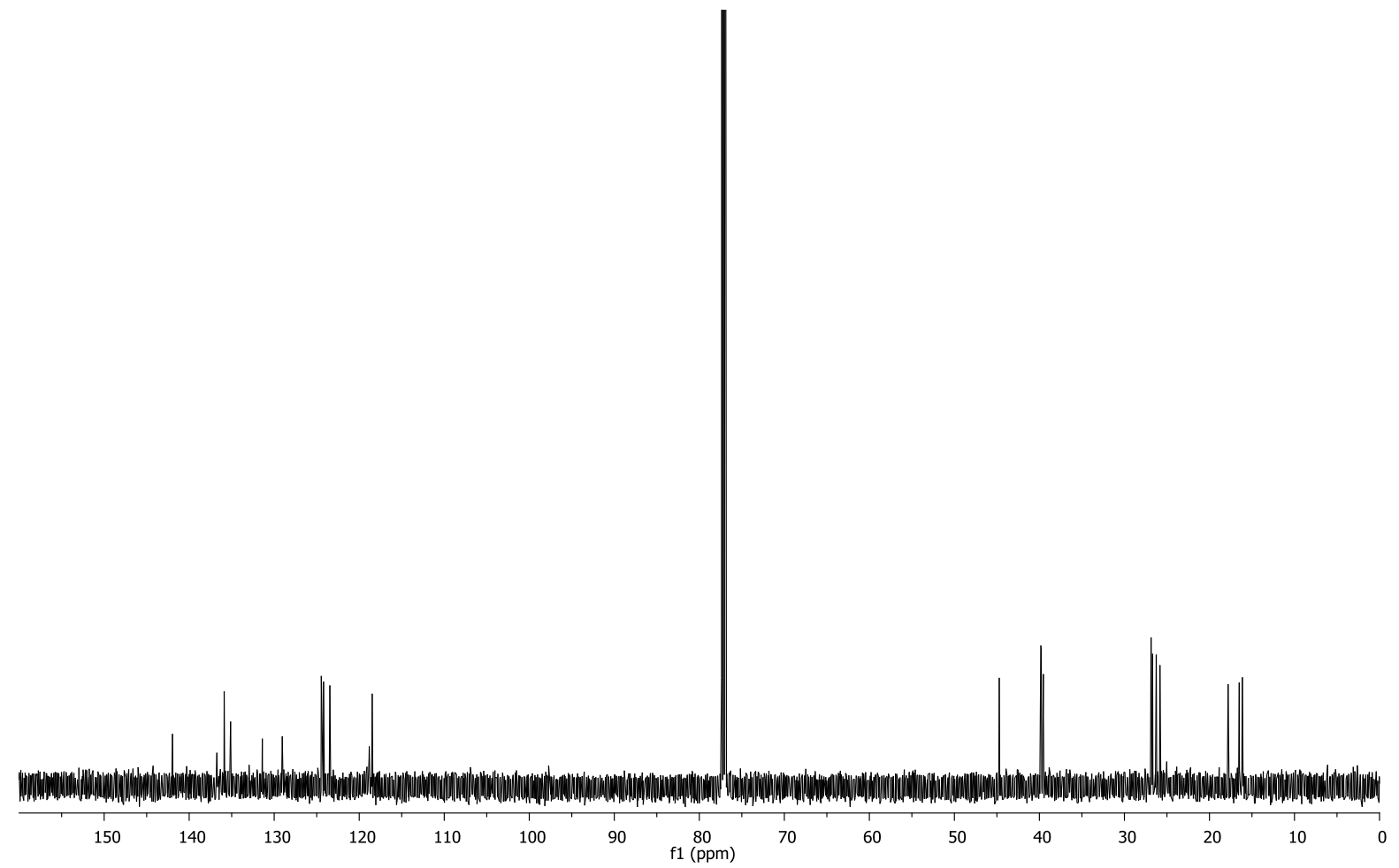

${ }^{13} \mathrm{C}$ NMR spectrum $\left(150 \mathrm{MHz}, \mathrm{CDCl}_{3}\right)$ of 146. 
(E)-2-(3,7-Dimethylocta-2,6-dien-1-yl)isoindoline-1,3-dione (148)
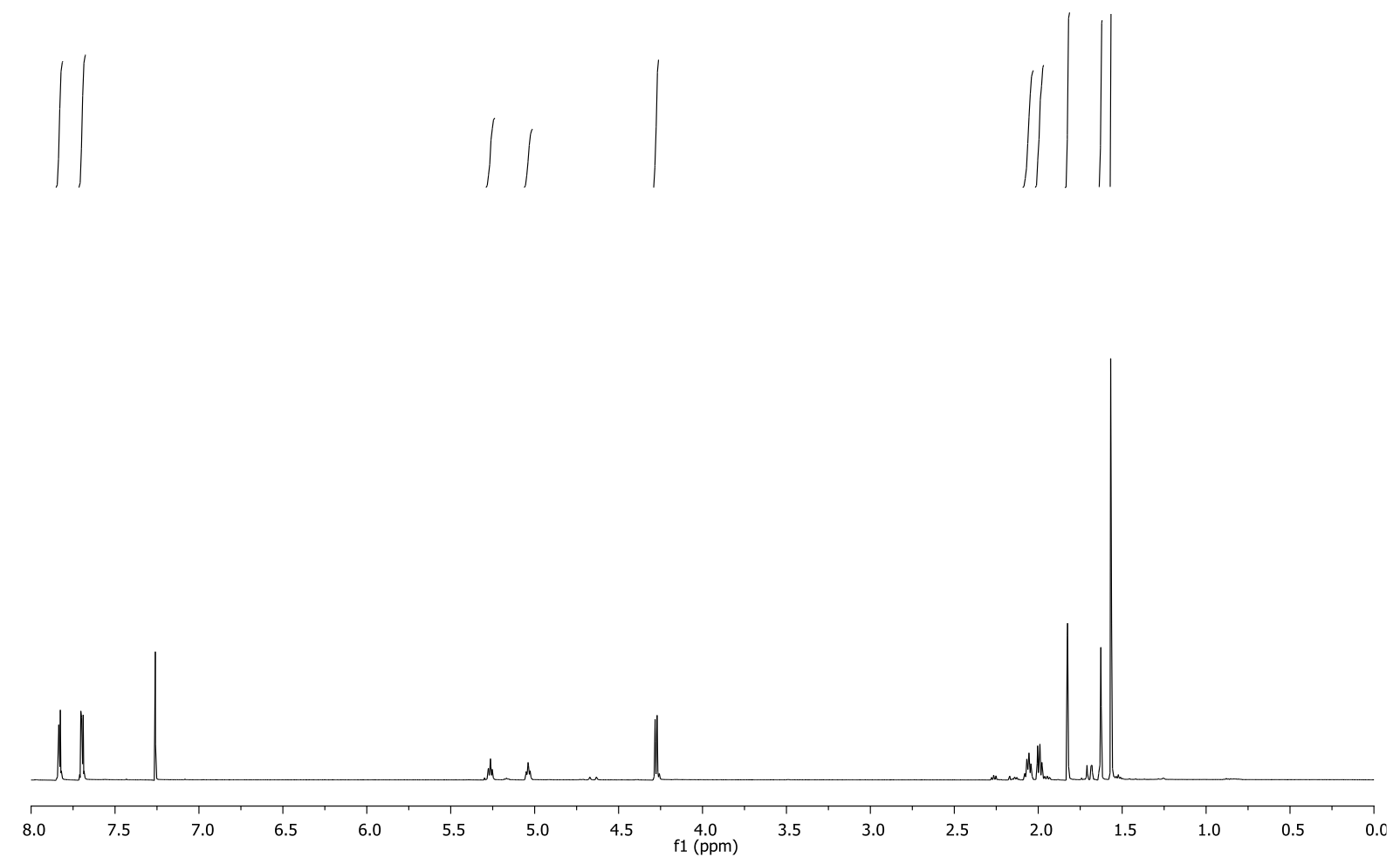

${ }^{1} \mathrm{H}$ NMR spectrum $\left(600 \mathrm{MHz}, \mathrm{CDCl}_{3}\right)$ of $\mathbf{1 4 8}$.

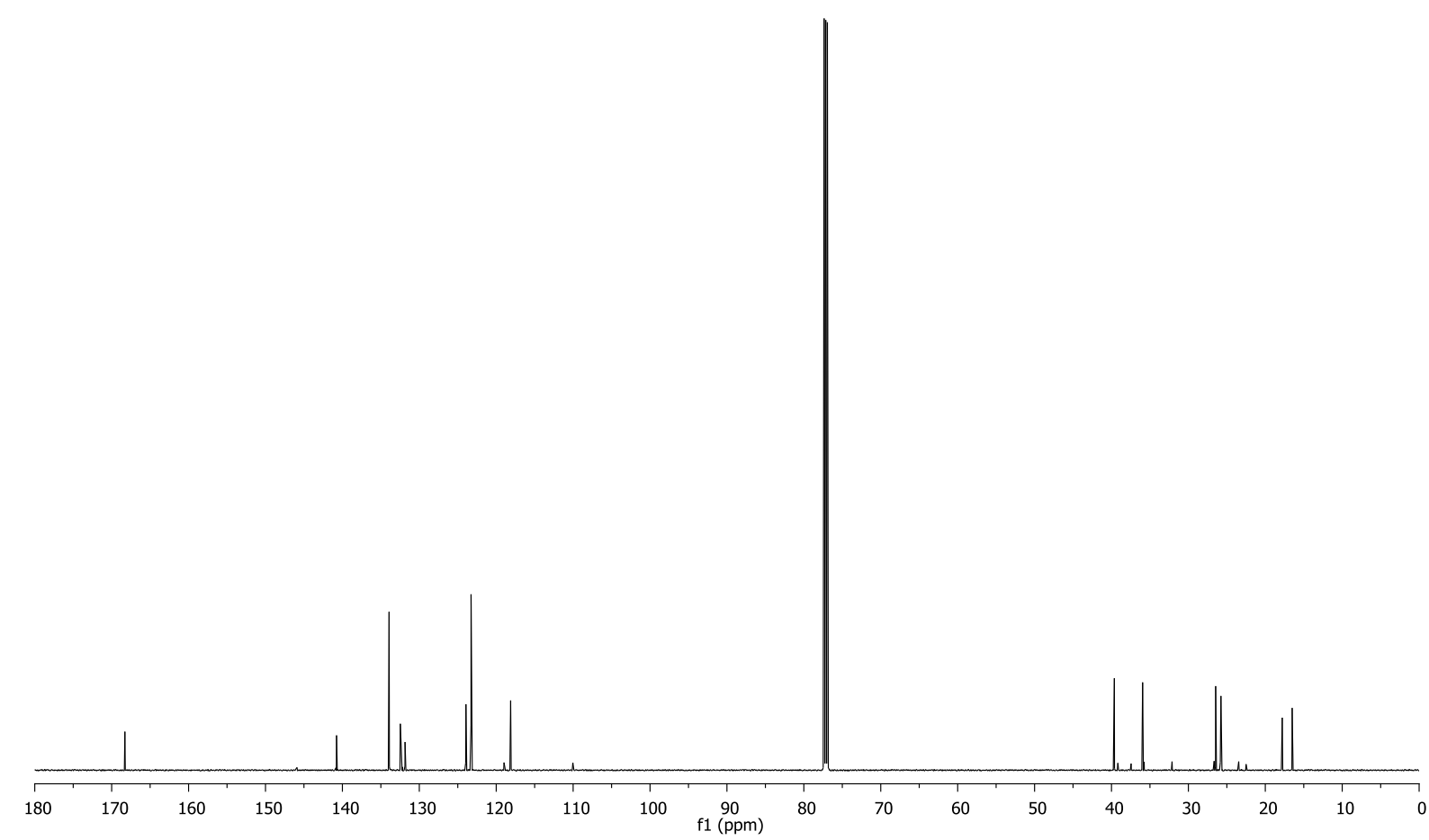

${ }^{13} \mathrm{C} \mathrm{NMR}$ spectrum $\left(150 \mathrm{MHz}, \mathrm{CDCl}_{3}\right)$ of $\mathbf{1 4 8}$. 
2-((6E)-3,7,11-Trimethyldodeca-2,6,10-trien-1-yl)isoindoline-1,3-dione (149)
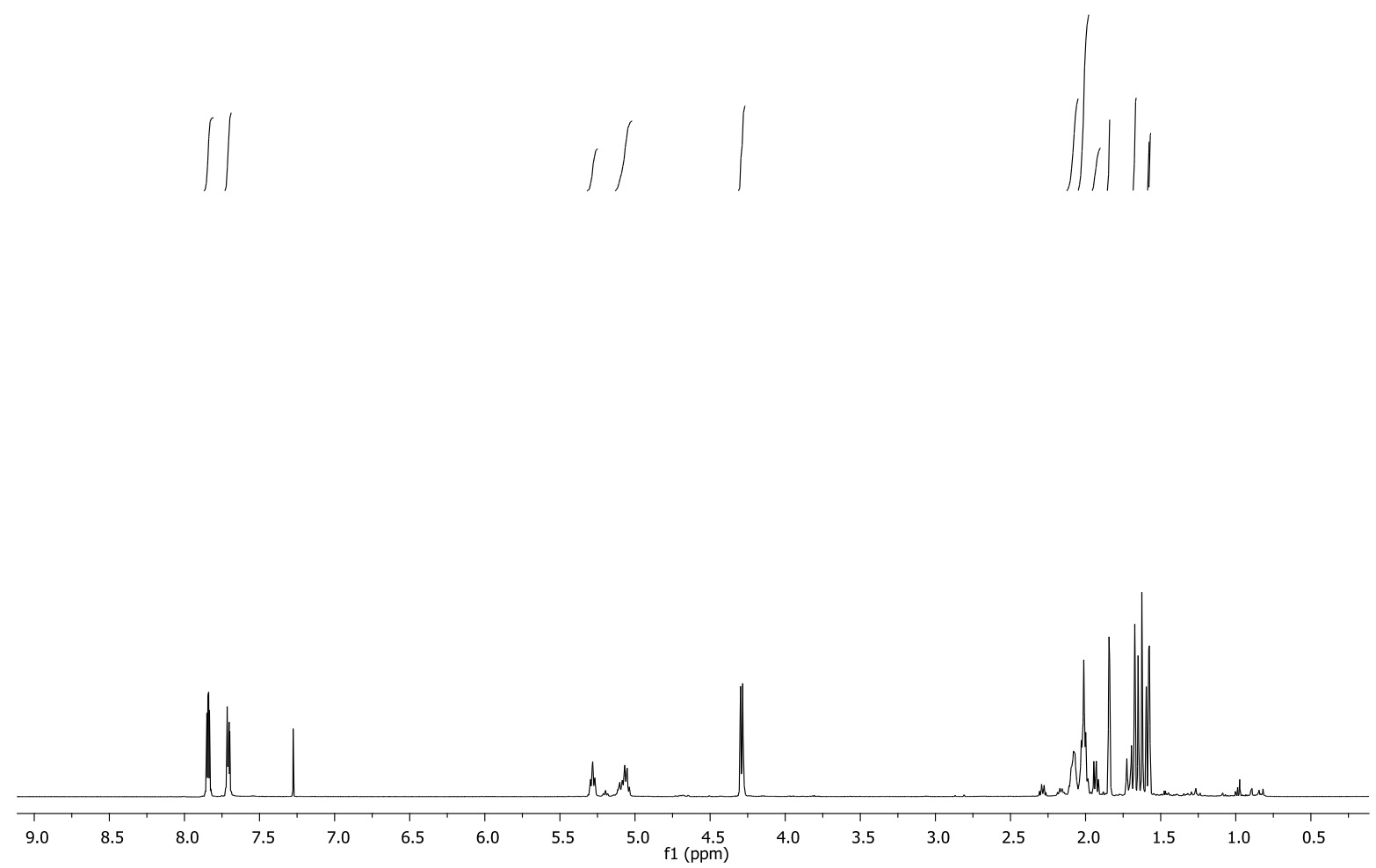

${ }^{1} \mathrm{H}$ NMR spectrum $\left(500 \mathrm{MHz}, \mathrm{CDCl}_{3}\right)$ of $\mathbf{1 4 9}$.

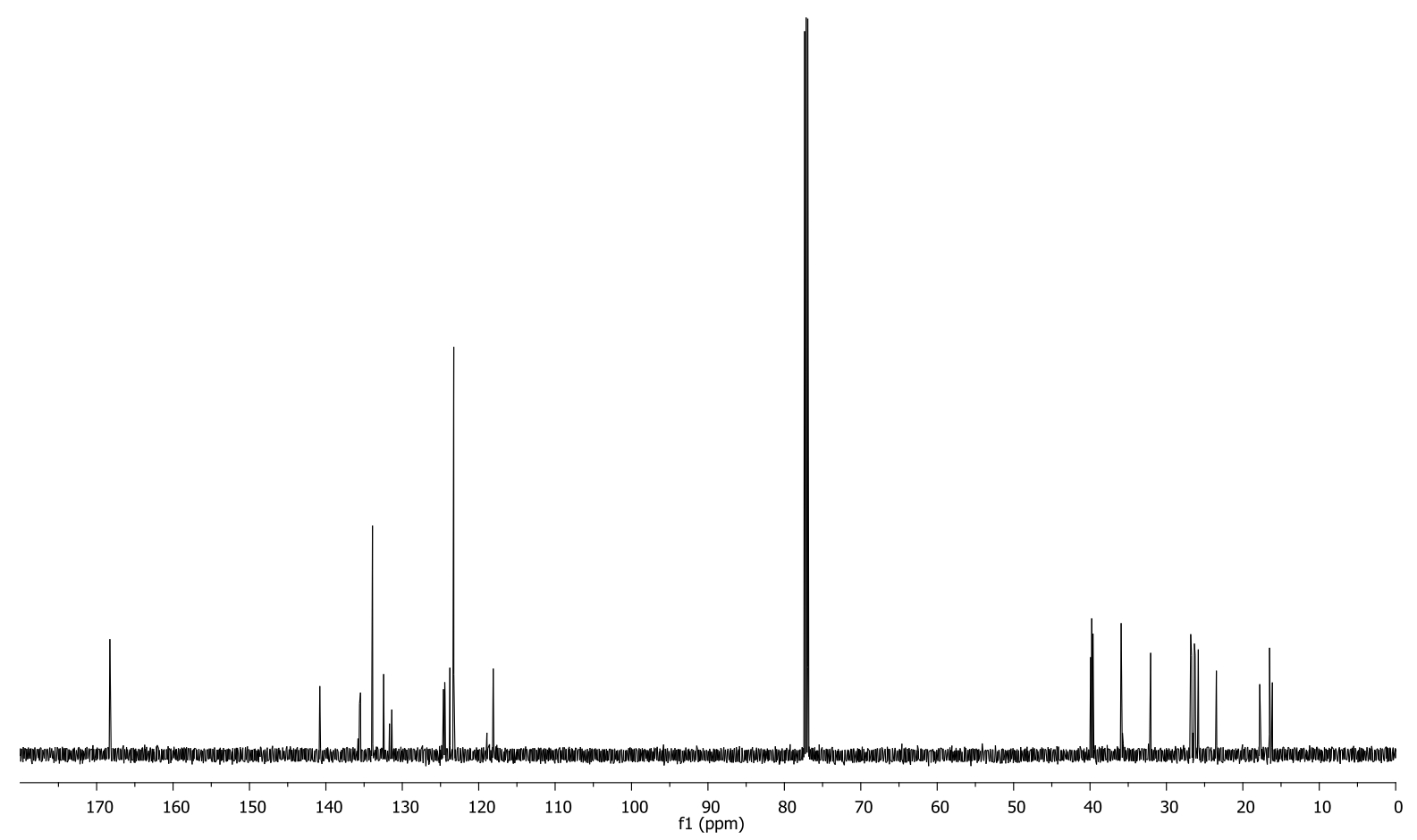

${ }^{13} \mathrm{C}$ NMR spectrum $\left(150 \mathrm{MHz}, \mathrm{CDCl}_{3}\right)$ of $\mathbf{1 4 9}$. 
2-((2E,6E,10E)-3,7,11,15-Tetramethylhexadeca-2,6,10,14-tetraen-1-yl)isoindoline-1,3dione (150)

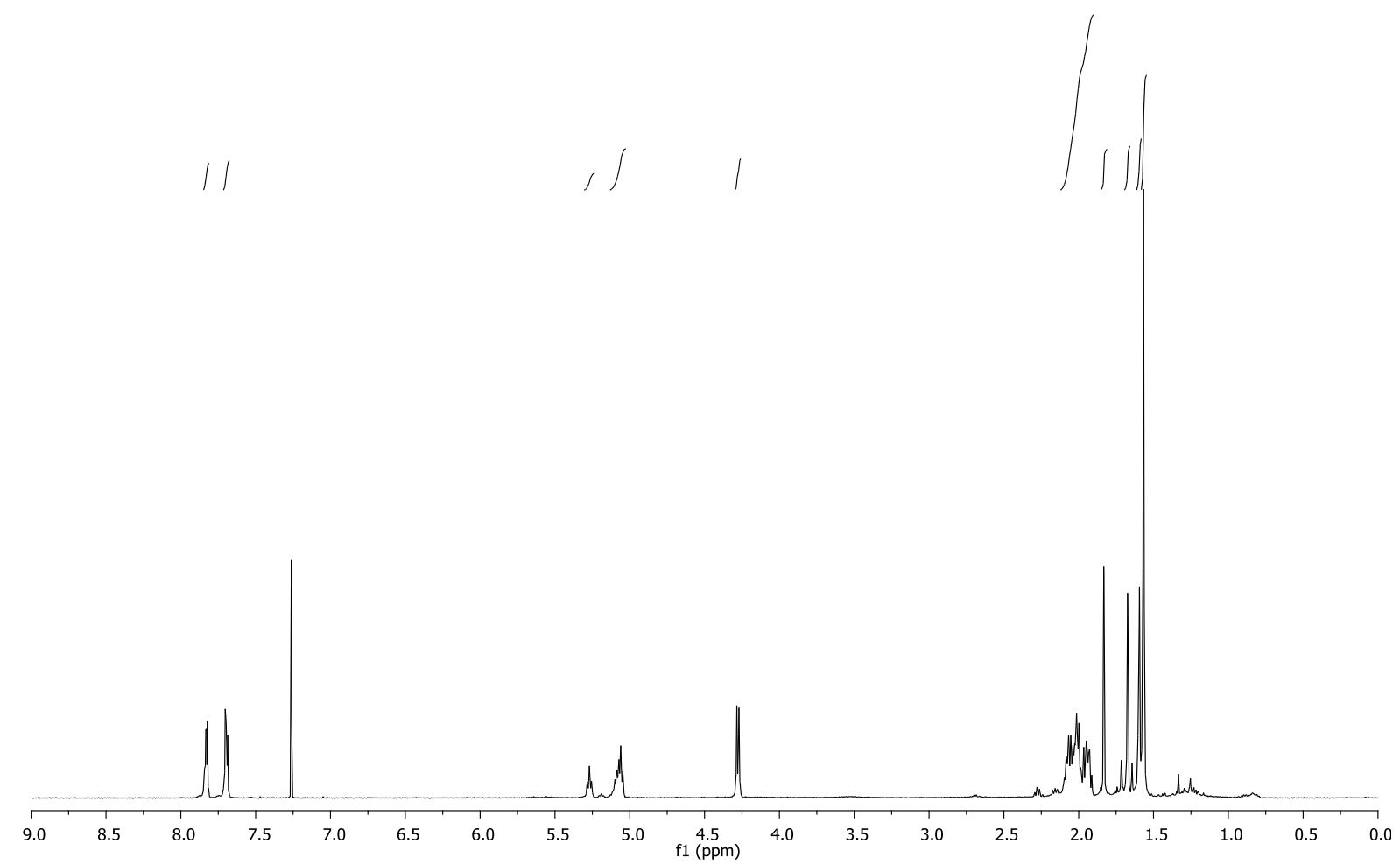

${ }^{1} \mathrm{H}$ NMR spectrum $\left(500 \mathrm{MHz}, \mathrm{CDCl}_{3}\right)$ of $\mathbf{1 5 0}$.

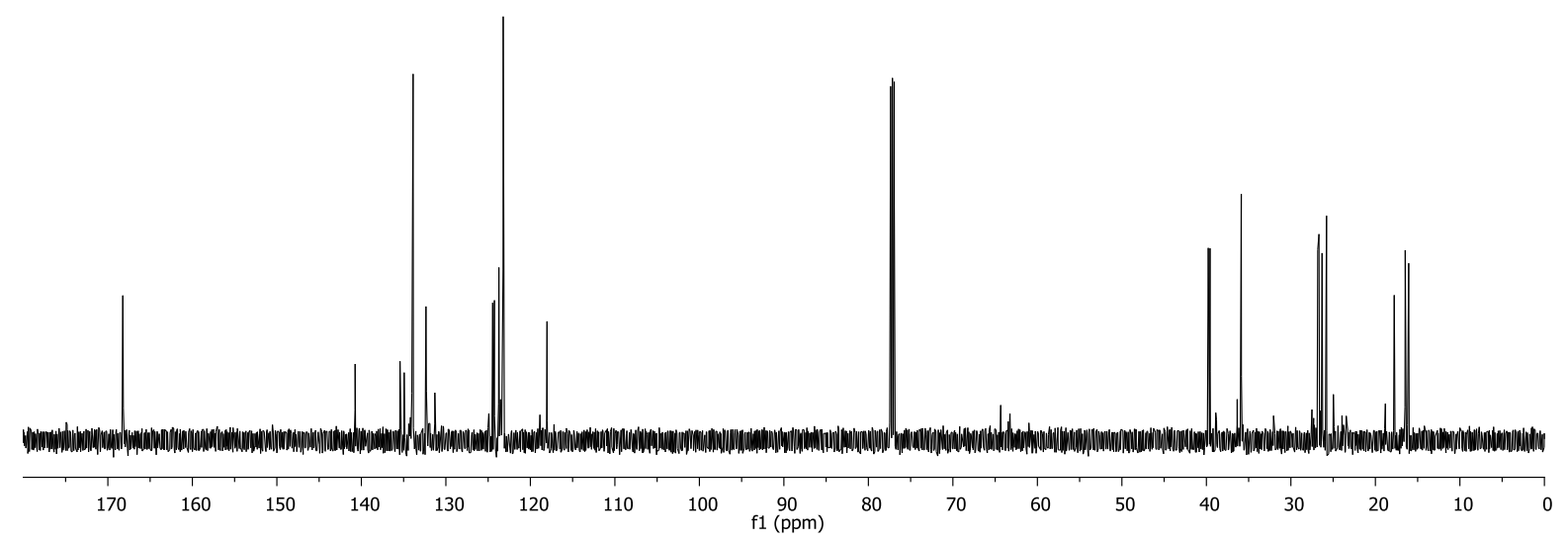

${ }^{13} \mathrm{C}$ NMR spectrum $\left(150 \mathrm{MHz}, \mathrm{CDCl}_{3}\right)$ of $\mathbf{1 5 0}$. 
(E)-5-(3,7-Dimethylocta-2,6-dien-1-yl)-5H-pyrazolo[3,4-d]pyrimidin-4-ol (155)

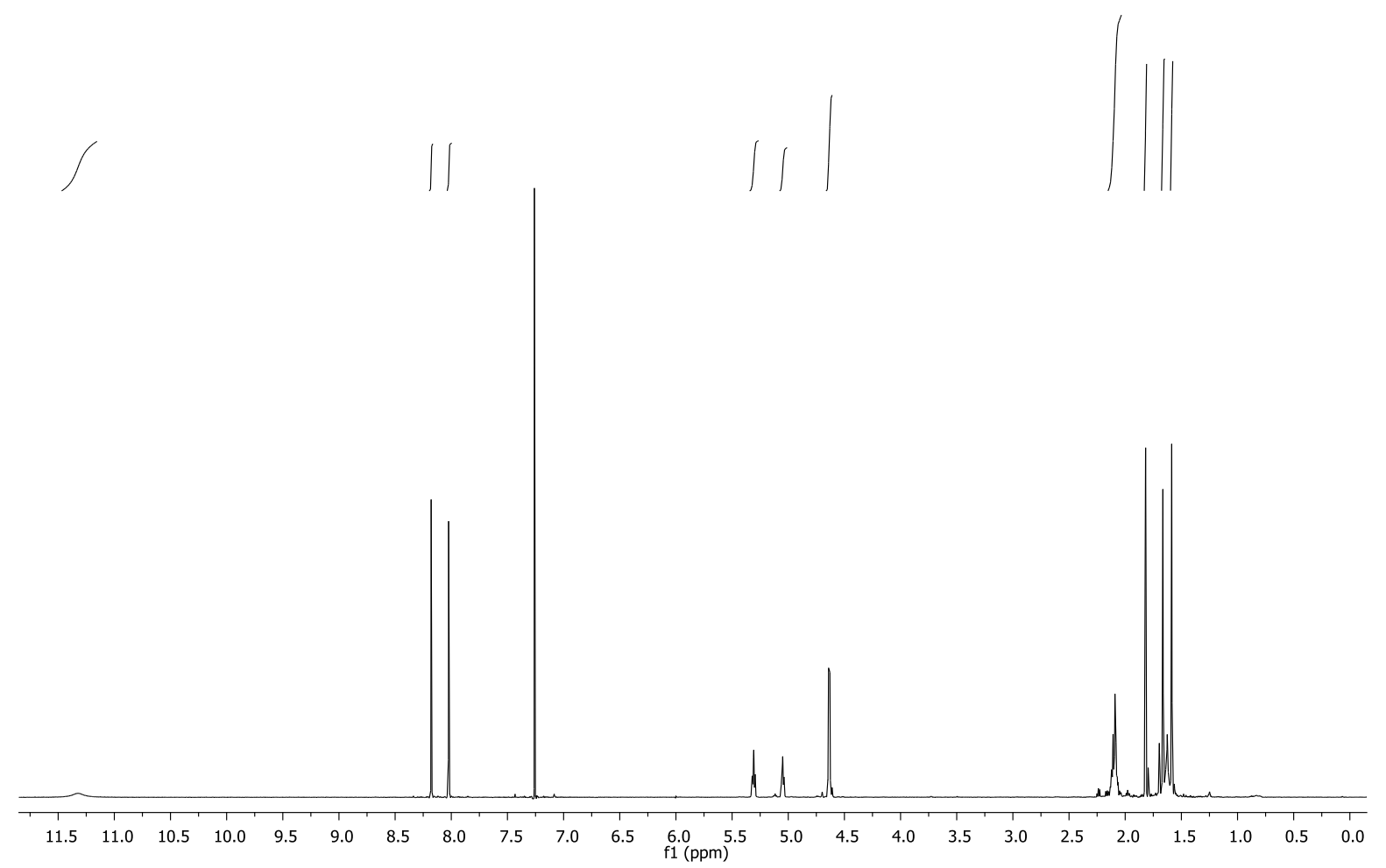

${ }^{1} \mathrm{H}$ NMR spectrum $\left(600 \mathrm{MHz}, \mathrm{CDCl}_{3}\right)$ of $\mathbf{1 5 5}$.



${ }^{13} \mathrm{C}$ NMR spectrum $\left(150 \mathrm{MHz}, \mathrm{CDCl}_{3}\right)$ of $\mathbf{1 5 5}$. 
1,5-bis((6E)-3,7,11-Trimethyldodeca-2,6,10-trien-1-yl)-1,5-dihydro-4H-pyrazolo[3,4d]pyrimidin-4-one (157)

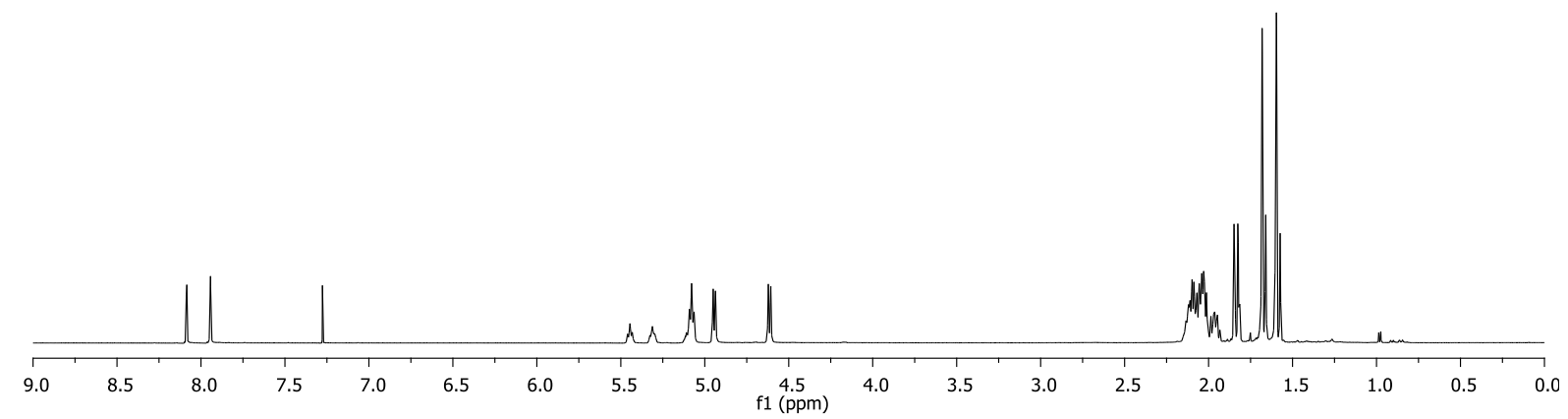

${ }^{1} \mathrm{H}$ NMR spectrum $\left(500 \mathrm{MHz}, \mathrm{CDCl}_{3}\right)$ of 157.

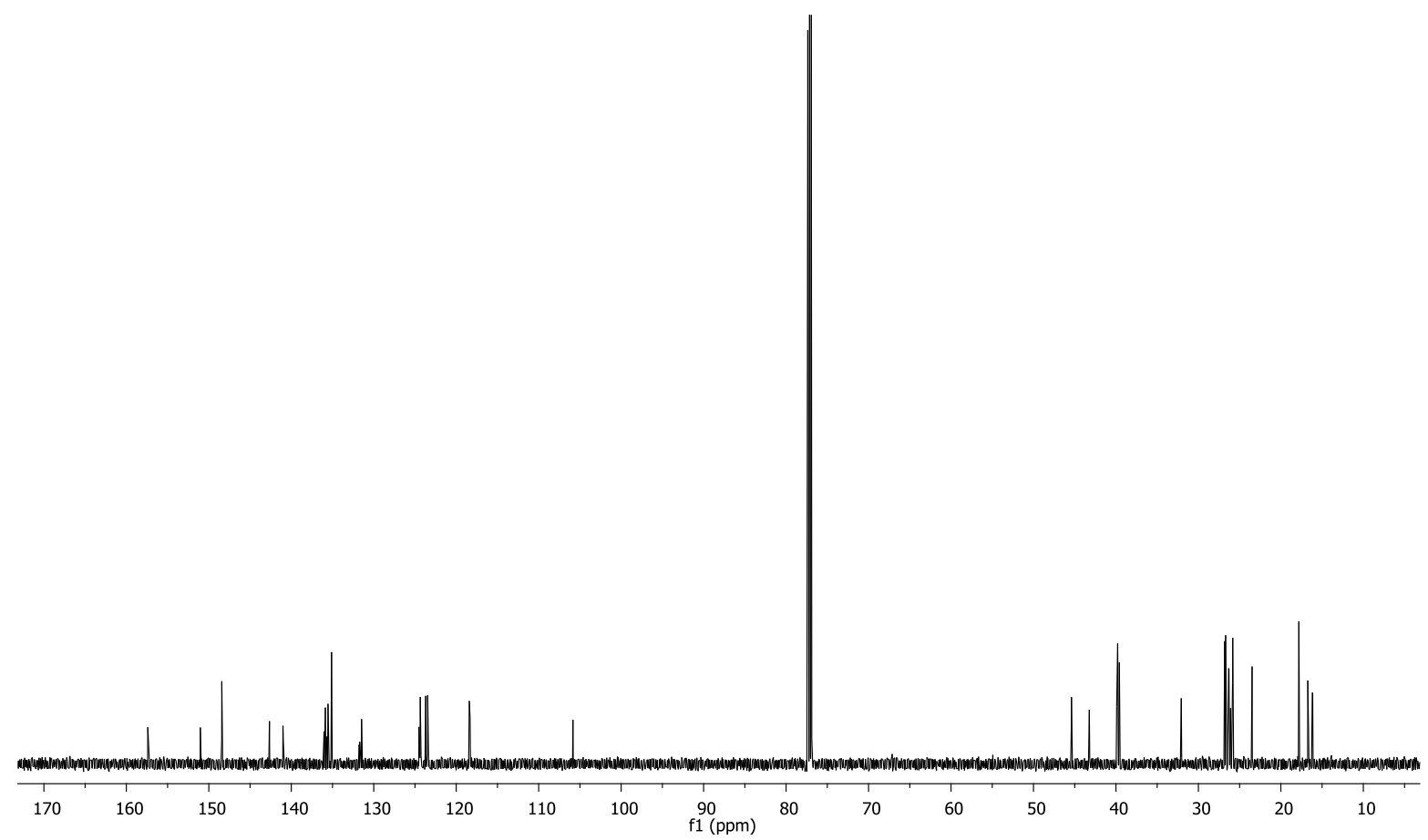

${ }^{13} \mathrm{C}$ NMR spectrum $\left(150 \mathrm{MHz}, \mathrm{CDCl}_{3}\right)$ of 157. 
2,7-bis((6E)-3,7,11-Trimethyldodeca-2,6,10-trien-1-yl)-2,7-dihydro-4H-pyrazolo[3,4d]pyrimidin-4-one (158)

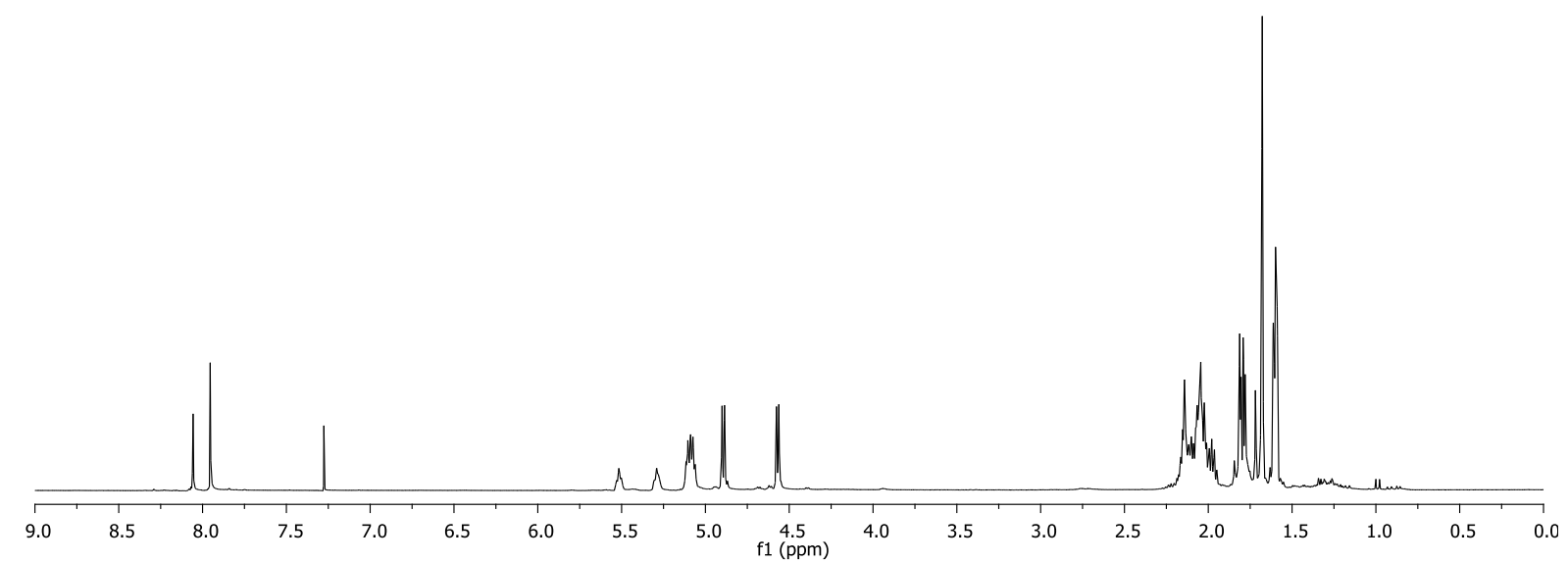

${ }^{1} \mathrm{H}$ NMR spectrum (500 MHz, $\mathrm{CDCl}_{3}$ ) of 158.

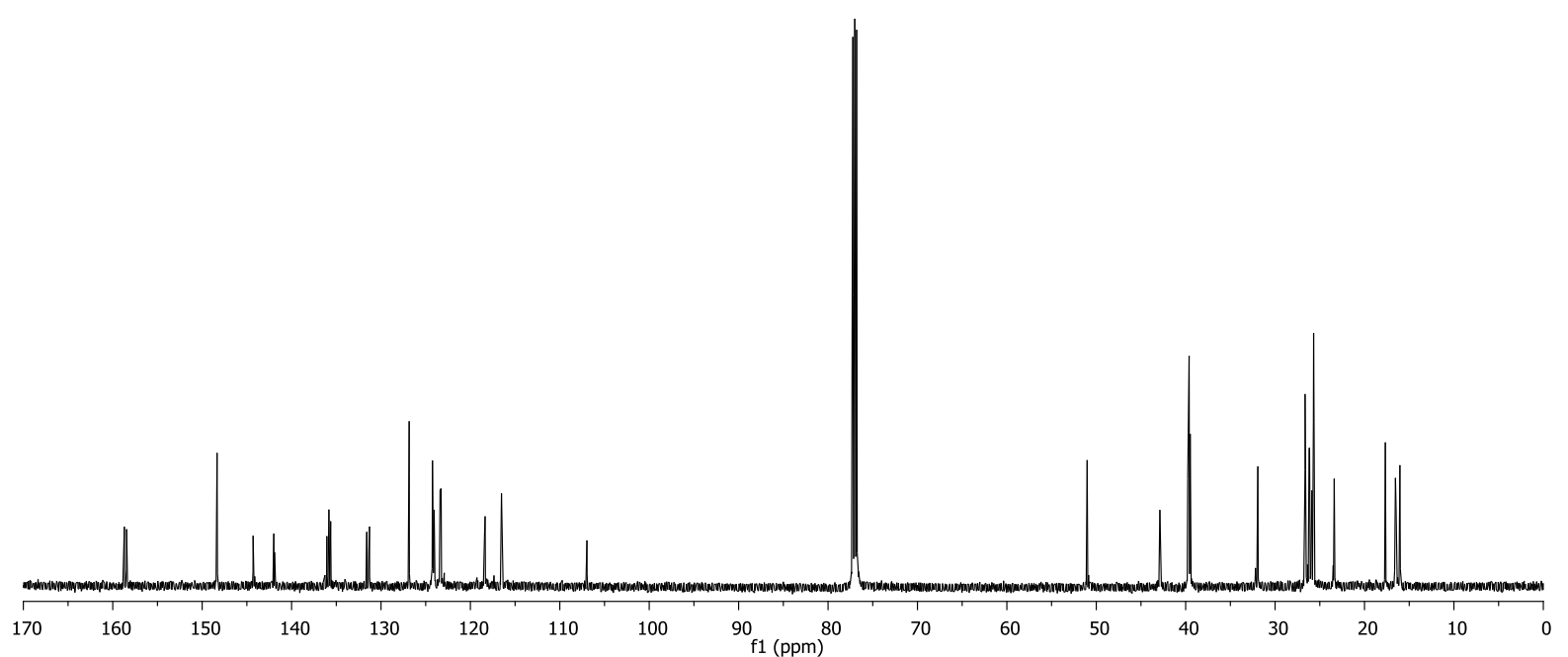

${ }^{13} \mathrm{C}$ NMR spectrum $\left(150 \mathrm{MHz}, \mathrm{CDCl}_{3}\right)$ of $\mathbf{1 5 8}$. 
5-((2E,6E)-3,7,11-Trimethyldodeca-2,6,10-trien-1-yl)-5H-pyrazolo[3,4-d]pyrimidin-4ol (156)

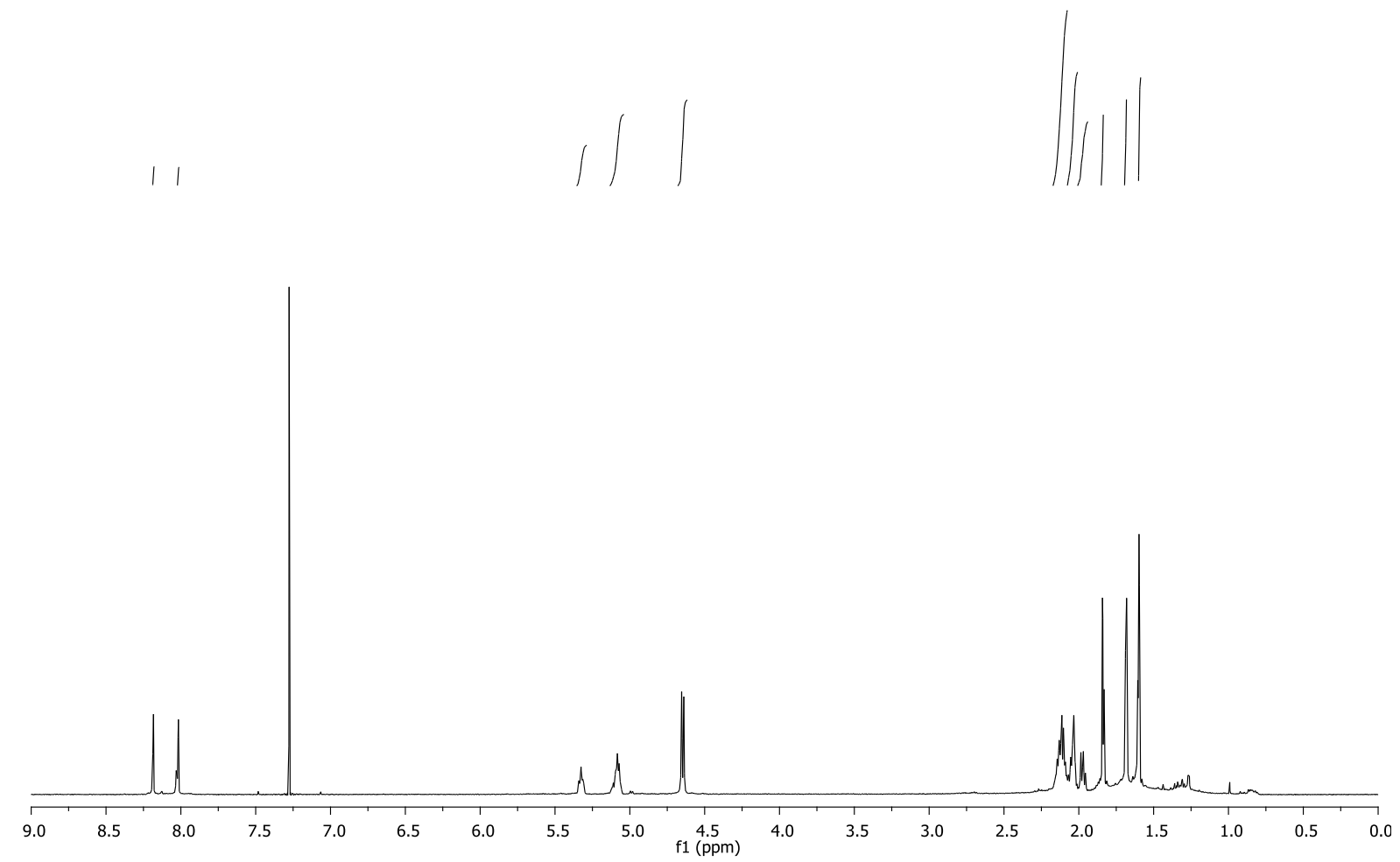

${ }^{1} \mathrm{H}$ NMR spectrum $\left(600 \mathrm{MHz}, \mathrm{CDCl}_{3}\right)$ of $\mathbf{1 5 6}$.

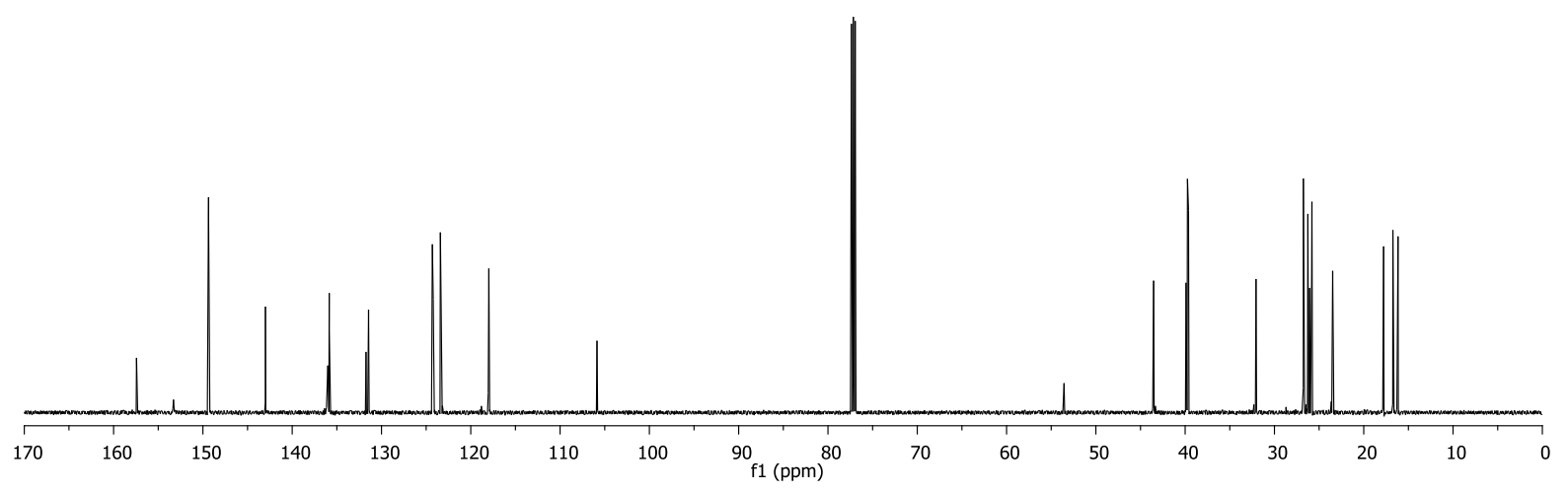

${ }^{13} \mathrm{C}$ NMR spectrum $\left(150 \mathrm{MHz}, \mathrm{CDCl}_{3}\right)$ of $\mathbf{1 5 6}$. 
5-((2E,6E,10E)-3,7,11,15-Tetramethylhexadeca-2,6,10,14-tetraen-1-yl)-5Hpyrazolo[3,4-d]pyrimidin-4-ol (159)

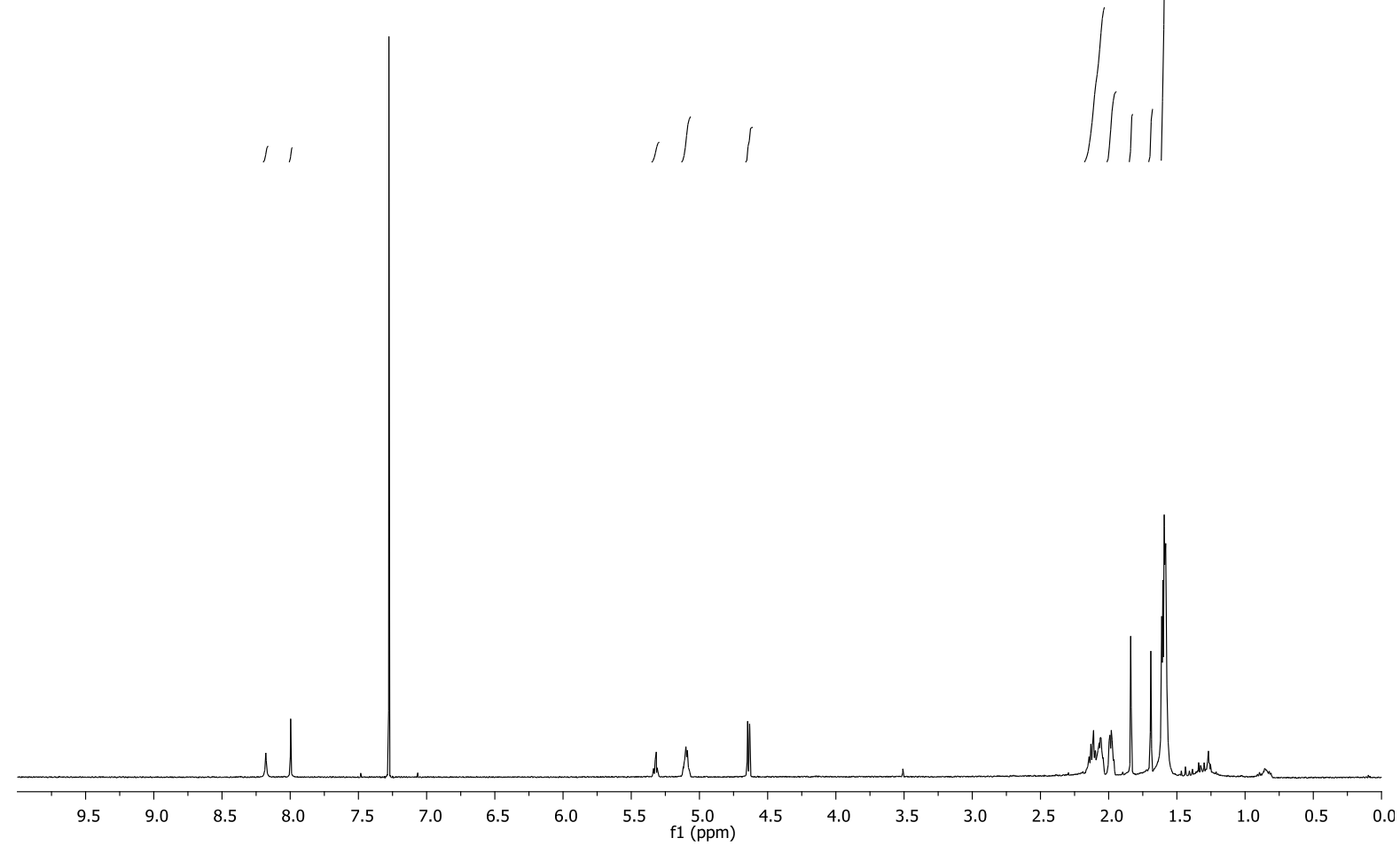

${ }^{1} \mathrm{H}$ NMR spectrum $\left(600 \mathrm{MHz}, \mathrm{CDCl}_{3}\right)$ of 159. 
1,5-bis((2E,6E,10E)-3,7,11,15-Tetramethylhexadeca-2,6,10,14-tetraen-1-yl)-1,5dihydro-4H-pyrazolo[3,4-d]pyrimidin-4-one (160)

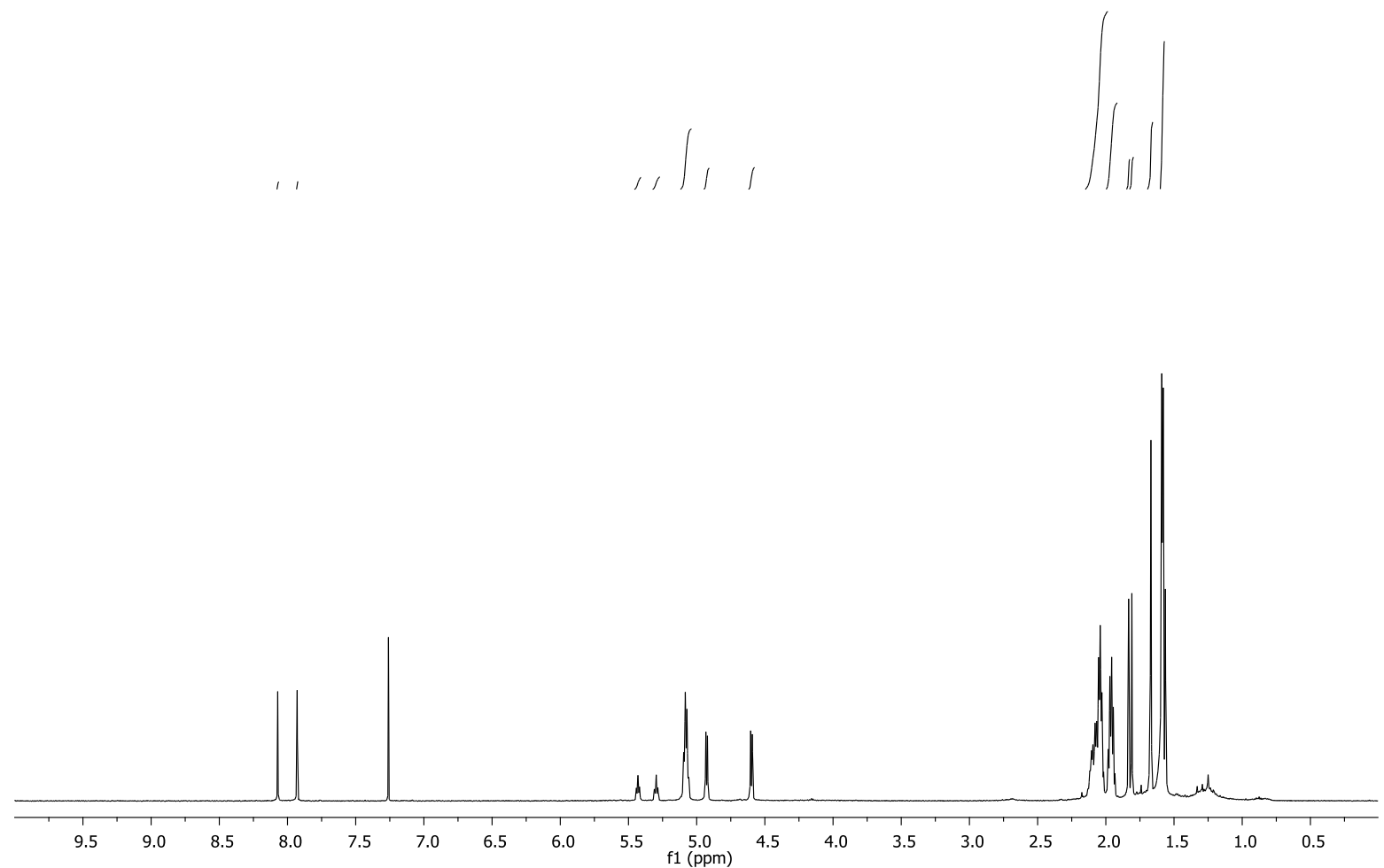

${ }^{1} \mathrm{H}$ NMR spectrum $\left(150 \mathrm{MHz}, \mathrm{CDCl}_{3}\right)$ of $\mathbf{1 6 0}$.

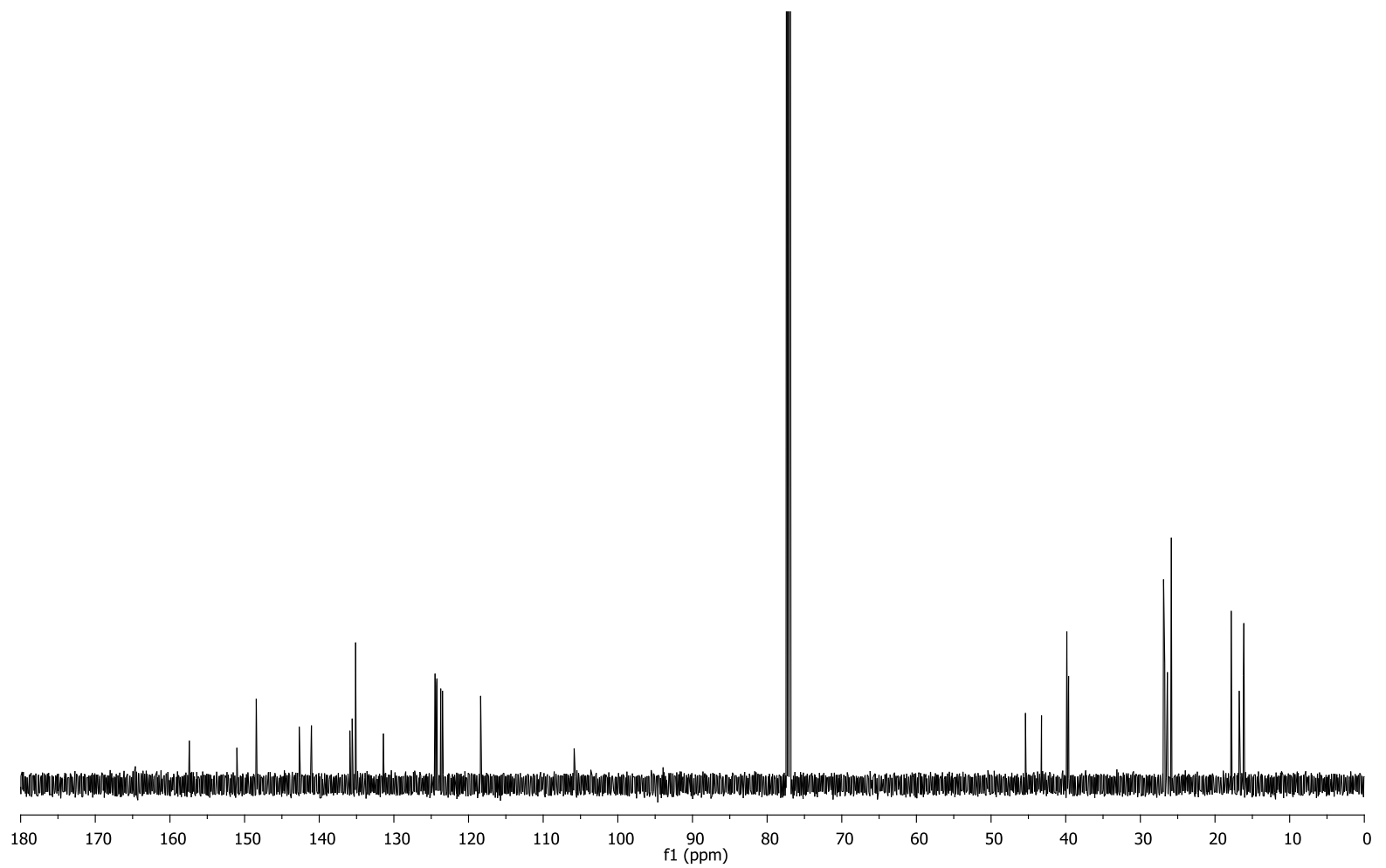

${ }^{13} \mathrm{C}$ NMR spectrum $\left(150 \mathrm{MHz}, \mathrm{CDCl}_{3}\right)$ of $\mathbf{1 6 0}$. 
Bis(trimethylsilyl)geranylamine

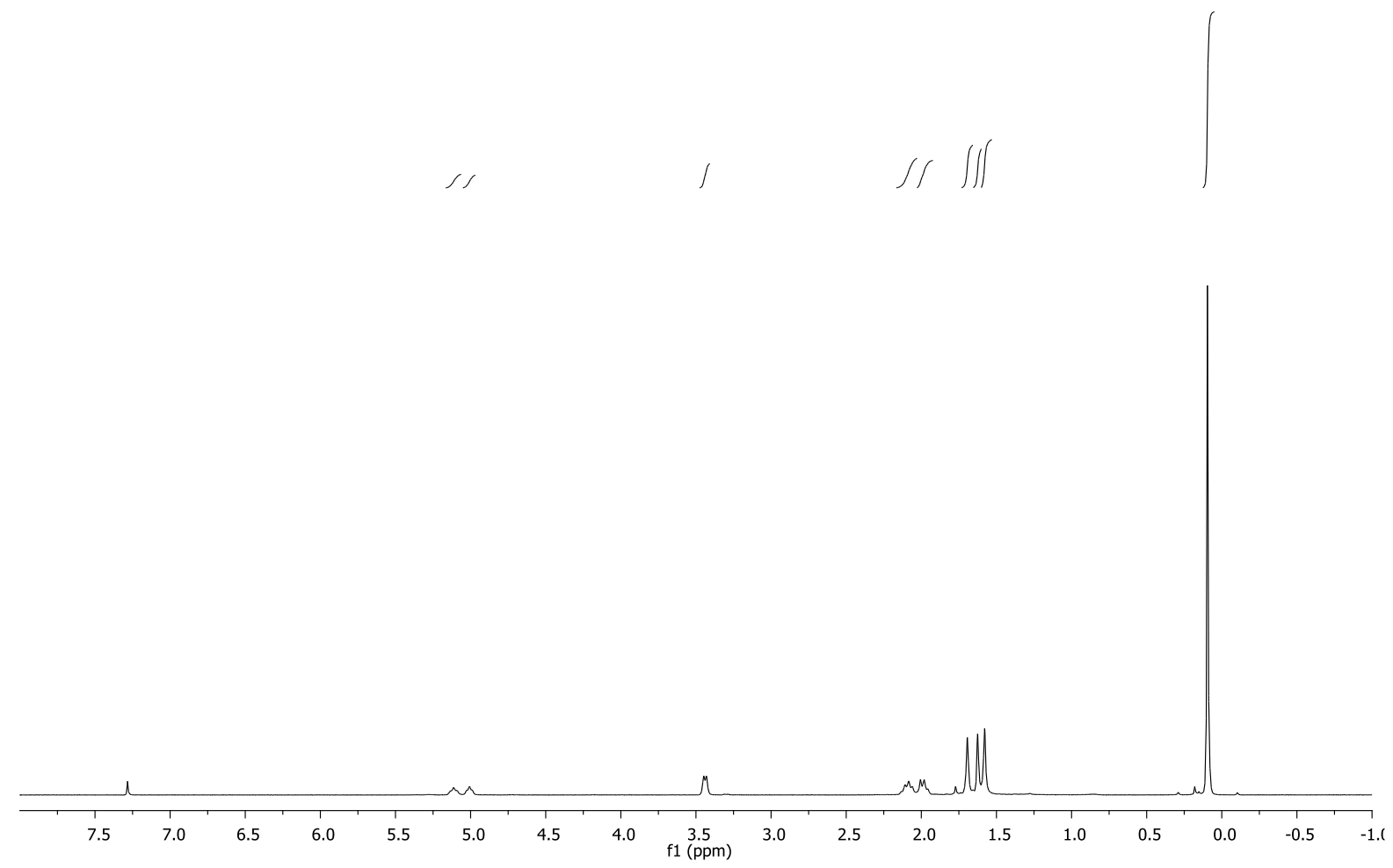

${ }^{1} \mathrm{H}$ NMR spectrum (300 MHz, $\mathrm{CDCl}_{3}$ ) of (E)-N-(3,7-dimethylocta-2,6-dien-1-yl)-1,1,1trimethyl- $N$-(trimethylsilyl)silanamine. 
(E)-3,7-Dimethylocta-2,6-dien-1-amine (161)

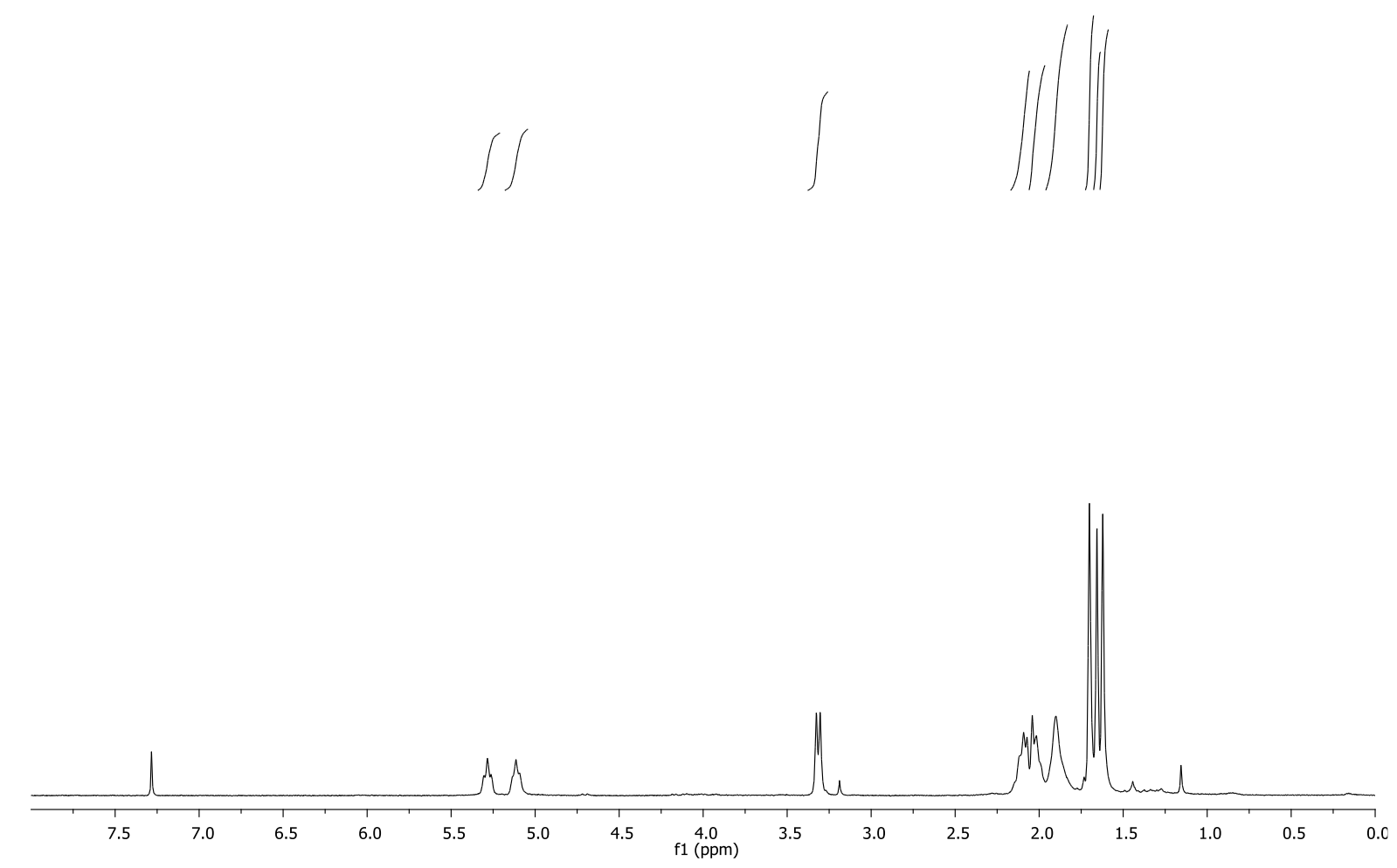

${ }^{13} \mathrm{H}$ NMR spectrum (300 MHz, $\mathrm{CDCl}_{3}$ ) of $\mathbf{1 6 1}$.

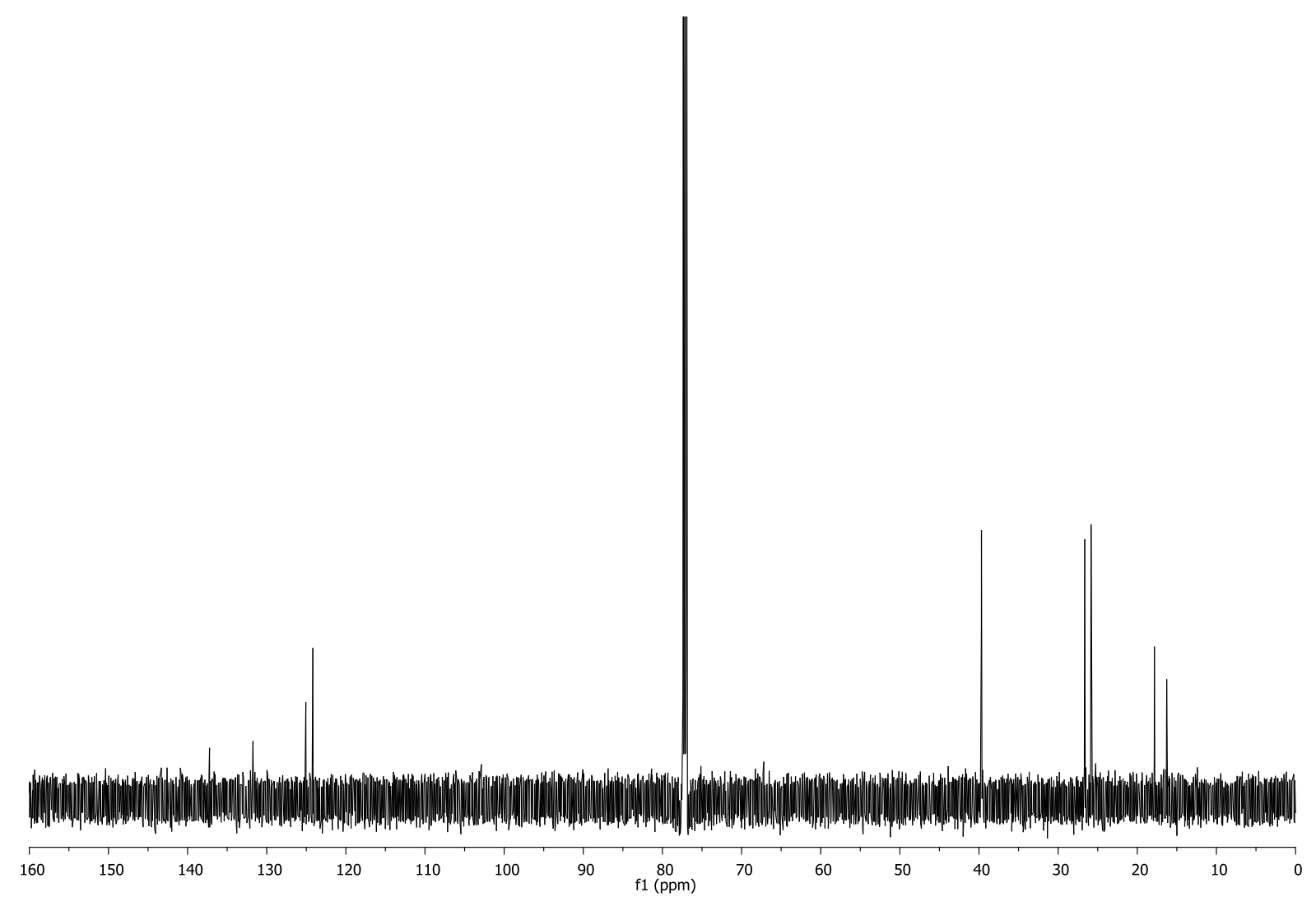

${ }^{13} \mathrm{C}$ NMR spectrum $\left(150 \mathrm{MHz}, \mathrm{CDCl}_{3}\right)$ of $\mathbf{1 6 1}$. 
Bis(trimethylsilyl)farnesylamine

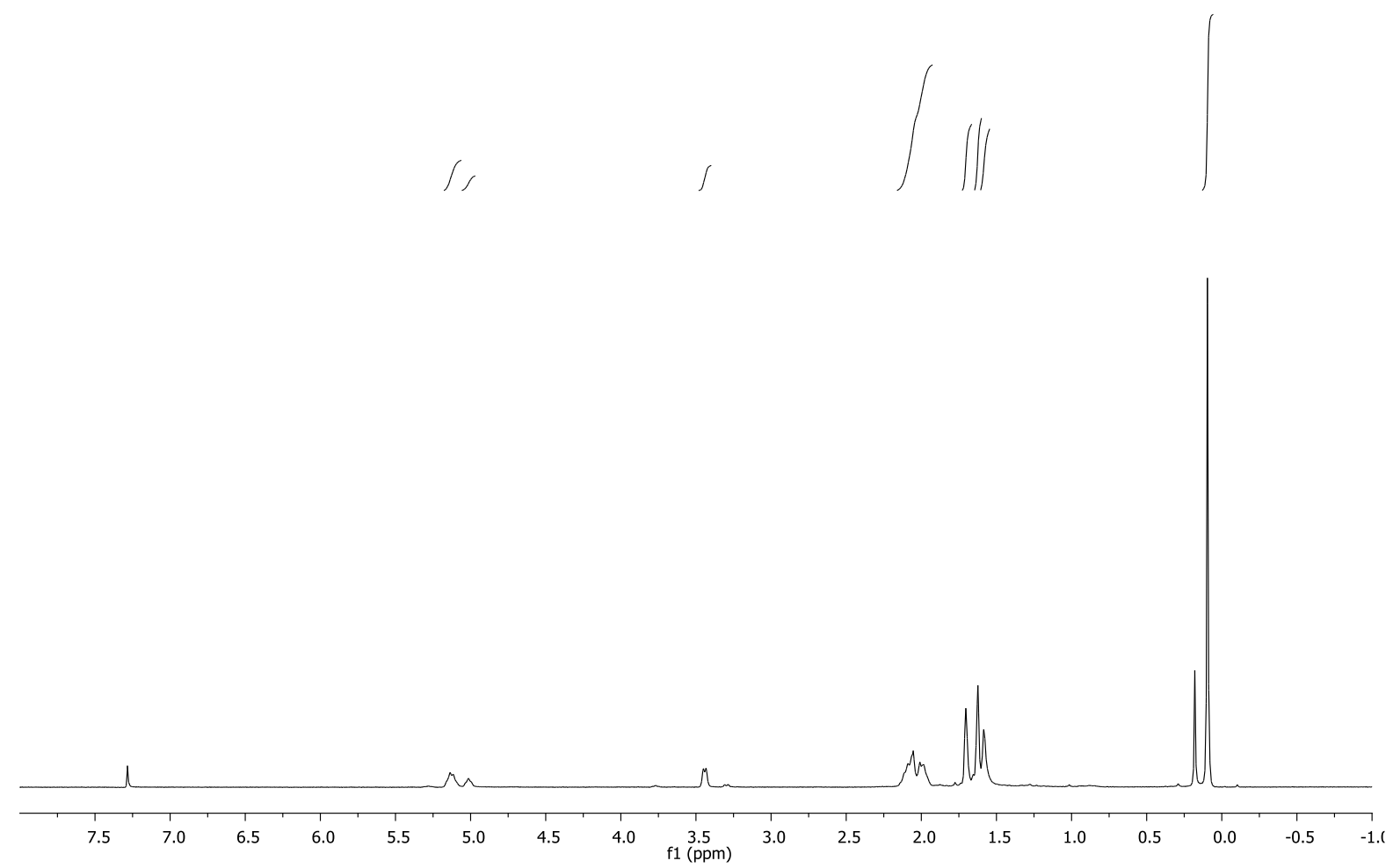

${ }^{1} \mathrm{H}$ NMR spectrum (300 MHz, $\mathrm{CDCl}_{3}$ ) of 1,1,1-trimethyl- $N$-((6E)-3,7,11trimethyldodeca-2,6,10-trien-1-yl)- $N$-(trimethylsilyl)silanamine. 
(6E)-3,7,11-Trimethyldodeca-2,6,10-trien-1-amine (162)



${ }^{1} \mathrm{H}$ NMR spectrum $\left(300 \mathrm{MHz}, \mathrm{CDCl}_{3}\right)$ of $\mathbf{1 6 2}$. 
Bis(trimethylsilyl)geranylgeranylamine

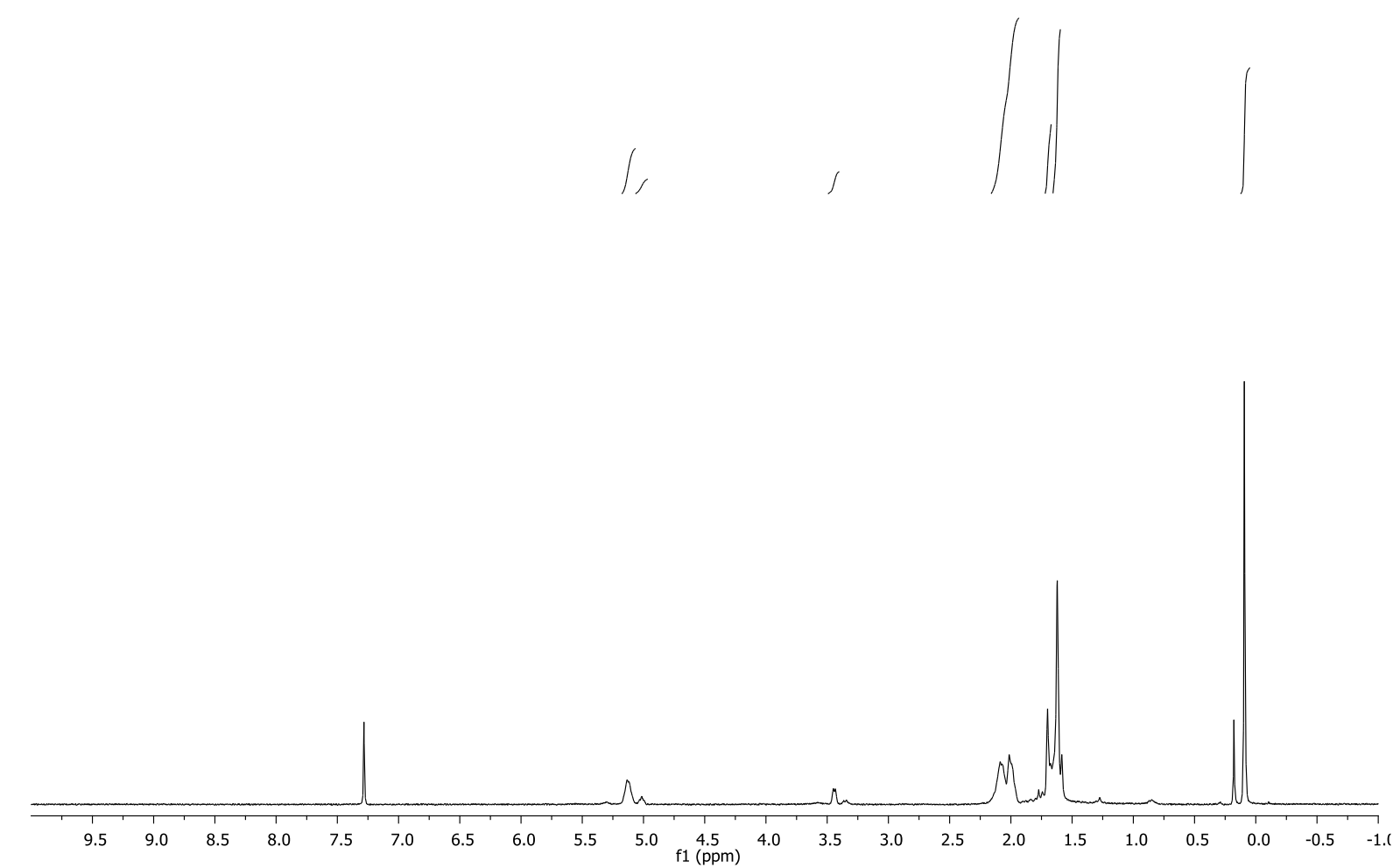

${ }^{1} \mathrm{H}$ NMR spectrum $\left(300 \mathrm{MHz}, \mathrm{CDCl}_{3}\right)$ of 1,1,1-trimethyl- $N-((6 E, 10 E)-3,7,11,15$ -

tetramethylhexadeca-2,6,10,14-tetraen-1-yl)- $N$-(trimethylsilyl)silanamine 
$(6 E, 10 E)-3,7,11,15$-Tetramethylhexadeca-2,6,10,14-tetraen-1-amine (163)

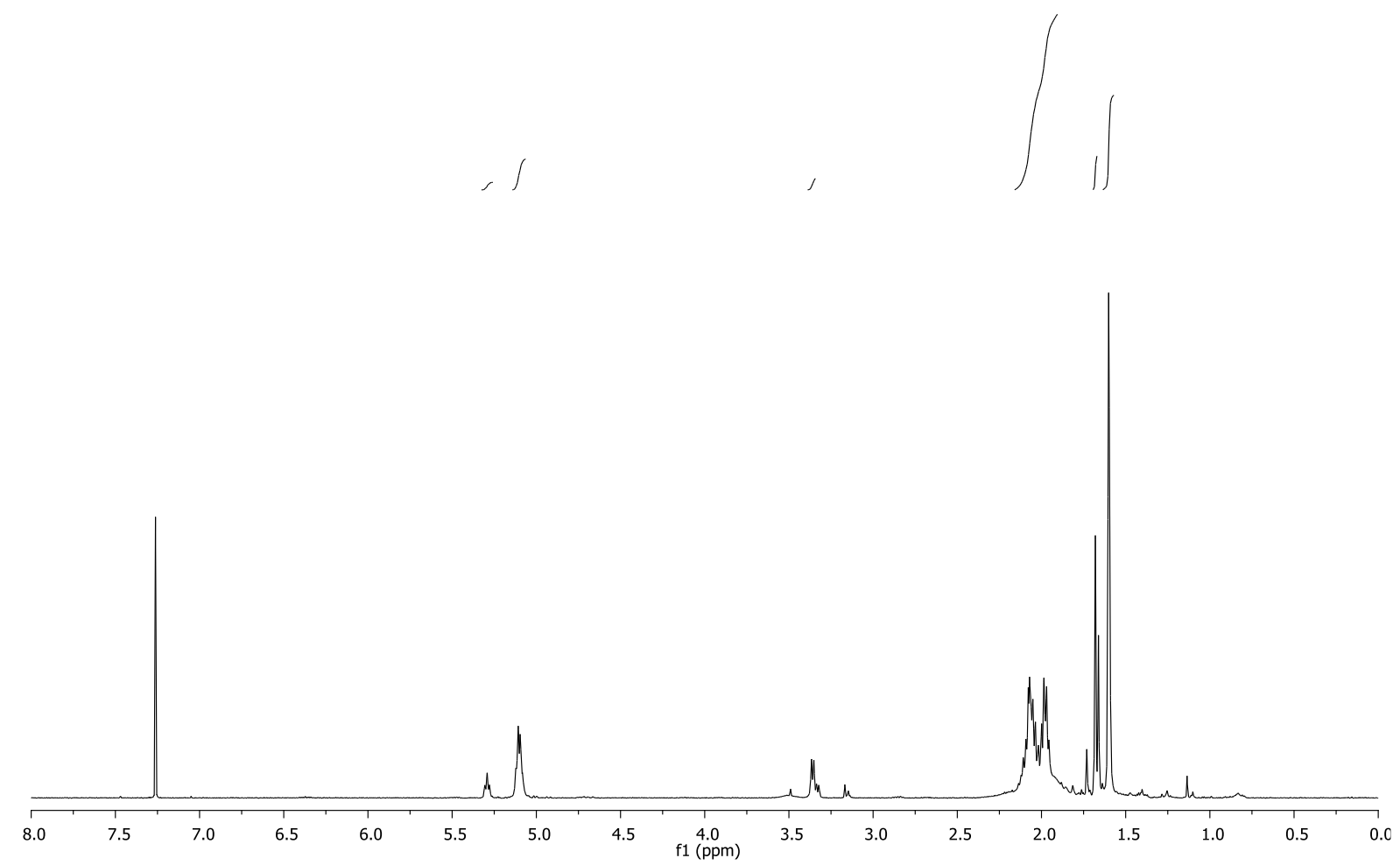

${ }^{1} \mathrm{H}$ NMR spectrum $\left(500 \mathrm{MHz}, \mathrm{CDCl}_{3}\right)$ of $\mathbf{1 6 3}$. 
E)-N-(3,7-Dimethylocta-2,6-dien-1-yl)formamide (164)

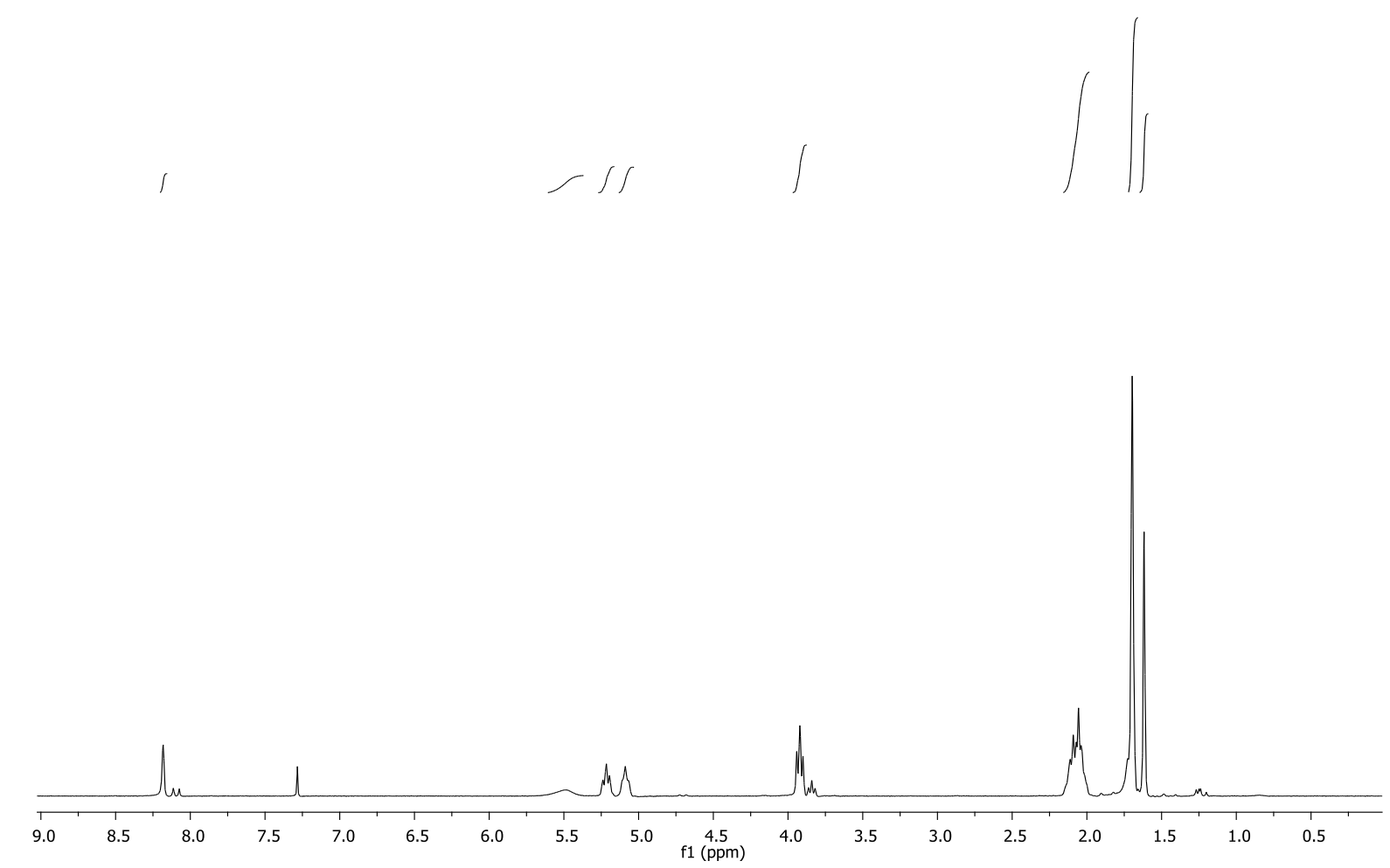

${ }^{1} \mathrm{H}$ NMR spectrum $\left(300 \mathrm{MHz}, \mathrm{CDCl}_{3}\right.$ ) of $\mathbf{1 6 4}$.

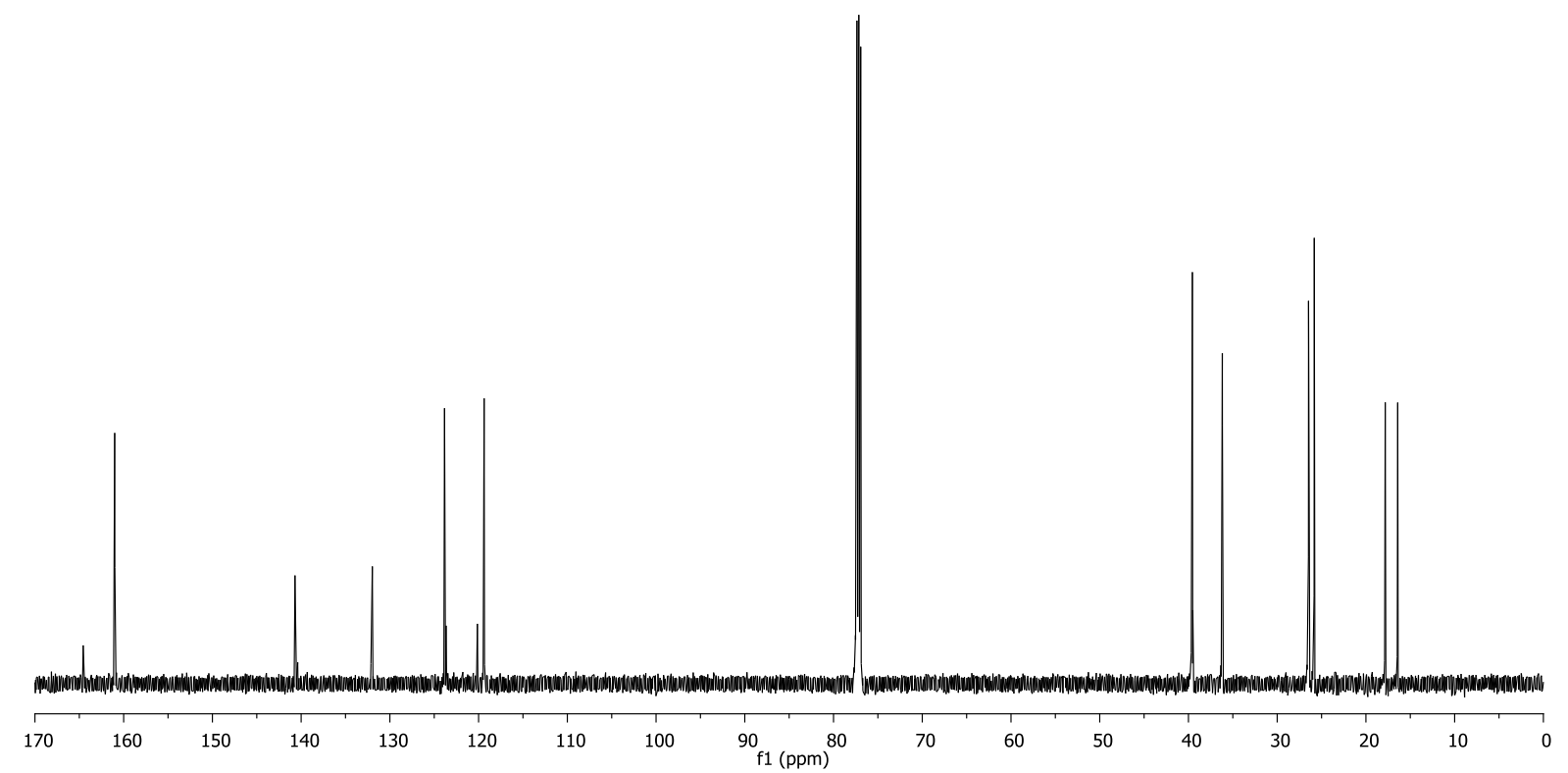

${ }^{13} \mathrm{C}$ NMR spectrum $\left(150 \mathrm{MHz}, \mathrm{CDCl}_{3}\right)$ of $\mathbf{1 6 4}$. 
$N-((2 Z, 6 E)-3,7,11-$ Trimethyldodeca-2,6,10-trien-1-yl)formamide (165)

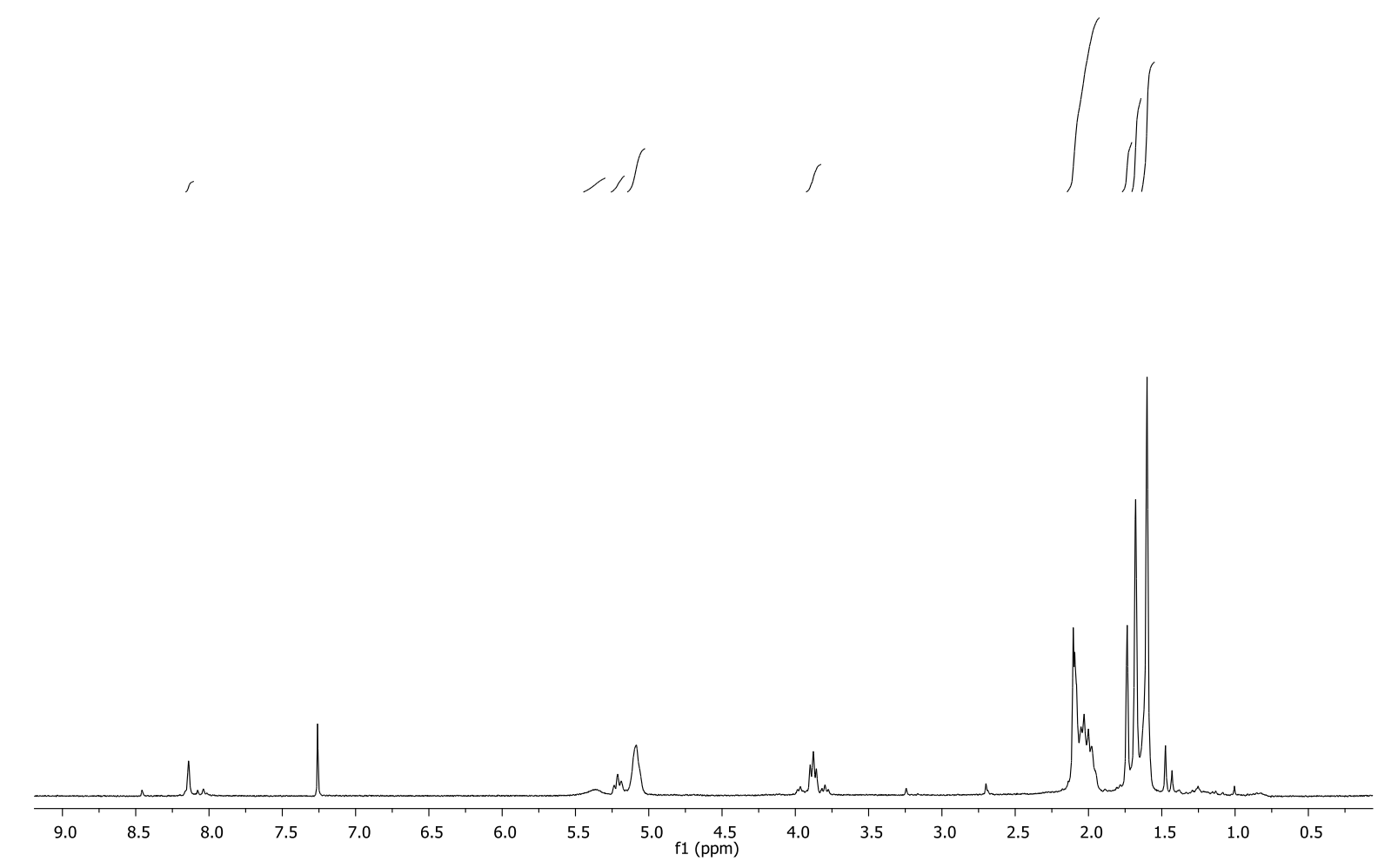

${ }^{1} \mathrm{H}$ NMR spectrum $\left(300 \mathrm{MHz}, \mathrm{CDCl}_{3}\right)$ of $\mathbf{1 6 5}$.

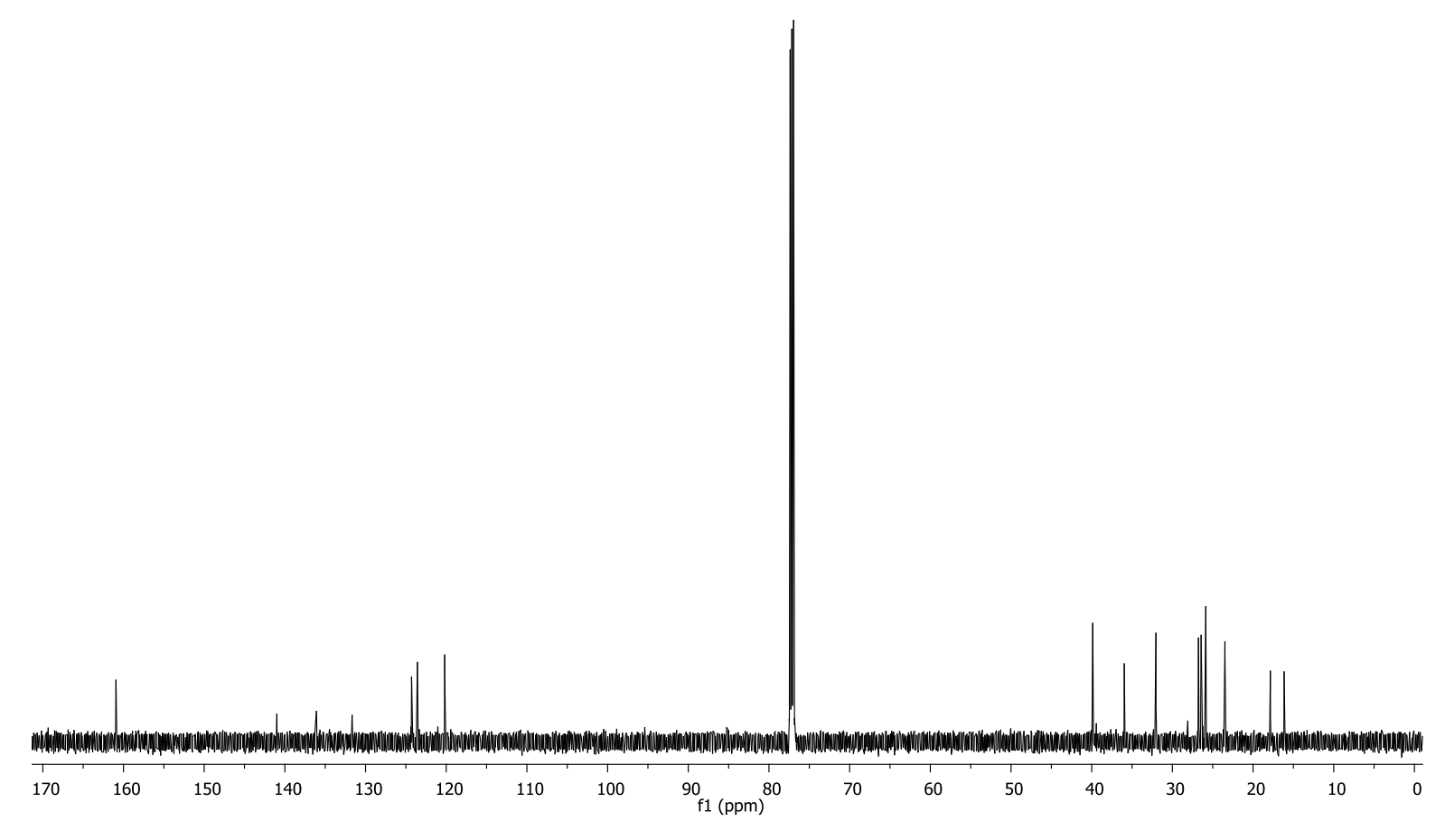

${ }^{13} \mathrm{C}$ NMR spectrum $\left(150 \mathrm{MHz}, \mathrm{CDCl}_{3}\right)$ of $\mathbf{1 6 5}$. 
$N$-((6E)-3,7,11-Trimethyldodeca-2,6,10-trien-1-yl)formamide (166)

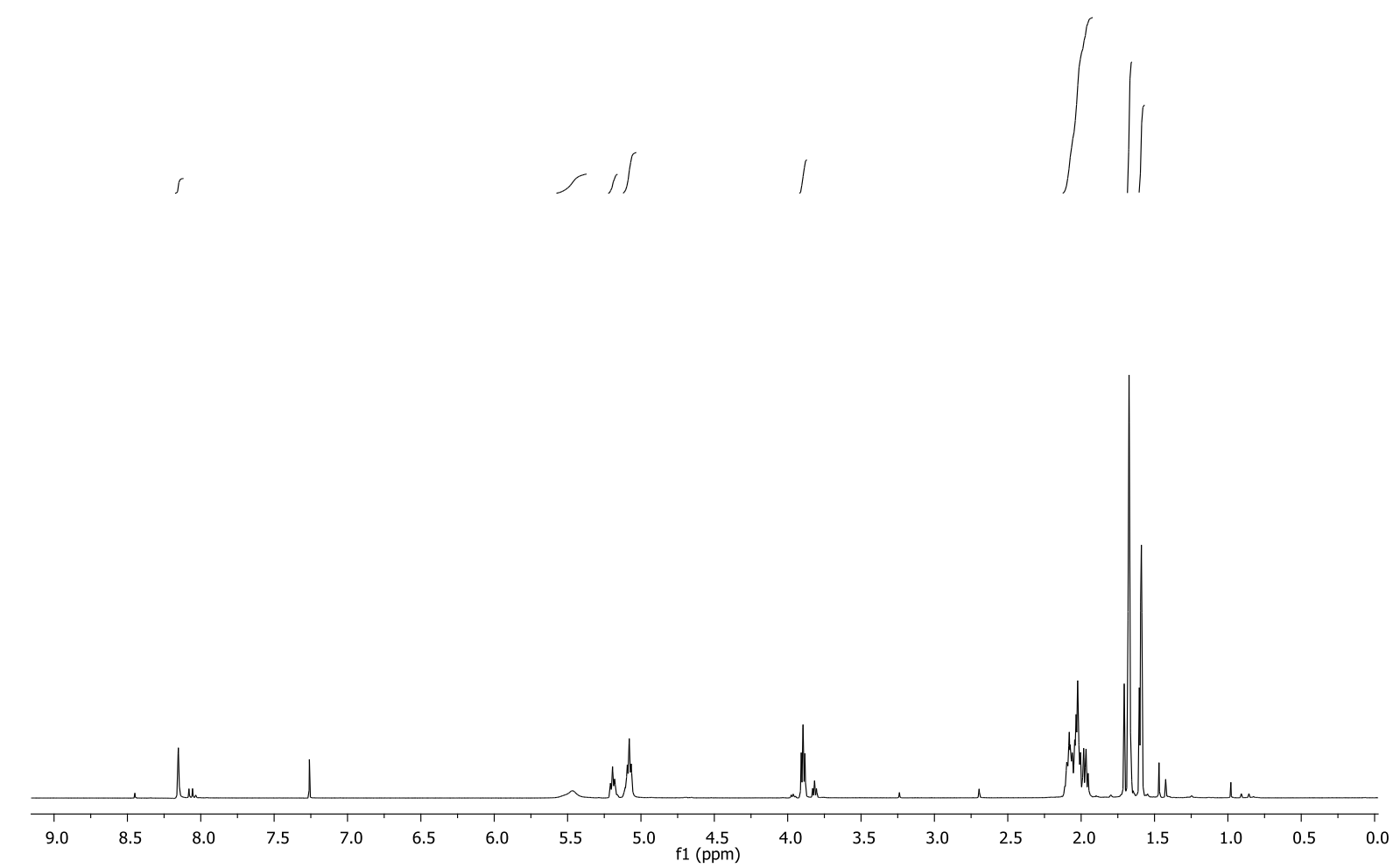

${ }^{1} \mathrm{H}$ NMR spectrum $\left(500 \mathrm{MHz}, \mathrm{CDCl}_{3}\right)$ of $\mathbf{1 6 6}$.

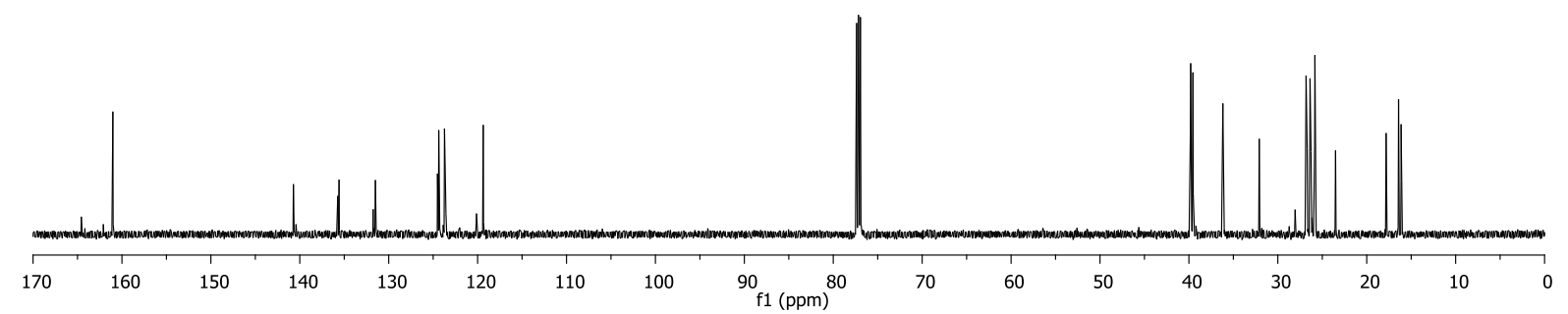

${ }^{13} \mathrm{C}$ NMR spectrum $\left(150 \mathrm{MHz}, \mathrm{CDCl}_{3}\right)$ of $\mathbf{1 6 5}$. 
$N$-((2Z,6E,10E)-3,7,11,15-Tetramethylhexadeca-2,6,10,14-tetraen-1-yl)formamide (167)

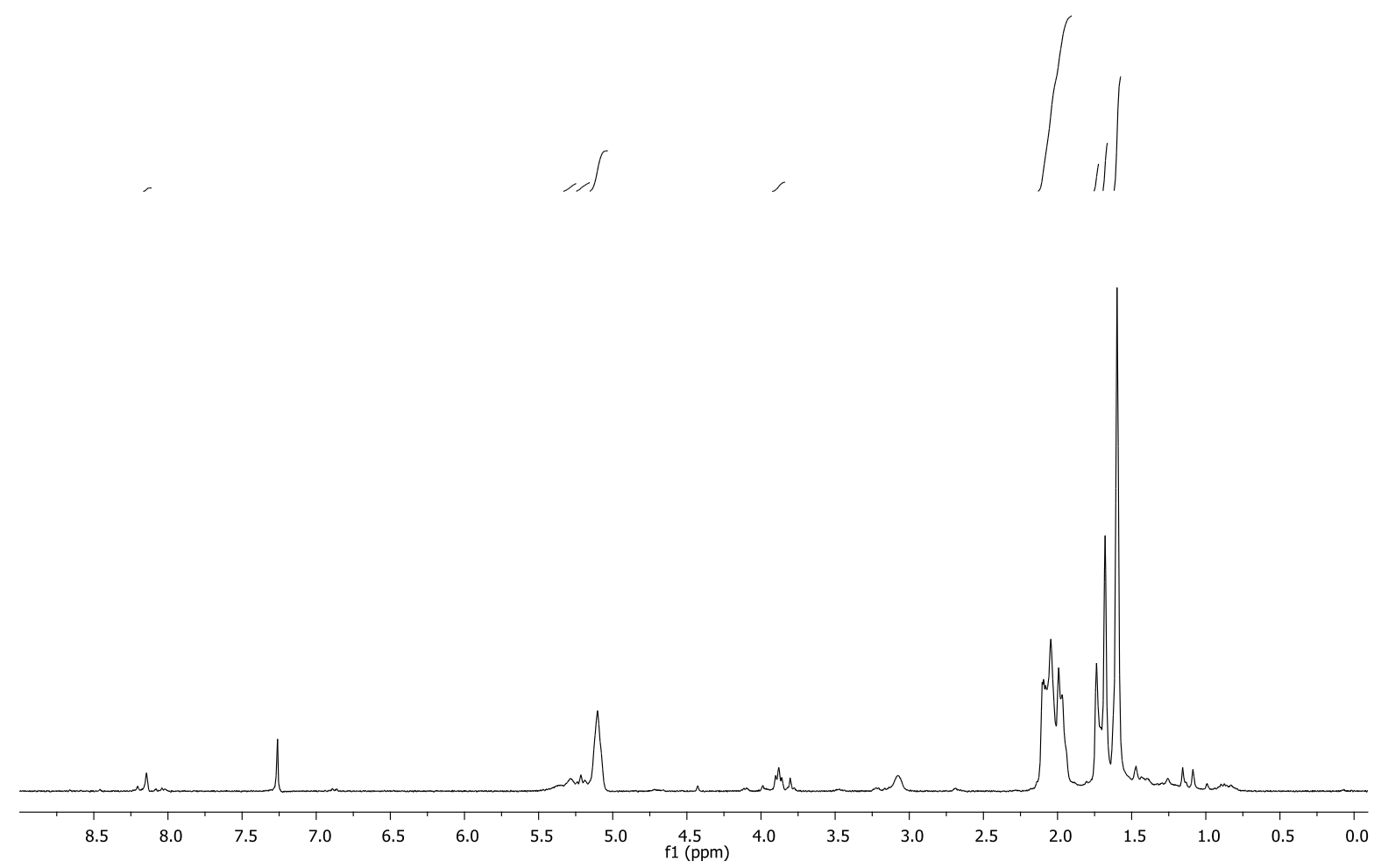

${ }^{13} \mathrm{C}$ NMR spectrum (300 MHz, $\mathrm{CDCl}_{3}$ ) of $\mathbf{1 6 7 .}$

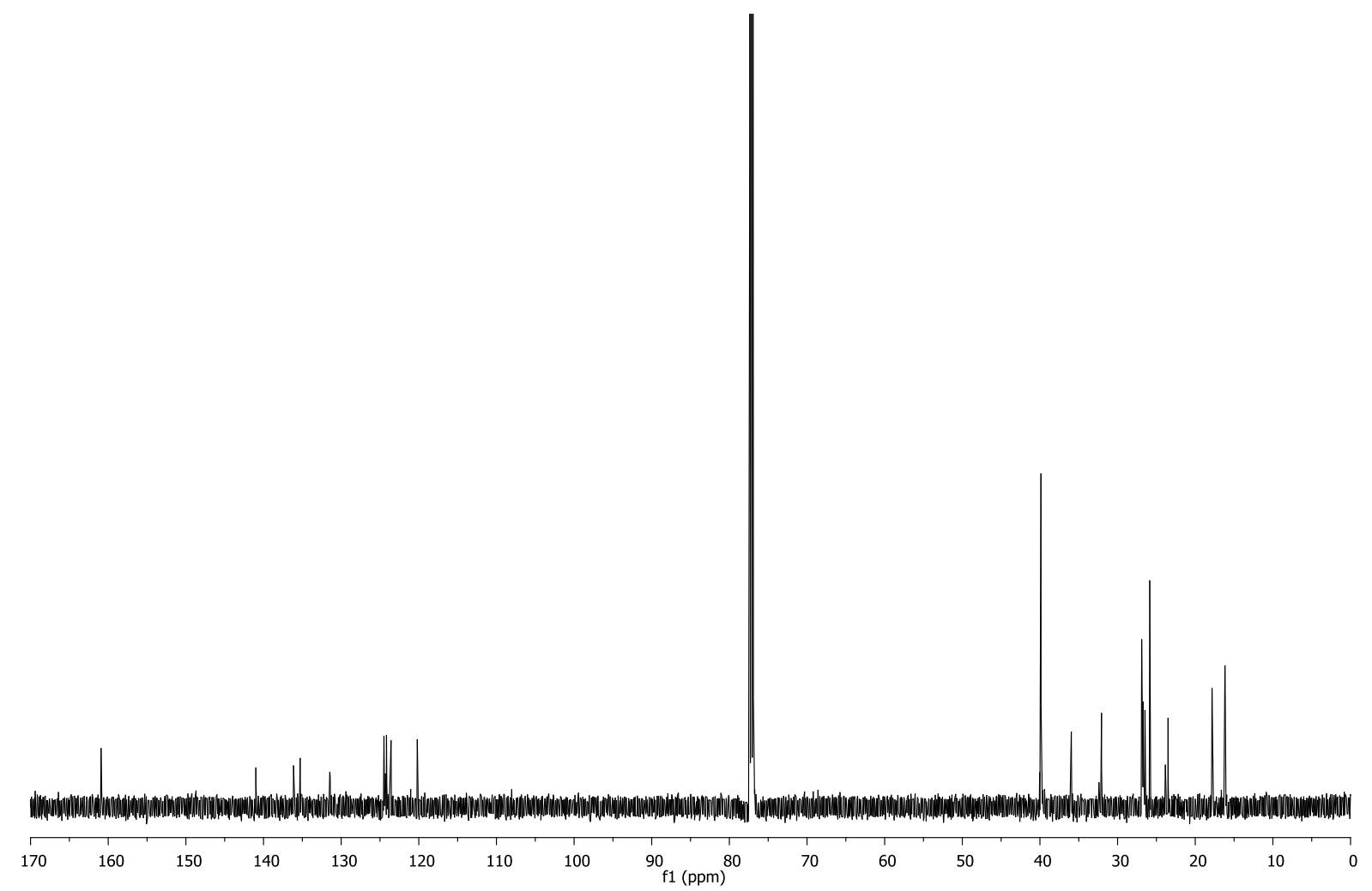

${ }^{13} \mathrm{C}$ NMR spectrum $\left(150 \mathrm{MHz}, \mathrm{CDCl}_{3}\right)$ of $\mathbf{1 6 7}$. 
$N$-((2E,6E,10E)-3,7,11,15-Tetramethylhexadeca-2,6,10,14-tetraen-1-yl)formamide (168)

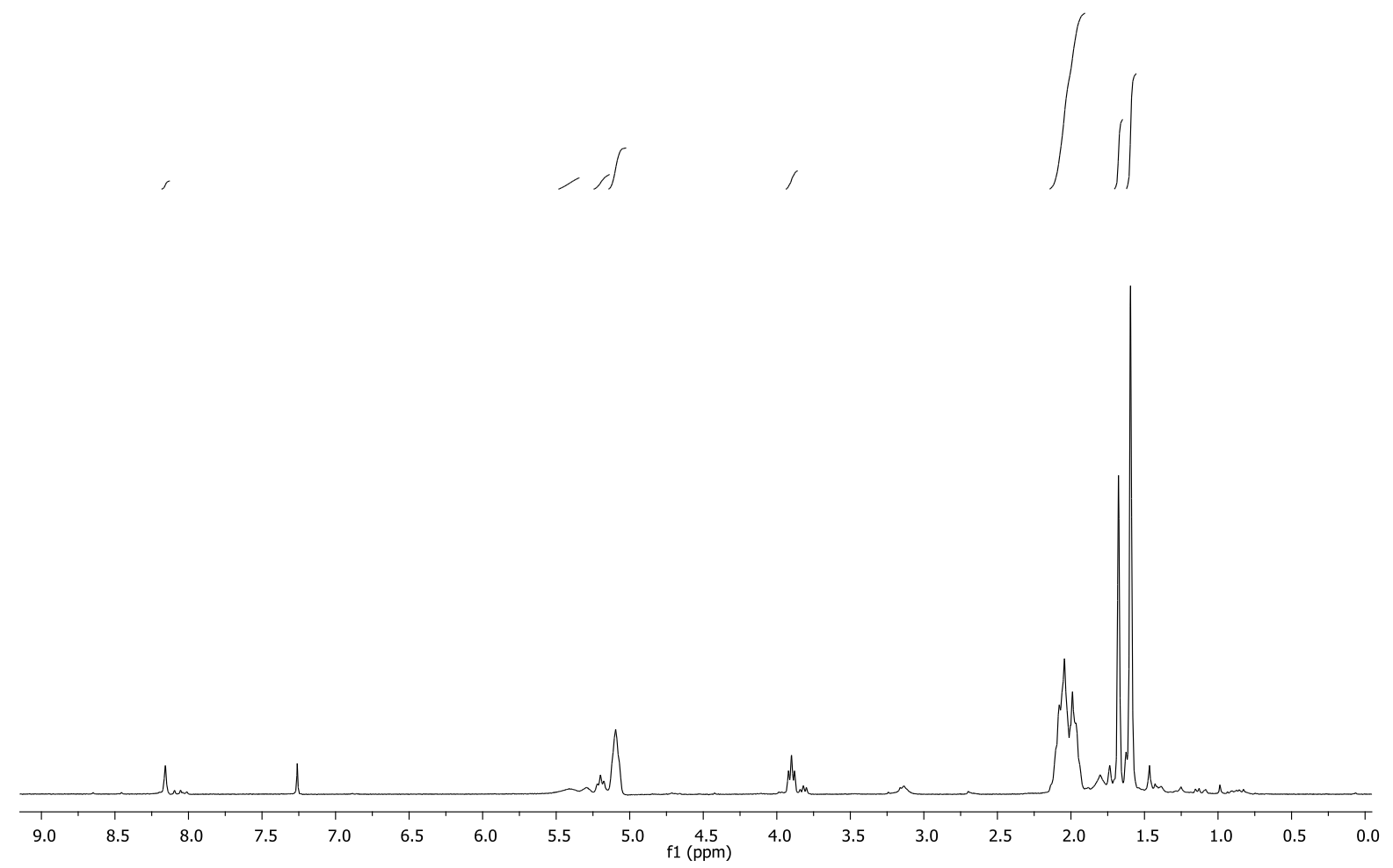

${ }^{1} \mathrm{H}$ NMR spectrum $\left(300 \mathrm{MHz}, \mathrm{CDCl}_{3}\right)$ of $\mathbf{1 6 8}$.

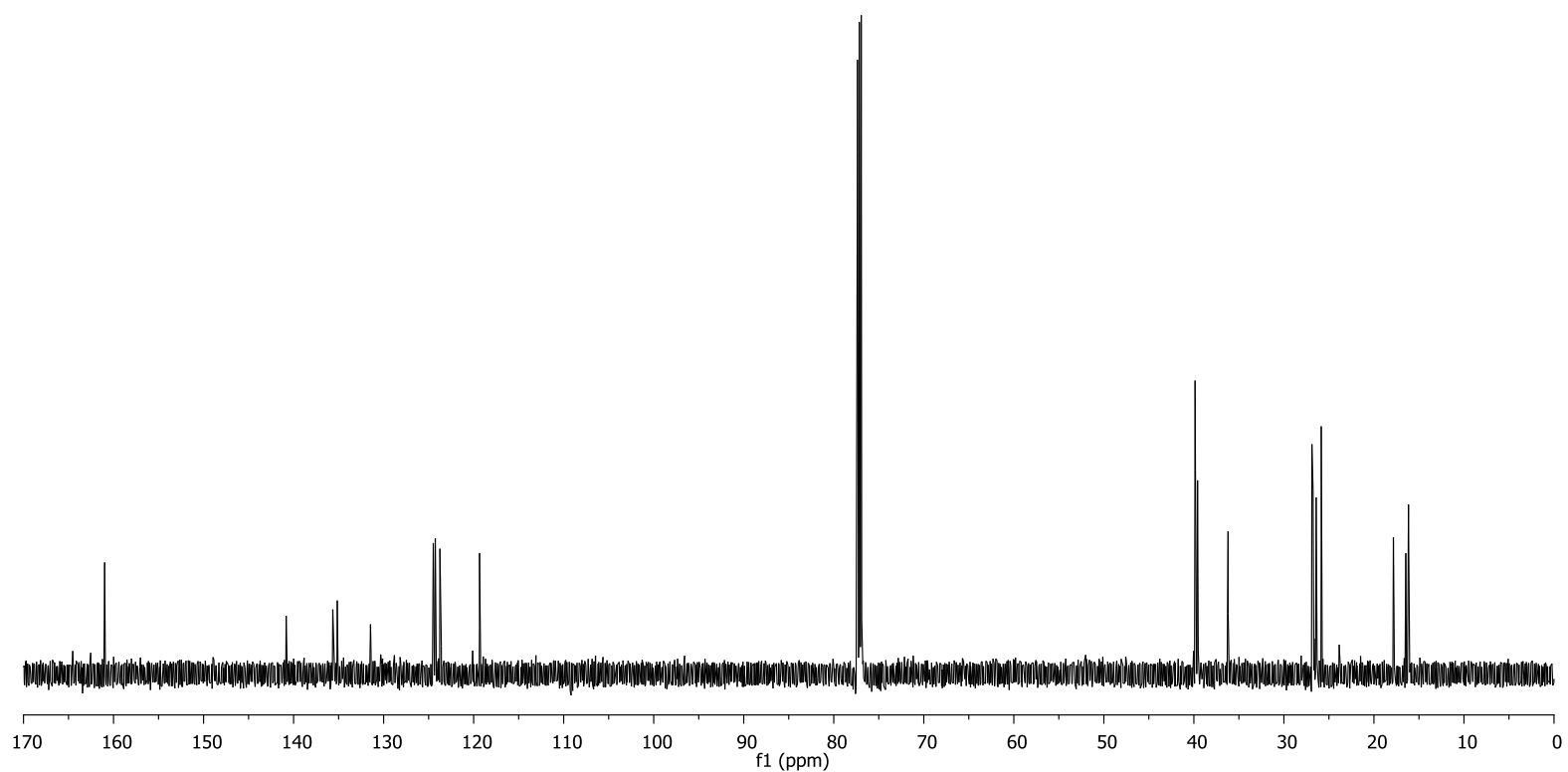

${ }^{13} \mathrm{C}$ NMR spectrum $\left(150 \mathrm{MHz}, \mathrm{CDCl}_{3}\right)$ of $\mathbf{1 6 8}$. 
(E)-N-(3,7-Dimethylocta-2,6-dien-1-yl)- $N$-methylformamide (169)

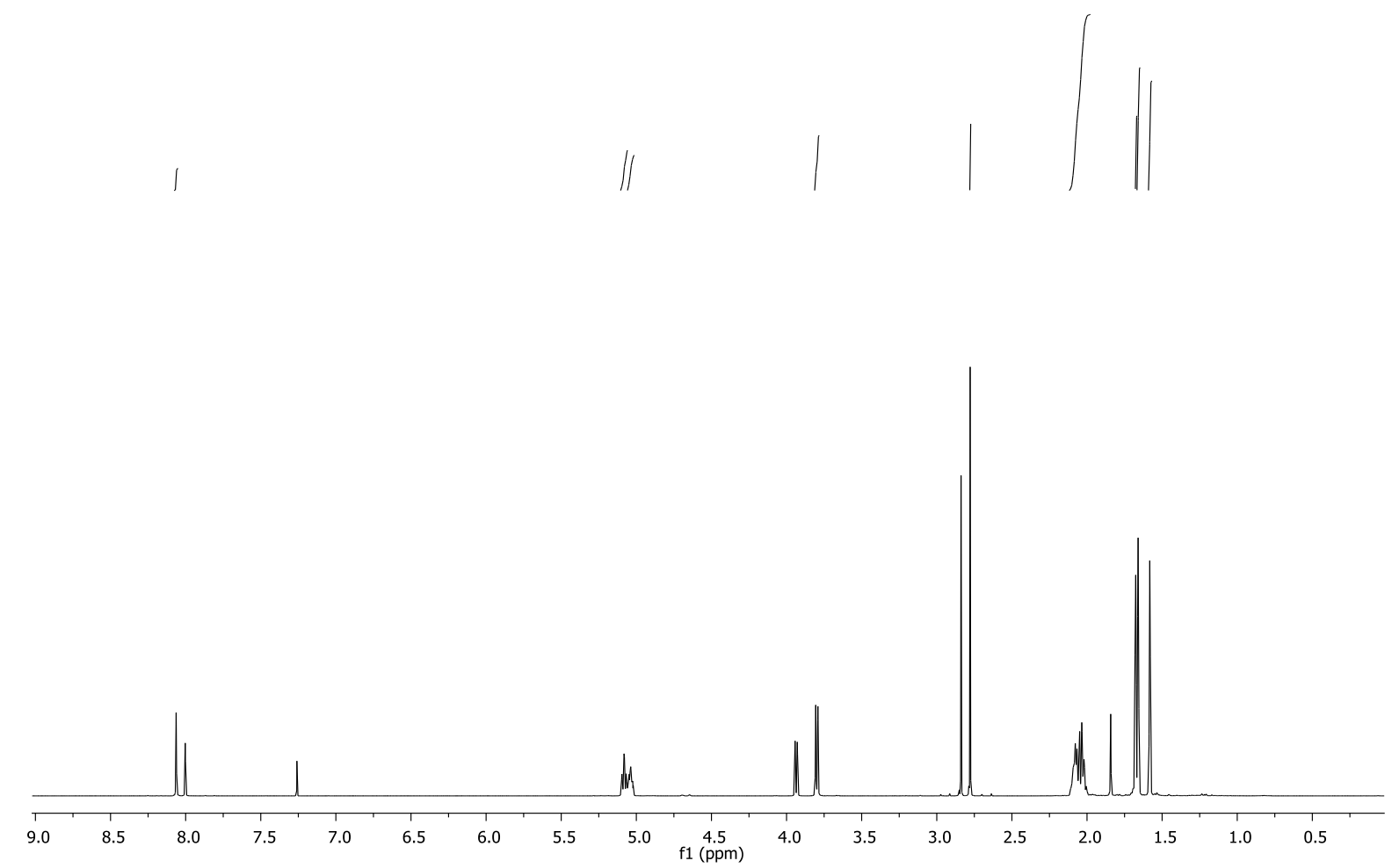

${ }^{1} \mathrm{H}$ NMR spectrum $\left(500 \mathrm{MHz}, \mathrm{CDCl}_{3}\right)$ of $\mathbf{1 6 9}$.

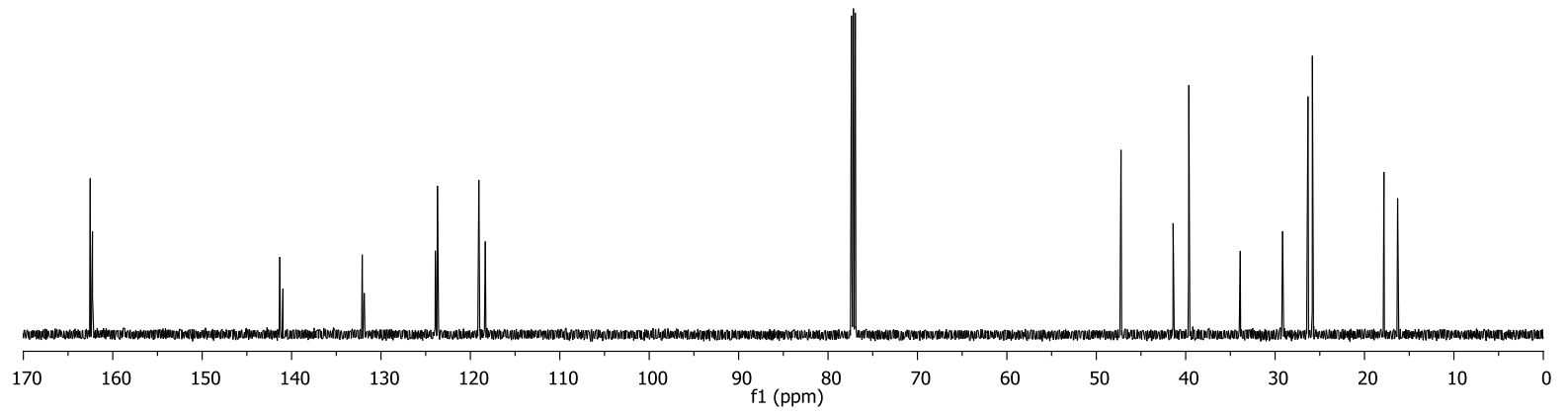

${ }^{13} \mathrm{C}$ NMR spectrum $\left(150 \mathrm{MHz}, \mathrm{CDCl}_{3}\right)$ of $\mathbf{1 6 9}$. 
$N$-Methyl- $N$-((6E)-3,7,11-trimethyldodeca-2,6,10-trien-1-yl)formamide (170)



${ }^{1} \mathrm{H}$ NMR spectrum $\left(500 \mathrm{MHz}, \mathrm{CDCl}_{3}\right)$ of $\mathbf{1 7 0}$.



${ }^{13} \mathrm{C}$ NMR spectrum $\left(150 \mathrm{MHz}, \mathrm{CDCl}_{3}\right)$ of $\mathbf{1 7 0}$. 
$N$-Methyl- $N$-((2E,6E,10E)-3,7,11,15-tetramethylhexadeca-2,6,10,14-tetraen-1yl)formamide (171)

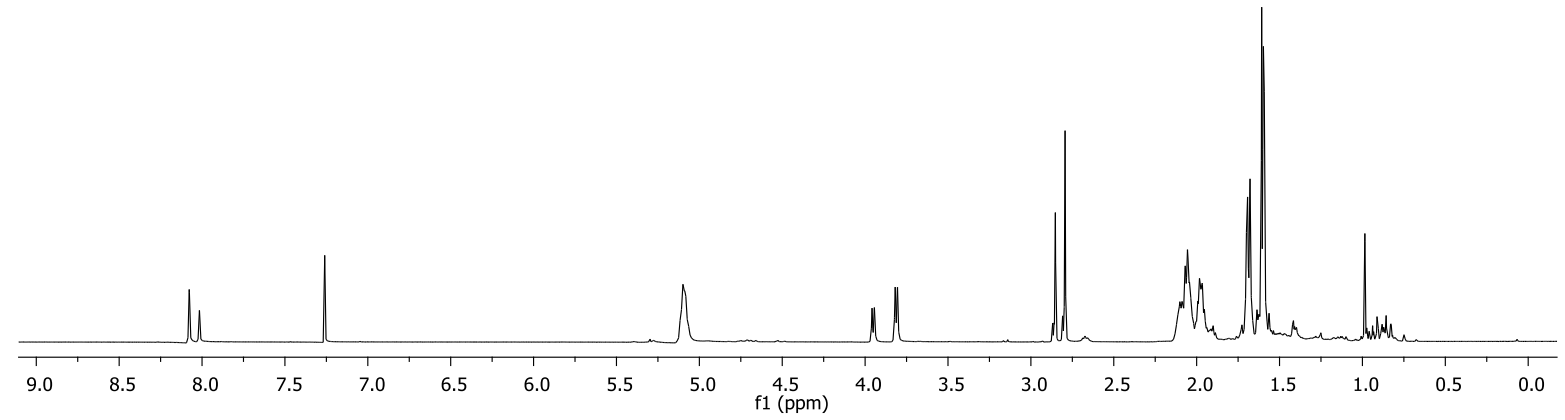

${ }^{1} \mathrm{H}$ NMR spectrum $\left(500 \mathrm{MHz}, \mathrm{CDCl}_{3}\right)$ of $\mathbf{1 7 1}$.



${ }^{13} \mathrm{C}$ NMR spectrum $\left(150 \mathrm{MHz}, \mathrm{CDCl}_{3}\right)$ of $\mathbf{1 7 1}$. 
(E)-N-(3,7-Dimethylocta-2,6-dien-1-yl)acetamide (172)

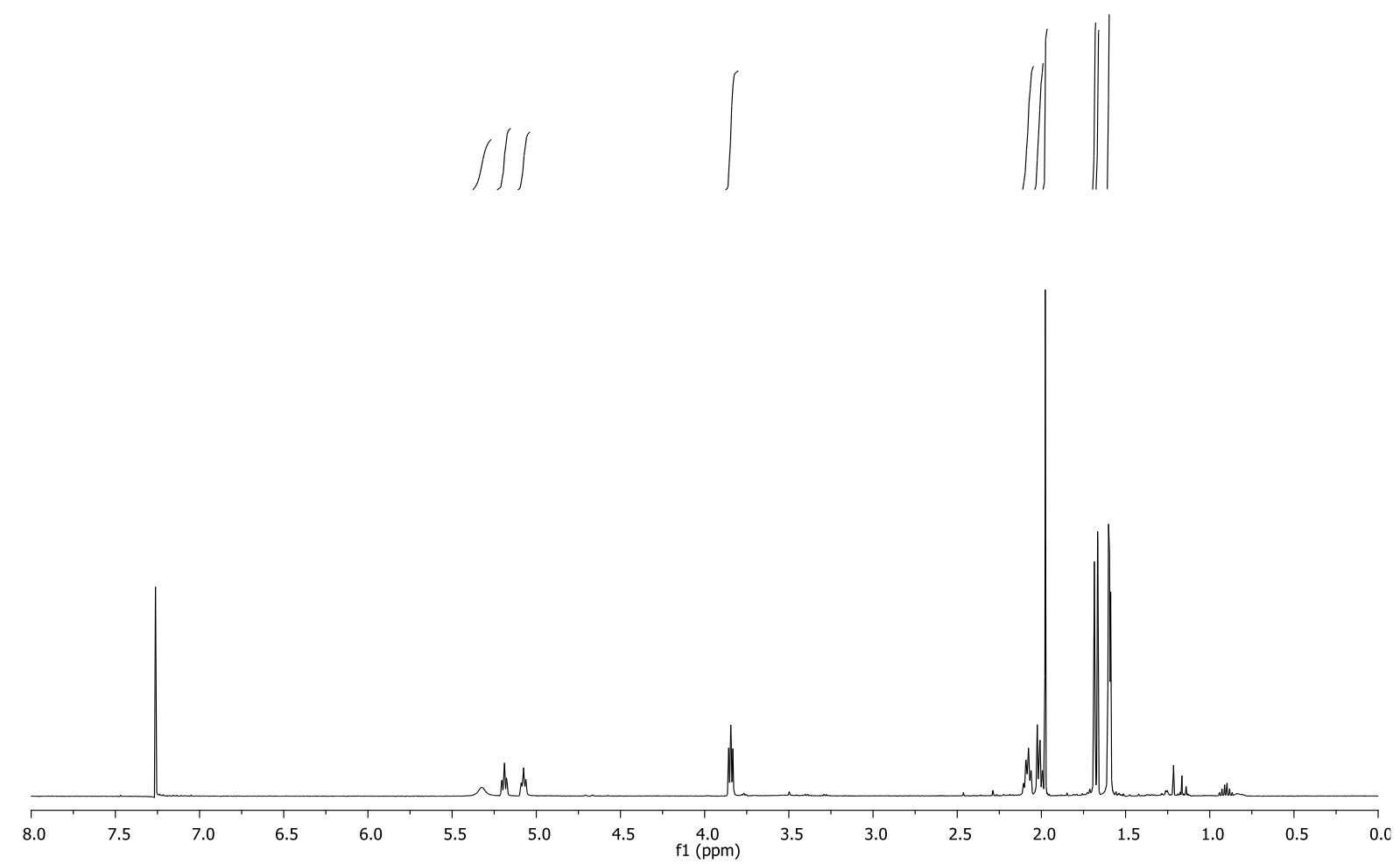

${ }^{1} \mathrm{H}$ NMR spectrum $\left(500 \mathrm{MHz}, \mathrm{CDCl}_{3}\right)$ of $\mathbf{1 7 2}$.

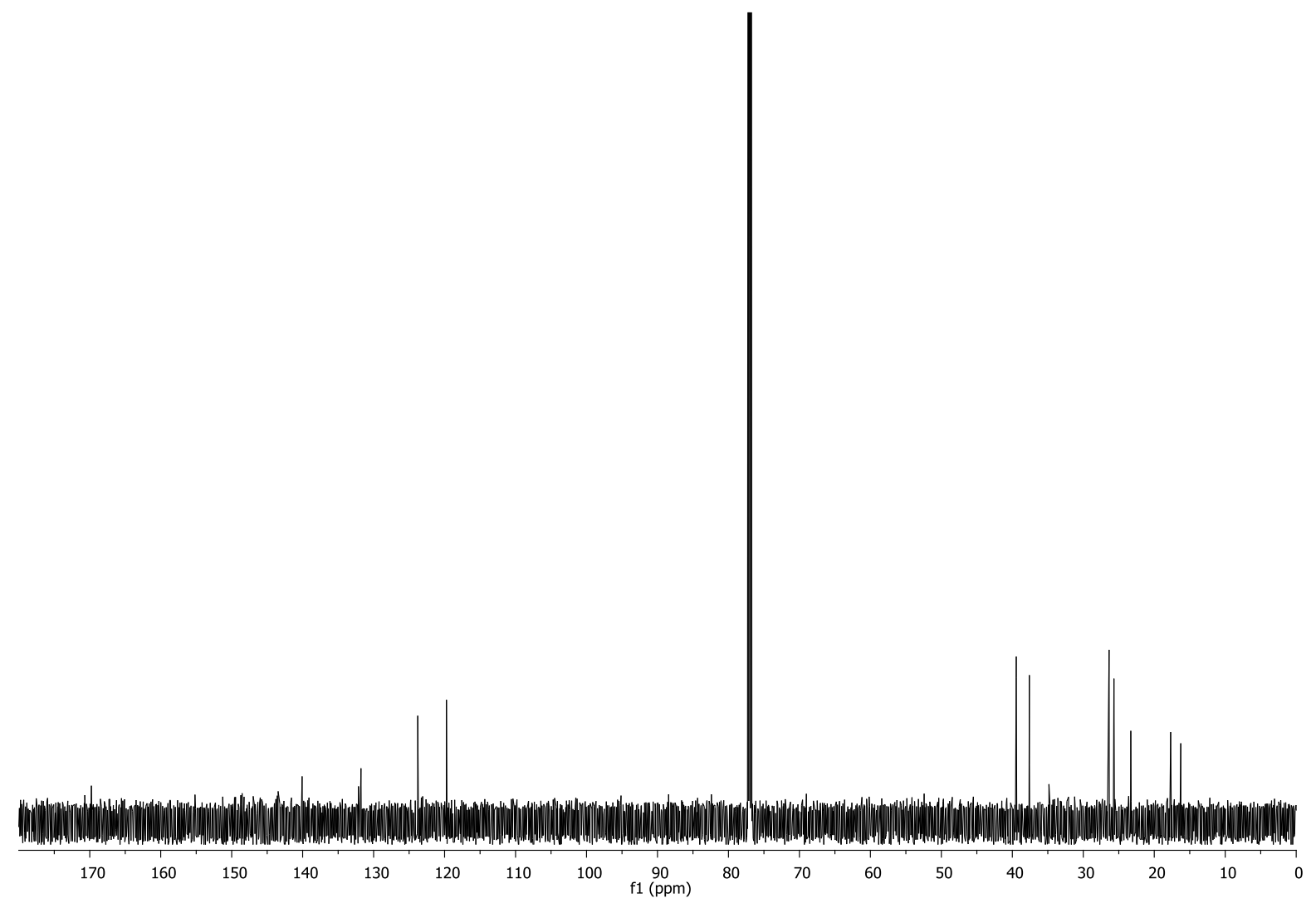

${ }^{13} \mathrm{C}$ NMR spectrum $\left(150 \mathrm{MHz}, \mathrm{CDCl}_{3}\right)$ of $\mathbf{1 7 2}$. 
$N-((2 Z, 6 E)-3,7,11-T r i m e t h y l d o d e c a-2,6,10-$ trien-1-yl)acetamide (173)

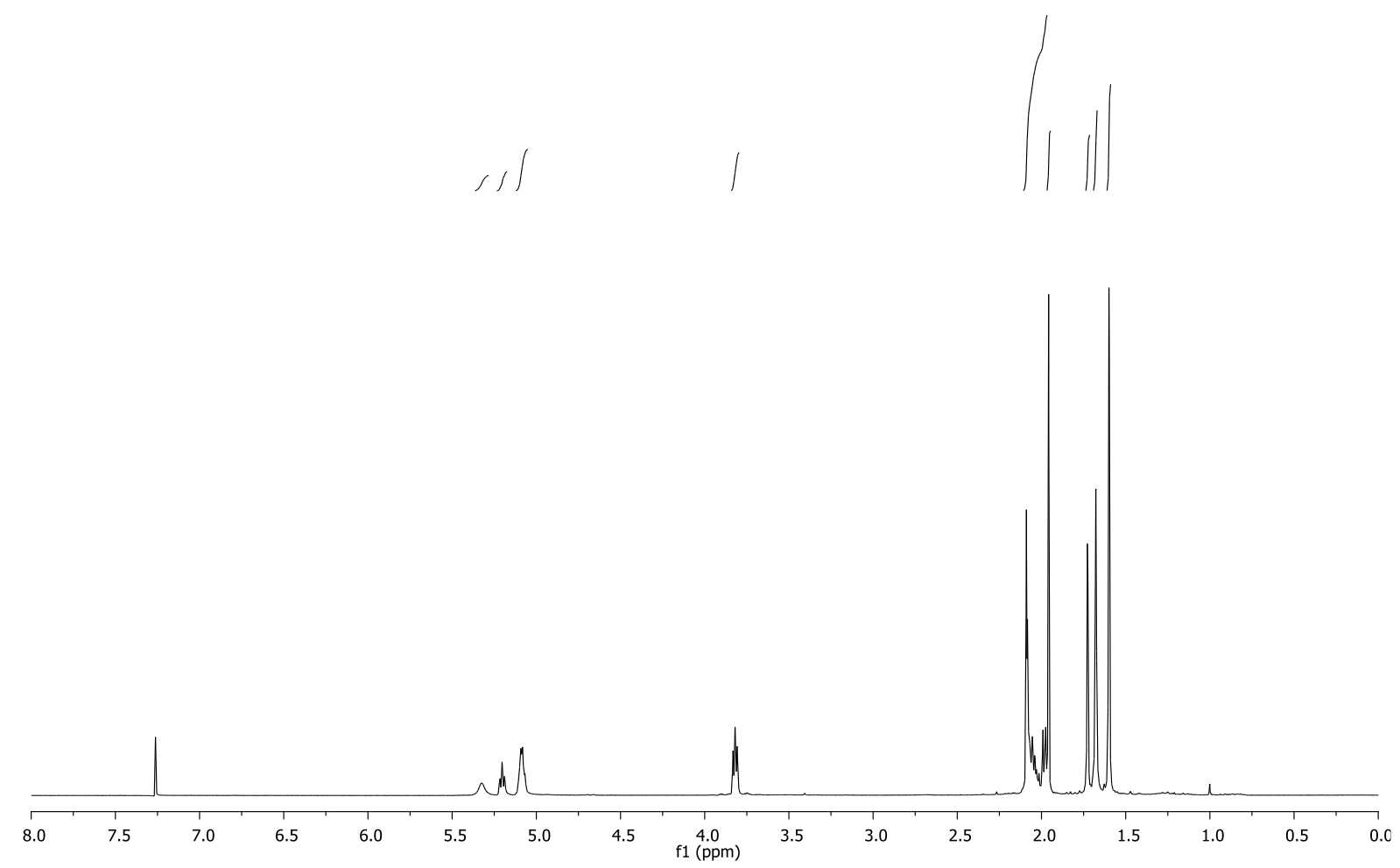

${ }^{1} \mathrm{H}$ NMR spectrum (500 MHz, $\mathrm{CDCl}_{3}$ ) of 173.

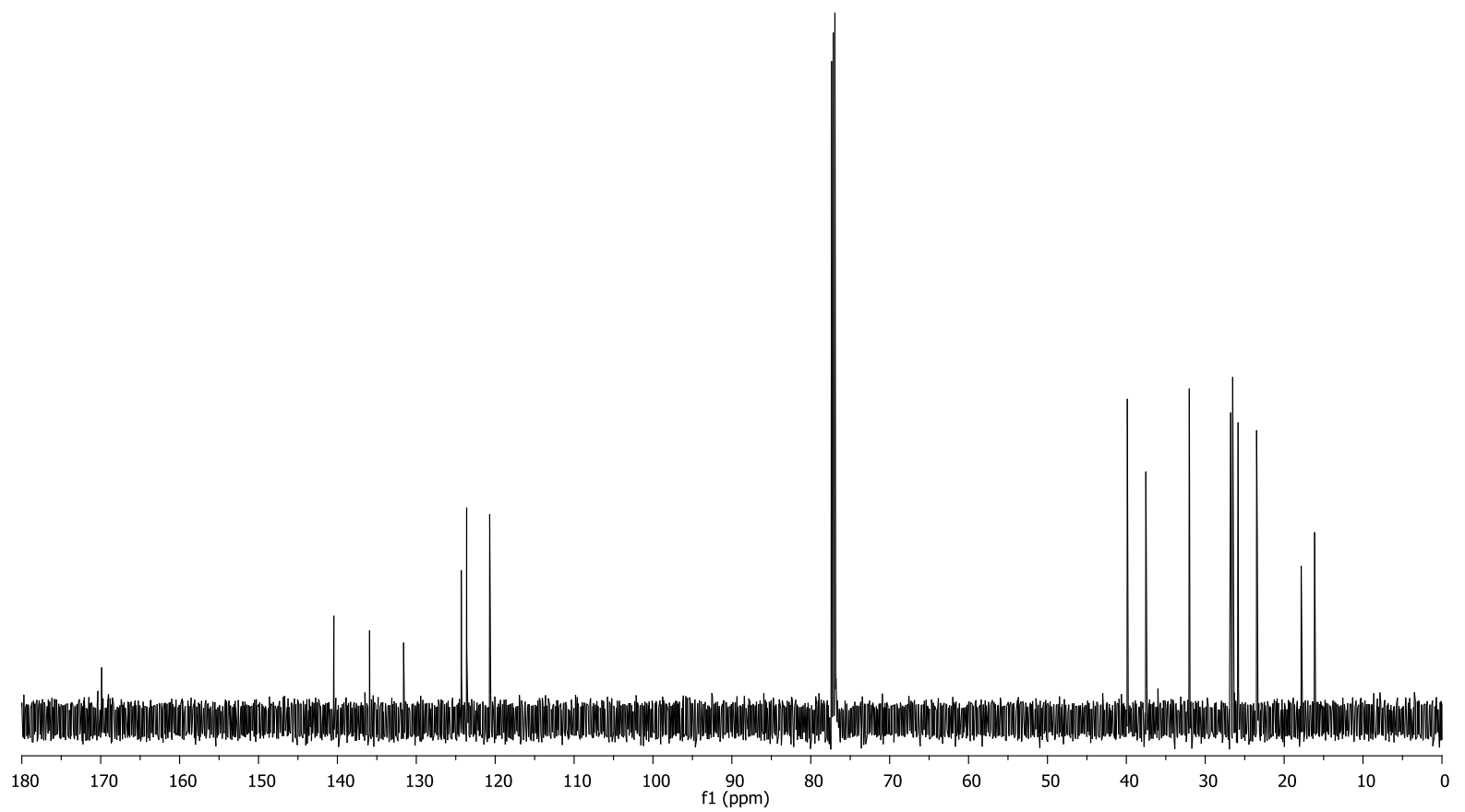

${ }^{13} \mathrm{C}$ NMR spectrum $\left(150 \mathrm{MHz}, \mathrm{CDCl}_{3}\right)$ of $\mathbf{1 7 3}$. 
$N$-((2E,6E)-3,7,11-Trimethyldodeca-2,6,10-trien-1-yl)acetamide (174)

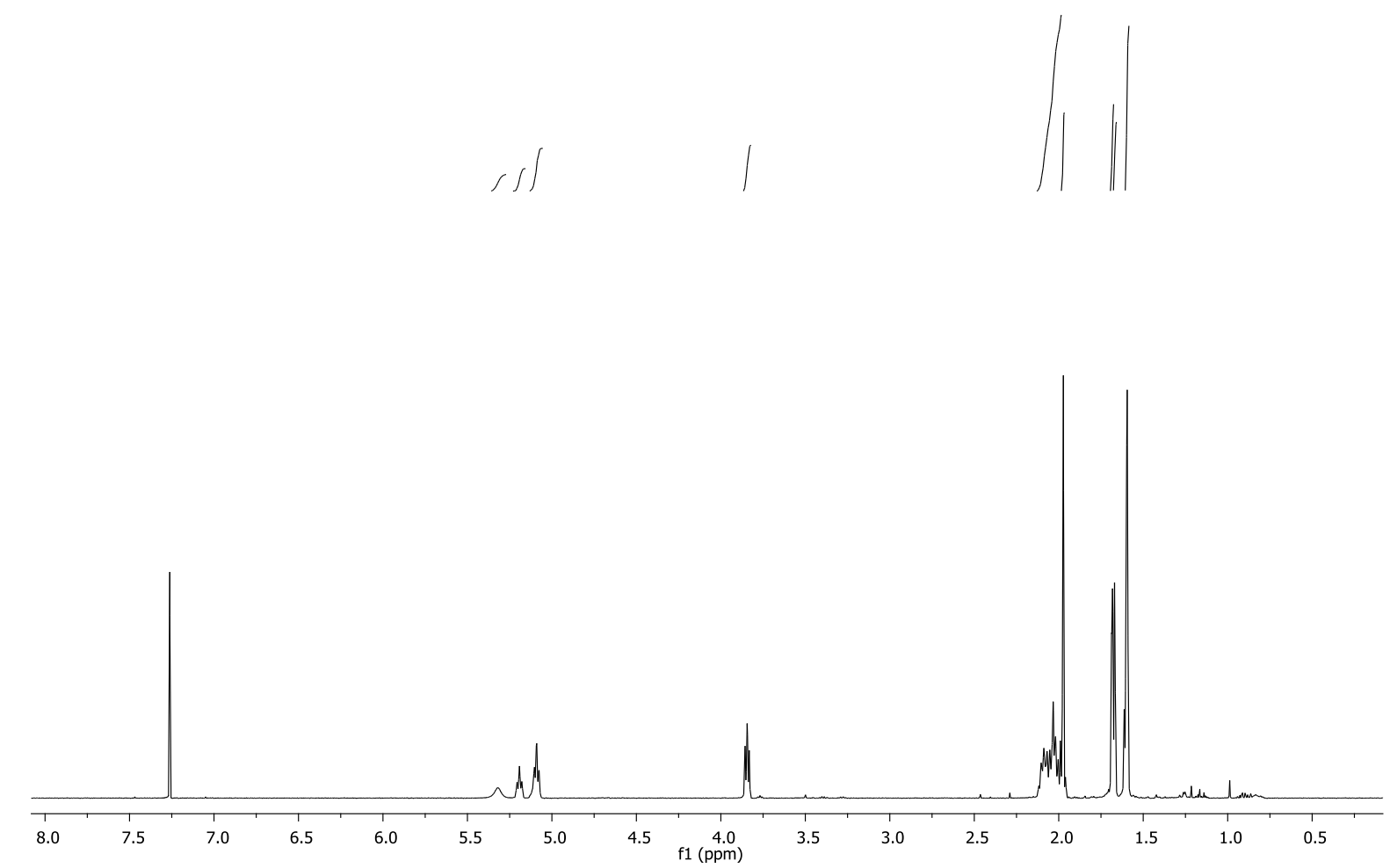

${ }^{1} \mathrm{H}$ NMR spectrum $\left(500 \mathrm{MHz}, \mathrm{CDCl}_{3}\right)$ of 174.

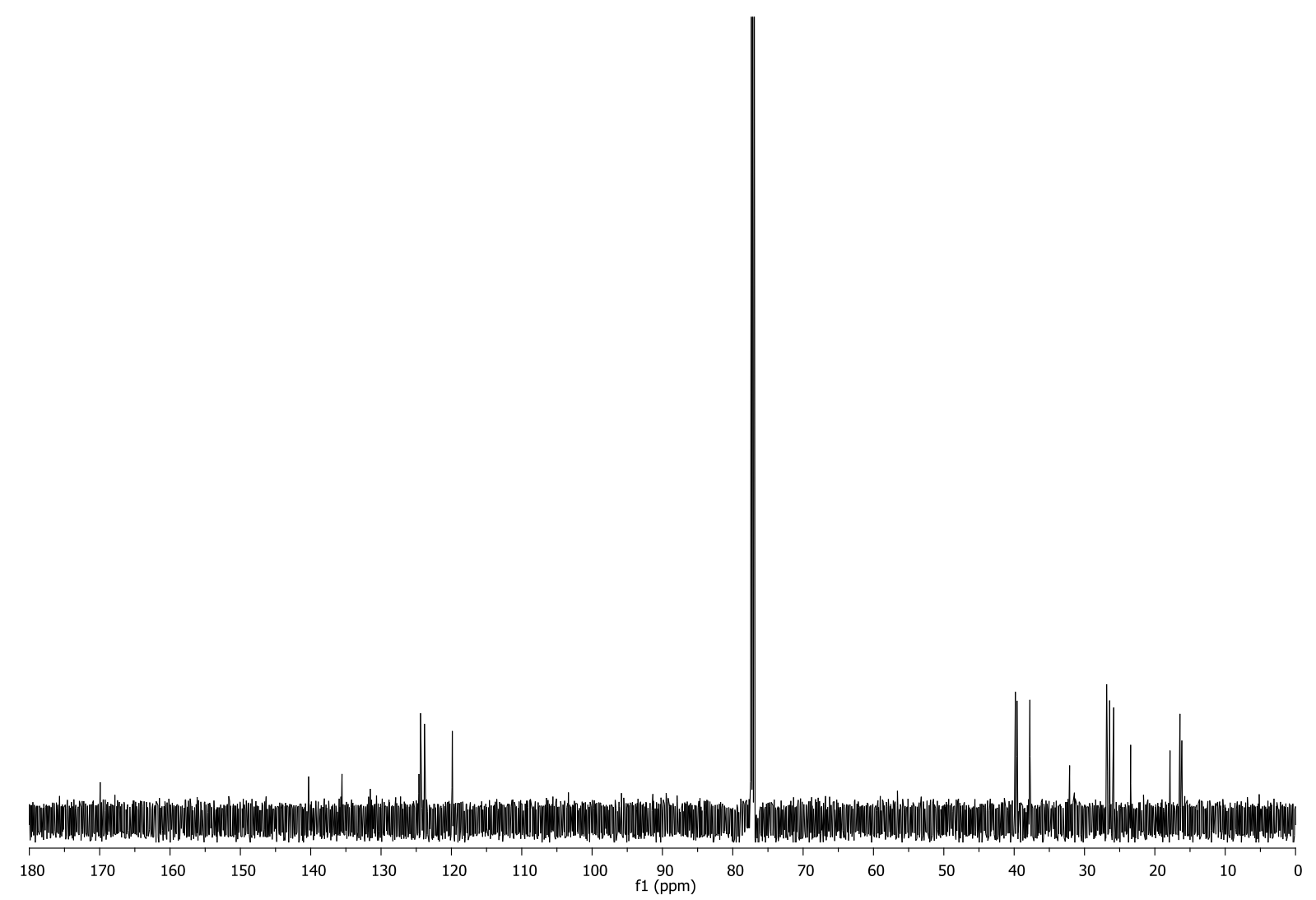

${ }^{13} \mathrm{C}$ NMR spectrum $\left(150 \mathrm{MHz}, \mathrm{CDCl}_{3}\right)$ of $\mathbf{1 7 4}$. 
$N-((2 Z, 6 E, 10 E)-3,7,11,15-T e t r a m e t h y l h e x a d e c a-2,6,10,14$-tetraen-1-yl)acetamide (175)

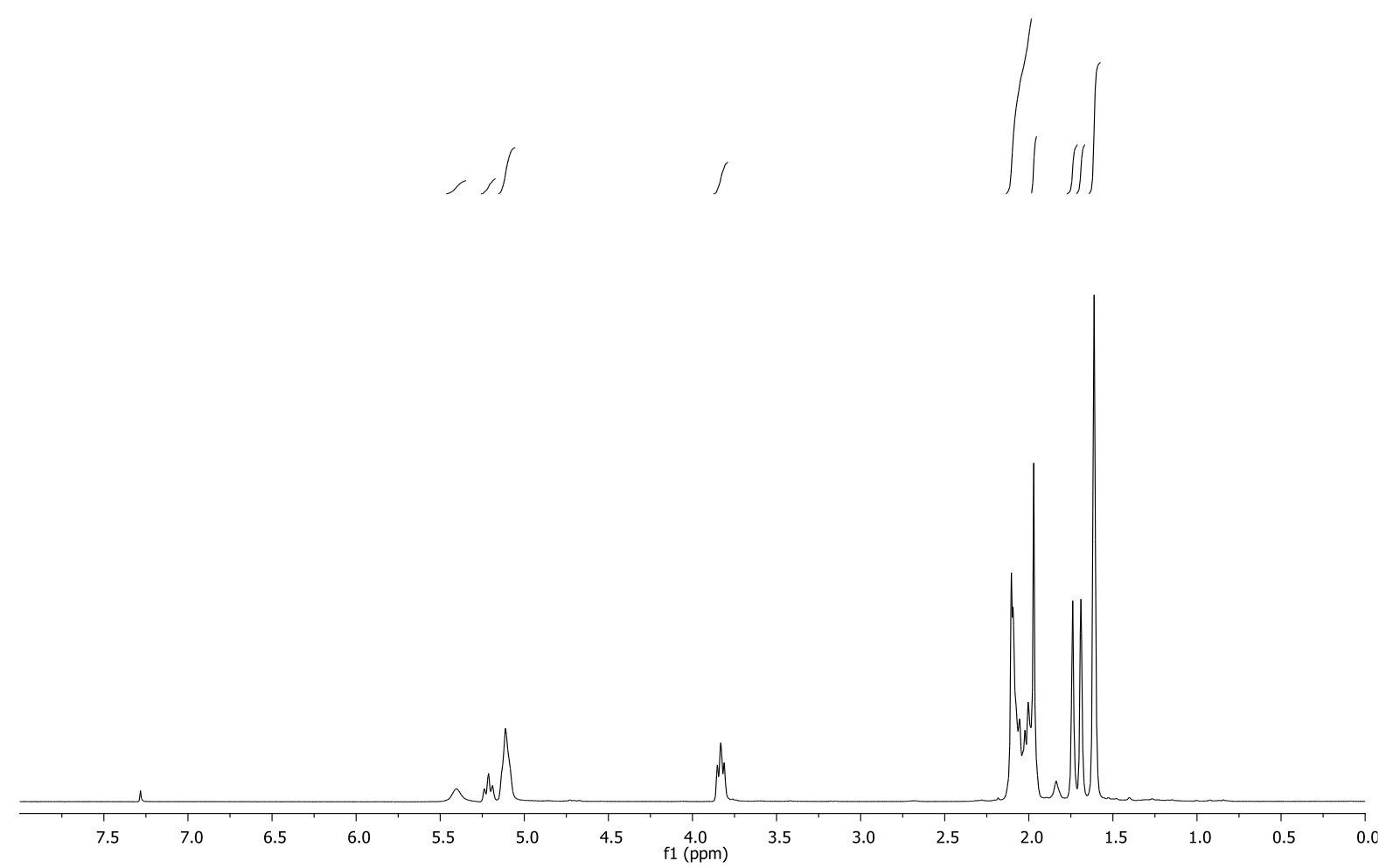

${ }^{1} \mathrm{H}$ NMR spectrum $\left(300 \mathrm{MHz}, \mathrm{CDCl}_{3}\right)$ of $\mathbf{1 7 5}$.

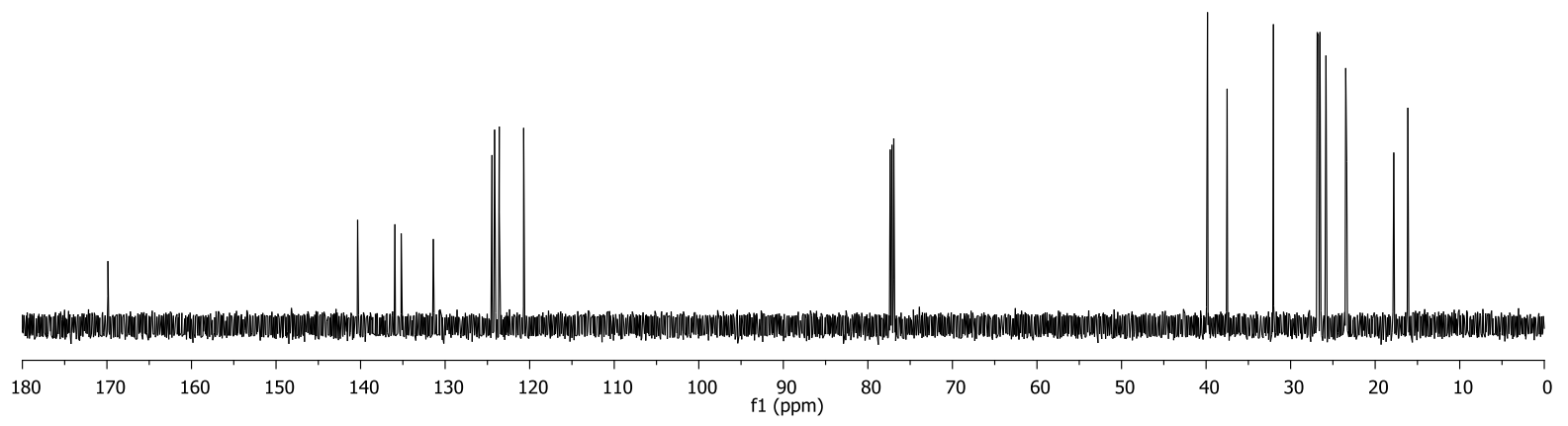

${ }^{13} \mathrm{C}$ NMR spectrum $\left(150 \mathrm{MHz}, \mathrm{CDCl}_{3}\right)$ of $\mathbf{1 7 5}$. 
$N-((2 E, 6 E, 10 E)-3,7,11,15-T e t r a m e t h y l h e x a d e c a-2,6,10,14$-tetraen-1-yl)acetamide (176)



${ }^{1} \mathrm{H}$ NMR spectrum $\left(3000 \mathrm{MHz}, \mathrm{CDCl}_{3}\right)$ of $\mathbf{1 7 6}$.

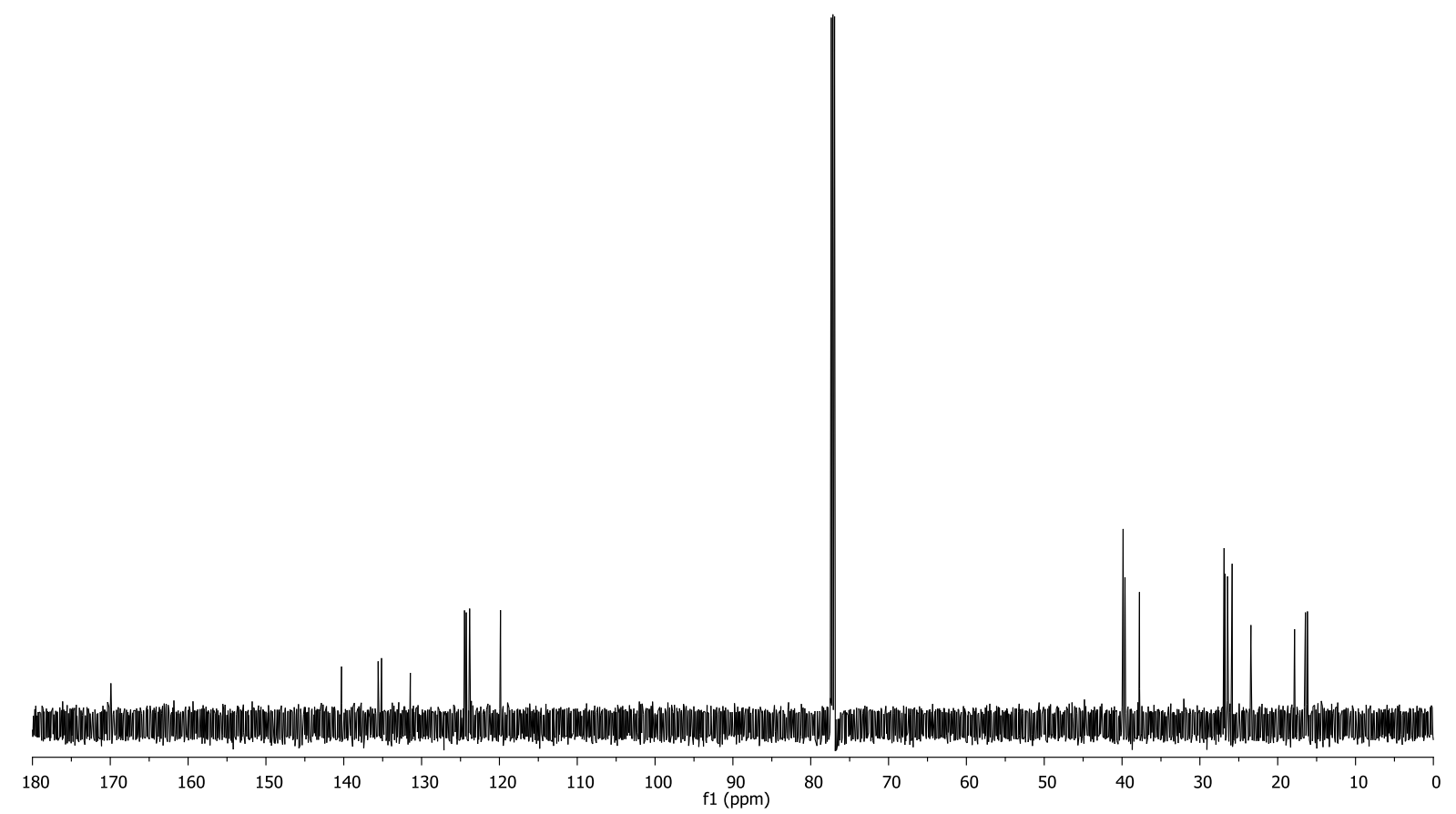

${ }^{13} \mathrm{C}$ NMR spectrum $\left(150 \mathrm{MHz}, \mathrm{CDCl}_{3}\right)$ of $\mathbf{1 7 6}$. 
(E)-N-(3,7-Dimethylocta-2,6-dien-1-yl)- $N$-methylacetamide (177)

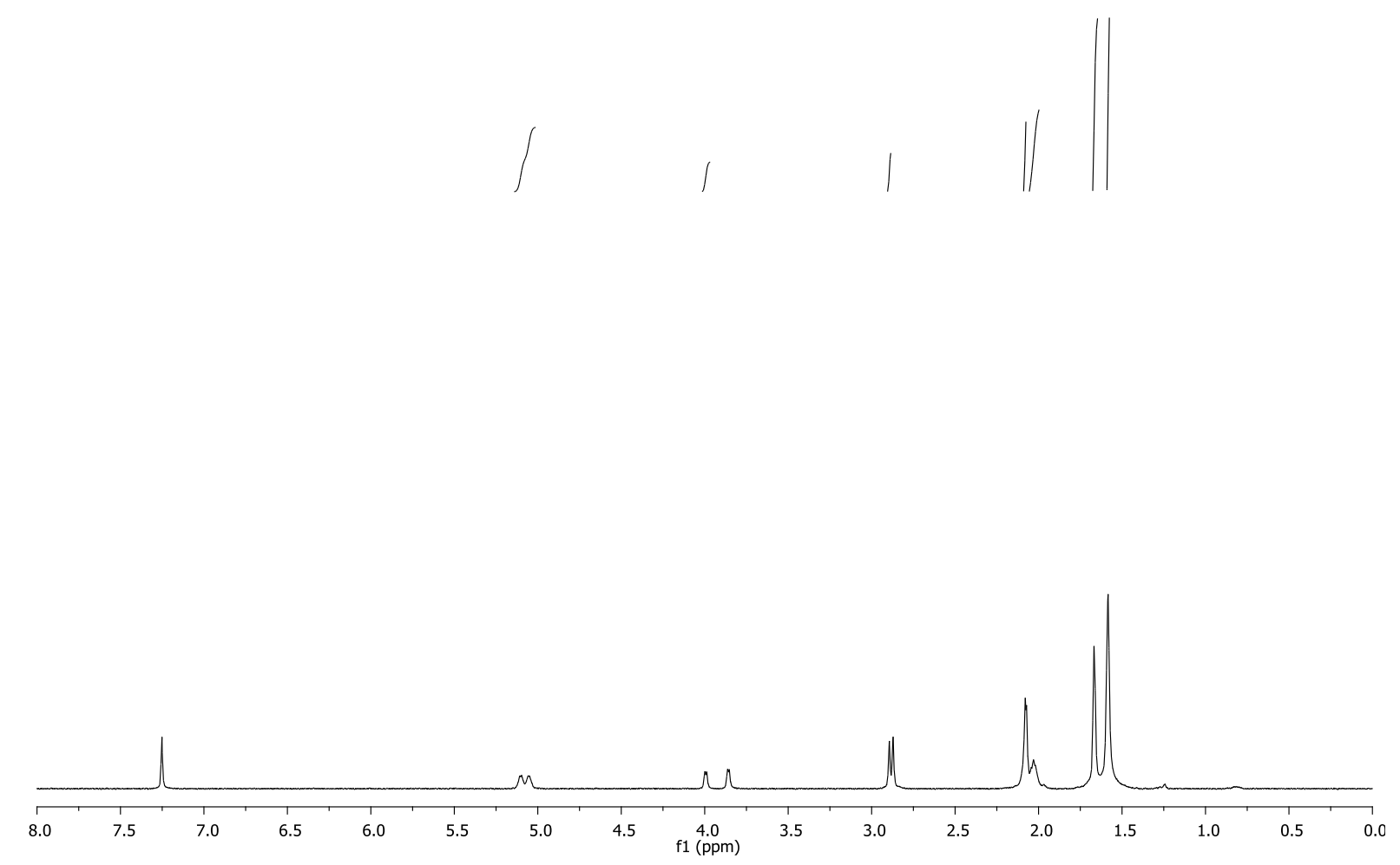

${ }^{1} \mathrm{H}$ NMR spectrum $\left(600 \mathrm{MHz}, \mathrm{CDCl}_{3}\right)$ of 177. 
$N$-Methyl- $N$-((2E,6E)-3,7,11-trimethyldodeca-2,6,10-trien-1-yl)acetamide (178)

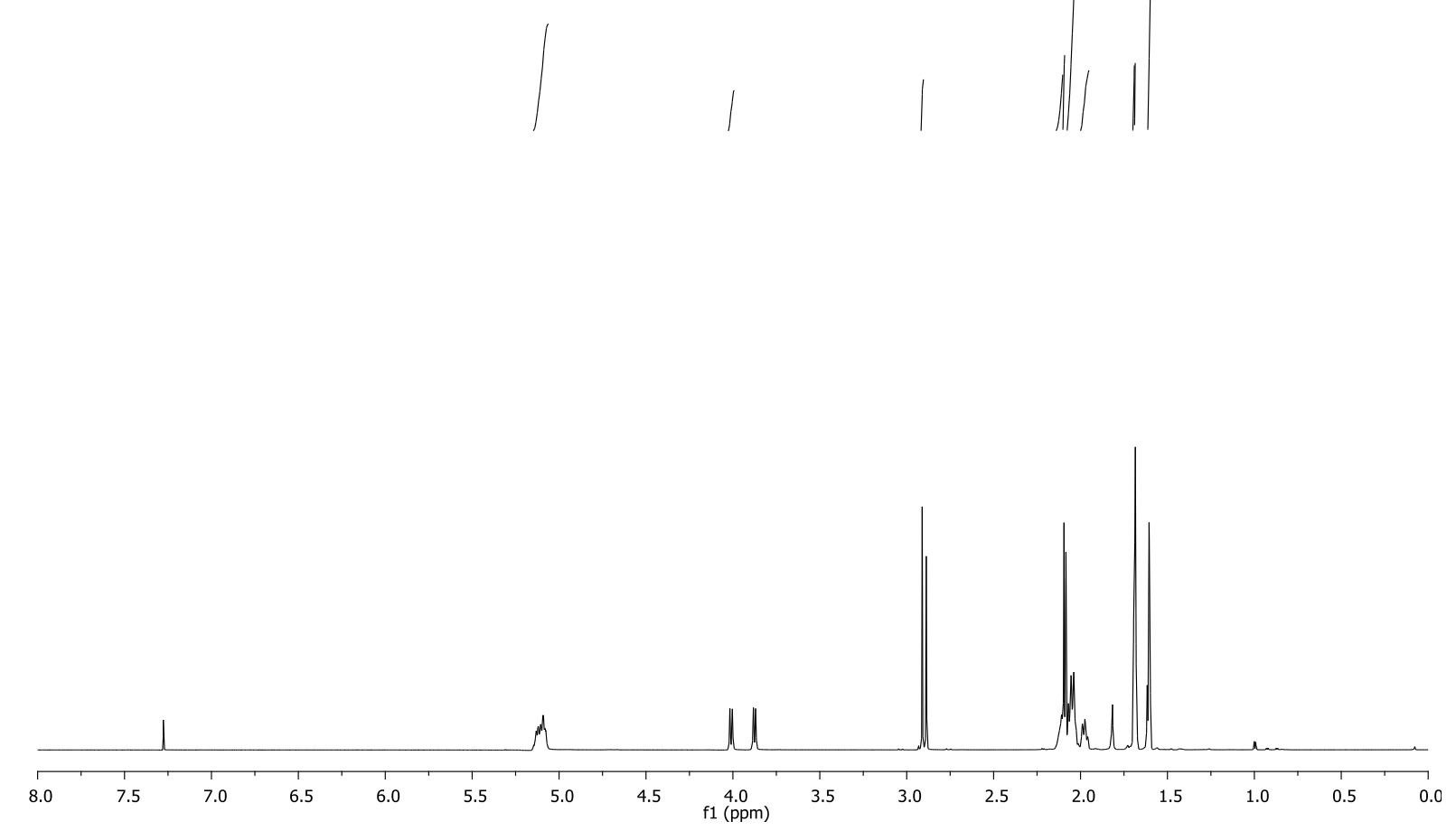

${ }^{1} \mathrm{H}$ NMR spectrum $\left(500 \mathrm{MHz}, \mathrm{CDCl}_{3}\right)$ of $\mathbf{1 7 8}$.

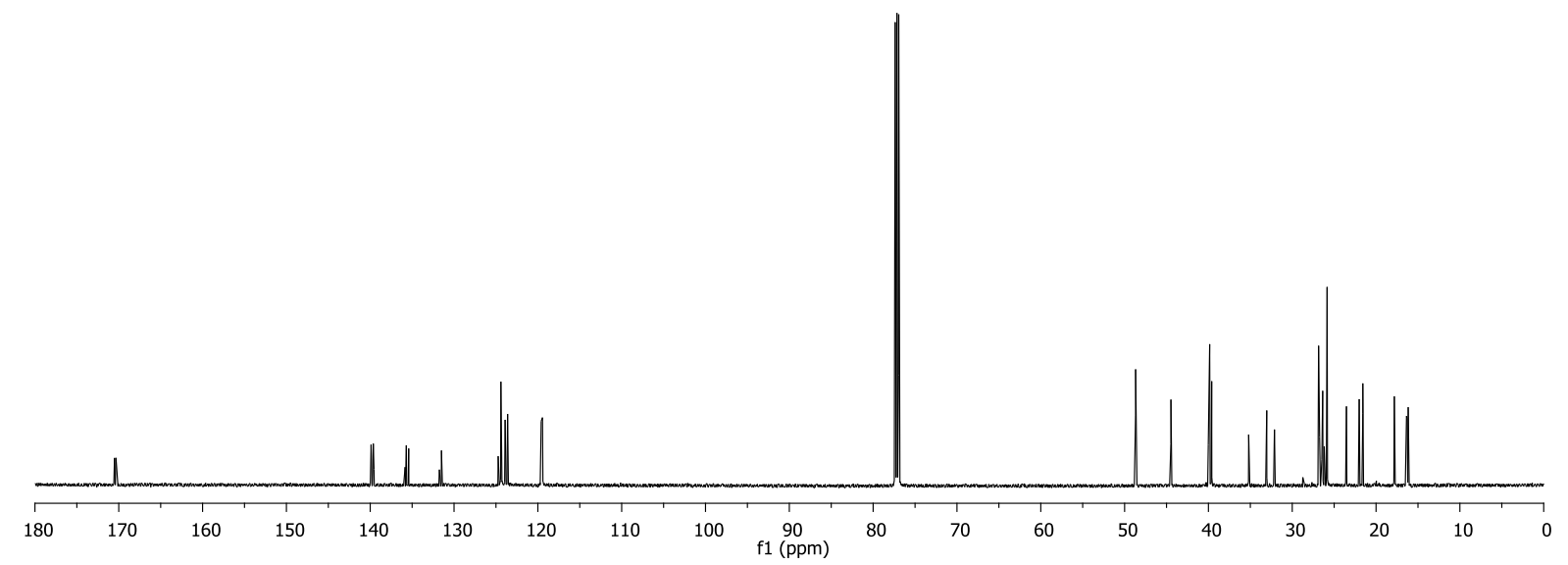

${ }^{13} \mathrm{C}$ NMR spectrum $\left(150 \mathrm{MHz}, \mathrm{CDCl}_{3}\right)$ of $\mathbf{1 7 8}$. 
$N$-Methyl- $N$-((2E,6E,10E)-3,7,11,15-tetramethylhexadeca-2,6,10,14-tetraen-1yl)acetamide (179)

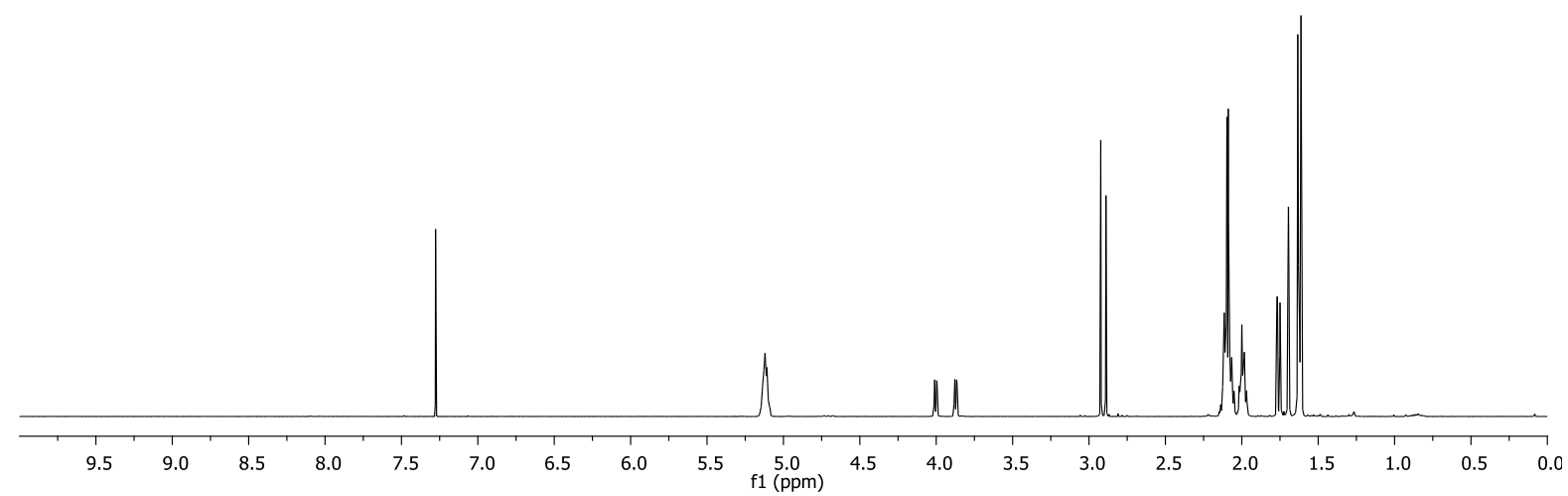

${ }^{1} \mathrm{H}$ NMR spectrum $\left(500 \mathrm{MHz}, \mathrm{CDCl}_{3}\right)$ of 179.

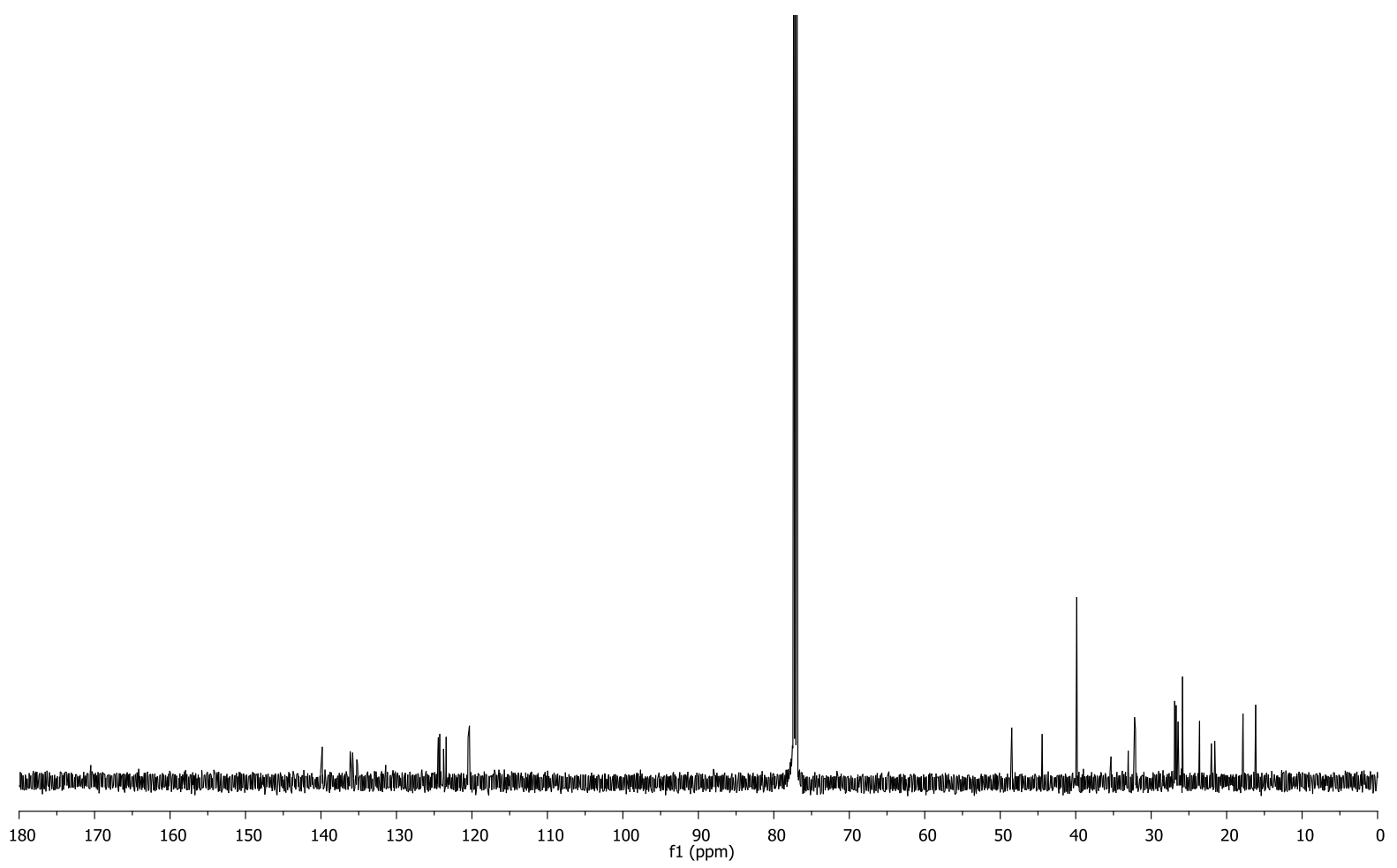

${ }^{13} \mathrm{C}$ NMR spectrum $\left(150 \mathrm{MHz}, \mathrm{CDCl}_{3}\right)$ of $\mathbf{1 7 9}$. 
$N$-Methyl- $N$-((2E,6E,10E)-3,7,11,15-tetramethylhexadeca-2,6,10,14-tetraen-1yl)acetamide (180)



${ }^{1} \mathrm{H}$ NMR spectrum $\left(500 \mathrm{MHz}, \mathrm{CDCl}_{3}\right)$ of $\mathbf{1 8 0}$.

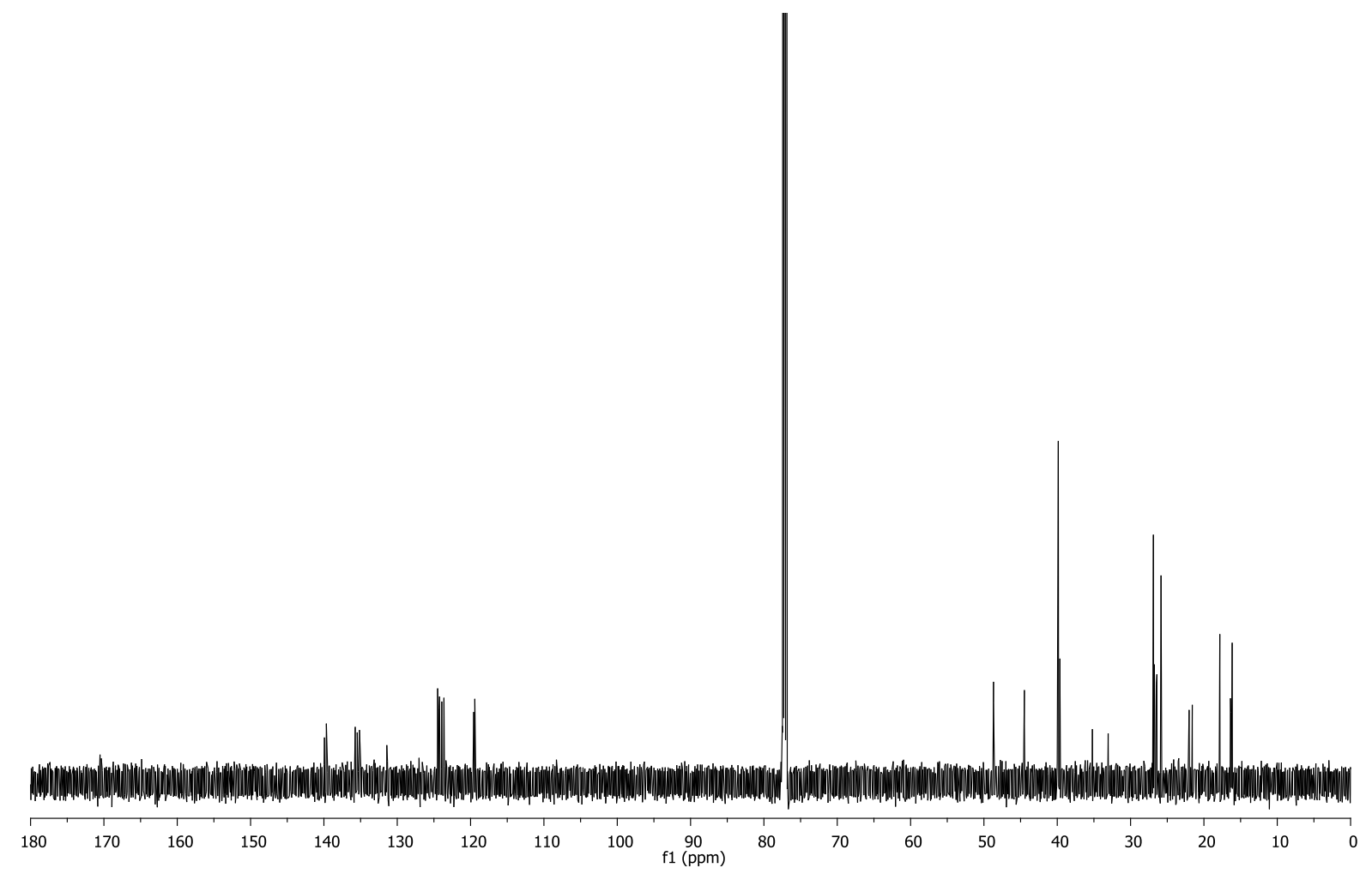

${ }^{13} \mathrm{C}$ NMR spectrum $\left(150 \mathrm{MHz}, \mathrm{CDCl}_{3}\right)$ of $\mathbf{1 8 0}$. 